FERNANDO CELOTTO MONTIJA

ASPECTOS DA VARIABILIDADE EXPERIMENTAL DO ENSAIO DE MÓDULO DE DEFORMAÇÃO DO CONCRETO 
FERNANDO CELOTTO MONTIJA

ASPECTOS DA VARIABILIDADE EXPERIMENTAL DO ENSAIO DE MÓDULO DE DEFORMAÇÃO DO CONCRETO

Dissertação apresentada à Escola Politécnica da Universidade de São Paulo para obtenção do título de Mestre em Engenharia 
FERNANDO CELOTTO MONTIJA

\section{ASPECTOS DA VARIABILIDADE EXPERIMENTAL DO ENSAIO DE MÓDULO DE DEFORMAÇÃO DO CONCRETO}

Dissertação apresentada à Escola Politécnica da Universidade de São Paulo para obtenção do título de Mestre em Engenharia

Área de Concentração:

Engenharia de Construção Civil e Urbana

Orientador:

Prof. Dr. Antonio Domingues de Figueiredo 


\section{DEDICATÓRIA}

Ao meu pai

(in memorian)

À minha família 


\section{AGRADECIMENTOS}

Ao professor e orientador Antonio Figueiredo pelo apoio contínuo na pesquisa, pela amizade, companheirismo e conforto de todas as horas.

Às bancas examinadoras, Ricardo Leopoldo e Silva França, Túlio Nogueira Bittencourt e Vladimir Antonio Paulon, pela atenção e generosidade.

Aos demais mestres, em especial Gaspar Djanikian, Mércia Barros, F.H. Sabbattini, Francisco Cardoso, José Nader, Maria Alba, Paulo Helene, Rafael Pileggi, Selmo Kuperman, Sílvia Selmo, Vanderley John e Vahan Agopyan, pelo incentivo.

Aos colegas Rui, Rosiany, Bruno, Juan, Fábia, Priscila, Fábio, Flávio, Juarez, Cléber, Clóvis, Heitor, Borín, Charles, Andréia, Carlos, Patrícia, Mauren, César, Jamil, Serra, Maurício, Elisabeth, Marcus, Marcelo, Atabyrio, Antonio, Fernanda, Heloísa, Marcos, Renata, Alexandre, Rodrigo, Rogério e Tiago.

A Reginaldo, Adílson, Mário, Ismael, Fátima, Engrácia, Talita, Léo, Elaine, Sara, Fabiane, Thiago, Rosivaldo e Regina, nos laboratórios, bibliotecas e secretarias.

À equipe da CPTI Tecnologia e Desenvolvimento, nas pessoas de Claudio Sbrighi Neto e João Carlos Marques, também generosos e presentes.

Aos demais amigos pessoais e profissionais que, graças a Deus, muitas vezes se confundiram e foram amigos profissionais e pessoais, e apoiaram minhas ausências. Às empresas:

- ABCP, nas pessoas de Rubens Curti, Flávio Munhoz, Claudio Silva e Inês Battagin;

- Embu S.A., nas pessoas de Luiz Eulálio de Moraes Terra, Amarildo Lima e Florisvaldo da Silva Guimarães;

- Engemix S.A., nas pessoas de Carlos Eduardo Regattieri, Carine Hartmann, Luiz Henrique Sartori, Adelino Boaventura, Wilson Castilho e Luiz Brito;

- Furnas Centrais Elétricas S.A., nas pessoas de Moacir Andrade, Joílson Inácio e Marco Aurélio Cupertino;

- IPT, nas pessoas de Ernan Silva (primeiro orientador profissional), Luiz Hamassaki, Valdecir Quarcioni, Carlos Tango, Gilberto Cavani, Claudia, Pedro, Silvia, Osmar, Léo, Rafael, Josias, Daniel, Fabiano...

À sociedade paulista e à Universidade de São Paulo, pela oportunidade. 
"Há três coisas na vida que nunca voltam atrás: a flecha lançada, a palavra pronunciada e a oportunidade perdida." 


\section{RESUMO}

Esta dissertação insere-se nas áreas de qualidade laboratorial e de ensaios de controle de concreto, especificamente quanto à propriedade 'módulo estático de deformação' ou 'módulo de Young'. A motivação do trabalho é a elevada variabilidade de resultados experimentais observada pelo meio técnico nacional em ensaios interlaboratoriais, cujos resultados indicam desvios-padrão totais da ordem de 3,5 GPa, valor significativo para o controle tecnológico de obras de construção civil.

Os objetivos buscados foram a identificação das parcelas da variabilidade oriundas da produção e do ensaio, com especial atenção àquela originada na instrumentação para medida das deformações durante o ensaio, e a discussão da aplicabilidade do conceito semiprobabilístico normativo à propriedade módulo de deformação do concreto. Além disso, a própria discussão da aplicabilidade da sistemática de pesquisa e análise sobre este tipo de ensaio e de material constou como um objetivo do trabalho.

Para tal, desenvolveu-se um programa experimental em duas etapas: a primeira foi destinada às avaliações de acurácia (precisão e exatidão) do método de ensaio. As avaliações se deram segundo roteiros da área metrológica para validação de métodos e sistemas de medida. De quatro instrumentações para medida das deformações testadas, uma se mostrou mais precisa (identificada como clip gages) e outra se mostrou a mais suscetível a erros sistemáticos e aleatórios entre as testadas (identificada como compressômetro com dois relógios comparadores).

Recomendou-se a ampliação do programa experimental para o âmbito interlaboratorial, pois, a rigor, o método de ensaio vigente não poderia ser considerado validado em termos de acurácia baseando-se unicamente nos resultados deste programa experimental. Porém, concluiu-se pela possibilidade de aceitação prática do método independentemente da utilização de três de um total de quatro tipos de instrumentação para medida das deformações testados em ensaio, sem que houvesse prejuízo para a produção ou o controle tecnológico usual desta propriedade.

Na segunda etapa, obteve-se um Diagrama de Dosagem e estudou-se um cenário de fornecimento de concreto sob critérios estatísticos diferentes de atendimento à 
especificação de módulo de deformação: utilização do valor característico e do valor médio, com diferença de $4 \mathrm{GPa}$ entre eles. Estimou-se um aumento da ordem de 9\% no deslocamento vertical de uma viga simples bi-apoiada quando executada com o concreto de menor módulo em relação à execução com o de maior módulo. Por sua vez, o concreto de maior módulo exigiria um aumento no consumo de cimento da ordem de até $200 \mathrm{~kg} / \mathrm{m}^{3}$, se conservados todos os insumos materiais e os demais parâmetros tecnológicos contidos nos traços.

Concluiu-se pela aplicabilidade do uso da sistemática empregada na avaliação da acurácia do método de ensaio e do uso do conceito semiprobabilístico para esta propriedade.

Palavras-chave: módulo de deformação; módulo de elasticidade; módulo de Young; controle de qualidade; controle tecnológico; variabilidade experimental (acurácia; precisão; exatidão); concreto (ensaios; propriedades). 


\begin{abstract}
This work is developed into the areas of laboratorial quality and concrete control tests, specifically focusing on the 'static modulus of elasticity' or 'Young's modulus'. The motivation of this work is the high variability of experimental results observed by national technicians in interlaboratorial tests. These results show total standard deviations of around 3.5 GPa, a significant value for the technological control for civil construction.
\end{abstract}

The main objectives are the identification of the variability fragments derived from the production and test, specially the ones related to the instrumentation for measuring deformations during the test, and the discussion of the semi-probabilistic concept applicability on the concrete Young's modulus control. Moreover, the discussion of the applicability of the procedure used in this work and its analysis are also objective pursued here.

The experimental program was developed in two steps: the first step covered the accuracy assessments (precision and exactness) of test method. The assessments were carried out according to instructions from Metrology concepts for the validation of the methods and the measure systems. One out of four instrumentations for measuring the tested deformations proved to be more precise (identified as clip gages) and another one proved to be more susceptible to systematic and random errors (identified as a compressometer with two dial indicators).

The extension of the experimental program to an interlaboratorial scope is recommended because the current test method could not be considered valid based only on the results of this experimental program. However, it was shown that the practical acceptance of the test method for three among the four kinds of instrumentations analyzed, without damaging the production or the usual technological control of this property, is possible.

On the second step, a mix design diagram was obtained and a case of supply of concrete under different statistical criteria (fulfillment the modulus of elasticity specification): the use of the characteristic value and the average value, with difference of $4 \mathrm{GPa}$ between them. An increase of $9 \%$ on the vertical transference of a simple dual supported beam was observed when using a lower modulus concrete, when compared to another one with a higher modulus. On the other hand, the 
modulus increase would require an increment in the cement consumption up to 200 $\mathrm{kg}$ per cubic meter, if all the material inputs and further technological parameters is maintained.

The final conclusion was that the procedure used on the assessment of the test method accuracy and the semi-probabilistic concept on this material property is applicable.

Keywords: modulus of elasticity; elastic modulus; Young's modulus; quality control tests; technological control; experimental variability (accuracy; precision; exactness); concrete (tests; properties). 


\section{LISTA DE ILUSTRAÇÕES}

Figura 2.1.2.1 - Representação de um corpo sob solicitação (de tração): (a) Tensão superficial $\Delta \mathrm{F} / \Delta \mathrm{S}$; (b) Tensão interna $\Delta \mathrm{F} / \Delta \mathrm{S}$

Figura 2.1.2.2 - Representação de elemento infinitesimal do corpo sob solicitação (de tração)

Figura 2.1.2.3 - Representação de um ponto do corpo em deformação

Figura 2.1.2.4 - Curvas tensão normal-deformação específica axial: (a) material elástico linear; (b) material elástico não-linear

Figura 2.1.2.5 - Curva tensão cisalhante-deformação angular de um material elástico linear ...28

Figura 2.1.2.6 - Diagrama de Ashby: Módulo de elasticidade x Densidade ................................30

Figura 2.1.3.1 - Representação indireta da energia das ligações atômicas ...............................32

Figura 2.1.3.2 - Representação da deformação elástica perfeita em nível atômico (na tração) 33

Figura 2.1.3.3 - Representação da deformação elastoplástica perfeita em nível atômico (na tração)

Figura 2.2.1 - Representação dos principais componentes da pasta endurecida e do concreto: (a), (b) e (c) Detalhes conforme legenda.

Figura 2.2.2 - Detalhe das fibras cristalinas de C-S-H (silicatos de cálcio hidratados) .37

Figura 2.2.3 - Representação das partículas de C-S-H: (a) Hidratação periférica do grão de cimento; (b) Vista geral do contato entre partículas; (c) (d) (e) (f) Detalhes A, B C e D do tamanho das partículas, respectivamente.

Figura 2.2.4 - Partículas de C-S-H: Módulo de elasticidade x Distância do núcleo anidro..........39

Figura 2.2.5 - Grão de Hadley com idade acima de 14 dias ....................................................40

Figura 2.2.6 - Detalhes de placas cristalinas de $\mathrm{CH}$ (hidróxido de cálcio) ..................................41

Figura 2.2.7 - Detalhe das agulhas cristalinas de AFt (etringita)..............................................42

Figura 2.2.8 - Representação da água na pasta endurecida .........................................................46

Figura 2.2.9 - Representação da zona de transição pasta-agregado.........................................47

Figura 2.2.1.1 - Diagrama de identificação das dimensões dos componentes do concreto e

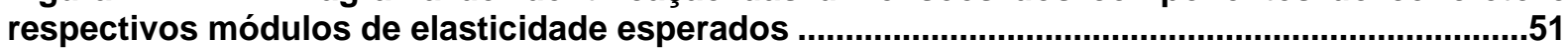

Figura 2.3.1 - Respostas de tensão-deformação do concreto e suas fases principais ...............53

Figura 2.3.2 - Representação esquemática da fissuração e do comportamento tensão-

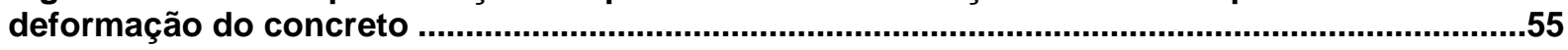

Figura 2.3.3 - Esquema do fraturamento: (a) fases; (b) detalhe dos campos de tensões ...........56

Figura 2.3.1.1 - Representação de modelos: (a) Fases em paralelo; (b) Fases em série.............57

Figura 2.3.1.2 - Representação de aplicação dos modelos de Voigt, Reuss e Hashin-Shtrikman

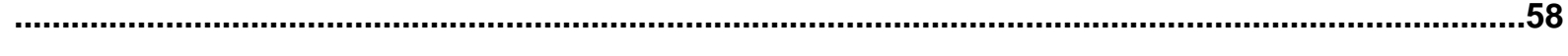

Figura 2.3.1.3 - Representação dos modelos de fases concêntricas: (a) Counto; (b) Hansen ...59

Figura 2.3.2.1 - Diagrama de Ashby: Módulo de Elasticidade x Resistência ..............................63

Figura 3.1.1 - Curva tensão-deformação específica para a obtenção do módulo de deformação 6

Figura 3.1.2 - Esforços no corpo-de-prova durante carregamento de compressão ...................68

Figura 3.2.1 - Resultados do interlaboratorial nacional (2005) ...............................................70 
Figura 3.2.2 - Resultados do interlaboratorial nacional (2006)

Figura 3.2.3 - Diagrama de causa e efeito para identificação dos fatores intervenientes...........75

Figura 3.3.1.1 - Traço de concreto com segregação ...............................................................76

Figura 3.3.2.1 - Exemplo de perturbação em uma curva tensão-deformação real ........................77

Figura 3.3.3.1 - Influência da saturação dos corpos-de-prova no módulo de deformação..........79

Figura 3.3.5.1.1 - Variação da relação tensão-deformação com a velocidade de carga ..............83

Figura 3.3.5.2.1 - Representação esquemática da curva tensão-deformação e os módulos

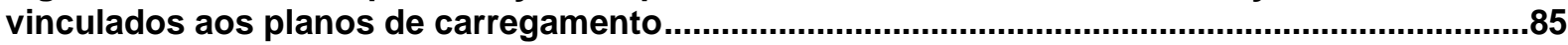

Figura 3.3.5.2.2 - Plano para obtenção direta do módulo de deformação tangente inicial ..........87

Figura 3.3.5.2.3 - Plano para obtenção direta do módulo de deformação secante .......................87

Figura 3.3.5.2.4 - Plano para obtenção indireta do módulo de deformação secante ...................88

Figura 3.3.5.2.5 - Estudo internacional: plano utilizado à época na Grã-Bretanha (BS 1881:1952)

Figura 3.3.5.2.6 - Estudo internacional: plano utilizado à época nos EUA (ASTM C-469:1965)..89

Figura 3.3.5.2.7 - Estudo internacional: plano utilizado à época na Alemanha Ocidental (DIN1048-1:1978)

Figura 3.3.5.2.8 - Estudo internacional: plano recomendado à época pela ISO 6784:1982.........90

Figura 3.3.5.3.1 - Instrumentos para medição da deformação: (a) dispositivos compressômetros; (b) compressômetro-expansômetro; (c) relógio comparador; (d) compressômetro com 2 relógios comparadores; (e) compressômetro com 1 relógio comparador.

Figura 3.3.5.3.2 - Detalhes do dispositivo compressômetro

Figura 3.3.5.3.3 - Instrumentos para medição da deformação: (a) LVDT; (b) compressômetros com LVDT.

Figura 3.3.5.3.4 - Princípio de funcionamento dos LVDT

Figura 3.2.5.3.5 - Instrumentos para medição da deformação: (a) strain gages de colagem superficial; (b) transdutores laminados de imersão; (c) transdutores cilíndricos de imersão ...95

Figura 3.3.5.3.6 - Princípio de funcionamento dos strain gages

Figura 3.3.5.3.7 - Instrumentos para medição da deformação: (a) clip gages de contato em lâmina com interligação rígida; (b) clip gages de contato em lâmina com ligação elástica por anéis de borracha; (c) clip gages de contato em lâmina com ligação elástica com molas ..........97

Figura 3.3.5.3.8 - Princípio de funcionamento dos clip gages.

Figura 3.3.5.3.9 - Instrumentos para medição da deformação: (a) laser; (b) microfilmagem sensorial programada.

Figura 3.3.5.3.10 - Aquisição e transmissão de dados: (a) aquisitor de sinais; (b) fibras ópticas . .98

Figura 3.3.5.3.11 - Estudo de Klink: (a) distribuição dos instrumentos de medição das deformações no corpo-de-prova; (b) deformações medidas para 4 níveis de solicitação .........100

Figura 3.3.5.3.12 - Estudo de Torrenti et al.: (a) distribuição dos instrumentos de medição de deformações nos corpos-de-prova; (b) deformações lidas em 4 níveis de solicitação diferentes

Figura 4.1.1 - Ciclo de desenvolvimento e validação de um método experimental ...................105

Figura 4.1.1.1 - Representação esquemática dos erros experimentais........................................107

Figura 4.1.1.2 - Representação ilustrativa das avaliações de acurácia .....................................109

Figura 4.1.1.1.1 - Representação da repetitividade da medição...............................................110 
Figura 4.1.1.1.2 - Representação da reprodutibilidade da medição.

Figura 4.3.1.1 - Divisão de amostras da primeira etapa do programa experimental.

Figura 4.3.1.2 - Planos de carregamento do programa experimental 123

Figura 4.3.1.3 - Instrumentação de SG: (a) Detalhe da colagem; (b) Detalhe do sistema.. 124

Figura 4.3.1.4 - Instrumentação de CG: Detalhe do sistema de medida. 125

Figura 4.4.1 - Fluxograma das atividades da avaliação de acurácia do método de ensaio ......130

Figura 4.4.2 - Fluxograma das atividades de discussão da aplicabilidade do conceito semiprobabilístico ao módulo de deformação. 131

Figura 5.1.1.1 - Distribuição volumétrica dos compostos resistentes e não-resistentes 137

Figura 5.1.2.1 - Cartas de controle das Instrumentações para o Concreto a/c 0,40: (a) Médias por betonada, plano secante; (b) Médias por betonada, plano tangente inicial; (c) Desviospadrão por betonada, plano secante; (d) Desvios-padrão por betonada, plano tangente inicial .140

Figura 5.1.2.2 - Cartas de controle das Instrumentações para o Concreto a/c 0,70: (a) Médias por betonada, plano secante; (b) Médias por betonada, plano tangente inicial; (c) Desviospadrão por betonada, plano secante; (d) Desvios-padrão por betonada, plano tangente inicial .141

Figura 5.1.2.3 - Hipótese de combinação de deformações durante o ensaio 142

Figura 5.1.2.4 - Cartas de controle das Betonadas para o plano de carregamento secante: (a) Médias globais, Concreto a/c 0,40; (b) Médias globais, Concreto a/c 0,70; (c) Desvios-padrão globais, Concreto a/c 0,40; (d) Desvios-padrão globais, Concreto a/c 0,70 .............................144

Figura 5.1.2.1.1 - Composição das variâncias dos resultados sob cada instrumentação ........144

Figura 5.1.2.1.2 - Composição das variâncias e desvios-padrão dos agrupamentos Ecs-1I-3bt040, por instrumentação. .146

Figura 5.1.2.1.3 - Composição das variâncias e desvios-padrão dos agrupamentos Eci-1l-3bt040, por instrumentação

Figura 5.1.2.1.4 - Composição das variâncias e desvios-padrão dos agrupamentos Ecs-1I-3bt070, por instrumentação 148

Figura 5.1.2.1.5 - Composição das variâncias e desvios-padrão dos agrupamentos Eci-1l-3bt070, por instrumentação. .150

Figura 5.1.2.1.6 - Histogramas e estatística de cada agrupamento estudado de resultados de módulo de deformação. 151

Figura 5.1.2.1.7 - Ilustração dos índices 'Desvio R\&R/Desvio total (\%)' de cada agrupamento .153

Figura 5.1.2.1.8 - Histogramas e estatística de cada agrupamento de resultados de resistência .154

Figura 5.1.2.1.9 - Composição das variâncias e desvios-padrão dos agrupamentos dos resultados de resistência .........................................................................................................155

Figura 5.1.2.2.1 - Representação da distribuição dos Z-scores dos agrupamentos Ecs-1I-1bt040, por betonada, por instrumentação 161

Figura 5.1.2.2.2 - Representação da distribuição dos Z-scores dos agrupamentos Eci-11-1bt040, por betonada, por instrumentação 163

Figura 5.1.2.2.3 - Representação da distribuição dos Z-scores dos agrupamentos Ecs-1I-1bt070, por betonada, por instrumentação 164

Figura 5.1.2.2.4 - Representação da distribuição dos Z-scores dos agrupamentos Eci-1I-1bt070, por betonada, por instrumentação

Figura 5.1.2.2.5 - Representação da distribuição das classificações de exatidão (Ecs) 167 
Figura 5.1.2.2.6 - Representação da distribuição das classificações de exatidão (Eci) 167

Figura 5.1.3.1 - Histogramas e estatística dos agrupamento globais por traço de concreto ...169 Figura 5.1.3.1.1 - Composição das variâncias dos resultados independentemente da

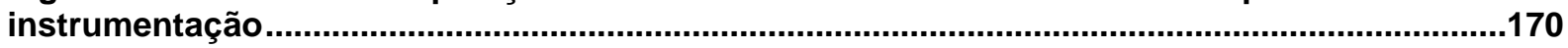

Figura 5.1.3.1.2 - Composição das variâncias e desvios-padrão dos agrupamentos dos concretos e planos de carregamento, independentemente das quatro instrumentações..........171

Figura 5.1.3.1.3 - Composição das variâncias e desvios-padrão dos agrupamentos dos concretos e planos de carregamento, independentemente de três instrumentações (3I) .........172

Figura 5.1.3.1.4 - Composição das variâncias e desvios-padrão dos agrupamentos dos concretos e planos de carregamento, independentemente de três instrumentações (3l), sendo

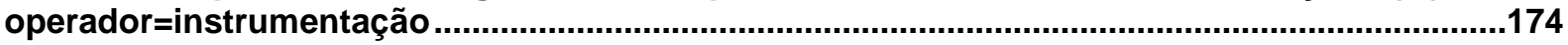

Figura 5.1.3.1.5 - Curvas de correlação: SG e 1R ...................................................................177

Figura 5.1.3.1.6 - Composição das variâncias e desvios-padrão dos agrupamentos dos concretos e planos de carregamento, independentemente de três instrumentações (SG, CG e

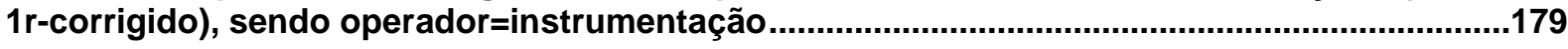

Figura 5.1.3.1.7 - Composição de variância e desvio-padrão ..................................................181

Figura 5.2.2.1 - Viga verificada quanto à deformação máxima admissível .................................195

Figura 5.2.2.1 - Viga verificada quanto à deformação máxima admissível .................................198

Figura 5.2.2.3 - Diferença na rigidez secante adimensional ..................................................199

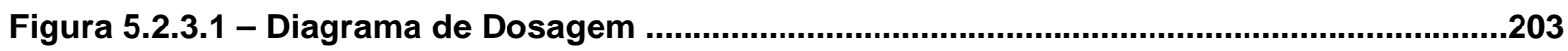

Figura 5.2.3.1.1 - Distribuição volumétrica dos compostos resistentes e não-resistentes ......206

Figura 5.2.3.1.2 - Distribuição volumétrica dos traços: ordem crescente de resistência .........208

Figura 5.2.3.1.3 - Distribuição volumétrica dos traços: ordem crescente de módulo ...............209

Figura 5.2.3.1.4 - Regressão linear: Ecs x CNR .....................................................................210

Figura 5.2.4.1 - Risco de não-conformidades em fornecimento de concreto ............................212

Figura 5.2.4.1.1 - Gráfico: Número de amostras total $x$ Desvio-padrão total $x$ Número de

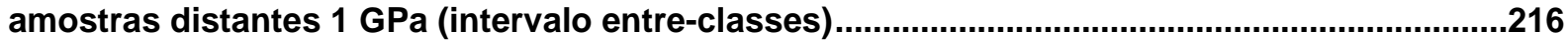

Figura 5.2.4.1.2 - Gráfico: Número de amostras total $x$ Desvio-padrão total $x$ Número de amostras distantes $3 \mathrm{GPa}$ (intervalo entre-classes).

Figura 5.2.4.1.3 - Gráfico: Número de amostras total $x$ Desvio-padrão total x Número de amostras distantes $5 \mathrm{GPa}$ (intervalo entre-classes) ...................................................................217 


\section{LISTA DE TABELAS}

Tabela 2.1.3.1 - Representações clássicas dos fenômenos reológicos .........................................35

Tabela 2.2.1 - Módulo de elasticidade das mais comuns rochas-matrizes de agregados ..........49

Tabela 2.2.1.1 - Quadro-resumo da distribuição volumétrica e respectivos módulos de

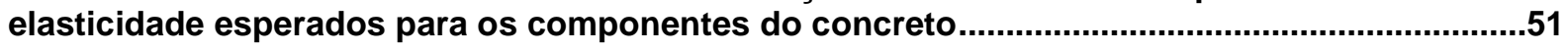

Tabela 2.3.1.1 - Pesquisadores e modelos micromecânicos............................................................59

Tabela 2.3.1.1 (continuação) - Pesquisadores e modelos micromecânicos ...............................60

Tabela 2.3.2.1. - Expressões recomendadas: Módulo de deformação do concreto x Resistência

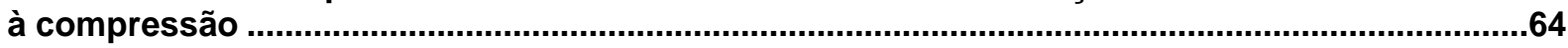

Tabela 3.2.1 - Resultados do interlaboratorial de módulo de deformação do concreto (2005) ..69

Tabela 3.2.1 (continuação) - Resultados do interlaboratorial de módulo de deformação do

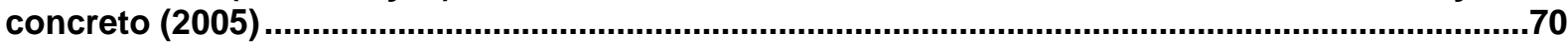

Tabela 3.2.2 - Resultados do interlaboratorial de módulo de deformação do concreto (2006) ..71

Tabela 3.2.3 - Análise dos resultados do interlaboratorial 2005 ..............................................74

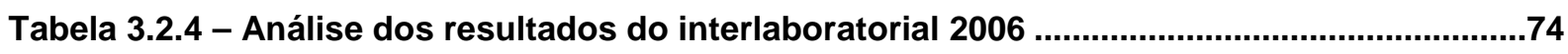

Tabela 3.3.3.1 - Tipos de regularização de base e topo de corpos-de-prova declarados no

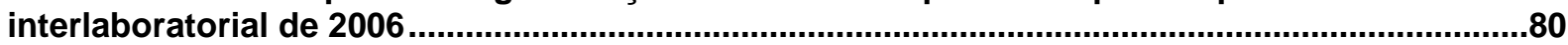

Tabela 3.3.5.1.1 - Velocidades de carregamento de algumas normas ..........................................84

Tabela 3.3.5.2.1 - Especificação do plano de carregamento de ensaio ........................................86

Tabela 4.1.1.1.1 - Tabela demonstrativa para os cálculos de precisão ......................................115

Tabela 4.3.1.1 - Traços e materiais utilizados na primeira etapa do programa experimental....126

Tabela 4.3.1.2 - Caracterização laboratorial do cimento utilizado (CPIII-40 RS)........................126

Tabela 4.3.1.2 (continuação) - Caracterização laboratorial do cimento utilizado (CPIII-40 RS) 127

Tabela 4.3.1.3 - Caracterização laboratorial dos agregados utilizados ...................................127

Tabela 4.3.2.1 - Traços e materiais utilizados na segunda parte do programa experimental....128

Tabela 4.3.2.2 - Caracterização laboratorial do cimento utilizado (CPIII-40 RS) - $2^{\text {a }}$ parte........129

Tabela 4.3.2.3 - Caracterização laboratorial da Brita 0 utilizada.................................................129

Tabela 5.1.1 - Resultados de módulo de deformação (GPa): a/c 0,40....................................132

Tabela 5.1.1 (continuação) - Resultados de módulo de deformação (GPa): a/c 0,40................133

Tabela 5.1.2 - Resultados de módulo de deformação (GPa): a/c 0,70 ...................................133

Tabela 5.1.2 (continuação) - Resultados de módulo de deformação (GPa): a/c 0,70................134

Tabela 5.1.1.1 - Cálculo dos compostos resistentes e não-resistentes ...................................136

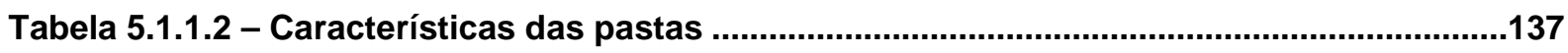

Tabela 5.1.1.3 - Características dos traços ensaiados ...............................................................138

Tabela 5.1.1.4 - Característica dos concretos obtida a partir dos modelos e dos experimentos 138

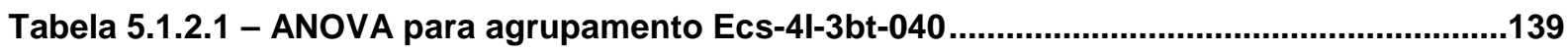

Tabela 5.1.2.2 - Verificação de 4l-3bt: instrumentações e betonadas........................................139 
Tabela 5.1.2.1.1 - Agrupamentos de módulo secante (Ecs) de três betonadas (3bt) do Concreto a/c 0,40 (040), por instrumentação: cálculo dos indicadores de precisão.

Tabela 5.1.2.1.2 - Agrupamentos de módulo tangente inicial (Eci) de três betonadas (3bt) do Concreto a/c 0,40 (040), por instrumentação: cálculo dos indicadores de precisão. 146

Tabela 5.1.2.1.3 - Agrupamentos de módulo secante (Ecs) de três betonadas (3bt) do Concreto a/c 0,70 (070), por instrumentação: cálculo dos indicadores de precisão.

Tabela 5.1.2.1.4 - Agrupamentos de módulo tangente inicial (Eci) de três betonadas (3bt) do Concreto a/c 0,70 (070), por instrumentação: cálculo dos indicadores de precisão..................149

Tabela 5.1.2.1.5 - Cálculos de precisão dos ensaios de resistência à compressão (3bt) .........154

Tabela 5.1.2.1.6 - Valores característicos sob instrumentações particulares: Ecs-1l-3bt-040..157

Tabela 5.1.2.1.7 - Valores característicos sob instrumentações particulares: Eci-1l-3bt-040...158

Tabela 5.1.2.1.8 - Valores característicos sob instrumentações particulares: Ecs-11-3bt-070..158

Tabela 5.1.2.1.9 - Valores característicos sob instrumentações particulares: Eci-1l-3bt-070...158

Tabela 5.1.2.2.1 - Agrupamentos de módulo secante (Ecs), por betonada (1bt), do Concreto a/c 0,40 (040), por instrumentação: cálculo dos indicadores de exatidão.. 160

Tabela 5.1.2.2.2 - Agrupamentos de módulo tangente inicial (Eci), por betonada (1bt), do Concreto a/c 0,40 (040), por instrumentação: cálculo dos indicadores de exatidão ...................162

Tabela 5.1.2.2.3 - Agrupamentos de módulo secante (Ecs), por betonada (1bt), do Concreto a/c 0,70 (070), por instrumentação: cálculo dos indicadores de exatidão

Tabela 5.1.2.2.4 - Agrupamentos de módulo tangente inicial (Eci), por betonada (1bt), do Concreto a/c 0,70 (070), por instrumentação: cálculo dos indicadores de exatidão ...................165

Tabela 5.1.2.2.5 - Freqüência de ocorrência das classificações de exatidão no conjunto dos agrupamentos de resultados de módulo de deformação secante (Ecs) ......................................167

Tabela 5.1.2.2.6 - Freqüência de ocorrência das classificações de exatidão no conjunto dos agrupamentos de resultados de módulo de deformação tangente inicial (Eci)..........................167

Tabela 5.1.3.1.1 - Agrupamentos de módulo secante (Ecs) e tangente inicial (Eci) de três betonadas (3bt) dos Concretos a/c 0,40 (040) e a/c 0,70 (070), independentemente das quatro instrumentações (4I): cálculo dos indicadores de precisão. 170

Tabela 5.1.3.1.2 - Agrupamentos de módulo secante (Ecs) e tangente inicial (Eci) de três betonadas (3bt) dos Concretos a/c 0,40 (040) e a/c 0,70 (070), independentemente de três instrumentações (3I): cálculo dos indicadores de precisão. 172

Tabela 5.1.3.1.3 - Agrupamentos de módulo secante (Ecs) e tangente inicial (Eci) de três betonadas (3bt) dos Concretos a/c 0,40 (040) e a/c 0,70 (070), independentemente de três instrumentações (3I), sendo operador=instrumentação: cálculo dos indicadores de precisão

Tabela 5.1.3.1.4 - Verificação de 3l-3bt: instrumentações e betonadas ....................................175

Tabela 5.1.3.1.5 - Verificação de 2l-3bt: instrumentações e betonadas ......................................176

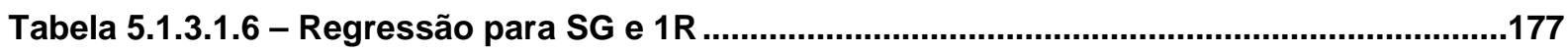

Tabela 5.1.3.1.7 - Verificação de 3I-3bt (1R-corrigido): instrumentações e betonadas ............178

Tabela 5.1.3.1.8 - Agrupamentos de módulo secante (Ecs) e tangente inicial (Eci) de três betonadas (3bt), Concretos a/c 0,40 (040) e a/c 0,70 (070), independentemente de três instrumentações (SG, CG e 1R-corrigido), operador=instrumentação: cálculos de precisão ..178

Tabela 5.1.3.1.9 - Cálculos de precisão: 3l-3bt

Tabela 5.1.3.1.10 - Cálculos comparativos de precisão: Dissertação x Interlaboratorial nacional 181

Tabela 5.1.3.2.1 - Planilha de cálculo de exatidão - Ecs-1I-1bt-040 (SG, CG, 1R) 183

Tabela 5.1.3.2.2 - Planilha de cálculo de exatidão - Eci-1l-1bt-040 (SG, CG, 1R) . 183 
Tabela 5.1.3.2.3 - Planilha de cálculo de exatidão - Ecs-1l-1bt-070 (SG, CG, 1R) .

Tabela 5.1.3.2.4 - Planilha de cálculo de exatidão - Eci-1l-1bt-070 (SG, CG, 1R)

Tabela 5.1.3.2.5 - Planilha de cálculo de exatidão - Ecs-1I-1bt-040 (SG, CG, 1R-corrigido) .....186

Tabela 5.1.3.2.6 - Planilha de cálculo de exatidão - Eci-1l-1bt-040 (SG, CG, 1R-corrigido) .....187

Tabela 5.1.3.2.7 - Planilha de cálculo de exatidão - Ecs-1l-1bt-070 (SG, CG, 1R-corrigido) ....188

Tabela 5.1.3.2.8 - Planilha de cálculo de exatidão - Eci-1l-1bt-070 (SG, CG, 1R-corrigido) .....189

Tabela 5.2.1 - Resultados prévios de resistência à compressão (MPa): a/c 0,42, 0,50 e 0,58...190

Tabela 5.2.2 - Resultados de módulo de deformação (GPa): a/c 0,42, 0,50 e 0,58 .

Tabela 5.2.1.1 - Resultados médios de módulo - Ecs,m-1l-1bt-040 (SG, CG, 1R-corrigido) .....191

Tabela 5.2.1.2 - Resultados médios de módulo - Eci,m-1l-1bt-040 (SG, CG, 1R-corrigido) .....192

Tabela 5.2.1.3 - Resultados médios de módulo - Ecs,m-1l-1bt-070 (SG, CG, 1R-corrigido) ....192

Tabela 5.2.1.4 - Resultados médios de módulo - Eci,m-1l-1bt-070 (SG, CG, 1R-corrigido) ......193

Tabela 5.2.1.5 - Resultados de módulo de deformação do Concreto a/c 0,40 (040): Individuais $x$ Médios (SG, CG, 1R-corrigido).

Tabela 5.2.1.6 - Resultados de módulo de deformação do Concreto a/c 0,70 (070): Individuais $x$ Médios (SG, CG, 1R-corrigido)....................................................................................................193

Tabela 5.2.2.1 - Verificação de ELS-DEF: módulo de deformação do concreto de 26 GPa.......196

Tabela 5.2.2.2 - Verificação de ELS-DEF: módulo de deformação do concreto de 22 GPa.......196

Tabela 5.2.2.3 - Diferença na rigidez secante adimensional .....................................................199

Tabela 5.2.3.1 - Resumo da caracterização de dosagens da segunda etapa..............................201

Tabela 5.2.3.2 - Regressão para Curva de Abrams .........................................................................201

Tabela 5.2.3.3 - Regressão para Curva de Lyse ........................................................................201

Tabela 5.2.3.4 - Regressão para Curva de Molinari ........................................................................202

Tabela 5.2.3.5 - Regressão para Curva de módulo de deformação x teor de materiais secos .202

Tabela 5.2.3.6 - Diagrama de Dosagem ....................................................................................202

Tabela 5.2.3.1.1 - Cálculo dos compostos resistentes e não-resistentes ...................................205

Tabela 5.2.3.1.2 - Características das pastas ................................................................................206

Tabela 5.2.3.1.3 - Características dos traços ensaiados ...........................................................207

Tabela 5.2.3.1.4 - Característica dos concretos obtida a partir dos modelos e dos experimentos .207

Tabela 5.2.3.1.5 - Modelo de composição para os resultados de resistência.............................209

Tabela 5.2.3.1.6 - Cálculo dos compostos resistentes e não-resistentes e Curva de regressão 210

Tabela 5.2.3.1.7 - Atualização do quadro-resumo de distribuição volumétrica e rigidez (28 dias)

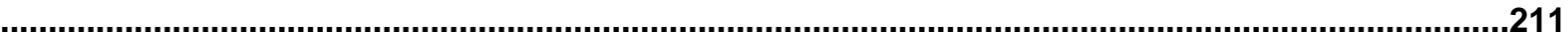

Tabela 5.2.4.1.1 - Classes de resistência atendidas .................................................................214

Tabela 5.2.4.1.2 - Valores de $t$-Student para nível de significância de $5 \%$.................................216

Tabela 5.2.4.1.3- Classes de resistência e módulo de deformação atendidas na segunda etapa do programa experimental ...............................................................................................219

Tabela A.1 - Resultados dos ensaios prévios de resistência à compressão: a/c 0,40 .............235

Tabela A.2 - Resultados de módulo de deformação: a/c 0,40...................................................235

Tabela A.3 - Resultados dos ensaios prévios de resistência à compressão: a/c 0,70 ..............247 
Tabela A.4 - Resultados de módulo de deformação: a/c 0,70

Tabela B.1 - Resultados dos ensaios prévios de resistência à compressão: a/c 0,42. 0,50 e

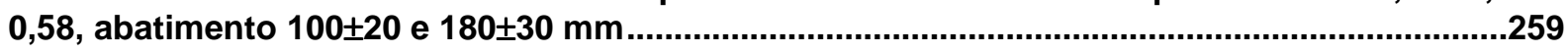

Tabela B.2 - Resultados de módulo de deformação: a/c 0,42. 0,50 e 0,58, abatimento $100 \pm 20$ e $180 \pm 30 \mathrm{~mm}$ 


\section{SUMÁRIO}

1 INTRODUÇÃO

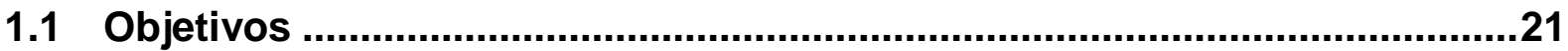

1.2 Limitações da pesquisa

2 FUNDAMENTOS DA DEFORMABILIDADE DO CONCRETO ..............................

2.10 conceito de elasticidade dos materiais.................................................23

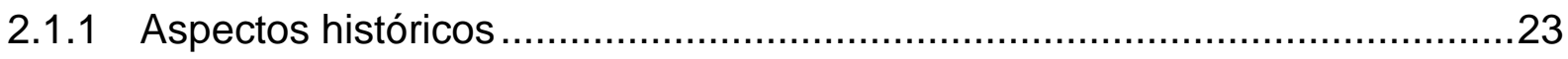

2.1.2 A Lei de Hooke generalizada (tridimensional) ........................................24

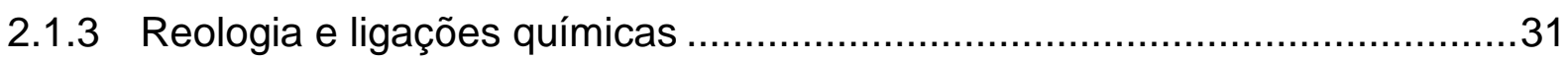

2.2 A microestrutura e a deformabilidade do concreto ...................................35

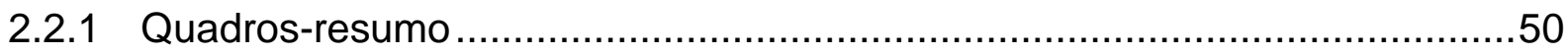

2.2.2 Modelo de quantificação da composição microestrutural .............................52

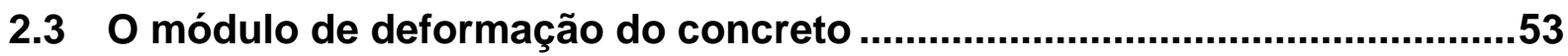

2.3.1 Modelos de previsão do módulo de deformação do concreto a partir da

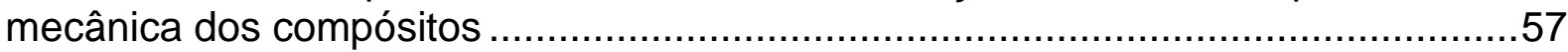

2.3.2 Inferência do módulo de deformação a partir da resistência à compressão..62

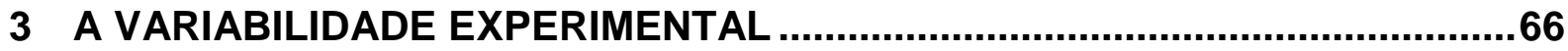

3.1 Controle de qualidade da propriedade: o ensaio de módulo.......................67

3.2 Evidências da variabilidade experimental ..................................................68

3.3 Principais fatores intervenientes (origens da variabilidade) .......................75

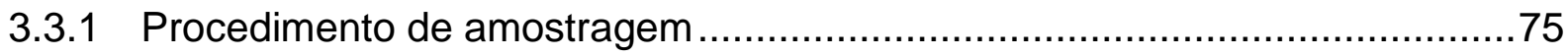

3.3.2 Procedimento de preparação da máquina de ensaios..................................76

3.3.3 Procedimento de preparação dos corpos-de-prova ......................................78

3.3.4 Ensaio prévio de resistência à compressão axial .......................................80

3.3.5 Ensaio de determinação do módulo de deformação .....................................82

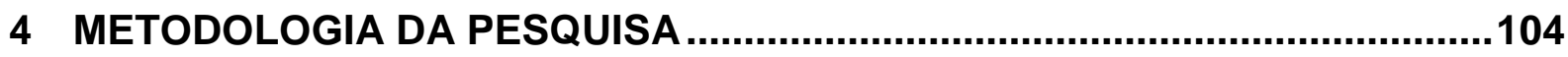

4.1 Avaliação da acurácia do método de ensaio.............................................104 
4.1.1 Ferramentas estatísticas para análise

4.2 Discussão da aplicação do conceito semiprobabilístico normativo à propriedade módulo de deformação

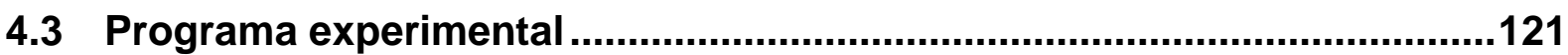

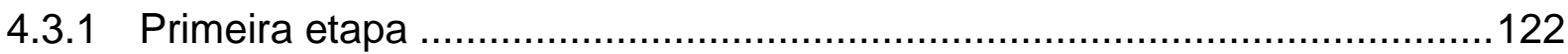

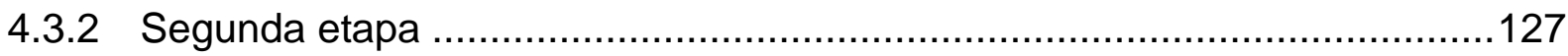

4.4 Fluxogramas das atividades da pesquisa ..............................................129

5 APRESENTAÇÃO E ANÁLISE DOS RESULTADOS …................................132

5.1 Avaliação da acurácia do método de ensaio..........................................132

5.1.1 Avaliação preliminar através dos modelos de previsão ………………......136

5.1.2 Análise do método sob cada uma das instrumentações para medida das deformações.

5.1.3 Avaliação global do método de ensaio 168

5.2 Discussão da aplicabilidade do conceito semiprobabilístico normativo 190

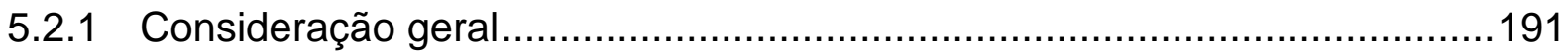

5.2.2 Implicações sobre a deformação estrutural .............................................195

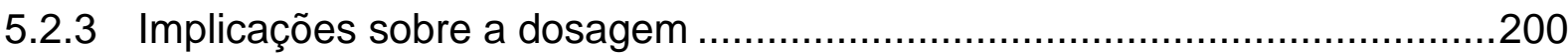

5.2.4 Implicações sobre o controle de qualidade de obra..................................212

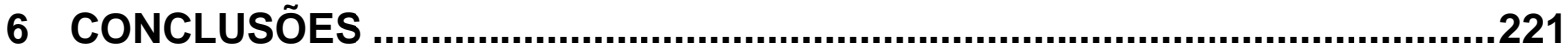

7 SUGESTÕES DE CONTINUIDADE DA PESQUISA …...................................227

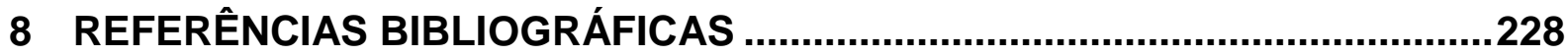

APÊNDICE A - RESULTADOS DOS ENSAIOS DA PRIMEIRA ETAPA ...............235

APÊNDICE B - RESULTADOS DOS ENSAIOS DA SEGUNDA ETAPA..............259 


\section{INTRODUÇÃO}

O controle experimental de qualidade dos produtos industriais tem sido a principal ferramenta de avaliação das cadeias produtivas.

Desde o período pós-guerras, o grande conceito de mercado que evidenciava o valor do controle experimental era o da Qualidade Total, idealizado por Willian Edwards Deming, estatístico do programa estratégico dos Estados Unidos na II Guerra Mundial. No final dos anos 1940 e após sucessivas tentativas fracassadas em seu próprio país, Deming divulgou no Japão seus conceitos estatísticos voltados para a qualidade aceitando convite para um seminário da União Japonesa de Cientistas e Engenheiros (JUSE). Nos anos seguintes, atuou junto a muitas empresas japonesas cedendo, inclusive, direitos autorais sobre métodos da Qualidade Total a algumas delas. Deming teve seu trabalho reconhecido pelo governo daquele país e, em 1960, recebeu das mãos do então primeiro-ministro Kishi Nobosuke a Ordem Segunda do Tesouro Sagrado, uma das mais importantes condecorações japonesas. O estatístico pregava que a produtividade só aumenta à medida que a qualidade avança comprovadamente - principalmente baseando-se em experimentos - gerando menor desperdício.

No final da década de 1980, outro conceito definiu-se e agregou-se ao da Qualidade Total: o do Desenvolvimento Sustentável. Nascido em 1987 com o Relatório intitulado "Nosso Futuro Comum", também conhecido como Relatório Brundtland - elaborado pela Comissão Mundial sobre o Meio Ambiente e Desenvolvimento, criada pelas Nações Unidas e presidida pela então PrimeiraMinistra da Noruega, Gro Harlen Brundtland - o conceito de Desenvolvimento Sustentável através da busca por um desenvolvimento que atendesse às necessidades do presente sem comprometer a possibilidade de as gerações futuras atenderem às suas próprias necessidades passou a participar do planejamento da produção e do controle da qualidade. Pode-se dizer, que um cenário de consciência global se forjou e o controle experimental da qualidade ganhou ainda mais força como fonte geradora de dados para a análise e a decisão sobre 0 atendimento às especificações planejadas e/ou projetadas para a garantia da sustentatibilidade das iniciativas de produção.

Mas, nesse sentido, o quê ou quem controla a qualidade do experimento que possibilitará o controle da qualidade do produto e conseqüentemente da produção? 
Evidentemente, o controle experimental que 'comprova' ou que constitui ferramenta para a 'garantia' do atendimento às especificações de projeto necessita ter acurácia e confiabilidade, e estas são geridas diretamente pelos teóricos dos experimentos e seus usuários e indiretamente pela própria sociedade. Acurácia e confiabilidade são conceitos oriundos da Metrologia que, em suma, significam a obtenção de um valor experimental próximo ao do valor verdadeiro da grandeza física que se está medindo em qualquer tempo ou lugar, sejam quantos forem os experimentos realizados.

Esta dissertação procura inserir-se como um estudo sobre o controle experimental da qualidade de uma grandeza física de um produto particular: a propriedade mecânica do módulo estático de deformação do concreto. Essa escolha é motivada pela elevada variabilidade de resultados experimentais observada para o ensaio pelo meio técnico nacional.

Para tal, optou-se por seguir uma ordenação de pesquisa que contém no Capítulo 2 uma revisão das características microestruturais do material inerentes à propriedade, no Capítulo 3 um levantamento de evidências e de fatores intervenientes para a variabilidade dos resultados experimentais e, por fim, nos Capítulos 4 e 5, o relato e a análise da execução de um programa experimental que aplicasse uma metodologia de avaliação da acurácia da determinação experimental principalmente sob a influência da alternância da instrumentação para medida das deformações e que permitisse avaliar a implicação da desconsideração normativa atual da variabilidade desta propriedade sobre o controle tecnológico realizado em obras de concreto.

\subsection{Objetivos}

Assim sendo, este trabalho tem o objetivo de avaliar a variabilidade nos resultados de módulo estático de deformação do concreto sob os seguintes aspectos:

- buscar a identificação das parcelas da variabilidade oriundas da produção e do ensaio, com especial atenção àquela originada na instrumentação para medida das deformações; 
- testar uma sistemática para avaliação da acurácia do método de ensaio através de ferramentas estatísticas;

- discutir a aplicação do conceito semiprobabilístico das normas nacionais de projeto, dosagem e controle tecnológico de estruturas de concreto no que se refere à propriedade módulo de deformação, avaliando a desconsideração, pelas normas técnicas, da variabilidade observada nos resultados experimentais.

\subsection{Limitações da pesquisa}

As conclusões desta pesquisa possuirão limitações principalmente pelo fato do programa experimental previsto:

- conter um pequeno número de traços de concreto e um único grupo de insumos ou materiais constituintes, não obstante privilegiar a quantidade de amostras ensaiadas de cada um desses traços;

- dispor apenas de resultados laboratoriais;

- restringir a utilização de equipamentos aos disponíveis no laboratório do Centro de Pesquisas e Desenvolvimento em Construção Civil (CpQDCC) da Escola Politécnica da Universidade de São Paulo;

- dispor de um único operador dos equipamentos.

A implicação desses itens sobre as conclusões é que as tornam incapazes de serem objetivas para a validação metrológica do método de ensaio dada a variabilidade quantificada e uma tolerância arbitrada ou calculada. Porém, consegue-se indicar as diretrizes para a compreensão das origens da variabilidade e as ações para a sua diminuição, o que atende aos objetivos propostos para o trabalho. 


\section{FUNDAMENTOS DA DEFORMABILIDADE DO CONCRETO}

Inicialmente devem ser apresentados os fundamentos teóricos da propriedade módulo de elasticidade dos materiais em geral, para, em seguida, ser abordada a propriedade de forma particular com respeito ao concreto.

\subsection{O conceito de elasticidade dos materiais}

\subsubsection{Aspectos históricos}

A formulação do conceito de elasticidade se deu a partir dos trabalhos do físico inglês Robert Hooke, que viveu de 1635 a 1703. Hooke observou que em alguns materiais existia proporcionalidade entre a força aplicada no sentido de alongamento do objeto e a extensão dele até um certo limite de solicitação. Atualmente, este enunciado fundamentalmente unidimensional é chamado de Lei de Hooke e é expresso da seguinte forma:

$$
F=k \cdot x
$$

onde $F$ representa a solicitação sobre o objeto, $x$ a deformação causada no objeto pela solicitação e $k$ a constante de proporcionalidade característica da natureza material do objeto, também chamada de constante elástica ou de mola.

Adiante, em 1802, Thomas Young — médico e físico inglês que viveu de 1773 a 1829 - retomou os estudos de Hooke e foi o primeiro a estabelecer a idéia de módulo de elasticidade ao relacionar o comprimento de um objeto àquilo que, após a formulação do conceito por Augustin L. Cauchy (matemático francês, 1789-1857) anos depois, poderia ser denominado de tensão sobre uma célula unitária do objeto (VASCONCELOS e GIAMMUSSO, 1998).

No século passado, todos os princípios matemáticos de modelagem do comportamento elástico dos materiais foram reunidos na chamada Teoria da Elasticidade. 
2.1.2 A Lei de Hooke generalizada (tridimensional)

As principais forças que podem atuar sobre um corpo são as forças de superfície - pressão de um corpo sobre outro, por exemplo - e as forças de massa ou volume - forças gravitacionais, magnéticas, etc.

Considere-se, pois, um corpo em equilíbrio estático. Quando solicitado por qualquer tipo de força, um campo de tensões será induzido nos elementos infinitesimais do corpo, conforme mostrado nas representações da Fig. 2.1.2.1.a-b.

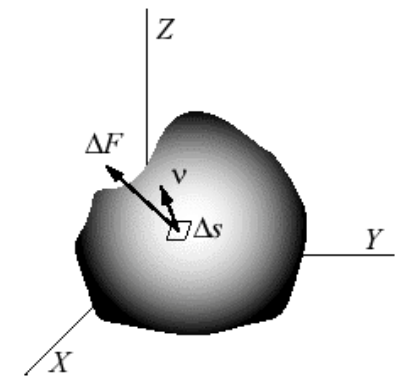

(a)

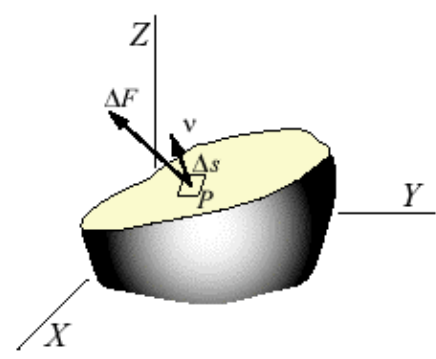

(b)

Figura 2.1.2.1 - Representação de um corpo sob solicitação (de tração): (a) Tensão superficial $\Delta F / \Delta S$; (b) Tensão interna $\Delta F / \Delta S$

A análise de um elemento infinitesimal desse corpo mostrará uma configuração de tensões atuantes como a da Fig. 2.1.2.2. Três dos símbolos representam as tensões normais $\left(\sigma_{x x}, \sigma_{y y}, \sigma_{z z}\right)$ e seis representam as tensões cisalhantes $\left(\sigma_{\mathrm{xy}}, \sigma_{\mathrm{xz}}, \sigma_{\mathrm{yx}}, \sigma_{\mathrm{yz}}, \sigma_{\mathrm{zx}}, \sigma_{\mathrm{zy}}\right)$ - que também podem são representadas usualmente por $\tau_{x y}, \tau_{y x}, \tau_{x z}, \tau_{z x}, \tau_{y z}, \tau_{z y}$

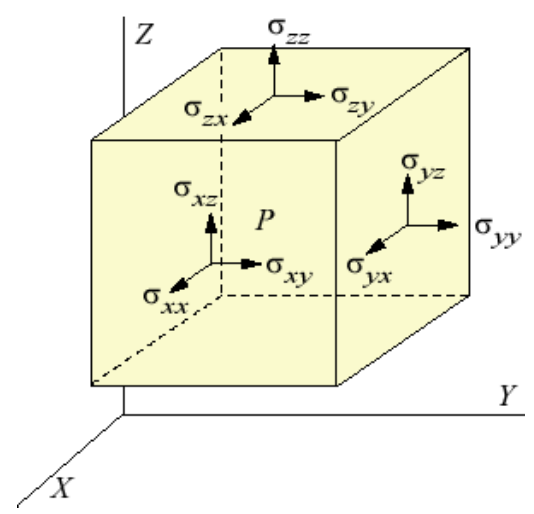

Figura 2.1.2.2 - Representação de elemento infinitesimal do corpo sob solicitação (de tração) 
A matriz de tensões no elemento será dada por:

$$
\left[\begin{array}{lll}
\sigma_{x x} & \sigma_{x y} & \sigma_{x z} \\
\sigma_{y x} & \sigma_{y y} & \sigma_{y z} \\
\sigma_{z x} & \sigma_{z y} & \sigma_{z z}
\end{array}\right]
$$

Timoshenko e Goodier (1980) já demonstraram que dessas nove componentes, seis seriam suficientes para compor a tensão no elemento porque $\sigma_{x y}$ $=\sigma_{y x}, \sigma_{x z}=\sigma_{z x}$ e $\sigma_{y z}=\sigma_{z y}$.

Esses autores mostraram também que se o material estiver inserido em um ambiente presumido com suficientes restrições para evitar o deslocamento de corpo rígido e as tensões solicitantes forem suficientes para causar a perturbação do equilíbrio estático mas não para causar a ruptura do material em qualquer das direções de atuação, este corpo (e seus elementos) apresentará deformações, isto é, deslocamento de partículas do corpo sem que o todo tenha se deslocado - vetor $u$ entre os pontos $\mathrm{P}$ e $\mathrm{P}^{\prime}$ na Fig. 2.1.2.3.

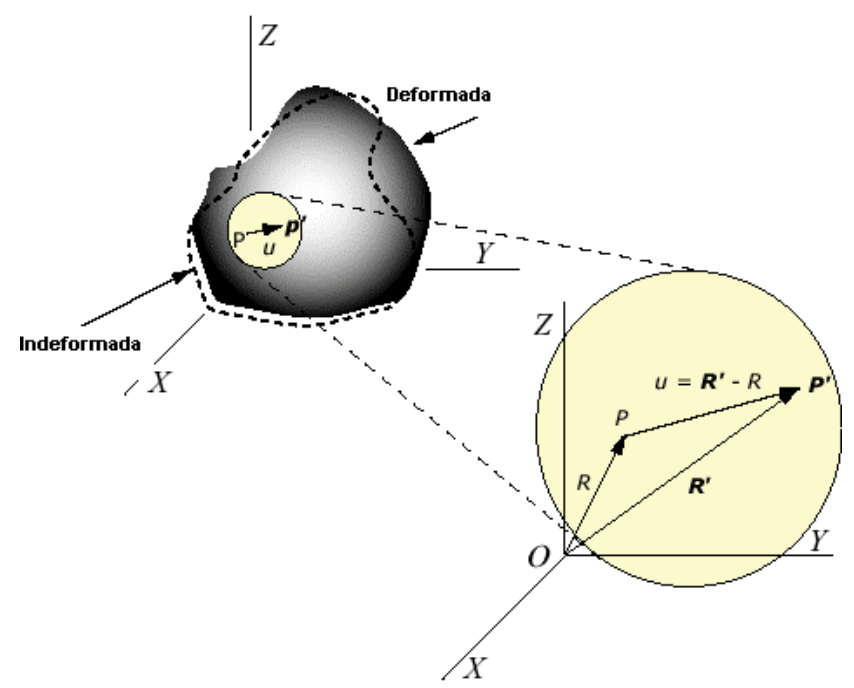

Figura 2.1.2.3 - Representação de um ponto do corpo em deformação

Assim, o elemento para o qual já foram apresentadas as componentes de tensão também terá suas componentes de deformação, num total de seis, em que: 


$$
\begin{array}{ll}
\varepsilon_{x x}=\frac{\partial r}{\partial x} & \varepsilon_{y z}=\left(\frac{\partial w}{\partial y}+\frac{\partial v}{\partial z}\right)=\varepsilon_{z y} \\
\varepsilon_{y y}=\frac{\partial v}{\partial y} & \varepsilon_{z x}=\left(\frac{\partial r}{\partial z}+\frac{\partial w}{\partial x}\right)=\varepsilon_{x z} \\
\varepsilon_{z z}=\frac{\partial w}{\partial z} & \varepsilon_{x y}=\left(\frac{\partial v}{\partial x}+\frac{\partial r}{\partial y}\right)=\varepsilon_{y x}
\end{array}
$$

onde $\varepsilon_{x x}, \varepsilon_{y y}, \varepsilon_{z z}$ são chamadas de deformações axiais específicas e $\varepsilon_{x y}, \varepsilon_{x z}, \varepsilon_{y x}, \varepsilon_{y z}, \varepsilon_{z x}$, $\varepsilon_{z y}$ ou também $\gamma_{x y}, \gamma_{x z}, \gamma_{y x}, \gamma_{y z}, \gamma_{z x}, \gamma_{z y}$ são chamadas de distorções ou deformações angulares.

Então, a matriz de deformações no elemento será dada por:

$$
\left[\begin{array}{lll}
\varepsilon_{x x} & \varepsilon_{x y} & \varepsilon_{x z} \\
\varepsilon_{y x} & \varepsilon_{y y} & \varepsilon_{y z} \\
\varepsilon_{z x} & \varepsilon_{z y} & \varepsilon_{z z}
\end{array}\right]
$$

Essas conclusões embasam o enunciado da Lei de Hooke generalizada para a modelagem de solicitações tridimensionais em corpos ditos elásticos, conforme a notação a seguir:

$$
\begin{gathered}
{\left[\begin{array}{c}
\sigma_{x x} \\
\sigma_{y y} \\
\sigma_{z z} \\
\sigma_{y z} \\
\sigma_{z x} \\
\sigma_{x y}
\end{array}\right]=\left[\begin{array}{cccccc}
C_{11} & \mathrm{C}_{12} & \mathrm{C}_{13} & \mathrm{C}_{14} & \mathrm{C}_{15} & \mathrm{C}_{16} \\
\mathrm{C}_{21} & \mathrm{C}_{22} & \mathrm{C}_{23} & \mathrm{C}_{24} & \mathrm{C}_{25} & \mathrm{C}_{26} \\
\mathrm{C}_{31} & \mathrm{C}_{32} & \mathrm{C}_{33} & \mathrm{C}_{34} & \mathrm{C}_{35} & \mathrm{C}_{36} \\
\mathrm{C}_{41} & \mathrm{C}_{42} & \mathrm{C}_{43} & \mathrm{C}_{44} & \mathrm{C}_{45} & \mathrm{C}_{46} \\
\mathrm{C}_{51} & \mathrm{C}_{52} & \mathrm{C}_{53} & \mathrm{C}_{54} & \mathrm{C}_{55} & \mathrm{C}_{56} \\
\mathrm{C}_{61} & \mathrm{C}_{62} & \mathrm{C}_{63} & \mathrm{C}_{64} & \mathrm{C}_{65} & \mathrm{C}_{66}
\end{array}\right]\left[\begin{array}{l}
\varepsilon_{x x} \\
\varepsilon_{y y} \\
\varepsilon_{z z} \\
\varepsilon_{y z} \\
\varepsilon_{z x} \\
\varepsilon_{x y}
\end{array}\right]} \\
\text { ou } \\
{[\sigma]=[C] \cdot[\varepsilon]}
\end{gathered}
$$

onde a matriz $[\sigma$ é a matriz de tensões, $[\varepsilon]$ é a matriz de deformações e $[C]$ é a chamada matriz de rigidez do corpo material. A inversa da matriz de rigidez é a chamada matriz de compliância ([S]).

Tal modelo constitutivo, de caráter micromecânico, colabora com a entendimento do desempenho mecânico de quaisquer materiais elásticos, isotrópicos ou anisotrópicos.

Lembra-se que, segundo Callister (2002), materiais isotrópicos ou isótropos são aqueles em que as propriedades mecânicas, elétricas, magnéticas, térmicas, 
acústicas ou ópticas independem da direção de avaliação. Isto quer dizer que a estrutura interna do material não possui direções preferenciais de formação cristalográfica ou que sua eventual orientação cristalográfica é de tal forma aleatoriamente distribuída na constituição do corpo que acaba por produzir resultado isotrópico. Os materiais anisotrópicos são, por conseguinte, o inverso disso.

Corpos materiais isotrópicos podem ser, por sua vez, homogêneos ou não. Homogeneidade é a observação de que as propriedades estão distribuídas de forma contínua por todo o corpo material e que, em tese, o menor elemento do corpo apresenta as mesmas características do todo. Esse conceito está implícito na formulação apresentada anteriormente e nas teorias particulares referentes ao concreto.

Freqüentemente a homogeneidade se confunde com o conceito de fase única, isto é, a homogeneidade enquanto propriedade do produto de uma mistura de materiais de características distintas, mas que compõem um outro material único em seu todo.

Note-se que isotropia e a homogeneidade são facilmente relacionáveis.

Nos materiais homogêneos, a isotropia é mais fácil de ser entendida. Nos materiais multifásicos, no entanto, nitidamente heterogêneos, a isotropia pode ocorrer também devido a aleatoriedade eventual das fases que permita ao todo responder de maneira isotrópica, como ocorre com a maioria dos materiais compósitos.

A Lei de Hooke para materiais isotrópicos e homogêneos tem a forma:

$$
\left[\begin{array}{c}
\sigma_{x x} \\
\sigma_{y y} \\
\sigma_{z z} \\
\sigma_{y z} \\
\sigma_{z x} \\
\sigma_{x y}
\end{array}\right]=\frac{E}{(1+v)(1-2 v)}\left[\begin{array}{cccccc}
1-v & v & v & 0 & 0 & 0 \\
v & 1-v & v & 0 & 0 & 0 \\
v & v & 1-v & 0 & 0 & 0 \\
0 & 0 & 0 & 1-2 v & 0 & 0 \\
0 & 0 & 0 & 0 & 1-2 v & 0 \\
0 & 0 & 0 & 0 & 0 & 1-2 v
\end{array}\right]\left[\begin{array}{c}
\varepsilon_{x x} \\
\varepsilon_{y y} \\
\varepsilon_{z z} \\
\varepsilon_{y z} \\
\varepsilon_{z x} \\
\varepsilon_{x y}
\end{array}\right]
$$

onde $E$ é a constante de proporcionalidade elástica característica da natureza material do corpo e é chamada de módulo de elasticidade axial ou módulo de Young, e $v$ é o coeficiente que relaciona as deformações transversais com as longitudinais conforme a direção principal do esforço atuante, sendo comumente denominado de coeficiente de Poisson. 
Suponha-se um corpo isotrópico e homogêneo solicitado por uma tensão normal unidirecional (suposta $\sigma_{x x}$ ). Haverá então um limite de proporcionalidade associado à relação entre a tensão e a deformação em que:

$$
\begin{gathered}
\sigma_{x x}=E \cdot \varepsilon_{x x} \\
\varepsilon_{y y}=\varepsilon_{z z}=-\nu \cdot \varepsilon_{x x}
\end{gathered}
$$

Acrescente-se a estas características um outro conceito associado ao resultado prático: o de elasticidade linear e não-linear. A proporcionalidade que existe entre tensão e deformação pode constituir uma curva tensão-deformação retilínea conforme mostrado na Fig. 2.1.2.4.a. Paralelamente, outros materiais podem ser classificados como elásticos não-lineares (Fig. 2.1.2.4.b). Em ambos os casos, no entanto, haverá reversão completa da deformação se anulada a solicitação. Note-se que a constante de proporcionalidade elástica denominada de módulo de elasticidade é numericamente igual ao coeficiente angular da reta tensãodeformação dos materiais elásticos lineares. No caso dos não-lineares, o valor do módulo de elasticidade axial constitui uma aproximação matemática.

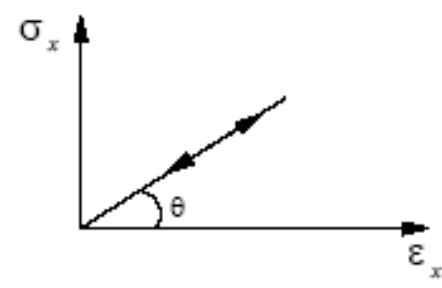

(a)

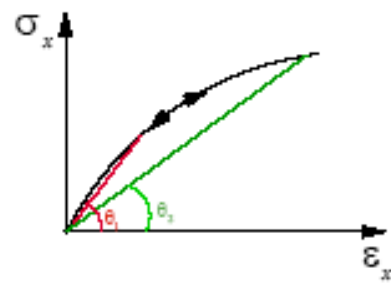

(b)

Figura 2.1.2.4 - Curvas tensão normal-deformação específica axial: (a) material elástico linear; (b) material elástico não-linear

Ainda acerca do corpo isotrópico, homogêneo e elástico linear, suponha-se agora solicitado por tensão cisalhante como pode ocorrer no caso de simultaneamente existirem tensões normais em planos ortogonais ( $\sigma_{x}=0, \sigma_{y}=-\sigma \mathrm{e}$ $\sigma_{y}=\sigma$ ). Timoshenko e Goodier (1980) demonstraram que a relação entre a deformação angular e a tensão cisalhante será dada por (Fig. 2.1.2.5):

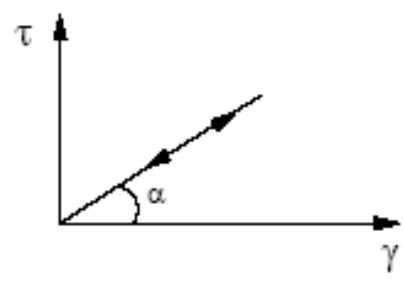

$$
\tau=G \cdot \gamma
$$

Figura 2.1.2.5 - Curva tensão cisalhante-deformação angular de um material elástico linear 
$E$ que:

$$
G=\frac{E}{2 \cdot(1+v)}
$$

onde $G$ é chamado de módulo de elasticidade transversal ou de cisalhamento do material.

Se ainda ocorrer sobre o corpo isotrópico, homogêneo e elástico linear um caso de solicitação por pressão hidrostática, valerá a expressão:

$$
K=\frac{E}{3 \cdot(1-2 v)}
$$

onde $K$ é chamado de módulo de elasticidade volumétrico. Neste caso, a elasticidade estará diretamente ligada à densidade do corpo material pois haverá mudança de volume sem a mudança de massa.

Note-se que ainda discutindo a Teoria da Elasticidade, valem as seguintes relações:

$$
E=\frac{9 K G}{3 K+G} \quad \text { e } \quad v=\frac{3 K-2 G}{6 K+2 G}
$$

Lembra-se, por fim que a propriedade módulo de elasticidade também está diretamente ligada à condutividade geral do material. Se for considerada a propagação de ondas de som em um material elástico perfeito, e se não há perdas no sistema, sabe-se que vale para corpos elásticos a relação:

$$
v s=\sqrt{\frac{C}{\rho}}
$$

onde vs é velocidade do som, $\rho$ é a densidade do material e $C$ é uma constante genérica de elasticidade do material. Em linhas gerais, então, para os materiais elásticos e lineares usuais, pode-se considerar que:

- nos sólidos: $\quad v s_{s o l}=\sqrt{\frac{E}{\rho}}$

- nos fluidos: $\quad v s_{f l u}=\sqrt{\frac{K}{\rho}}$

onde $v s_{s o l}$ é velocidade de propagação da onda sonora unidirecional no corpo sólido, $v s_{f l u}$ é velocidade de propagação da onda sonora multidirecional (hidrostática) em um fluido. 
A relação $E / \rho$ foi também bastante difundida na Engenharia a partir dos Diagramas de Ashby - um deles representado na Fig. 2.1.2.6. Mostra-se que quanto maior o coeficiente angular da reta entre $E$ e $\rho$, maior a eficiência do material em termos de rigidez por unidade de massa.

Nota: A figura foi mantida com textos em idioma estrangeiro dada a complexidade da alteração do original.

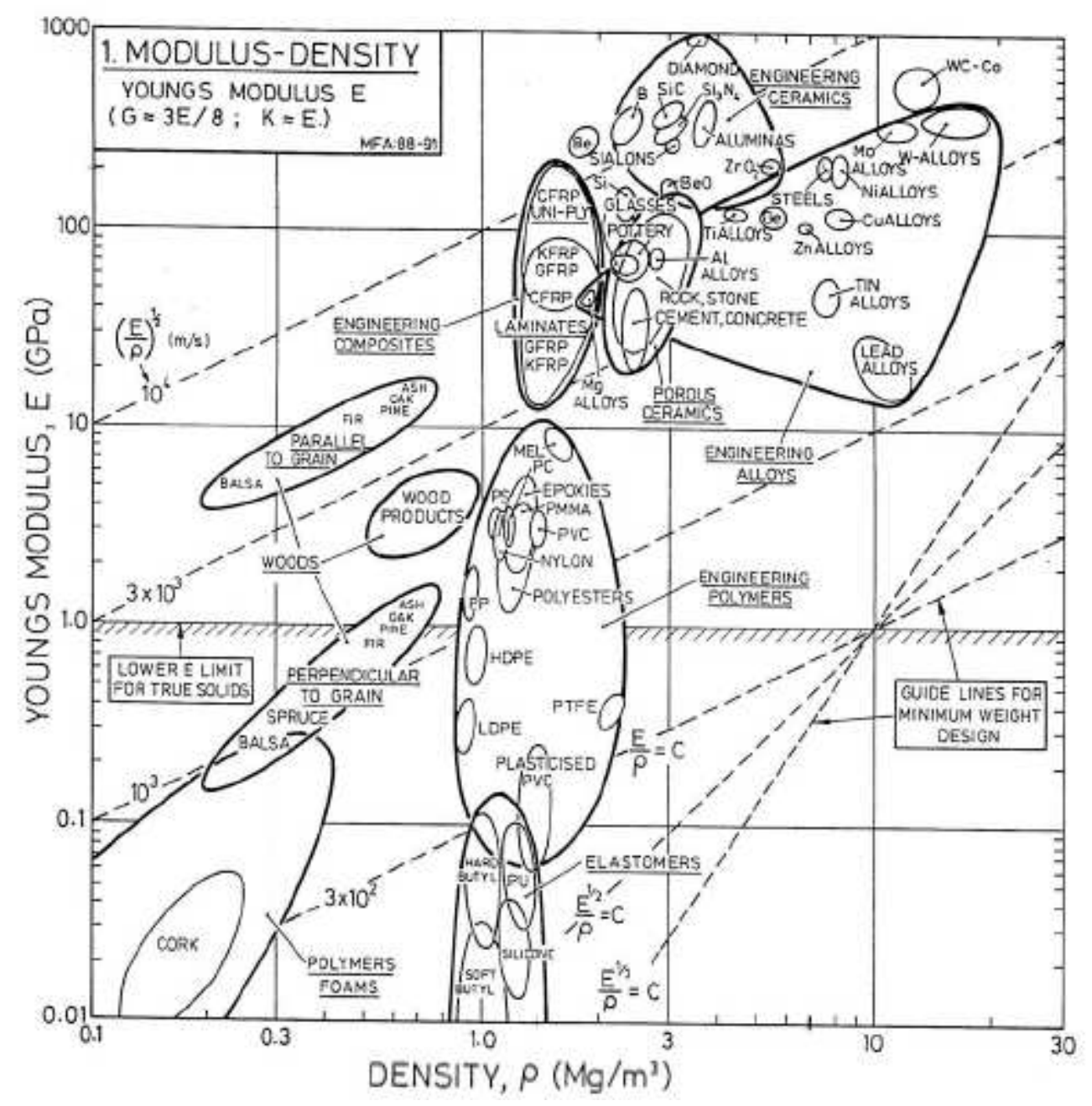

Figura 2.1.2.6 - Diagrama de Ashby: Módulo de elasticidade x Densidade

Fonte: Frey (2007)

É importante agora discutir a dependência da elasticidade diante da microestrutura dos materiais. 


\subsubsection{Reologia e ligações químicas}

A elasticidade supõe a ocorrência do fenômeno de aparecimento de deformações imediatas e reversíveis em um corpo em decorrência de tensões solicitantes temporárias. Obedecendo a um maior rigor técnico, Zagottis (1979) definiu as deformações imediatas como aquelas que apareciam simultaneamente com as tensões e que permaneciam constantes ao longo do tempo se as tensões correspondentes permanecessem também constantes, e as deformações reversíveis como aquelas que se anulariam ao se anularem as tensões correspondentes, ou seja, aquelas que desapareceriam integralmente com o descarregamento das tensões correspondentes. Note-se que não se ressalta dependência da magnitude das deformações em relação à taxa de carregamento da solicitação.

Se, então, o termo elasticidade revela a capacidade dos materiais de retornarem à sua forma e volume originais após serem removidas as solicitações atuantes, fica evidente que essa propriedade é dependente da composição estrutural dos materiais ao nível atômico, porque a recuperação física apenas se dá quando o material busca retornar a sua conformação de equilíbrio elétrico e de menor dissipação de energia. Em outras palavras, revela-se que o módulo de elasticidade deve depender fortemente das forças de ligação entre os elementos constituintes da microestrutura dos materiais, em seus arranjos atômicos cristalinos ou não.

Na Fig. 2.1.3.1, originalmente publicada por Callister (2002), duas curvas que indiretamente representam a energia de ligações atômicas são sobrescritas por duas retas $(d F / d r)_{r 0}$ que, por sua vez, indicam as respostas unidirecionais de solicitaçãodeformação características daquelas ligações. Uma das ligações é mais fraca (menor coeficiente angular de reta) e outra mais forte (maior coeficiente angular de reta) até os picos das curvas onde se representa a quebra das ligações e a seqüência de separação dos átomos já com menores dispêndios de energia. Se aliviadas antes dos picos, as ligações retornariam ao estágio de equilíbrio de energia inicial (Força $F=0$ ). 


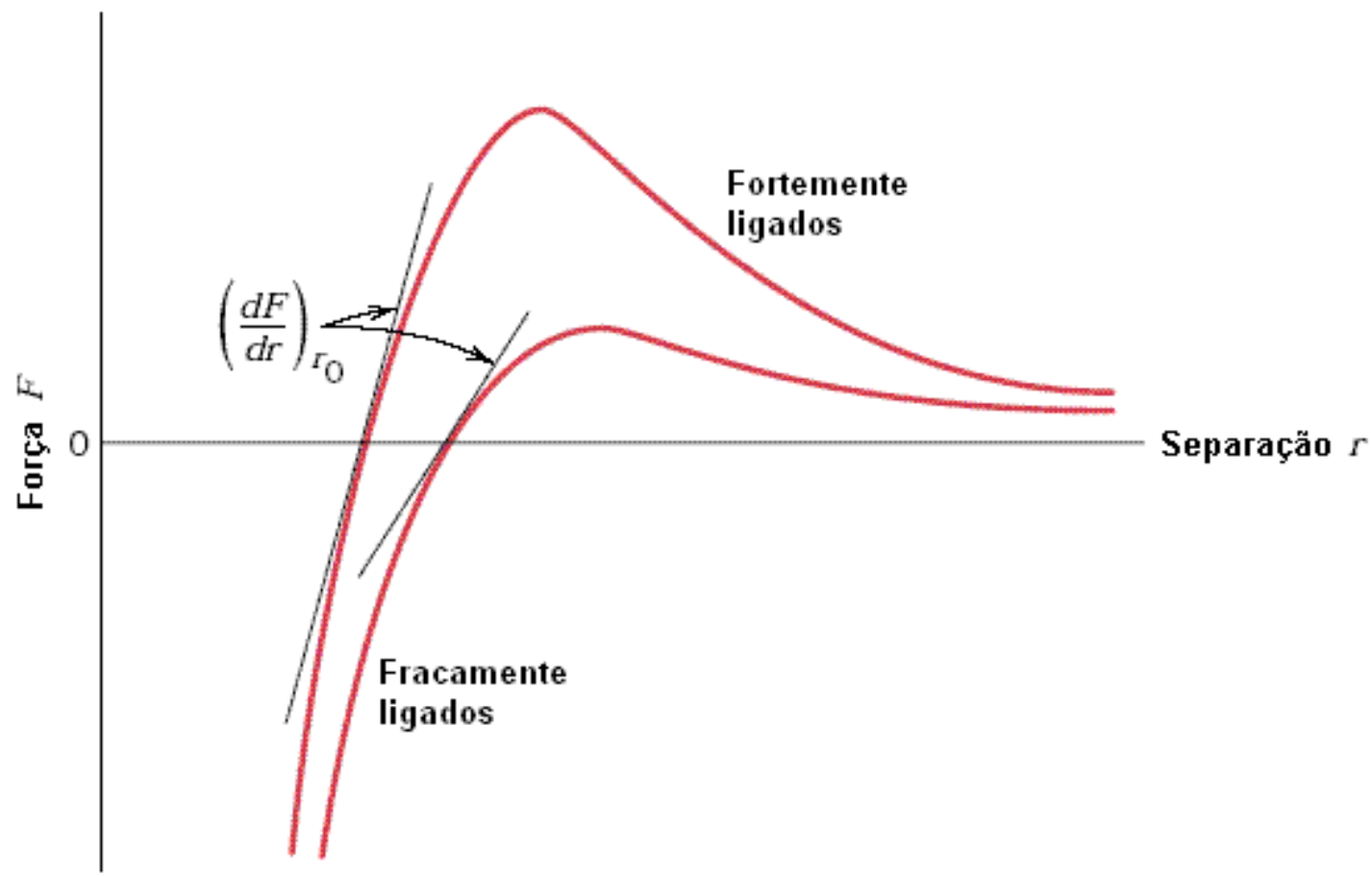

Figura 2.1.3.1 - Representação indireta da energia das ligações atômicas

Fonte: Callister (2002)

Essas retas que indicam a energia dissipada para a deformação interatômica representam também, indiretamente, as constantes elásticas como o módulo de elasticidade axial ou simplesmente módulo de elasticidade $(E)$, o módulo de elasticidade transversal $(G)$ e o módulo de elasticidade volumétrico $(K)$. Em outros termos, pode-se dizer que $E=\frac{d \sigma}{d \varepsilon} \approx \frac{d F}{d r}$.

Essa conceituação auxilia na compreensão do fato de a magnitude da propriedade estar vinculada ao termo 'módulo' e não a 'elasticidade', pois traz a interpretação de que quanto maior o módulo, maior a energia despendida pelo esforço solicitante para a deformação. Se o material for pensado como uma mola, maior também será a energia potencial acumulada para o retorno ao estado de equilíbrio.

Segundo Figueiredo (2004), dentre as quatro maiores classes de materiais artificiais utilizados pela engenharia, metais, polímeros, cerâmicos e compósitos, aquelas cujos materiais forem formados por microestrutura mais complexa tenderão a ter maiores módulos de elasticidade. Por microestrutura complexa entendam-se os arranjos robustos e isentos ou praticamente isentos de imperfeições - falhas de 
continuidade - e de planos direcionais preferenciais de rigidez, seja pela elevada reatividade, como no caso das "nuvens de elétrons" das ligações metálicas, seja pela capacidade de imbricamento cristalino interlamelar das ligações iônicas de uma parte dos materiais cerâmicos ou pela taxa de amorfização de outra. Nos materiais poliméricos, ao contrário, as ligações covalentes são altamente direcionais e como resultado, formam-se moléculas de longas cadeias de arranjo característico que exibem ângulos de ligação bem definidos configurando planos preferenciais de rigidez. Nos materiais compósitos, enfim, pode haver a combinação de algumas dessas características químicas, com a obtenção de materiais de variados níveis de rigidez. Na Fig. 2.1.3.2. mostra-se uma representação simplificada de um arranjo cristalino genérico submetido a deformação elástica perfeita sob uma solicitação de tração. Para a solicitação de compressão, a representação do fenômeno perfeito teria apenas o sentido das deformações alterado.

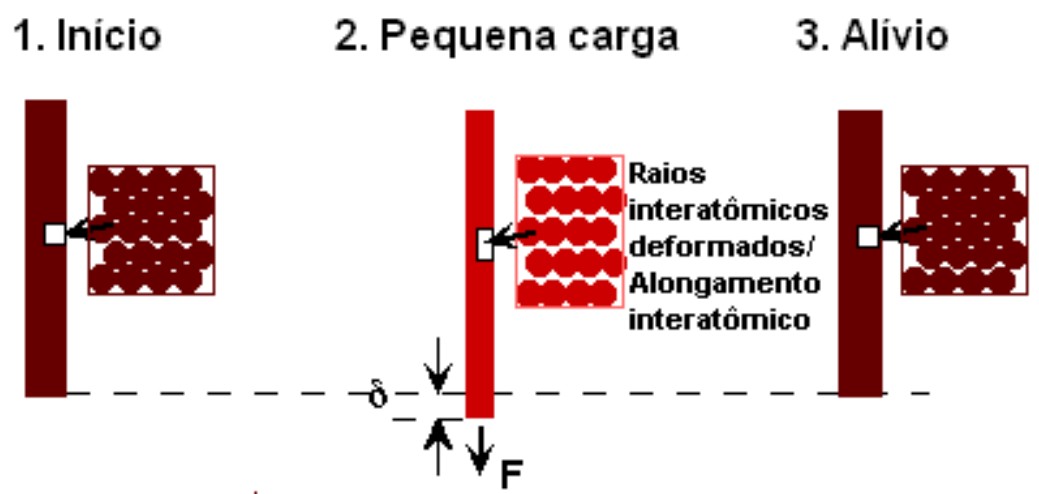

Figura 2.1.3.2 - Representação da deformação elástica perfeita em nível atômico (na tração)

Deve-se lembrar que ao se ultrapassar o nível de resistência das forças interatômicas, pode-se causar movimentações atômicas irreversíveis mesmo enquanto houver capacidade de rearranjo por novas ligações químicas e de nova conformação para o material. Reologicamente é o que se denomina de plastificação, isto é, a manifestação do fenômeno da Plasticidade. Na Fig. 2.1.3.3 tem-se uma representação simplificada de um arranjo cristalino submetido a uma deformação combinada (elastoplástica) perfeita sob solicitação de tração. Para a compressão o fenômeno é similar, mas com aproximação interatômica. 
1. Início

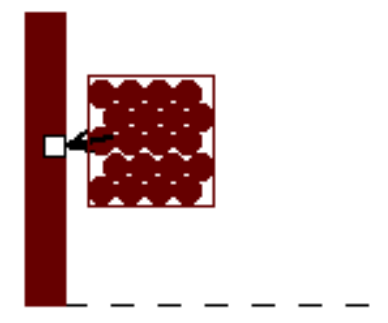

2. Carga significativa

3. Alivio

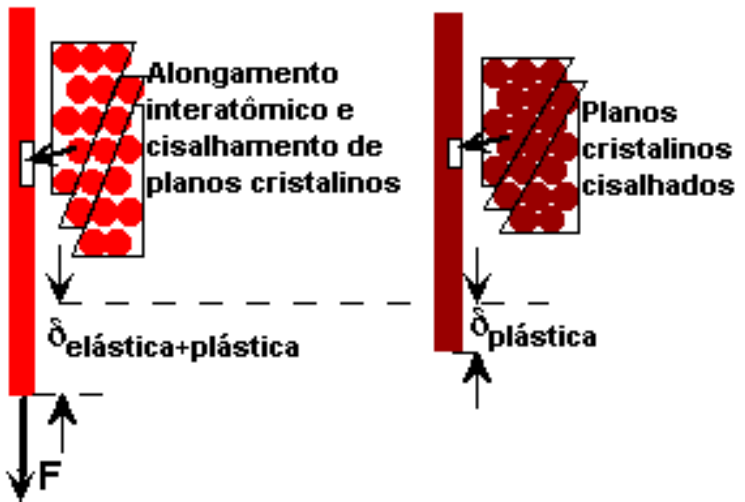

Figura 2.1.3.3 - Representação da deformação elastoplástica perfeita em nível atômico (na tração)

Note-se que o cisalhamento dos planos cristalinos causa uma deformação permanente no corpo material que não é anulada com o alívio das solicitações. No caso de não haver condições de ser assumida uma nova forma sem a interrupção completa de ligações, haverá uma fratura na microestrutura do material.

Entre os principais comportamentos reológicos dos materiais, resta ainda a chamada Viscosidade. Sua principal característica, a deformação crescente sob solicitação constante ao longo do tempo, está ligada fundamentalmente à movimentação causada pelo cisalhamento (quebra) de ligações fracas de superfície entre arranjos interatômicos - e não intra-arranjos como no caso da plasticidade. Isto a coloca como um fenômeno que pode ocorrer conjuntamente com a elasticidade e a plasticidade e que também a faz altamente dependente de fenômenos outros, externos ao corpo material, como os fatores ambientais umidade e temperatura. A deformação viscosa é também irreversível.

Na Tab. 2.1.3.1 segue a representação clássica de todos os fenômenos reológicos citados. 
Tabela 2.1.3.1 - Representações clássicas dos fenômenos reológicos

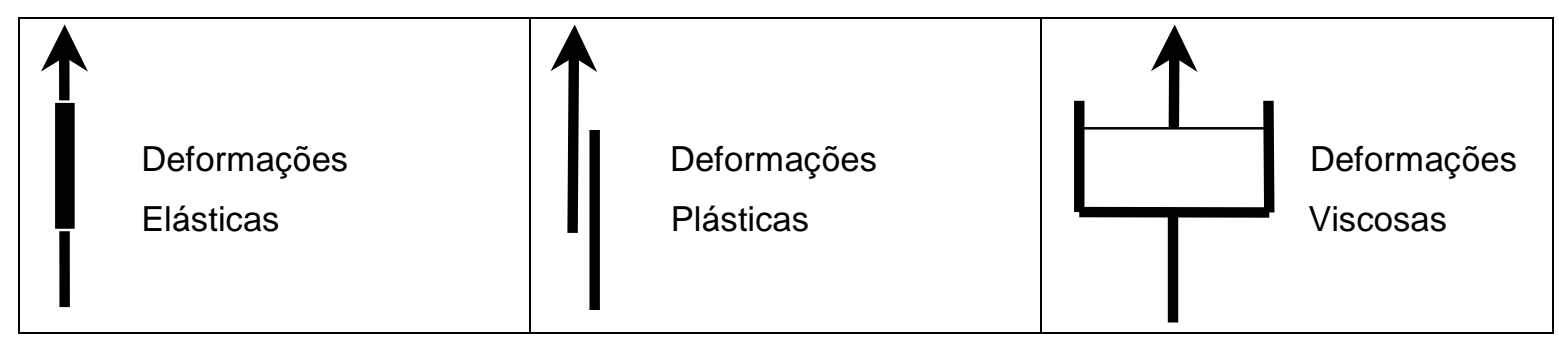

Ressalte-se que até o momento realizou-se a descrição de materiais perfeitos. Na realidade, o que existe na engenharia são materiais imperfeitos estruturalmente, com falhas de formação importantes para o desempenho das propriedades. Isso ficará bem nítido quando, a seguir, for estudado um material como o concreto.

\subsection{A microestrutura e a deformabilidade do concreto}

No concreto de cimento Portland coexistem e interagem diversos arranjos microestruturais na fase chamada de pasta endurecida e na fase particulada dispersa na matriz de pasta endurecida chamada genericamente de agregados.

Compondo a pasta endurecida estão os produtos de hidratação do cimento, os grãos de cimento anidro e diversos tipos de poros e seus preenchimentos. Adaptando-se um estudo organizado por Kaefer (2002), seguem nas Fig. 2.2.1.a-c alguns exemplos de componentes da pasta retratados originalmente por MoranvilleRegourd (1992), Mehta e Monteiro (1994) e Dal Molin (1995). Na Fig. 2.2.1.c está representada também outra característica do concreto - por vezes considerada outra fase - que é a zona de transição entre a pasta e os agregados. 


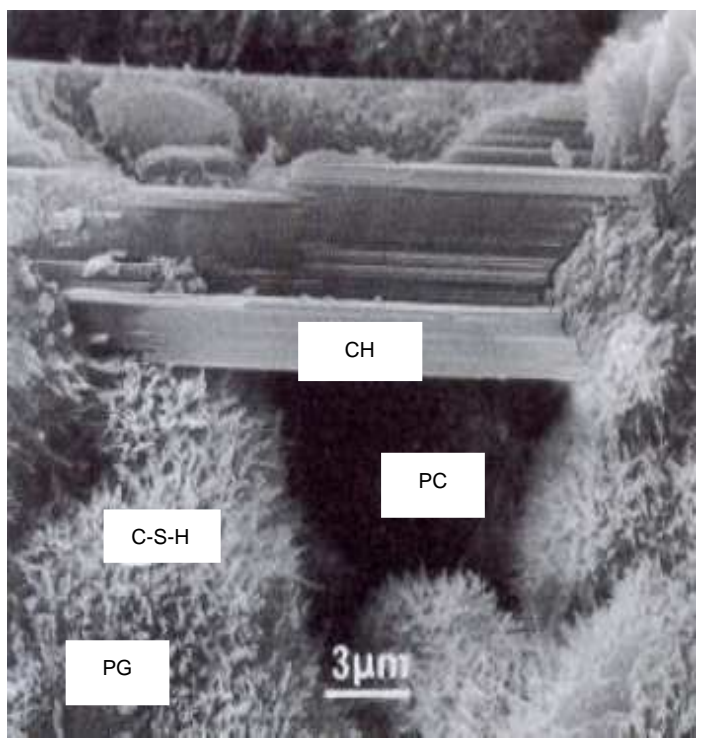

(a)

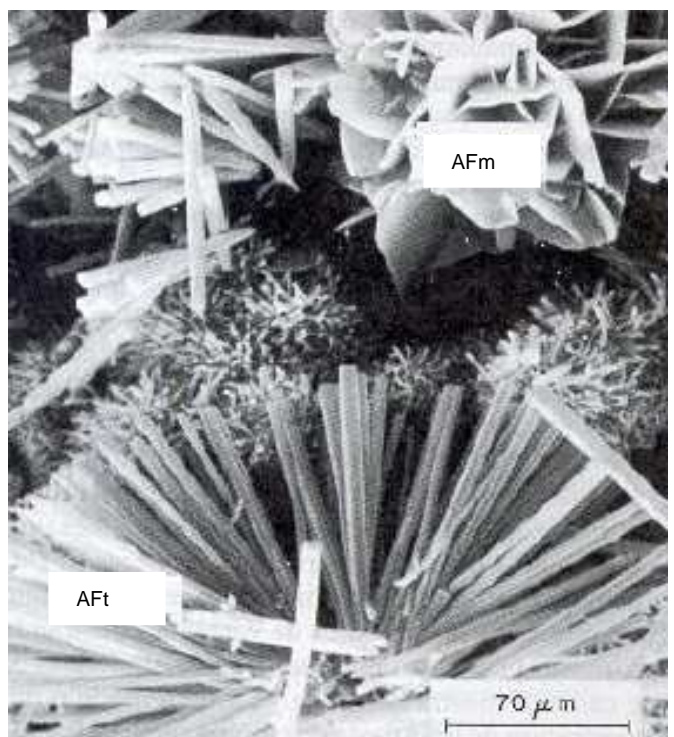

(b)

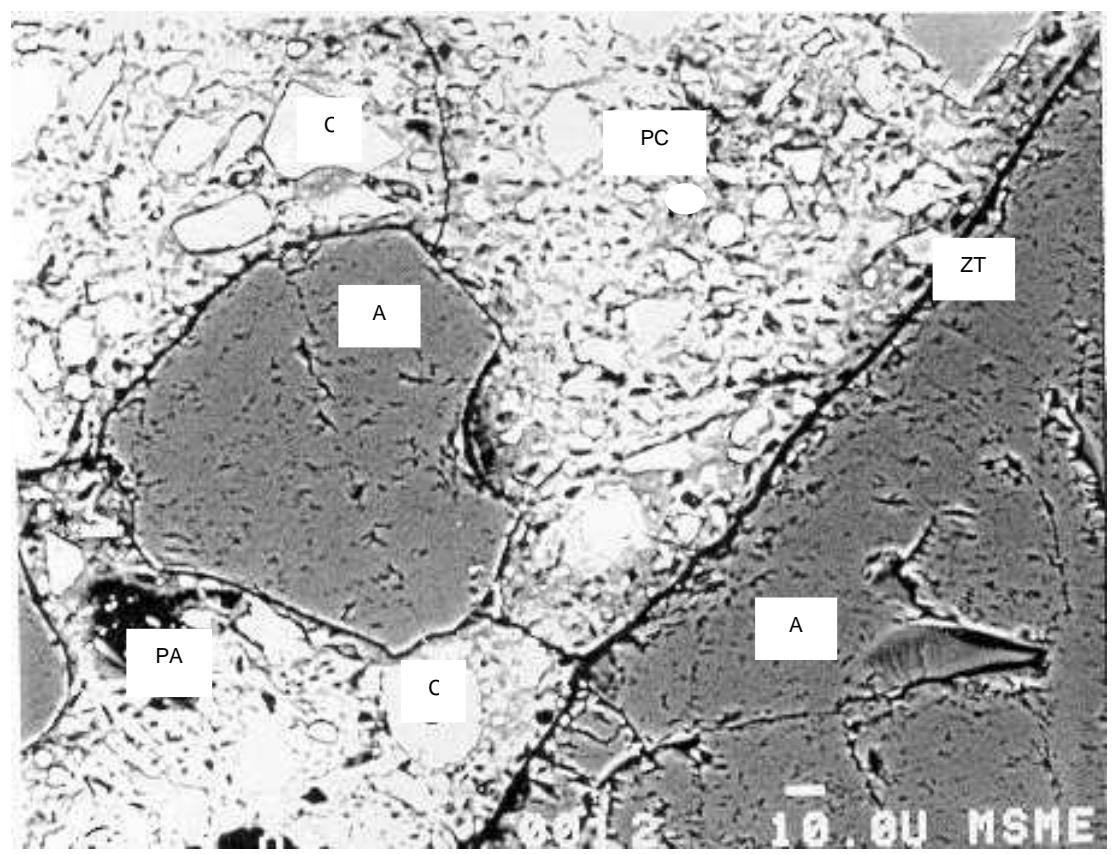

LEGENDA

C-S-H:

Silicatos de cálcio hidratados

$\mathrm{CH}$ :

Hidróxido de cálcio

AFt e AFm:

Sulfoaluminatos de

cálcio

C:

Grãos de cimento anidro PG, PC e PA:

Poros ou vazios

A:

Agregados

ZT:

Zona de transição

(c)

Figura 2.2.1 - Representação dos principais componentes da pasta endurecida e do concreto: (a), (b) e (c) Detalhes conforme legenda

Fontes: (a) Moranville-Regourd (1992)

(b) Mehta e Monteiro (1994)

(c) Dal Molin (1995)

Agora apresenta-se uma descrição breve de cada um destes componentes, partindo-se dos compostos sólidos da pasta endurecida. A cada item será dado um enfoque especial sobre o tamanho do componente e o módulo de elasticidade $(E)$ adotado ou obtido para cada um deles em diversos estudos internacionais. 
C-S-H. Os silicatos de cálcio hidratados constituem o maior volume de sólidos de uma pasta de cimento endurecida, perfazendo entre 50 a $60 \%$ do total segundo Mehta e Monteiro (1994). A morfologia do C-S-H varia inicialmente de fibras pouco cristalinas a até um reticulado cristalino, numa distribuição espacial coloidal que the garante a classificação de "gel" e, algumas vezes "gel de tobermorita", dada a sua semelhança química com o mineral natural de mesmo nome. Powers (1966) definiu esse corpo coloidal como quasi-cristalino e repleto de ligações covalentes ou iônicas de composição (ligações fortes) na formação das suas fibras ou lamelas, constituindo um espaço de elevada superfície específica - 100 a $700 \mathrm{~m}^{2} / \mathrm{g}$. Essa superfície específica e a baixíssima distância entre sólidos do gel, estimada em 2 $\mathrm{nm}$, favorecem a interação lamelar pela possibilidade de imbricamento dos cristais e a concentração das forças interlamelares mais fracas - forças de Van der Waals a estágios mais resistentes. Os compostos C-S-H são, por isso, os responsáveis principais pela resistência e pela rigidez da pasta endurecida. Na Fig. 2.2.2 há uma representação em detalhe destes compostos.

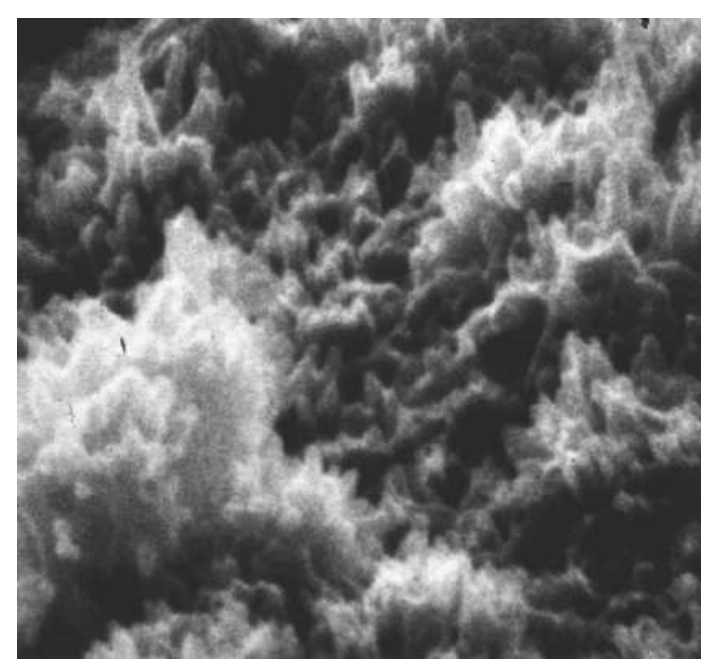

Figura 2.2.2 - Detalhe das fibras cristalinas de C-S-H (silicatos de cálcio hidratados)

Fonte: Monteiro (2007)

A formação química dos arranjos de C-S-H é dada pelas seguintes reações químicas de estequiometria aproximada:

$$
2 \mathrm{C}_{3} \mathrm{~S}+6 \mathrm{H} \rightarrow \mathrm{C}_{3} \mathrm{~S}_{2} \mathrm{H}_{3}+3 \mathrm{CH}+120 \mathrm{cal} / \mathrm{g}
$$

$($ silicato tricálcico $)+($ água $)=(\mathrm{C}-\mathrm{S}-\mathrm{H})+($ hidróxido de cálcio $)+$ energia

$$
2 \mathrm{C}_{2} \mathrm{~S}+4 \mathrm{H} \rightarrow \mathrm{C}_{3} \mathrm{~S}_{2} \mathrm{H}_{3}+\mathrm{CH}+62 \mathrm{cal} / \mathrm{g}
$$

(silicato dicálcico $)+($ água $)=(\mathrm{C}-\mathrm{S}-\mathrm{H})+($ hidróxido de cálcio $)+$ energia 
onde:

- $\quad \mathrm{C}_{3} \mathrm{~S}$ ou silicato tricálcico ou alita é constituído por [3CaO. $\mathrm{SiO}_{2}$ ];

- $\quad \mathrm{C}_{2} \mathrm{~S}$ ou silicato dicálcico ou belita é constituído por [2CaO.SiO${ }_{2}$;

- H ou água é constituída por $\left[\mathrm{H}_{2} \mathrm{O}\right]$;

- $\quad \mathrm{CH}$ ou hidróxido de cálcio é constituído por [ $\left.\mathrm{Ca}(\mathrm{OH})_{2}\right]$;

- $\mathrm{C}_{3} \mathrm{~S}_{2} \mathrm{H}_{3}$ ou C-S-H ou silicato de cálcio hidratado é constituído por $\left[3 \mathrm{CaO} .2 \mathrm{SiO}_{2} \cdot 3 \mathrm{H}_{2} \mathrm{O}\right]$.

Segundo Mondal; Shah e Marks (2006), os arranjos cristalinos fibrosos de CS-H tendem a formar agrupamentos maiores, esféricos, ditos partículas, com tamanho mínimo identificado em Microscopia de Força Atômica da ordem de $40 \mathrm{~nm}$ e máximo da ordem de $700 \mathrm{~nm}$ (Fig. 2.2.3.a-f).

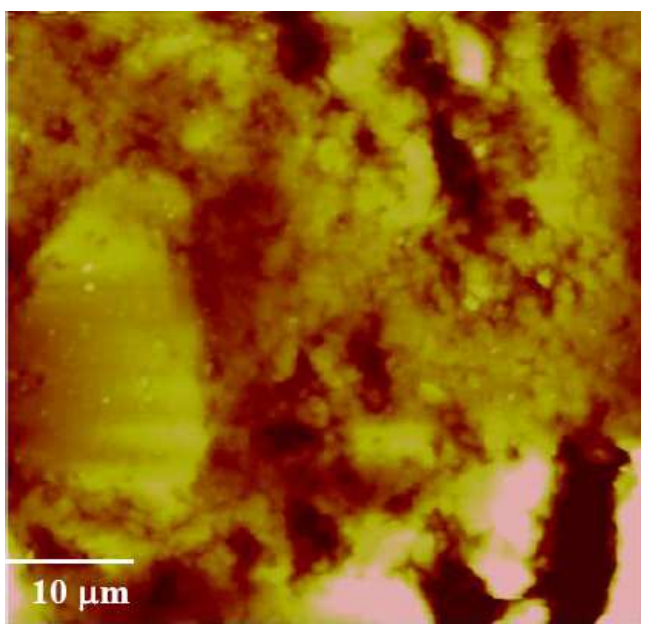

(a)

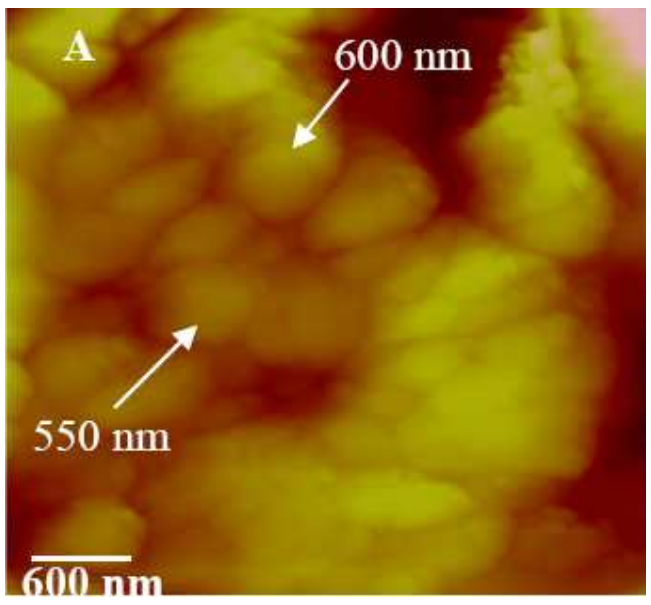

(c)

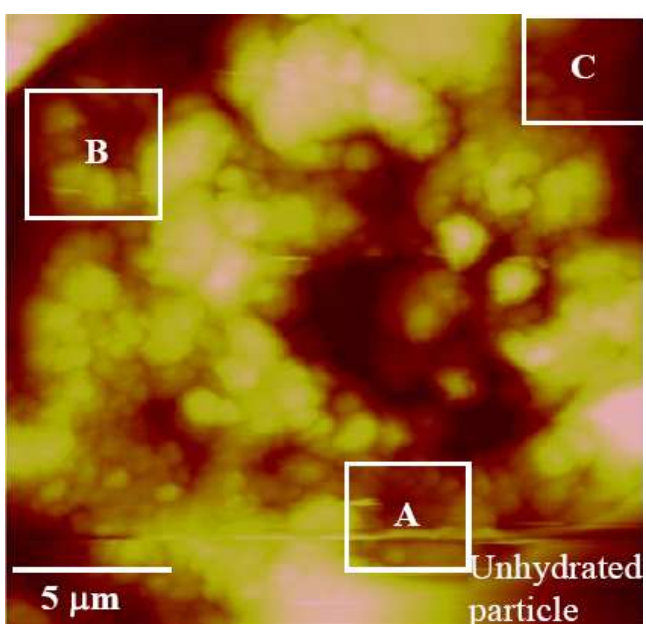

(b)

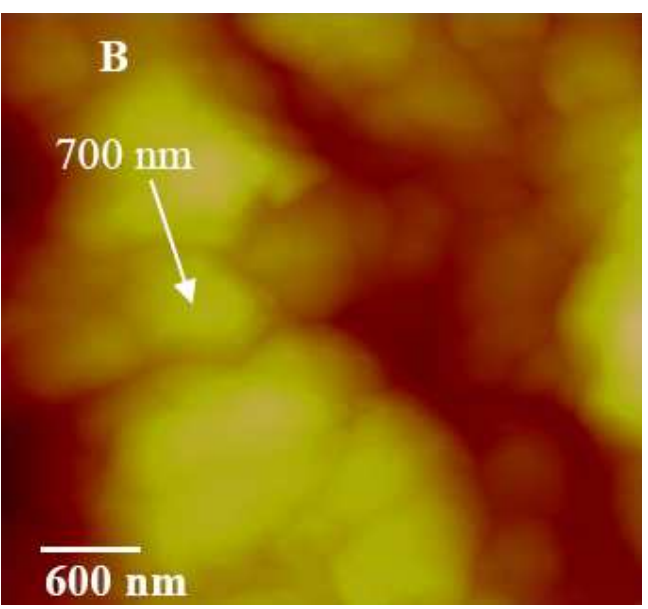

(d) 


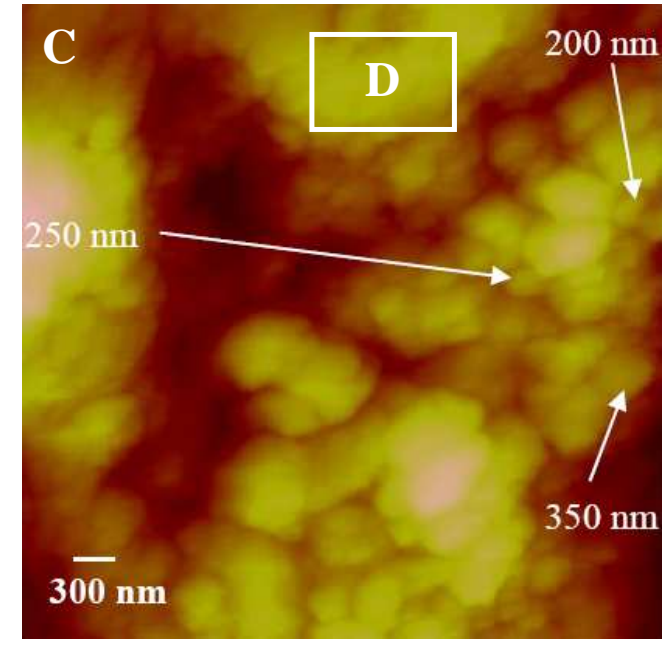

(e)

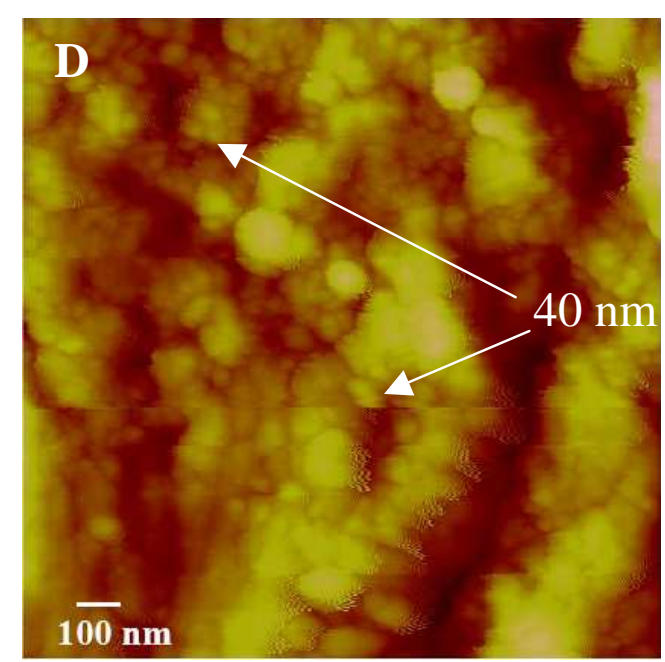

(f)

Figura 2.2.3 - Representação das partículas de C-S-H: (a) Hidratação periférica do grão de cimento; (b) Vista geral do contato entre partículas; (c) (d) (e) (f) Detalhes A, B C e D do tamanho das partículas, respectivamente

Fonte: Mondal; Shah e Marks (2006)

Ainda segundo os autores, pode-se avaliar a rigidez das partículas de C-S-H através de um equipamento capaz de causar um entalhe nanométrico na pasta endurecida e fornecer, a partir do módulo de ruptura, o módulo de elasticidade no ponto de entalhe. Dessa forma obtiveram os resultados reproduzidos na Fig. 2.2.4, onde se mostra que a proximidade em relação ao núcleo de cimento anidro garantiu a algumas partículas um módulo de elasticidade maior:

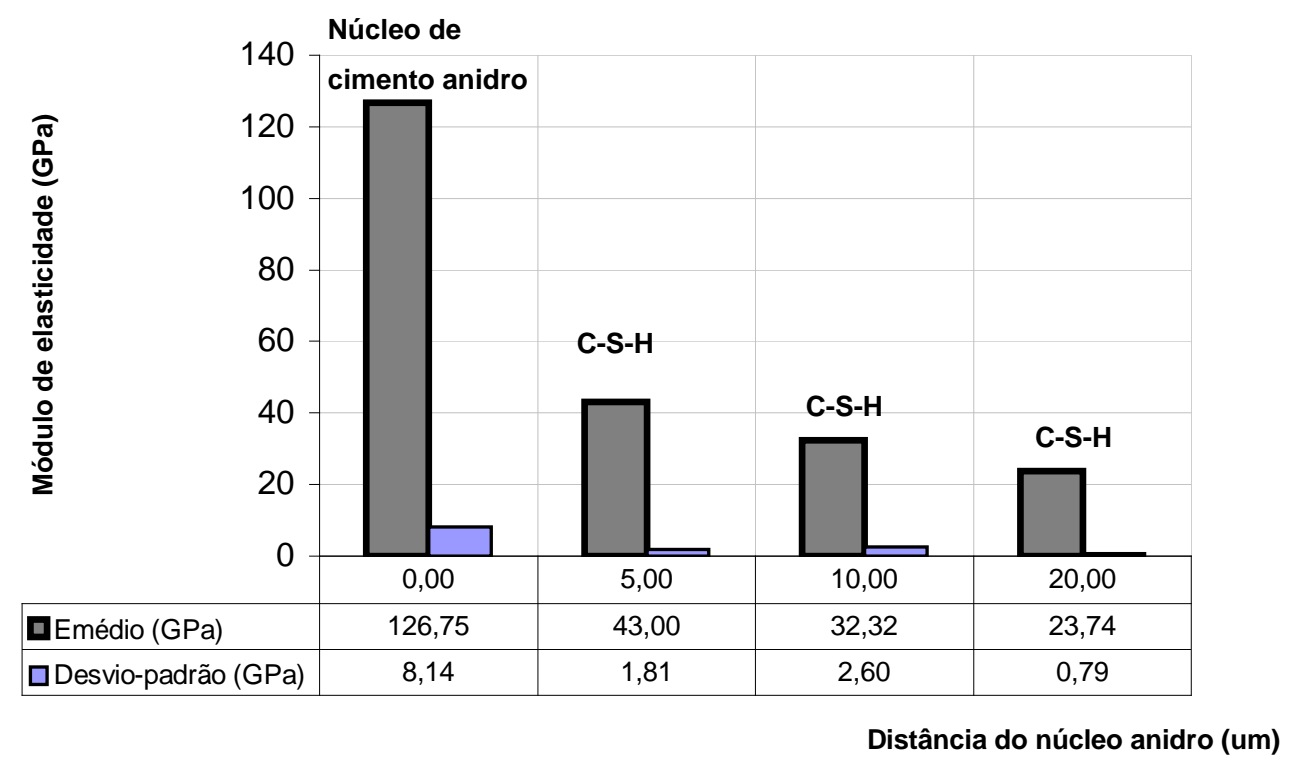

Figura 2.2.4 - Partículas de C-S-H: Módulo de elasticidade x Distância do núcleo anidro 
Curiosamente, como se pode notar, o estágio de hidratação do cimento que se dá no sentido da periferia para o núcleo do grão parece não ser o único responsável pela rigidez nos pontos amostrados. Isto porque:

- segundo o esquema de desenvolvimento da hidratação proposto por Bentur e Monteiro apud Paulon (2005) e representado em parte na Fig. 2.2 .5 - grão de Hadley no estado endurecido, com idade maior que 14 dias - deve existir um maior desenvolvimento das partículas de $\mathrm{C}-\mathrm{S}-\mathrm{H}$ mais periféricas em relação às mais nucleares por causa do maior tempo de formação das fibras. Conseqüentemente, dever-se-ia obter maior rigidez nas partículas de C-S-H quanto maior o distanciamento do núcleo anidro;

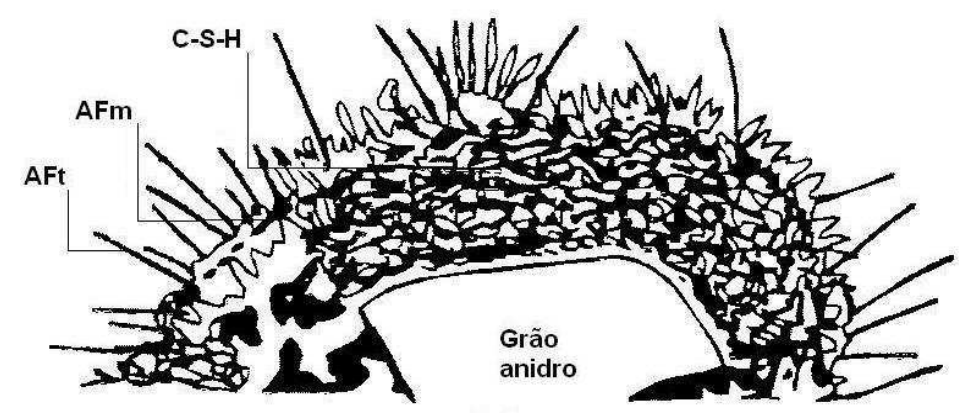

Figura 2.2.5 - Grão de Hadley com idade acima de 14 dias

Fonte: Bentur e Monteiro apud Paulon (2005)

- no entanto, sabe-se que as partículas de C-S-H mais nucleares, apesar de menos fibrosas, estão circundadas por partículas mais rígidas - cimento anidro e partículas de C-S-H periféricas - enquanto as mais periféricas estão envolvidas por partículas menos rígidas - partículas de C-S-H nucleares e partículas de sulfoaluminatos de cálcio (AFt e AFm) acompanhadas da maior porosidade limítrofe ao grão de Hadley. Esse fenômeno poderia estar configurando um desempenho de compósito naqueles pontos ensaiados por Mondal; Shah e Marks (2006). Ou seja, o resultado mecânico obtido decorreria da interação das propriedades individuais das fases componentes ou influentes (vizinhanças) na determinação da rigidez naqueles pontos.

Vale ressaltar que Boumiz et al. (1997) e Damidot et al (2003) já haviam inferido o módulo de elasticidade do grão de cimento anidro e o da partícula de C-S$\mathrm{H}$; os valores obtidos por eles foram de 117,6 GPa e 22,4 GPa, respectivamente. 
Garboczi et al. (2006), por exemplo, já utilizaram estes valores no desenvolvimento do modelo computacional CEMHYD3D para caracterização tridimensional da hidratação da pasta de cimento. Se comparados com os valores de 123,75 e 23,74 GPa obtidos por Moldal; Shah e Marks (2006) para o grão anidro e a partícula distante $20 \mu \mathrm{m}$ do grão anidro, será notada grande correspondência entre os resultados.

CH. As partículas cristalinas de hidróxido de cálcio, $\mathrm{Ca}(\mathrm{OH})_{2}$, também chamadas de portlandita, tendem a ser muito maiores que os de C-S-H - tamanhos variáveis, da ordem de até algumas dezenas de micrômetros - e a ter o formato de prismas hexagonais distribuídos, em geral, quase isolados ou em pilhas de placas unidas por forças de Van der Waals (Fig. 2.2.6).
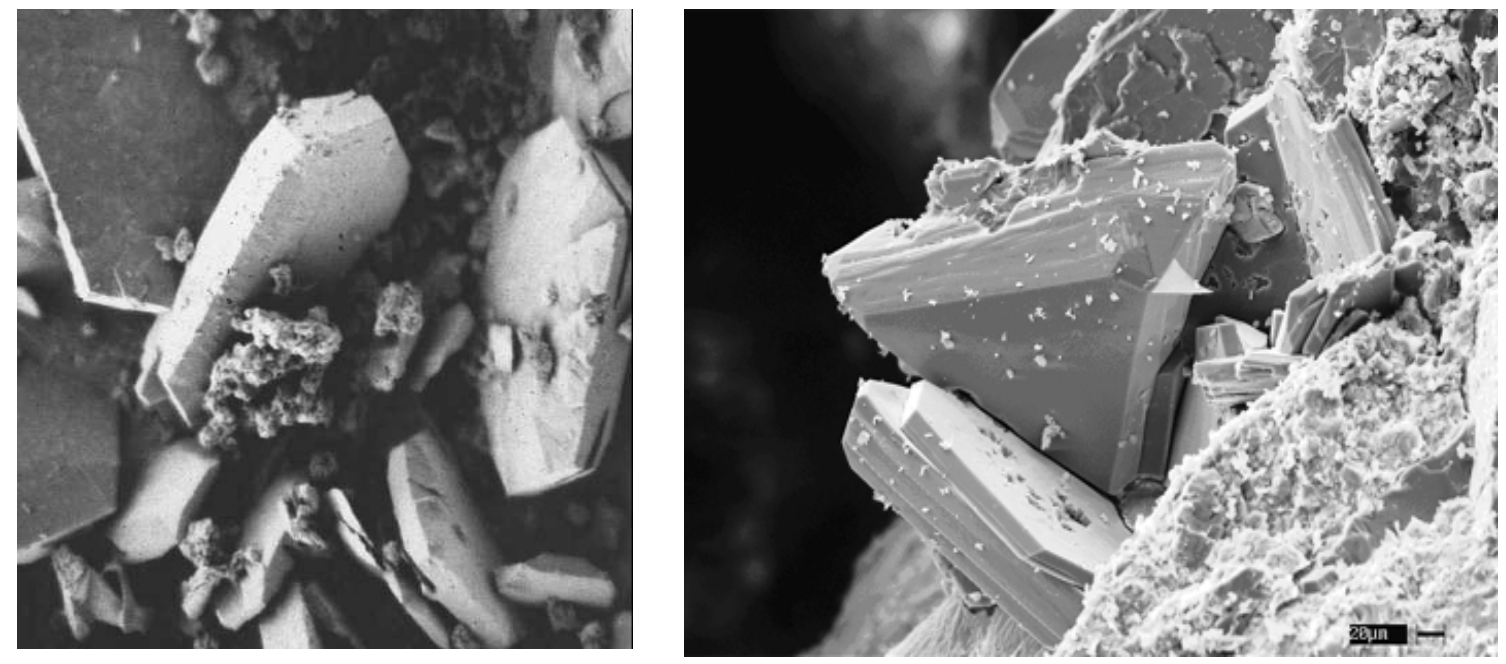

Figura 2.2.6 - Detalhes de placas cristalinas de CH (hidróxido de cálcio)

Fonte: Monteiro (2007)

Segundo Mehta e Monteiro (1994), as placas de CH constituem entre 20 e $25 \%$ do volume de sólidos de uma pasta de cimento endurecida. Os mesmos autores, além de Paulon (2005), constataram que o $\mathrm{CH}$ é um dos principais compostos formados na região da pasta próxima aos agregados — zona de transição interfacial pasta-agregado (ZT) - e distribui-se nela em planos de orientação bem definidos.

Monteiro e Chang (1995) discutiram a rigidez deste tipo de partícula e inferiram para ela um módulo de elasticidade de 42,3 GPa. Note-se que esse 
resultado é até maior que alguns dos apresentados para o C-S-H. Assim, a presença desse composto endurecido pode garantir maior rigidez a uma pasta se comparada a outra em que se tenha dissolvido-o e lixiviado de alguma maneira. Porém, a presença desse composto não é mais importante em termos de rigidez do que o C$\mathrm{S}-\mathrm{H}$ porque traz consigo entre as pilhas de placas um grau de porosidade difícil de ser preenchido e uma tendência à implicação de direcionalidade (anisotropia) ao meio em que está inserido.

Adiante, quando descrita a zona de transição, uma nova abordagem sobre esse composto será feita.

AFt e AFm. Os cristais dos sulfoaluminatos de cálcio são formados, em geral, nos primeiros estágios da hidratação do cimento Portland, resultantes da relação iônica sulfato-alumina. $\mathrm{O}$ composto $\mathrm{C}_{6} \mathrm{AS}_{3} \mathrm{H}_{32}$, ou etringita na fase $\mathrm{AFt}$, forma cristais prismáticos aciculares de tamanho estimado entre 20 e $50 \mu \mathrm{m}$ mas menos resistentes que os dos compostos C-S-H (Fig. 2.2.7).

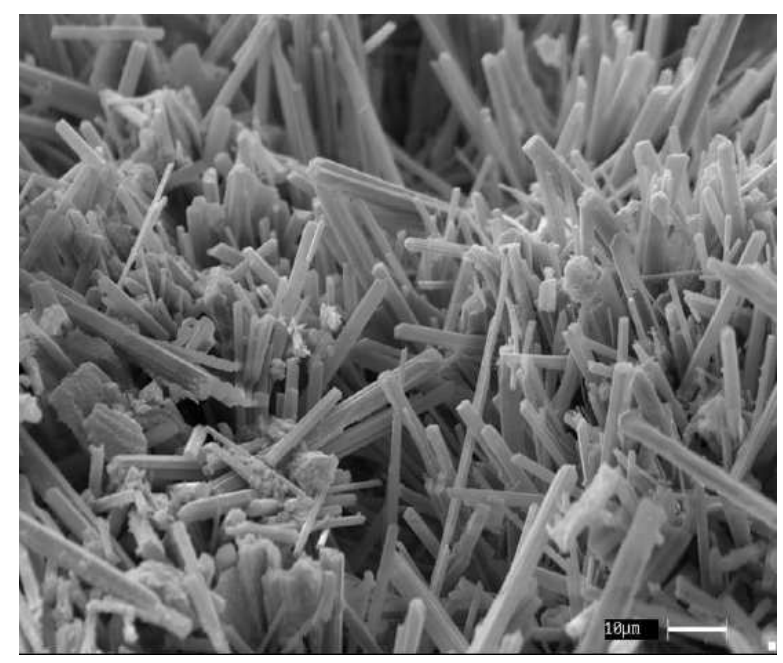

Figura 2.2.7 - Detalhe das agulhas cristalinas de AFt (etringita)

Fonte: Monteiro (2007)

Nas baixas idades, a etringita constitui também grande parte do volume de sólidos da zona de transição pasta-agregados (ZT). Com o avanço da idade do concreto, parte de toda a etringita da pasta transforma-se em monossulfato hidratado, $\mathrm{C}_{4} \mathrm{ASH}_{18}$ (fase $\mathrm{AFm}$ ), um composto que se cristaliza em placas hexagonais e propriedade mecânicas similares ao $\mathrm{CH}$. 
Os sulfoaluminatos de cálcio constituem, em geral, entre 15 e 20\% do volume de sólidos de uma pasta de cimento endurecida. Os compostos AFt e AFm são formados, em estequiometria aproximada, através das seguintes reações químicas:

$$
\mathrm{C}_{3} \mathrm{~A}+3 \mathrm{CSH}_{2}+26 \mathrm{H} \rightarrow \mathrm{C}_{6} \mathrm{AS}_{3} \mathrm{H}_{32}+300 \mathrm{cal} / \mathrm{g}
$$

(aluminato tricálcico $)+($ gesso $)+($ água $)=($ etringita $)+$ energia

$$
\mathrm{C}_{6} \mathrm{AS}_{3} \mathrm{H}_{32}+2 \mathrm{C}_{3} \mathrm{~A}+22 \mathrm{H} \rightarrow 3 \mathrm{C}_{4} \mathrm{ASH}_{18}+\mathrm{n} \mathrm{cal} / \mathrm{g}
$$

$($ etringita $)+($ aluminato tricálcico $)+($ água $)=($ monossulfato hidratado $)+$ energia onde:

- $\mathrm{C}_{3} \mathrm{~A}$ ou aluminato tricálcico é constituído por [3CaO. $\left.\mathrm{Al}_{2} \mathrm{O}_{3}\right]$;

- $\mathrm{CSH}_{2}$ ou gesso é constituída por $\left[\mathrm{CaSO}_{4} .2 \mathrm{H}_{2} \mathrm{O}\right]$;

- H ou água é constituída por $\left[\mathrm{H}_{2} \mathrm{O}\right]$;

- $\mathrm{C}_{6} \mathrm{AS}_{3} \mathrm{H}_{32}$ ou etringita na fase AFt é constituído por $\left[6 \mathrm{CaO} \cdot \mathrm{Al}_{2} \mathrm{O}_{3} \cdot 3 \mathrm{SiO}_{2} \cdot 32 \mathrm{H}_{2} \mathrm{O}\right.$;

- $\mathrm{C}_{4} \mathrm{ASH}_{18}$ ou monossulfato hidratado (fase AFm) é constituído por $\left[4 \mathrm{CaO} \cdot \mathrm{Al}_{2} \mathrm{O}_{3} \cdot \mathrm{SiO}_{2} \cdot 18 \mathrm{H}_{2} \mathrm{O}\right]$.

Garboczi et al. (2007) adotaram para os compostos AFt e AFm os mesmos módulos de elasticidade utilizados por eles para o C-S-H $(22,4 \mathrm{GPa})$ e o $\mathrm{CH}(42,3$ $\mathrm{GPa}$ ), respectivamente. Isso se deveu principalmente às formas similares dos arranjos cristalinos desses compostos - fibras aciculares no caso da etringita e placas hexagonais no caso do monossulfato hidratado. Essas magnitudes são aceitáveis principalmente porque esses compostos constituem níveis de evolução de uma mesma parcela de produtos de hidratação.

C. Os grãos de cimento anidro ou não-hidratado têm, em geral, tamanho entre 1 e $50 \mu \mathrm{m}$. Cada grão, por si, já constitui um composto de fases peculiares $-\mathrm{C}_{3} S$, $\mathrm{C}_{2} \mathrm{~S}, \mathrm{C}_{3} \mathrm{~A}, \mathrm{C}_{4} \mathrm{AF}$, gesso, pozolanas, entre outros.

Considerando o mesmo nível de adições, os cimentos com maior quantidade de silicatos de cálcio tenderão a formar maior volume de produtos de hidratação do tipo C-S-H que outros com ênfase em aluminatos, contribuindo para a rigidez global da pasta endurecida. Não cabe aqui descrever todos os possíveis tipos de cimento, suas composições e desempenho. O que se deseja é apenas destacar de maneira geral a existência na pasta endurecida por até alguns anos de idade de grãos de cimento anidro, independentemente do tipo de cimento utilizado. 
A reação química incompleta do grão se baseia em diversas causas: mesmo que admitidos todos com a mesma reatividade, alguns grãos são originalmente maiores ou mais grosseiramente moídos e por isso são naturalmente mais difíceis de reagirem por completo; se na ausência de aditivos dispersantes — os chamados aditivos plastificantes - estes ainda sofrem com processos de aglomeração física com outras partículas formando grãos ainda maiores. Além disso, o próprio processo de hidratação constitui, quando em um grau elevado, uma barreira à reação completa porque se dá na direção superfície-núcleo e os produtos inicialmente formados tendem a dificultar a difusão da água até a região nuclear para a continuidade das reações químicas, conforme visto na configuração de Hadley mostrada anteriormente.

Lembra-se que os cimentos compostos com adições pozolânicas de diferentes naturezas em até mais de $50 \%$ de sua massa tendem a ter modificada a expectativa original de comportamento de hidratação de seus grãos quando comparados aos de um cimento dito puro pois quase sempre reage mais lentamente. Novamente, prefere-se não detalhar todas as possibilidades de comportamento em favor de obedecer ao objetivo principal do trabalho.

A massa ou volume percentual de grãos de cimento anidro em uma pasta endurecida é considerada inversamente proporcional ao chamado grau de hidratação da pasta. O módulo de elasticidade destas partículas já foi citado quando da análise do estudo de Mondal; Shah e Marks (2006): está em torno de 120 GPa.

A seguir é apresentada uma descrição breve dos elementos não-sólidos da pasta endurecida: os poros.

PG. Os poros de gel têm origem complexa. Espaços interlamelares do C-S-H são formados a partir da distância entre sólidos do gel que, segundo Powers (1966), é da ordem de $18 \AA$ - Feldman e Sereda apud Mehta e Monteiro (1994) indicam distâncias entre 5 e $25 \AA$. Ainda segundo Powers (1966), ao menos 28\% do volume do gel de C-S-H podem ser considerados como espaço interlamelar e, normalmente, uma fração da água da pasta fica retida nesses espaços por pontes de hidrogênio: é a chamada água interlamelar ou de gel. Volumetricamente, o espaço interlamelar do C-S-H é considerado como parte dos sólidos do gel e, conseqüentemente, da pasta. No entanto, Neville (1997) observou que para o grau de hidratação de $100 \%$ e 
devido à chamada retração química no gel durante a formação dos produtos de hidratação, a soma dos volumes absolutos dos reagentes é menor que a soma dos volumes absolutos dos produtos em um volume numericamente da ordem de 25,4\% do volume de água reagida (água quimicamente combinada). Essa redução de volume absoluto de componentes rígidos dá origem aos chamados poros de gel, que, a rigor, serão incorporados aos poros capilares.

PC. Os poros capilares são oriundos dos vazios não preenchidos pelos compostos rígidos totais da pasta. Mehta e Monteiro (1994) estimam que os produtos formados distribuem-se no dobro do espaço físico que o anteriormente ocupado pelos reagentes configurando o maior volume aparente; essa diferença volumétrica entre o volume aparente e o volume absoluto dos produtos independentemente dos poros de gel - origina os poros capilares. Os mesmo autores afirmam que pastas com elevado grau de hidratação e baixa relação água/cimento apresentam diâmetro dos poros capilares entre 10 e 100 nm. Pastas com baixo grau de hidratação, caso das baixas idades, e elevada relação água/cimento têm poros capilares de até $5 \mu \mathrm{m}$.

Em condições de saturação, os poros capilares tenderão a estar preenchidos com água. Quando exposto às intempéries, o concreto sofre com o favorecimento da ocorrência do fenômeno de exsudação e a percolação da água de exsudação até a superfície exposta também gera poros capilares.

PA. Os poros de ar aprisionado ou macroporos são aqueles originados nos processos de mistura, aplicação ou adensamento do concreto. Segundo Mehta; Monteiro (1994), esses poros podem chegar a até $3 \mathrm{~mm}$ de diâmetro. A nomenclatura 'ar aprisionado' é tecnicamente mais recomendada que 'ar incorporado' porque há a possibilidade real de o concreto receber em sua mistura aditivos especiais incorporadores de microbolhas de ar de tamanho entre $100 \mu \mathrm{m} \mathrm{e}$ $500 \mu \mathrm{m}$ que devidamente formariam os devidos poros de ar incorporado.

Em geral, o volume de poros de ar aprisionado está em torno de 1 a $5 \%$ do volume do concreto.

A título de plena identificação das regiões em que ocorre, a água na pasta de cimento pode ser subdividida em: 
- Água quimicamente combinada ou de cristalização: é a água constituinte dos vários produtos de hidratação do cimento Portland. Só pode ser eliminada por aquecimento excessivo da pasta, como no caso de incêndio;

- Água interlamelar ou de gel: como dito, esta é a água associada à estrutura do C-S-H e está ligada por pontes de hidrogênio. A eliminação da água interlamelar se daria a $11 \%$ de umidade relativa do ar externo, causando grave retração da pasta;

- Água adsorvida: é a água sujeita à influência das forças de superfície dos sólidos. Segundo Mehta; Monteiro (1994), podem ser retidas diversas camadas moleculares de água que formam uma espessura de até $15 \AA$. A eliminação da água adsorvida se dá a 30\% de umidade relativa do ar externo, causando a retração da pasta por secagem e a fluência por secagem (aumento da deformação sob esforço solicitante constante);

- Água livre ou capilar: é a água livre da influência das forças de superfície dos produtos de hidratação, e está presente nos vazios maiores que $50 \mathrm{~nm}$. Essa água também só começa a ser transportada para o meio externo através de difusão, isto é, há a necessidade de gradiente de concentração (queda da umidade relativa do ar externo em relação à umidade da pasta) para se dar o transporte. No entanto, a condição natural de exposição às intempéries já é suficiente para que haja esse transporte.

$\mathrm{Na}$ Fig. 2.2.8 abaixo original de Taylor (1990), segue um modelo de representação da água na pasta de cimento endurecida.

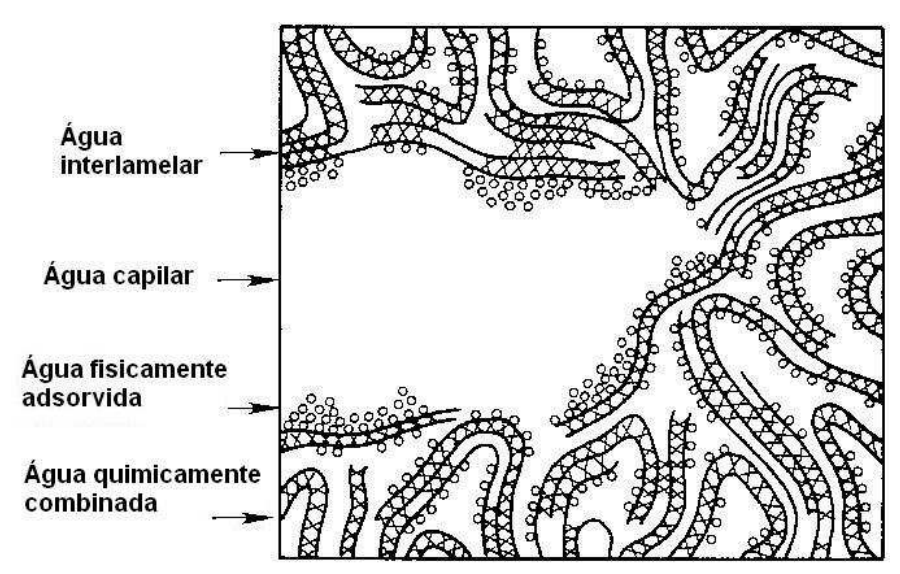

Figura 2.2.8 - Representação da água na pasta endurecida 
Em termos de elasticidade, deve-se observar que ao contrário dos poros preenchidos com ar que apresentam rigidez praticamente nula, os poros preenchidos com água tendem a, instantaneamente, colaborar com a rigidez do todo durante a transferência dos esforços cisalhantes para a estrutura rígida em que está inserida.

Agora é apresentada uma descrição breve dos elementos sólidos da zona de transição entre pasta e agregados.

ZT. Segundo Paulon (2005), a zona de transição entre agregados e pasta de cimento endurecida é caracterizada por ser fortemente anisotrópica, principalmente a baixas e médias idades (alguns meses). Conforme já foi dito, a zona de transição concentra grande parte do volume de $\mathrm{CH}$ (hidróxido de cálcio) e de etringita da pasta endurecida e estes produtos se desenvolvem preferencialmente na vizinhança dos agregados de uma maneira que tende à direcionalidade pela própria deficiência de ocupação tridimensional desses arranjos cristalinos - prismas hexagonais com duas dimensões muito maiores que a terceira e prismas aciculares com uma dimensão muito maior que as outras duas, respectivamente. Uma representação da zona de transição é apresentada na Fig. 2.2.9.

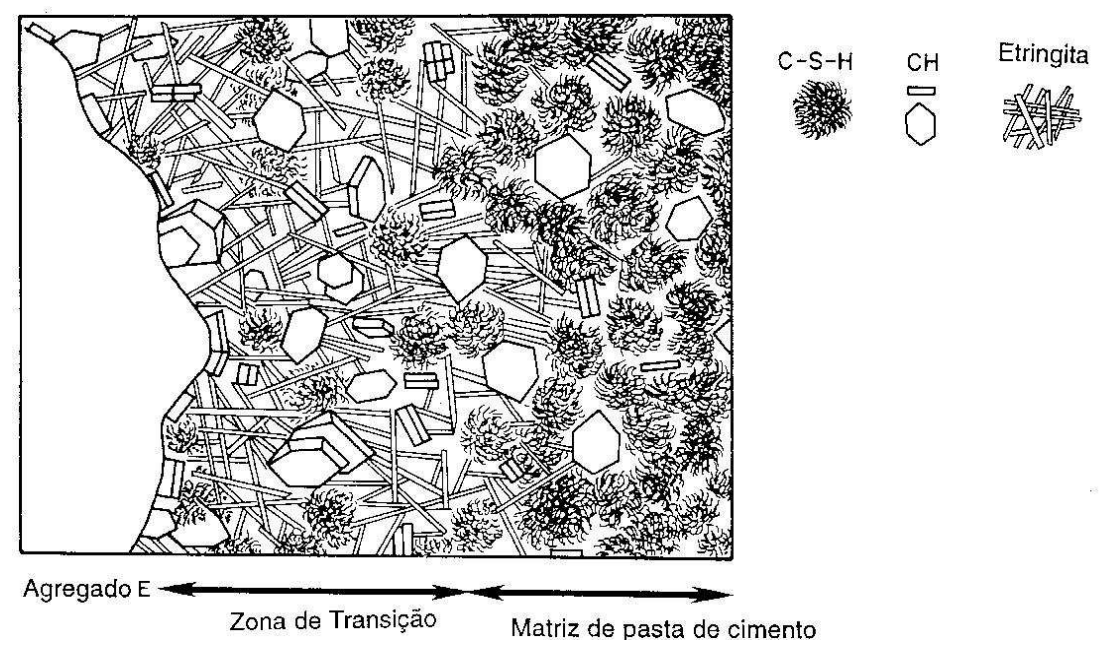

Figura 2.2.9 - Representação da zona de transição pasta-agregado 
É por isso que esta região tem a tendência de ser a primeira a sofrer com os efeitos das solicitações atuantes no concreto, mesmo com os efeitos intrínsecos de retração. Segundo Mehta e Monteiro (1994), a zona de transição pode atingir a mesma capacidade resistente e de rigidez que o restante da pasta endurecida com o avanço da idade do concreto. Essa consideração, claramente, considera que o concreto não tenha sofrido processo de exsudação com concentração excessiva de água sob os agregados graúdos - principalmente aqueles mais achatados e/ou alongados - que tenha dificultado a ocupação do espaço por grãos de cimento em hidratação e que também não tenha sofrido processo de microfissuração, o que, na prática, é pouco provável.

Segundo Paulon (2005), a "auréola" de zona de transição comum que circunda os agregados tem uma espessura da ordem de $50 \mu \mathrm{m}$. Corroborando com o observado por Mehta e Monteiro (1994), o autor acrescenta que a espessura da auréola tende a diminuir com a idade do concreto pela reação de hidratação contínua na região e até mesmo pela reação química (superficial) com os agregados, principalmente os de natureza calcária.

Sobre o módulo de elasticidade da zona de transição, Hashin e Monteiro (2002) recomendaram a estimativa de seu valor em $50 \%$ daquele atingido pela pasta de cimento propriamente dita. Mehta e Monteiro (1994) fazem referência ao módulo de elasticidade de pastas endurecidas com valores entre 7 e $28 \mathrm{GPa}$, o que pode dar a medida da rigidez da zona de transição.

Por fim, deve ser apresentada uma descrição breve dos elementos sólidos da fase de maior volume no concreto, a dos agregados.

A. $O$ agregados naturais ou britados são usualmente divididos em agregado miúdo, de diâmetro abaixo de $4,75 \mathrm{~mm}$, e graúdo, de tamanho acima da faixa referida. $\mathrm{O}$ agregado miúdo, por sua vez, pode ser dividido em material menor que $75 \mu \mathrm{m}$ (pulverulento) e maior que $75 \mu \mathrm{m}$. O primeiro grupo está fundamentalmente sujeito a forças de superfície quando inserido no concreto enquanto o segundo está sujeito a forças de massa.

Os agregados de um único concreto podem ser de diversas origens mineralógicas e, por isso, estão sujeitos a composições químicas próprias e normalmente independentes daquelas que surgem na pasta de cimento. Os 
agregados mais comumente utilizados na dosagem de concretos estruturais são mais resistentes e menos deformáveis que a pasta de cimento endurecida.

$\mathrm{Na}$ Tab. 2.2.1 são apresentados os principais tipos de rochas utilizados como matriz de agregados para concreto e seus respectivos módulo de elasticidade. Esta lista foi originalmente publicada por Sbrighi Neto (2005).

Tabela 2.2.1 - Módulo de elasticidade das mais comuns rochas-matrizes de agregados

\begin{tabular}{|c|c|}
\hline Tipo de rocha & Módulo de elasticidade (GPa) \\
\hline Arenito & $20-40$ \\
\hline Basalto & $60-100$ \\
\hline Calcário & $30-50$ \\
\hline Gnaisse & $40-70$ \\
\hline Granito & $40-70$ \\
\hline Quartzito & $50-100$ \\
\hline Xisto & $25-40$ \\
\hline
\end{tabular}

Fonte: Sbrighi Neto (2005)

Nota-se que a variação de rigidez dos possíveis agregados de concreto é bastante grande, principalmente se considerada em um país rico em rochas-matrizes como o Brasil.

A microestrutura das rochas não será aqui objeto de detalhamento dada a complexidade do assunto e a variedade de naturezas que se deveria abordar. Devese lembrar, porém, que uma única rocha pode constituir-se microestruturalmente em um compósito multifásico de arranjos cristalográficos que, além das falhas de continuidade, conjugam diferentes propriedades como no caso do granito que é composto de minerais como o quartzo, o feldspato e a mica.

Ainda assim, para o estudo do concreto, quaisquer desses principais tipos de rocha citados são considerados como isotrópicos e homogêneos e isso garante a consideração de que as mesmas propriedades medidas ou admitidas para o agregado graúdo podem ser consideradas também para o agregado miúdo.

Outra questão importante a ser ressaltada quanto aos agregados é a composição granulométrica no arranjo da estrutura do concreto. Se para a pasta de cimento endurecida a porosidade é de fundamental importância para a definição da rigidez, nos agregados a microporosidade intrínseca à rocha-matriz tende a ser tão importante quanto a distribuição granulométrica dos grãos que gerarão a 
macroporosidade, porque é esta última que a pasta de cimento deverá preencher. Pela simples comparação entre os módulos de elasticidade de cada um dos componentes apresentados até aqui, a composição granulométrica de cada tipo de agregado que gerar a menor porosidade a ser preenchida com pasta de cimento tenderá a fornecer o compósito mais rígido.

Pode-se dizer então que, em suma, quando o concreto é solicitado a deformar-se, esta deformação se distribuirá entre elementos cristalinos e nãocristalinos de diferentes tamanhos, naturezas de rigidez e estágios temporais de desenvolvimento, além de poros e microfissuras que representam falhas de continuidade de rigidez originadas na própria formação dos produtos de hidratação, na retração do material e no amassamento do concreto. Essas falhas, por sua vez, podem estar preenchidas com ar ou água, que se comportam distintamente quando solicitados a deformarem-se.

Por fim, a deformação do concreto ainda dependerá da distribuição espacial de todos esses elementos que é idealizada como aleatória. Na prática, porém, sabese que os poros capilares oriundos da exsudação de parte da água de amassamento tendem a ser ascendentes e intercomunicantes (direcionais) e que as camadas superficiais do concreto tendem a sofrer mais química e fisicamente com as interações ambientais que as mais nucleares. Sabe-se também que a própria aplicação do concreto fresco poderá provocar segregação das fases do compósito, mas esta consideração normalmente é vista como desprezível.

Todas essas considerações são importantes quando se deseja, como é o caso, discutir a eficiência do método experimental para determinação da rigidez do concreto compreendendo-se esta propriedade desde a sua origem microestrutural.

\subsubsection{Quadros-resumo}

$\mathrm{Na}$ Tab. 2.2.1.1 é apresentado um quadro-resumo com as distribuições volumétricas prováveis dos componentes da pasta endurecida e do concreto detalhados até aqui, com suas respectivas expectativas de módulos de elasticidade. 
Tabela 2.2.1.1 - Quadro-resumo da distribuição volumétrica e respectivos módulos de elasticidade esperados para os componentes do concreto

\begin{tabular}{|c|c|c|c|c|}
\hline Componente & $\begin{array}{c}\text { Volume de } \\
\text { sólidos da } \\
\text { pasta } \\
(\%)\end{array}$ & $\begin{array}{c}\text { Volume na } \\
\text { pasta } \\
(\%)\end{array}$ & $\begin{array}{c}\text { Volume no } \\
\text { concreto } \\
(\%)\end{array}$ & $\begin{array}{c}\text { Módulo de } \\
\text { elasticidade } \\
(\mathbf{G P a})\end{array}$ \\
\hline C-S-H & $50-60$ & & & $20-40$ \\
\hline CH & $20-25$ & & & 40 \\
\hline AFm/AFt & $15-20$ & & & $20-40$ \\
\hline C & $(1)$ & & & 120 \\
\hline PG & & $(2)$ & & 0 \\
\hline PC & & $(3)$ & & 0 \\
\hline PA & & & $1-5$ & 0 \\
\hline Pasta & & & $30-40$ & $7-28$ \\
\hline ZT & & & $(4)$ & $4-14$ \\
\hline Agregados & & & $60-70$ & $40-100$ \\
\hline Concreto & & & 100 & $20-40$ \\
\hline
\end{tabular}

(1) Dependente do grau de hidratação da pasta. $O$ valor diminui com a idade.

(2) Numericamente igual a $25,4 \%$ do volume de água quimicamente combinada no gel de $\mathrm{C}-\mathrm{S}-\mathrm{H}$.

(3) Aproximadamente igual ao volume de sólidos da pasta somado aos poros provenientes da exsudação.

(4) Dependente do grau de hidratação da pasta. Do ponto de vista químico, o valor diminui com a idade, mas, na prática, a zona de transição não se anula porque é "substituída" freqüentemente por uma microfissuração.

É apresentada agora na Fig 2.2.1.1 outra forma de quadro-resumo que é dada por um diagrama de barras que mostra as dimensões usuais de cada um dos componentes do concreto detalhados até aqui e as respectivas faixas de expectativa de módulos de elasticidade.

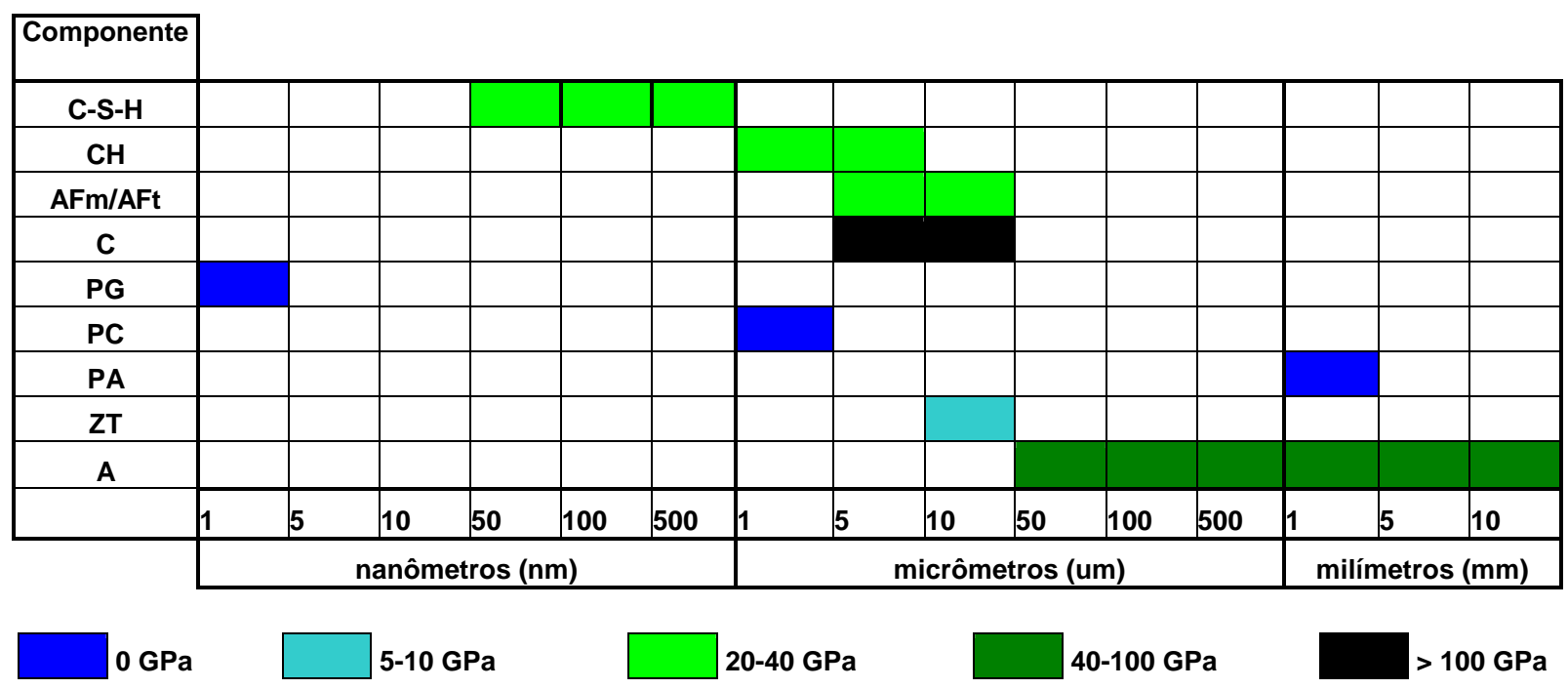

Figura 2.2.1.1 - Diagrama de identificação das dimensões dos componentes do concreto e respectivos módulos de elasticidade esperados 
2.2.2 Modelo de quantificação da composição microestrutural

A título de informação, recorda-se que Neville (1997) e Helene (2004) mostram que a partir de um traço em massa do tipo 1:a:b:a/c, sendo $\gamma_{c}, \gamma_{a}, \gamma_{b}$ e $\gamma_{h}$ as massas específicas absolutas do cimento, areia, brita e da água, respectivamente, pode-se admitir:

- Volume de cimento: $V c=\frac{1}{\gamma_{c}}$

- Volume de areia: $V a=\frac{a}{\gamma_{a}}$

- Volume de brita: $V b=\frac{b}{\gamma_{b}}$

- Volume de água: $V h=\frac{a / c}{\gamma_{h}}$

- Volume de ar aprisionado medido ou calculado: Var

- Volume de concreto: $V c o n c=V c+V a+V h+V a r$

- Grau de cristalização: $\alpha$

- Volume de água de cristalização: Vhc , para grau de hidratação $\alpha=100 \%$

- Volume de produtos de hidratação sólidos: $V s=[V c+V h c \cdot(1-0,254)] \cdot \alpha$

- Volume de cimento anidro: $V c a=V c \cdot(1-\alpha)$

- Volume de água de gel: Vhgel $=\frac{0,28 \cdot V s}{(1-0,28)} \cdot \alpha$

- Volume de poros de gel: Vpgel $=0,254 \cdot$ Vhgel $\cdot \alpha$

- Volume de poros capilares (água livre):Vhlivre $=$ Vh - Vhgel $-\alpha \cdot$ Vhc

- Volume percentual de vazios permeáveis: $V v=\frac{\text { Var }+ \text { Vhlivre }}{\text { Vconc }}$

De posse desses valores, obtém-se estimativas dos volumes de compostos resistentes e não-resistentes presentes no traço através das expressões a seguir:

- Volume percentual de componentes resistentes:

$$
C R=\frac{V s+V h g e l+V c a+V a+V b}{V c o n c}
$$


- Volume percentual de componentes não-resistentes:

$$
C N R=\frac{\text { Vpgel }+ \text { Vhlivre }+ \text { Var }}{\text { Vconc }}
$$

Dessa forma, estas expressões são freqüentemente utilizadas para o entendimento do desempenho do traço quanto à resistência à compressão. Porém, dada a revisão teórica anterior e a evidente coincidência entre os compostos resistentes e os rígidos, parece intuitivo que também possam ser utilizadas durante a modelagem do traço de concreto quanto ao desempenho de elasticidade/rigidez. Por isso, cabe aqui a sua citação.

\subsection{O módulo de deformação do concreto}

Como visto, o concreto de cimento Portland constitui-se de uma mistura de componentes cujas ligações químicas são características dos materiais cerâmicos, mas que se comporta globalmente como um compósito. Isto porque as propriedades da pasta de cimento endurecida, incluindo a zona de transição, apresentam magnitudes muito diferentes daquelas dos agregados e as respostas do concreto colocam-se ainda em um outro nível, em geral, composto entre o nível da resposta da pasta e o nível da resposta dos agregados. Esta resposta diferenciada do concreto pode ser vista nas relações tensão-deformação específica individualizadas, para a compressão, constantes da Fig. 2.3.1 de Neville (1997).

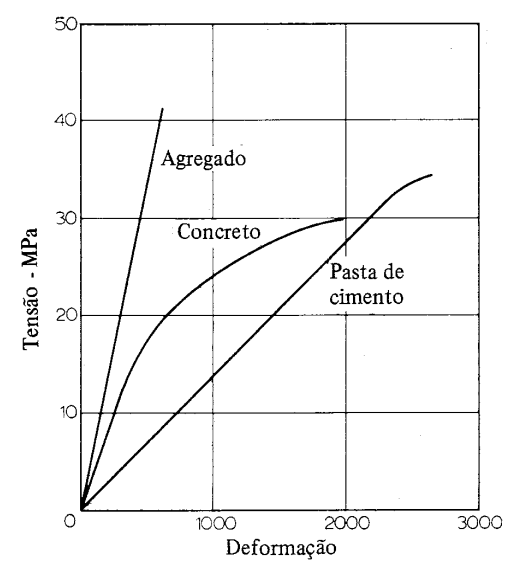

Figura 2.3.1 - Respostas de tensão-deformação do concreto e suas fases principais 
Note-se que a curva tensão-deformação do concreto para as solicitações usuais de compressão axial não é linear, ao contrário daquelas curvas que se referem genericamente aos agregados e à pasta endurecida.

Esse comportamento quanto à relação tensão-deformação é melhor compreendido a partir das seguintes informações: Neville (1997) afirmou que o concreto antes mesmo de sofrer a aplicação de qualquer solicitação possuía microfissuras principalmente na zona de transição que, com a aplicação e o incremento gradual de uma solicitação, tendem a evoluir acentuadamente justificando a taxa de deformação proporcionalmente maior que a da tensão aplicada. A tensão inicial a partir da qual se desenvolveriam estas microfissuras seria dependente da relação água/cimento, isto é, da qualidade da pasta. Essas microfissuras evoluiriam inicialmente dentro da zona de transição com a aplicação da solicitação e permaneceriam estáveis até um nível em torno de $30 \%$ da resistência à compressão do concreto. Para solicitações entre 70 e 90\% desta tensão última, passariam a se propagar também através da pasta.

Mehta e Monteiro (1994) também afirmaram a existência das microfissuras no momento pré-aplicação da solicitação e detalharam a evolução do sistema de fissuração do concreto através de um elemento gráfico desde então bastante divulgado (Fig. 2.3.2). Nele, os autores destacam um estágio inicial na relação tensão-deformação que é aproximadamente linear e que vai até $30 \%$ da tensão última de resistência desse concreto, apresentando microfissuras restritas à zona de transição. Entre 30 e 50\% da tensão última, admitiu-se que as microfissuras aumentam em número, abertura e comprimento mas que o sistema de fissuração permanece estabilizado e concentrado dentro da zona de transição. Ou seja, não haveria propagação de fissuração da zona de transição para o seio da pasta endurecida. Em tese, se daria neste nível o término da relação aproximadamente linear entre tensão e deformação. Acima dele, passaria a haver a formação e a propagação das fissuras pela pasta — principalmente na direção dos poros capilares - até a ruptura. 
(2) $50 \%$ DA TENSĀO ÚLTIMA

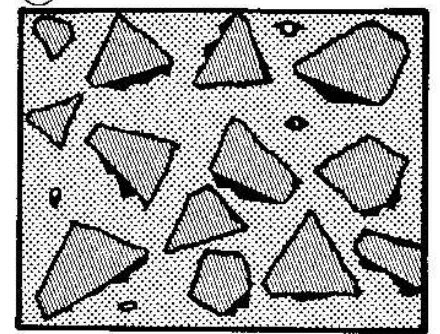

(1) $30 \%$ DA TENSÄO ỨLTIMA

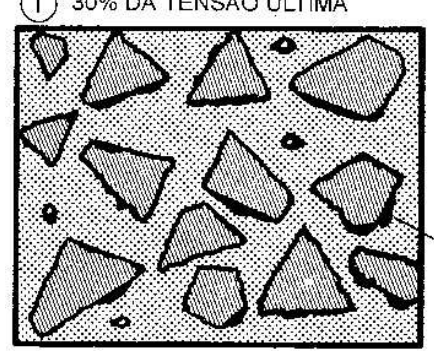

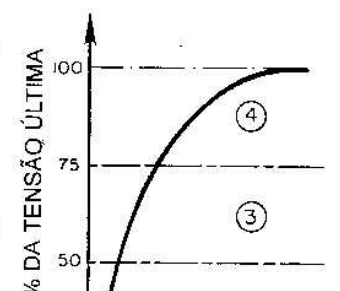

(2)

怘

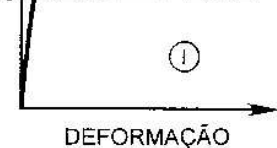

MICROFISSURAS

NA ZONA DE TRANSIÇĀO
(4) TENSÃO DE RUPTURA

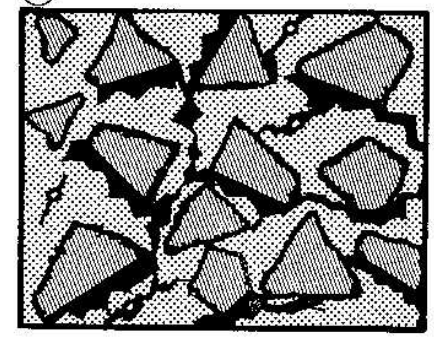

(3) $75 \%$ DA TENSÃO ÚLTIMA

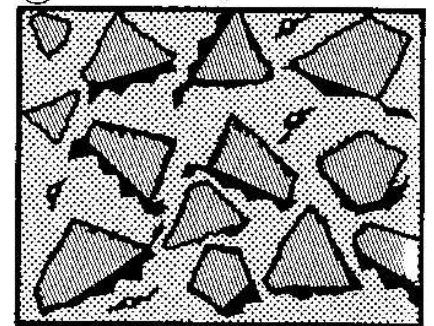

Figura 2.3.2 - Representação esquemática da fissuração e do comportamento tensãodeformação do concreto

Fonte: Mehta e Monteiro (1994)

A partir dessas informações é possível depreender que o nível de deformação interatômica imposto pela carga entre 30 e 50\% da resistência do concreto é suficiente para que haja deformação plástica em partículas localizadas na zona de transição, principalmente, mas basicamente apenas elástica naquelas partículas localizadas no seio da pasta ou dos agregados.

Kotsovos e Pavlovic (1995) denominaram a faixa entre 0 e $30-50 \%$ da resistência como aquela de Início do Fraturamento Localizado (Local fracture initiation ou $L F I$ ) e de grande parte da Propagação Estável do Fraturamento (Onset of stable fracture propagation ou OSFP), caracterizadas pelo início da orientação geométrica das fissuras na direção do esforço solicitante e da inserção dos esforços transversais elementares no corpo material que provoca o prolongamento das fissuras existentes. Esses autores denominaram ainda a fase seguinte de propagação do fraturamento de Propagação instável (Onset of unstable fracture propagation ou OUFP), que seguiria até a tensão última do concreto (Fig. 2.3.3.a-b). 


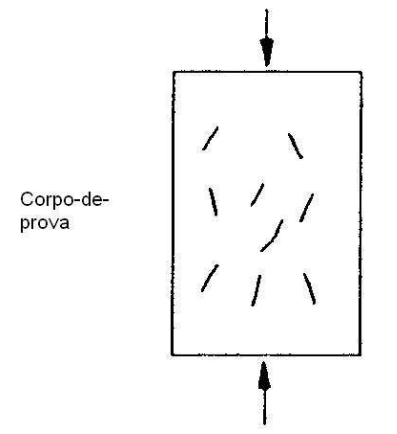

Fissura

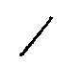

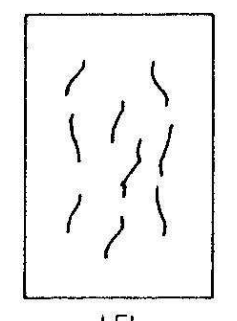

LFI

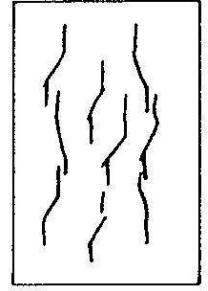

OSFP

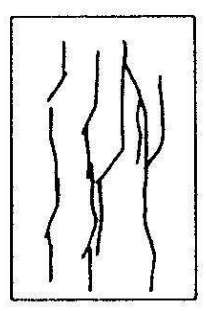

OUFP

(a)<smiles>c1ccccc1</smiles>

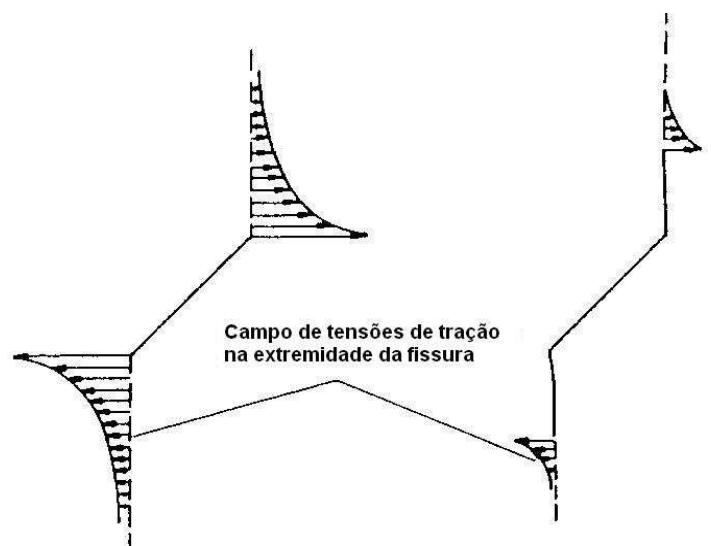

(b)

Figura 2.3.3 - Esquema do fraturamento: (a) fases; (b) detalhe dos campos de tensões

Fonte: Kotsovos e Pavlovic (1995)

Na prática experimental, a faixa de solicitação entre 0 e 30-50\% da resistência é aquela utilizada para a quantificação do módulo de elasticidade do concreto a partir do coeficiente angular de uma reta aproximada sobre a curva tensãodeformação específica obtida entre estes níveis. Aliás, este é o motivo pelo qual esta dissertação preferirá a designação da propriedade pelo termo 'módulo de deformação', já que para a faixa de carregamento referida as deformações não se restringem às de natureza elástica. Ressalte-se que as opções de terminologia não implicam necessariamente em incongruência técnica porque a demanda pelo estudo do módulo do concreto vem da área de projeto e construções de estruturas de concreto armado e, a esta, o que importa é a determinação do comportamento global do material frente às aplicações que se queira dar pela Engenharia. 
2.3.1 Modelos de previsão do módulo de deformação do concreto a partir da mecânica dos compósitos

O concreto, na forma mais simples de compósito, pode ser considerado como um material bifásico em que uma fase particulada (agregados) está dispersa aleatoriamente numa matriz de base cimentícia (pasta de cimento endurecida).

Aitcïn e Mehta (1990) e Baalbaki et al. (1991) já demonstraram que o módulo de deformação do concreto é influenciado pelas propriedades elásticas individuais, pelo fracionamento volumétrico e pela interação das suas fases constituintes. Quando é possível determinar com confiabilidade, o módulo dessas fases através de moldagens ou extração de testemunhos da rocha-matriz, pode-se inferir o módulo do concreto. A única compensação puramente matemática a ser realizada é a consideração da interação entre os módulos individuais e as frações volumétricas dos constituintes.

Em geral, essa interação busca ser representada matematicamente adotando-se um fenômeno físico possível de resposta do compósito, como a consideração de que, sob solicitação, ambas as fases sofrerão a mesma tensão em seus componentes, ou, ao contrário, a mesma deformação.

De acordo com Mehta e Monteiro (1994) e Yang (1997), o pesquisador W. Voigt, em 1889, ao considerar a uniformidade de deformações de um material compósito bifásico genérico sob solicitação, encontrou um limite superior para a previsão do módulo de elasticidade do compósito, como mostrou a experiência de uso posterior. Seu modelo também é conhecido como o das Fases em Paralelo. Anos depois, em 1929, A. Reuss propôs a consideração da uniformidade das tensões nas fases e encontrou um limite inferior para a propriedade, conhecido como o das Fases em Série (Fig. 2.3.1.1).

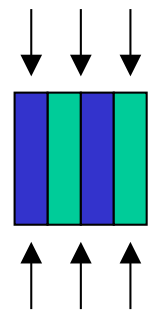

(a) Voigt

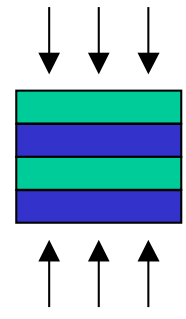

(b) Reuss

Figura 2.3.1.1 - Representação de modelos: (a) Fases em paralelo; (b) Fases em série 
Hirsch (1962), revisou o trabalho desses pesquisadores aplicando-os diretamente ao concreto e expressou o módulo de deformação em termos de uma constante empírica que indicava a contribuição dos modelos de deformação uniforme e tensão uniforme simultaneamente, além de acrescentar resultados experimentais de ensaios com diferentes tipos de agregados. No mesmo ano, Hashin e Shtrikman apud Mehta e Monteiro (1994) propuseram um princípio diferente para a previsão do desempenho da interação entre as fases de compósitos e chegaram a limites mais precisos do que os de Voigt e Reuss através de considerações da Teoria da Elasticidade aplicada a materiais isotrópicos multifásicos, com geometria de fase arbitrária. Na Fig. 2.3.1.2, originalmente de Mehta; Monteiro (1994), consta um exemplo de aplicação dos modelos de Voigt, Reuss e Hashin-Shtrikman (H-S).

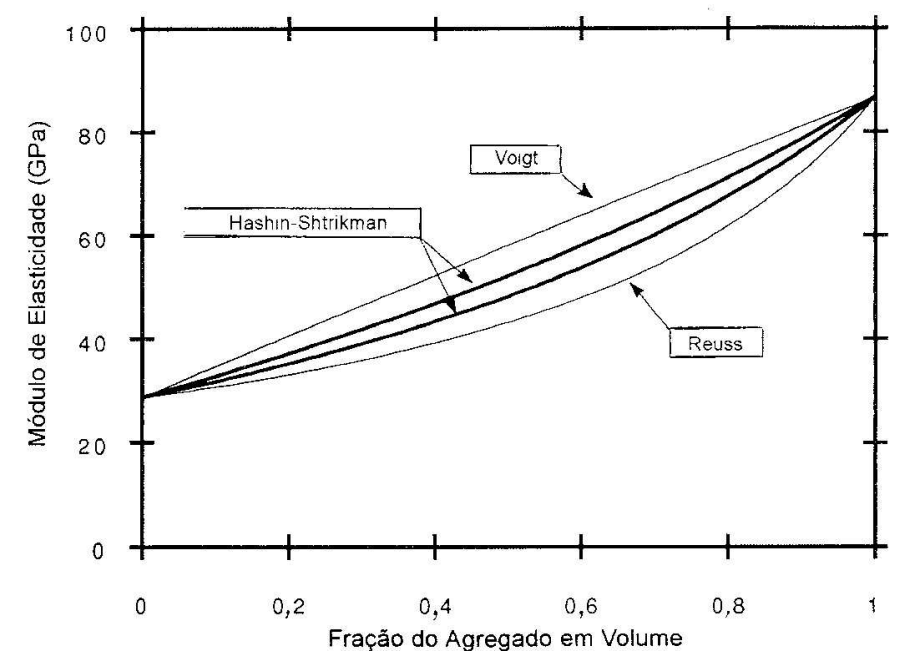

Figura 2.3.1.2 - Representação de aplicação dos modelos de Voigt, Reuss e Hashin-Shtrikman Fonte: Mehta e Monteiro (1994)

Por fim, em 1964, Counto apud Mehta e Monteiro (1994) e Hansen (1965) completam a lista básica dos pesquisadores que desenvolveram modelos para compósitos bifásicos aplicáveis ao concreto. Eles consideraram o compósito com a fase particulada contida no núcleo da matriz, mas sob formatos distintos: esférico e cúbico, respectivamente (Fig. 2.3.1.3). 


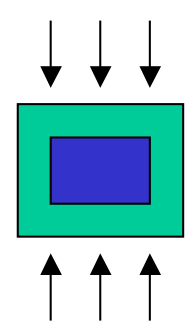

(a)

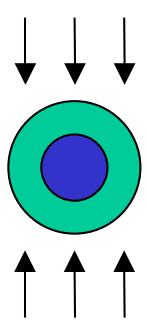

(b)

Figura 2.3.1.3 - Representação dos modelos de fases concêntricas: (a) Counto; (b) Hansen

Fonte: Mehta e Monteiro (1994)

As formulações matemáticas conclusivas apresentadas por todos esses pesquisadores constam da Tab. 2.3.1.1. A título de informação, optou-se por acrescentou-se à lista duas outras expressões recuperadas no levantamento bibliográfico que foram elaboradas respectivamente por Hansen (1965) e MüllerRochholz apud Zhou; Lydon e Barr (1995) referente a um trabalho de 1974 daquele pesquisador. A primeira é recomendada à previsão do módulo de elasticidade da pasta de cimento endurecida considerando-a como um compósito bifásico onde a fase matriz é a dos seus componentes rígidos (produtos hidratados e cimento anidro) e a fase particulada é a dos poros capilares, de módulo de elasticidade nulo. A segunda é recomendada à previsão do módulo de elasticidade dos agregados, com base unicamente em sua massa específica absoluta.

Tabela 2.3.1.1 - Pesquisadores e modelos micromecânicos

Voigt (1889)

\begin{tabular}{c|c}
$K_{c}=K_{m} V_{m}+K_{p} V_{p}$ & $G_{c}=G_{m} V_{m}+G_{p} V_{p}$
\end{tabular}

$$
E_{c}=E_{m} V_{m}+E_{p} V_{p}
$$

Obs: Formulação que considera a relação deformações transversais/deformações longitudinais (coeficiente de Poisson) igual para as duas fases do compósito

Reuss (1929)

$$
\begin{gathered}
K_{c}=\frac{K_{m} E_{p}}{K_{m} V_{p}+K_{p} V_{m}} \quad G_{c}=\frac{G_{m} E_{p}}{G_{m} V_{p}+G_{p} V_{m}} \\
E_{c}=\frac{E_{m} E_{p}}{E_{m} V_{p}+E_{p} V_{m}}
\end{gathered}
$$

Obs: Formulação que considera a relação deformações transversais/deformações longitudinais (coeficiente de Poisson) igual para as duas fases do compósito 
Tabela 2.3.1.1 (continuação) - Pesquisadores e modelos micromecânicos

Hirsch (1962)

$$
\frac{1}{E_{c}}=(1-x) \cdot\left(\frac{V_{p}}{E_{p} V_{c}}+\frac{V_{c}-V_{p}}{E_{m} V_{c}}\right)+x \cdot\left(\frac{V_{c}}{V_{p} E_{p}-V_{p} E_{m}+E_{m}}\right)
$$

Obs: $x$ e $(1-x)$ representam a contribuição relativa entre os modelos de Voigt e Reuss

\section{Hashin e Shtrikman (1962)}

$$
\begin{gathered}
K_{c}^{\text {sup }}=K_{p}+\frac{V_{m}}{\frac{1}{K_{m}-K_{p}}+\frac{3 V_{p}}{3 K_{p}+4 G_{p}}} \quad G_{c}^{\text {sup }}=G_{p}+\frac{1}{\frac{1}{G_{m}-G_{p}}+\frac{V_{m}}{5 G_{p}\left(3 K_{p}+4 G_{p}\right)}} \\
K_{c}^{\text {inf }}=K_{m}+\frac{V_{p}}{\frac{1}{K_{p}-K_{m}}+\frac{3 V_{m}}{3 K_{m}+4 G_{m}}} \quad G_{c}^{\text {inf }}=G_{m}+\frac{V_{p}}{\frac{1}{G_{p}-G_{m}}+\frac{6\left(K_{m}+2 G_{m}\right) V_{m}}{5 G_{m}\left(3 K_{m}+4 G_{m}\right)}} \\
E=\frac{9 K G}{3 K+G}=2 G(1+v)=3 K(1-2 v)
\end{gathered}
$$

\section{Counto (1964)}

$$
\frac{1}{E_{c}}=\frac{1-\sqrt{V_{p}}}{E_{m}}+\frac{1}{\left(\frac{1-\sqrt{V_{p}}}{\sqrt{V_{p}}}\right) E_{m}+E_{p}}
$$

\section{Hansen (1965)}

$$
\frac{E_{c}}{E_{m}}=\frac{V_{m} E_{m}+E_{p}\left(1+V_{p}\right)}{E_{m}\left(1+V_{p}\right)+V_{m} E_{p}}
$$

Obs: Formulação que considera a relação deformações transversais/deformações longitudinais (coeficiente de Poisson) igual para as duas fases do compósito (valor de 0,20)

Hansen (1965) - Módulo da pasta endurecida

$$
E_{\text {pasta }}=\frac{1-V_{\text {capilares }}}{1+2 \cdot V_{\text {capilares }}} \cdot E_{\text {sólidosglobais }}
$$

\section{Müller-Hochholz (1974) - Módulo dos agregados}

$$
E_{\text {agregado }}=8,1 \cdot \gamma_{\text {agregado }}^{2}
$$

Nota: A nomenclatura universal da área de compósitos foi mantida por uma questão de coerência com as teorias propostas. Isso significa dizer que os índices $c$, de compósito, $m$, de matriz, e $p$, de particulado, devam ser adaptados a concreto, pasta e agregados, respectivamente. Da mesma forma: $K$ é o módulo volumétrico, $G$ é o módulo de cisalhamento, $E$ é o módulo de elasticidade ou de deformação, $V$ é a fração volumétrica e os índices sup e inf correspondem a limite superior e limite inferior, respectivamente. 
A partir dos anos 1970, com T. Mori e K. Tanaka e outros pesquisadores oriundos da área de pesquisa de micromecânica dos compósitos, desenvolveram-se os modelos matemáticos para compósitos multifásicos aplicando-se o conceito de campo de médias microscópicas para analisar as propriedades macroscópicas dos materiais. Esse campo de médias consideraria que o corpo contém inclusões (fibras, particulados, poros, fissuras) com microdeformações específicas. Para a plena demonstração dessa teoria fez-se uso, entre outros, do estudo do vetor de microdeformações de Eshelby para avaliação do efeito da forma dos dispersos e de toda a Teoria da Elasticidade de corpos isotrópicos e anisotrópicos. Para ilustração resumida da aplicação, segue a forma proposta por Yang e Huang (1996), ainda para compósitos bifásicos, mas que já utiliza esse tipo de modelagem. No caso, foram consideradas as hipóteses de aplicação da Lei de Hooke generalizada para materiais isotrópicos e homogêneos tanto para o concreto como para as fases pasta de cimento endurecida e agregados (inclusões). Esta última, ainda, inclusive, considerada como de inclusões esféricas:

$$
C_{c}=\left\{C_{m}{ }^{-1}+V_{p} \cdot\left[\left(1-V_{p}\right) \cdot\left(C_{p}-C_{m}\right) \cdot T-V_{p} \cdot\left(C_{m}-C_{p}\right)+C_{m}\right]^{-1} \cdot\left(C_{m}-C_{p}\right) \cdot C_{m}{ }^{-1}\right\}
$$

onde:

$C_{c}$ é a matriz de rigidez do concreto

$C_{m}$ é a matriz de rigidez da pasta de cimento endurecida

$C_{p}$ é a matriz de rigidez dos agregados

$V_{p}$ é a fração volumétrica de agregados no concreto

$T$ é o tensor de Eshelby para inclusões esféricas. Neste caso, as componentes do tensor $T$ valem:

$$
\begin{aligned}
& T_{11}=T_{22}=T_{33}=\frac{7-5 v}{15 \cdot(1-v)} ; \\
& T_{12}=T_{13}=T_{21}=T_{23}=T_{31}=T_{32}=\frac{5 v-1}{15 \cdot(1-v)} ; \\
& T_{44}=T_{55}=T_{66}=\frac{4-5 v}{15 \cdot(1-v)} ;
\end{aligned}
$$

$v$ admitido igual para as fases e o concreto. 
Nilsen e Monteiro (1993), Lutz; Monteiro e Zimmerman (1997), Li et al. (1999) e Hashin e Monteiro (2002) propuseram e desenvolveram modelos trifásicos para previsão do módulo de deformação do concreto sob considerações similares, ora considerando a fase "poros" como uma inclusão além da dos agregados, ora considerando a zona de transição pasta-agregado como uma fase particular por possuir volume e propriedades elásticas específicas, ainda que de difícil mensuração. Observa-se que essas teorias têm formulação ainda mais complexa e seu estudo diverge do escopo desta dissertação; por isso, a escolha de apenas citar as pesquisas mas de não qualificá-las profundamente.

O que fica evidente em todos os conceitos de modelagem é que a resposta de deformabilidade do concreto é tida mesmo como dependente da qualidade (de rigidez) individual das fases, de sua distribuição quantitativa e da forma como estas interagem, configurando uma característica de natureza contributiva e interativa.

2.3.2 Inferência do módulo de deformação a partir da resistência à compressão

Em geral, a relação resistência-módulo $(\sigma / E)$ é utilizada na execução do projeto estrutural, quaisquer que sejam os materiais de Engenharia disponibilizados.

Nos Diagramas de Ashby citados no início deste capítulo, relaciona-se a resistência global do material ao módulo através da relação denominada de energia elástica armazenada por unidade de volume, dada por $\sigma / E$ (mínima energia), $\sigma^{3 / 2} / E$ (energia intermediária) ou $\sigma^{2} / E$ (máxima energia). Quanto maior o resultado da relação resistência-módulo, maior a energia acumulada por unidade de volume durante a deformação e até a ruptura (Fig. 2.3.2.1).

Nota: A figura foi mantida com textos em idioma estrangeiro dada a complexidade da alteração do original. 


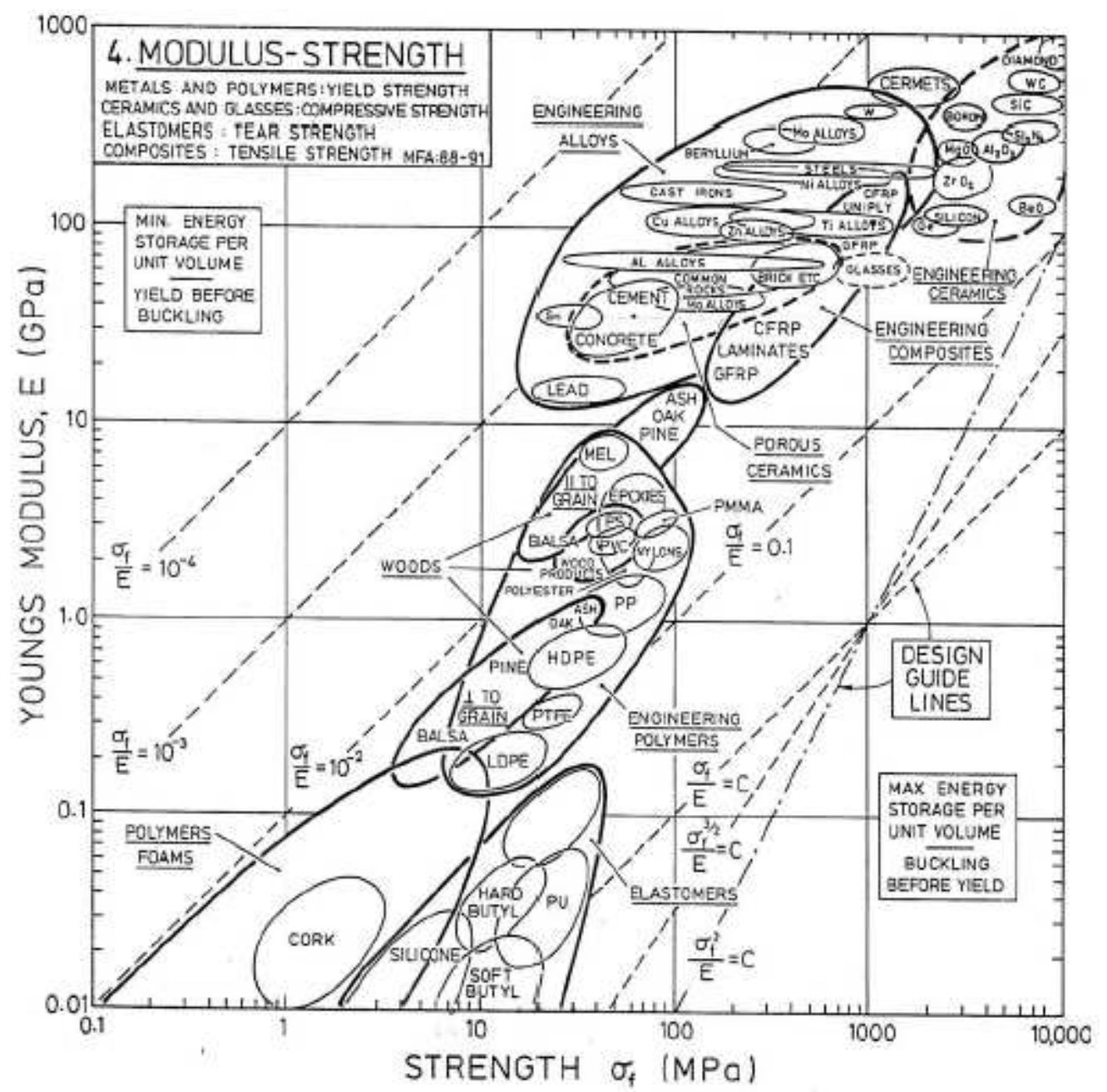

Figura 2.3.2.1 - Diagrama de Ashby: Módulo de Elasticidade x Resistência

Fonte: Frey (2007)

No concreto, ao contrário, é comum relacionar o módulo de deformação à resistência à compressão de maneira inversa, isto é, como $\sigma / E^{3}$ ou $\sigma / E^{2}$. Aparentemente, esta relação contém um significado físico único que se refere à limitação do crescimento do módulo de deformação independentemente da resistência a partir de um ponto da correlação em que o volume de pasta passa a prevalecer sobre a qualidade da pasta para os concretos usuais. Na Tab. 2.3.2.1 são apresentadas as relações mais comuns constantes nas normas e recomendações técnicas internacionais de projetos de estruturas de concreto. 
Tabela 2.3.2.1. - Expressões recomendadas: Módulo de deformação do concreto x Resistência à compressão

\begin{tabular}{|c|c|}
\hline Norma/recomendação & Expressão* $^{*}$ \\
\hline NBR 6118:2003 & $\begin{array}{l}E_{c i, N B R}=5,6 \cdot f_{c k}^{1 / 2} \\
E_{c s, N B R}=0,85 * E_{c i}\end{array}$ \\
\hline ACI 318M:2002 & \multicolumn{1}{|c|}{$E_{c s, A C I}=4,70 \cdot f_{c k}^{1 / 2}$} \\
\hline CEB-FIP Model Code 1990 & $\begin{array}{l}E_{c i, C E B}=a \cdot\left[10 \cdot\left(f_{c k}+8\right)^{1 / 3}\right. \\
0,7 \leq a \leq 1,2 \ldots \ldots . .(\text { agregado })\end{array}$ \\
\hline
\end{tabular}

*Obs.: $E_{c i}$ e $E_{c s}$ significam módulo de deformação tangente inicial e módulo de deformação secante, respectivamente. Essa diferença advém de um dos procedimentos de ensaio conforme será detalhado no capítulo seguinte desta dissertação. Apesar dessas denominações serem universais, os procedimentos mudam nos diversos raios de ação das normas e recomendações e, por isso, optou-se ainda pelo acréscimo, nas expressões, dos índices que as identificam (NBR, ACl e CEB).

Nota-se que o volume das fases do concreto e a qualidade da rigidez dos agregados não são contemplados na maioria dessas expressões matemáticas de correlação, pois têm origem fundamentalmente empírica e, admite-se, universalizada. Por universalizada entenda-se independente de consistência do concreto, tipo ou classe de cimento e natureza mineralógica ou composição granulométrica dos agregados. Detalhadamente, no que diz respeito à qualidade da pasta ou dos agregados, pode-se dizer que todas as expressões contemplam a variável qualidade da pasta pois contém o termo ' $\mathfrak{f}_{\mathrm{ck}}$ ' mas apenas a expressão do CEB contempla também a qualidade dos agregados, quando considera a variável 'a' de acordo com a natureza mineralógica dos agregados recomendando, de forma resumida, o valor de 0,7 quando arenito, 0,9 quando calcário, 1,0 quando granítico ou gnáissico e 1,2 quando basáltico. Sabe-se que a variabilidade de rigidez em uma única natureza mineralógica pode ser grande e dificultar a aplicação destes coeficientes; mesmo assim, a sua aplicação está de acordo com o fenômeno físico.

Quanto aos expoentes da relação entre o módulo de deformação e a resistência à compressão, Shehata (2005) identificou que para resistências médias menores - da ordem de até $40 \mathrm{MPa}$, estima-se - atende aos requisitos de projeto estrutural aquela do tipo $\sigma / \mathrm{E}^{2}$, como consta nas normas e recomendações de origem brasileira $(\mathrm{NBR})$ e norte-americana $(\mathrm{ACl})$. Já para resistências médias maiores - 
superiores a $40 \mathrm{MPa}$, estima-se - recomenda-se a relação $\sigma / \mathrm{E}^{3}$, como a de origem européia (CEB).

De toda forma, ressalta-se, as recomendações não devem ter caráter outro que não o uso durante o projeto estrutural, pois em comparação com as demais etapas da cadeia da construção civil - dosagem (produção) e recebimento/utilização (controle tecnológico) - esta é a única que pode desconsiderar aqueles outros parâmetros de especificação ligados aos fatores físicos que alteram a resposta de deformabilidade do concreto, como a consistência, por exemplo. Se a expectativa é de que quanto maior a fluidez do concreto, maior o volume de pasta e menor o módulo de deformação do compósito, isto pode ser praticamente independente de variação da resistência do concreto se a qualidade da pasta (relação água/cimento) tiver sido mantida. Assim sendo, tal fenômeno não pode ser desconsiderado durante a produção ou o controle tecnológico estando vinculado unicamente a uma relação do tipo $\sigma / E$, como pode ser durante o projeto estrutural. 


\section{A VARIABILIDADE EXPERIMENTAL}

De acordo com Helene (1986) e Andriolo e Sgarboza (1993), o controle tecnológico das construções em concreto armado consiste em um conjunto de ações pró-ativas de execução e fiscalização que visam a obtenção da estrutura com a qualidade projetada. Segundo esses autores, o controle tecnológico incluiria controles de qualidade de materiais e de serviços, realizados através de ensaios e inspeções. Poderiam ser citados como alguns dos itens a serem controlados:

\section{Quanto aos materiais}

- desempenho mecânico do aço;

- trabalhabilidade e desempenho mecânico do concreto, com a possibilidade de controle individualizado do cimento, agregados, água, aditivos e adições;

- durabilidade do concreto armado;

Quanto aos serviços

- serviços preliminares à concretagem como a montagem da planta de escoramento, os níveis e as dimensões das formas e a montagem da armadura nas peças;

- dosagem, mistura, transporte, lançamento, vibração, acabamento e cura do concreto;

- mapeamento do lançamento;

- serviços de desforma e reescoramento até a retirada conclusiva do escoramento;

- tratamento estatístico dos resultados dos ensaios de controle de materiais com suporte através de monitoramento de eventual fissuração, deformação excessiva ou outro sintoma de deficiência do processo, seguido das devidas atitudes corretivas sobre as quais também recairia a necessidade de controle tecnológico específico.

Nota-se que há no termo controle tecnológico o conceito implícito de qualidade de produção, tanto da estrutura quanto dos insumos materiais que são utilizados. E controlar a qualidade de uma produção, nada mais é que buscar garantir a obtenção de uma ou mais propriedades tecnológicas. Por isso, na área de ensaios laboratoriais utiliza-se o termo controle de qualidade da propriedade para identificar uma parte contida naquele mais amplo denominado controle tecnológico. 
É importante essa diferenciação devido ao fato da cadeia de produção de estruturas em concreto armado estar atualmente mais próxima da configuração de uma indústria seriada que de uma indústria de transformação, como já foi, e como ainda é o caso das empresas fornecedoras de concreto pré-misturado dosado em central, por exemplo. Cabe, cada dia mais, a fornecedores como as centrais dosadoras de concreto garantir a qualidade de atendimento às propriedades solicitadas aos materiais que entregam às construtoras para que esta possa gerenciar o processo de construção realizando o controle tecnológico global.

\subsection{Controle de qualidade da propriedade: o ensaio de módulo}

De forma simplificada, o ensaio de determinação do módulo estático de deformação do concreto se dá através da construção de uma curva 'tensãodeformação específica' com um mínimo de dois pontos. A relação das diferenças de tensão e deformação nesses dois pontos fornece o módulo de deformação, conforme mostrado na Fig. 3.1.1. Em geral os pontos escolhidos referem-se a uma tensão básica pequena $\left(\sigma_{\mathrm{a}}\right)$ que garanta uma deformação mínima de compressão sobre o concreto e uma tensão de limite elástico $\left(\sigma_{\mathrm{b}}\right)$ normalmente adotada entre 30 e $50 \%$ da resistência do concreto pelos motivos apresentados no capítulo anterior.

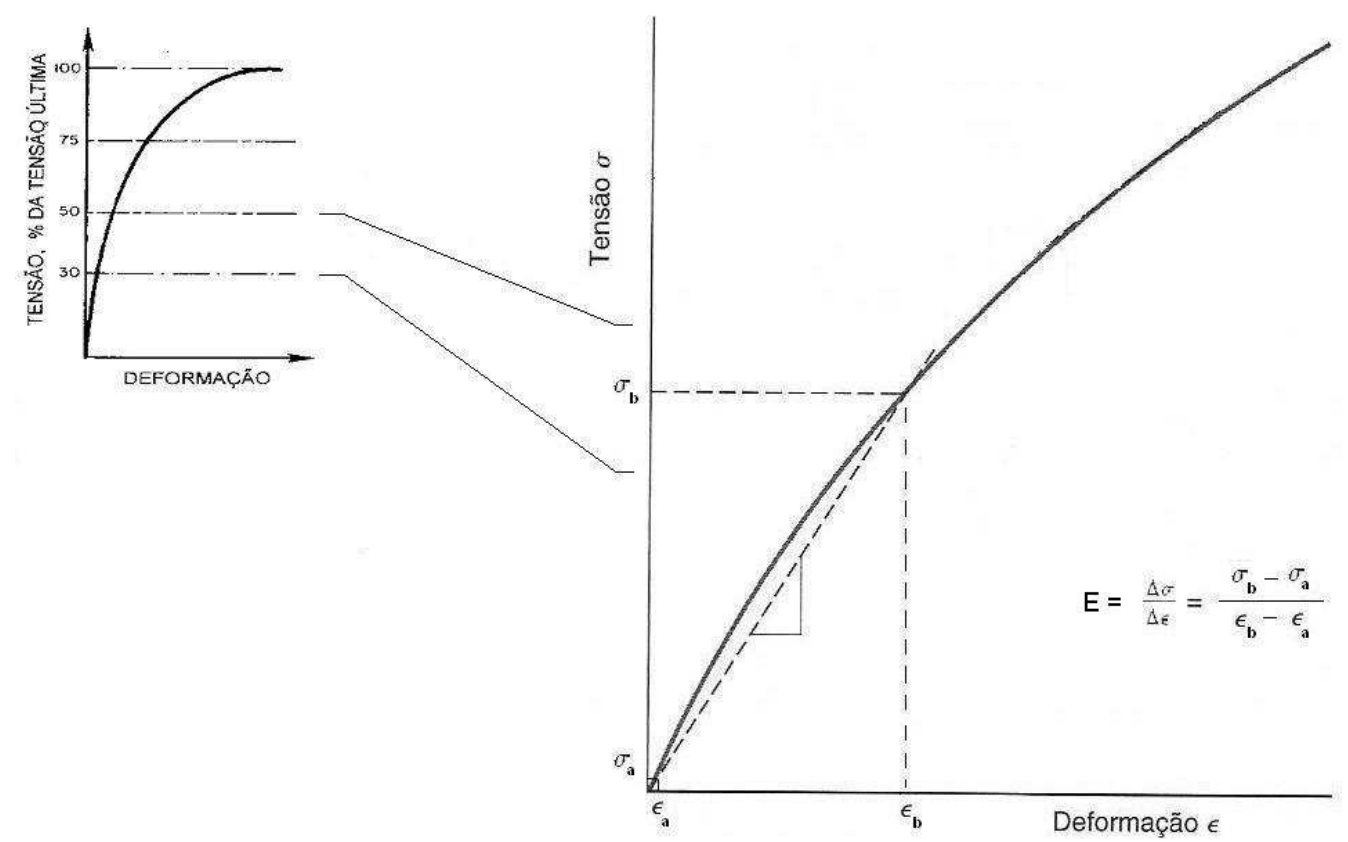

Figura 3.1.1 - Curva tensão-deformação específica para a obtenção do módulo de deformação 
A medição das deformações deve se dar preferencialmente no terço médio longitudinal do corpo-de-prova (ou terço central) por ser esta região praticamente isenta de esforços externos transversais, conforme mostraram Kotsovos e Pavlovic (1995) no original reproduzido na Fig. 3.1.2. A leitura das deformações se dá através de medidores ou sistemas de medida com sensibilidade de milésimo de milímetro colados ou ancorados no corpo-de-prova. As tensões atingidas são obtidas diretamente da máquina de ensaio (prensa).

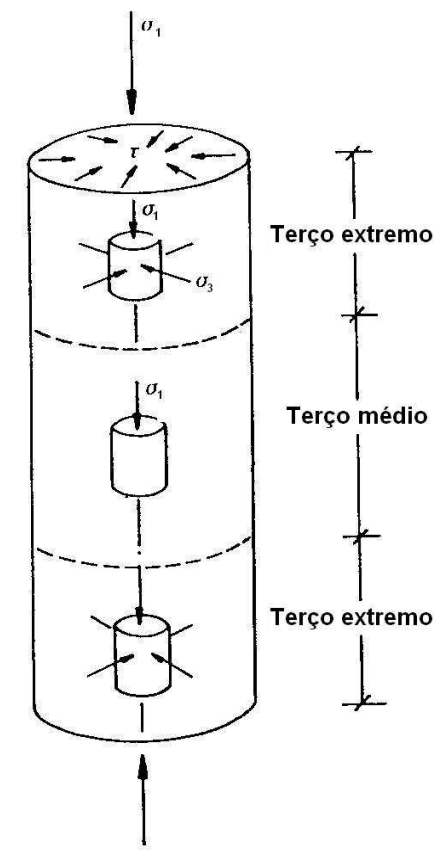

Figura 3.1.2 - Esforços no corpo-de-prova durante carregamento de compressão

Fonte: Kotsovos e Pavlovic (1995)

Apesar da normalização de ensaio clara, esse tipo de controle de qualidade requer uma análise particular. Na prática acadêmica ou de mercado há diversas evidências de variabilidade experimental acima do que é tido como intuitivamente admissível pelo meio técnico.

\subsection{Evidências da variabilidade experimental}

As mais recentes evidências da variabilidade excessiva envolvida neste tipo de determinação constam dos relatórios técnicos de Inácio; Andrade e Bittencourt (2005) e Inácio; Andrade e Bittencourt (2006) referentes a ensaios interlaboratoriais de alcance nacional de 2004 e 2005, respectivamente. Esses trabalhos foram 
realizados pelo Laboratório de Concreto de Furnas Centrais Elétricas S.A. para a Comissão Técnica de Laboratórios de Ensaios em Construção Civil do Instituto Nacional de Metrologia, Normalização e Qualidade Industrial (INMETRO/CTLE-01).

Nos Relatórios Técnicos citados são expostos, entre outros, os resultados de ensaios de determinação do módulo de deformação de amostras de dois tipos de concreto (Concreto 1 e Concreto 2) enviadas a diferentes laboratórios e ensaiadas, em tese, à mesma idade e seguindo devidamente o procedimento de ensaio descrito na norma brasileira NBR 8522:2003 - "Concreto - Determinação dos módulos estáticos de elasticidade e de deformação e da curva tensão-deformação". Por cortesia desses pesquisadores e das instituições envolvidas, os resultados obtidos puderam ser reproduzidos a seguir nas Tab. 3.2.1 e 3.2.2 e nas Fig. 3.2.1 e 3.2.2. Observa-se que cada laboratório recebeu, aleatoriamente, uma identificação alfanumérica que inclui o ano do relatório. Não houve necessariamente repetição desta ordem nos dois anos, isto é, o laboratório A/05 não é necessariamente o mesmo que A/06. Os valores apresentados para cada um dos concretos são as médias dos resultados de três corpos-de-prova ensaiados pelo laboratório.

Tabela 3.2.1 - Resultados do interlaboratorial de módulo de deformação do concreto (2005)

\begin{tabular}{|c|c|c|}
\hline Laboratórios* & $\begin{array}{l}\text { Módulo de } \\
\text { deformação } \\
\text { Concreto } 1 \\
\text { (GPa) }\end{array}$ & $\begin{array}{c}\text { Módulo de } \\
\text { deformação } \\
\text { Concreto } 2 \\
\text { (GPa) }\end{array}$ \\
\hline $\mathrm{A} / 05$ & 26,7 & 26,3 \\
\hline $\mathrm{B} / 05$ & 25,9 & 25,9 \\
\hline $\mathrm{C} / 05$ & 29,6 & 31,9 \\
\hline $\mathrm{D} / 05$ & 26,9 & 24,7 \\
\hline $\mathrm{E} / 05$ & 31,4 & 31,3 \\
\hline $\mathrm{F} / 05$ & 25,3 & 24,9 \\
\hline $\mathrm{G} / 05$ & 27,7 & 28,3 \\
\hline $\mathrm{H} / 05$ & 26,1 & 24,9 \\
\hline $\mathrm{I} / 05$ & 29,2 & 30,6 \\
\hline $\mathrm{J} / 05$ & 20,0 & 20,6 \\
\hline L/05 & 25,5 & 26,6 \\
\hline $\mathrm{M} / 05^{\star \star}$ & 35,2 & 30,9 \\
\hline $\mathrm{N} / 05$ & 33,2 & 31,3 \\
\hline
\end{tabular}


Tabela 3.2.1 (continuação) - Resultados do interlaboratorial de módulo de deformação do concreto (2005)

\begin{tabular}{|c|c|c|}
\hline Laboratórios $^{*}$ & $\begin{array}{c}\text { Módulo de } \\
\text { deformação } \\
\text { Concreto 1 } \\
(\mathrm{GPa})\end{array}$ & $\begin{array}{c}\text { Módulo de } \\
\text { deformação } \\
\text { Concreto 2 } \\
\text { (GPa) }\end{array}$ \\
\hline $\mathrm{O} / 05$ & 28,1 & 27,8 \\
\hline $\mathrm{P} / 05$ & 25,5 & 26,2 \\
\hline $\mathrm{Q} / 05$ & 31,7 & 31,2 \\
\hline $\mathrm{R} / 05$ & 21,8 & 21,2 \\
\hline $\mathrm{S} / 05$ & 24,1 & 23,9 \\
\hline Mínimo (GPa) & $\mathbf{2 0 , 0}$ & $\mathbf{2 0 , 6}$ \\
\hline Média (GPa) & $\mathbf{2 7 , 4}$ & $\mathbf{2 7 , 1}$ \\
\hline Máximo (GPa) & $\mathbf{3 5 , 2}$ & $\mathbf{3 1 , 9}$ \\
\hline Desvio-padrão (GPa) & $\mathbf{3 , 8}$ & $\mathbf{3 , 5}$ \\
\hline
\end{tabular}

Fonte: Inácio; Andrade e Bittencourt (2005) Cortesia: Furnas e INMETRO/CTLE-01

* Os laboratórios não receberam as mesmas denominações em 2005 e 2006.

** Laboratório(s) cujos resultados foram classificados como insatisfatórios no programa.

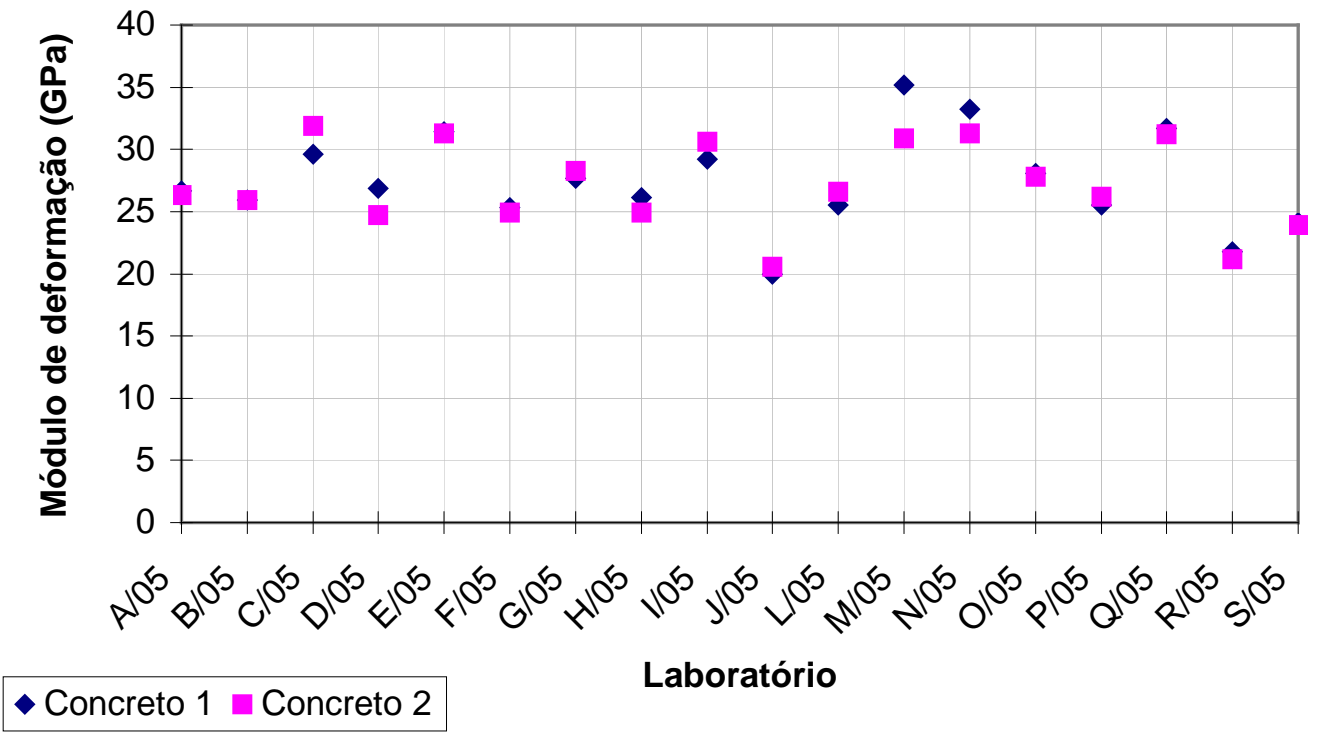

Figura 3.2.1 - Resultados do interlaboratorial nacional (2005) 
Tabela 3.2.2 - Resultados do interlaboratorial de módulo de deformação do concreto (2006)

\begin{tabular}{|c|c|c|}
\hline Laboratórios* & $\begin{array}{c}\text { Módulo de } \\
\text { deformação } \\
\text { Concreto } 1 \\
\text { (GPa) }\end{array}$ & $\begin{array}{c}\text { Módulo de } \\
\text { deformação } \\
\text { Concreto } 2 \\
\text { (GPa) }\end{array}$ \\
\hline $\mathrm{A} / 06$ & 30,0 & 26,7 \\
\hline $\mathrm{B} / 06$ & 23,7 & 23,3 \\
\hline $\mathrm{C} / 06$ & 31,0 & 28,0 \\
\hline $\mathrm{D} / 06$ & 21,3 & 19,3 \\
\hline$E / 06$ & 21,4 & 19,7 \\
\hline $\mathrm{F} / 06$ & 21,1 & 19,5 \\
\hline $\mathrm{G} / 06$ & 24,1 & 21,8 \\
\hline $\mathrm{H} / 06$ & 30,1 & 29,0 \\
\hline $1 / 06$ & 26,4 & 24,2 \\
\hline $\mathrm{J} / 06$ & 23,8 & 21,8 \\
\hline $\mathrm{L} / 06^{\star *}$ & 8,7 & 15,1 \\
\hline $\mathrm{M} / 06$ & 23,0 & 22,2 \\
\hline $\mathrm{N} / 06$ & 22,5 & 21,4 \\
\hline $\mathrm{O} / 06$ & 19,6 & 18,4 \\
\hline $\mathrm{P} / 06^{\star *}$ & 22,6 & 17,3 \\
\hline Q/06 & 24,6 & 23,4 \\
\hline $\mathrm{R} / 06$ & 22,2 & 23,0 \\
\hline $\mathrm{S} / 06$ & 20,7 & 22,3 \\
\hline $\mathrm{T} / 06^{\star *}$ & 24,8 & 28,0 \\
\hline $\mathrm{U} / 06$ & 20,4 & 20,2 \\
\hline $\mathrm{V} / 06$ & 26,7 & 25,7 \\
\hline $\mathrm{X} / 06$ & 18,5 & 17,4 \\
\hline $\mathrm{Z} / 06$ & 25,8 & 22,7 \\
\hline Mínimo (GPa) & 8,7 & 15,1 \\
\hline Média (GPa) & 23,2 & 22,2 \\
\hline Máximo (GPa) & 31,0 & 29,0 \\
\hline Desvio-padrão (GPa) & 4,6 & 3,6 \\
\hline
\end{tabular}

Fonte: Inácio; Andrade e Bittencourt (2006) Cortesia: Furnas e INMETRO/CTLE-01

* Os laboratórios não receberam as mesmas denominações em 2005 e 2006.

** Laboratório(s) cujos resultados foram classificados como insatisfatórios no programa. 


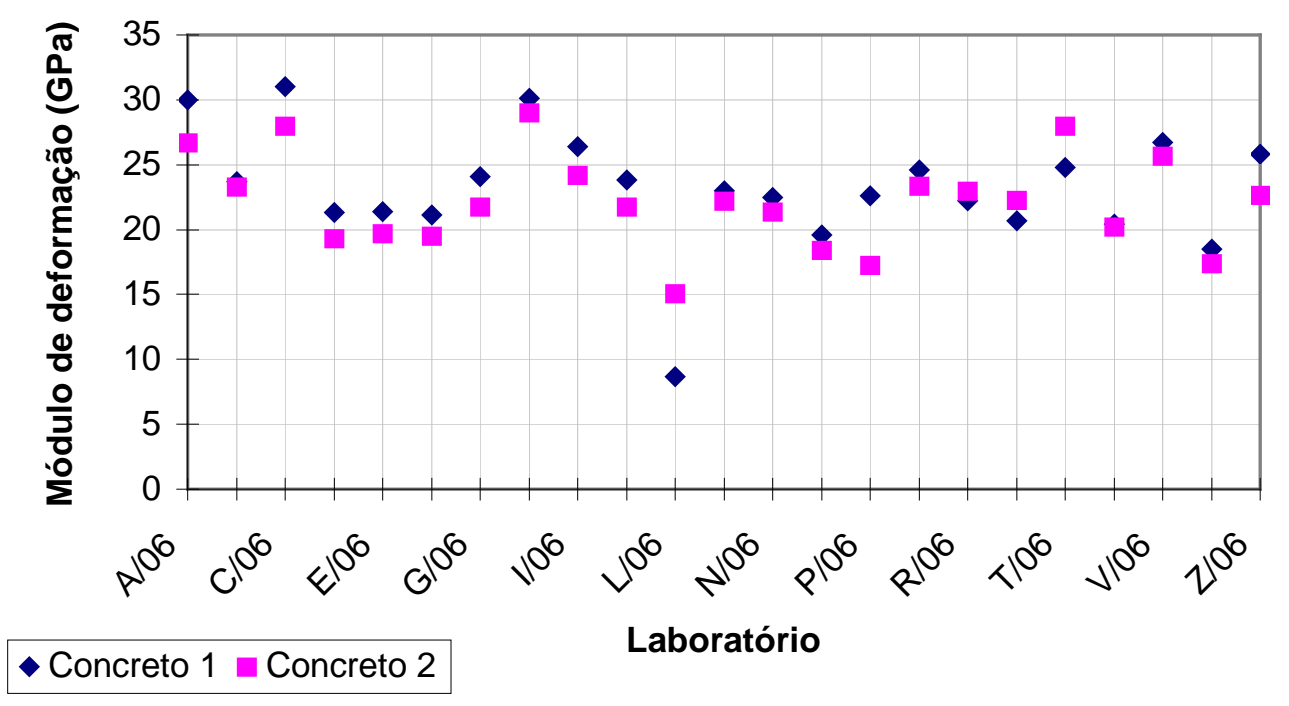

Figura 3.2.2 - Resultados do interlaboratorial nacional (2006)

Note-se que a diferença entre os resultados máximos e mínimos dos ensaios de mesmos concretos esteve entre 11 e $15 \mathrm{GPa}$ nos dois anos - foram desprezados os valores apresentados por L/06, provavelmente subestimados, o que aumentaria ainda mais a diferença naquele ano - e o desvio-padrão ficou em torno de 3,5 GPa também nos dois anos, com a eliminação de L/06. Esses valores seriam suficientes para, de modo prático, gerar insegurança em qualquer controle tecnológico. Ressalte-se que são resultados de laboratórios de todo o território nacional, com recursos diversos, mas obedientes a um mesmo método de ensaio.

Quais seriam as principais causas da variação dos resultados obtidos nestes programas experimentais interlaboratoriais? Quanto desta variação teria origem na amostragem ou na moldagem realizadas por um laboratório único, com insumos materiais de mesmos lotes e mão-de-obra especializada? Quanto estaria vinculada ao transporte das amostras até os laboratórios de ensaio inscritos nos programas? $E$, por fim, quanto seria devido à preparação final e o ensaio realizado pelos laboratórios inscritos?

Definitivamente, neste momento, a única expectativa de composição desta variação indica que sua porção mais significativa advém, provavelmente, da preparação final dos corpos-de-prova e do ensaio propriamente dito, realizados pelos laboratórios. Sabe-se que todos os corpos-de-prova foram moldados e curados até os 28 dias de idade pelo laboratório coordenador do programa para então serem protegidos individualmente e acondicionados em caixas adequadas ao 
transporte rodoviário realizado até os laboratórios inscritos. A estes coube a cura complementar até a idade aproximada de 63 dias e a preparação final de acordo com o procedimento interno usualmente utilizado para a regularização das superfícies de base e topo dos corpos-de-prova (retificação ou capeamento), além da instrumentação para a leitura das deformações e do ensaio propriamente dito, com os equipamentos disponíveis em cada localidade e utilizados rotineiramente. Cada laboratório utilizou mão-de-obra própria e treinada de forma particular, dependente do histórico de treinamentos de cada empresa. Ao final dos ensaios, cada um dos resultados obtidos foi enviado ao laboratório coordenador do programa para a compilação e a análise segundo critérios de Elipse de Confiança (Elipse de Youden) e Estatística Robusta (Z-score).

Sobre as análises realizadas, sabe-se que no relatório de 2005 apenas um laboratório obteve classificação de resultados como insatisfatórios (Laboratório M/05). No relatório de 2006, três laboratórios tiveram seus resultados classificados como insatisfatórios (Laboratórios L/06, P/06 e T/06). Porém, mesmo se desprezados os resultados referentes a estes laboratórios, a diferença máxima de resultados em 2005 e em 2006 não deixaria de estar entre 11 e 13 GPa e o desviopadrão em torno de 3,4 GPa para cada um dos concretos ensaiados, conforme mostrado nas Tab. 3.2.3 e Tab 3.2.4. Isto significa que a variação dos resultados "dentro" dos laboratórios e principalmente "entre" os laboratórios - sempre em corpos-de-prova irmãos - indicou distinta acurácia nas determinações. Ressalte-se ainda o seguinte fato: não há como afirmar qual é a magnitude de resultado experimental mais próxima do valor verdadeiro do módulo de deformação dos concretos ensaiados. A média ou a mediana desses resultados não significa necessariamente isso, e nem mesmo os resultados do laboratório coordenador. $O$ interlaboratorial realizado não teve como objetivo definir o valor verdadeiro da propriedade para os concretos estudados, mas apenas comparar os laboratórios entre si. 
Tabela 3.2.3 - Análise dos resultados do interlaboratorial 2005

\begin{tabular}{|c|c|c|c|c|c|c|c|}
\hline Ano & $\begin{array}{c}\text { Laboratórios } \\
\text { excluídos }\end{array}$ & Concreto & $\begin{array}{c}\text { Mínimo } \\
(\mathrm{GPa})\end{array}$ & $\begin{array}{c}\text { Máximo } \\
(\mathrm{GPa})\end{array}$ & $\begin{array}{c}\text { Diferença } \\
(\mathrm{GPa})\end{array}$ & $\begin{array}{c}\text { Média } \\
(\mathrm{GPa})\end{array}$ & $\begin{array}{c}\text { Desvio-padrão } \\
(\mathrm{GPa})\end{array}$ \\
\hline \multirow{3}{*}{$\mathbf{2 0 0 5}$} & Nenhum & 1 & 20,0 & 35,2 & $\mathbf{1 5 , 2}$ & 27,4 & $\mathbf{3 , \mathbf { 8 }}$ \\
\cline { 2 - 8 } & Nenhum & 2 & 20,6 & 31,9 & $\mathbf{1 1 , 3}$ & 27,1 & $\mathbf{3 , 5}$ \\
\cline { 2 - 8 } & $\mathrm{M} / 05$ & 1 & 20,0 & 33,2 & $\mathbf{1 3 , 2}$ & 27,0 & $\mathbf{3 , 4}$ \\
\cline { 2 - 8 } & $\mathrm{M} / 05$ & 2 & 20,6 & 31,9 & $\mathbf{1 1 , 3}$ & 26,9 & $\mathbf{3 , 5}$ \\
\hline
\end{tabular}

Tabela 3.2.4 - Análise dos resultados do interlaboratorial 2006

\begin{tabular}{|c|c|c|c|c|c|c|c|}
\hline Ano & $\begin{array}{c}\text { Laboratórios } \\
\text { excluídos }\end{array}$ & Concreto & $\begin{array}{c}\text { Mínimo } \\
(\mathrm{GPa})\end{array}$ & $\begin{array}{c}\text { Máximo } \\
(\mathrm{GPa})\end{array}$ & $\begin{array}{c}\text { Diferença } \\
(\mathrm{GPa})\end{array}$ & $\begin{array}{c}\text { Média } \\
(\mathrm{GPa})\end{array}$ & $\begin{array}{c}\text { Desvio-padrão } \\
(\mathrm{GPa})\end{array}$ \\
\hline \multirow{4}{*}{2006} & $\mathrm{~L} / 06$ & 1 & 18,5 & 31,0 & $\mathbf{1 2 , 5}$ & 23,8 & $\mathbf{3 , 4}$ \\
\cline { 2 - 8 } & $\mathrm{L} / 06$ & 2 & 17,3 & 29,0 & $\mathbf{1 1 , 7}$ & 22,5 & $\mathbf{3 , 4}$ \\
\cline { 2 - 8 } & $\mathrm{L} / 06, \mathrm{P} / 06$ e T/06 & 1 & 18,5 & 31,0 & $\mathbf{1 2 , 5}$ & 23,8 & $\mathbf{3 , 6}$ \\
\cline { 2 - 8 } & $\mathrm{L} / 06, \mathrm{P} / 06$ e T/06 & 2 & 17,4 & 29,0 & $\mathbf{1 1 , 6}$ & 22,5 & $\mathbf{3 , 1}$ \\
\hline
\end{tabular}

O que distingue os laboratórios ou até mesmo distingue um ensaio de outro realizado no mesmo laboratório é a acurácia de cada um dos procedimentos realizados a cada ensaio. Por procedimentos de ensaio entendam-se as técnicas e seus instrumentos que constituam fatores intervenientes nos resultados. Uma forma de apresentação desses procedimentos que constituem fatores intervenientes pode se dar através da construção do Diagrama de Causa e Efeito do método completo de ensaio. Aliás, note-se que se está considerando o termo método para designar o conjunto de procedimentos para a preparação e a execução do ensaio propriamente dito. Em outras palavras, nesta dissertação, o termo designa o conjunto das informações preconizadas na norma de ensaio, e que podem ser divididas em procedimento de amostragem, de instrumentação, de quantificação da resistência à compressão, entre outros. O Diagrama de Causa e Efeito admitido para o método de ensaio laboratorial de determinação do módulo estático de deformação do concreto segue na Fig. 3.2.3. 


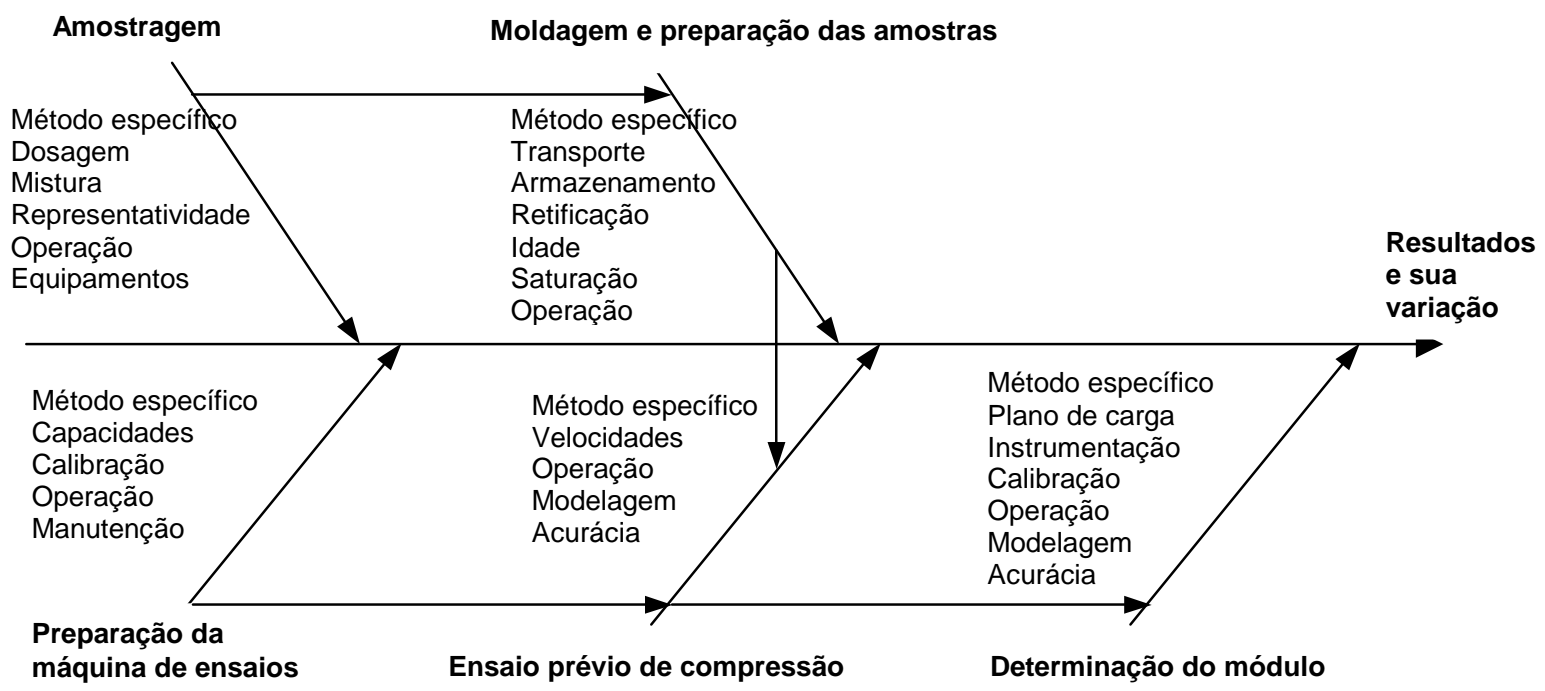

Figura 3.2.3 - Diagrama de causa e efeito para identificação dos fatores intervenientes

\subsection{Principais fatores intervenientes (origens da variabilidade)}

\subsubsection{Procedimento de amostragem}

A amostragem do concreto deve obedecer a requisitos práticos especificados em norma - no Brasil, na NBR NM 33:1994 - "Concreto - Amostragem de concreto fresco" e, do ponto de visto do controle tecnológico de produção de estruturas, também na NBR 12655:2006 - "Concreto de cimento Portland - Preparo, controle e recebimento - Procedimento", a fim de que se consiga realizar a formação de lotes de ensaio de maneira racional. A maior possibilidade de erro de amostragem propriamente dita se dá quando da coleta de material com deficiência de mistura ou não-representativo do lote misturado.

Deve-se lembrar que, como a propriedade módulo de deformação é dependente do fracionamento volumétrico das fases constituintes do concreto, só haverá efetivamente representatividade do material coletado se o traço da amostra for semelhante ao do lote. Se o traço de concreto do lote apresentar naturalmente segregação das fases como o mostrado na Fig. 3.3.1.1, pode-se, na ausência de outra recomendação, rejeitar de imediato o lote e evitar o ensaio. A amostragem de concretos que não podem desempenhar funções isotrópicas e homogêneas, como 
os segregados, é, por si, um descumprimento das prerrogativas que baseiam esta determinação experimental de propriedade deste material.

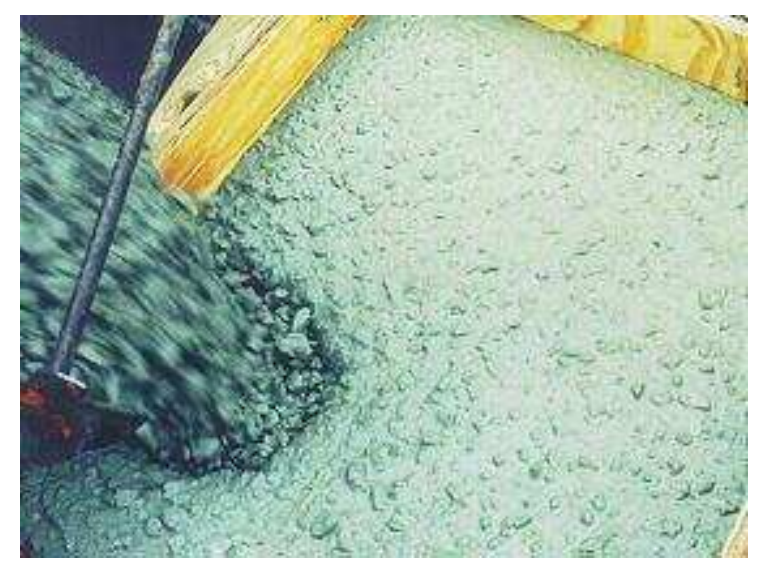

Figura 3.3.1.1 - Traço de concreto com segregação

\subsubsection{Procedimento de preparação da máquina de ensaios}

A máquina de ensaios deve apresentar rigidez suficiente para não interferir na qualidade do ensaio. No Brasil, de acordo com o item 3.1.1 da NBR 5739:1994 "Determinação da resistência à compressão de corpos-de-prova cilíndricos de concreto", a máquina de ensaios "deve ter capacidade compatível com os ensaios a serem realizados, permitindo a aplicação controlada da carga sobre o corpo-deprova colocado entre os pratos de compressão". A NBR 5739:1994 ainda descreve uma série de exigências quanto à planeza, paralelismo, mobilidade/fixação e dimensões dos pratos inferior e superior da máquina de ensaios, além de uma periodicidade mínima recomendada para a calibração, que fazem desta etapa aquela trivial e mais importante de todo o método de ensaio pelo seguinte motivo: não há correção possível ao longo do ensaio para um carregamento de compressão que se dá incorretamente por deficiência na transmissão dos esforços na seção transversal do corpo-de-prova, por inconsistência na taxa de carregamento ou por erro na indicação da carga aplicada.

Deve-se destacar que ao se prever a exigência da compatibilidade entre a capacidade da máquina e o ensaio a ser realizado, faz-se necessário avaliar não só a capacidade máxima da máquina para a obtenção da resistência do concreto, mas também a aptidão da máquina em manter carregamentos estáveis durante períodos de tempo pré-definidos. 
Além disso, cabe avaliar a aptidão da máquina de trabalhar em solicitações pequenas frente a sua capacidade máxima. Pereira Neto (1994) já registrava a perturbação na conservação de cargas pequenas como mostrado na Fig. 3.3.2.1 original do autor, onde nota-se uma variação significativa da carga para níveis de tensão menores que $1 \mathrm{MPa}$ - aproximadamente 2 tf de carga em um corpo-deprova cilíndrico de dimensões de 150 x 300 mm - para uma máquina de capacidade nominal de 200 tf. Essa preocupação é pertinente devido ao fato de que no ensaio de módulo de deformação deve-se pretensamente executar patamares de estabilização temporal no nível de carregamento da tensão básica de 0,5 MPa, de acordo com a norma nacional e muitas normas internacionais.

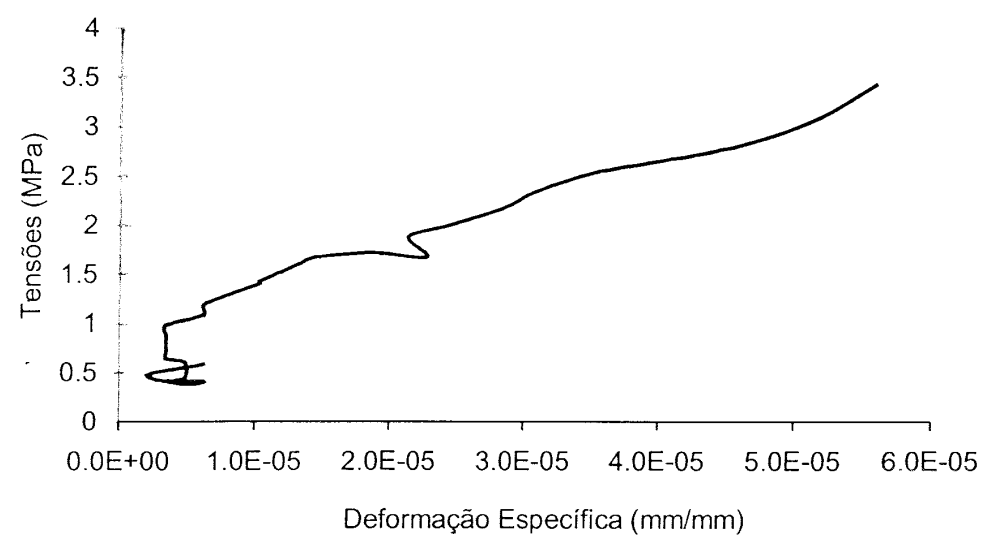

Figura 3.3.2.1 - Exemplo de perturbação em uma curva tensão-deformação real

Fonte: Pereira Neto (1994)

Sabe-se que quanto maior a capacidade nominal de carga da máquina de ensaios - 200 ou 300 tf, por exemplo - mais difícil é a obtenção e a conservação da carga a níveis de tensão tão baixos. Se combinados com o uso de corpos-deprova cilíndricos de seção menores, como os de $100 \mathrm{~mm}$ de diâmetro, tensões de 0,5 MPa significariam aplicação e conservação temporal da carga de $400 \mathrm{kgf}(0,4 \mathrm{tf})$ pela máquina, isto é, $0,2 \%$ da capacidade nominal de uma máquina de 200 tf ou $0,1 \%$ da capacidade nominal de uma máquina de $300 \mathrm{tf}$, o que é praticamente irrealizável independentemente da qualidade da fabricação ou da calibração dessas máquinas.

Os diversos tipos de máquinas e modos de controle não serão aqui detalhados por saber-se da complexidade do tema. Apenas se deseja ressaltar que, muitas vezes, a máquina não possui automação suficiente para a operação e o 
operador passa também a desempenhar papel preponderante na qualidade do ensaio e conseqüentemente do resultado. Essa interação máquina-operador só pode ser qualificada através de estudos de precisão, que inclui ferramentas estatísticas como o cálculo de repetitividade e reprodutibilidade da operação. Esses conceitos serão melhor discutidos nos itens subseqüentes.

\subsubsection{Procedimento de preparação dos corpos-de-prova}

A moldagem, a cura e o capeamento ou retificação dos corpos-de-prova são de fundamental importância para a uniformidade dos resultados e por isso têm recomendações e procedimentos descritos em norma específica - no Brasil, na NBR 5738:2003 - "Concreto - Procedimento para moldagem e cura de corpos-deprova" e na NBR 5739:1994 - "Determinação da resistência à compressão de corpos-de-prova cilíndricos de concreto".

De maneira geral, e complementarmente aos princípios que embasam a necessidade de cuidado na preparação da máquina de ensaios, pode-se considerar que também a etapa de preparação dos corpos-de-prova sustenta a prática de determinação do ensaio de compressão. Em outras palavras, a consideração de que um corpo-de-prova de concreto constitui uma amostra de um material isotrópico é uma aproximação profundamente dependente da amostragem mas também de sua preparação. Por preparação entenda-se a moldagem, o cuidado na desforma, no transporte, no armazenamento e na preparação final para o ensaio - cura e saturação o mais homogênea possível e a retificação ou capeamento do topo e da base dos corpos-de-prova - para garantir que não haja ou que seja minimizada a segregação entre as fases constituintes e a incorporação imprevista de vazios na pasta, além de que a integridade dos corpos-de-prova ao longo do período de endurecimento tenha sido respeitada.

Outra fundamental consideração é de que há uniformidade de desempenho entre corpos-de-prova de uma mesma amostra - corpos de prova ditos irmãos também apenas se configurará se houver adequada e indiferente preparação dos corpos-de-prova.

Estudando especificamente a saturação dos corpos-de-prova até o momento do ensaio, Neville (1997) apresentou alguns indicadores de influência desta condição sobre resultados de determinação do módulo de deformação do concreto 
(Fig. 3.3.3.1). Segundo esta experiência, os resultados dos corpos-de-prova saturados mostraram-se com maior módulo de deformação do que os secos, ao contrário do que se encontra para a resistência à compressão. Isto pode ser entendido dada a incompressibilidade da água presente nos poros capilares do concreto e que tende a transmitir os esforços durante a compressão na direção transversal ao carregamento, mas sem contribuir fortemente com a deformação longitudinal do corpo-de-prova em carregamentos rápidos, como é o caso do ensaio de módulo de deformação. Note-se que o ensaio com a condição saturada é o que obedece à recomendação das normas NBR 5739:1994 e NBR 8522:2003.

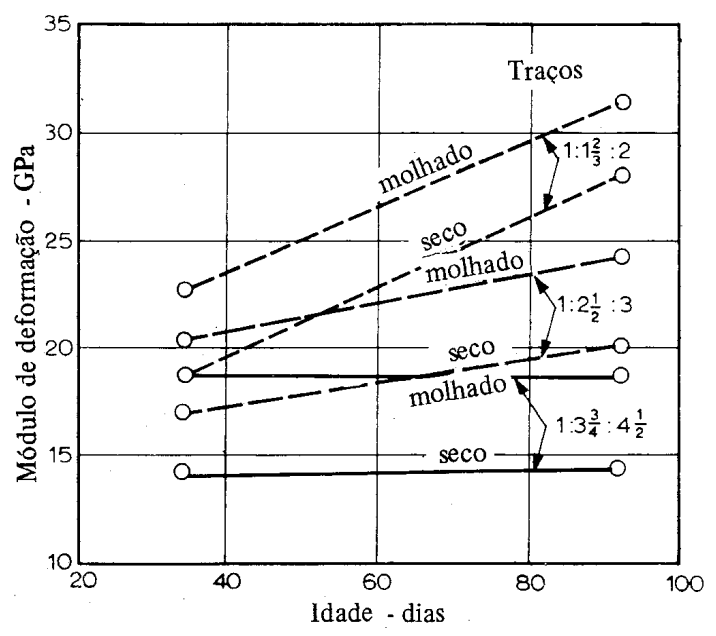

Figura 3.3.3.1 - Influência da saturação dos corpos-de-prova no módulo de deformação

Fonte: Neville (1997)

Também inserida entre os procedimentos de preparação dos corpos-de-prova convém destacar a etapa de regularização por retificação ou capeamento das superfícies de base e topo como possível fonte de variação. Esta etapa possui diversas alternativas de execução, umas incentivadas mais que outras pela constante modificação das classes de resistência mecânica de concreto e as questões de saúde, segurança do trabalho e produtividade inerentes ao serviço. A título de informação, consta do relatório de Inácio; Andrade e Bittencourt (2006) uma lista de tipos de regularização utilizados pelos laboratórios de todo o Brasil inscritos naquele programa experimental, conforme o resumo apresentado na Tab. 3.3.3.1. 
Tabela 3.3.3.1 - Tipos de regularização de base e topo de corpos-de-prova declarados no interlaboratorial de 2006

\begin{tabular}{|c|c|c|}
\hline Item & Regularização dos corpos-de-prova & Freqüência (\%) \\
\hline $\mathbf{1}$ & Capeamento com pasta de enxofre & $23 \%$ \\
\hline $\mathbf{2}$ & Capeamento com mistura de enxofre (95\%) e pozolana (5\%) & $3 \%$ \\
\hline $\mathbf{3}$ & Capeamento com mistura de enxofre (80\%) e pozolana (20\%) & $17 \%$ \\
\hline $\mathbf{4}$ & Capeamento com mistura de enxofre (75\%) e pozolana (25\%) & $13 \%$ \\
\hline $\mathbf{5}$ & Capeamento com mistura de enxofre (70\%) e pozolana (30\%) & $3 \%$ \\
\hline $\mathbf{6}$ & Capeamento com mistura de enxofre e cimento & $3 \%$ \\
\hline $\mathbf{7}$ & Capeamento com mistura de enxofre e pó quartzozo & $7 \%$ \\
\hline $\mathbf{8}$ & Capeamento com mistura de enxofre e pó calcário & $3 \%$ \\
\hline $\mathbf{9}$ & Capeamento com pasta de cimento CP II Z 32 & $7 \%$ \\
\hline $\mathbf{1 0}$ & Capeamento com pasta de cimento CP II E 32 + cimento aluminoso & $3 \%$ \\
\hline $\mathbf{1 1}$ & Retificação com disco-de-corte & $17 \%$ \\
\hline
\end{tabular}

* Nenhum laboratório informou se reaproveita material de capeamento no processo.

** Total de 30 laboratórios dos quais 23 participaram do programa do ensaio de módulo de deformação.

Nota-se que a maior parte dos laboratórios utilizou capeamento com enxofre ou uma mistura deste material com pozolanas; restou saber qual a espessura efetivamente executada e o tempo de cura destes capeamentos, pois VichitVadakan; Carino e Mullings (1998) afirmaram que estas variáveis podem influenciar fortemente a uniformidade da distribuição das tensões pela seção transversal do corpo-de-prova principalmente para concretos mais resistentes - acima de $40 \mathrm{MPa}$ - alterando os resultados de resistência à compressão e conseqüentemente os de módulo de deformação do concreto. Sabe-se que a regularização através de retificação com disco de corte também é um procedimento que exige elevada capacitação profissional do operador e precisão do equipamento para a plena execução do serviço.

De toda forma é preciso que se diga que nenhuma das onze opções citadas de preparo de topo e base dos corpos-de-prova encontra restrição de uso nas normas nacionais para qualquer que seja a classe de resistência do concreto a ser ensaiado.

\subsubsection{Ensaio prévio de resistência à compressão axial}

Todos os fatores especialmente intervenientes no ensaio prévio de resistência à compressão axial tenderão a recair duplamente sobre o ensaio de módulo de deformação, que também é, a rigor, um ensaio de compressão. Além disso, o ensaio de resistência é essencial ao ensaio de determinação do módulo de deformação 
porque este último se baseia na solicitação de uma fração ou de frações da resistência obtida previamente a partir de corpos-de-prova da mesma amostra.

Nesse sentido, se durante a obtenção prévia da resistência $\left(f_{c}\right)$ ocorrerem resultados espúrios, haverá alteração no nível de dano ideal do ensaio de módulo de deformação e só será percebido após a conclusão dos ensaios de módulo individuais de cada corpo-de-prova porque a ação prevista para minimizar o efeito dessa variabilidade é de desprezar o resultado de módulo individual do corpo-deprova que, eventualmente, ao ser rompido, apresente uma resistência que difira em mais de $20 \%$ da resistência considerada para aquele concreto a partir dos ensaios prévios.

Ainda assim, a variação dos resultados do ensaio prévio de resistência influi nos resultados de módulo pois, como se admite a divergência de 20\%, admite-se que a fração máxima da resistência utilizada no ensaio de determinação do módulo de deformação - fração $X$ usualmente entre 30 e 50\% da resistência - na verdade, constitui uma faixa de valores que vai de $X_{\text {inf }}$ a $X_{\text {sup, conforme segue: }}$

$$
X_{\mathrm{inf}}=\frac{X \cdot f_{c}}{(1+0,2) \cdot f_{c}} \quad X_{\text {sup }}=\frac{X \cdot f_{c}}{(1-0,2) \cdot f_{c}}
$$

Se, por exemplo, a fração estabelecida para o ensaio de módulo de deformação for de $30 \%$ da resistência, tem-se que:

$$
X_{\mathrm{inf}}=\frac{0,3 \cdot f_{c}}{(1+0,2) \cdot f_{c}}=0,25=25 \% \quad X_{\text {sup }}=\frac{0,3 \cdot f_{c}}{(1-0,2) \cdot f_{c}}=0,375=37,5 \%
$$

Ou seja, as amostras poderão estar sendo submetidas a solicitações de compressão entre 25 e 37,5\% de sua resistência. Se a fração adotada for de $40 \%$ de $\mathrm{f}_{\mathrm{c}}$, estes valores são substituídos por 33 e 50\%, respectivamente. Se a fração for de $50 \%$ de $\mathrm{f}_{\mathrm{c}}$, estes valores são substituídos por 42 e $62,5 \%$, respectivamente.

A definição da fração máxima da resistência representa, então, na prática, a escolha de uma faixa de nível de dano microestrutural a que pode ter sido submetido o concreto durante o ensaio. Por isso, deve ser apropriadamente definida.

É preciso que se diga ainda que a norma de ensaio nacional oferece a possibilidade de se estabelecer tensões máximas para a determinação do módulo de deformação desvinculadas do conceito de 'nível percentual da resistência real $\left(f_{c}\right)$ ' e mais aproximadas do conceito de 'nível percentual da resistência característica do concreto $\left(f_{c k}\right)^{\prime}$. Essa abertura, ainda que atenda aos interesses de projeto estrutural, prejudica a comparação universalizada de resultados e, conseqüentemente, 0 
controle de variabilidade do ensaio, porque este controle deve ser independente da classe do material mas dependente da uniformidade na aplicação da teoria que embasa o método. Esta, recorda-se, só existe com a consolidação do nível de dano assumido como de limite elástico, e é numericamente dado por um nível percentual da resistência real do concreto $\left(f_{c}\right)$.

Como exemplo deste tipo de aplicação do método de ensaio, a rigor, errônea, imagine-se um concreto denominado de resistência característica $\left(f_{c k}\right)$ de $30 \mathrm{MPa}$ cuja resistência real $\left(\mathrm{f}_{\mathrm{c}}\right)$ seja de $40 \mathrm{MPa}$ e cuja propriedade módulo de deformação tenha sido determinada a partir das retas entre os níveis de carregamento de 0,5 $\mathrm{MPa}$ e $30 \%$ de $\mathrm{f}_{\mathrm{ck}}$. Nitidamente se estará verificando a propriedade do material em nível distinto de dano do qual seria atingido se o procedimento utilizado tivesse sido entre os níveis de carregamento de 0,5 MPa e 30\% de $\mathrm{f}_{\mathrm{c}}$. Como dito, este resultado não poderá contribuir com um eventual estudo de controle da variabilidade do método de ensaio pois não o respeitou em sua teoria.

\subsubsection{Ensaio de determinação do módulo de deformação}

A quantificação do módulo de deformação do concreto faz uso de uma aproximação matemática gráfica que constitui por si só um dos fatores intervenientes na interpretação do resultado de um ensaio. A aceitação de que há um trecho de deformabilidade linear capaz de fornecer através de seu coeficiente angular o indicador da propriedade pode tornar-se fonte de variabilidade, principalmente entre laboratórios, quando não se garante que os limites deste trecho retilíneo estejam bem definidos e confiáveis.

Outras fontes de variabilidade inerentes ao ensaio e que devem ser mais bem detalhadas são a velocidade de aplicação da carga, a definição do plano de carga e o tipo de instrumentação para a medição das deformações.

\subsubsection{Velocidade ou taxa de aplicação da carga}

Como elemento básico do Ensaio de determinação do módulo de deformação mas que também poderia estar contido no item de Ensaio prévio de resistência à compressão, tem-se que considerar a velocidade de aplicação da carga. 
A uniformidade da velocidade de aplicação de carga está diretamente ligada à uniformidade dos resultados de módulo de deformação porque o concreto não é um material perfeitamente elástico. A Fig. 3.3.5.1.1, extraída de Andrade (1997), ilustra o resultado de um estudo de relação entre a tensão e a deformação com a velocidade de carregamento. Em suma, quanto mais rápida a aplicação da carga, menor a capacidade de propagação das fissuras e acomodação microestrutural das deformações. Conseqüentemente, a tendência observada é de obtenção de um resultado de módulo maior.

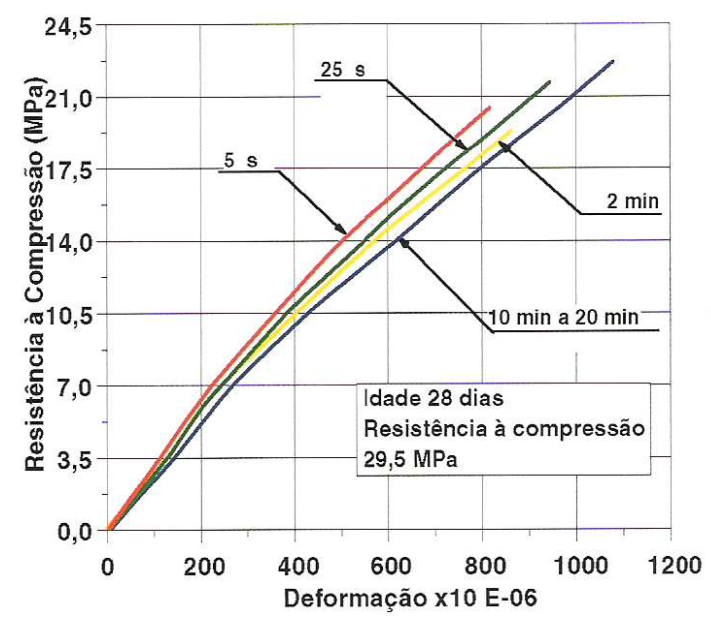

Figura 3.3.5.1.1 - Variação da relação tensão-deformação com a velocidade de carga

Fonte: Andrade (1997)

Quanto à resistência, os resultados do gráfico anterior mostram-se um pouco contraditórios. Mehta e Monteiro (1994), no entanto, afirmam que quanto maior a velocidade de carregamento, maior a resistência obtida, ainda que para os padrões de velocidade das normas internacionais que preconizam ensaios de resistência com duração da ordem de 2 a 3 minutos, esta diferença possa não passar de 12\%. Assim sendo, em tese, se a velocidade de aplicação de carga no ensaio prévio de resistência for maior do que no ensaio de determinação do módulo de deformação, haverá o alcance de maior resistência e conseqüentemente de maior nível de solicitação em termos de fração da tensão última em que se deseja determinar o módulo; isso significaria diminuir o resultado potencial do módulo de deformação daquele concreto.

A velocidade de carregamento dos ensaios de resistência e módulo de deformação de algumas das principais normas internacionais vigentes consta da Tab. 3.3.5.1.1. Apenas com estas informações já fica nítido não ser possível a 
comparação pura e simples entre resultados de ensaios de módulo de deformação executados sob diferentes métodos normativos.

Tabela 3.3.5.1.1 - Velocidades de carregamento de algumas normas

\begin{tabular}{|c|c|c|c|}
\hline Norma de Resistência & Velocidade (MPa/s) & Norma de Módulo & Velocidade (MPa/s) \\
\hline NBR 5739:1994 & 0,3 a 0,8 & NBR 8522:2003 & $0,25 \pm 0,05$ \\
\hline ISO 4012:1978 & $0,60 \pm 0,40$ & ISO 6784:1982 & $0,60 \pm 0,40$ \\
\hline ASTM C 39:2003 & 0,15 a 0,35 & ASTM C 469:2002 & $0,241 \pm 0,034$ \\
\hline
\end{tabular}

\subsubsection{Planos de carregamento}

Em função da resposta não-linear do concreto, recomenda-se em norma internacionalmente a definição dos chamados planos de carregamento. Os planos de carregamento definem a solicitação da amostra, em termos de ciclos de carregamento e descarregamento, os níveis de solicitação (frações da resistência entre as quais se dará a reta para a obtenção do coeficiente angular), os tempos de conservação da carga nos níveis de tensão e as velocidades de carregamento e descarregamento.

Em termos de ciclos, todos os planos de carregamento tendem a ter, inicialmente, ciclos de verificação da instrumentação e do posicionamento do corpode-prova na máquina de ensaios através da medição das deformações a baixas tensões de compressão. A isto se dá o nome de tentativas de centragem ou de compatibilização dos medidores de deformação.

Em seguida, os planos podem ser divididos entre aqueles que estabelecem a realização de pré-ciclos de carregamento e os que não os utilizam.

Os ensaios que não utilizam planos de carregamento com pré-ciclos de carga buscam diretamente o módulo de deformação dito secante à curva tensãodeformação obtida no ensaio. A rigor, a reta para cálculo do coeficiente angular é uma corda entre dois pontos da curva, em que um desses pontos deve ser baixo o bastante para garantir que o método de ensaio e os equipamentos utilizados sejam sensíveis a pequenas cargas e deformações e o segundo é aquele correspondente à fração da resistência correspondente ao limite elástico admitido. A reta pode ser vista na Fig. 3.3.5.2.1, original de Neville (1997). Por sua vez, os ensaios que utilizam planos de carregamento com pré-ciclos de carga buscam a obtenção do 
módulo de deformação dito tangente inicial. Segundo Neville (1997), uma reta cordal à curva tensão-deformação pós-carregamento ao nível desejado e já no descarregamento até tensão bastante baixa mas não nula, é praticamente paralela à reta tangente à curva de carregamento em seu início (a partir da tensão nula), como se vê também na Fig. 3.3.5.2.1. Note-se que não há alívio absoluto da solicitação, ou seja, será registrada apenas a deformação elástica proveniente do alívio parcial, mas suficiente para inferir o indicador que se deseja. Ainda segundo o autor, observou-se também que em aproximadamente três ou quatro ciclos de carregamento e descarregamento sucessivos, sem a anulação da carga em nenhum dos ciclos mas com redução a tensões bastante baixas, podia-se obter no último carregamento outra reta também paralela à tangente na origem (tangente inicial). Isto se daria pela eliminação de parte da deformação plástica do concreto e, embora de origem fundamentalmente empírica, o conceito acabou consagrado em muitas recomendações internacionais.

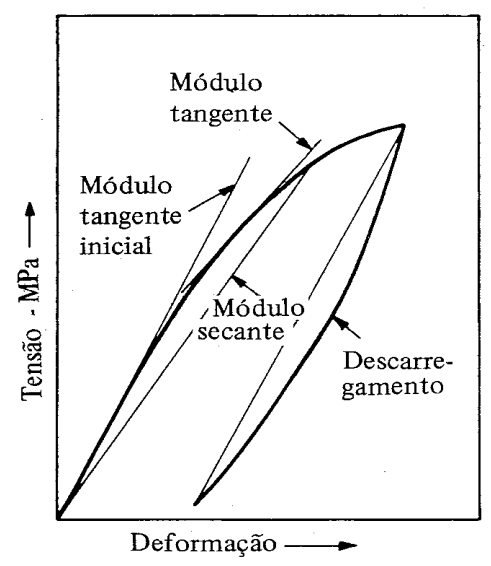

Figura 3.3.5.2.1 - Representação esquemática da curva tensão-deformação e os módulos vinculados aos planos de carregamento

Fonte: Neville (1997)

Nas normas nacionais de ensaio de determinação do módulo de deformação estático do concreto, NBR 8522:2003, e de procedimento de projeto de estruturas de concreto armado, NBR 6118:2003, há uma distinção clara de como e quando realizar cada um desses planos de ensaio (Tab. 3.3.5.2.1). Note-se que a norma considera aplicável o termo módulo de elasticidade do concreto no caso da designação do resultado obtido com a determinação dita tangente inicial. 
Tabela 3.3.5.2.1 - Especificação do plano de carregamento de ensaio

\begin{tabular}{|c|c|c|}
\hline $\begin{array}{c}\text { Título da } \\
\text { determinação }\end{array}$ & $\begin{array}{l}\text { Plano de carga indicado para o } \\
\text { ensaio de determinação do módulo }\end{array}$ & \\
\hline $\begin{array}{l}\text { Módulo de } \\
\text { elasticidade ou } \\
\text { módulo de } \\
\text { deformação } \\
\text { tangente inicial } \\
\left(\mathrm{E}_{\mathrm{ci}}\right)\end{array}$ & $\begin{array}{l}\text { O plano de carga prevê a realização de } \\
3 \text { pré-ciclos de carregamento entre a } \\
\text { tensão mínima }\left(\sigma_{\mathrm{a}}\right) \text { de } 0,5 \mathrm{MPa} \text { e a } \\
\text { tensão máxima }\left(\sigma_{\mathrm{b}}\right) \text { de } 30 \% \text { da tensão } \\
\text { de ruptura }\left(0,3 . \mathrm{f}_{\mathrm{c}}\right) \text { - aceita-se a } \\
\text { especificação de até } 40 \% \text { de } \mathrm{f}_{\mathrm{c}}-\mathrm{com} \\
\text { períodos de estabilização de } \\
\text { deformação de } 60 \mathrm{~s} \text { em cada patamar. } \\
\text { Um quarto carregamento até } 0,3 . \mathrm{f}_{\mathrm{c}} \text { é } \\
\text { realizado para determinação efetiva do } \\
\text { módulo tangente inicial. }\end{array}$ & $\begin{array}{l}\text { Deve ser aquele utilizado para } \\
\text { caracterizar a deformabilidade do } \\
\text { concreto. } \\
\text { A norma NBR 6118:2003 indica este } \\
\text { resultado para ser aquele } \\
\text { especificado em projeto e controlado } \\
\text { tecnologicamente pelas obras. } \\
\text { Este valor pode ser utilizado } \\
\text { diretamente pelos projetistas na } \\
\text { avaliação do comportamento global } \\
\text { de uma estrutura e para o cálculo de } \\
\text { perdas de protensão. }\end{array}$ \\
\hline $\begin{array}{l}\text { Módulo de } \\
\text { deformação } \\
\text { secante }\left(E_{c s}\right) \\
\text { a uma tensão } \\
\text { indicada ou a } \\
\text { partir do } \\
\text { diagrama tensão- } \\
\text { deformação }\end{array}$ & $\begin{array}{l}\text { Este plano de carga prevê a realização } \\
\text { do carregamento de } 0,5 \mathrm{MPa}\left(\sigma_{\mathrm{a}}\right) \text { até a } \\
\text { tensão máxima }\left(\sigma_{\mathrm{b}}\right) \text { sem a necessidade } \\
\text { de realização dos } 3 \text { pré-ciclos. É a } \\
\text { chamada determinação direta. } \\
\text { Alternativamente, pode-se realizar o } \\
\text { carregamento de } 0,5 \mathrm{MPa}\left(\sigma_{\mathrm{a}}\right) \text { até } \\
\text { patamares subseqüentes de frações } \\
\text { ideais da tensão última ( } 10 \text { em } 10 \%) \text {, } \\
\text { para construção da curva tensão- } \\
\text { deformação, também sem a } \\
\text { necessidade de realização dos } 3 \text { pré- } \\
\text { ciclos de carregamento. É a chamada } \\
\text { determinação indireta. }\end{array}$ & $\begin{array}{l}\text { Deve ser aquele utilizado quando há } \\
\text { interesse na simulação de uma } \\
\text { estrutura cuja carga permanente } \\
\text { prevaleça desde o primeiro } \\
\text { carregamento. } \\
\text { A norma NBR } 6118: 2003 \text { indica este } \\
\text { resultado para ser aquele utilizado } \\
\text { pelos projetistas em análises } \\
\text { elásticas de projeto, especialmente } \\
\text { para determinação de esforços } \\
\text { solicitantes e verificação de estados } \\
\text { limites de serviço na avaliação do } \\
\text { comportamento de um elemento } \\
\text { estrutural ou seção transversal } \\
\text { durante o projeto. }\end{array}$ \\
\hline \multicolumn{3}{|c|}{$\begin{array}{l}\text { Observações: } \\
\text { a) Se a tensão máxima estiver entre } 30 \text { e } 50 \% \text { de } f_{c} \text {, faculta-se nos dois casos, antes da } \\
\text { determinação efetiva, a realização da centragem das bases do instrumento medidor das } \\
\text { deformaçães (em geral, } 2 \text { bases de medida), através de cargas de } 20 \% \text { de } f_{c} \text {. } \\
\text { b) Em projeto, de acordo com a NBR } 6118: 2003 \text {, ao dispor-se do valor de } E_{c i} \text { pode-se usar a } \\
\text { seguinte correlação para obtenção de } E_{c s}: \quad E_{c s}=0,85 . E_{c i}\end{array}$} \\
\hline
\end{tabular}


Nas Fig. 3.3.5.2.2, 3.3.5.2.3 e 3.3.5.2.4 são representados os planos de carregamento previstos no método de ensaio brasileiro, em seu formato tensãotempo. Na Fig. 3.3.5.2.4 há a representação do ensaio sob o plano de carregamento secante que prevê a construção completa da curva tensão-deformação específica.

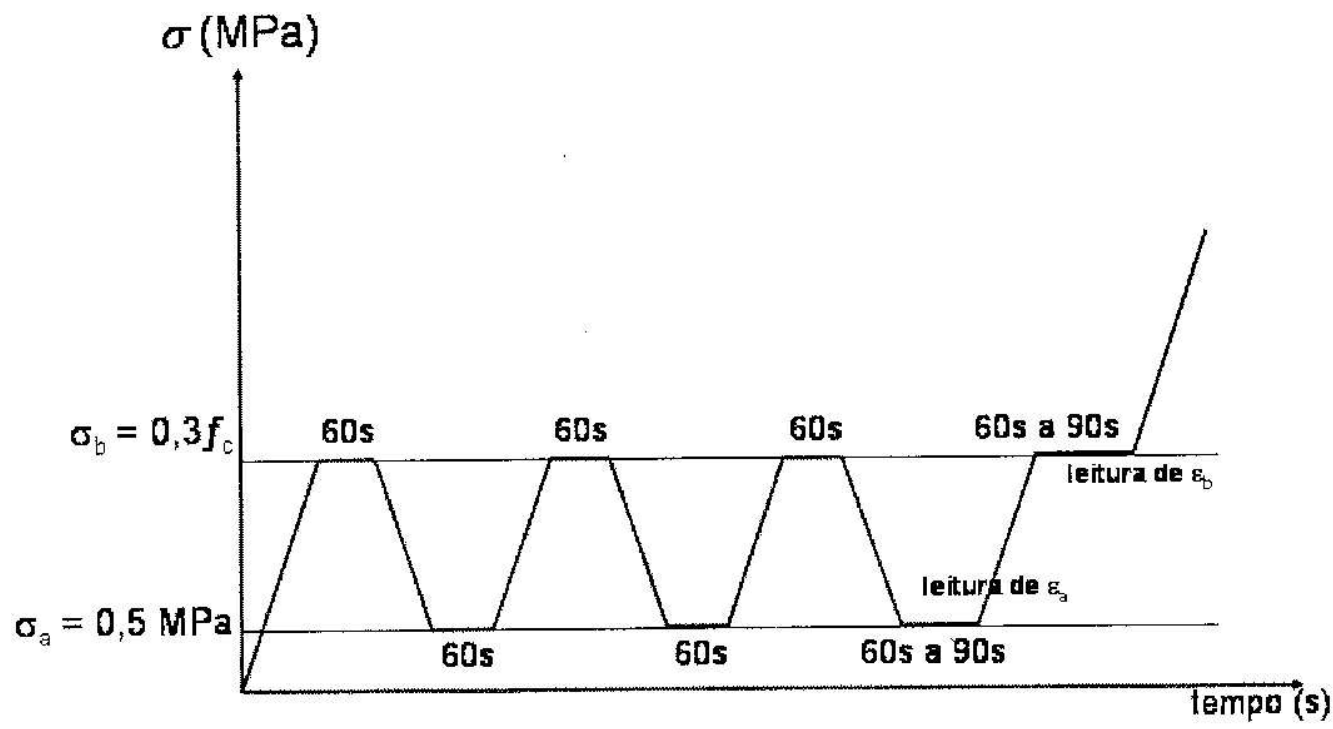

Figura 3.3.5.2.2 - Plano para obtenção direta do módulo de deformação tangente inicial

Fonte: NBR 8522:2003

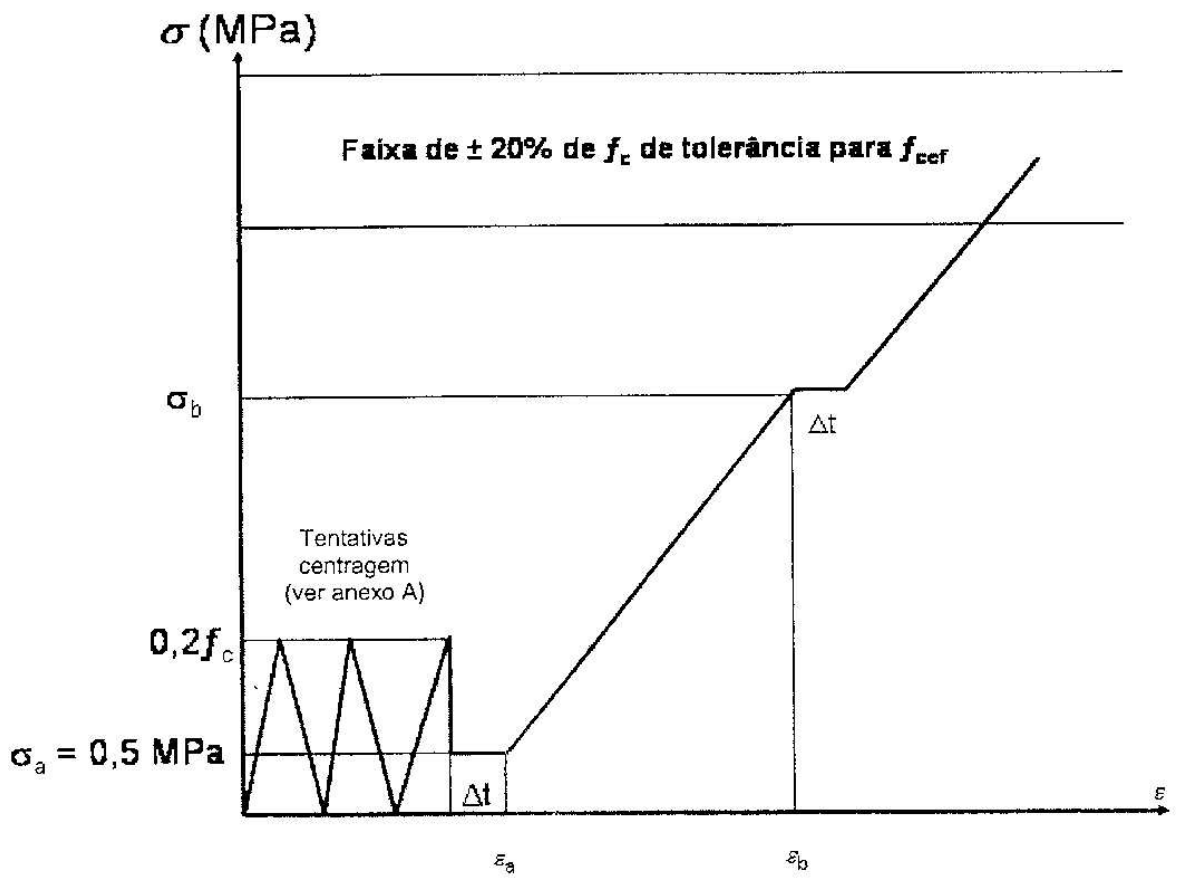

Figura 3.3.5.2.3 - Plano para obtenção direta do módulo de deformação secante 


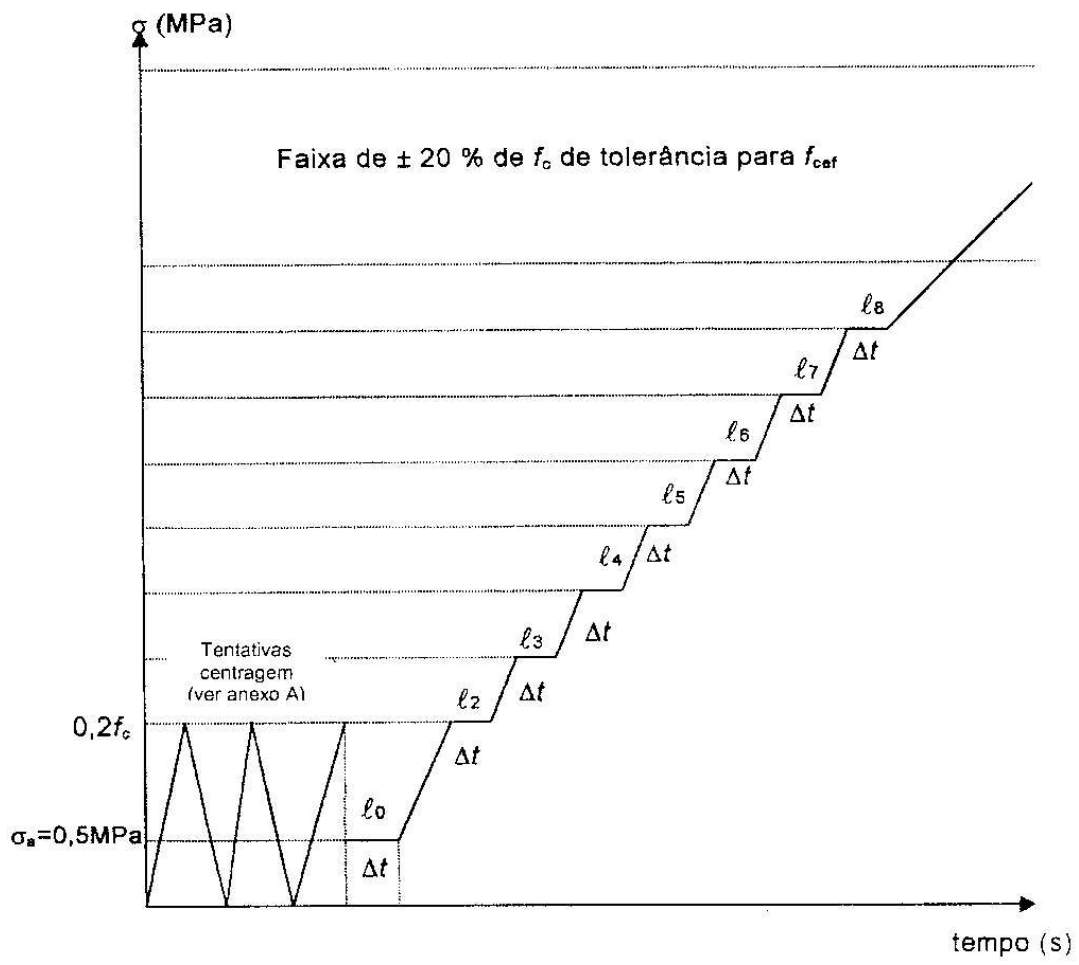

Figura 3.3.5.2.4 - Plano para obtenção indireta do módulo de deformação secante

Fonte: NBR 8522:2003

Wesche e Manns apud Tango e Tarran (1983) apresentaram trabalhos que identificaram e compararam 18 planos de carregamento visivelmente distintos entre si, normalizados em diversos países e utilizados àquela época. Tango e Tarran (1983) apresentavam também sua proposta para os planos de carregamento a serem previstos na norma do ensaio nacional que seria originalmente publicada no ano seguinte. Os principais planos de carregamento internacionais descritos no trabalho, em seu formato tensão-tempo, são reproduzidos nas Fig. 3.3.5.2.5 à Fig.

\subsubsection{8.}

Nota: Nas figuras a seguir, os pequenos círculos representam os pontos de medida da tensão e da deformação. 


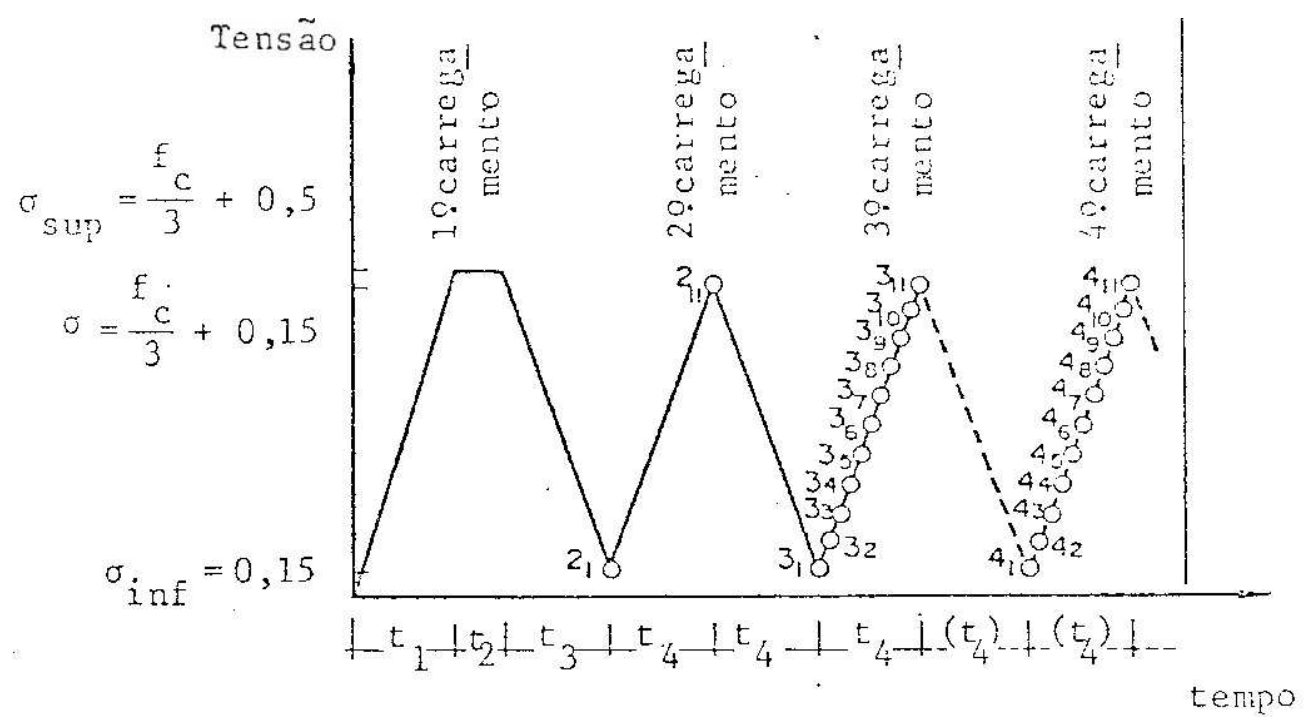

Figura 3.3.5.2.5 - Estudo internacional: plano utilizado à época na Grã-Bretanha (BS 1881:1952)

Fonte: Wesche; Manns apud Tango; Tarran (1983)

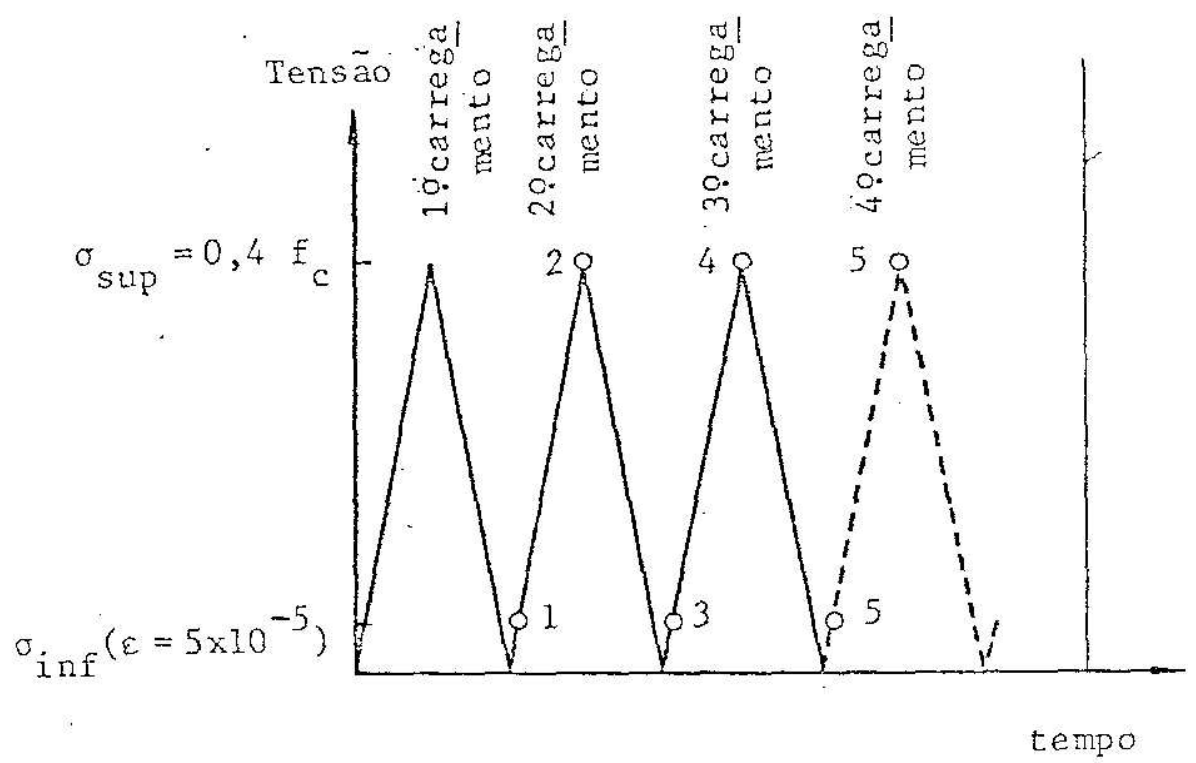

Figura 3.3.5.2.6 - Estudo internacional: plano utilizado à época nos EUA (ASTM C-469:1965)

Fonte: Wesche; Manns apud Tango; Tarran (1983) 


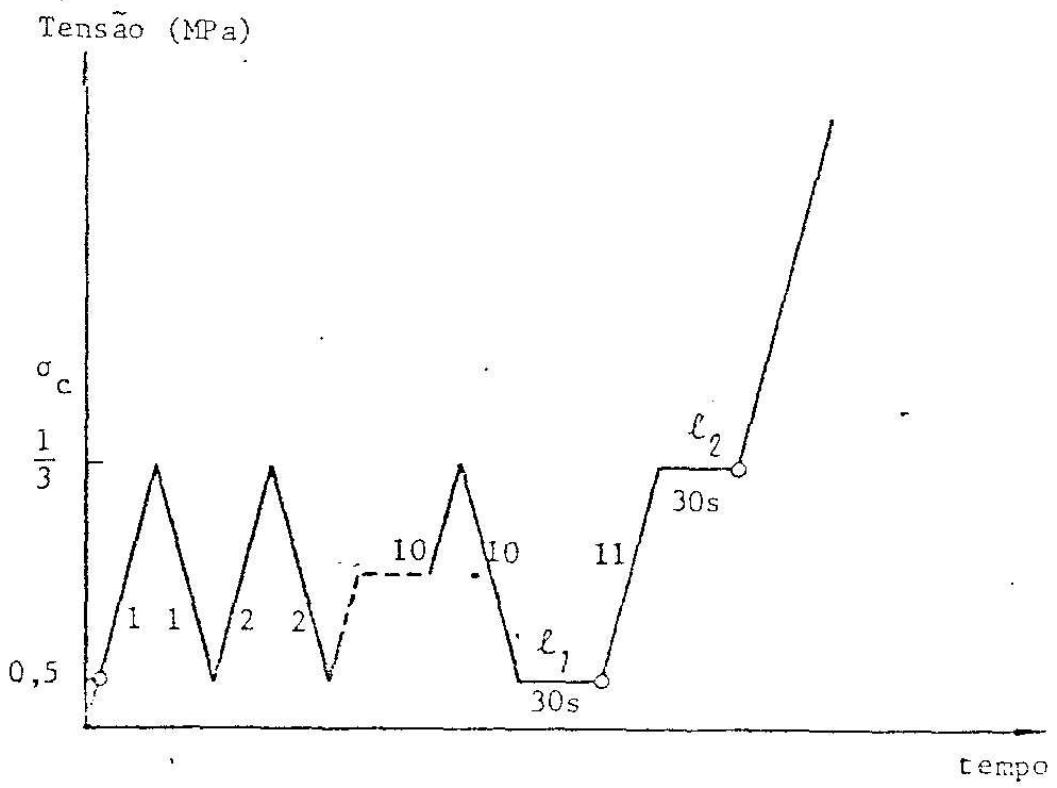

Figura 3.3.5.2.7 - Estudo internacional: plano utilizado à época na Alemanha Ocidental (DIN1048-1:1978)

Fonte: Wesche; Manns apud Tango; Tarran (1983)

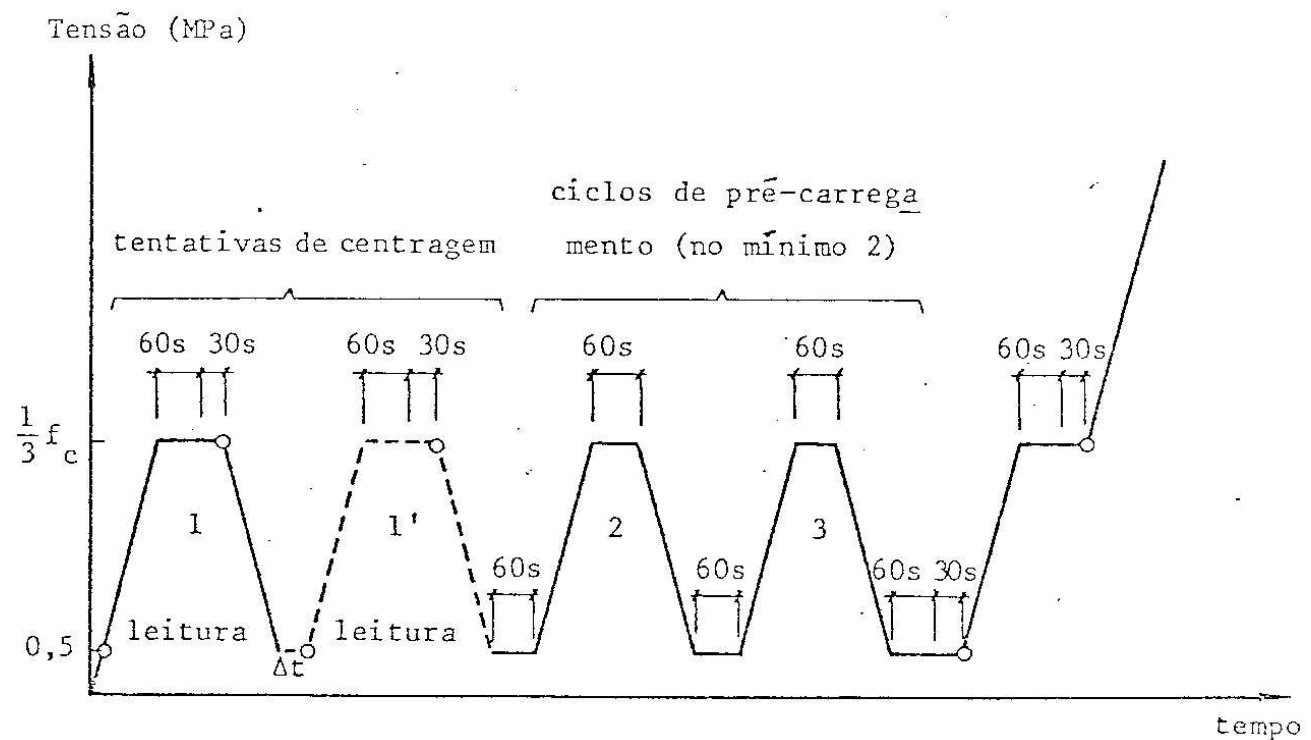

Figura 3.3.5.2.8 - Estudo internacional: plano recomendado à época pela ISO 6784:1982 
$\mathrm{Na}$ atualidade, sabe-se que alguns desses planos de carregamento, como o da ASTM C-469 (última atualização em 2002) e da ISO 6784:1982, permanecem como os apresentados.

Fica nítido que entre os métodos de ensaio preconizados nas normas técnicas ASTM C-469, ISO 6784 e NBR 8522 restam diferenças significativas quanto aos parâmetros utilizados nos planos de carregamento. Como ficaria, então, a questão da uniformidade do nível de dano no concreto e a discussão universalizada dos resultados? Essa é uma questão ainda não resolvida no meio técnico. A resposta previsível é de que a discussão não poderia se dar sobre bases simples de comparação.

É claro também que qualquer dos planos de carregamento testados historicamente carecem de acurácia na construção da curva tensão-deformação. As determinações não são, realmente, tangentes ou secantes à curva que identifica a propriedade, mas simplificações, o que aproxima muito estas magnitudes.

\subsubsection{Instrumentação para medição das deformações}

Os instrumentos para medição das deformações mais comuns utilizados no ensaio de determinação do módulo estático de deformação do concreto são: compressômetro com relógios comparadores, compressômetro com transdutores de deslocamento indutivos (linear variable differential transformer ou LVDT), transdutores resistivos ou extensômetros elétricos tipo strain gages de colagem superficial, de imersão ou de ancoragem tipo clip gage. Todos eles foram desenvolvidos para trabalhar na captação da deformação durante o ensaio de compressão através de sua instalação, pelo operador, a partir do ponto central da altura do corpo-de-prova. Em geral, a captação dessa deformação se dá sobre uma base de medida longitudinal de comprimento igual ao diâmetro do corpo-de-prova, o que a faz ultrapassar o comprimento do terço central da altura do corpo-de-prova.

Nas Fig. 3.3.5.3.1.a-e estão representados alguns modelos de compressômetro e compressômetros com relógios comparadores acoplados. 

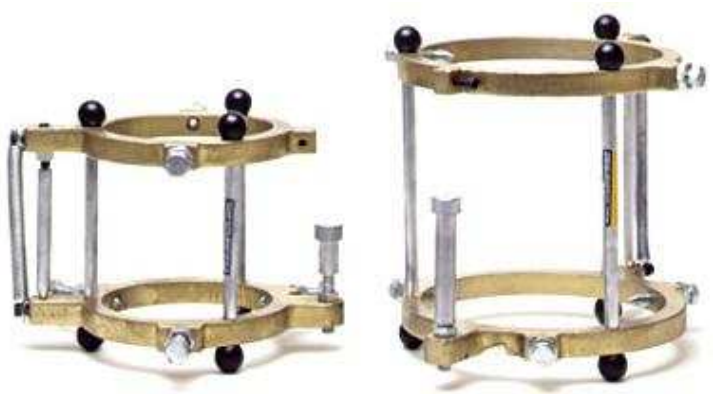

(a)

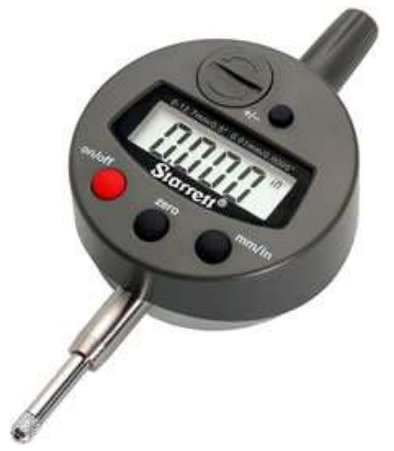

(c)

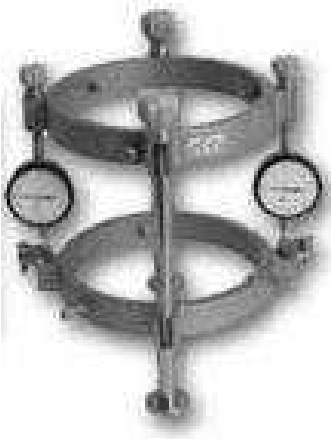

(d)

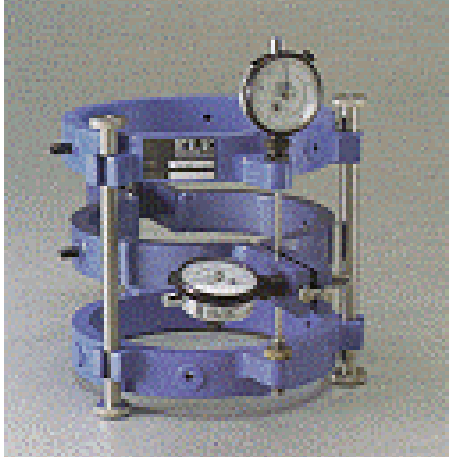

(b)

Figura 3.3.5.3.1 - Instrumentos para medição da deformação: (a) dispositivos compressômetros; (b) compressômetro-expansômetro; (c) relógio comparador; (d) compressômetro com 2 relógios comparadores; (e) compressômetro com 1 relógio comparador

Os compressômetros-expansômetros são dispositivos mundialmente conhecidos devido à sua divulgação na norma norte-americana ASTM C-469 desde a década de 1960 como aparelhagem básica para o ensaio de módulo de deformação do concreto. O dispositivo dito compressômetro é aquele utilizado para a ancoragem do medidor de deformação propriamente dito para leitura da deformação longitudinal do corpo-de-prova. A parte dita expansômetro é complementar à estrutura do dispositivo anterior e é utilizada para instalação de outro medidor de deformação para leitura da deformação transversal do corpo-deprova enquanto solicitado à compressão no eixo longitudinal; é utilizada para a determinação do coeficiente de Poisson do concreto.

O compressômetro idealizado e apresentado na norma técnica ASTM C-469 tem uma representação na Fig. 3.3.5.3.2. Nesta figura, estão as partes principais da estrutura do aparelho, conforme segue:

- $S_{1}, S_{2}, S_{3}, S_{4}, S_{5}$ são os parafusos de ancoragem no corpo-de-prova; 
- $R_{1}, R_{2}$ são os chamados yokes de sustentação do medidor de deformação propriamente dito;

- $\quad T_{1}$ é o conjunto pino-mola para transferência de deformação de um dos lados dos yokes para o outro em que está instalado o medidor de deformação, conforme detalhe A-B da figura;

- D representa a posição de instalação do medidor da deformação e também a distância entre yokes que, na prática, corresponde ao comprimento inicial do trecho onde será feita a medida.
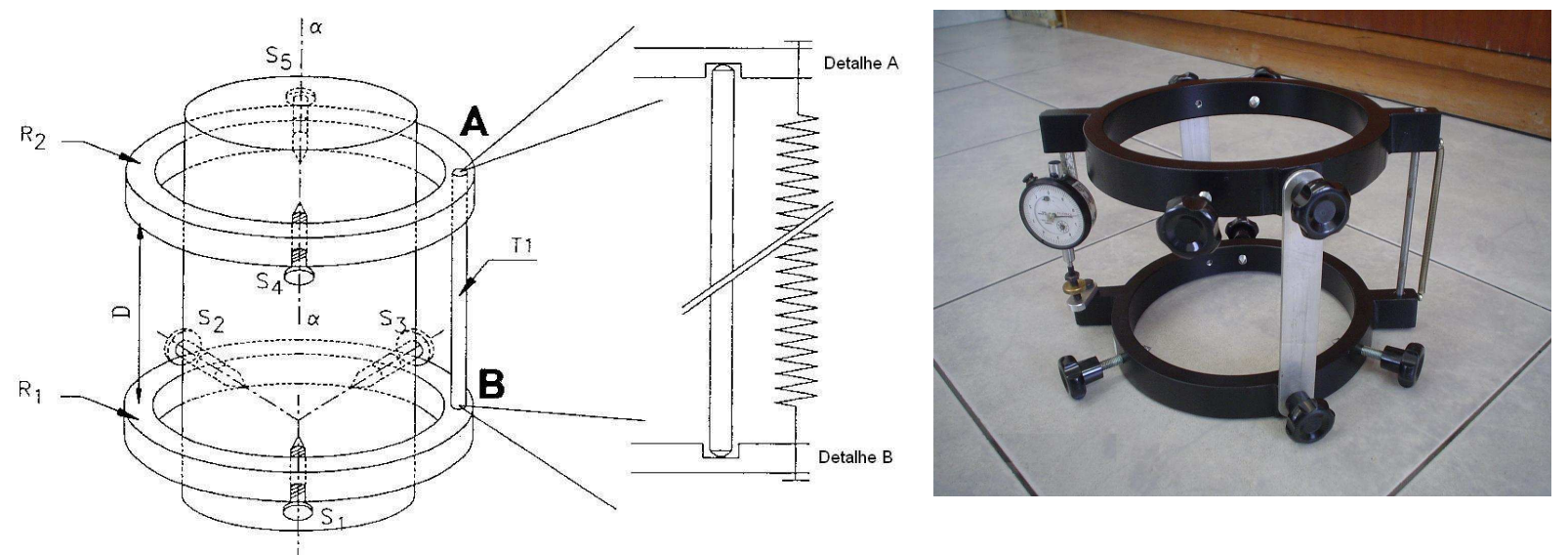

Figura 3.3.5.3.2 - Detalhes do dispositivo compressômetro

A instalação de um segundo medidor de deformação no compressômetro pode ser feita mediante a remoção do conjunto pino-mola. Neste caso, a deformação longitudinal admitida em ensaio pode ser tomada como a média das deformações individuais nos medidores. Neste caso, há uma controvérsia a respeito da necessidade de modificação no número e na disposição dos parafusos de ancoragem no yoke superior; para muitos, este deverá passar a repetir a configuração de três parafusos já utilizada na configuração do yoke inferior.

Os medidores mais comuns acoplados ao compressômetro são os relógios comparadores. Resumidamente, seu mecanismo de funcionamento reage através de um pino de detecção da deformação (pino apalpador) em contato com um anteparo a uma força imposta pela aproximação dos yokes durante a compressão do corpode-prova. 
Como foi dito, aos compressômetros também podem ser acoplados transdutores como os LVDT. Na Fig. 3.3.5.3.3.a-b estão representados modelos de transdutores indutivos LVDT e compressômetros com LVDT.

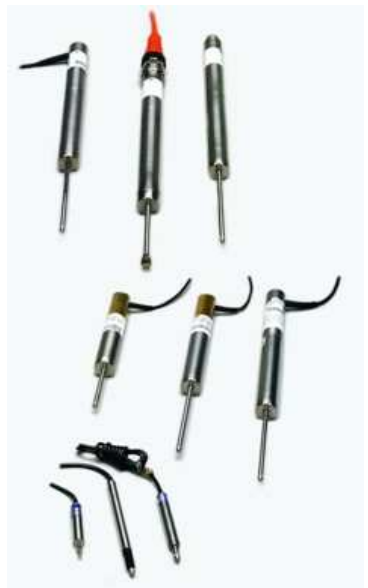

(a)

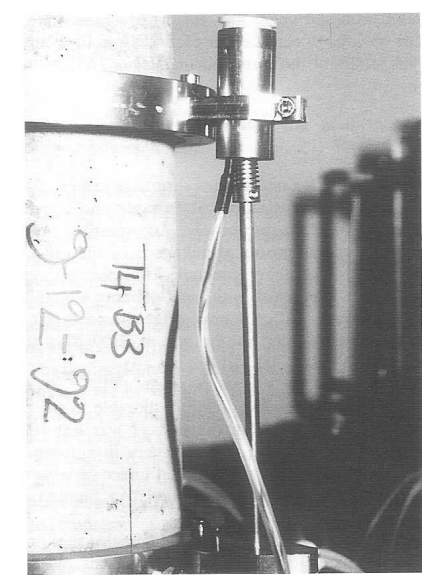

(b)

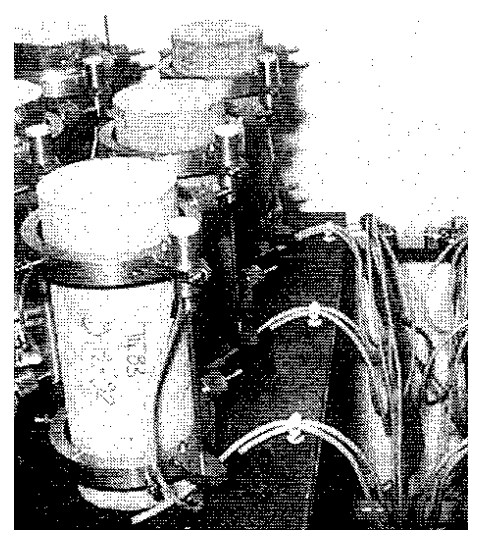

(b)

Figura 3.3.5.3.3 - Instrumentos para medição da deformação: (a) LVDT; (b) compressômetros com LVDT

Os LVDT possuem três bobinas montadas axialmente e ligadas em série, conforme detalhado na Fig. 3.3.5.3.4. Quando excitadas por uma corrente, forças eletromotrizes são induzidas entre as bobinas. As amplitudes das ondas geradas pelas bobinas extremas (secundárias) são distintas daquela da bobina central (primária) e dependentes da posição da haste ou núcleo de ferro. Porém, existe um ponto de localização da haste em que a tensão de saída dada pela diferenças entre as forças eletromotrizes se anula e esta é a referência para a medição da deformação através do deslocamento da haste.

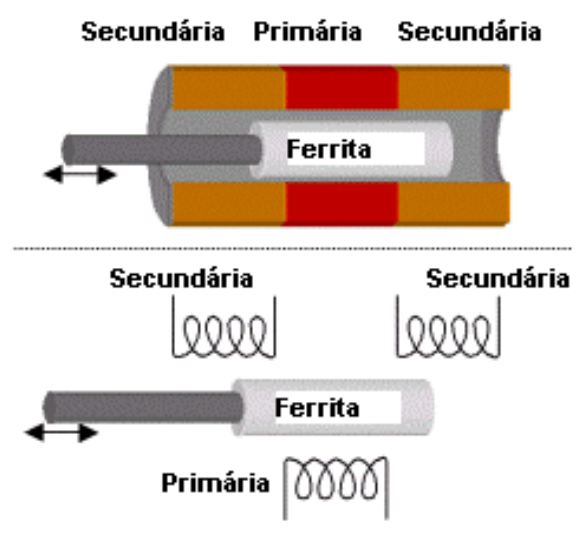

Figura 3.3.5.3.4 - Princípio de funcionamento dos LVDT 
Agora, nas Fig. 3.3.5.3.5.a-c estão representados modelos de transdutores resistivos tipo strain gages, de colagem superficial e de imersão.
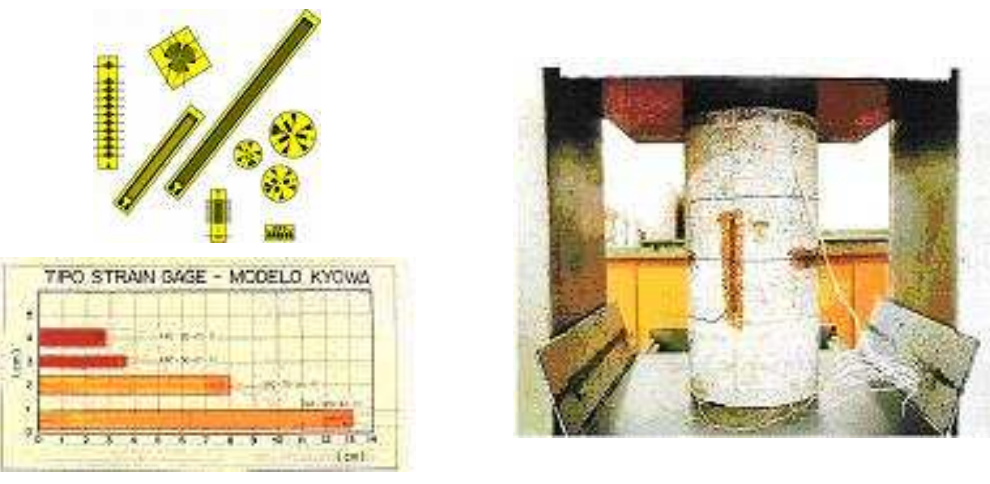

(a)
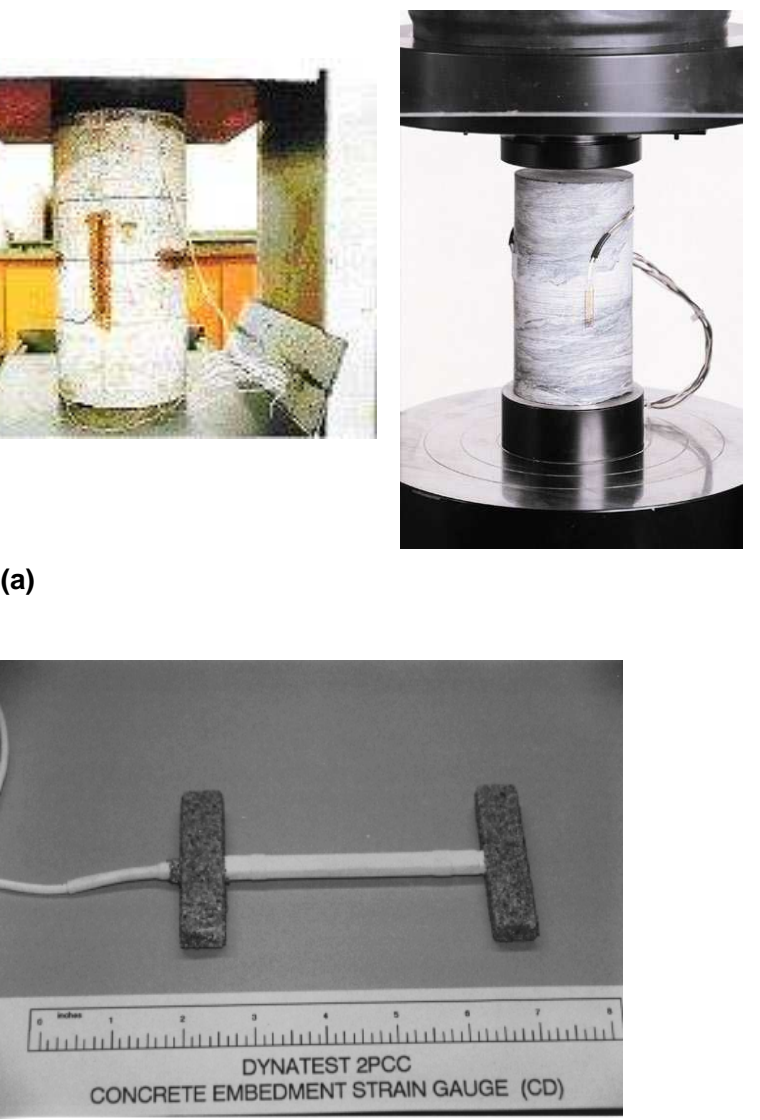

(b)

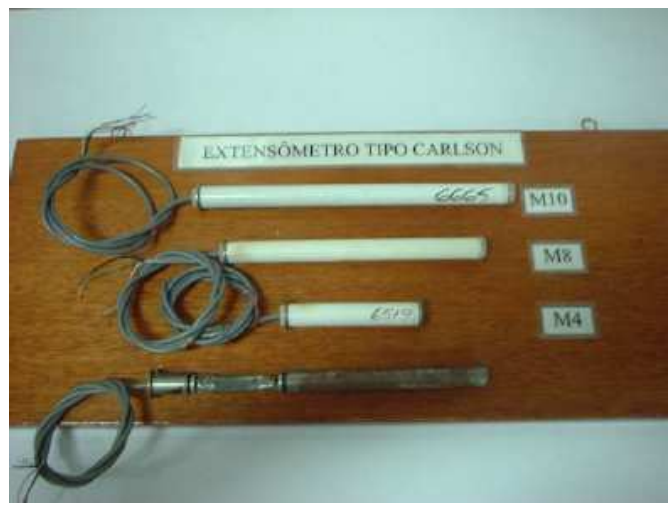

(c)

Figura 3.2.5.3.5 - Instrumentos para medição da deformação: (a) strain gages de colagem superficial; (b) transdutores laminados de imersão; (c) transdutores cilíndricos de imersão

Os extensômetros ou transdutores elétricos transformam variação de resistência elétrica em deformação. São constituídos de filamentos condutores metálicos embebidos em uma solução ou proteção capaz de mantê-los isolados e 
simultaneamente aderidos por colagem e/ou atrito no material em que se deseja medir a deformação. Os filamentos estão dispostos em Ponte de Wheatstone para ampliação da confiabilidade do conjunto. Com a excitação elétrica, a diferença de potencial $\left(E_{0}\right)$ entre as extremidades da ponte é alterada com a deformação $(x)$ do corpo-de-prova por causa da mudança da resistência do conjunto condutor que é dada pela expressão $R=\frac{\eta}{A} \cdot L$, onde $R$ é a resistência elétrica, $\eta$ a resistividade característica do material condutor, $A$ a área da seção transversal e $L$ o comprimento do condutor, variável que se altera com a deformação. Conforme Almeida (2004), a diferença de potencial é proporcional à deformação lida após o condicionamento e amplificação do sinal elétrico. Na Fig. 3.3.5.3.6 estão representados um conjunto condutor de strain gage e a curva de resposta da relação linear entre a diferença de potencial a deformação lida com o medidor.
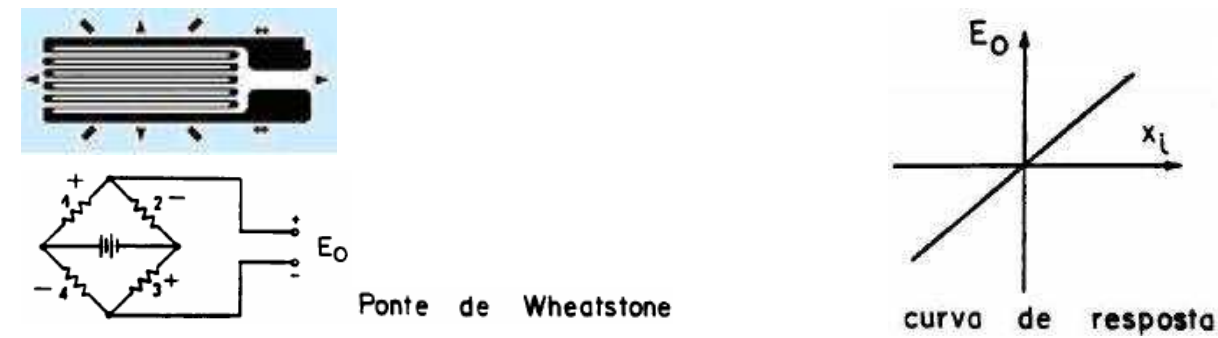

Figura 3.3.5.3.6 - Princípio de funcionamento dos strain gages

Fonte: Almeida (2004)

Os transdutores elétricos também podem ser montados de outras formas, como as da Fig. 3.3.5.3.7.a-c em que estão representados alguns modelos de extensômetros elétricos de ancoragem tipo clip gage — os strain gages estão isolados nas pequenas caixas acopladas à ancoragem. 


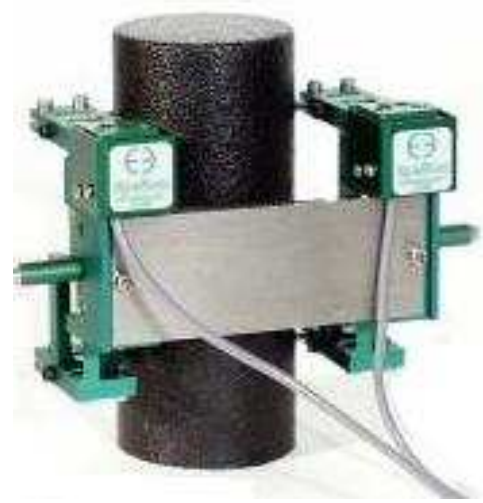

(a)

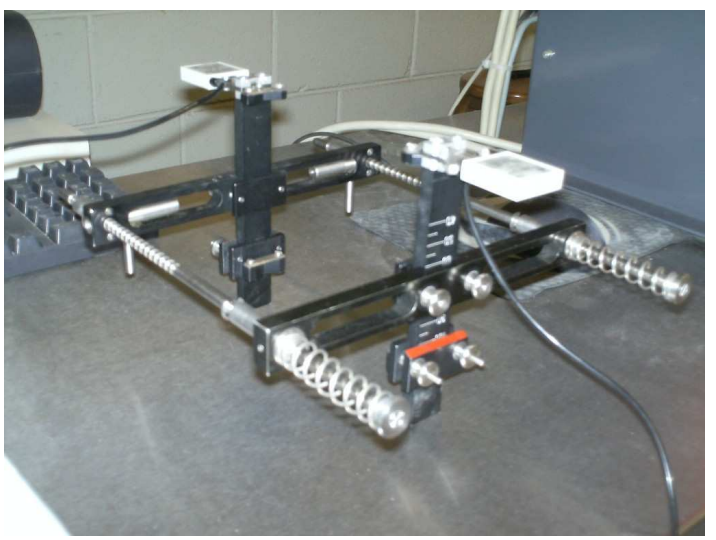

(c)

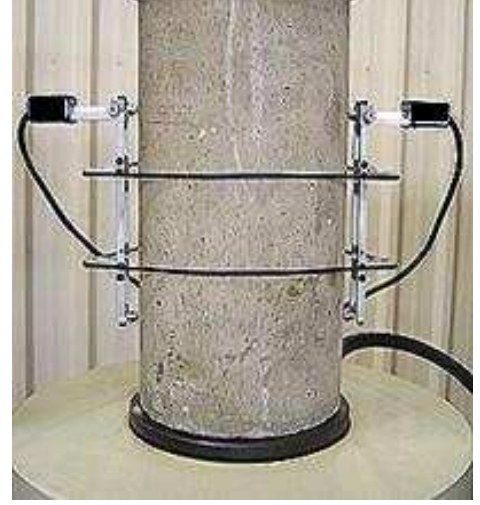

(b)

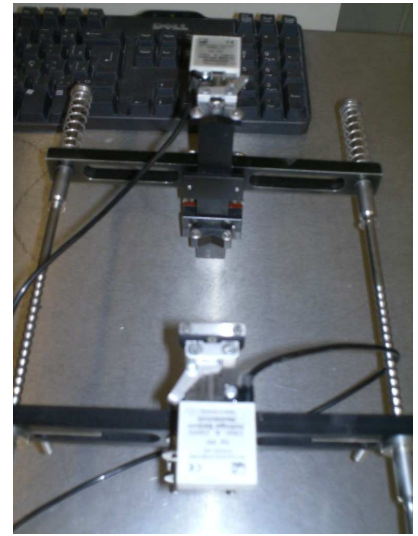
Figura 3.3.5.3.7 - Instrumentos para medição da deformação: (a) clip gages de contato em
lâmina com interligação rígida; (b) clip gages de contato em lâmina com ligação elástica por anéis de borracha; (c) clip gages de contato em lâmina com ligação elástica com molas

Os clip gages, a rigor, utilizam variações da aplicação dos strain gages colados ou de superfície. Neste caso, porém, os strain gages estão colados nas faces superior e inferior da lâmina metálica de ancoragem no corpo-de-prova e a deformação deste, que corresponde ao deslocamento vertical da extremidade da lâmina em balanço, será inferida a partir da deformação dos strain gages. A deformação dos filamentos é dependente da rotação e do braço de alavanca da lâmina. Na Fig. 3.3.5.3.8, original de Almeida (2004), está uma representação do princípio de funcionamento do sistema medidor dito clip gage.

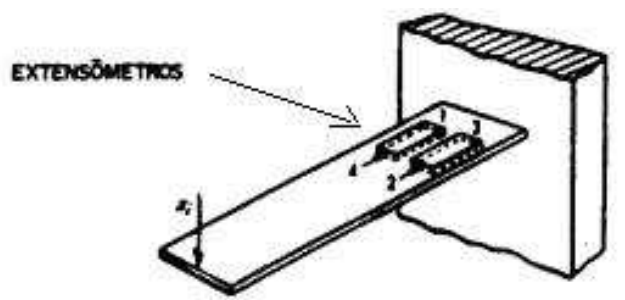

Figura 3.3.5.3.8 - Princípio de funcionamento dos clip gages

Fonte: Almeida (2004) 
Há ainda outros tipos de instrumentos para medição de deformações como os óptico-eletrônicos (Fig. 3.3.5.3.9) que não serão aqui detalhados.

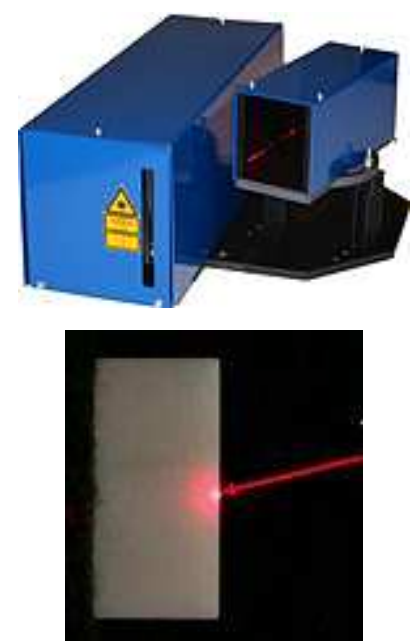

(d)

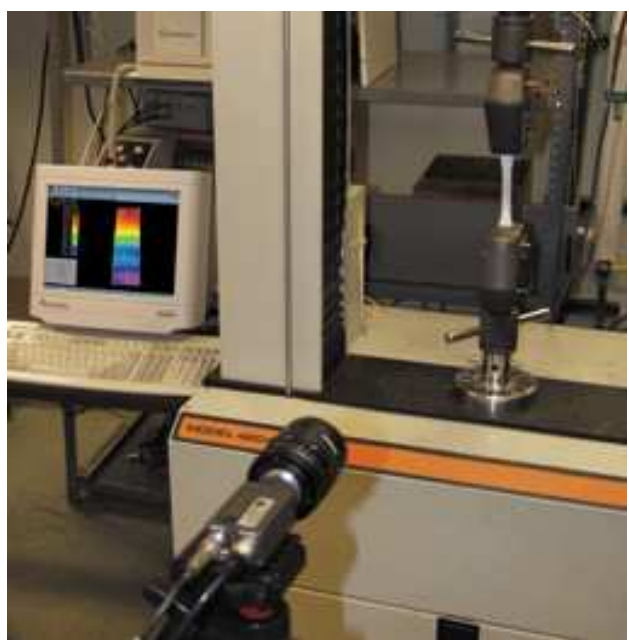

(e)

Figura 3.3.5.3.9 - Instrumentos para medição da deformação: (a) laser; (b) microfilmagem sensorial programada

Como se vê, todos os instrumentos apresentados são acompanhados de sistemas de leitura ou de aquisição de dados com os mais variados níveis de sofisticação, que vão desde a visualização através de mostrador analógico ou com aquisição de dados através de um condicionador e um amplificador de sinais elétricos (Fig. 3.3.5.3.10.a) até aquela que utiliza transmissão a fibra óptica (Fig. 3.3.5.3.10.b).

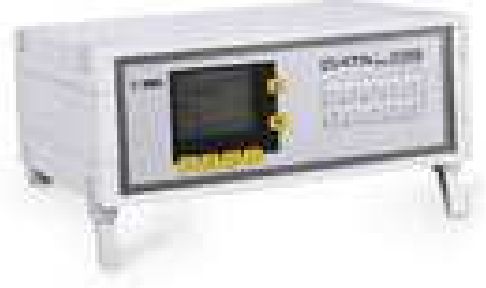

(a)

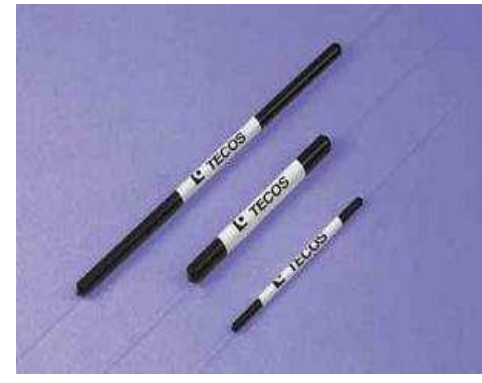

(b)

Figura 3.3.5.3.10 - Aquisição e transmissão de dados: (a) aquisitor de sinais; (b) fibras ópticas

Os instrumentos ou dispositivos de medição das deformações e as técnicas de operação utilizadas durante a execução do ensaio, ou seja, os procedimentos de medição das deformações podem ser fatores geradores de variabilidade. As 
incertezas mais comuns residem no poder de captação das deformações de cada sistema e sua técnica e nas dificuldades de instalação de cada sistema sobre os corpos-de-prova.

Em geral, a confiabilidade inerente à montagem dos sistemas é fundamentalmente dependente do treinamento do operador. Os strain gages, mais que os outros, sejam de imersão ou de superfície, exigem a execução de uma série de técnicas preparatórias para sua montagem que envolvem o planejamento total do experimento, desde o período pré-amostragem (FIGUEIREDO et al., 1991).

No caso dos strain gages colados superficialmente, por exemplo, exige-se a remoção dos corpos-de-prova do tanque ou câmara úmida algumas horas antes do ensaio para que haja uma pequena secagem superficial natural dos corpos-de-prova que possibilite o lixamento, a limpeza e a colagem desses medidores. No caso dos de imersão, deve-se cuidar do posicionamento dos medidores e considerar fortemente sua influência ou sua degradação já durante o processo de vibração do concreto na forma.

Os clip gages, assim como o compressômetro com relógios comparadores ou com LVDT, são mais facilmente montados apesar de não dispensarem o adequado traçado dos eixos verticais e horizontais de posicionamento dos medidores, de forma que sejam posicionados o mais perfeitamente possível ao longo do terço médio da altura dos corpos-de-prova.

A norma brasileira NBR 8522:2003 não descreve o procedimento de instrumentação e de medição das deformações, mas apenas cita no item 4.2 que "os instrumentos para medir as deformações podem ser mecânicos, elétricos ou outros, e devem ter resolução de $\pm 1 \times 10^{-3} \mathrm{~mm}$ e erro relativo máximo inferior a $1 \%$ ". As normas internacionais também procedem de forma semelhante. Note-se que o fato de os medidores atenderem a esta prescrição não implica necessariamente que o sistema - compressômetro e relógio(s) ou extensômetros elétricos e amplificadores de sinal - também atenda.

A título de discussão sobre a eficiência do procedimento de instrumentação para medição das deformações, cabe a citação de alguns trabalhos acerca do assunto, para que a própria pesquisa experimental que embasa esta dissertação possa ter a sua expectativa de resultados.

Klink (1975) realizou diversos experimentos para determinação do módulo de deformação do concreto segundo o método descrito na ASTM C-469. O autor 
instalou medidores de deformação em diversas regiões dos corpos-de-prova extensômetros embebidos localizados no centro de cada corpo-de-prova e a $50 \mathrm{~mm}$ e $100 \mathrm{~mm}$ do centro, além de extensômetros colados na superfície - e deduziu que durante o ensaio, as seções transversais não teriam permanecido planas pois havia nítido crescimento da deformação do centro para a superfície que implicava em queda de $55 \%$ dos resultados de módulo de deformação quantificados. $O$ autor ainda reafirmou tal resultado em Klink (1986) e (1992). Segue nas Fig. 3.3.5.3.11.a-b a representação dos resultados originalmente obtidos pelo autor.

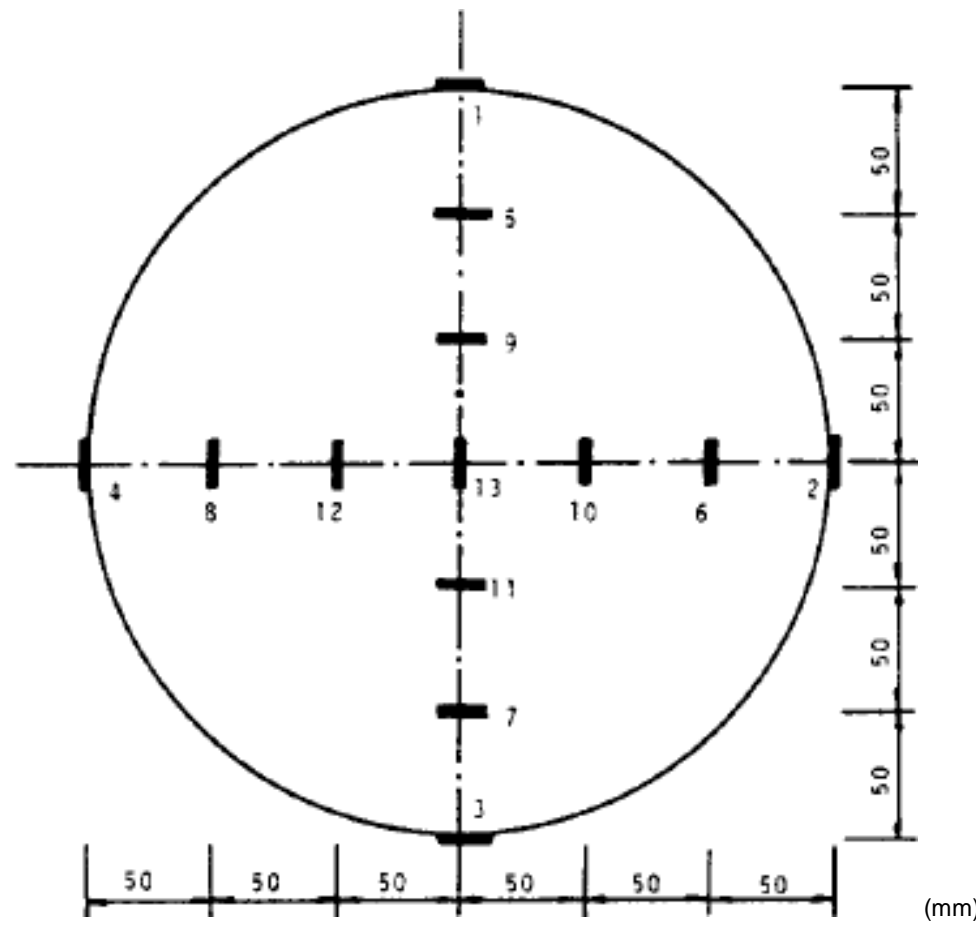

(a)

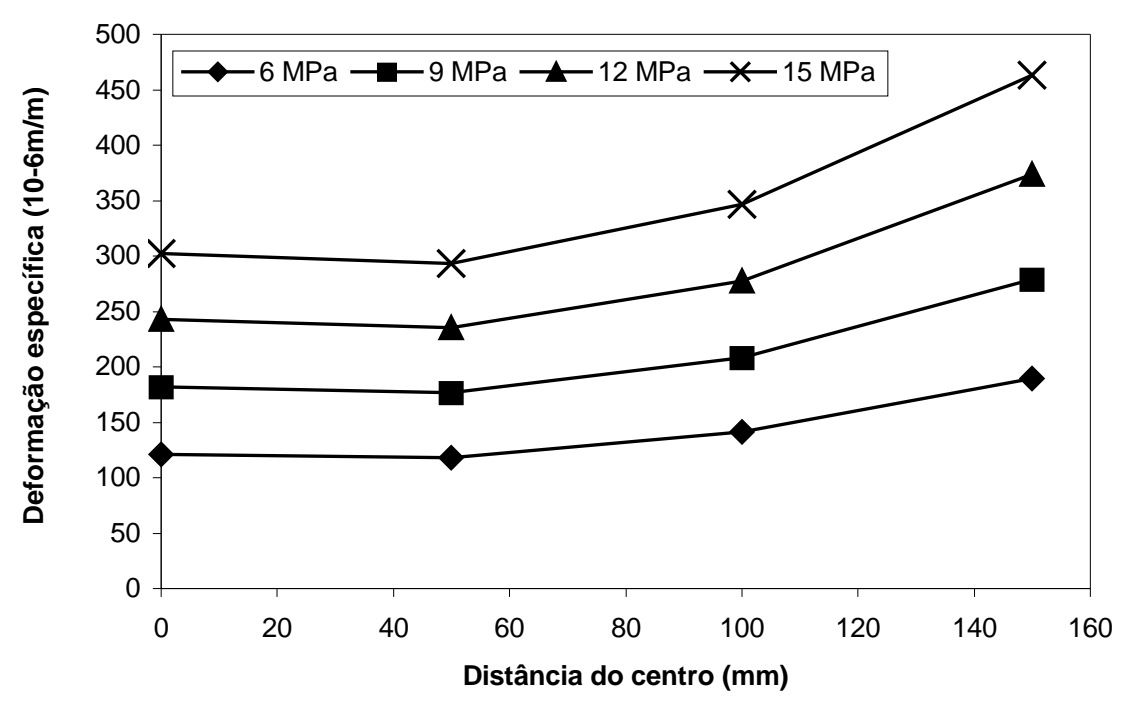

(b)

Figura 3.3.5.3.11 - Estudo de Klink: (a) distribuição dos instrumentos de medição das deformações no corpo-de-prova; (b) deformações medidas para 4 níveis de solicitação 
Os principais contrapontos de Klink ocorreram com Torrenti; Boulay e Puch (1994) e Brandt (1995), tendo este último também se referido a uma pesquisa própria anterior, de 1973. Esses autores discordaram de Klink com as seguintes observações:

- O autor (Klink) não teria preparado corretamente a superfície dos corpos-deprova para receber extensômetros colados, o que poderia ter causado os acréscimos de deformação de até $100 \%$ quando comparada à de superfícies bem preparadas;

- O autor teria realizado um trabalho com deficiências de cura, o que teria causado retração por secagem principalmente nas zonas próximas à superfície das amostras, aumentando a fissuração e a deformabilidade desta região em relação ao centro ou núcleo do corpo-de-prova;

- O autor teria utilizado corpos-de-prova ou a máquina de ensaios com pratos com problemas de planeza;

- O autor teria utilizado carregamentos excêntricos;

- O autor teria utilizado corpos-de-prova com relação comprimento/diâmetro (L/d) maior que 2 e isso teria favorecido deformações diferenciais - o autor utilizou L/d igual a 2,5;

Como contra-prova, Torrenti; Boulay e Puch (1994) realizaram experimentos com três tipos de instrumentos diferentes e quatro níveis de carregamento nos mesmos corpos-de-prova e obtiveram os resultados reproduzidos nas Fig. 3.3.5.3.12.a-b.

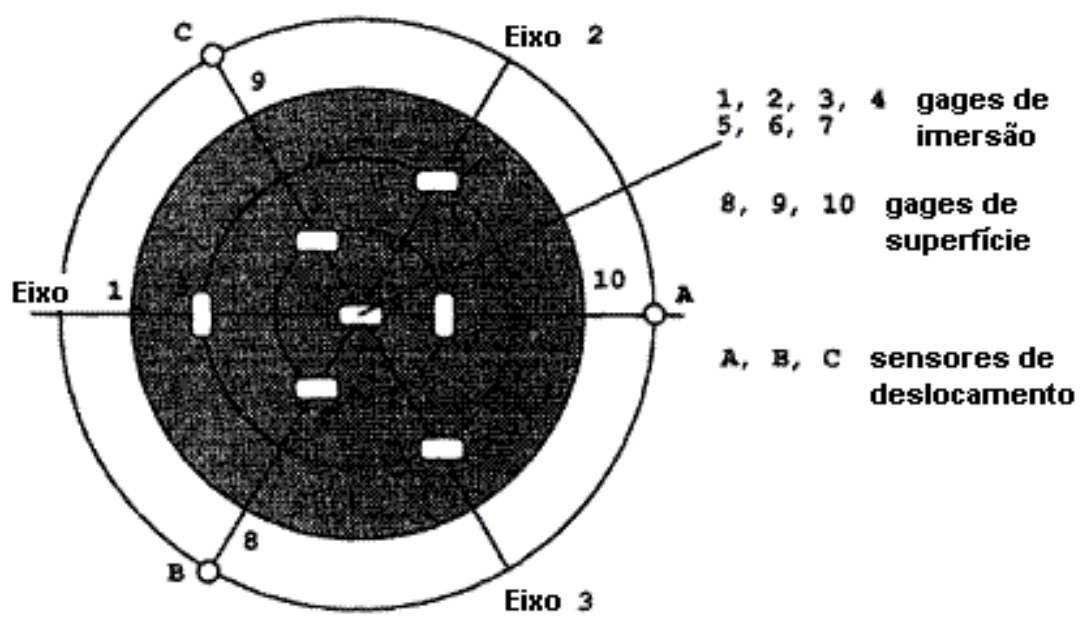




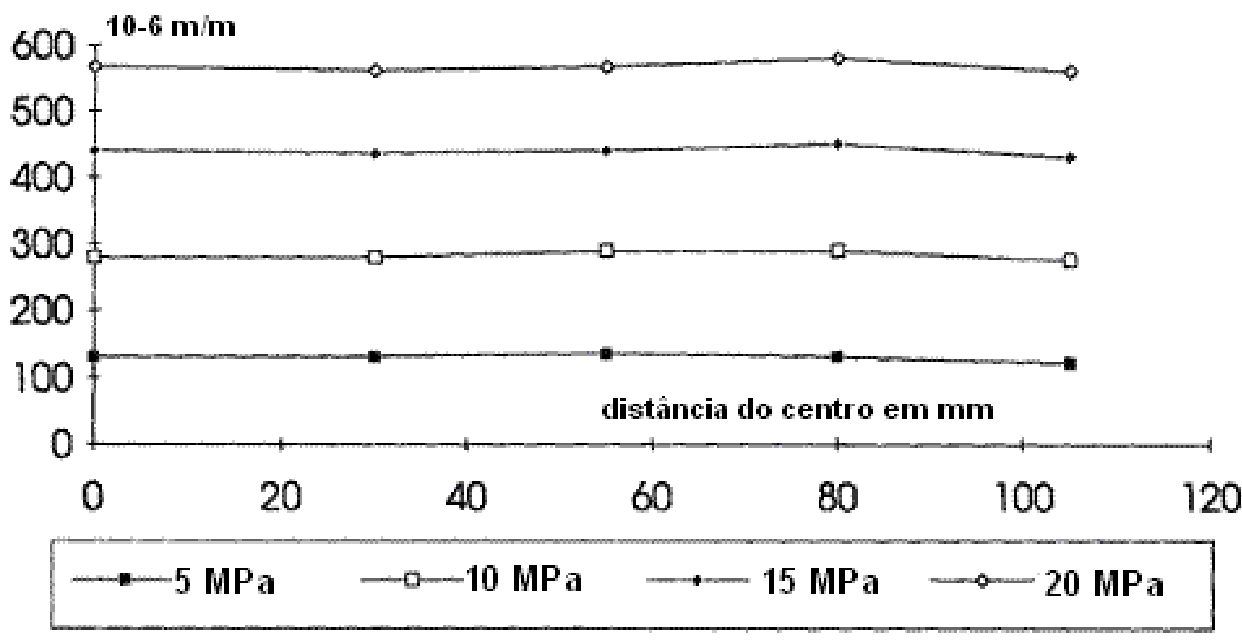

(b)

Figura 3.3.5.3.12 - Estudo de Torrenti et al.: (a) distribuição dos instrumentos de medição de deformações nos corpos-de-prova; (b) deformações lidas em 4 níveis de solicitação diferentes

Fonte: Torrenti; Boulay e Puch (1994)

Note-se que, segundo Torrenti; Boulay e Puch (1994), não haveria porque não considerar a conservação da seção como plana em qualquer dos níveis de carregamento.

Além disso, os autores ainda afirmaram, no que obtiveram a concordância de Brandt (1995), que não haveria motivo para se alterar o método de ensaio de determinação do módulo de deformação do concreto para qualquer que fosse a instrumentação utilizada.

Surge um questionamento fundamental: admitidas como solucionadas as questões da conservação das seções planas e da adequação do método de ensaio a todas as instrumentações usuais, o que explicaria a variabilidade dos resultados dos ensaios de módulo de deformação como a constatada nos interlaboratoriais nacionais relatados em Inácio; Andrade e Bittencourt (2005) e (2006)?

Pode-se dizer que apesar de terem variado a instrumentação, Torrenti; Boulay e Puch (1994) mantiveram constantes os procedimentos de preparação ou de ensaio dos corpos-de-prova, o que não acontece com os laboratórios participantes do interlaboratorial. Apesar da mistura, da cura e do transporte terem sido idênticos (realizados pelo laboratório coordenador), os laboratórios participantes realizaram a preparação final dos corpos-de-prova através de retificação ou capeamento, a instrumentação para medição das deformações, os ensaios prévios de resistência à compressão, além do ensaio de determinação do módulo de deformação 
propriamente dito, cada um com seus equipamentos e operadores, ainda que respeitando a mesma norma de ensaio brasileira.

Ainda assim, note-se no gráfico da Fig. 3.3.5.3.11.b que a diferença entre os resultados captados a partir dos strain gages de superfície (distância do centro igual a $80 \mathrm{~mm}$ ) e os sensores de deslocamento associados a dispositivo de contato com o corpo-de-prova que provavelmente se tratava de um compressômetro (distância do centro pouco maior que $100 \mathrm{~mm}$ ) é significativa: para a tensão de $15 \mathrm{MPa}$ (3ํㅡível), por exemplo, pode-se inferir deformações específicas de $460.10^{-6}$ e $430.10^{-6}$, respectivamente, o que significaria aproximadamente 2,3 GPa de diferença entre as determinações. Esse resultado já seria um valor significativo considerando-se a acurácia esperada para uma pesquisa realizada dentro de um único laboratório, e com variação metodológica unicamente dada pela alternância de instrumentações. A expectativa para um interlaboratorial seria de uma dispersão ainda maior.

Ressalte-se ainda que sendo a magnitude desta diferença unicamente dada pela variação da instrumentação já que, inclusive, as leituras se deram nos mesmos corpos-de-prova, é de se esperar que a medida das deformações seja um dos mais significativos fatores intervenientes para a variabilidade observada nos resultados de módulo de deformação.

Rodrigues (2003) realizou outra pesquisa sobre a propriedade módulo de deformação do concreto sob diversos aspectos, incluindo o tempo de cura, o tipo de agregado graúdo e o tipo de instrumentação para medida das deformações. Restringindo a análise sobre o tópico 'alternância das instrumentações', lê-se que a autora mostrou através de diversas análises de regressão linear que nenhuma das correlações entre as instrumentações podia ser considerada aceitável - no caso foram utilizados strain gages de imersão, clip gages, um comparador mecânico de base móvel tipo tensotast e um compressômetro com relógio comparador — pois os coeficientes de determinação ' $r$ ' que indicavam a confiabilidade das equações de correlação ficaram entre 0,23 e 0,64.

Portanto, como se vê, a variabilidade dos resultados das determinações experimentais do módulo estático de deformação do concreto desperta dúvidas sobre a acurácia do método de ensaio e sobre alguns de seus procedimentos, ainda que não se conteste a priori a teoria que os embasa (método e procedimentos). De toda forma, há espaço para agregar às pesquisas existentes abordagens com maior enfoque metrológico e estatístico. 


\section{METODOLOGIA DA PESQUISA}

Esta dissertação procura inserir-se no cenário de ampliação da discussão a respeito da variabilidade observada entre laboratórios e/ou equipamentos e a utilização adequada dos resultados obtidos. Obviamente, o teste da metodologia apresentada a seguir se dá sob a limitação do âmbito laboratorial e do operador único, mas se espera que ela seja expansível e aplicável a um âmbito maior sem alterações significativas.

A pesquisa contém, assim, dois enfoques:

- avaliação da acurácia do método de ensaio;

- discussão da possibilidade de aplicação do conceito semiprobabilístico normativo aos resultados de controle experimental do módulo de deformação do concreto.

\subsection{Avaliação da acurácia do método de ensaio}

Se a variabilidade dos resultados desperta dúvidas sobre a acurácia do método de ensaio, esta, por si, só se consegue verificar por completo através da chamada Validação (INMETRO, 2003).

A Validação é a aplicação de um conjunto de técnicas experimentais com base estatística capaz de atribuir a um método de ensaio um indicador de confiabilidade, a fim de que aos usuários seja dado um parâmetro para decidir pela continuidade e pela viabilidade de universalização do uso daquele método. Um método de ensaio inválido é aquele que precisa ser revisto em sua teoria e/ou modelagem - atente-se que, neste caso, é a modelagem em que se baseia o experimento e não a propriedade. Na Fig. 4.1.1 é apresentada uma sistemática de desenvolvimento, aprimoramento e validação de um método experimental, na forma de um ciclo, baseada em Valavala e Odegard (2005). Neste ciclo, as etapas de montagem do Experimento, Determinação e Análise dos resultados é que suportam as decisões de aceitação ou aprimoramento do método através de revisões em sua Teoria, Modelagem das expectativas e Simulação do funcionamento e/ou aplicação. 


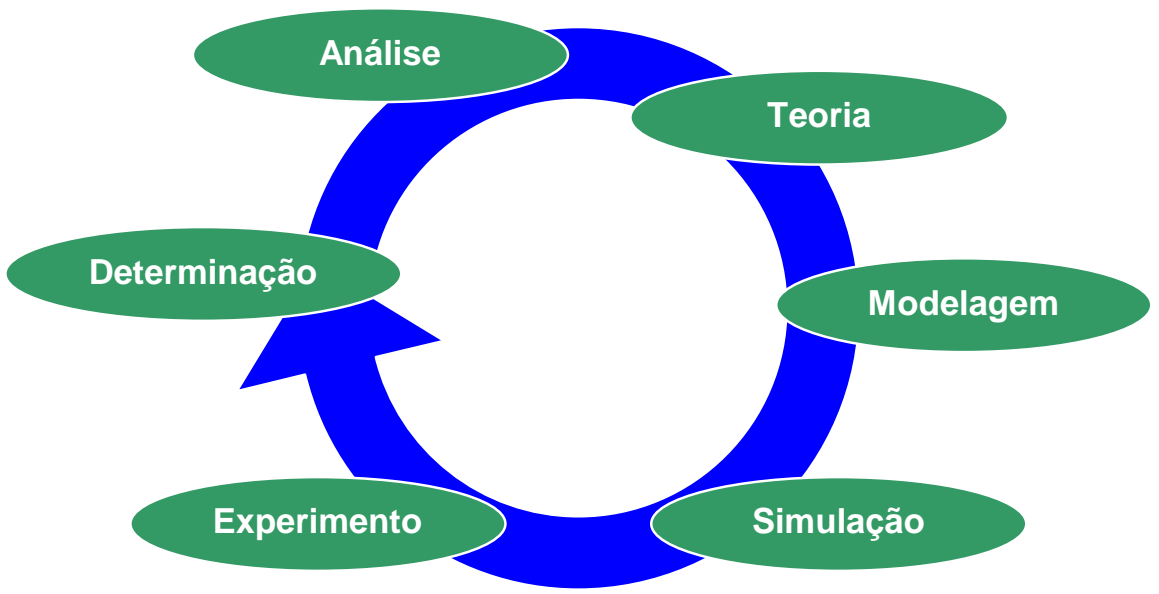

Figura 4.1.1 - Ciclo de desenvolvimento e validação de um método experimental

Se dois métodos de determinação de uma mesma propriedade chegam a resultados distintos, deve-se considerar a teoria que embasa cada um para apurar a devida interpretação dos resultados e identificar o válido. Pode-se até chegar à conclusão de que, para um certo cenário de condições, ambos os métodos sejam válidos, como em determinações experimentais de uma propriedade em laboratório e em campo com distintos recursos de preparo de amostra, por exemplo. Note-se, contudo, que esses resultados deverão coexistir tecnicamente se acompanhados da identificação do método de ensaio sob o qual foi obtido.

Um método de ensaio pode ser composto por diversos tipos de procedimentos e estes também podem ser validados de forma independente. $O$ método de ensaio para determinação do módulo estático de deformação do concreto, como visto, deve ter validados, minimamente, os equipamentos e as técnicas de amostragem, preparação dos corpos-de-prova (moldagem, transporte, cura e regularização de base e topo), ensaio prévio de resistência e ensaio de módulo propriamente dito.

$\mathrm{Na}$ pesquisa que embasa esta dissertação admitiram-se válidos todos os procedimentos executados até o ensaio prévio de resistência. Essa estratégia foi seguida por uma questão prática: deu-se o aproveitamento da estrutura do Centro de Pesquisas e Desenvolvimento em Construção Civil (CPqDCC) da Escola Politécnica da Universidade de São Paulo, reiteradamente testada. Note-se que esta ação não desvinculou o estudo da acurácia do método de ensaio de módulo 
propriamente dito dos procedimentos iniciais. Pode-se dizer que todos os resultados obtidos também são dependentes deles. O que foi limitado com isso é a possibilidade de formulação das tolerâncias para o método e a decisão sobre sua aceitabilidade, conforme previsto no capítulo introdutório desta dissertação.

Assim sendo, optou-se por seguir a análise da acurácia do método de ensaio sob três aspectos:

1으 Avaliação preliminar: teste dos resultados de módulo de deformação de concretos de classes de rigidez distintas através dos modelos de previsão apresentados no Capítulo 2. Se os resultados estiverem de acordo com os modelos, ao menos na ordem de grandeza, poder-se-á dar prosseguimento à metodologia sem o risco de estar-se avaliando o método comprometido por erros grosseiros;

$\left.2^{\underline{0}}\right)$ Avaliação dos indicadores de precisão e exatidão do método de ensaio considerando os procedimentos fixados até o ensaio prévio de resistência e o variável (procedimento de instrumentação para medida das deformações). Com isso conseguiu-se uma forma de inferir a acurácia do método sob cada instrumentação em particular, já que seu uso e a estimativa de variabilidade inerente só têm sentido se inseridos no ensaio;

$3^{\circ}$ ) Avaliação dos indicadores de precisão e exatidão do método de ensaio como um todo, mantendo-se fixados os procedimentos iniciais e considerando-se os resultados obtidos a partir de cada instrumentação em particular como se provenientes de um procedimento de instrumentação único. A rigor, é assim que funciona o método de ensaio normalizado, não-restritivo a quaisquer dessas instrumentações.

\subsubsection{Ferramentas estatísticas para análise}

A série de normas ISO 5725:2000, que trata de acurácia, exatidão e precisão de métodos de medida, traz os conceitos fundamentais para a formação do juízo de valor sobre os procedimentos de ensaio da determinação do módulo de deformação do concreto. Prefere-se, no entanto, relembrar a conceituação baseada na Teoria dos Erros apresentada por Vuolo (1992), pela amplitude e simplicidade, dada a partir da conceituação de grandezas básicas de ensaio: 
- grandeza física: semelhante a 'propriedade'. No entanto, o termo grandeza só tem sentido a partir da tentativa de medição através de modelagem pelo homem, e acompanhada de um ensaio, experimento ou dedução matemática;

- grandeza física experimental: qualquer grandeza física cujo valor é determinado a partir de um conjunto de dados experimentais, onde está implícito um modelo de medição;

- valor verdadeiro de uma grandeza experimental $\left(y_{\mathrm{v}}\right)$ : do ponto de vista da Teoria dos Erros, existe um valor verdadeiro para toda grandeza física experimental; note-se que esse valor depende do modelo experimental;

- melhor valor da grandeza experimental (y): valor mais próximo do valor verdadeiro de uma grandeza experimental. Na prática, é o valor experimental, aquele obtido a partir dos experimentos;

- valor médio de $\mathrm{n}$ medidas (ŷ): valor de aproximação matemática ao valor verdadeiro a partir de $\mathrm{n}$ valores experimentais; normalmente, o erro do valor médio em relação ao valor verdadeiro é menor que o erro em cada medida;

- erro experimental: diferença entre o valor verdadeiro de uma grandeza experimental e o valor experimental ou seu valor médio; os erros, por sua vez, podem ser divididos em:

- erro estatístico ou aleatório: é um erro tal que as $n$ medidas $y_{i}$ se distribuem de maneira aleatória em torno do valor verdadeiro $y_{v}$, e o valor médio $\hat{y}$ das medidas tende a $\mathrm{y}_{v}$ conforme o número $\mathrm{n}$ de medidas tende a infinito;

- erro sistemático: é um erro tal que as $n$ medidas $y_{i}$ são iguais, mas diferem do valor verdadeiro $\mathrm{y}_{\mathrm{v}}$ de uma maneira constante $\delta \mathrm{y}$. Os erros estatístico e sistemático são representados na Fig. 4.1.1.1.

Erro estatístico ou aleatório puro

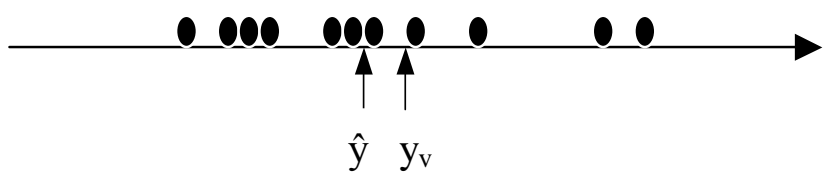

Erro sistemático puro

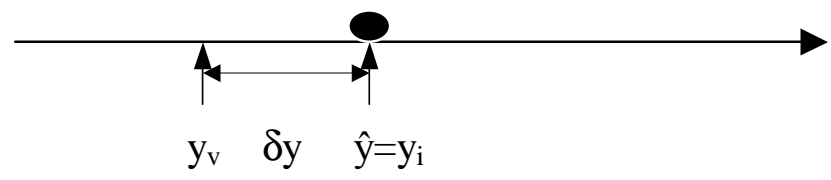

Figura 4.1.1.1 - Representação esquemática dos erros experimentais 
- precisão: é a indicação qualitativa da ocorrência e da magnitude do erro estatístico ou aleatório em um experimento, isto é, o grau de concordância entre repetidas medidas da mesma propriedade;

- exatidão: é a indicação qualitativa da ocorrência e da magnitude do erro sistemático em um experimento, isto é, o grau de concordância entre o valor médio obtido a partir de uma série de experimentos e o valor verdadeiro;

- acurácia: é a indicação qualitativa da ocorrência e da magnitude do erro total, estatístico e sistemático, em um experimento, isto é, o grau de concordância entre repetidas medidas da mesma propriedade e o valor verdadeiro.

Ainda segundo Vuolo (1992), os erros estatísticos resultam de variações aleatórias devido a fatores que não podem ser controlados ou que, por qualquer motivo, não são controlados. Os erros sistemáticos, por sua vez, podem ser instrumentais, teóricos, ambientais ou observacionais.

$\mathrm{Na}$ Fig. 4.1.1.2 segue uma representação elaborada por Nascimento (2001) para análises experimentais baseadas em avaliações de precisão e exatidão.

valor verdadeiro

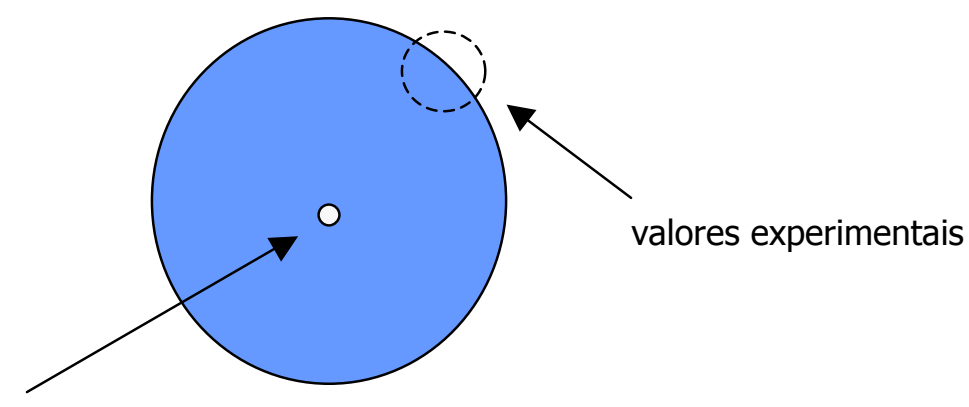

Valores experimentais precisos mas não exatos (baixa acurácia)

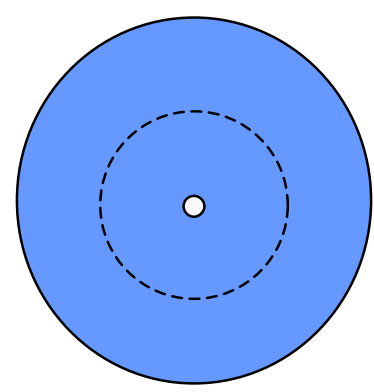

Valores experimentais não precisos mas exatos (boa acurácia do valor médio) 


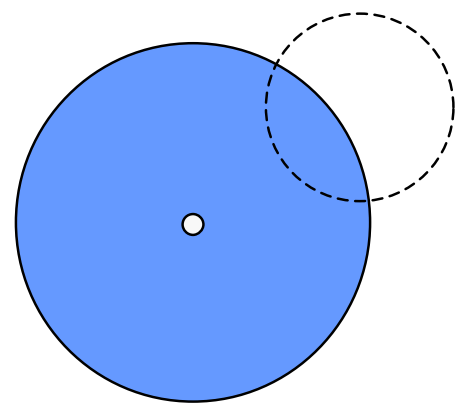

Valores experimentais não precisos e não exatos (baixa acurácia)

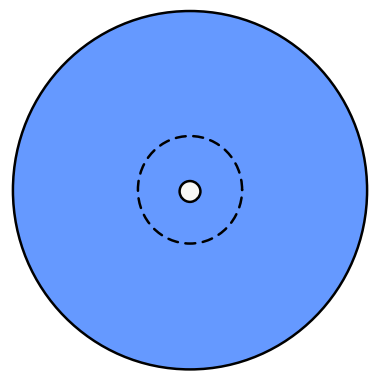

Valores experimentais precisos e exatos (boa acurácia total)

Figura 4.1.1.2 - Representação ilustrativa das avaliações de acurácia

Fonte: Nascimento (2001)

Por fim, deve-se ressaltar que erros grosseiros ou enganos observacionais na leitura, anotação ou cálculo dos resultados não são erros do ponto de vista da Teoria dos Erros, isto é, todos os valores experimentais obtidos devem a priori ser considerados em análise.

Note-se que a melhor maneira de identificar a natureza dos erros é mesmo aquela baseada na comparação das medidas entre os diversos experimentos, pois um sistema calibrado e bem conservado (controlado), mas eventualmente montado ou instalado de forma inadequada no experimento, poderá gerar erro estatístico ou aleatório. O mesmo sistema controlado mas repetidamente mal operado, gerará erro sistemático. Isso corrobora com o fato de esta dissertação utilizar a precisão, a exatidão e a acurácia aplicadas ao método de ensaio sob um procedimento de instrumentação em particular e não sobre o instrumento em si. 


\subsubsection{Cálculo da precisão}

A precisão de um método, procedimento ou sistema de medida pode ser avaliada através do cálculo dos limites de repetitividade e reprodutibilidade e com o acompanhamento da constância de sua aplicabilidade ao longo do tempo.

Por repetitividade, Carpinetti (2003, p. 141) entende a "medida da dispersão dos resultados de medições sucessivas da mesma grandeza e realizadas por um mesmo operador". De um modo geral e aproximado, a repetitividade de um tipo de medição de uma propriedade que apresenta uma distribuição populacional normal de resultados é dada dentro da faixa de 6 erros-padrão $(\sigma)$, isto é, o intervalo de $99,74 \%$ de probabilidade de ocorrência, ou de 5,15 erros-padrão $(\sigma)$, isto é, o intervalo de $99 \%$ de probabilidade de ocorrência do resultado dentro desse intervalo. $\mathrm{Na}$ verdade, como em experimentos trata-se normalmente de amostras e não de populações, é mais comum a utilização do termo desvio-padrão (s) como indicador da probabilidade de ocorrência de uma medida em uma distribuição de $\mathrm{n}$ medidas. $\mathrm{A}$ variância populacional $\left(\sigma^{2}\right)$ e amostral $\left(s^{2}\right)$ são dadas pelo quadrado dos valores do erro e do desvio-padrão, respectivamente. Na Fig. 4.1.1.1.1. está representada a repetitividade dos resultados de um tipo de medição em função do Desvio devido à repetitividade.

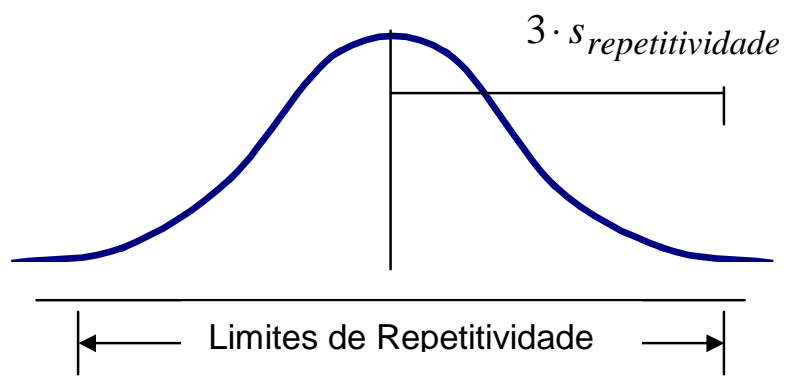

Figura 4.1.1.1.1 - Representação da repetitividade da medição

Fonte: Carpinetti (2003)

Por reprodutibilidade, Carpinetti (2003, p. 141) entende a "variação máxima entre resultados médios obtidos por diferentes operadores para a mesma grandeza e sob as mesmas condições de operação". Na Fig. 4.1.1.1.2. está representada a reprodutibilidade dos resultados de um tipo de medição. 


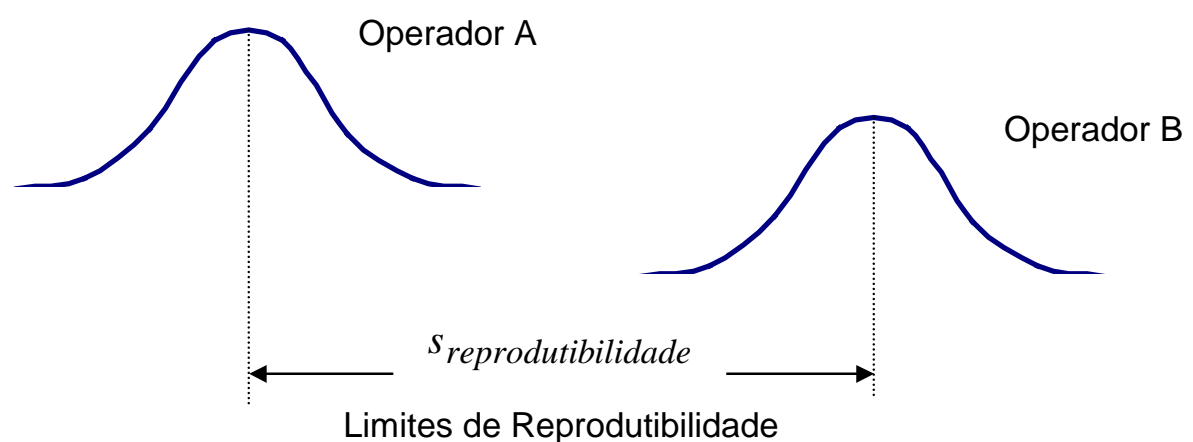

Figura 4.1.1.1.2 - Representação da reprodutibilidade da medição

Fonte: Carpinetti (2003)

A ferramenta estatística comumente utilizada para o cálculo dos indicadores de precisão é a Análise de Variância (Analysis of Variance ou ANOVA).

Ocorre que, a rigor, pesquisadores como Waeny (1980) recomendavam a ANOVA para o cálculo dos indicadores de precisão com fins de comparação entre métodos, procedimentos ou sistemas de medida apenas se os experimentos realizados fossem determinações em um mesmo analito (corpo-de-prova). Em geral, esses usos estavam vinculados a validações metrológicas ou a controles de qualidade de produção aplicados, na maior parte das vezes, em determinações nãodestrutivas como no controle dimensional de peças metálicas da indústria seriada, por exemplo. No caso dos ensaios mecânicos em concreto não haveria essa possibilidade.

No entanto, com a evolução da aplicação das ferramentas estatísticas na área industrial - mecânica e química principalmente - novas possibilidades de uso foram testadas utilizando a ANOVA e metodologias para controle através de determinações destrutivas foram encontradas. A consideração adotada nesta dissertação, por exemplo, foi de que os corpos-de-prova de uma amostra/betonada (corpos-de-prova irmãos) fossem tão semelhantes entre si que pudessem ser considerados iguais, configurando uma condição hipotética de que os experimentos dentro de uma mesma betonada estivessem se dando em um corpo-de-prova único. As betonadas de um mesmo traço não foram consideradas necessariamente iguais.

Nesse sentido, é apresentado a seguir o roteiro utilizado para o cálculo dos indicadores de precisão de métodos, procedimentos ou sistemas de medida, 
utilizado na análise dos resultados obtidos no plano experimental que embasa esta dissertação.

Roteiro de cálculo dos indicadores de precisão (desvios de repetitividade e reprodutibilidade)

a) Preparação aleatória de pelo menos 2 amostras (betonadas) com 2 corposde-prova cada para determinação laboratorial por pelo menos 2 operadores diferentes;

b) Experimentos aleatórios de determinação da propriedade utilizando o método, procedimento ou sistema de medida a ser avaliado;

c) Aplicação do Teste de Grubbs para rejeição dos resultados espúrios de uma Distribuição Normal, em que:

$$
z=\frac{\left|y_{\text {extremo }}-y_{\text {médio }}\right|}{S_{\text {amosstra }}}
$$

onde:

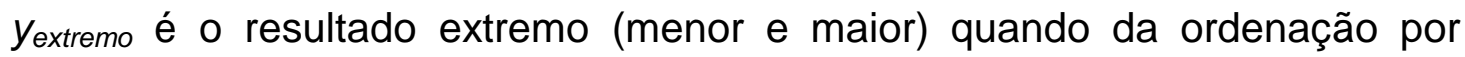
ordem crescente ou decrescente dos resultados dos experimentos;

$y_{\text {médio }}$ é o valor médio dos resultados dos experimentos;

$S_{\text {amostra }}$ é o desvio-padrão dos resultados dentro da amostra;

$z$ é o indicador dos valores espúrios, em que:

$\mathrm{H}_{0}$ : $y_{\text {extremo }}$ é um resultado extremo pertencente à distribuição

$\mathrm{H}_{1}$ : Yextremo não é um resultado pertencente à distribuição (é espúrio)

Rejeita-se $\mathrm{H}_{0}$ se $z>2,575$ (intervalo de confiança de 99\%).

d) Cálculo, através de ANOVA, das somas quadráticas $(S Q)$, graus de liberdade $(G L)$, médias quadráticas das variâncias $(M Q)$ e do indicador $F$ de Snedecor para avaliação da significância do impacto dos fatores sobre os resultados das variâncias, conforme segue:

Somas Quadráticas (SQ):

$$
\text { SQAmostra }=b \cdot n \cdot \sum\left(y_{i . .}-y_{\ldots .}\right)^{2}
$$

onde:

$b$ é o número de operadores;

$n$ é o número de replicações (corpos-de-prova por amostra);

$y_{i . .}$ é a média de cada amostra;

$y$... é a grande média 


$$
\text { SQOperador }=a \cdot n \cdot \sum\left(y_{. j .}-y_{\ldots}\right)^{2}
$$

onde:

$a$ é o número de amostras;

$n$ é o número de replicações (corpos-de-prova por amostra);

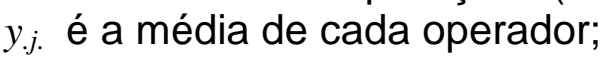

$y_{\ldots}$ é a grande média

$$
\text { SQrepetitividade }=\sum \sum \sum\left(y_{i j k}-y_{i j}\right)^{2}
$$

onde:

$y_{i j k}$ é cada uma das observações

$y_{i j}$ é a média de cada fator

$$
\text { SQTotal }=\sum \sum \sum\left(y_{i j k}-y_{\ldots}\right)^{2}
$$

onde:

$y_{i j k}$ é cada uma das observações

$y_{i j}$ é a grande média

SQAmostra $*$ Operador $=$ SQTotal $-($ SQAmostra + SQOperador + SQrepetitividade $)$

\section{Graus de Liberdade (GL):}

$$
\text { GLAmostra }=a-1
$$

onde:

$a$ é o número de amostras

$$
\text { GLOperador }=b-1
$$

onde:

$b$ é o número de operadores

$$
\text { GLAmostra } * \text { Operador }=(a-1) \cdot(b-1)
$$

onde:

$a$ é o número de amostras

$b$ é o número de operadores

$$
\text { GLrepetitividade }=n-(a \cdot b)
$$

onde:

$n$ é o número total de observações 
$a$ é o número de amostras

$b$ é o número de operadores

$$
\text { GLTotal }=n-1
$$

onde: $n$ é o número total de observações

\section{Médias Quadráticas (MQ):}

$$
\begin{aligned}
\text { MQAmostra } & =\frac{\text { SQAmostra }}{\text { GLAmostra }} \\
\text { MQOperador } & =\frac{\text { SQOperador }}{\text { GLOperador }} \\
\text { MQAmostra } * \text { Operador } & =\frac{\text { SQAmostra } * \text { Operador }}{\text { GLAmostra } * \text { Operador }} \\
\text { MQrepetitividade } & =\frac{\text { SQrepetitividade }}{\text { GLrepetitividade }}
\end{aligned}
$$

Fcalculado e p-value (Fcrítico tabelado):

$$
\begin{gathered}
\text { FAmostra }=\frac{\text { MQAmostra }}{\text { MQAmostra } * \text { Operador }} \\
\text { FOperador }=\frac{\text { MQOperador }}{\text { MQAmostra } * \text { Operador }} \\
\text { FAmostra } * \text { Operador }=\frac{\text { MQAmostra } * \text { Operador }}{\text { MQrepetitividade }}
\end{gathered}
$$

\section{Composição das variâncias:}

\section{Componente}

Variância Repetitividade

Variância Operador

Variância Amostra*Operador

\section{Fórmula}

MQrepetitividade

$\frac{\text { MQOperador }- \text { MQAmostra } * \text { Operador }}{a \cdot n}$

$\underline{\text { MQAmostra* Operador-MQrepetitividade }}$

$n$

Variância Reprodutibilidade Variância Operador + Variância Amostra*Operador 
Variância $R \& R$

Variância Amostra

Variância Total
Variância Repetitividade+Variância Reprodutibilidade

$\frac{\text { MQAmostra }- \text { MQAmostra* Operador }}{b \cdot n}$

Variância $R \& R+$ Variância Amostra

onde:

$n$ é o número total de observações

$a$ é o número de amostras

$b$ é o número de operadores

Note-se que os desvios de repetitividade (Variância Repetitividade) e de reprodutibilidade (Variância Reprodutibilidade) podem ser classificados como desvios de ensaio, assim como os desvios entre betonadas (Variância Amostra), classificados como desvio de produção. Ressalte-se a consideração prevista nesta dissertação de que os resultados obtidos pudessem ser agrupados e admitidos como de operadores diferentes.

A análise dos resultados obtidos a partir do roteiro dispõe de tabelas-resumo com o seguinte conteúdo (Tab. 4.1.1.1.1 e observações):

Tabela 4.1.1.1.1 - Tabela demonstrativa para os cálculos de precisão

\begin{tabular}{|c|c|}
\hline Item & INDICADORES ESTATísTICOS \\
\hline 1 & Média (GPa) \\
\hline 2 & Desvio-padrão (GPa) \\
\hline 3 & Incerteza da média (GPa) \\
\hline 4 & Compatibilidade entre médias \\
\hline 5 & Desvio de repetitividade (GPa) \\
\hline 6 & Desvio de reprodutibilidade (GPa) \\
\hline 7 & Desvio R\&R (GPa) \\
\hline 8 & Desvio de betonadas (GPa) \\
\hline 9 & Desvio-padrão total (GPa) \\
\hline 10 & Desvio R\&R/Desvio total $(\%)$ \\
\hline 11 & Betonadas distinguidas \\
\hline
\end{tabular}


- Item 1: Média considerando-se todas as determinações;

- Item 2: Desvio-padrão considerando-se todas as determinações;

- Item 3: Incerteza da média calculada a partir da divisão do desvio-padrão pela raiz quadrada do número de experimentos;

- Item 4: Compatibilidade entre médias considera o encaixe de cada média dentro dos intervalos de confiança das demais, considerando-se as Incertezas das médias;

- Item 5: Desvio de repetitividade dado pela raiz quadrada da Variância Repetitividade;

- Item 6: Desvio de reprodutibilidade dado pela raiz quadrada da Variância Reprodutibilidade;

- Item 7: Desvio R\&R dado pela raiz quadrada da Variância $R \& R$;

- Item 8: Desvio de betonadas dado pela raiz quadrada da Variância Amostra;

- Item 9: Desvio-padrão total obtido a partir dos estudos de R\&R; pode ser diferente daquele do Item 2 devido ao fato de ser obtido a partir de agrupamentos de resultados, como na consideração da existência de operadores distintos;

- Item 10: Desvio R\&R / Desvio total (\%); esta relação sugere a incapacidade do método ou do instrumento de medida de perceber a variação entre amostras (betonadas). Quanto maior o resultado da relação, menor a sua percepção à variação entre amostras e conseqüentemente, menos indicado à aceitação como método ou sistema de medida universal. Carpinetti (2003) indica que a norma QS 9000, utilizada na indústria automobilística, recomenda como resultado desta relação o valor máximo de $10 \%$ para o indicativo de Validação do método ou sistema de medida. A mesma norma preconiza que se o resultado da relação estiver entre 10 e $30 \%$, deve-se considerar que o método/sistema pode ser adequado dependendo da importância da aplicação ou da propriedade a ser medida, ou ainda do custo de fabricação ou de manutenção do sistema; se acima de $30 \%$, o método/sistema necessitaria de melhorias teóricas ou de modelagem. No caso do método de determinação do módulo estático de deformação do concreto, entende-se, o rigor pode não ser da mesma intensidade.

- Item 11: Betonadas distinguidas é dado pela relação entre o Desvio de betonadas e o Desvio R\&R, multiplicada por 1,41 , e tem como resultado 
sempre um número inteiro. Este número está ligado à relação anterior, Desvio R\&R / Desvio total (\%);

Ressalte-se por fim que, se a rigor as análises estatísticas particulares de precisão e exatidão das instrumentações precisariam se dar sobre as 'leituras de deformação' que são o produto destes sistemas, a opção feita pela análise dos resultados do método de ensaio permite o estudo diretamente sobre os 'resultados de módulo'. Em outras palavras, os indicadores de acurácia se referem então ao método, globalmente ou sob cada instrumentação para medida das deformações em particular, e não às instrumentações em si.

\subsubsection{Cálculo da exatidão}

A exatidão do resultado de um experimento pode ser comprovada basicamente através da sua comparação com o resultado de uma amostra de referência previamente estudada.

A utilização de materiais de referência certificados é, por isso, um requisito recomendado no processo de validação de um método de ensaio. Quando existente, o material é acompanhado de um certificado de análise que menciona os valores das propriedades mais significativas com as respectivas incertezas. Na avaliação da exatidão de um método de determinação de uma propriedade qualquer com o auxílio de um material de referência certificado, os valores obtidos pelo laboratório - a média e o desvio-padrão de uma série de ensaios em replicata - devem ser comparados com o valor da incerteza estimada no certificado do material de referência para a propriedade determinada. Quando o valor obtido não estiver dentro do intervalo da incerteza indicado para o valor certificado, o laboratório deve procurar as causas deste desvio e tentar eliminá-las ou aceitá-las, dependendo do critério definido para os resultados.

Em casos como o da determinação do módulo de deformação do concreto, há dificuldade na definição de um elemento de referência. A exatidão do método tende então a ser avaliada através de programas interlaboratoriais associados a cartas de controle temporal dos indicadores de qualidade. O cálculo da exatidão em programas interlaboratoriais vem normalmente da estatística robusta, que procura diminuir a influência dos resultados extremos dos experimentos considerando como 
valor verdadeiro a mediana da distribuição dos resultados, e a formulação mais comumente utilizada na análise é a da técnica do Z-score.

A técnica do Z-score realiza uma comparação entre os resultados dos laboratórios inferindo uma tendência do valor verdadeiro e utilizando na identificação dos laboratórios de resultados discrepantes um desvio-padrão admitido para o grupo dos não-discrepantes. Em outras palavras, para comparar o desvio do valor obtido em um experimento com o valor verdadeiro esperado, considera-se um desviopadrão admissível e atribui-se uma nota de discrepância entre o valor obtido e o valor esperado a qual se compara com os limites de 1, 2 ou 3 desvios-padrão admissíveis. Dependendo da "distância" - em termos de desvios-padrão admissíveis - do valor do experimento em relação ao valor verdadeiro admitido, considera-se o procedimento experimental exato ou não-exato, conforme o roteiro descrito a seguir.

Roteiro de cálculo do indicador de exatidão (Z-score)

a) Preparação aleatória de pelo menos 2 amostras com 2 corpos-de-prova cada para determinação laboratorial por pelo 3 laboratórios diferentes;

b) Experimentos aleatórios de determinação da propriedade utilizando o método, procedimento ou sistema de medida característico de cada laboratório a ser avaliado;

c) Aplicação do Teste de Grubbs para rejeição dos resultados dispersos de uma Distribuição Normal (conforme técnica descrita anteriormente);

d) Admissão do valor verdadeiro $(Y)$ como sendo a mediana dos resultados;

e) Admissão do desvio padrão $(s)$ como sendo amplitude interquartílica normalizada (IQN) dos resultados - a diferença entre os valores que identificam o maior quartil e o menor quartil multiplicada pelo fator 0,7413 que vem da distribuição normal e aproxima a IQN do desvio-padrão amostral;

f) Aplicação da técnica Z-score conforme segue:

Nota (Z-score):

$$
Z=\frac{(y-Y)}{s}
$$

onde:

$Z$ é a nota do laboratório

$y$ é o resultado do experimento do laboratório 
$Y$ é o valor verdadeiro admitido

$s$ é o desvio-padrão admitido

Interpretação estatística:

Se $Z<1$ ( $67,8 \%$ dos casos), o laboratório tem exatidão adequada

Se $1 \leq Z<2$ (27,5\% dos casos), o laboratório tem exatidão satisfatória

Se $2 \leq Z<3$ (4,4\% dos casos), o laboratório tem exatidão questionável

Se $Z \geq 3$ ( $0,3 \%$ dos casos), o laboratório tem exatidão insatisfatória

Esse roteiro também será utilizado na análise dos resultados obtidos no programa experimental desta dissertação. A única consideração prevista é de que os resultados pudessem ser agrupados e admitidos como de laboratórios diferentes.

\subsection{Discussão da aplicação do conceito semiprobabilístico normativo à propriedade módulo de deformação}

Sabe-se que a determinação laboratorial do módulo de deformação do concreto é mais complexa que a da resistência. Inerente a essa discussão existe outra acerca da interpretação corrente dada aos resultados obtidos nestes ensaios.

O conceito usual das obras é de que a reprodução dos resultados de desempenho obtidos em laboratório é sempre vista como um objetivo a ser alcançado, e que estes últimos são, na realidade, resultados potenciais das propriedades do concreto aplicado nas estruturas.

O questionamento que surge é o da avaliação da aplicabilidade dos conceitos semiprobabilísticos de normas técnicas de dosagem, controle e projeto de estruturas de concreto já considerados para a resistência à compressão uniaxial, também para o caso do módulo de deformação.

Atualmente, a NBR 6118:2003 considera que o módulo de deformação a ser especificado em projeto e a ser controlado nas obras deve ser o módulo de deformação tangente inicial, apesar de recomendar a utilização do módulo de deformação secante no cálculo de esforços solicitantes e verificação de estados limites de serviço dos elementos estruturais da edificação. Ressalte-se que a determinação do módulo de deformação tangente inicial tem plano de carregamento com solicitação de $30 \%$ da resistência à compressão do concreto e na prática do 
meio técnico nacional, e por uma questão cultural provavelmente vinculada ao próprio hábito do cálculo estrutural, ainda prevalece a especificação e o controle do módulo de deformação secante, geralmente a $40 \%$ da resistência do concreto.

Do ponto de vista do controle de qualidade das obras, uma vez ensaiado o concreto - muitas vezes amostrado de um lote que corresponde a uma única betonada escolhida aleatoriamente mas sem respeitar um critério formal de formação de lote com base estatística - o resultado médio obtido é comparado diretamente com o valor especificado, não sendo considerado qualquer coeficiente matemático associado à distribuição estatística inerente aos experimentos laboratoriais. Exige-se então, implicitamente, que este coeficiente matemático associado à distribuição estatística do ensaio tenha sido considerado anteriormente, durante a dosagem. Ocorre que não há item normalizado sobre a consideração estatística durante a dosagem para atendimento de especificação de módulo de deformação $\left(E_{c}\right)$, como há para a resistência à compressão $\left(f_{c k}\right)$. Desconsidera-se que o termo ' $f_{c k}$ ' traz consigo o resultado de uma distribuição estatística experimental e 'E$E_{c}$ ' não traz, como se representasse um valor absoluto.

Além disso, não há na norma de projetos estruturais, objetivamente, coeficientes de segurança vinculados à diferença entre o resultado do concreto da amostra sob ensaio laboratorial de módulo de deformação - dito potencial - e aquele do concreto aplicado no elemento estrutural. Sabe-se que muitos acabam considerando, erroneamente, a especificação do módulo de deformação secante em detrimento da especificação do módulo de deformação tangente inicial como uma forma de aplicar em projeto um coeficiente de segurança sobre esta propriedade. Ainda que a diferença normativa possa estar superestimada — de acordo com a NBR 6118:2003, considera-se $E_{c s}=0,85 . E_{c i}$ - em teoria, não se está obedecendo à lógica do conceito semiprobabilístico que orienta a mesma norma.

O conceito semiprobabilístico visa ser uma orientação que basicamente introduz coeficientes multiplicadores dos esforços solicitantes - em geral de majoração - e dos esforços resistentes - em geral de minoração - de acordo com critérios estatísticos de cálculo estrutural e tecnologia dos materiais.

Como não há em norma esses coeficientes para o caso do módulo de deformação na dosagem, no controle tecnológico ou no projeto estrutural, pode-se supor que uma parte da incerteza ou da variabilidade que se atribui aos resultados 
dos ensaios pode estar vinculada ao inadequado uso dos resultados, e não aos resultados em si.

Assim sendo, orientou-se a discussão da aplicabilidade do conceito semiprobabilístico aos resultados de módulo de deformação sob três aspectos:

1ํ) Implicação indicativa da desconsideração do conceito semiprobabilístico sobre a deformação das estruturas, considerando um exemplo simples de verificação do estado limite de serviço para deformações excessivas (ELSDEF) no projeto de um elemento de concreto armado sob esforços de flexão simples;

$2^{\circ}$ ) Implicações da desconsideração do conceito semiprobabilístico sobre a tecnologia do concreto, realizando um diagrama de dosagem que contemplasse a propriedade módulo de deformação do concreto;

3ํ) Implicações da desconsideração do conceito semiprobabilístico sobre o controle de qualidade realizado nas obras, principalmente quanto à formação dos lotes.

Como a sistemática dos cálculos de todas essas implicações envolve formulações normalizadas, optou-se por não repeti-las de forma alongada. Nesta perspectiva, apenas as mais importantes foram detalhadas ao longo da própria análise dos resultados, sem prejuízo da discussão ou do entendimento da obtenção desses resultados.

\subsection{Programa experimental}

O programa experimental foi dividido em duas etapas: a primeira contemplou o estudo dos resultados das determinações do módulo estático de deformação do concreto para avaliação da acurácia do método sob instrumentações particulares para medida da deformação e da acurácia do método como um todo (sob todas as instrumentações); a segunda etapa contemplou o estudo dos resultados dos ensaios de determinação do módulo estático de deformação do concreto sob uma instrumentação particular aleatória para a construção do Diagrama de Dosagem a ser utilizado na avaliação das implicações da desconsideração do conceito 
semiprobabilístico sobre a produção deste material. Todos os ensaios foram planejados para a execução obedecendo à norma brasileira NBR 8522:2003.

\subsubsection{Primeira etapa}

Realizou-se a amostragem de dois traços de concreto de relações água/cimento iguais a 0,40 e $0,70 \mathrm{~kg} / \mathrm{kg}$. De cada traço foi realizada amostragem em três datas distintas ( 3 betonadas) com moldagem de 50 corpos-de-prova de dimensões $100 \times 200 \mathrm{~mm}$ em cada data. A execução desta amostragem se deu no prazo de 15 dias. Todos os corpos-de-prova foram curados em câmara úmida por 28 dias, quando receberam capeamento com pasta de enxofre. Todos os ensaios foram realizados à idade de 29 ou 30 dias.

A amostra de cada betonada foi dividida em 5 séries de 10 corpos-de-prova. A primeira série foi destinada aos ensaios prévios de resistência à compressão. As demais foram destinadas ao ensaio de determinação do módulo de deformação sendo que cada uma utilizaria o procedimento de instrumentação referente a cada um dos sistemas de medida selecionados para a pesquisa: strain gages colados de superfície (SG), clip gages (CG), compressômetro com 1 relógio comparador acoplado (1R) e compressômetro com 2 relógios comparadores acoplados (2R). $\mathrm{O}$ plano de divisão das amostras segue na Fig. 4.3.1.1.
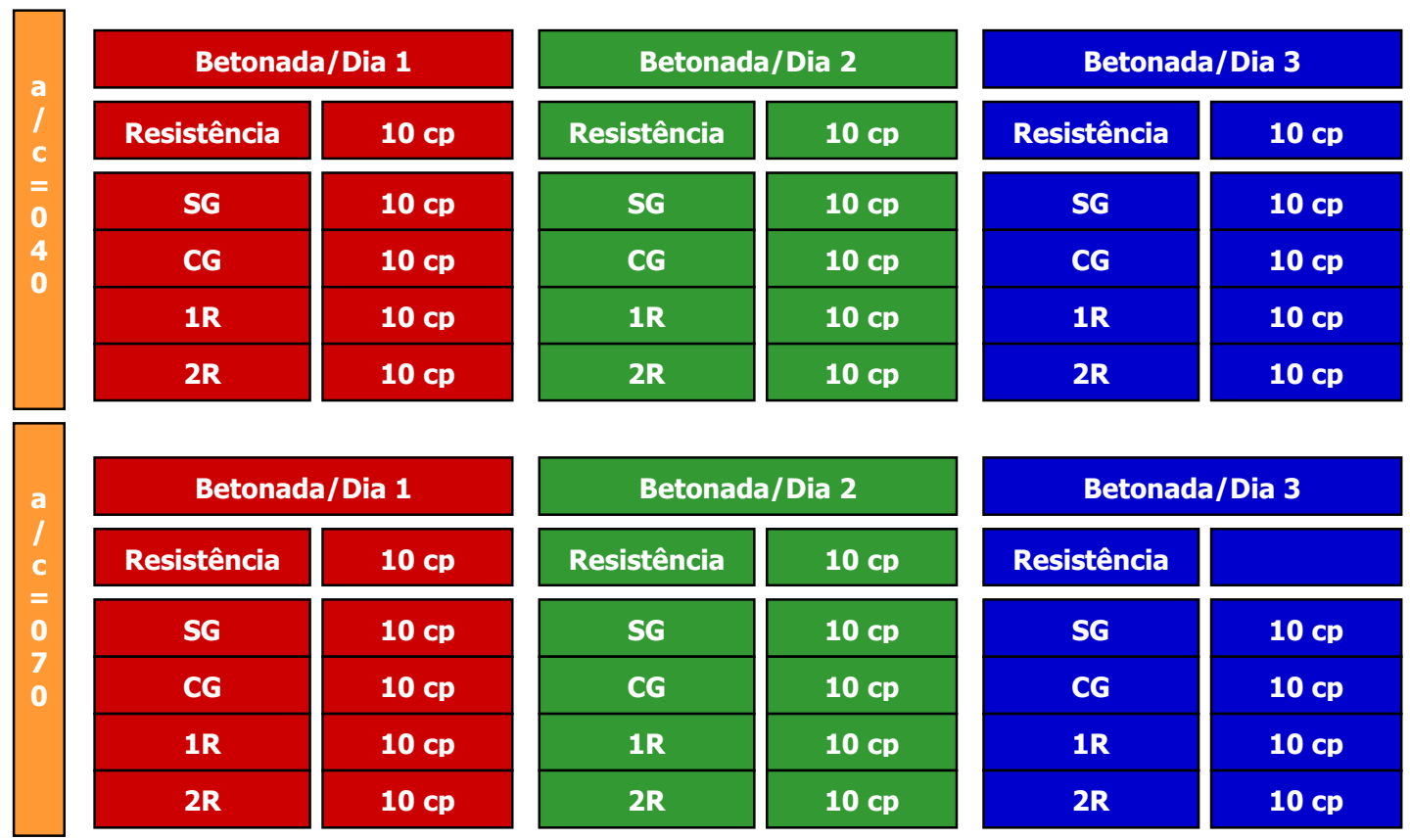

Figura 4.3.1.1 - Divisão de amostras da primeira etapa do programa experimental 
Foram realizadas 480 determinações de módulo de deformação, sendo 240 com plano de carregamento secante e $240 \mathrm{com}$ plano de carregamento tangente inicial, todas a $30 \%$ da tensão de ruptura do concreto, de acordo com o diagrama tensão-tempo constante da Fig. 4.3.1.2 - cada corpo-de-prova foi submetido inicialmente ao plano de carregamento secante para, em seguida, ter seu plano de carregamento complementado com mais três ciclos, ao final dos quais atingiu-se a configuração do plano tangente inicial; os patamares de estabilização temporal foram de 60 a 90 segundos. Ressalta-se que, por uma questão de economia de tempo para viabilização dos ensaios dentro das datas previstas, a maior parte dos corpos-de-prova não foi levada à ruptura após a conclusão dos ciclos de carregamento. Além disso, observe-se que a tensão básica dos planos de carregamento não foi de 0,5 MPa mas de 1,0 MPa, a fim de minorar a influência da perturbação do plano nas baixas tensões, dada a capacidade máxima da máquina de ensaio, no caso de 200 tf.

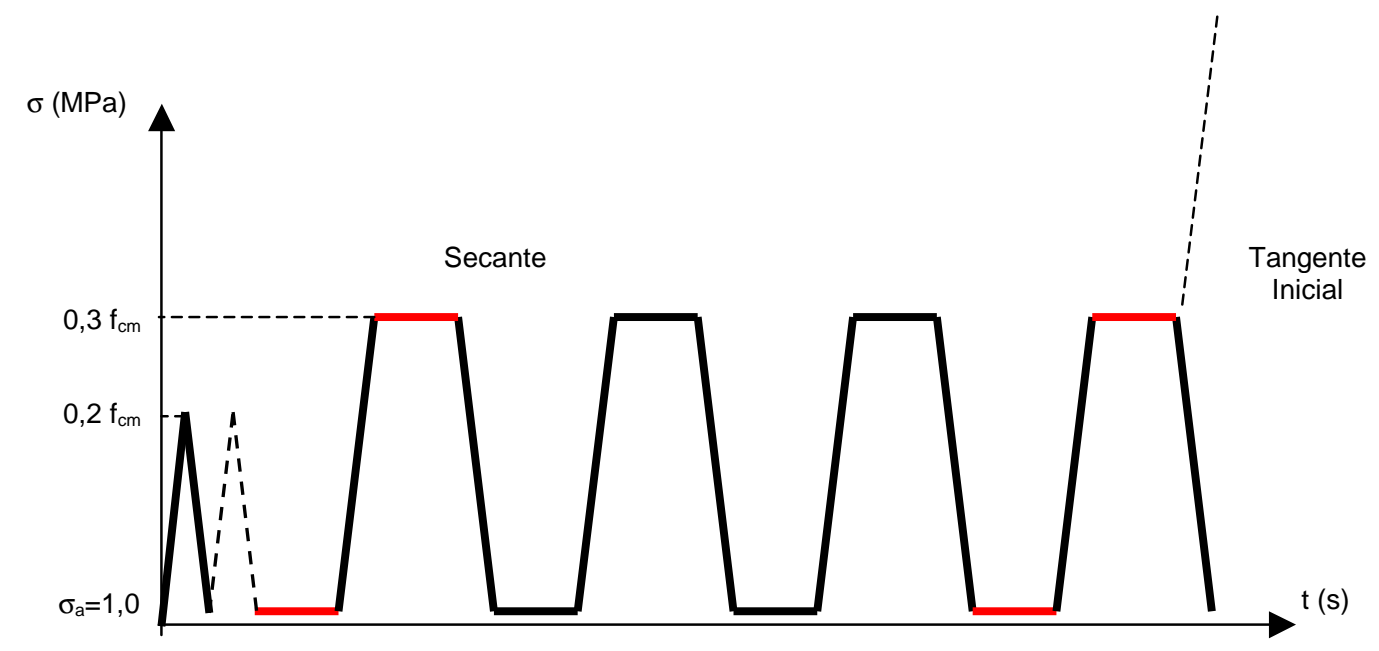

Figura 4.3.1.2 - Planos de carregamento do programa experimental

Note-se, por fim, que a compatibilização das bases de medida da instrumentação foi restringida a um máximo de duas tentativas, sendo apenas uma obrigatória. Isto porque não se quis impor diferenças de plano de carregamento entre os medidores, já que a "reinstrumentação" com strain gages é muito mais complexa que aquelas com os outros medidores.

Resumidamente, os procedimentos de instrumentação envolveram as seguintes atividades: 
a) Strain gages colados (Fabricante: Kyowa Electronic Instruments Ltda., Japão) associados com sistema de condicionamento e amplificação de sinais ADS (Fabricante: Lynx Tecnologia Eletrônica, Brasil): Duas áreas longitudinais dos corpos-de-prova, diametralmente opostas, de aproximadamente $50 \times 150 \mathrm{~mm}^{2}$, foram lixadas superficialmente na direção de suas diagonais (lixa massa grão 120) e limpas com malha de tecido tipo gaze embebida em álcool isopropílico, a fim de eliminar completamente os resíduos sólidos do lixamento. Em seguida foram traçados os eixos horizontais e verticais de indicação da área de colagem com auxílio de uma mesa de marcação e esquadro. A aderência strain gages-corpo-deprova pôde então ser feita com adesivo químico base-cianocrilato (Loctite 451). Os strain gages foram ligados ao ADS através de cabos curtos para minimizar a perda de carga elétrica. O software de decodificação do sinal foi o AqDados 7.02 do mesmo fabricante do ADS. Nas Fig. 4.3.1.3.a-b estão algumas fotos referentes a esta instrumentação. A sensibilidade conseguida com o sistema foi prejudicada pelo ruído na aquisição do sinal elétrico, da ordem de $2 \times 10^{-3} \mathrm{~mm}$; a solução encontrada foi a tomada das deformações considerando a média de 300 leituras realizadas no período dos 10 segundos finais dos patamares de estabilização temporal dada a freqüência de aquisição de sinais de 30 Hertz.

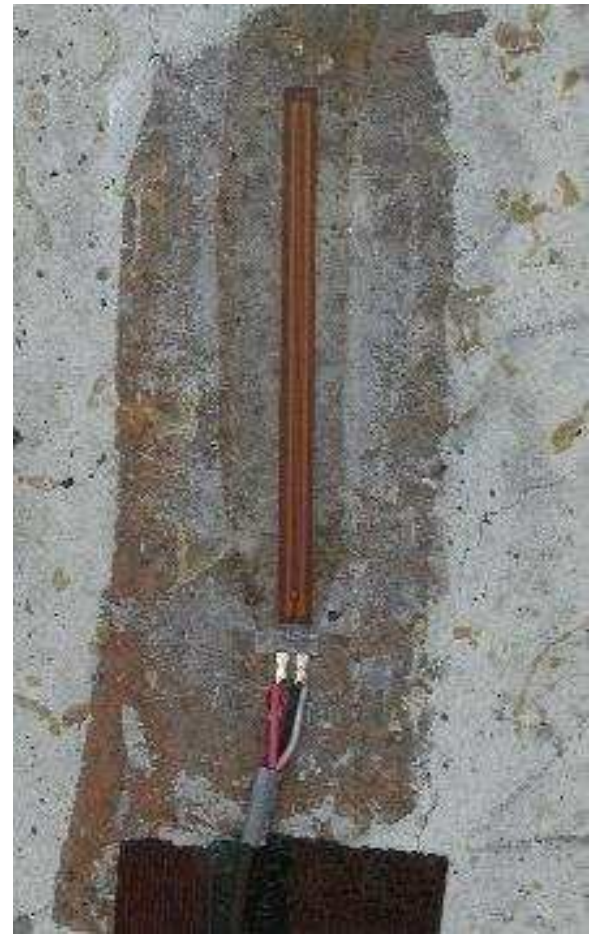

(a)
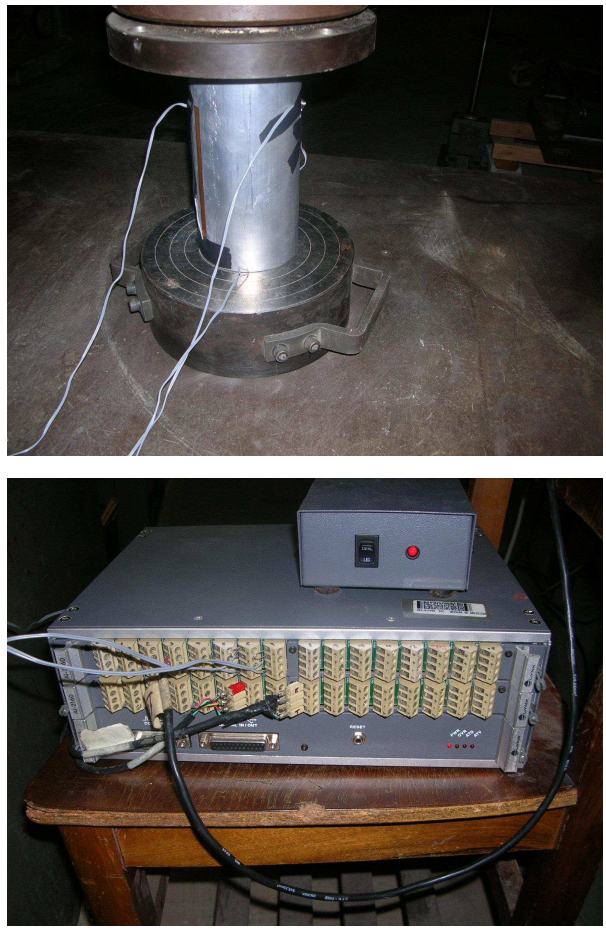

(b)

Figura 4.3.1.3 - Instrumentação de SG: (a) Detalhe da colagem; (b) Detalhe do sistema 
b) Clip gages (Fabricante: Dinateste Indústria e Comércio Ltda., Brasil): Inicialmente foram traçados os eixos horizontais e verticais de indicação dos pontos de montagem dos medidores. A instalação destes é suportada por dois anéis de borracha (o-rings) mantidos até o término do ensaio. A leitura da deformação é realizada um decodificador de sinal com mostrador digital do mesmo fabricante. $O$ decodificador realiza também o condicionamento e a amplificação do sinal elétrico; neste caso, a sensibilidade direta foi de $1 \times 10^{-3} \mathrm{~mm}$. Na Fig. 4.3.1.4 estão algumas fotos referentes a este sistema de instrumentação.
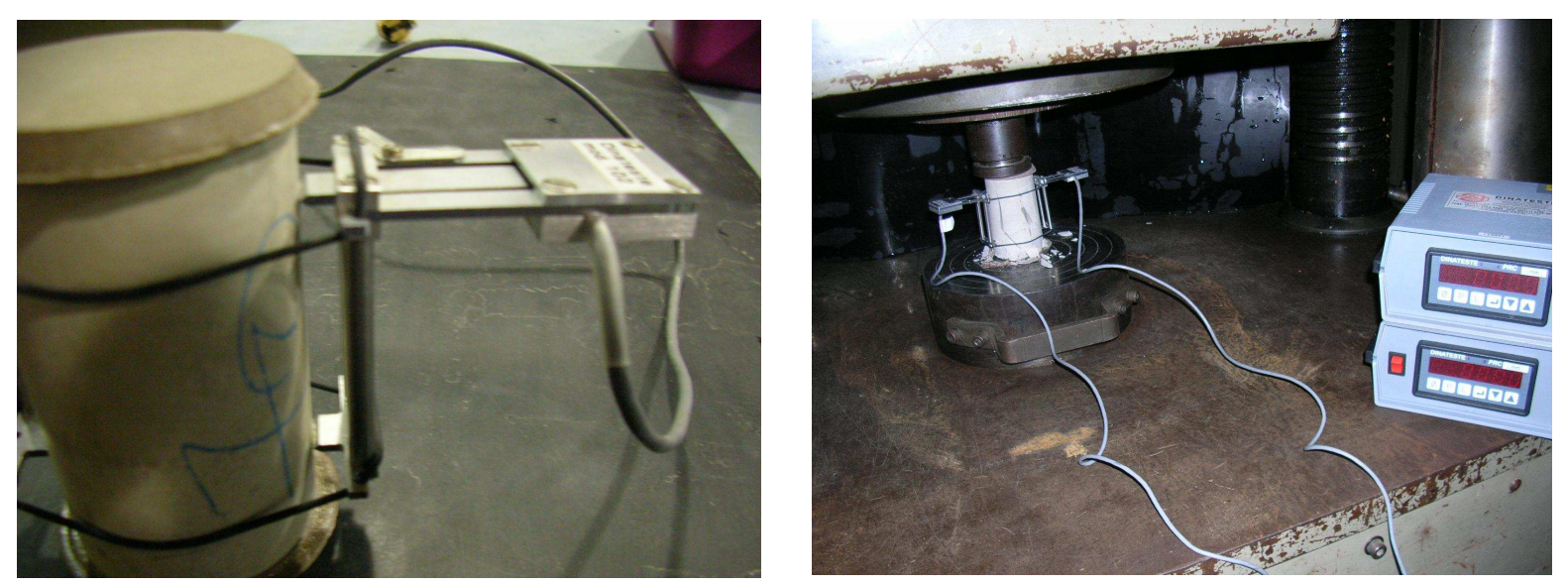

Figura 4.3.1.4 - Instrumentação de CG: Detalhe do sistema de medida

c) Compressômetro com 1 e 2 relógios (Fabricante do compressômetro: Dinateste Indústria e Comércio Ltda., Brasil; fabricante dos relógios comparadores: Mitutoyo Sul Americana Ltda., Brasil): Inicialmente foram traçados os eixos horizontais e verticais de indicação da área de montagem dos medidores. Em seguida, o compressômetro é superposto ao corpo-de-prova e a ancoragem com os parafusos dos yokes pode ser feita. Obviamente, a montagem de 1 ou 2 relógios comparadores no compressômetro é sempre realizada de forma prévia. Depois de levado à prensa, podem ser removidos do sistema os separadores metálicos utilizados para garantir o espaçamento entre os yokes. A leitura da deformação é realizada diretamente nos mostradores digitais dos relógios. Apesar da sensibilidade dos relógios comparadores atender ao valor de $1 \times 10^{-3} \mathrm{~mm}$, nada se pode afirmar a respeito do sistema compressômetro-relógio(s); de toda forma, a expectativa é de que essa sensibilidade possa ter se diminuído, embora as leituras das deformações 
continuassem sendo tomadas considerando as indicações da unidade de milésimo de milímetro mostradas no(s) relógio(s). As fotos referentes à instrumentação repetem o conteúdo já detalhado no capítulo anterior.

A velocidade de carregamento e descarregamento dos ensaios prévios de resistência à compressão e de determinação do módulo de deformação do concreto esteve na faixa de 0,2 a 0,4 MPa/s.

Os traços de concreto escolhidos são usuais do mercado de concreto dosado em central da cidade de São Paulo, principalmente em termos de insumos materiais. Os traços e materiais utilizados constam da Tab. 4.3.1.1. A caracterização físicoquímica do cimento utilizado consta da Tab. 4.3.1.2.

Tabela 4.3.1.1 - Traços e materiais utilizados na primeira etapa do programa experimental

\begin{tabular}{|c|c|c|c|c|c|c|c|c|}
\hline & \multirow{2}{*}{ Traço } & \multirow{2}{*}{$\mathbf{c}$} & Abatimento & \multicolumn{5}{|c|}{ Quantidado insumo por $\mathbf{m}^{3}$ de concreto } \\
\cline { 4 - 9 } & $(\mathbf{k g} / \mathbf{k g})$ & $(\mathbf{m m})$ & Cimento & Areia & $\begin{array}{c}\text { Pedrisco } \\
\text { misto }\end{array}$ & Brita 1 & Água & Aditivo \\
\hline $\begin{array}{c}\text { T1-040- } \\
\text { A100 }\end{array}$ & 0,40 & $100 \pm 20$ & 465 & 547 & 295 & 908 & 185 & 2,80 \\
\hline $\begin{array}{c}\text { T2-040- } \\
\text { A100 }\end{array}$ & 0,70 & $100 \pm 20$ & 263 & 706 & 380 & 845 & 185 & 1,05 \\
\hline
\end{tabular}

\begin{tabular}{|c|c|}
\hline Materiais & Procedência \\
\hline Cimento CPIII-40 RS Votoran & Fábrica Santa Helena - Votorantim/SP \\
\hline Areia de brita lavada granítica & Mineração Juruaçu - São Paulo/SP \\
\hline Pedrisco misto (Brita 0 e pó calcário) & Min. Araçariguama - Araçariguarma/SP \\
\hline Brita 1 calcária & Min. Araçariguama - Araçariguarma/SP \\
\hline Água & Rede pública de abastecimento \\
\hline Aditivo plastificante Mira 95 & Grace do Brasil - Sorocaba/SP \\
\hline
\end{tabular}

Tabela 4.3.1.2 - Caracterização laboratorial do cimento utilizado (CPIII-40 RS)

\begin{tabular}{|c|c|}
\hline Determinação & Resultado \\
\hline Água para pasta de consistência normal (\%) & 30,7 \\
\hline Início de pega (h:min) & $03: 25$ \\
\hline Fim de pega (h:min) & $\mathbf{0 4 : 2 5}$ \\
\hline Resistência à compressão aos 3 dias (MPa) & 25,9 \\
\hline Resistência à compressão aos 7 dias (MPa) & 37,7 \\
\hline Resistência à compressão aos 28 dias $(\mathrm{MPa})$ & 48,8 \\
\hline Finura Blaine $\left(\mathrm{cm}^{2} / \mathrm{g}\right)^{*}$ & 3900 \\
\hline Finura na peneira \#200 $(\%)^{*}$ & $\mathbf{0 , 2}$ \\
\hline Perda ao fogo $(\%)^{*}$ & $\mathbf{1 , 7 6}$ \\
\hline
\end{tabular}


Tabela 4.3.1.2 (continuação) - Caracterização laboratorial do cimento utilizado (CPIII-40 RS)

\begin{tabular}{|c|c|}
\hline Teor de $\mathrm{MgO}(\%)^{*}$ & $\mathbf{5 , 8 9}$ \\
\hline Teor de $\mathrm{SO}_{3}(\%)^{*}$ & $\mathbf{1 , 9 4}$ \\
\hline Resíduo insolúvel (\%) & $\mathbf{0 , 5 6}$ \\
\hline
\end{tabular}

* Obs.: Dados fornecidos pelo fabricante.

A caracterização física dos agregados utilizados consta da Tab. 4.3.1.3.

Tabela 4.3.1.3 - Caracterização laboratorial dos agregados utilizados

\begin{tabular}{|c|c|c|c|}
\hline $\begin{array}{c}\text { Abertura da } \\
\text { peneira }\end{array}$ & $\begin{array}{c}\text { Areia de brita lavada } \\
\text { granítica }\end{array}$ & $\begin{array}{l}\text { Pedrisco misto } \\
\text { (B0 e pó calcário) }\end{array}$ & $\begin{array}{c}\text { Brita } 1 \\
\text { calcária }\end{array}$ \\
\hline$(\mathrm{mm})$ & \% Retida Acumulada & $\%$ Retida Acumulada & $\%$ Retida Acumulada \\
\hline 19 & & & 0,6 \\
\hline $12,5^{\star}$ & & & 53,6 \\
\hline 9,5 & & 1,5 & 79,5 \\
\hline $6,3^{*}$ & & 14,6 & 95,7 \\
\hline 4,75 & 0,4 & 26 & 96,5 \\
\hline 2,36 & 10,4 & 45 & 96,8 \\
\hline 1,18 & 32,2 & 61,4 & 97,5 \\
\hline 0,6 & 52,8 & 70,7 & 97,8 \\
\hline 0,3 & 71,5 & 81,1 & 97,8 \\
\hline 0,15 & 93,1 & 91,7 & 98,4 \\
\hline Fundo & 100,0 & 100,0 & 100,0 \\
\hline Diâmetro máximo (mm) & 4,75 & 9,5 & 19 \\
\hline Módulo de finura & 2,6 & 3,77 & 6,65 \\
\hline Material pulverulento (\%) & 2,3 & 12,9 & 1,9 \\
\hline Massa específica $\left(\mathrm{g} / \mathrm{cm}^{3}\right)$ & 2,65 & 2,72 & 2,74 \\
\hline
\end{tabular}

* Obs.: Peneiras que não fazem parte da série normal.

\subsubsection{Segunda etapa}

Realizou-se a amostragem de seis traços de concreto, sendo um de cada relação água/cimento escolhida $(0,42,0,50$ e $0,58 \mathrm{~kg} / \mathrm{kg})$ e consistência escolhida (plástica $=100 \pm 20 \mathrm{~mm}$, ou fluida $=180 \pm 30 \mathrm{~mm}$ ). As opções se basearam nas expectativas de maior demanda do mercado de fornecimento de concreto dosado em central da cidade de São Paulo. De cada traço foi realizada amostragem de uma única betonada com moldagem padrão de acordo com a norma NBR 8522:2003 de 
5 corpos-de-prova de dimensões $100 \times 200 \mathrm{~mm}$ para ensaio prévio de resistência de dois corpos-de-prova e ensaio de módulo propriamente dito dos outros três corposde-prova. Todos os corpos-de-prova receberam a mesma cura e preparação que os da etapa anterior.

Os ensaios de determinação do módulo de deformação foram realizados sob apenas uma instrumentação (CG) e seguiram o plano de carregamento secante e a velocidade de carregamento conforme a primeira etapa.

Os traços ensaiados constam da Tab. 4.3.2.1. Dos insumos utilizados durante a primeira etapa, apenas o cimento foi proveniente de lote distinto e acrescentou-se em alguns traços a Brita 0 granítica. Os resultados dos ensaios de caracterização da nova amostra de cimento constam da Tab. 4.3.2.2. A caracterização física da Brita 0 utilizada consta da Tab. 4.3.2.3.

Tabela 4.3.2.1 - Traços e materiais utilizados na segunda parte do programa experimental

\begin{tabular}{|c|c|c|c|c|c|c|c|c|c|}
\hline \multirow{2}{*}{ Traço } & \multirow{2}{*}{$\begin{array}{c}\mathrm{a} / \mathrm{c} \\
(\mathrm{kg} / \mathrm{kg})\end{array}$} & \multirow{2}{*}{$\begin{array}{l}\text { Abatimento } \\
\text { (mm) }\end{array}$} & \multicolumn{7}{|c|}{ Quantidado insumo por $\mathrm{m}^{3}$ de concreto } \\
\hline & & & Cimento & Areia & Ped.misto & Brita 0 & Brita 1 & Água & Aditivo \\
\hline $\begin{array}{c}\text { T3-042- } \\
\text { A100 }\end{array}$ & 0,42 & $100 \pm 20$ & 462 & 543 & 293 & 0 & 902 & 185 & 2,77 \\
\hline $\begin{array}{c}\text { T4-050- } \\
\text { A100 }\end{array}$ & 0,50 & $100 \pm 20$ & 370 & 598 & 322 & 0 & 896 & 185 & 2,22 \\
\hline $\begin{array}{c}\text { T5-058- } \\
\text { A100 }\end{array}$ & 0,58 & $100 \pm 20$ & 308 & 634 & 342 & 0 & 893 & 185 & 1,85 \\
\hline $\begin{array}{c}\text { T6-042- } \\
\text { A180 }\end{array}$ & 0,42 & $180 \pm 30$ & 526 & 520 & 281 & 478 & 319 & 210 & 3,16 \\
\hline $\begin{array}{c}\text { T7-050- } \\
\text { A180 }\end{array}$ & 0,50 & $180 \pm 30$ & 420 & 585 & 315 & 475 & 317 & 210 & 2,52 \\
\hline $\begin{array}{c}\text { T8-058- } \\
\text { A180 }\end{array}$ & 0,58 & $180 \pm 30$ & 350 & 626 & 337 & 473 & 315 & 210 & 2,10 \\
\hline
\end{tabular}

\begin{tabular}{|c|c|}
\hline Materiais & Procedência \\
\hline Cimento CPIII-40 RS Votoran & Fábrica Santa Helena - Votorantim/SP \\
\hline Areia de brita lavada granítica & Mineração Juruaçu - São Paulo/SP \\
\hline Pedrisco misto (Brita 0 e pó calcário) & Min. Araçariguama - Araçariguarma/SP \\
\hline Brita 0 granítica & Mineração Juruaçu - São Paulo/SP \\
\hline Brita 1 calcária & Min. Araçariguama - Araçariguarma/SP \\
\hline Água & Rede pública de abastecimento \\
\hline Aditivo plastificante Mira 95 & Grace do Brasil - Sorocaba/SP \\
\hline
\end{tabular}


Tabela 4.3.2.2 - Caracterização laboratorial do cimento utilizado (CPIII-40 RS) $-2^{\mathrm{a}}$ parte

\begin{tabular}{|c|c|}
\hline Determinação & Resultado \\
\hline Água para pasta de consistência normal (\%) & 30,7 \\
\hline Início de pega (h:min) & $\mathbf{0 3 : 2 5}$ \\
\hline Fim de pega (h:min) & $\mathbf{0 4 : 3 5}$ \\
\hline Resistência à compressão aos 3 dias (MPa) & $\mathbf{2 6 , 0}$ \\
\hline Resistência à compressão aos 7 dias (MPa) & 36,1 \\
\hline Resistência à compressão aos 28 dias (MPa) & 49,2 \\
\hline Finura Blaine (cm $\left.{ }^{2} / \mathrm{g}\right)^{*}$ & 3900 \\
\hline Finura na peneira \#200 (\%) & $\mathbf{0 , 2}$ \\
\hline Perda ao fogo (\%) & $\mathbf{1 , 5 6}$ \\
\hline Teor de ${\mathrm{MgO}(\%)^{*}}^{*}$ & $\mathbf{6 , 1 5}$ \\
\hline Teor de $\mathrm{SO}_{3}(\%)^{*}$ & $\mathbf{1 , 8 8}$ \\
\hline Resíduo insolúvel $(\%)^{*}$ & $\mathbf{0 , 8 3}$ \\
\hline
\end{tabular}

* Obs.: Dados fornecidos pelo fabricante.

Tabela 4.3.2.3 - Caracterização laboratorial da Brita 0 utilizada

\begin{tabular}{|c|c|}
\hline $\begin{array}{c}\text { Abertura da } \\
\text { peneira } \\
(\mathbf{m m})\end{array}$ & $\begin{array}{c}\text { Brita 0 } \\
\text { granítica }\end{array}$ \\
\hline $\mathbf{1 9}$ & \% Retida Acumulada \\
\hline $\mathbf{1 2 , 5 ^ { \star }}$ & \\
\hline $\mathbf{9 , 5}$ & 1,0 \\
\hline $\mathbf{6 , 3 ^ { * }}$ & 23,1 \\
\hline $\mathbf{4 , 7 5}$ & 51,4 \\
\hline $\mathbf{2 , 3 6}$ & 89,9 \\
\hline $\mathbf{1 , 1 8}$ & 97,2 \\
\hline $\mathbf{0 , 6}$ & 98,2 \\
\hline $\mathbf{0 , 3}$ & 98,8 \\
\hline $\mathbf{0 , 1 5}$ & 99,3 \\
\hline Fundo & 100,0 \\
\hline Miâmetro máximo (mm) & 9,5 \\
\hline Módulo de finura & 5,36 \\
\hline Material pulverulento (\%) & 0,5 \\
\hline Massa específica (g/cm $\left.{ }^{\mathbf{3}}\right)$ & 2,66 \\
\hline
\end{tabular}

* Obs.: Peneiras que não fazem parte da série normal.

\subsection{Fluxogramas das atividades da pesquisa}

Cabe, neste momento, apresentar um resumo da metodologia da pesquisa com o auxílio de dois fluxogramas de atividades (Fig 4.4.1 e Fig 4.4.2). 


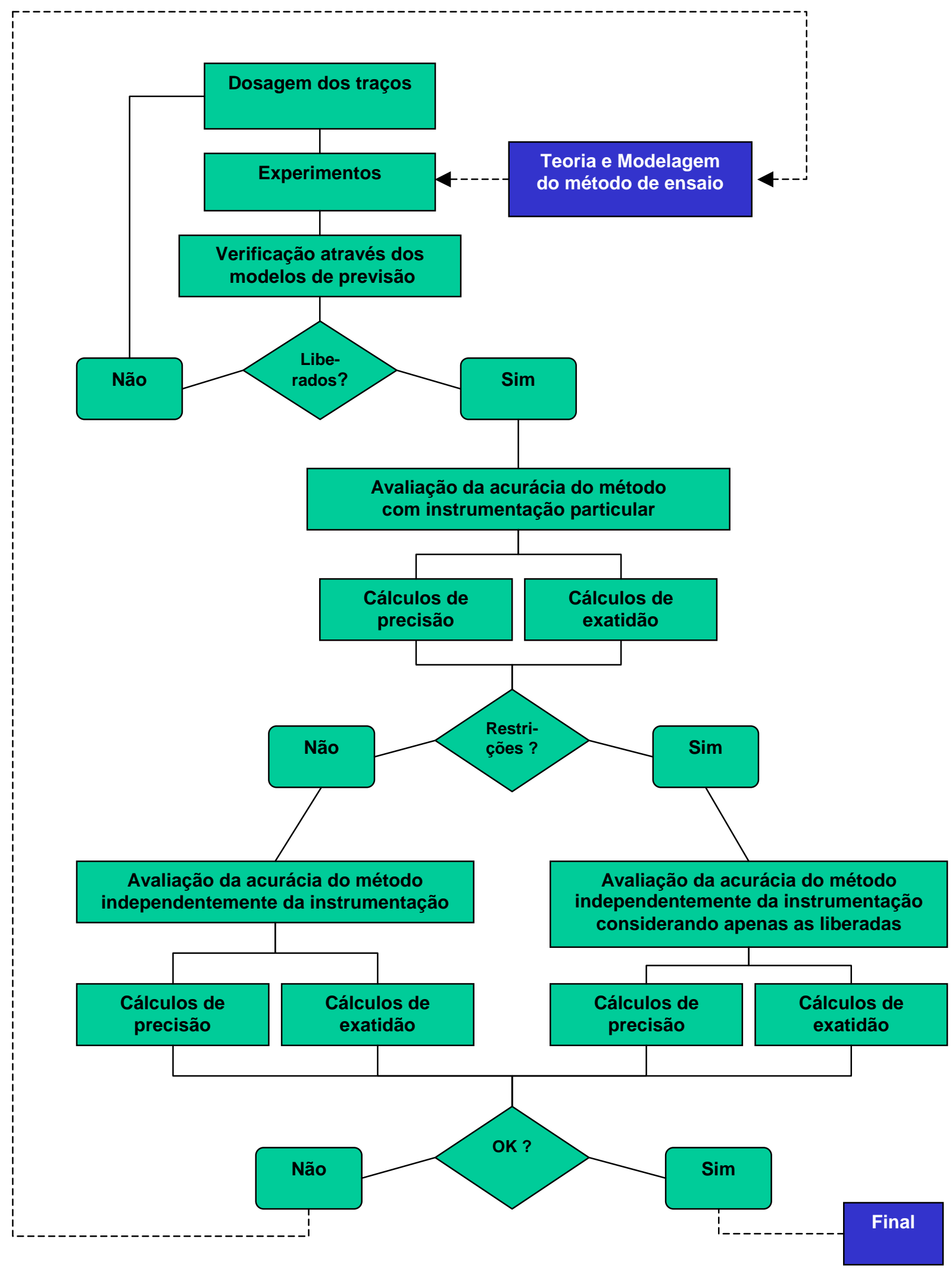

linha contínua: atividades realizadas

linha descontínua: atividades possíveis mas não realizadas

Figura 4.4.1 - Fluxograma das atividades da avaliação de acurácia do método de ensaio 


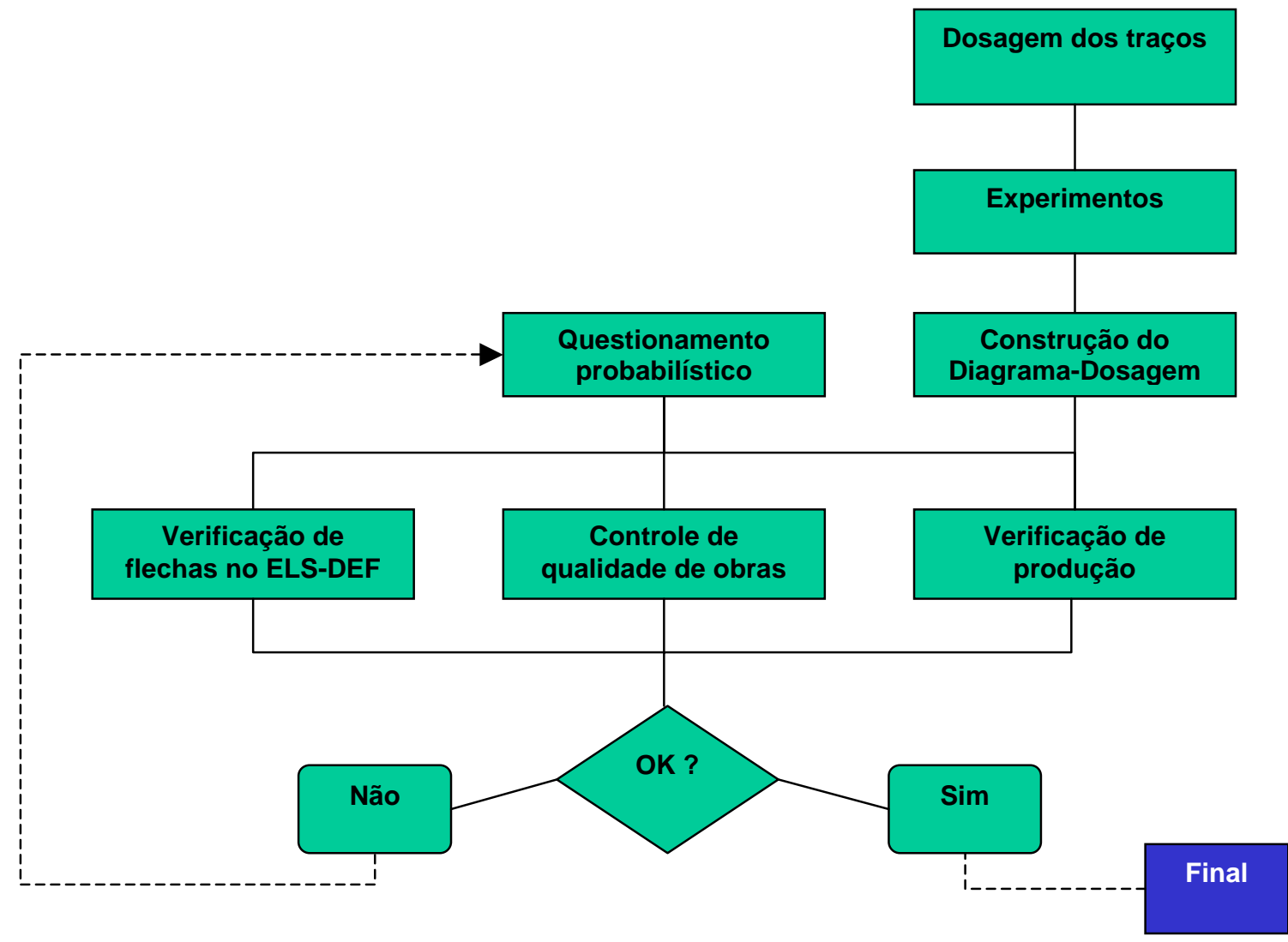

linha contínua: atividades realizadas

linha descontínua: atividades possíveis mas não realizadas

Figura 4.4.2 - Fluxograma das atividades de discussão da aplicabilidade do conceito semiprobabilístico ao módulo de deformação

As diferenças entre as atividades realizadas e as não realizadas é que estas últimas não foram previstas na pesquisa por exigirem conclusões mais universalizadas que as obtidas sob este programa experimental. Porém, não se deixa de apresentar as tendências observadas.

A seguir são, enfim, apresentados os resultados dos ensaios de determinação do módulo estático de deformação dos concretos dosados no programa experimental e a análise realizada de acordo com estas rotinas descritas. 


\section{APRESENTAÇÃO E ANÁLISE DOS RESULTADOS}

Seguindo os fluxogramas de análise do programa experimental, primeiramente é apresentado todo o conteúdo referente à avaliação da acurácia do método de ensaio para, em seguida, ser apresentada a discussão da aplicabilidade do conceito semiprobabilístico normativo quanto à variabilidade observada nos resultados experimentais da determinação do módulo de deformação do concreto.

\subsection{Avaliação da acurácia do método de ensaio}

Os resultados dos ensaios de módulo de deformação da primeira parte do programa experimental são apresentados nas Tab. 5.1.1 e 5.1.2 e detalhados no Apêndice A, Tab. A.1 a A.3.

Tabela 5.1.1 - Resultados de módulo de deformação (GPa): a/c 0,40

Betonada 1 SECANTE TANGENTE

Strain gages
\begin{tabular}{|c|c|c|}
\hline $\mathbf{1}$ & 35,4 & 35,8 \\
\hline $\mathbf{2}$ & 36,2 & 38,5 \\
\hline $\mathbf{3}$ & 34,5 & 34,7 \\
\hline $\mathbf{4}$ & 34,3 & 36,4 \\
\hline $\mathbf{5}$ & 35,5 & 35,7 \\
\hline $\mathbf{6}$ & 35,9 & 36,5 \\
\hline $\mathbf{7}$ & 37,6 & 39,9 \\
\hline $\mathbf{8}$ & 33,2 & 34,0 \\
\hline $\mathbf{9}$ & 36,2 & 36,6 \\
\hline $\mathbf{1 0}$ & 34,3 & 35,2 \\
\hline Média & $\mathbf{3 5 , 3 1}$ & $\mathbf{3 6 , 3 3}$ \\
\hline Desvio & $\mathbf{1 , 2 6}$ & $\mathbf{1 , 7 5}$ \\
\hline Ecs/Eci & $\mathbf{0 , 9 7}$ & \\
\hline
\end{tabular}

Clip gages
\begin{tabular}{|c|c|c|}
\hline $\mathbf{1}$ & 33,2 & 34,3 \\
\hline $\mathbf{2}$ & 32,6 & 33,7 \\
\hline $\mathbf{3}$ & 34,3 & 35,0 \\
\hline $\mathbf{4}$ & 34,7 & 35,4 \\
\hline $\mathbf{5}$ & 33,2 & 34,3 \\
\hline $\mathbf{6}$ & 33,4 & 34,3 \\
\hline $\mathbf{7}$ & 35,1 & 36,2 \\
\hline $\mathbf{8}$ & 34,5 & 35,4 \\
\hline $\mathbf{9}$ & 34,4 & 35,2 \\
\hline $\mathbf{1 0}$ & 33,9 & 35,0 \\
\hline Média & $\mathbf{3 3 , 9 3}$ & $\mathbf{3 4 , 8 8}$ \\
\hline Desvio & $\mathbf{0 , 8 0}$ & $\mathbf{0 , 7 3}$ \\
\hline Ecs/Eci & $\mathbf{0 , 9 7}$ & \\
\hline
\end{tabular}

Betonada 2 SECANTE TANGENTE

\begin{tabular}{|c|c|}
\hline 40,1 & 35,3 \\
\hline 34,1 & 35,3 \\
\hline 36,1 & 36,2 \\
\hline 37,6 & 39,7 \\
\hline 40,3 & 40,7 \\
\hline 32,9 & 35,2 \\
\hline 36,3 & 36,8 \\
\hline 32,1 & 32,5 \\
\hline 35,8 & 37,5 \\
\hline 36,5 & 38,3 \\
\hline $\mathbf{3 6 , 1 8}$ & $\mathbf{3 6 , 7 5}$ \\
\hline $\mathbf{2 , 7 2}$ & $\mathbf{2 , 4 1}$ \\
\hline $\mathbf{0 , 9 8}$ & \\
\hline
\end{tabular}

\begin{tabular}{|c|c|}
\hline 35,8 & 37,7 \\
\hline 36,8 & 38,1 \\
\hline 36,8 & 36,6 \\
\hline 36,0 & 36,8 \\
\hline 34,7 & 36,6 \\
\hline 36,0 & 37,1 \\
\hline 37,0 & 38,3 \\
\hline 36,8 & 37,8 \\
\hline 34,7 & 35,8 \\
\hline 34,7 & 35,9 \\
\hline $\mathbf{3 5 , 9 3}$ & $\mathbf{3 7 , 0 7}$ \\
\hline $\mathbf{0 , 9 4}$ & $\mathbf{0 , 8 8}$ \\
\hline $\mathbf{0 , 9 7}$ & \\
\hline
\end{tabular}

Betonada 3 SECANTE TANGENTE

\begin{tabular}{|c|c|}
\hline 35,8 & 36,5 \\
\hline 36,1 & 37,5 \\
\hline 35,7 & 37,0 \\
\hline 31,0 & 32,1 \\
\hline 35,9 & 36,9 \\
\hline 35,8 & 37,0 \\
\hline 35,1 & 36,1 \\
\hline 34,7 & 36,1 \\
\hline 33,8 & 35,0 \\
\hline 35,7 & 36,5 \\
\hline $\mathbf{3 4 , 9 6}$ & $\mathbf{3 6 , 0 7}$ \\
\hline $\mathbf{1 , 5 6}$ & $\mathbf{1 , 5 5}$ \\
\hline $\mathbf{0 , 9 7}$ & \\
\hline
\end{tabular}

\begin{tabular}{|c|c|}
\hline 30,1 & 30,7 \\
\hline 36,2 & 37,0 \\
\hline 37,6 & 38,6 \\
\hline 35,5 & 36,4 \\
\hline 35,3 & 36,4 \\
\hline 35,3 & 36,4 \\
\hline 35,0 & 36,2 \\
\hline 36,7 & 37,5 \\
\hline 36,6 & 37,5 \\
\hline 34,9 & 35,8 \\
\hline $\mathbf{3 5 , 3 2}$ & $\mathbf{3 6 , 8 7}$ \\
\hline $\mathbf{2 , 0 3}$ & $\mathbf{0 , 8 7}$ \\
\hline $\mathbf{0 , 9 6}$ & \\
\hline
\end{tabular}


Tabela 5.1.1 (continuação) - Resultados de módulo de deformação (GPa): a/c 0,40

\begin{tabular}{|c|c|c|}
\hline \multirow{2}{*}{1 relógio } & \multicolumn{2}{|c|}{ Betonada 1} \\
\hline & SECANTE & TANGENTE \\
\hline 1 & 36,6 & 39,5 \\
\hline 2 & 37,2 & 38,2 \\
\hline 3 & 35,9 & 37,2 \\
\hline 4 & 33,7 & 35,5 \\
\hline 5 & 33,7 & 35,7 \\
\hline 6 & 32,7 & 35,3 \\
\hline 7 & 34,8 & 35,7 \\
\hline 8 & 36,8 & 37,2 \\
\hline 9 & 37,5 & 39,0 \\
\hline 10 & 34,2 & 35,5 \\
\hline Média & 35,31 & 36,88 \\
\hline Desvio & 1,70 & 1,58 \\
\hline Ecs/Eci & 0,96 & \\
\hline
\end{tabular}

Betonada 2 SECANTE TANGENTE

\begin{tabular}{|c|c|}
\hline 40,7 & 41,9 \\
\hline 36,8 & 38,5 \\
\hline 34,5 & 37,6 \\
\hline 33,6 & 36,4 \\
\hline 38,3 & 39,4 \\
\hline 36,0 & 37,6 \\
\hline 36,8 & 38,5 \\
\hline 38,9 & 40,4 \\
\hline 35,2 & 36,0 \\
\hline 34,8 & 36,4 \\
\hline $\mathbf{3 6 , 5 6}$ & $\mathbf{3 8 , 2 7}$ \\
\hline $\mathbf{2 , 2 1}$ & $\mathbf{1 , 8 9}$ \\
\hline $\mathbf{0 , 9 6}$ & \\
\hline
\end{tabular}

2 relógios

\begin{tabular}{|c|c|c|}
\hline $\mathbf{1}$ & 34,5 & 35,2 \\
\hline $\mathbf{2}$ & 36,6 & 37,0 \\
\hline $\mathbf{3}$ & 36,6 & 38,8 \\
\hline $\mathbf{4}$ & 39,3 & 39,8 \\
\hline $\mathbf{5}$ & 34,7 & 35,5 \\
\hline $\mathbf{6}$ & 36,3 & 37,5 \\
\hline $\mathbf{7}$ & 40,4 & 40,3 \\
\hline $\mathbf{8}$ & 35,4 & 36,6 \\
\hline $\mathbf{9}$ & 39,5 & 39,3 \\
\hline $\mathbf{1 0}$ & 36,2 & 37,5 \\
\hline Média & $\mathbf{3 6 , 9 5}$ & $\mathbf{3 7 , 7 5}$ \\
\hline Desvio & $\mathbf{2 , 0 7}$ & $\mathbf{1 , 7 6}$ \\
\hline Ecs/Eci & $\mathbf{0 , 9 8}$ & \\
\hline
\end{tabular}

\begin{tabular}{|c|c|}
\hline 36,0 & 38,6 \\
\hline 37,3 & 39,4 \\
\hline 39,7 & 41,0 \\
\hline 34,7 & 37,9 \\
\hline 35,6 & 36,8 \\
\hline 35,8 & 37,9 \\
\hline 35,2 & 36,0 \\
\hline 38,9 & 40,7 \\
\hline 37,6 & 44,7 \\
\hline 37,1 & 38,8 \\
\hline $\mathbf{3 6 , 7 9}$ & $\mathbf{3 9 , 1 8}$ \\
\hline $\mathbf{1 , 6 3}$ & $\mathbf{2 , 4 9}$ \\
\hline $\mathbf{0 , 9 4}$ & \\
\hline
\end{tabular}

Betonada 3 SECANTE TANGENTE

\begin{tabular}{|c|c|}
\hline 35,8 & 36,4 \\
\hline 37,6 & 39,3 \\
\hline 36,2 & 38,0 \\
\hline 35,1 & 36,8 \\
\hline 40,2 & 41,1 \\
\hline 37,6 & 39,0 \\
\hline 34,3 & 36,1 \\
\hline 35,3 & 36,8 \\
\hline 36,9 & 38,9 \\
\hline 37,6 & 38,4 \\
\hline $\mathbf{3 6 , 6 6}$ & $\mathbf{3 8 , 0 8}$ \\
\hline $\mathbf{1 , 7 0}$ & $\mathbf{1 , 5 7}$ \\
\hline $\mathbf{0 , 9 6}$ & \\
\hline
\end{tabular}

\begin{tabular}{|c|c|}
\hline 47,9 & 40,5 \\
\hline 37,1 & 41,0 \\
\hline 33,2 & 34,8 \\
\hline 32,7 & 34,8 \\
\hline 37,5 & 40,1 \\
\hline 36,3 & 40,1 \\
\hline 38,3 & 39,2 \\
\hline 36,3 & 37,9 \\
\hline 38,7 & 40,5 \\
\hline 35,6 & 37,5 \\
\hline $\mathbf{3 7 , 3 6}$ & $\mathbf{3 8 , 6 4}$ \\
\hline $\mathbf{4 , 1 9}$ & $\mathbf{2 , 3 2}$ \\
\hline $\mathbf{0 , 9 7}$ & \\
\hline
\end{tabular}

Tabela 5.1.2 - Resultados de módulo de deformação (GPa): a/c 0,70

Betonada 1 SECANTE TANGENTE Strain gages

\begin{tabular}{|c|c|c|}
\hline $\mathbf{1}$ & 24,9 & 25,6 \\
\hline $\mathbf{2}$ & 23,2 & 23,9 \\
\hline $\mathbf{3}$ & 23,9 & 25,0 \\
\hline $\mathbf{4}$ & 23,1 & 23,5 \\
\hline $\mathbf{5}$ & 21,5 & 23,2 \\
\hline $\mathbf{6}$ & 23,7 & 24,9 \\
\hline $\mathbf{7}$ & 20,0 & 21,3 \\
\hline $\mathbf{8}$ & 21,9 & 22,9 \\
\hline $\mathbf{9}$ & 22,2 & 23,3 \\
\hline $\mathbf{1 0}$ & 24,6 & 25,5 \\
\hline Média & $\mathbf{2 2 , 9 0}$ & $\mathbf{2 3 , 9 1}$ \\
\hline Desvio & $\mathbf{1 , 5 1}$ & $\mathbf{1 , 3 5}$ \\
\hline Ecs/Eci & $\mathbf{0 , 9 6}$ & \\
\hline
\end{tabular}

Betonada 2 SECANTE TANGENTE

\begin{tabular}{|c|c|}
\hline 25,3 & 26,7 \\
\hline 26,3 & 27,3 \\
\hline 23,4 & 23,9 \\
\hline 25,9 & 27,3 \\
\hline 21,2 & 22,3 \\
\hline 25,7 & 26,8 \\
\hline 25,1 & 26,4 \\
\hline 25,6 & 26,7 \\
\hline 25,9 & 27,1 \\
\hline 26,8 & 28,1 \\
\hline $\mathbf{2 5 , 1 2}$ & $\mathbf{2 6 , 2 6}$ \\
\hline $\mathbf{1 , 6 5}$ & $\mathbf{1 , 7 7}$ \\
\hline $\mathbf{0 , 9 6}$ & \\
\hline
\end{tabular}

Betonada 3 SECANTE TANGENTE

\begin{tabular}{|c|c|}
\hline 24,3 & 25,8 \\
\hline 24,0 & 25,5 \\
\hline 25,2 & 26,7 \\
\hline 24,0 & 25,4 \\
\hline 24,1 & 25,8 \\
\hline 25,9 & 27,3 \\
\hline 22,6 & 23,8 \\
\hline 25,9 & 27,1 \\
\hline 22,9 & 24,3 \\
\hline 29,5 & 33,4 \\
\hline $\mathbf{2 4 , 8 4}$ & $\mathbf{2 6 , 5 1}$ \\
\hline $\mathbf{1 , 9 8}$ & $\mathbf{2 , 6 7}$ \\
\hline $\mathbf{0 , 9 4}$ & \\
\hline
\end{tabular}


Tabela 5.1.2 (continuação) - Resultados de módulo de deformação (GPa): a/c 0,70

Betonada 1 SECANTE TANGENTE

Clip gages

\begin{tabular}{|c|c|c|}
\hline $\mathbf{1}$ & 23,5 & 24,2 \\
\hline $\mathbf{2}$ & 24,7 & 24,7 \\
\hline $\mathbf{3}$ & 25,8 & 25,5 \\
\hline $\mathbf{4}$ & 24,5 & 24,2 \\
\hline $\mathbf{5}$ & 23,7 & 26,1 \\
\hline $\mathbf{6}$ & 25,8 & 25,5 \\
\hline $\mathbf{7}$ & 23,1 & 24,0 \\
\hline $\mathbf{8}$ & 25,5 & 25,8 \\
\hline $\mathbf{9}$ & 23,7 & 24,7 \\
\hline $\mathbf{1 0}$ & 22,8 & 23,2 \\
\hline Média & $\mathbf{2 4 , 3 1}$ & $\mathbf{2 4 , 7 9}$ \\
\hline Desvio & $\mathbf{1 , 1 1}$ & $\mathbf{0 , 9 2}$ \\
\hline Ecs/Eci & $\mathbf{0 , 9 8}$ & \\
\hline
\end{tabular}

$\mathbf{1}$ relógio
\begin{tabular}{|c|c|c|}
\hline $\mathbf{1}$ & 23,7 & 26,4 \\
\hline $\mathbf{2}$ & 27,3 & 30,1 \\
\hline $\mathbf{3}$ & 26,6 & 28,0 \\
\hline $\mathbf{4}$ & 27,3 & 29,4 \\
\hline $\mathbf{5}$ & 23,3 & 25,5 \\
\hline $\mathbf{6}$ & 28,0 & 28,6 \\
\hline $\mathbf{7}$ & 24,5 & 27,0 \\
\hline $\mathbf{8}$ & 25,0 & 27,3 \\
\hline $\mathbf{9}$ & 27,0 & 28,0 \\
\hline $\mathbf{1 0}$ & 30,4 & 30,9 \\
\hline Média & $\mathbf{2 6 , 3 1}$ & $\mathbf{2 8 , 1 2}$ \\
\hline Desvio & $\mathbf{2 , 1 9}$ & $\mathbf{1 , 6 8}$ \\
\hline Ecs/Eci & $\mathbf{0 , 9 4}$ & \\
\hline
\end{tabular}

\section{2 relógios}

\begin{tabular}{|c|c|c|}
\hline 1 & 27,5 & 27,3 \\
\hline 2 & 32,6 & 35,6 \\
\hline 3 & 21,6 & 24,5 \\
\hline 4 & 20,6 & 23,5 \\
\hline 5 & 29,7 & 31,4 \\
\hline 6 & 25,5 & 27,3 \\
\hline 7 & 28,0 & 28,6 \\
\hline 8 & 30,1 & 31,7 \\
\hline 9 & 25,2 & 26,7 \\
\hline 10 & 26,4 & 28,0 \\
\hline Média & 26,72 & 28,46 \\
\hline Desvio & 3,72 & 3,60 \\
\hline Ecs/Eci & 0,94 & \\
\hline
\end{tabular}

Betonada 2 SECANTE TANGENTE

\begin{tabular}{|c|c|}
\hline 24,0 & 25,2 \\
\hline 25,2 & 25,8 \\
\hline 25,5 & 26,3 \\
\hline 26,0 & 26,3 \\
\hline 26,0 & 26,6 \\
\hline 25,2 & 26,3 \\
\hline 26,0 & 27,2 \\
\hline 24,5 & 25,0 \\
\hline 26,0 & 26,9 \\
\hline 24,5 & 25,7 \\
\hline $\mathbf{2 5 , 2 9}$ & $\mathbf{2 6 , 1 3}$ \\
\hline $\mathbf{0 , 7 4}$ & $\mathbf{0 , 7 1}$ \\
\hline $\mathbf{0 , 9 7}$ & \\
\hline
\end{tabular}

\begin{tabular}{|c|c|}
\hline 23,8 & 25,0 \\
\hline 30,8 & 31,2 \\
\hline 26,6 & 28,4 \\
\hline 27,4 & 29,0 \\
\hline 29,0 & 30,5 \\
\hline 25,7 & 29,0 \\
\hline 22,5 & 25,0 \\
\hline 24,0 & 26,0 \\
\hline 22,9 & 25,5 \\
\hline 28,0 & 29,0 \\
\hline $\mathbf{2 6 , 0 7}$ & $\mathbf{2 7 , 8 6}$ \\
\hline $\mathbf{2 , 7 7}$ & $\mathbf{2 , 3 0}$ \\
\hline $\mathbf{0 , 9 4}$ & \\
\hline
\end{tabular}

\begin{tabular}{|c|c|}
\hline 29,0 & 29,7 \\
\hline 28,7 & 31,2 \\
\hline 24,5 & 24,5 \\
\hline 30,5 & 30,5 \\
\hline 24,5 & 26,6 \\
\hline 29,0 & 29,7 \\
\hline 33,2 & 37,8 \\
\hline 28,4 & 31,2 \\
\hline 30,0 & 32,0 \\
\hline 34,7 & 36,7 \\
\hline $\mathbf{2 9 , 2 5}$ & $\mathbf{3 0 , 9 9}$ \\
\hline $\mathbf{3 , 2 3}$ & $\mathbf{4 , 0 1}$ \\
\hline $\mathbf{0 , 9 4}$ & \\
\hline
\end{tabular}

\begin{tabular}{|c|c|}
\hline 24,7 & 26,3 \\
\hline 24,3 & 27,8 \\
\hline 26,6 & 28,4 \\
\hline 22,5 & 24,5 \\
\hline 21,2 & 23,1 \\
\hline 27,4 & 28,7 \\
\hline 20,0 & 21,5 \\
\hline 31,2 & 30,5 \\
\hline 28,0 & 29,0 \\
\hline 30,8 & 30,5 \\
\hline $\mathbf{2 5 , 6 7}$ & $\mathbf{2 7 , 0 3}$ \\
\hline $\mathbf{3 , 8 2}$ & $\mathbf{3 , 0 9}$ \\
\hline $\mathbf{0 , 9 5}$ & \multicolumn{2}{|l}{} \\
\hline
\end{tabular}

Betonada 3 SECANTE TANGENTE

\begin{tabular}{|c|c|}
\hline 23,1 & 24,3 \\
\hline 23,6 & 24,0 \\
\hline 25,2 & 26,3 \\
\hline 25,7 & 26,6 \\
\hline 24,3 & 25,5 \\
\hline 25,0 & 26,0 \\
\hline 23,8 & 24,5 \\
\hline 24,5 & 25,5 \\
\hline 25,2 & 26,0 \\
\hline 27,2 & 27,8 \\
\hline $\mathbf{2 4 , 7 6}$ & $\mathbf{2 5 , 6 5}$ \\
\hline $\mathbf{1 , 1 8}$ & $\mathbf{1 , 1 6}$ \\
\hline $\mathbf{0 , 9 7}$ & \\
\hline
\end{tabular}

\begin{tabular}{|c|c|}
\hline 25,2 & 26,0 \\
\hline 25,5 & 29,7 \\
\hline 23,1 & 25,0 \\
\hline 21,8 & 25,0 \\
\hline 29,0 & 30,5 \\
\hline 21,4 & 24,0 \\
\hline 29,0 & 32,0 \\
\hline 28,3 & 32,0 \\
\hline 25,0 & 31,2 \\
\hline 23,1 & 28,4 \\
\hline $\mathbf{2 5 , 1 4}$ & $\mathbf{2 8 , 3 8}$ \\
\hline $\mathbf{2 , 8 6}$ & $\mathbf{3 , 1 3}$ \\
\hline $\mathbf{0 , 8 9}$ & \\
\hline
\end{tabular}

Inicialmente, o Teste de Grubbs realizado para eliminação dos valores espúrios indicou a eliminação do resultado de 30,7 GPa do experimento 1 para clip gage no Concreto a/c 0,40, plano de carregamento tangente inicial, marcado em 
vermelho na Tab. 5.1.1. Optou-se por inserir nesta um resultado substitutivo igual à média da série, 36,9 GPa, por ser este um caso único e produzir uma assimetria no número de experimentos com as demais séries no caso de omissão do valor.

Ressalta-se que, como os cálculos apresentados a seguir utilizam quase sempre parcialmente os resultados obtidos, optou-se por seguir uma nomenclatura de identificação dos grupos de resultados utilizados em cada momento, com a seguinte convenção:

- As siglas "Ecs" e "Eci" identificam os planos de carregamento, sendo:

- Ecs: resultado de um corpo-de-prova sob o plano Secante;

- Eci: resultado de um corpo-de-prova sob o plano Tangente Inicial;

- Ecs,m: resultado médio de três corpos-de-prova sob o plano Secante;

- Eci,m: resultado médio de três corpos-de-prova sob o plano Tangente Inicial;

- A letra "I" identifica as instrumentações, sendo que:

- 4 I representa a utilização dos resultados obtidos com as quatro instrumentações: strain gages (SG), clip gages (CG), compressômetro com 1 relógio comparador (1R) e compressômetro com 2 relógios comparadores (2R);

- 3l representa uma situação especial de utilização dos resultados obtidos com apenas três instrumentações: strain gages (SG), clip gages (CG) e compressômetro com 1 relógio comparador (1R);

- 2I representa uma situação de utilização dos resultados obtidos com apenas duas instrumentações: strain gages (SG) e clip gages (CG);

- 11 representa qualquer instrumentação em particular, devendo para tanto ser identificada também com uma das siglas: SG, CG, $1 R$ ou $2 R$.

- A sigla "bt" identifica as betonadas, sendo que:

- 3bt representa a utilização dos resultados obtidos com as três betonadas;

- bt1, bt2 ou bt3 representam a utilização dos resultados obtidos com a apenas a primeira, a segunda ou a terceira betonada, respectivamente;

- As siglas "040" e "070" identificam os concretos, sendo:

- 040: concreto de relação água/cimento igual a 0,40;

- 070: concreto de relação água/cimento igual a 0,70. 


\subsubsection{Avaliação preliminar através dos modelos de previsão}

Esta abordagem, recorda-se, tem o intuito de promover o teste das dosagens da primeira parte do programa experimental para liberá-las às próximas avaliações sem o risco de se estar incorrendo em análise sobre resultados comprometidos com erros grosseiros. Os testes baseiam-se na estimativa da composição microestrutural e na verificação dos resultados experimentais através dos modelos bifásicos oriundos da Teoria da Elasticidade. Todos os modelos utilizados estão descritos em itens específicos do Capítulo 2 desta dissertação.

Assim, segue a rotina obedecida de forma explicativa:

a) Admita-se que o volume de água de cristalização $(V h c)$ do traço de concreto seja igual a $16 \%$ da massa de cimento CPIII-40 RS para um grau de hidratação de $100 \%$ - redução arbitrada de $30 \%$ sobre a fração ideal de água para hidratação do cimento que seria de 23\%, baseando-se em Neville (1997). A redução é necessária devido ao nível de adições do cimento. Dessa forma, obtêm-se através do modelo de quantificação da composição microestrutural constante do item 2.2.2 desta dissertação os resultados da Tab. 5.1.1.1 e da Fig. 5.1.1.1 para um grau de hidratação de $67 \%$ estimado para a idade de ensaio do programa (em torno de 28 dias):

Tabela 5.1.1.1 - Cálculo dos compostos resistentes e não-resistentes

\begin{tabular}{|c|c|c|c|c|c|c|c|c|}
\hline & \multirow{2}{*}{\multicolumn{2}{|c|}{ Compostos }} & \multicolumn{3}{|c|}{ T1-040-A100 } & \multicolumn{3}{|c|}{ T2-070-A100 } \\
\hline & & & Volume & Volume & Total & Volume & Volume & Total \\
\hline \multirow{5}{*}{$\begin{array}{l}\text { compostos } \\
\text { resistentes }\end{array}$} & \multirow{2}{*}{$\begin{array}{c}\text { volume de } \\
\text { gel }\end{array}$} & sólidos & 0,30 & 13,9 & \multirow{5}{*}{89,1} & 0,30 & 7,8 & \multirow{5}{*}{85,0} \\
\hline & & água de gel & 0,12 & 5,4 & & 0,12 & 3,0 & \\
\hline & \multicolumn{2}{|c|}{ volume de areia } & 0,65 & 30,0 & & 1,48 & 38,6 & \\
\hline & \multicolumn{2}{|c|}{ volume pedra } & 0,75 & 34,7 & & 1,25 & 32,7 & \\
\hline & \multicolumn{2}{|c|}{ volume de cimento anidro } & 0,11 & 5,0 & & 0,11 & 2,8 & \\
\hline \multirow{3}{*}{$\begin{array}{c}\text { compostos não } \\
\text { resistentes }\end{array}$} & \multicolumn{2}{|c|}{ volume de ar aprisionado } & 0,03 & 1,6 & \multirow{3}{*}{10,9} & 0,07 & 1,8 & \multirow{3}{*}{15,0} \\
\hline & \multirow{2}{*}{\multicolumn{2}{|c|}{\begin{tabular}{|l|} 
volume de poros de gel \\
volume de áqua livre
\end{tabular}}} & 0,03 & 1,3 & & 0,03 & 0,7 & \\
\hline & & & 0,17 & 8,1 & & 0,48 & 12,5 & \\
\hline \multicolumn{3}{|c|}{$\begin{array}{l}\text { volume total do concreto endurecido igual ao } \\
\text { do concreto fresco }\end{array}$} & 2,15 & 100,0 & 100,0 & 3,83 & 100,0 & 100,0 \\
\hline \multicolumn{3}{|c|}{ Volume de vazios permeáveis (\%) } & \multicolumn{3}{|c|}{9,7} & \multicolumn{3}{|c|}{14,3} \\
\hline
\end{tabular}




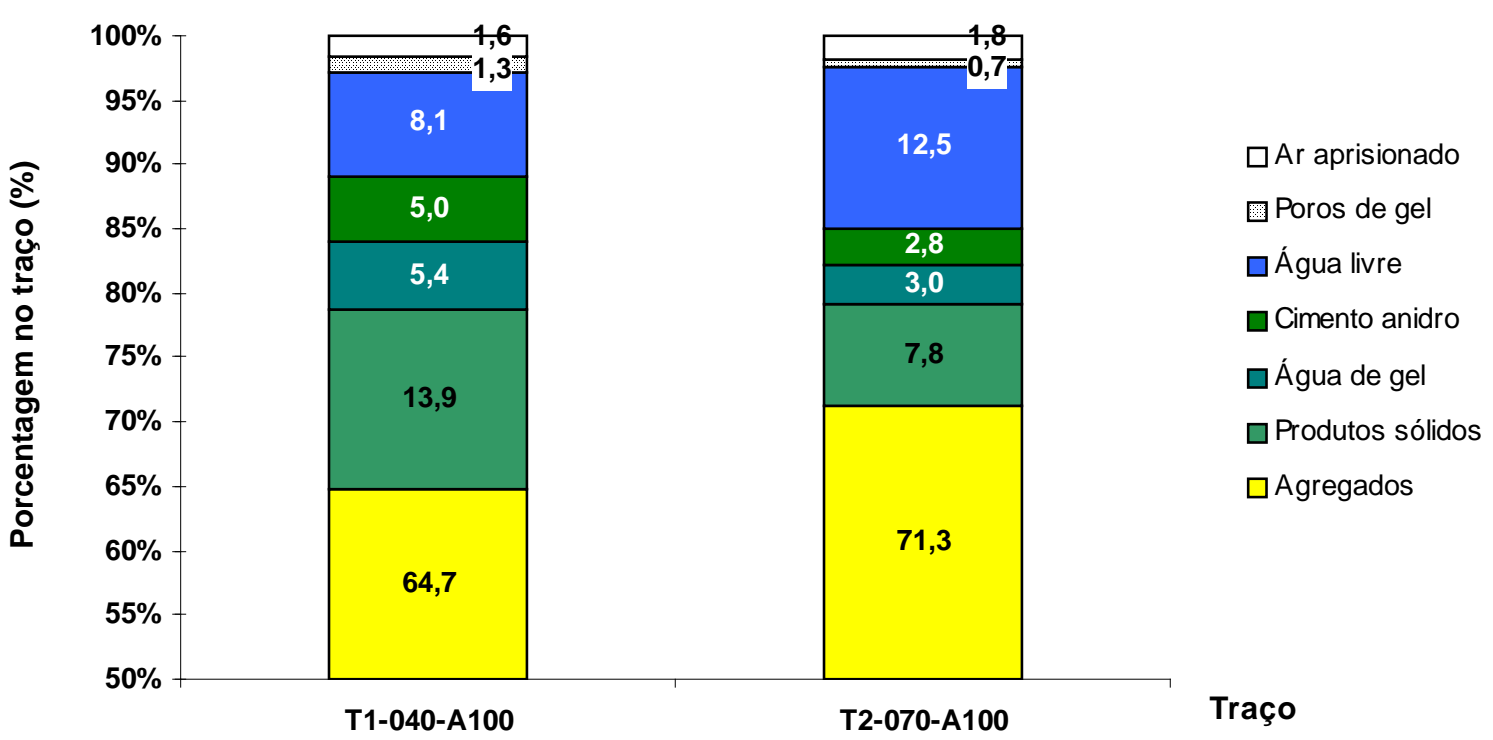

Figura 5.1.1.1 - Distribuição volumétrica dos compostos resistentes e não-resistentes

b) Com esses percentuais volumétricos, pode-se estimar o módulo de elasticidade da pasta endurecida através da expressão fornecida por Hansen (1965), constante do item 2.3.1 da dissertação. Note-se que, para tal, deve-se ainda admitir o módulo de elasticidade dos componentes sólidos globais da pasta que, conforme o primeiro quadro-resumo da revisão bibliográfica constante do item 2.2.1, pode ser admitido como igual a $30 \mathrm{GPa}$. O módulo de elasticidade dos poros capilares admitido é nulo. Assim, obtêm-se os resultados da Tab. 5.1.1.2.

Tabela 5.1.1.2 - Características das pastas

\begin{tabular}{|c|c|c|c|c|}
\hline Traço & Esolglobais(GPa) & Vsolglobais (\%) & Vcapilares (\%) & Epasta = Em (GPa) \\
\cline { 1 - 3 } T1-040-A100 & \multirow{2}{*}{30} & 75,1 & 24,9 & 15,0 \\
\cline { 1 - 3 } T2-070-A100 & & 52,2 & 47,8 & 8,0 \\
\cline { 3 - 5 } & & 52,8 &
\end{tabular}

c) Através da formulação de Müller-Rochholz (1974), também do item 2.3.1 da dissertação, pode-se calcular o módulo de elasticidade dos agregados. Admitindo-se a massa específica absoluta de $2,7 \mathrm{~kg} / \mathrm{dm}^{3}$, tem-se que $E_{p}=8,1 \cdot 2,7^{2}=59,0 \mathrm{GPa}$.

d) Agora, pode-se calcular os módulos de deformação previstos para os concretos através dos demais modelos micromecânicos apresentados no item $2.3 .1 \mathrm{e}$ 
compará-los com a média global (independentemente da instrumentação) obtida experimentalmente - admitidos os valores do módulo de deformação obtidos sob o plano de carregamento tangente inicial (Eci).

Assim, tem-se que as características ensaiadas dos traços constantes da Tab. 5.1.1.3 dão origem aos resultados constantes da Tab. 5.1.1.4.

Tabela 5.1.1.3 - Características dos traços ensaiados

\begin{tabular}{|c|c|c|c|c|}
\hline Traço & Em (GPa) ${ }^{*}$ & Vm (\%) & \multirow{2}{*}{ Ep (GPa) } & Vp (\%) \\
\hline T1-040-A100 & 15,0 & 35,3 & \multirow{2}{*}{59,0} & 64,7 \\
\cline { 1 - 3 } \cline { 5 - 6 } T2-070-A100 & 8,0 & 28,7 & & 71,3 \\
\hline
\end{tabular}

* Os índices c, p, m indicam concreto, particulado (agregados) e matriz (pasta endurecida) respectivamente.

Tabela 5.1.1.4 - Característica dos concretos obtida a partir dos modelos e dos experimentos

\begin{tabular}{|c|c|c|c|c|c|c|c|c|}
\hline \multirow{2}{*}{ Traço } & \multicolumn{7}{|c|}{$\begin{array}{l}\text { Módulo de deformação do concreto de acordo com o modelo } \\
\qquad \mathrm{Ec}(\mathrm{GPa})\end{array}$} & \multirow{2}{*}{$\begin{array}{c}\text { Média } \\
\text { experimental } \\
\text { Eci (GPa) }\end{array}$} \\
\hline & Voigt & Reuss & H-S ${ }^{\text {sup * }}$ & $\mathrm{H}-\mathrm{S}^{\text {inf }}$ * & Counto & Hansen & $\mathbf{Y}-\mathrm{H}^{* *}$ & \\
\hline $\begin{array}{c}\text { T1-040- } \\
\text { A100 }\end{array}$ & 43,5 & 29,0 & 38,5 & 33,8 & 34,5 & 33,8 & 33,8 & 37,2 \\
\hline $\begin{array}{c}\text { T2-070- } \\
\text { A100 }\end{array}$ & 44,4 & 20,9 & 37,8 & 27,0 & 27,8 & 27,0 & 27,0 & 27,0 \\
\hline
\end{tabular}

${ }^{*}$ H-S: Hashin e Shtrikman

** Y-H: Yang e Huang. Coeficiente de Poisson das fases e do concreto igual a 0,20.

e) Como se vê, os resultados de previsão dos modelos Hashin-Shtrikman inferior, Counto e Hansen, da década de 1960, e Yang e Huang (Y-H), de 1996, mostram-se convergentes e da mesma ordem de grandeza que os obtidos experimentalmente. Isto libera estes últimos para a continuidade das avaliações desta dissertação.

Ressalte-se que as diferenças absolutas observadas entre os valores das médias experimentais globais de 37,2 e 27,0 GPa e os valores de convergência dos modelos de aproximadamente 34,0 e $27,0 \mathrm{GPa}$ indicam que as aproximações admitidas para a obtenção dos primeiros e/ou a execução dos procedimentos para obtenção dos segundos mereceram continuidade de abordagem ainda neste estudo. 
5.1.2 Análise do método sob cada uma das instrumentações para medida das deformações

Os questionamentos a serem respondidos primeiramente devem ser:

- Os resultados do método de ensaio sob cada uma das quatro instrumentações em particular podem ser considerados estatisticamente iguais?

- As três betonadas podem ser consideradas estatisticamente iguais?

Através da função ANOVA e considerando todos os resultados obtidos com o método sob as quatro instrumentações e as três betonadas, pode-se dizer que para o plano de carregamento secante e o traço de concreto de a/c 0,40 há diferenças significativas entre as instrumentações, mas não entre as betonadas, conforme pode ser visto na Tab. 5.1.2.1, onde F é maior que Fcrítico apenas para o primeiro fator.

Tabela 5.1.2.1 - ANOVA para agrupamento Ecs-4I-3bt-040

\begin{tabular}{|c|c|c|c|c|c|c|}
\hline Fonte da variação & $S Q$ & $G L$ & $M Q$ & $F$ & valor-P & F crítico \\
\hline Instrumentação & 67,02967 & 3 & 22,34322 & 5,131982 & 0,002343 & 2,688694 \\
\hline Betonadas & 20,72267 & 2 & 10,36133 & 2,379879 & 0,0974 & 3,080388 \\
\hline Interações & 21,22933 & 6 & 3,538222 & 0,812689 & 0,562317 & 2,183654 \\
\hline Dentro & 470,202 & 108 & 4,353722 & & & \\
\hline Total & 579,1837 & 119 & & & & \\
\hline
\end{tabular}

Repetindo-se esta técnica para os demais planos de carregamento e traços de concreto, pode-se resumir na Tab. 5.1.2.2 as respostas para as perguntas formuladas.

Tabela 5.1.2.2 - Verificação de 4l-3bt: instrumentações e betonadas

\begin{tabular}{|c|c|c|c|}
\cline { 3 - 4 } \multicolumn{2}{c|}{} & \multicolumn{2}{c|}{ São estatisticamente iguais ? } \\
\hline Plano & Concreto & Instrumentações & Betonadas \\
\hline \multirow{2}{*}{ Ecs } & 040 & Não & Sim \\
\cline { 2 - 4 } & 070 & Não & Não \\
\hline \multirow{2}{*}{ Eci } & 040 & Não & Não \\
\cline { 2 - 4 } & 070 & Não & Não \\
\hline
\end{tabular}


Assim, ao se considerar os resultados das quatro instrumentações e das três betonadas (4I-3bt), a análise de variâncias identifica que há diferença estatisticamente significativa de pelo menos uma delas em relação às demais na maioria dos casos analisados.

As diferenças entre as médias e os desvios-padrão sob cada instrumentação, betonada a betonada, podem ser vistas nas Fig. 5.1.2.1 e 5.1.2.2. Nelas, as linhas dos limites superior (LS) e inferior (LI) representam valores de controle distanciados de frações dos desvios gerados entre os 12 grupos de resultados de módulo de deformação de cada concreto - 4 instrumentações vezes 3 betonadas - onde Limites $=$ Média $\pm 3 \cdot D P / \sqrt{12}=$ Média $\pm 0,866 \cdot D P$, o que permite a rápida identificação dos grupos de resultados divergentes.

\section{Ecs (GPa)}

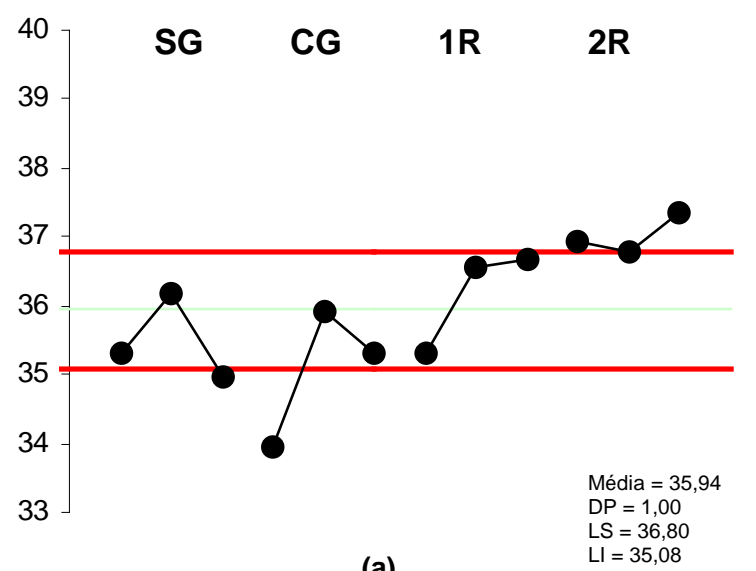

DP (GPa)

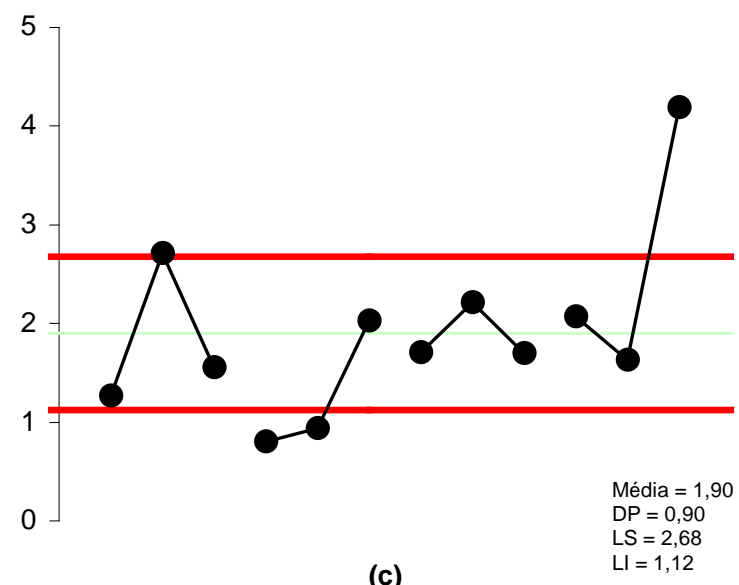

(c)

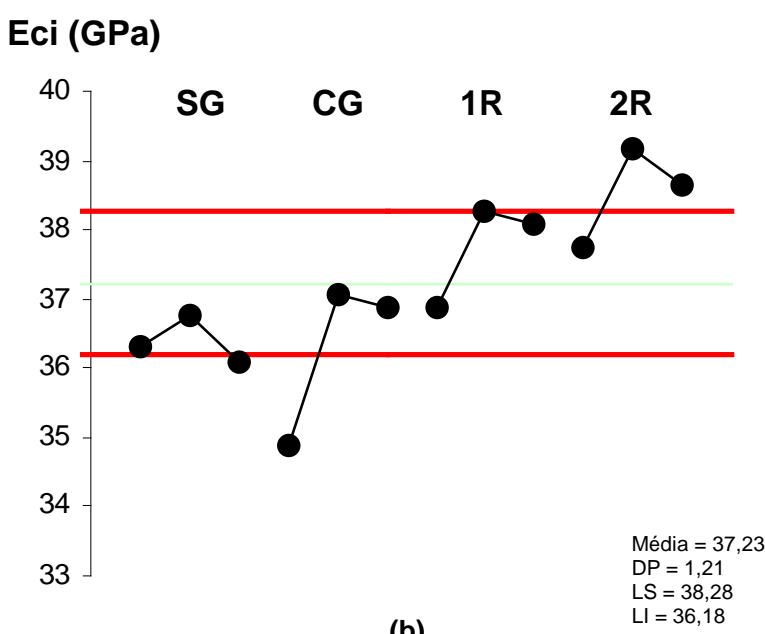

DP (GPa)

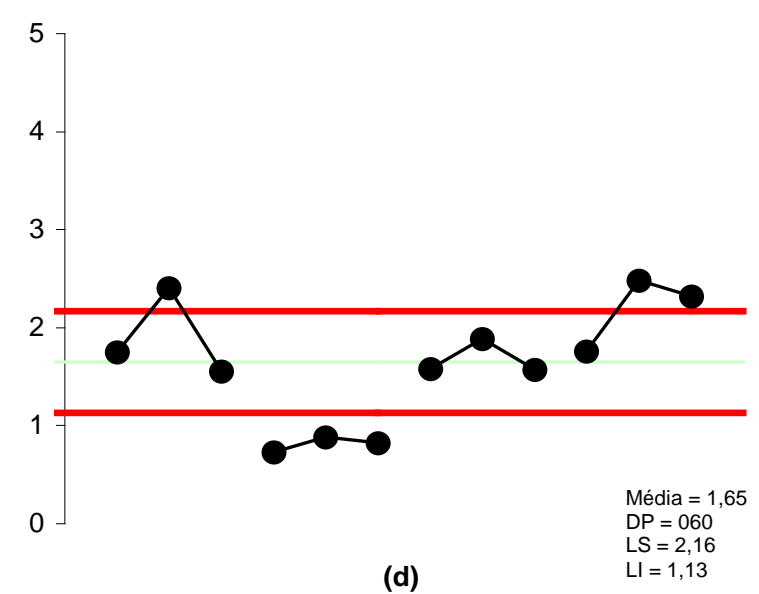

Figura 5.1.2.1 - Cartas de controle das Instrumentações para o Concreto a/c 0,40: (a) Médias por betonada, plano secante; (b) Médias por betonada, plano tangente inicial; (c) Desviospadrão por betonada, plano secante; (d) Desvios-padrão por betonada, plano tangente inicial 


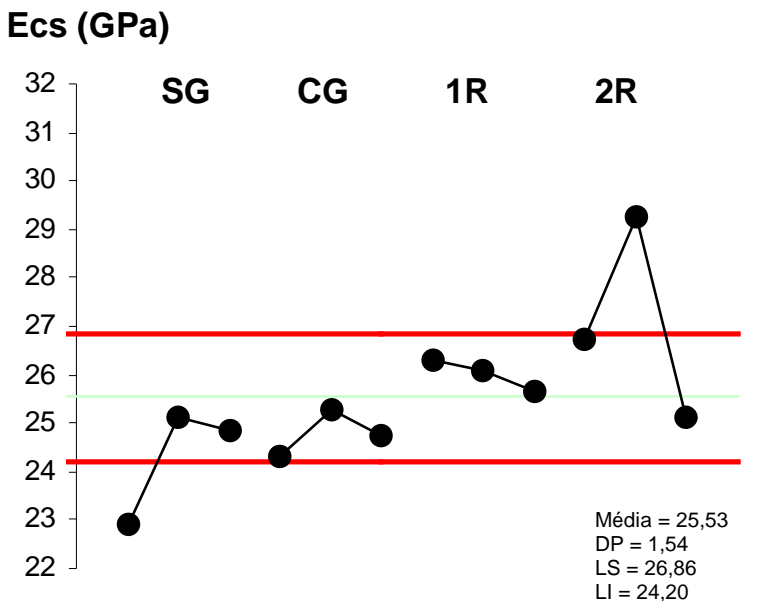

(a)

DP (GPa)

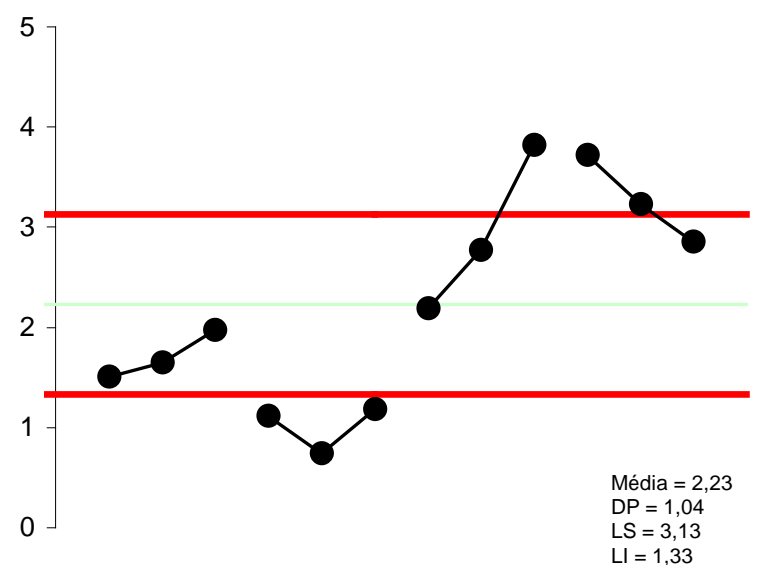

(c)
Eci (GPa)

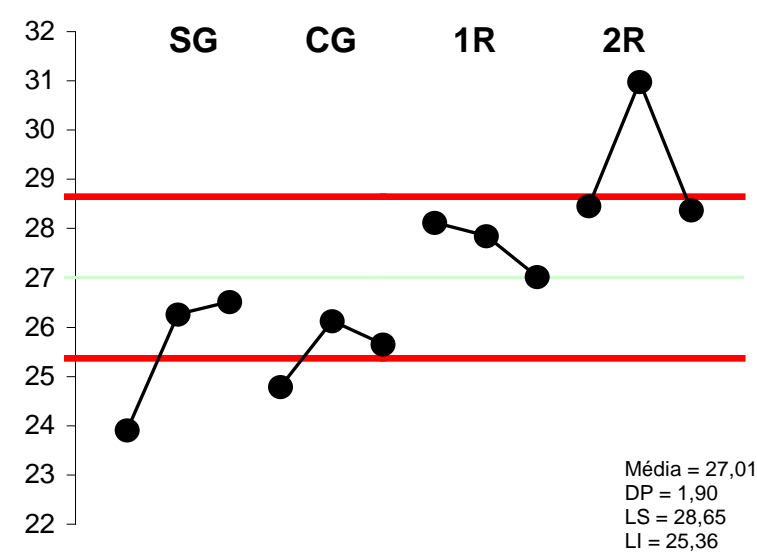

(b)

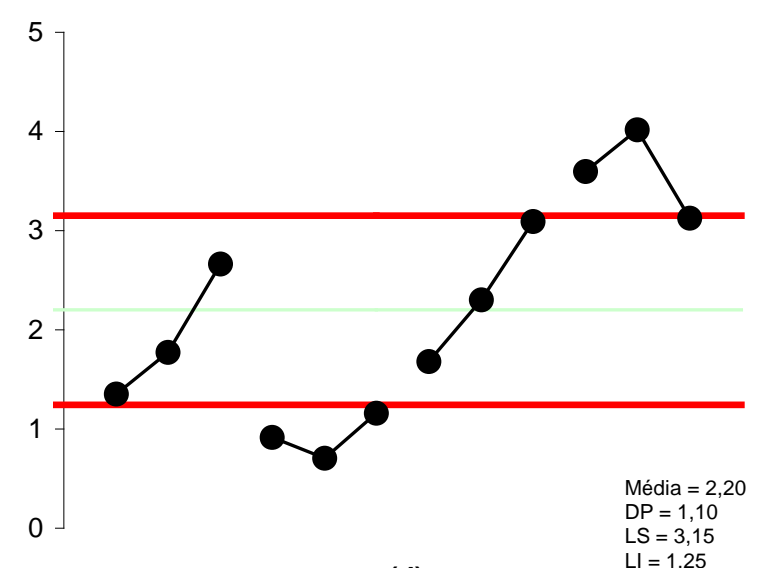

(d)

Figura 5.1.2.2 - Cartas de controle das Instrumentações para o Concreto a/c 0,70: (a) Médias por betonada, plano secante; (b) Médias por betonada, plano tangente inicial; (c) Desviospadrão por betonada, plano secante; (d) Desvios-padrão por betonada, plano tangente inicial

Analisando-se todos os casos, o método sob o procedimento de instrumentação $2 R$ foi o que se mostrou fora dos limites calculados (LS e LI) em mais oportunidades, além de apresentar sistematicamente a maior média e desviopadrão. Isto talvez possa ser explicado pelas seguintes observações:

- a ausência do terceiro parafuso de ancoragem do yoke superior do compressômetro causou, em alguns momentos dos experimentos, uma desigual distribuição de deformações sobre os relógios comparadores. Apesar disso, pela definição dos planos de carregamento do programa, esses experimentos não receberam mais do que duas tentativas de compatibilização dos medidores; 
- a instrumentação $2 R$, assim como $1 R$, sofre fortemente a influência do operador pois a ancoragem do compressômetro se dá através de aparafusamento deste contra a superfície do corpo-de-prova e, algumas vezes, o aparafusamento supera a força necessária para a ancoragem causando dano nesta superfície e podendo comprometer a estabilidade do sistema durante o ensaio, principalmente no caso dos concretos com menor resistência à perfuração como no Concreto 070;

- outra questão rigorosamente hipotética pode ser descrita baseada na expansão transversal do concreto indicada pelo coeficiente de Poisson que, mesmo a baixas tensões de ensaio, poderia gerar alongamento dos medidor(es) de deformação(ões) longitudinal(ais). De forma detalhada, a Fig. 5.1.2.3 mostra o esquema hipotético dessa tendência, admitido praticamente nulo para o CG, de pequeno grau para o SG - não ilustrado na figura mas admitido superposto ao contorno do corpo-de-prova pela colagem - e em maior grau para o $1 \mathrm{R}$ e $\circ 2 \mathrm{R}$. A instrumentação $C G$ teria sua ancoragem praticamente independente deste fenômeno pois é pontual e traz aderido em si o medidor. Apesar de $1 \mathrm{R}$ e $2 \mathrm{R}$ também possuírem ancoragem pontual, esta não sendo diretamente vinculada ao medidor seria admitida como transferidora das deformações a partir dos yokes, tornando o sistema sujeito a um alongamento que minoraria as leituras e majoraria os resultados de módulo de deformação.

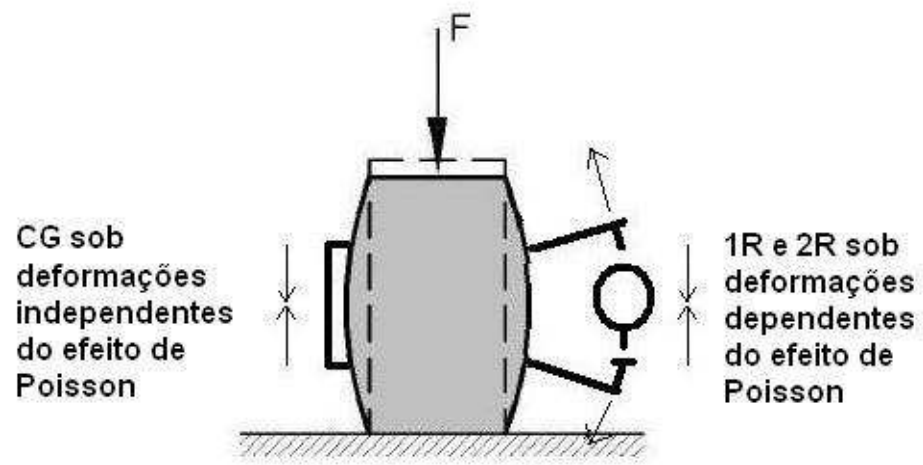

Figura 5.1.2.3 - Hipótese de combinação de deformações durante o ensaio

Esta hipótese não pôde ser avaliada neste estudo e nem se encontrou referência bibliográfica que justificasse sua defesa. Sua origem é meramente observacional. Ainda assim, é curioso ressaltar que o trabalho de Torrenti; 
Boulay e Puch (1994), já discutido anteriormente, também apresentou a mesma tendência de leituras de deformação finais menores para instrumentação com dispositivo de ancoragem tipo compressômetro.

Paralelamente às diferenças entre instrumentações, nota-se que o Concreto 070 apresentou, em geral, uma tendência de maior desvio em relação à média. Também a partir da observação experimental, pode-se dizer que isso se deve à maior suscetibilidade deste tipo de concreto à degradação superficial e, conseqüentemente, a variações originadas na montagem da instrumentação. Como exemplos de fontes de variação podem ser citados o lixamento e a limpeza superficial dos corpos-de-prova para a instrumentação de SG e as diferenças de estabilidade de algumas montagens de $1 \mathrm{R}$ e $2 \mathrm{R}$ pela penetração da superfície do corpo-de-prova durante o aparafusamento do compressômetro já citadas.

Analise-se agora os agrupamentos dos resultados unicamente dados pelas betonadas, conforme Fig. 5.1.2.4. Não há como identificar com facilidade a betonada classificada como divergente das demais. Se a terceira betonada apresentou a maior resistência à compressão média, o mesmo não aconteceu para ela com os módulos de deformação secante e tangente inicial a 30\% dessa resistência. A melhor tendência de divergência existe entre as betonadas 1 e 2, pelas diferenças entre médias de módulos de deformação e semelhança entre desvios-padrão. Um método de ensaio que tende à validação deveria ser capaz de perceber essa diferença. Em outras palavras, a dispersão de ensaio não deveria ser significativamente mais importante que a dispersão de produção. Note-se que foram selecionados apenas os resultados de Ecs dada a semelhança nas respostas com os resultados de Eci.

Ecs (GPa) - Concreto 040

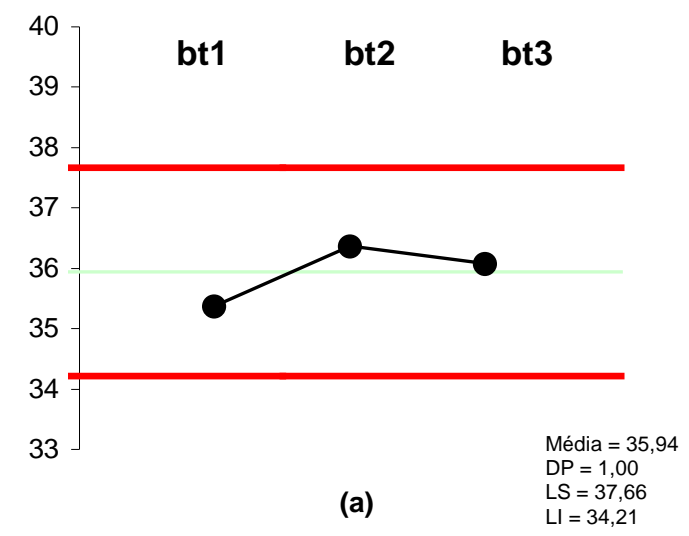

\section{Ecs (GPa) - Concreto 070}

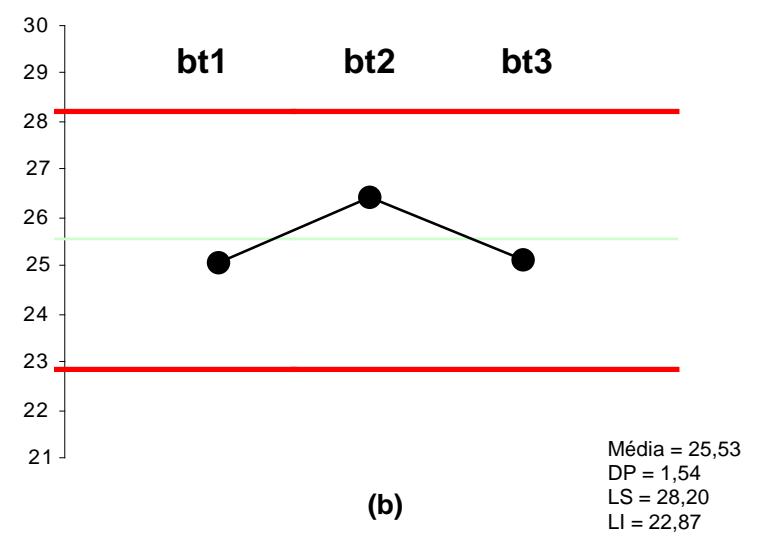


DP (GPa)

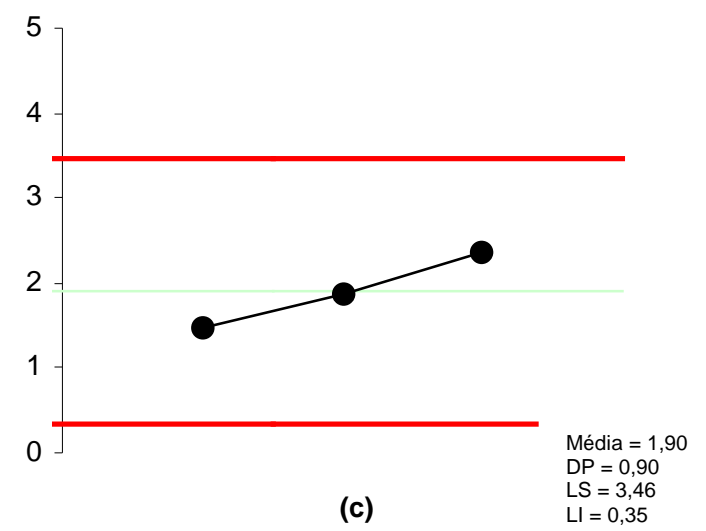

DP (GPa)

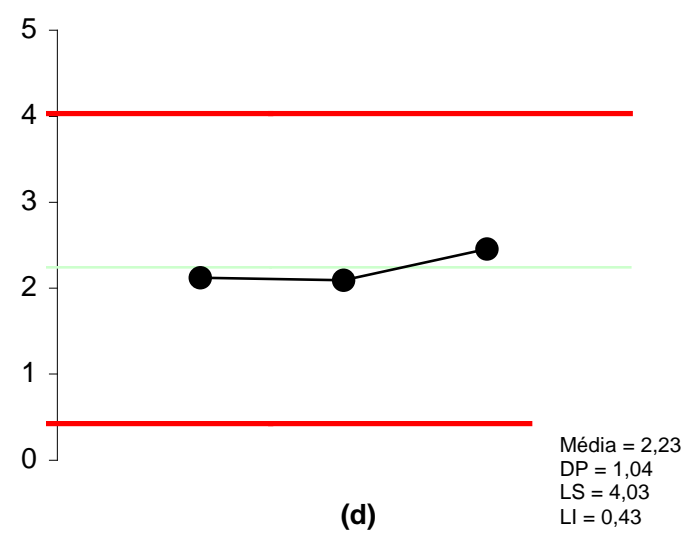

Figura 5.1.2.4 - Cartas de controle das Betonadas para o plano de carregamento secante: (a) Médias globais, Concreto a/c 0,40; (b) Médias globais, Concreto a/c 0,70; (c) Desvios-padrão globais, Concreto a/c 0,40; (d) Desvios-padrão globais, Concreto a/c 0,70

\subsubsection{Cálculos da precisão do método sob cada instrumentação}

A composição das variâncias pode ser fundamentalmente baseada na variação dos procedimentos de amostragem (variação de produção das betonadas) e de instrumentação, conforme a Fig. 5.1.2.1.1.

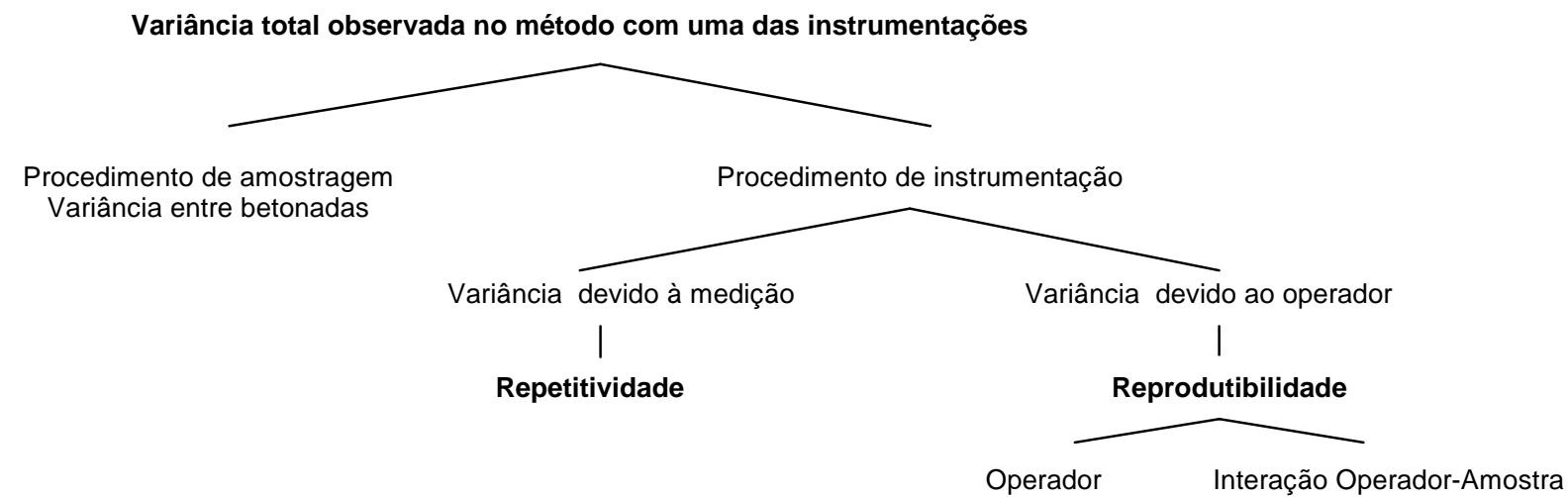

Figura 5.1.2.1.1 - Composição das variâncias dos resultados sob cada instrumentação

Conforme já foi dito, o programa experimental pôde apenas ser realizado por um operador, impossibilitando a inferência da reprodutibilidade real de cada instrumentação e permitindo apenas o cálculo da repetitividade com elevada confiabilidade. Mesmo assim, optou-se por seguir a metodologia proposta na pesquisa como uma forma de testar a sua aplicação a este tipo de material e de 
experimento. Para tal, admitiu-se que houve dois operadores diferentes nas determinações e que cada um deles ensaiou 5 dos 10 corpos-de-prova de cada betonada. Previsivelmente, essa condição tenderia a anular o valor do desvio de reprodutibilidade pois "ambos" os operadores têm a mesma probabilidade de cometerem os mesmos erros.

Seguem agora nas Tab. 5.1.2.1.1 a 5.1.2.1.4 e nas Fig. 5.1.2.1.2.a-d a 5.1.2.1.5.a-d os resultados dos indicadores de precisão para os valores de módulo de deformação obtidos com o método de ensaio sob cada instrumentação, seguidos de alguns comentários. Nessas figuras, as barras alaranjadas representam a distribuição das Variâncias de $R \& R$, Repetitividade, Reprodutibilidade e Betonadas e as barras esverdeadas as relações entre os Desvios de R\&R, Repetitividade, Reprodutibilidade e Betonadas e o Desvio total.

I) Agrupamentos Ecs-1I-3bt-040

Tabela 5.1.2.1.1 - Agrupamentos de módulo secante (Ecs) de três betonadas (3bt) do Concreto a/c 0,40 (040), por instrumentação: cálculo dos indicadores de precisão

\begin{tabular}{|c|c|c|c|c|}
\hline INDICADORES ESTATÍSTICOS & SG & CG & $\mathbf{1 R}$ & 2R \\
\hline Média (GPa) & 35,48 & 35,06 & 36,18 & 37,03 \\
\hline Desvio-padrão (GPa) & 1,95 & 1,57 & 1,93 & 2,77 \\
\hline Incerteza da média (GPa) & 0,36 & 0,29 & 0,35 & 0,51 \\
\hline Compatibilidade entre médias & -- & -- & -- & -- \\
\hline Desvio de repetitividade (GPa) & 1,84 & 1,38 & 1,91 & 2,91 \\
\hline Desvio de reprodutibilidade (GPa) & 0,97 & 0,00 & 0,00 & 0,00 \\
\hline Desvio R\&R (GPa) & 2,08 & 1,38 & 1,91 & 2,91 \\
\hline Desvio de betonadas (GPa) & 0,00 & 0,93 & 0,45 & 0,00 \\
\hline Desvio-padrão total (GPa) & 2,08 & 1,66 & 1,96 & 2,91 \\
\hline Desvio R\&R/Desvio total (\%) & 100 & 83 & 97 & 100 \\
\hline Variância R\&R/Variância total (\%) & 100 & 69 & 95 & 100 \\
\hline Betonadas distinguidas & 1 & 1 & 1 & 1 \\
\hline
\end{tabular}

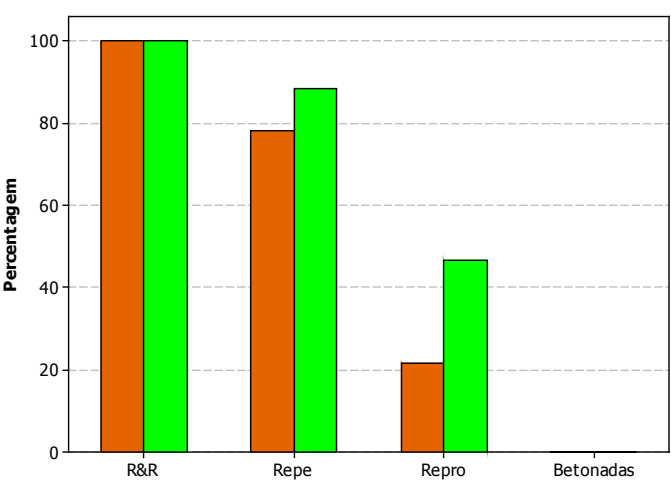

(a) SG

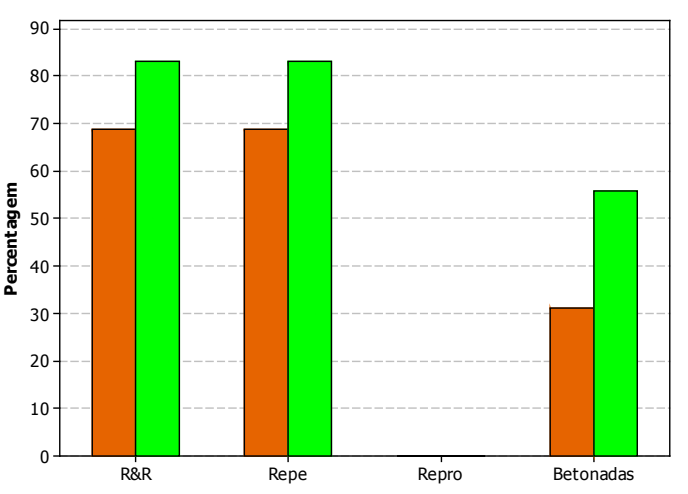

(b) $C G$ 


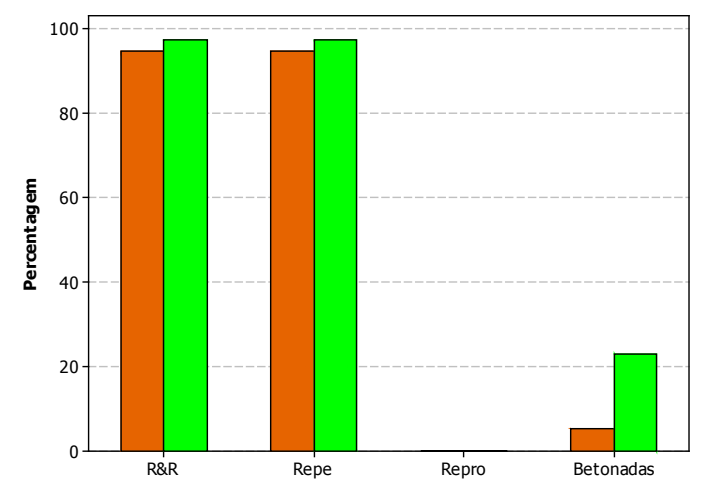

(c) $1 \mathrm{R}$

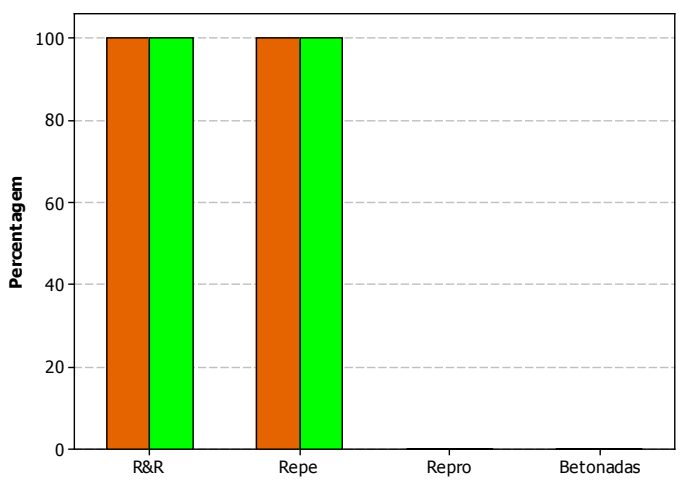

(d) $2 \mathrm{R}$

Figura 5.1.2.1.2 - Composição das variâncias e desvios-padrão dos agrupamentos Ecs-1l-3bt040, por instrumentação

Observa-se que os agrupamentos Ecs-1I-3bt-040 mostraram distintos níveis de dispersão dos resultados, ainda que todos tenham apresentado Variância devido à R\&R maior ou igual a $69 \%$ da Variância total ('Variância R\&R/Variância total (\%)'.

Os resultados da relação 'Desvio $R \& R /$ Desvio total (\%)' indicam que o método sob CG mostrou-se mais sensível à variação entre betonadas, sendo o mais preciso entre os quatro, em tese, dados os elevados valores gerais desta relação. Essa tendência de dispersão já poderia ser prevista a partir da comparação entre os desvios-padrão normalmente quantificados sob cada instrumentação ( $2^{\circ}$ item da tabela), já que as médias ficaram muito próximas entre si à exceção de $2 \mathrm{R}$.

II) Agrupamentos Eci-1I-3bt-040

Tabela 5.1.2.1.2 - Agrupamentos de módulo tangente inicial (Eci) de três betonadas (3bt) do Concreto a/c 0,40 (040), por instrumentação: cálculo dos indicadores de precisão

\begin{tabular}{|c|c|c|c|c|}
\hline INDICADORES ESTATíSTICOS & SG & CG & $\mathbf{1 R}$ & 2R \\
\hline Média (GPa) & 36,38 & 36,27 & 37,74 & 38,52 \\
\hline Desvio-padrão (GPa) & 1,89 & 1,28 & 1,74 & 2,22 \\
\hline Incerteza da média (GPa) & 0,35 & 0,23 & 0,32 & 0,40 \\
\hline Compatibilidade entre médias & \multicolumn{2}{|c|}{ COMPATíVEIS } & -- & -- \\
\hline Desvio de repetitividade (GPa) & 1,97 & 0,83 & 1,68 & 2,20 \\
\hline Desvio de reprodutibilidade (GPa) & 0,00 & 0,00 & 0,26 & 0,26 \\
\hline Desvio R\&R (GPa) & 1,97 & 0,83 & 1,70 & 2,22 \\
\hline Desvio de betonadas (GPa) & 0,00 & 1,18 & 0,54 & 0,19 \\
\hline Desvio-padrão total (GPa) & 1,97 & 1,44 & 1,78 & 2,23 \\
\hline Desvio R\&R/Desvio total (\%) & 100 & 57 & 95 & 100 \\
\hline Variância R\&R/Variância total (\%) & 100 & 33 & 91 & 99 \\
\hline Betonadas distinguidas & 1 & 2 & 1 & 1 \\
\hline
\end{tabular}




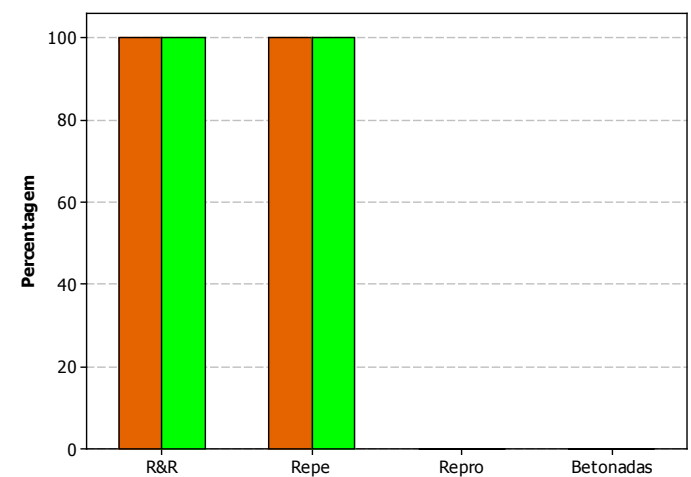

(a) SG

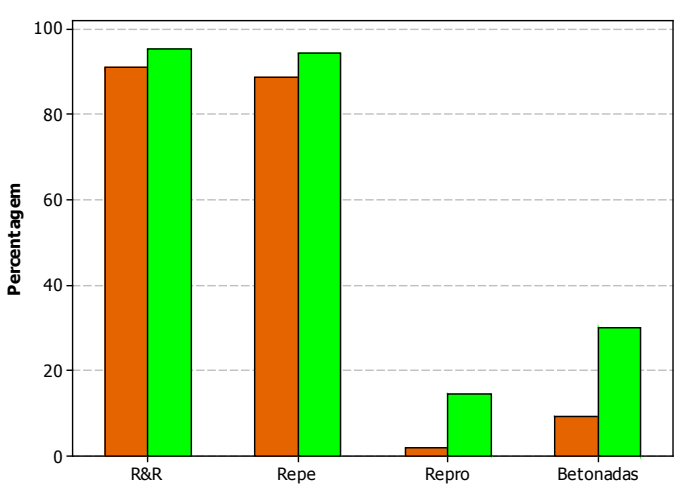

(c) $1 \mathrm{R}$

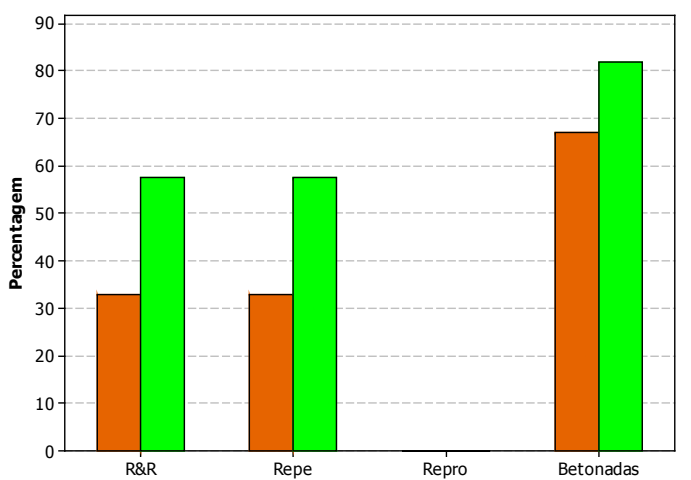

(b) $C G$

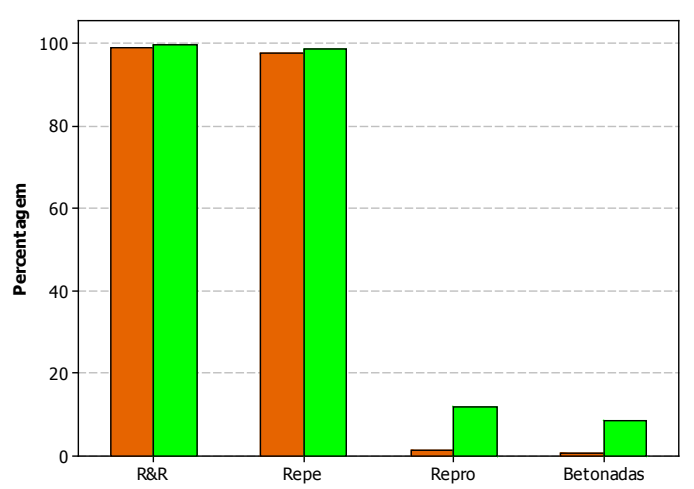

(d) $2 \mathrm{R}$

Figura 5.1.2.1.3 - Composição das variâncias e desvios-padrão dos agrupamentos Eci-1l-3bt040, por instrumentação

Observa-se que os agrupamentos Eci-1l-3bt-040 mostraram níveis muito distintos de dispersão dos resultados.

Os resultados da relação 'Desvio R\&R/Desvio total (\%)' indicam que o método sob CG manteve-se como o mais preciso na mudança do plano de carregamento secante para o tangente inicial. Destaca-se a capacidade de distinção apresentada por CG de perceber diferença entre duas das três betonadas ensaiadas Betonadas distinguidas, $12^{\circ}$ item da tabela.

III) Agrupamentos Ecs-1I-3bt-070 
Tabela 5.1.2.1.3 - Agrupamentos de módulo secante (Ecs) de três betonadas (3bt) do Concreto a/c 0,70 (070), por instrumentação: cálculo dos indicadores de precisão

\begin{tabular}{|c|c|c|c|c|}
\hline INDICADORES ESTATísTICOS & SG & CG & $\mathbf{1 R}$ & 2R \\
\hline Média (GPa) & 24,29 & 24,79 & 26,02 & 27,04 \\
\hline Desvio-padrão (GPa) & 1,94 & 1,08 & 2,91 & 3,61 \\
\hline Incerteza da média (GPa) & 0,35 & 0,20 & 0,53 & 0,66 \\
\hline Compatibilidade entre médias & -- & -- & -- & -- \\
\hline Desvio de repetitividade (GPa) & 1,73 & 1,05 & 2,78 & 3,24 \\
\hline Desvio de reprodutibilidade (GPa) & 0,00 & 0,00 & 1,98 & 0,73 \\
\hline Desvio R\&R (GPa) & 1,73 & 1,05 & 3,41 & 3,32 \\
\hline Desvio de betonadas (GPa) & 1,10 & 0,36 & 0,00 & 1,80 \\
\hline Desvio-padrão total (GPa) & 2,04 & 1,11 & 3,41 & 3,78 \\
\hline Desvio R\&R/Desvio total (\%) & 85 & 95 & 100 & 88 \\
\hline Variância R\&R/Variância total (\%) & 72 & 89 & 100 & 77 \\
\hline Betonadas distinguidas & 1 & 1 & 1 & 1 \\
\hline
\end{tabular}

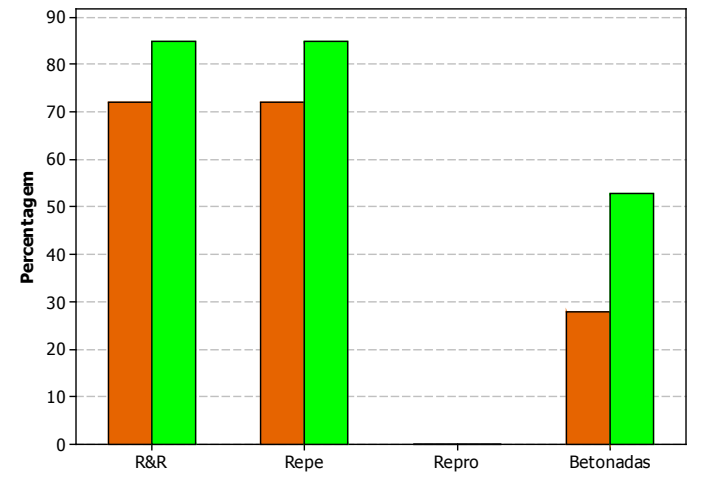

(a) $S G$

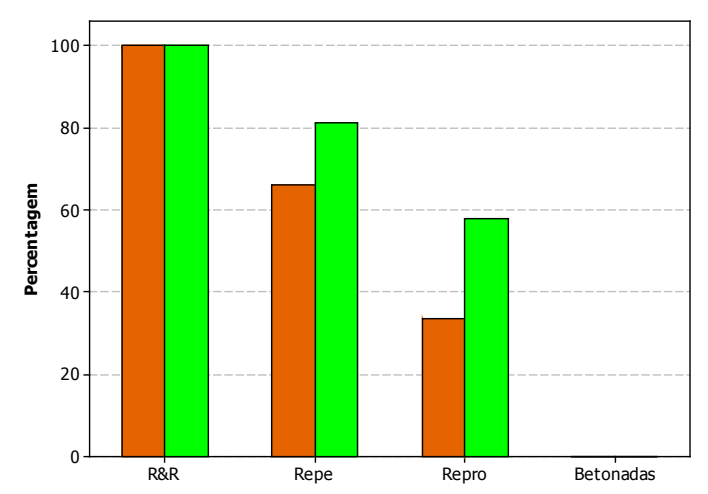

(c) $1 \mathrm{R}$

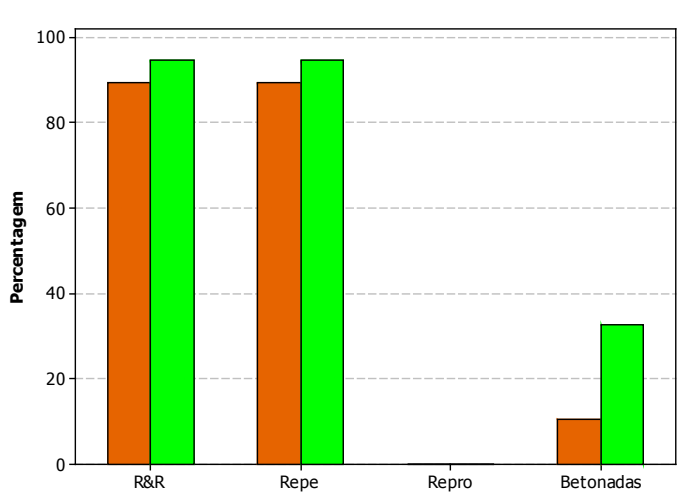

(b) CG

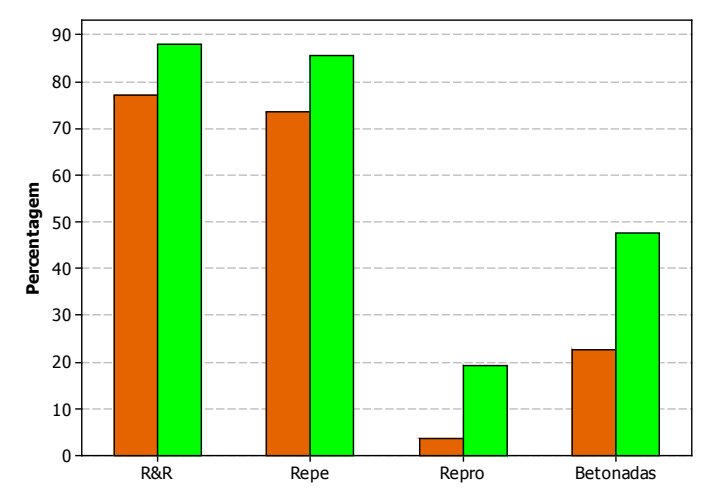

(d) $2 R$

Figura 5.1.2.1.4 - Composição das variâncias e desvios-padrão dos agrupamentos Ecs-1l-3bt070, por instrumentação

Observa-se que os agrupamentos Ecs-1I-3bt-070 mostraram níveis muito distintos de dispersão dos resultados embora todos tenham apresentado Variância devido à R\&R acima de $70 \%$ da Variância total, repetindo o que já havia ocorrido no plano de carregamento secante para o Concreto 040. 
Os resultados da relação 'Desvio R\&R/Desvio total (\%)' indicam que o método sob SG e 2R mostraram leve tendência à maior capacidade de distinção entre betonadas, apesar dos elevados níveis de desvios-padrão totais observados. Ao contrário, o método sob CG mostrou-se com menor percepção à variação das amostras mas obteve o menor desvio-padrão total entre todos os agrupamentos.

IV) Agrupamentos Eci-1I-3bt-070

Tabela 5.1.2.1.4 - Agrupamentos de módulo tangente inicial (Eci) de três betonadas (3bt) do Concreto a/c 0,70 (070), por instrumentação: cálculo dos indicadores de precisão

\begin{tabular}{|c|c|c|c|c|}
\hline INDICADORES ESTATÍSTICOS & SG & CG & 1R & 2R \\
\hline Média (GPa) & 25,56 & 25,52 & 27,67 & 29,28 \\
\hline Desvio-padrão (GPa) & 2,27 & 1,07 & 2,39 & 3,68 \\
\hline Incerteza da média (GPa) & 0,42 & 0,20 & 0,44 & 0,67 \\
\hline Compatibilidade entre médias & \multicolumn{2}{|c|}{ COMPATíVEIS } & -- & -- \\
\hline Desvio de repetitividade (GPa) & 2,01 & 0,96 & 2,41 & 3,43 \\
\hline Desvio de reprodutibilidade (GPa) & 0,03 & 0,00 & 0,90 & 1,46 \\
\hline Desvio R\&R (GPa) & 2,01 & 0,96 & 2,57 & 3,73 \\
\hline Desvio de betonadas (GPa) & 1,29 & 0,61 & 0,00 & 1,01 \\
\hline Desvio-padrão total (GPa) & 2,38 & 1,14 & 2,57 & 3,86 \\
\hline Desvio R\&R/Desvio total (\%) & 84 & 85 & 100 & 97 \\
\hline Variância R\&R/Variância total (\%) & 71 & 71 & 100 & 93 \\
\hline Betonadas distinguidas & 1 & 1 & 1 & 1 \\
\hline
\end{tabular}

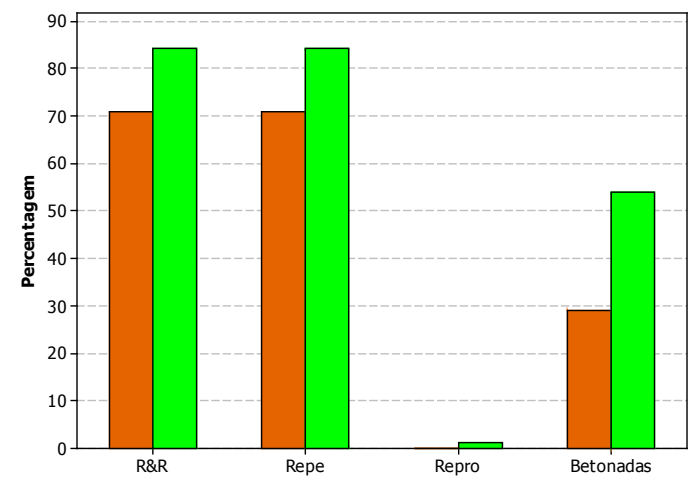

(a) SG

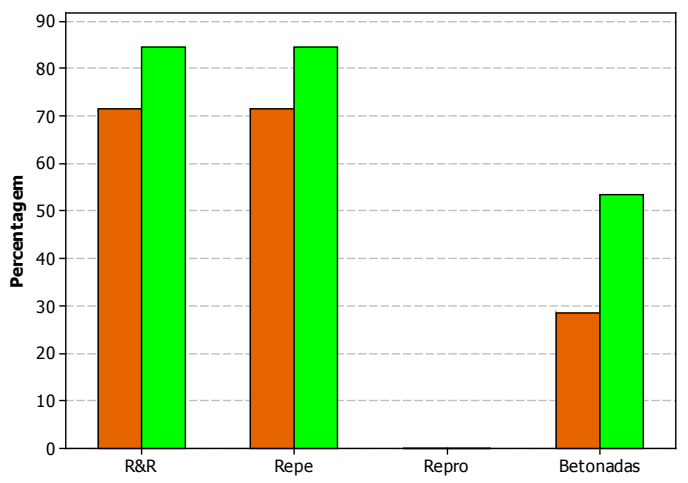

(b) $C G$ 


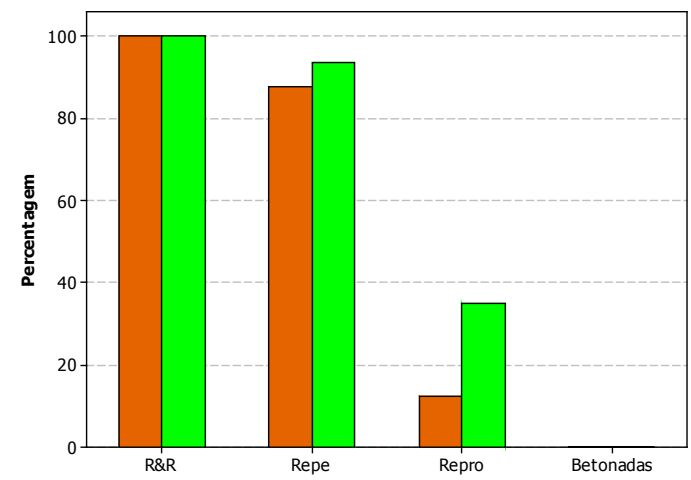

(c) $1 \mathrm{R}$

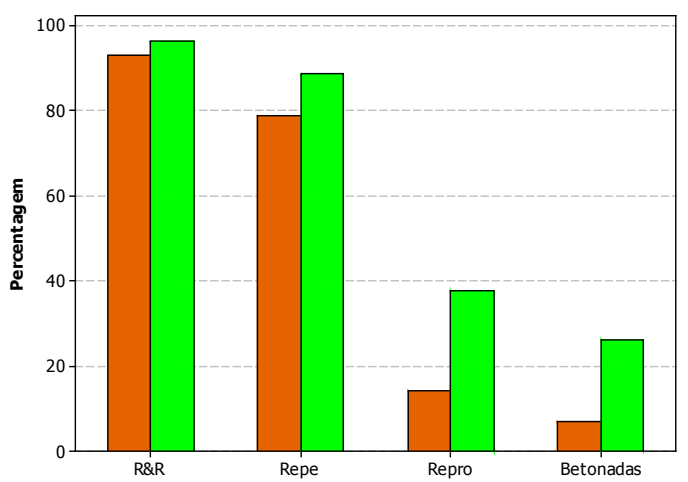

(d) $2 \mathrm{R}$

Figura 5.1.2.1.5 - Composição das variâncias e desvios-padrão dos agrupamentos Eci-1l-3bt070, por instrumentação

Observa-se que os agrupamentos Eci-1l-3bt-070 mantiveram os níveis muito distintos de dispersão dos resultados, onde continuou predominando a variância de ensaio (Variância devido à R\&R acima do $70 \%$ da Variância total) em relação à variância de produção (fração complementar da Variância total) em todos os casos.

Por outro lado, houve uma recuperação em relação ao plano secante na percepção do método sob CG à variação entre betonadas, equiparando-o ao método sob SG, mas com a vantagem da menor dispersão total.

V) Resumo

Apresentam-se na Fig. 5.1.2.1.6.a-d os histogramas e os parâmetros estatísticos relacionados aos resultados experimentais de cada agrupamento analisado.

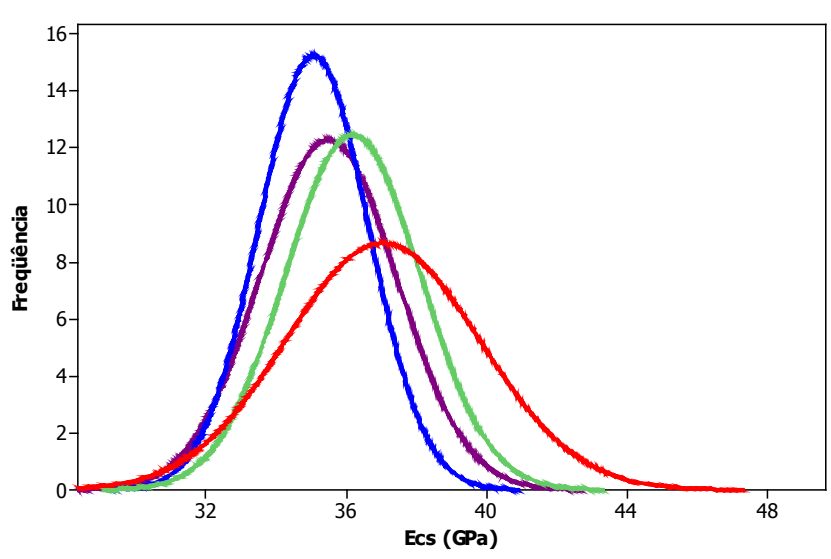

$\begin{array}{ccc}\text { Curva } & \text { Média } & \text { DP } \\ \text { Ecs-SG-3bt-040 } & 35,48 & 1,95 \\ \text { Ecs-CG-3bt-040 } & 35,06 & 1,57 \\ \text { Ecs-1R-3bt-040 } & 36,18 & 1,93 \\ \text { Ecs-2R-3bt-040 } & 37,03 & 2,77 \\ & & (\text { GPa })\end{array}$

(a) Ecs-1I-3bt-040 


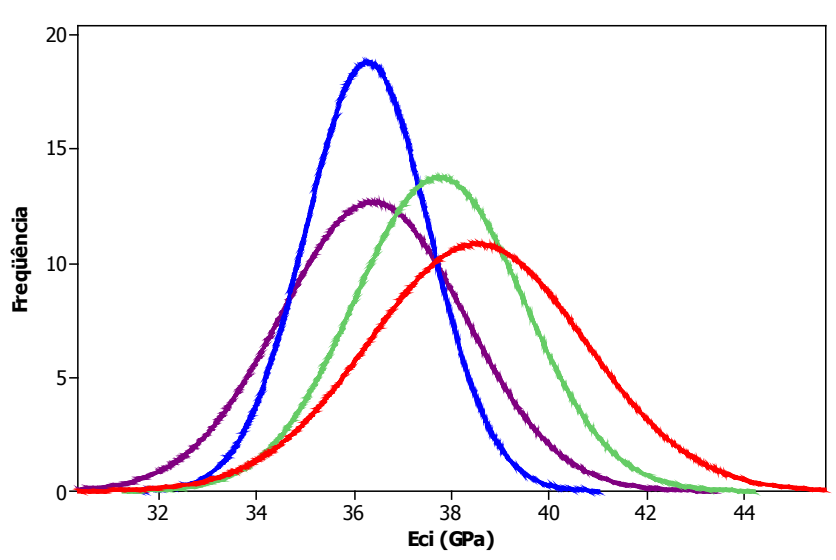

$\begin{array}{ccc}\text { Curva } & \text { Média } & \text { DP } \\ \text { Eci-SG-3bt-040 } & 36,38 & 1,89 \\ \text { Eci-CG-3bt-040 } & 36,27 & 1,28 \\ \text { Eci-1R-3bt-040 } & 37,74 & 1,74 \\ \text { Eci-2R-3bt-040 } & 38,52 & 2,22 \\ & & (\mathrm{GPa})\end{array}$

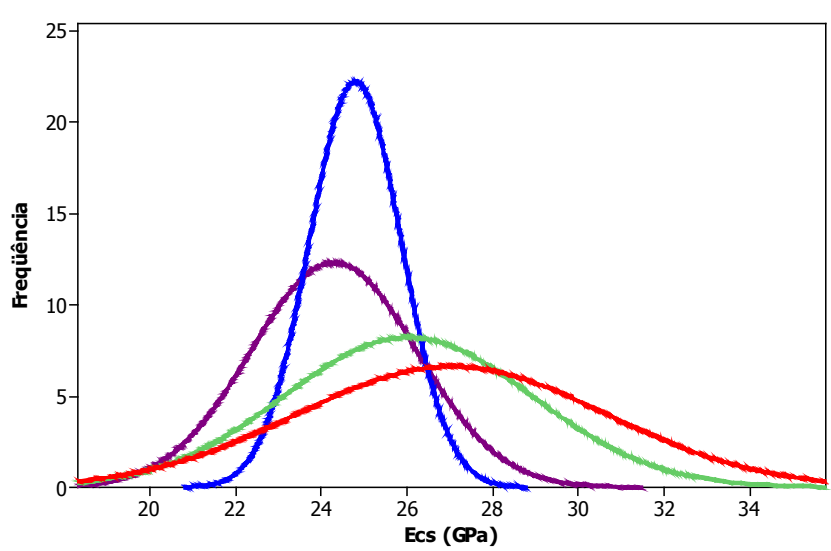

$\begin{array}{ccc}\text { Curva } & \text { Média } & \text { DP } \\ \text { Ecs-SG-3bt-070 } & 24,29 & 1,94 \\ \text { Ecs-CG-3bt-070 } & 24,79 & 1,08 \\ \text { Ecs-1R-3bt-070 } & 26,02 & 2,91 \\ \text { Ecs-2R-3bt-070 } & 27,04 & 3,61 \\ & & (\mathrm{GPa})\end{array}$

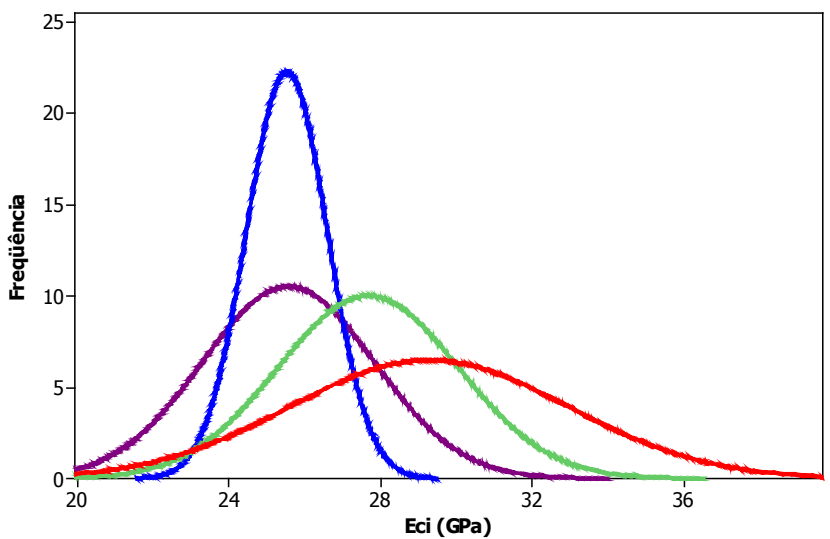

$\begin{array}{ccl}\text { Curva } & \text { Média } & \text { DP } \\ \text { Eci-SG-3bt-070 } & 25,56 & 2,27 \\ \text { Eci-CG-3bt-070 } & 25,52 & 1,07 \\ \text { Eci-1R-3bt-070 } & 27,67 & 2,39 \\ \text { Eci-2R-3bt-070 } & 29,28 & 3,68 \\ & & (\text { GPa) }\end{array}$

Figura 5.1.2.1.6 - Histogramas e estatística de cada agrupamento estudado de resultados de módulo de deformação

Fica claro que os menores resultados de dispersão do método de ensaio se deram com os dois concretos ensaiados sob o plano de carregamento tangente inicial, e principalmente sob a instrumentação CG. Essa conclusão ilustra bem a 
questão da influência dos procedimentos de ensaio que constituem fatores intervenientes nos resultados que, de certa forma, são minorados no caso do plano tangente inicial e na instrumentação de CG. No plano tangente inicial despreza-se, empiricamente, o arranjo de acomodação inicial da instrumentação e da amostra de concreto através dos carregamentos cíclicos que desprezam as deformações lidas nos medidores nos primeiros ciclos. Tal plano de carregamento também tende a promover uma distribuição cada vez mais eqüitativa das tensões na microestrutura do concreto, principalmente no entorno das regiões de menor rigidez mas de fissuração ainda estável, como a zona de transição pasta-agregados. Na instrumentação de CG diminuem-se as fontes de possíveis erros aleatórios intrínsecos à captação das deformações já discutidas anteriormente, principalmente aquelas advindas do trabalho do operador, como na preparação superficial dos corpos-de-prova para receber SG ou no posicionamento e aparafusamento da ancoragem de $1 \mathrm{R}$ e $2 \mathrm{R}$.

Esta análise comparativa pode ainda considerar alguns aspectos qualitativos:

- o procedimento de instrumentação de CG está entre aqueles mais simples e rápidos em termos de montagem;

- o método sob 1R ou 2R também podem oferecer rapidez quando utilizado por operador devidamente treinado e capacitado. O principal cuidado exigido no caso do exemplar/modelo utilizado neste programa experimental recaía sobre a deficiência de garantia de manutenção do posicionamento dos yokes superior e inferior do dispositivo, suportada apenas pelas duas hastes finas;

- o método sob SG exige maior tempo de montagem dos equipamentos auxiliares para a realização do ensaio e, diferentemente dos demais, é caracterizado pela não-reaproveitamento dos medidores após cada ensaio.

Os resultados da relação 'Desvio R\&R/Desvio total (\%)', ilustrados novamente na Fig. 5.1.2.1.7.a-d, indicaram que o método sob CG apresentou por mais vezes o menor índice e, conseqüentemente, a maior tendência de percepção da variação entre betonadas. No entanto, em apenas um agrupamento, Eci-1I-3bt-040, o método sob tal instrumentação configurou uma situação próxima da ideal para uma discussão de Validação Quanto à Precisão que seria a da combinação, ainda que subjetiva, dos fatores 'baixo desvio-padrão total' e 'alta percepção à variação entre betonadas'. Se fosse encontrada esta combinação com mais freqüência existiria, 
então, a possibilidade real de formatação das tolerâncias admissíveis para a atribuição do termo 'validado' ao método sob aquela ou qualquer outra instrumentação. Note-se que, mesmo assim, não é impeditivo que se continue analisando comparativamente o método sob cada instrumentação ou de forma global, independentemente da instrumentação.

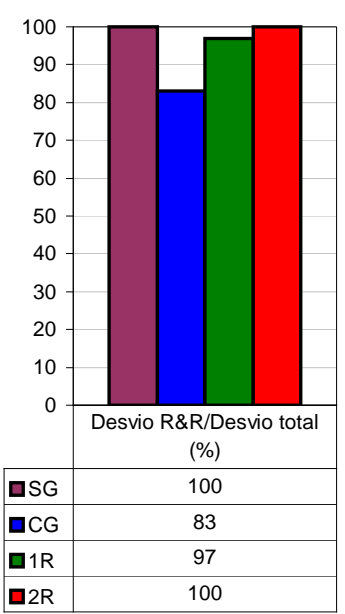

(a) Ecs-1I-3bt-040

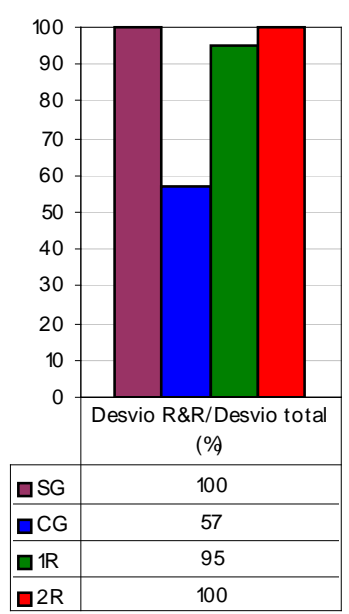

(b) Eci-11-3bt-040

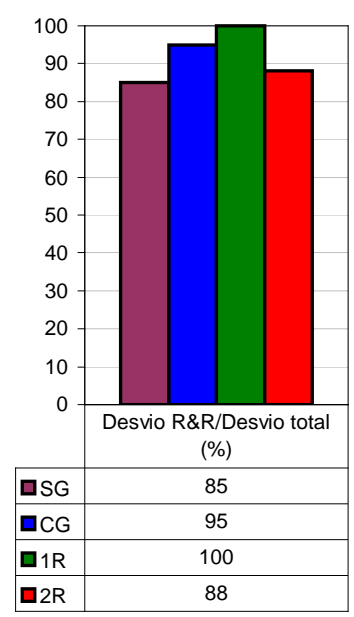

(c) Ecs-1I-3bt-070

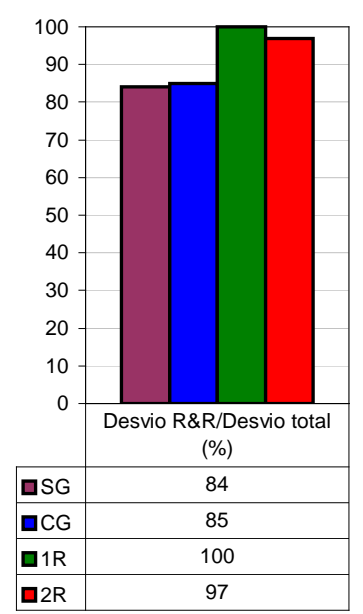

(d) Eci-1l-3bt-070

Figura 5.1.2.1.7 - Ilustração dos índices 'Desvio R\&R/Desvio total (\%)' de cada agrupamento

Surgem as seguintes dúvidas: já que não se consegue, nem no âmbito restrito desta pesquisa, chegar a resultados que concluam pela Validação Quanto à Precisão do método sob qualquer instrumentação, poderia-se estudar o oposto e concluir sobre o comprometimento com erros grosseiros de algum dos procedimentos? Ou, sob outro ângulo, estaria realmente um procedimento de instrumentação aparentemente tão preciso e historicamente tão validado como os SG recebendo uma classificação errônea? Não é essa uma instrumentação utilizada com sucesso na própria indústria automobilística de elevado rigor de validação em que a norma QS 9000 estabeleceu a utilização da relação 'Desvio R\&R/Devio total (\%)' abaixo de 30\% como um indicador eficiente da tendência de Validação Quanto à Precisão de um método ou sistema de medida?

Neste ponto, deve-se recordar que em termos de cálculo, até este momento, foram desconsideradas entre os indicadores de precisão as variações advindas da máquina de ensaios, da hipótese de perfeita semelhança entre corpos-de-prova irmãos e do próprio cálculo do módulo de deformação que depende, por exemplo, da 
tomada dos percentuais da resistência prévia que, se sabe, traduz-se numa faixa de dano e não em um valor absoluto.

Considere-se, por exemplo, a análise de precisão dos resultados do ensaio prévio de resistência das betonadas do programa experimental (Tab. 5.1.2.1.5 e Fig. 5.1.2.1.8.a-b e Fig. 5.1.2.1.9.a-b).

Tabela 5.1.2.1.5 - Cálculos de precisão dos ensaios de resistência à compressão (3bt)

\begin{tabular}{|c|c|c|}
\hline INDICADORES ESTATíSTICOS & Concreto 040 & Concreto 070 \\
\hline Média (MPa) & 59,39 & 24,56 \\
\hline Desvio-padrão (MPa) & 2,50 & 1,05 \\
\hline Incerteza da média (MPa) & 0,46 & 0,19 \\
\hline Desvio de repetitividade (MPa) & 1,44 & 0,82 \\
\hline Desvio de reprodutibilidade (MPa) & 0,00 & 0,16 \\
\hline Desvio de R\&R (MPa) & 1,44 & 0,84 \\
\hline Desvio de betonadas (MPa) & 2,46 & 0,77 \\
\hline Desvio-padrão total (MPa) & 2,85 & 1,14 \\
\hline Desvio R\&R/Desvio total (\%) & 50 & 74 \\
\hline Variância R\&R/Variância total (\%) & 25 & 54 \\
\hline Betonadas distinguidas & 2 & 1 \\
\hline
\end{tabular}

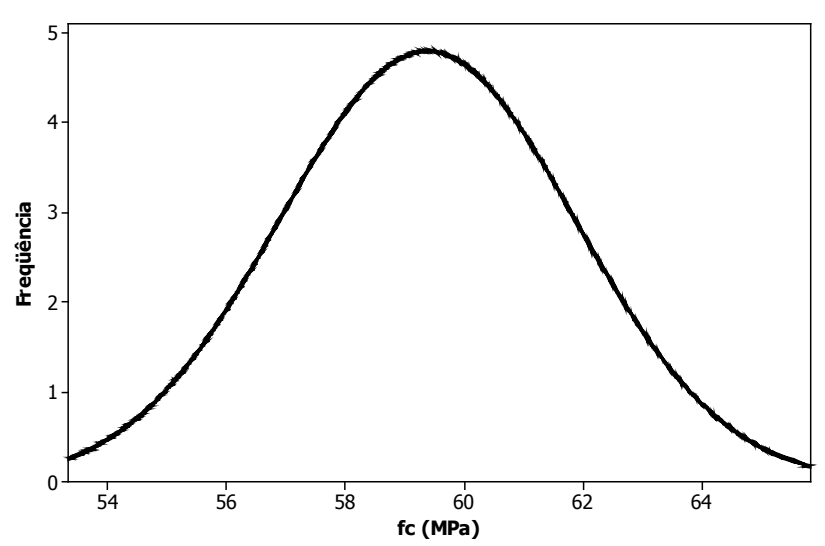

$\begin{array}{ccc}\text { Curva } & \text { Média } & \text { DP } \\ \text { fc-3bt-040 } & 59,39 & 2,50 \\ & & (\mathrm{MPa})\end{array}$

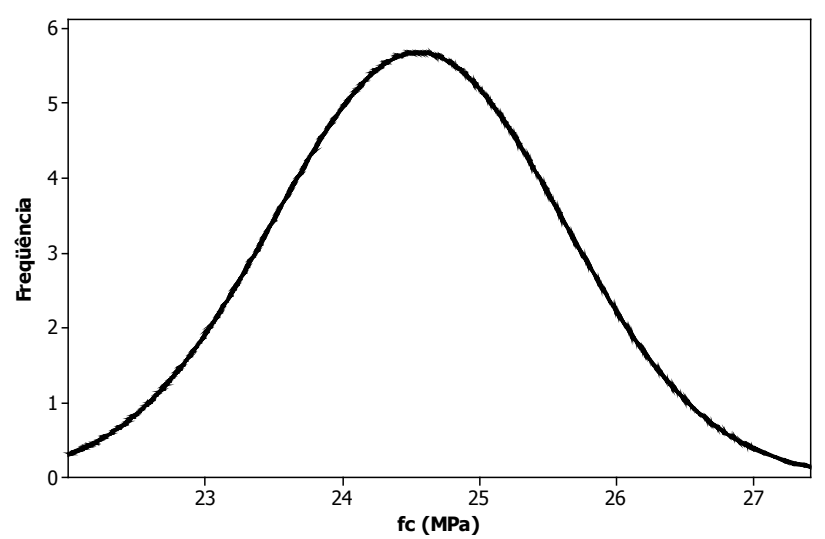

$\begin{array}{ccl}\text { Curva } & \text { Média } & \text { DP } \\ \text { fc-3bt-070 } & 24,56 & 1,05 \\ & & \text { (MPa) }\end{array}$

(b) Concreto 070

Figura 5.1.2.1.8 - Histogramas e estatística de cada agrupamento de resultados de resistência 


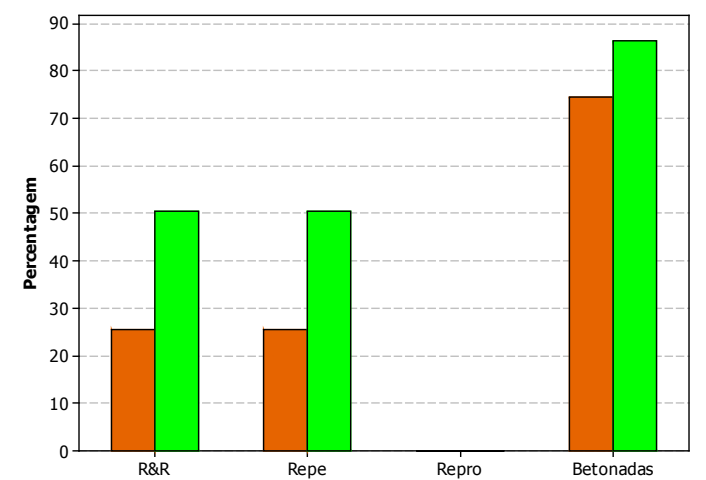

(a) Concreto 040

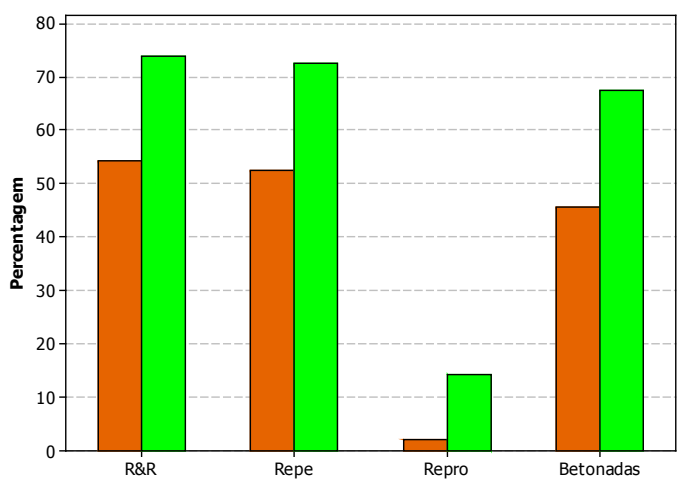

(b) Concreto 070

Figura 5.1.2.1.9 - Composição das variâncias e desvios-padrão dos agrupamentos dos resultados de resistência

Note-se que mesmo no ensaio prévio de resistência à compressão, que constitui a base do ensaio de determinação do módulo de deformação, o nível de variação decorrente do sistema de medida dado pela relação 'Desvio $\mathrm{R} \& \mathrm{R} /$ desvio total (\%) atingiu 50\% para o Concreto 040 e $74 \%$ para o Concreto 070 , o que não seria o recomendável em nenhum dos casos. Neste caso, a variação do método/sistema é dado pela máquina de ensaios, seu operador e pelo próprio cálculo da resistência. Note-se que não se conseguiu distinguir entre mais que duas betonadas, e ainda em apenas um dos traços.

Pode-se afirmar então que, quando se quantificava até agora a variação dos resultados dos ensaios de módulo de deformação, efetivamente também se estava recebendo/percebendo a interferência do efeito da variação do desempenho da máquina de ensaios ou da própria variação entre corpos-de-prova irmãos já sofrida no ensaio prévio de compressão. Esses efeitos de variação são inseparáveis e precisam ser contemplados paralelamente no estudo de validação ou de comparação dos métodos sob qualquer instrumentação para determinação do módulo de deformação do concreto. Em outras palavras, o método de ensaio de determinação do módulo de deformação do concreto é muito suscetível a qualquer variação microestrutural do concreto amostrado em cada um dos corpos-de-prova, bem como a qualquer variação da solicitação a que esta microestrutura é submetida ao longo do ensaio pela conseqüente variação da deformação causada. Por isso, o estabelecimento de restrições a qualquer das instrumentações de medida das deformações unicamente baseada na relação 'Desvio R\&R/Desvio total (\%), para 
este método de ensaio, não parece ser a melhor alternativa, devendo-se manter apenas para fins comparativos (não restritivos).

Isso quer dizer que no caso dos SG, por exemplo, para os resultados obtidos neste programa experimental, mantém-se a confiabilidade sobre o sistema mas ressalva-se que os procedimentos operacionais de instrumentação necessitam ser aprimorados para que se atinja o nível de desvio total e de percepção à variação entre amostras já mostrado pelos CG. No caso de $2 \mathrm{R}$, por outro lado, não se afirma terem ocorrido erros grosseiros de operação, mas é intuitivo o comprometimento dos resultados globais do método de ensaio se considerados os resultados sob esta instrumentação com o mesmo "peso" que os obtidos sob as demais. Lembra-se que, até o momento, foram identificadas para este procedimento mais fontes possíveis de erros aleatórios que para os demais.

Pode-se ainda, neste resumo, apresentar outros comentários dirigidos aos valores dos desvios observados nos experimentos sob cada instrumentação, mas sob a perspectiva do método como um todo para os usuários dos resultados. Ressalta-se, porém, que esses comentários se prestam, a rigor, unicamente ao entendimento do programa experimental realizado, pois também fazem parte dos objetivos desta dissertação como forma de testar a aplicabilidade da metodologia de pesquisa. Isto, obviamente, não impede que haja uma posterior complementação crítica, principalmente quanto à já prevista limitação desta pesquisa pela utilização de um operador único e um número restrito de traços de concreto, insumos materiais e exemplares/modelos de sistemas de medida das deformações.

Se considerados apenas os desvio-padrão de repetitividade, em que para SG foram da ordem de 1,70 a 2,00 GPa, para CG da ordem de 0,80 a 1,40 GPa, para $1 \mathrm{R}$ da ordem de 1,70 a 2,80 GPa, e para 2R da ordem de 2,20 a 3,40 GPa, fica nítido que o método de ensaio, sob qualquer das instrumentações, já apresenta uma amplitude de resultados amostrais bastante importante para análise do ponto de vista do controle de qualidade da propriedade como um todo. Considerando-se a amplitude de 5,15 desvios-padrão para o intervalo de confiança de 99\%, diferenças assim nos desvios podem acarretar uma amplitude entre os limites de repetitividade de 4,1 GPa (caso do menor desvio obtido sob CG) a até 17,5 GPa (maior desvio sob 2R). Para o desvio médio de 2,0 GPa, a amplitude de resultados para $99 \%$ de confiança seria de 10,3 GPa, o que é bastante significativo. 
$\mathrm{Na}$ área de ensaios mecânicos de concreto, o limite inferior da distribuição estatística dos resultados considerando a variação de produção e de ensaio (desviopadrão total) é utilizado como valor nominal ou característico da propriedade determinada, pois está vinculado ao valor mínimo garantido para a propriedade que se pode dispor no projeto de estruturas. O exemplo mais claro dessa prática se dá com a resistência característica do concreto $\left(f_{c k}\right) . O f_{c k}$ indica que inerente à magnitude da determinação experimental da propriedade há uma distribuição estatística, e esta só pode ser identificada completamente caso também se disponha do desvio-padrão da distribuição, que nada mais é que uma forma de quantificação dos erros de produção e ensaio.

Observe-se nas Tab. 5.1.2.1.6 a 5.1.2.1.9 outro aspecto peculiar dos resultados obtidos neste programa experimental. Para o Concreto 040 e o Concreto 070, o método de ensaio sob cada uma das instrumentações tendeu a maior semelhança quando considerados os valores nominais ou característicos obtidos

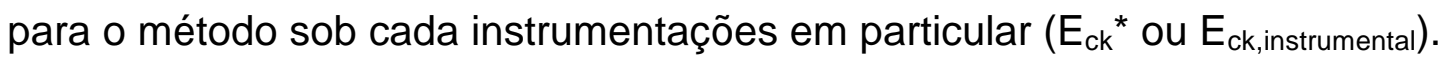

Tabela 5.1.2.1.6 - Valores característicos sob instrumentações particulares: Ecs-1I-3bt-040

\begin{tabular}{|c|c|c|c|c|c|c|}
\hline \multirow{2}{*}{ Índices } & \multicolumn{5}{|c|}{ Instrumentação } & \multirow{2}{*}{$\begin{array}{l}\text { Soma das } \\
\text { diferenças } \\
\text { quadráticas }\end{array}$} \\
\hline & SG & CG & 1R & $2 R$ & Média ${ }_{\text {GERAL }}$ & \\
\hline Média (GPa) & 35,48 & 35,06 & 36,18 & 37,03 & 35,94 & 2,2 \\
\hline Desvio-padrão (GPa) & 1,95 & 1,57 & 1,93 & 2,77 & & \\
\hline$E_{c k}{ }^{*}, I C=99 \%(G P a)^{(1)}$ & 30,5 & 31,0 & 31,2 & 29,9 & 30,65 & 1,0 \\
\hline$E_{c k}{ }^{*}, I C=95 \%(G P a)^{(2)}$ & 31,6 & 31,9 & 32,3 & 31,5 & 31,83 & 0,4 \\
\hline$E_{c k}{ }^{*}, I C=90 \%(G P a)^{(3)}$ & 32,3 & 32,5 & 33,0 & 32,5 & 32,55 & 0,3 \\
\hline$E_{c k}{ }^{*}, I C=87 \%(G P a){ }^{(4)}$ & 32,6 & 32,7 & 33,3 & 32,9 & 32,86 & 0,3 \\
\hline $\mathrm{E}_{\mathrm{ck}}{ }^{*}, \mathrm{IC}=80 \%(\mathrm{GPa})^{(5)}$ & 33,0 & 33,0 & 33,7 & 33,5 & 33,31 & 0,4 \\
\hline$E_{c k}{ }^{*}, I C=68 \%(G P a)^{(6)}$ & 33,5 & 33,5 & 34,3 & 34,3 & 33,88 & 0,6 \\
\hline
\end{tabular}
(1) IC = 99\% representa o intervalo de confiança de $99 \%$ dado pela amplitude de 5,15 vezes o desvio-padrão
(2) IC = 95\% representa o intervalo de confiança de $95 \%$ dado pela amplitude de 4,0 vezes o desvio-padrão
(3) IC $=90 \%$ representa o intervalo de confiança de $90 \%$ dado pela amplitude de 3,3 vezes o desvio-padrão
(4) IC $=87 \%$ representa o intervalo de confiança de $87 \%$ dado pela amplitude de 3,0 vezes o desvio-padrão
(5) IC $=80 \%$ representa o intervalo de confiança de $80 \%$ dado pela amplitude de 2,56 vezes o desvio-padrão
(6) IC $=68 \%$ representa o intervalo de confiança de $68 \%$ dado pela amplitude de 2,0 vezes o desvio-padrão 
Tabela 5.1.2.1.7 - Valores característicos sob instrumentações particulares: Eci-1l-3bt-040

\begin{tabular}{|c|c|c|c|c|c|c|}
\hline \multirow{2}{*}{ Índices } & \multicolumn{5}{|c|}{ Instrumentação } & \multirow{2}{*}{$\begin{array}{l}\text { Soma das } \\
\text { diferenças } \\
\text { quadráticas }\end{array}$} \\
\hline & SG & CG & $1 R$ & $2 R$ & Média $_{\text {GERAL }}$ & \\
\hline Média (GPa) & 36,38 & 36,27 & 37,74 & 38,52 & 37,23 & 3,6 \\
\hline Desvio-padrão (GPa) & 1,89 & 1,28 & 1,74 & 2,22 & & \\
\hline$E_{c k}{ }^{*}, I C=99 \%(G P a)^{(1)}$ & 31,5 & 33,0 & 33,3 & 32,8 & 32,64 & 1,8 \\
\hline$E_{c k}{ }^{*}, I C=95 \%(G P a)^{(2)}$ & 32,6 & 33,7 & 34,3 & 34,1 & 33,67 & 1,7 \\
\hline$E_{c k}{ }^{*}, I C=90 \%(G P a)^{(3)}$ & 33,3 & 34,2 & 34,9 & 34,9 & 34,29 & 1,7 \\
\hline$E_{c k}{ }^{*}, I C=87 \%(G P a)^{(4)}$ & 33,5 & 34,4 & 35,1 & 35,2 & 34,56 & 1,8 \\
\hline$E_{c k}{ }^{*}, I C=80 \%(G P a)^{(5)}$ & 34,0 & 34,6 & 35,5 & 35,7 & 34,95 & 1,9 \\
\hline$E_{c k}{ }^{*}, I C=68 \%(G P a)^{(6)}$ & 34,5 & 35,0 & 36,0 & 36,3 & 35,45 & 2,2 \\
\hline
\end{tabular}

(1) (2) (3) (4) (5) (6) idem.

Tabela 5.1.2.1.8 - Valores característicos sob instrumentações particulares: Ecs-1l-3bt-070

\begin{tabular}{|c|c|c|c|c|c|c|}
\hline \multirow{2}{*}{ Índices } & \multicolumn{5}{|c|}{ Instrumentação } & \multirow{2}{*}{$\begin{array}{l}\text { Soma das } \\
\text { diferenças } \\
\text { quadráticas }\end{array}$} \\
\hline & SG & CG & $1 R$ & 2R & Média ${ }_{\text {GERAL }}$ & \\
\hline Média (GPa) & 24,29 & 24,79 & 26,02 & 27,04 & 25,53 & 4,6 \\
\hline Desvio-padrão (GPa) & 1,94 & 1,08 & 2,91 & 3,61 & & \\
\hline$E_{c k}{ }^{*}, I C=99 \%(G P a)^{(1)}$ & 19,3 & 22,0 & 18,5 & 17,7 & 19,39 & 10,4 \\
\hline$E_{\mathrm{ck}^{*}}, \mathrm{IC}=95 \%(\mathrm{GPa})^{(2)}$ & 20,4 & 22,6 & 20,2 & 19,8 & 20,76 & 4,8 \\
\hline$E_{c k}{ }^{*}, I C=90 \%(G P a)^{(3)}$ & 21,1 & 23,0 & 21,2 & 21,1 & 21,60 & 2,7 \\
\hline$E_{c k}{ }^{*}, I C=87 \%(G P a)^{(4)}$ & 21,4 & 23,2 & 21,7 & 21,6 & 21,96 & 2,0 \\
\hline$E_{\mathrm{ck}^{*}}, \mathrm{IC}=80 \%(\mathrm{GPa})^{(5)}$ & 21,8 & 23,4 & 22,3 & 22,4 & 22,48 & 1,4 \\
\hline$E_{c k}{ }^{*}, I C=68 \%(G P a)^{(6)}$ & 22,3 & 23,7 & 23,1 & 23,4 & 23,15 & 1,0 \\
\hline
\end{tabular}

(1) (2) (3) (4) (5) (6) idem.

Tabela 5.1.2.1.9 - Valores característicos sob instrumentações particulares: Eci-11-3bt-070

\begin{tabular}{|c|c|c|c|c|c|c|}
\hline \multirow{2}{*}{ Índices } & \multicolumn{5}{|c|}{ Instrumentação } & \multirow{2}{*}{$\begin{array}{l}\text { Soma das } \\
\text { diferenças } \\
\text { quadráticas }\end{array}$} \\
\hline & SG & CG & $1 R$ & $2 \mathbf{R}$ & Média $_{\text {GERAL }}$ & \\
\hline Média (GPa) & 25,56 & 25,52 & 27,67 & 29,28 & 27,01 & 9,9 \\
\hline Desvio-padrão (GPa) & 2,27 & 1,07 & 2,39 & 3,68 & & \\
\hline$E_{c k}{ }^{*}, I C=99 \%(G P a)^{(1)}$ & 19,7 & 22,8 & 21,5 & 19,8 & 20,94 & 6,5 \\
\hline$E_{c k^{*}}, I C=95 \%(G P a)^{(2)}$ & 21,0 & 23,4 & 22,9 & 21,9 & 22,30 & 3,3 \\
\hline$E_{c k}{ }^{*}, I C=90 \%(G P a)^{(3)}$ & 21,8 & 23,8 & 23,7 & 23,2 & 23,12 & 2,5 \\
\hline$E_{c k}{ }^{\star}, I C=87 \%(G P a)^{(4)}$ & 22,2 & 23,9 & 24,1 & 23,8 & 23,47 & 2,4 \\
\hline$E_{c k}{ }^{*}, I C=80 \%(G P a)^{(5)}$ & 22,7 & 24,1 & 24,6 & 24,6 & 23,99 & 2,5 \\
\hline$E_{c k}{ }^{*}, I C=68 \%(G P a)^{(6)}$ & 23,3 & 24,4 & 25,3 & 25,6 & 24,65 & 3,2 \\
\hline
\end{tabular}

(1) (2) (3) (4) (5) (6) idem. 
A soma das diferenças quadráticas em relação às médias gerais é nitidamente menor no caso dos valores característicos. Se for considerado o intervalo de confiança usualmente recomendado para a resistência à compressão que é o de $90 \%$ - que garante $95 \%$ dos resultados maiores que o $\mathrm{f}_{\mathrm{ck}}$ - a soma das diferenças quadráticas no Concreto 040 cai $86 \%$ nos ensaios de plano secante e $53 \%$ nos ensaios de plano tangente inicial. No caso dos valores característicos das betonadas do Concreto 070 , a soma das diferenças quadráticas diminui $41 \%$ nos ensaios de plano secante e $75 \%$ nos ensaios de plano tangente inicial.

A causa dessa aproximação entre os valores é meramente estatística, mas sua utilidade física (prática) é inegável na caracterização dos concretos segundo esta propriedade mecânica, principalmente em termos de especificação.

Esse pode ser um indicador que aponte a direção da continuidade da nãorestrição em norma técnica do método de ensaio a apenas um ou alguns dos tipos de instrumentação estudados, caso se constate também em outros estudos.

\subsubsection{Cálculos da exatidão do método sob cada instrumentação}

A exatidão do método de ensaio sob cada uma das quatro instrumentações só poderia se dar com alto nível de confiabilidade caso se dispusesse de valores de referência para a avaliação dos resultados. Como não se dispõe, as estimativas de valor de referência e do desvio-padrão vêm da estatística robusta, podendo-se utilizar a mediana e a amplitude interquartílica (IQN) para os cálculos de exatidão.

Para o uso da técnica de cálculo do indicador de exatidão (Z-score), admitiuse que o programa experimental tivesse sido realizado por diversos laboratórios. Cada laboratório foi representado por um resultado individual de cada betonada, ao longo das diversas instrumentações. Ou seja, toda betonada teria sido ensaiada por 40 "laboratórios", sendo 10 referentes a cada instrumentação. Isso foi necessário porque a avaliação da exatidão sem que haja o valor de referência é normalmente feita de forma interlaboratorial. A mediana adotada como valor verdadeiro foi obtida do agrupamento das quatro instrumentações dentro de cada betonada. Ressalta-se, novamente, que como não houve variação de operador, espera-se menor reprovação de "laboratórios" do que poderia haver na realidade. A conceituação dos "laboratórios" como de exatidão questionável ou insatisfatória, segundo a técnica do Z-score, servirá de parâmetro para a avaliação de exatidão do método sob cada 
instrumentação e até para o método como um todo. As planilhas do estudo de exatidão são apresentadas nas Tab. 5.1.2.2.1 a 5.1.2.2.4 e Fig. 5.1.2.2.1 a 5.1.2.2.4.

I) Agrupamentos Ecs-1l-1bt-040 (tabela única para as 4 instrumentações)

Tabela 5.1.2.2.1 - Agrupamentos de módulo secante (Ecs), por betonada (1bt), do Concreto a/c 0,40 (040), por instrumentação: cálculo dos indicadores de exatidão

LablBetonada

SG

\begin{tabular}{|c|c|c|c|} 
SG & \multicolumn{1}{c}{ bt1 } & bt2 & bt3 \\
\hline $\mathbf{1}$ & 35,4 & 40,1 & 35,8 \\
\hline $\mathbf{2}$ & 36,2 & 34,1 & 36,1 \\
\hline $\mathbf{3}$ & 34,5 & 36,1 & 35,7 \\
\hline $\mathbf{4}$ & 34,3 & 37,6 & 31,0 \\
\hline $\mathbf{5}$ & 35,5 & 40,3 & 35,9 \\
\hline $\mathbf{6}$ & 35,9 & 32,9 & 35,8 \\
\hline $\mathbf{7}$ & 37,6 & 36,3 & 35,1 \\
\hline $\mathbf{8}$ & 33,2 & 32,1 & 34,7 \\
\hline $\mathbf{9}$ & 36,2 & 35,8 & 33,8 \\
\hline $\mathbf{1 0}$ & 34,3 & 36,5 & 35,7 \\
\hline
\end{tabular}

CG

\begin{tabular}{|c|c|c|c|}
\hline $\mathbf{1}$ & 33,2 & 35,8 & 30,1 \\
\hline $\mathbf{2}$ & 32,6 & 36,8 & 36,2 \\
\hline $\mathbf{3}$ & 34,3 & 36,8 & 37,6 \\
\hline $\mathbf{4}$ & 34,7 & 36,0 & 35,5 \\
\hline $\mathbf{5}$ & 33,2 & 34,7 & 35,3 \\
\hline $\mathbf{6}$ & 33,4 & 36,0 & 35,3 \\
\hline $\mathbf{7}$ & 35,1 & 37,0 & 35,0 \\
\hline $\mathbf{8}$ & 34,5 & 36,8 & 36,7 \\
\hline $\mathbf{9}$ & 34,4 & 34,7 & 36,6 \\
\hline $\mathbf{1 0}$ & 33,9 & 34,7 & 34,9 \\
\hline
\end{tabular}

$1 R$

\begin{tabular}{|l|l|l|l|}
\hline $\mathbf{R}$ & 36,6 & 40,7 & 35,8 \\
\hline $\mathbf{2}$ & 37,2 & 36,8 & 37,6 \\
\hline $\mathbf{3}$ & 35,9 & 34,5 & 36,2 \\
\hline $\mathbf{4}$ & 33,7 & 33,6 & 35,1 \\
\hline $\mathbf{5}$ & 33,7 & 38,3 & 40,2 \\
\hline $\mathbf{6}$ & 32,7 & 36,0 & 37,6 \\
\hline $\mathbf{7}$ & 34,8 & 36,8 & 34,3 \\
\hline $\mathbf{8}$ & 36,8 & 38,9 & 35,3 \\
\hline $\mathbf{9}$ & 37,5 & 35,2 & 36,9 \\
\hline $\mathbf{1 0}$ & 34,2 & 34,8 & 37,6 \\
\hline
\end{tabular}
2R

\begin{tabular}{|l|l|l|l|}
\hline $\mathbf{R}$ & & \\
\hline $\mathbf{1}$ & 34,5 & 36,0 & 47,9 \\
\hline $\mathbf{2}$ & 36,6 & 37,3 & 37,1 \\
\hline $\mathbf{3}$ & 36,6 & 39,7 & 33,2 \\
\hline $\mathbf{4}$ & 39,3 & 34,7 & 32,7 \\
\hline $\mathbf{5}$ & 34,7 & 35,6 & 37,5 \\
\hline $\mathbf{6}$ & 36,3 & 35,8 & 36,3 \\
\hline $\mathbf{7}$ & 40,4 & 35,2 & 38,3 \\
\hline $\mathbf{8}$ & 35,4 & 38,9 & 36,3 \\
\hline $\mathbf{9}$ & 39,5 & 37,6 & 38,7 \\
\hline $\mathbf{1 0}$ & 36,2 & 37,1 & 35,6 \\
\hline
\end{tabular}

Z-score

\begin{tabular}{|c|c|c|}
\multicolumn{1}{c|}{ bt1 } & \multicolumn{1}{c}{ bt2 } & \multicolumn{1}{c}{ bt3 } \\
\hline 0,29 & 2,67 & 0,00 \\
\hline 0,80 & $-1,28$ & 0,22 \\
\hline$-0,29$ & 0,03 & $-0,07$ \\
\hline$-0,42$ & 1,02 & $-3,50$ \\
\hline 0,35 & 2,80 & 0,07 \\
\hline 0,61 & $-2,07$ & 0,00 \\
\hline 1,70 & 0,16 & $-0,51$ \\
\hline$-1,12$ & $-2,60$ & $-0,80$ \\
\hline 0,80 & $-0,16$ & $-1,46$ \\
\hline$-0,42$ & 0,30 & $-0,07$ \\
\hline
\end{tabular}

\begin{tabular}{|c|c|c|}
\hline$-1,12$ & $-0,16$ & $-4,16$ \\
\hline$-1,51$ & 0,49 & 0,29 \\
\hline$-0,42$ & 0,49 & 1,31 \\
\hline$-0,16$ & $-0,03$ & $-0,22$ \\
\hline$-1,12$ & $-0,89$ & $-0,36$ \\
\hline$-1,00$ & $-0,03$ & $-0,36$ \\
\hline 0,10 & 0,63 & $-0,58$ \\
\hline$-0,29$ & 0,49 & 0,66 \\
\hline$-0,35$ & $-0,89$ & 0,58 \\
\hline$-0,67$ & $-0,89$ & $-0,66$ \\
\hline
\end{tabular}

\begin{tabular}{|c|c|c|}
\hline 1,06 & 3,06 & 0,00 \\
\hline 1,45 & 0,49 & 1,31 \\
\hline 0,61 & $-1,02$ & 0,29 \\
\hline$-0,80$ & $-1,61$ & $-0,51$ \\
\hline$-0,80$ & 1,48 & 3,21 \\
\hline$-1,45$ & $-0,03$ & 1,31 \\
\hline$-0,10$ & 0,49 & $-1,09$ \\
\hline 1,19 & 1,88 & $-0,36$ \\
\hline 1,64 & $-0,56$ & 0,80 \\
\hline$-0,48$ & $-0,82$ & 1,31 \\
\hline
\end{tabular}

\begin{tabular}{|c|c|c|}
\hline$-0,29$ & $-0,03$ & 8,82 \\
\hline 1,06 & 0,82 & 0,95 \\
\hline 1,06 & 2,40 & $-1,90$ \\
\hline 2,79 & $-0,89$ & $-2,26$ \\
\hline$-0,16$ & $-0,30$ & 1,24 \\
\hline 0,87 & $-0,16$ & 0,36 \\
\hline 3,50 & $-0,56$ & 1,82 \\
\hline 0,29 & 1,88 & 0,36 \\
\hline 2,92 & 1,02 & 2,11 \\
\hline 0,80 & 0,69 & $-0,15$ \\
\hline
\end{tabular}




$\begin{array}{lccc}\text { mediana } & 34,95 & 36,05 & 35,80 \\ \text { quartil 3 } & 36,38 & 37,15 & 36,95 \\ \text { quartil 1 } & 34,28 & 35,10 & 35,10 \\ \text { IQ } & 2,10 & 2,05 & 1,85 \\ \text { IQN } & 1,56 & 1,52 & 1,37 \\ \text { IQNmédio } & 1,48 & & \end{array}$

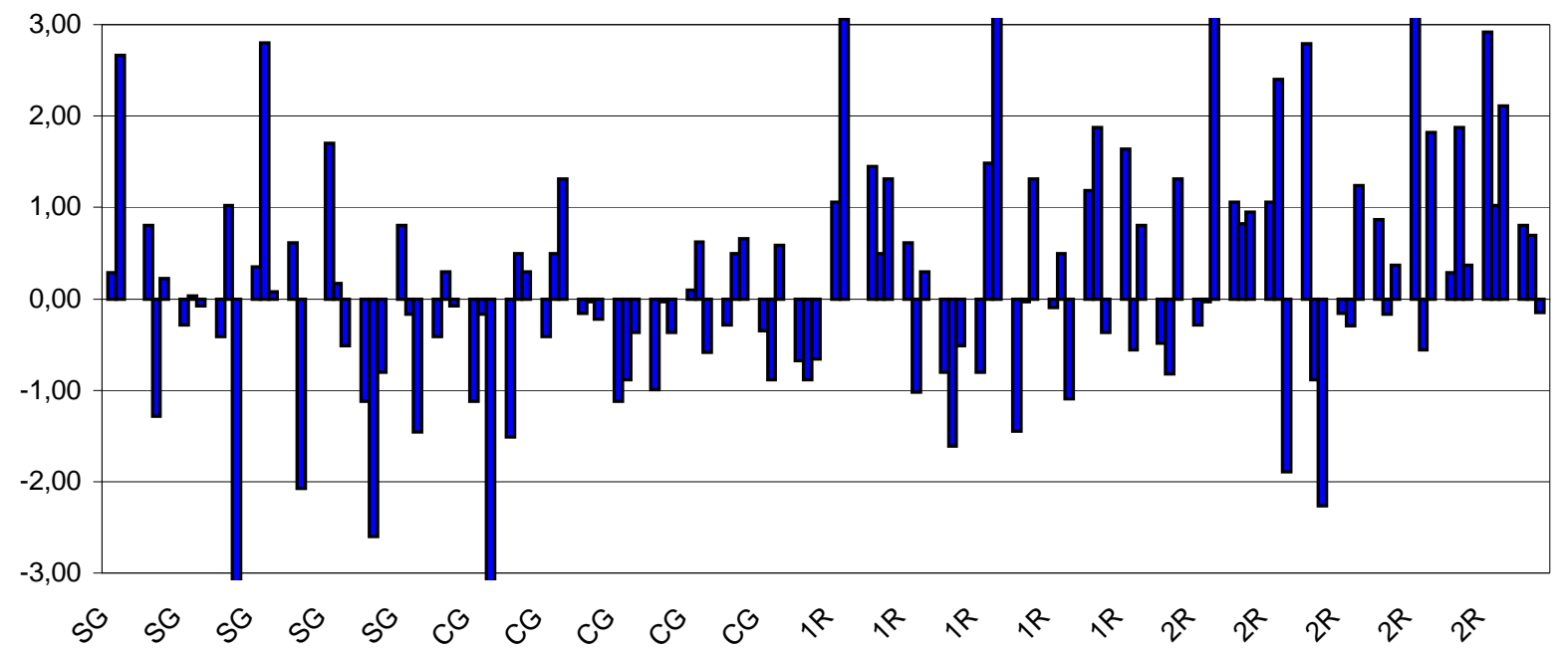

Figura 5.1.2.2.1 - Representação da distribuição dos Z-scores dos agrupamentos Ecs-1I-1bt040, por betonada, por instrumentação

Para os agrupamentos Ecs-1l-1bt-040, seis valores foram considerados de exatidão insatisfatória (SG-bt3, CG-bt3, 1R-bt2, 1R-bt3, 2R-bt1 e 2R-bt3, Z-score $\geq$ 3) e oito de exatidão questionável $(2 \leq Z$-score $<3)$ dois quais cinco sob $2 \mathrm{R}$, contra 30 de exatidão satisfatória $(1 \leq Z$-score $<2)$ e 76 de exatidão adequada $(Z$-score < 1). Lembra-se que Z-score indica o número de desvios-padrão normalizados em relação à mediana de cada betonada.

II) Agrupamentos Eci-1l-1bt-040 (tabela única para as 4 instrumentações) 
Tabela 5.1.2.2.2 - Agrupamentos de módulo tangente inicial (Eci), por betonada (1bt), do Concreto a/c 0,40 (040), por instrumentação: cálculo dos indicadores de exatidão

Lab\Betonada

SG

\begin{tabular}{|c|c|c|c|}
\hline SG & bt1 & bt2 & bt3 \\
\hline 1 & 35,8 & 35,3 & 36,5 \\
\hline 2 & 38,5 & 35,3 & 37,5 \\
\hline 3 & 34,7 & 36,2 & 37,0 \\
\hline 4 & 36,4 & 39,7 & 32,1 \\
\hline 5 & 35,7 & 40,7 & 36,9 \\
\hline 6 & 36,5 & 35,2 & 37,0 \\
\hline 7 & 39,9 & 36,8 & 36,1 \\
\hline 8 & 34,0 & 32,5 & 36,1 \\
\hline 9 & 36,6 & 37,5 & 35,0 \\
\hline 10 & 35,2 & 38,3 & 36,5 \\
\hline
\end{tabular}

CG

\begin{tabular}{|c|c|c|c|}
\hline $\mathbf{1}$ & 34,3 & 37,7 & 36,9 \\
\hline $\mathbf{2}$ & 33,7 & 38,1 & 37,0 \\
\hline $\mathbf{3}$ & 35,0 & 36,6 & 38,6 \\
\hline $\mathbf{4}$ & 35,4 & 36,8 & 36,4 \\
\hline $\mathbf{5}$ & 34,3 & 36,6 & 36,4 \\
\hline $\mathbf{6}$ & 34,3 & 37,1 & 36,4 \\
\hline $\mathbf{7}$ & 36,2 & 38,3 & 36,2 \\
\hline $\mathbf{8}$ & 35,4 & 37,8 & 37,5 \\
\hline $\mathbf{9}$ & 35,2 & 35,8 & 37,5 \\
\hline $\mathbf{1 0}$ & 35,0 & 35,9 & 35,8 \\
\hline
\end{tabular}
$1 \mathrm{R}$

1R
\begin{tabular}{|c|c|c|c|}
\hline $\mathbf{1}$ & 39,5 & 41,9 & 36,4 \\
\hline $\mathbf{2}$ & 38,2 & 38,5 & 39,3 \\
\hline $\mathbf{3}$ & 37,2 & 37,6 & 38,0 \\
\hline $\mathbf{4}$ & 35,5 & 36,4 & 36,8 \\
\hline $\mathbf{5}$ & 35,7 & 39,4 & 41,1 \\
\hline $\mathbf{6}$ & 35,3 & 37,6 & 39,0 \\
\hline $\mathbf{7}$ & 35,7 & 38,5 & 36,1 \\
\hline $\mathbf{8}$ & 37,2 & 40,4 & 36,8 \\
\hline $\mathbf{9}$ & 39,0 & 36,0 & 38,9 \\
\hline $\mathbf{1 0}$ & 35,5 & 36,4 & 38,4 \\
\hline
\end{tabular}
2R

\begin{tabular}{|c|c|c|c|}
\hline $\mathbf{1}$ & 35,2 & 38,6 & 40,5 \\
\hline $\mathbf{2}$ & 37,0 & 39,4 & 41,0 \\
\hline $\mathbf{3}$ & 38,8 & 41,0 & 34,8 \\
\hline $\mathbf{4}$ & 39,8 & 37,9 & 34,8 \\
\hline $\mathbf{5}$ & 35,5 & 36,8 & 40,1 \\
\hline $\mathbf{6}$ & 37,5 & 37,9 & 40,1 \\
\hline $\mathbf{7}$ & 40,3 & 36,0 & 39,2 \\
\hline $\mathbf{8}$ & 36,6 & 40,7 & 37,9 \\
\hline $\mathbf{9}$ & 39,3 & 44,7 & 40,5 \\
\hline \multicolumn{1}{|c|}{$\mathbf{1 0}$} & 37,5 & 38,8 & 37,5 \\
\hline mediana & $\mathbf{3 5 , 7 5}$ & $\mathbf{3 7 , 6 5}$ & $\mathbf{3 7 , 0 0}$ \\
quartil 3 & $\mathbf{3 7 , 5 0}$ & $\mathbf{3 8 , 6 5}$ & $\mathbf{3 8 , 6 8}$ \\
quartil 1 & $\mathbf{3 5 , 2 0}$ & $\mathbf{3 6 , 4 0}$ & $\mathbf{3 6 , 4 0}$ \\
IQ & $\mathbf{2 , 3 0}$ & $\mathbf{2 , 2 5}$ & $\mathbf{2 , 2 8}$ \\
IQN & $\mathbf{1 , 7 0}$ & $\mathbf{1 , 6 7}$ & $\mathbf{1 , 6 9}$ \\
IQNmédio & $\mathbf{1 , 6 9}$ & &
\end{tabular}

Z-score

\begin{tabular}{|c|c|c|}
\multicolumn{1}{c}{ bt1 } & \multicolumn{1}{c}{ bt2 } & bt3 \\
\hline 0,03 & $-1,41$ & $-0,30$ \\
\hline 1,61 & $-1,41$ & 0,30 \\
\hline$-0,62$ & $-0,87$ & 0,00 \\
\hline 0,38 & 1,23 & $-2,91$ \\
\hline$-0,03$ & 1,83 & $-0,06$ \\
\hline 0,44 & $-1,47$ & 0,00 \\
\hline 2,43 & $-0,51$ & $-0,53$ \\
\hline$-1,03$ & $-3,09$ & $-0,53$ \\
\hline 0,50 & $-0,09$ & $-1,19$ \\
\hline$-0,32$ & 0,39 & $-0,30$ \\
\hline
\end{tabular}

\begin{tabular}{|c|c|c|}
\hline$-0,85$ & 0,03 & $-0,06$ \\
\hline$-1,20$ & 0,27 & 0,00 \\
\hline$-0,44$ & $-0,63$ & 0,95 \\
\hline$-0,21$ & $-0,51$ & $-0,36$ \\
\hline$-0,85$ & $-0,63$ & $-0,36$ \\
\hline$-0,85$ & $-0,33$ & $-0,36$ \\
\hline 0,26 & 0,39 & $-0,47$ \\
\hline$-0,21$ & 0,09 & 0,30 \\
\hline$-0,32$ & $-1,11$ & 0,30 \\
\hline$-0,44$ & $-1,05$ & $-0,71$ \\
\hline
\end{tabular}

\begin{tabular}{|c|c|c|}
\hline 2,20 & 2,55 & $-0,36$ \\
\hline 1,44 & 0,51 & 1,36 \\
\hline 0,85 & $-0,03$ & 0,59 \\
\hline$-0,15$ & $-0,75$ & $-0,12$ \\
\hline$-0,03$ & 1,05 & 2,43 \\
\hline$-0,26$ & $-0,03$ & 1,19 \\
\hline$-0,03$ & 0,51 & $-0,53$ \\
\hline 0,85 & 1,65 & $-0,12$ \\
\hline 1,91 & $-0,99$ & 1,13 \\
\hline$-0,15$ & $-0,75$ & 0,83 \\
\hline
\end{tabular}

\begin{tabular}{|c|c|c|}
\hline$-0,32$ & 0,57 & 2,08 \\
\hline 0,73 & 1,05 & 2,37 \\
\hline 1,79 & 2,01 & $-1,30$ \\
\hline 2,38 & 0,15 & $-1,30$ \\
\hline$-0,15$ & $-0,51$ & 1,84 \\
\hline 1,03 & 0,15 & 1,84 \\
\hline 2,67 & $-0,99$ & 1,30 \\
\hline 0,50 & 1,83 & 0,53 \\
\hline 2,08 & 4,23 & 2,08 \\
\hline 1,03 & 0,69 & 0,30 \\
\hline
\end{tabular}




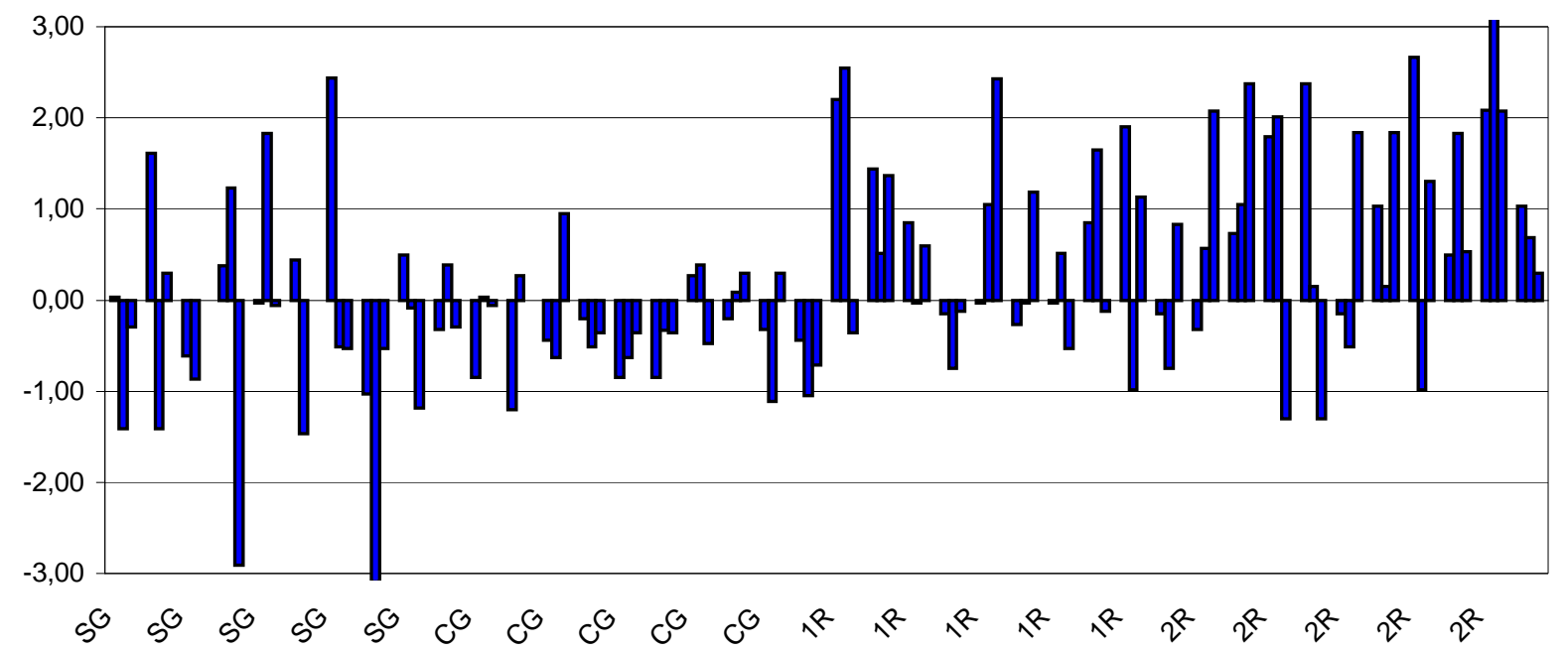

Figura 5.1.2.2.2 - Representação da distribuição dos Z-scores dos agrupamentos Eci-1l-1bt040, por betonada, por instrumentação

Para os agrupamentos Eci-1l-1bt-040, dois valores foram considerados de exatidão insatisfatória (SG-bt2 e 2R-bt2), 12 foram considerados de exatidão questionável dos quais sete sob $2 \mathrm{R}$, outros 28 obtiveram exatidão satisfatória e 78 de exatidão adequada.

III) Agrupamentos Ecs-1I-1bt-070 (tabela única para as 4 instrumentações)

Tabela 5.1.2.2.3 - Agrupamentos de módulo secante (Ecs), por betonada (1bt), do Concreto a/c $0,70(070)$, por instrumentação: cálculo dos indicadores de exatidão

Lab\Betonada

SG

SG
\begin{tabular}{|c|c|c|c|}
\hline $\mathbf{1}$ & bt1 & bt2 & bt3 \\
\hline $\mathbf{2}$ & 24,9 & 25,3 & 24,3 \\
\hline $\mathbf{3}$ & 23,2 & 26,3 & 24,0 \\
\hline $\mathbf{4}$ & 23,1 & 23,4 & 25,2 \\
\hline $\mathbf{5}$ & 21,5 & 25,9 & 24,0 \\
\hline $\mathbf{6}$ & 23,7 & 21,2 & 24,1 \\
\hline $\mathbf{7}$ & 20,0 & 25,7 & 25,9 \\
\hline $\mathbf{8}$ & 21,9 & 25,6 & 22,6 \\
\hline $\mathbf{9}$ & 22,2 & 25,9 & 25,9 \\
\hline $\mathbf{1 0}$ & 24,6 & 26,8 & 22,9 \\
\hline
\end{tabular}
CG

\begin{tabular}{|l|l|l|l|}
\hline $\mathbf{1}$ & 23,5 & 24,0 & 23,1 \\
\hline $\mathbf{2}$ & 24,7 & 25,2 & 23,6 \\
\hline $\mathbf{3}$ & 25,8 & 25,5 & 25,2 \\
\hline $\mathbf{4}$ & 24,5 & 26,0 & 25,7 \\
\hline $\mathbf{5}$ & 23,7 & 26,0 & 24,3 \\
\hline $\mathbf{6}$ & 25,8 & 25,2 & 25,0 \\
\hline $\mathbf{7}$ & 23,1 & 26,0 & 23,8 \\
\hline $\mathbf{8}$ & 25,5 & 24,5 & 24,5 \\
\hline $\mathbf{9}$ & 23,7 & 26,0 & 25,2 \\
\hline $\mathbf{1 0}$ & 22,8 & 24,5 & 27,2 \\
\hline
\end{tabular}

Z-score

\begin{tabular}{|c|c|c|}
\multicolumn{1}{c}{ bt1 } & \multicolumn{1}{c}{ bt2 } & bt3 \\
\hline 0,10 & $-0,22$ & $-0,29$ \\
\hline$-0,57$ & 0,15 & $-0,44$ \\
\hline$-0,30$ & $-0,94$ & 0,18 \\
\hline$-0,61$ & 0,00 & $-0,44$ \\
\hline$-1,24$ & $-1,76$ & $-0,39$ \\
\hline$-0,37$ & $-0,07$ & 0,54 \\
\hline$-1,83$ & $-0,30$ & $-1,17$ \\
\hline$-1,08$ & $-0,11$ & 0,54 \\
\hline$-0,96$ & 0,00 & $-1,01$ \\
\hline$-0,02$ & 0,34 & 2,41 \\
\hline
\end{tabular}

\begin{tabular}{|c|c|c|}
\hline$-0,45$ & $-0,71$ & $-0,91$ \\
\hline 0,02 & $-0,26$ & $-0,65$ \\
\hline 0,45 & $-0,15$ & 0,18 \\
\hline$-0,06$ & 0,04 & 0,44 \\
\hline$-0,37$ & 0,04 & $-0,29$ \\
\hline 0,45 & $-0,26$ & 0,08 \\
\hline$-0,61$ & 0,04 & $-0,54$ \\
\hline 0,33 & $-0,52$ & $-0,18$ \\
\hline$-0,37$ & 0,04 & 0,18 \\
\hline$-0,73$ & $-0,52$ & 1,22 \\
\hline
\end{tabular}


$1 R$

\begin{tabular}{|c|c|c|c|}
\hline $\mathbf{1}$ & 23,7 & 23,8 & 24,7 \\
\hline $\mathbf{2}$ & 27,3 & 30,8 & 24,3 \\
\hline $\mathbf{3}$ & 26,6 & 26,6 & 26,6 \\
\hline $\mathbf{4}$ & 27,3 & 27,4 & 22,5 \\
\hline $\mathbf{5}$ & 23,3 & 29,0 & 21,2 \\
\hline $\mathbf{6}$ & 28,0 & 25,7 & 27,4 \\
\hline $\mathbf{7}$ & 24,5 & 22,5 & 20,0 \\
\hline $\mathbf{8}$ & 25,0 & 24,0 & 31,2 \\
\hline $\mathbf{9}$ & 27,0 & 22,9 & 28,0 \\
\hline $\mathbf{1 0}$ & 30,4 & 28,0 & 30,8 \\
\hline
\end{tabular}

\begin{tabular}{|c|c|c|}
\hline$-0,37$ & $-0,79$ & $-0,08$ \\
\hline 1,04 & 1,84 & $-0,29$ \\
\hline 0,77 & 0,26 & 0,91 \\
\hline 1,04 & 0,56 & $-1,22$ \\
\hline$-0,53$ & 1,16 & $-1,89$ \\
\hline 1,32 & $-0,07$ & 1,32 \\
\hline$-0,06$ & $-1,27$ & $-2,52$ \\
\hline 0,14 & $-0,71$ & 3,29 \\
\hline 0,93 & $-1,12$ & 1,63 \\
\hline 2,26 & 0,79 & 3,09 \\
\hline
\end{tabular}

\begin{tabular}{|c|r|}
\hline $\mathbf{1}$ & 27 \\
\hline $\mathbf{2}$ & 32 \\
\hline $\mathbf{3}$ & 21 \\
\hline $\mathbf{4}$ & 20 \\
\hline $\mathbf{5}$ & 29 \\
\hline $\mathbf{6}$ & 25 \\
\hline $\mathbf{7}$ & 28 \\
\hline $\mathbf{8}$ & 30, \\
\hline $\mathbf{9}$ & 25 \\
\hline $\mathbf{1 0}$ & 26,4 \\
\hline
\end{tabular}

mediana 24,

quartil $3 \quad 26,70$

\begin{tabular}{l|l}
\hline & \\
\hline 75 & 29,0 \\
\hline
\end{tabular}

29,0

\begin{tabular}{|c|c|c|}
\hline 1,12 & 1,16 & 0,18 \\
\hline 3,13 & 1,05 & 0,34 \\
\hline$-1,20$ & $-0,52$ & $-0,91$ \\
\hline$-1,60$ & 1,72 & $-1,58$ \\
\hline 1,99 & $-0,52$ & 2,15 \\
\hline 0,33 & 1,16 & $-1,79$ \\
\hline 1,32 & 2,74 & 2,15 \\
\hline 2,15 & 0,94 & 1,79 \\
\hline 0,22 & 1,54 & 0,08 \\
\hline 0,69 & 3,30 & $-0,91$ \\
\hline
\end{tabular}

quartil 1

26,70

28

\begin{tabular}{l|r}
25,2 \\
28,7
\end{tabular}

25,5

\begin{tabular}{|l|l|l}
21,6 & 24,5 & 23,1 \\
\hline
\end{tabular}

\begin{tabular}{l|l}
20,6 & 30 \\
29,7 & 24 \\
\hline
\end{tabular}

\begin{tabular}{|l|l|l}
25,5 & 29,0 & 21,4 \\
\hline
\end{tabular}

\begin{tabular}{l|l}
28,0 & 33,2 \\
\hline 30,1 & 28,4
\end{tabular}

5,2

6,4

30

IQ

IQN

25,90

28,10

24,85

IQNmédio

2,38

$24,50 \quad 23,48$

$3,60 \quad 2,60$

$2,67 \quad 1,93$

\begin{tabular}{l}
21,8 \\
\hline 9,0 \\
9,4 \\
\hline 8,3 \\
\hline 5,0 \\
\hline, 1 \\
\hline, 85 \\
1,93 \\
480 \\
\hline, 48
\end{tabular}

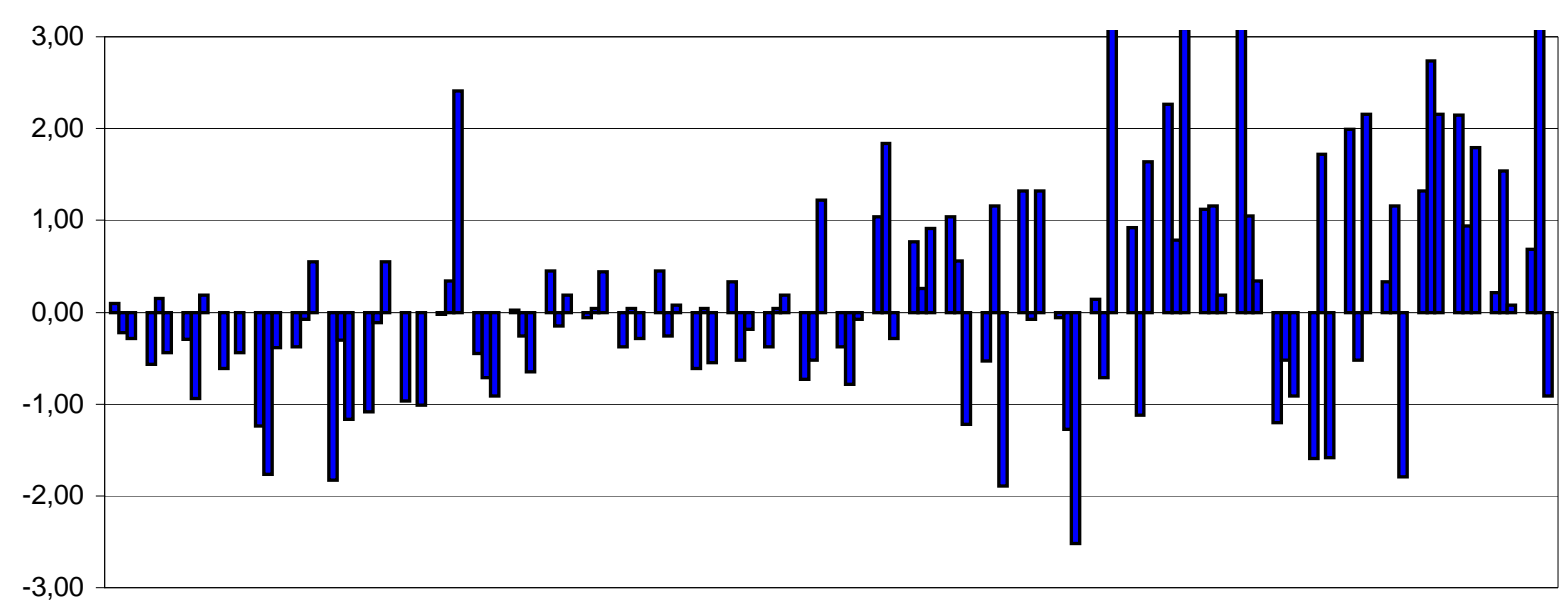

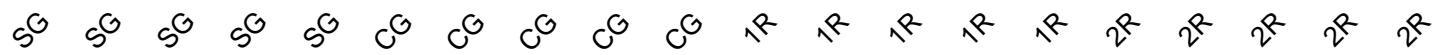

Figura 5.1.2.2.3 - Representação da distribuição dos Z-scores dos agrupamentos Ecs-11-1bt070, por betonada, por instrumentação

No agrupamento Ecs-11-3bt-070, quatro foram os valores considerados de exatidão insatisfatória (1R-bt3, 1R-bt3, 2R-bt1 e 2R-bt2), sete de exatidão questionável dos quais quatro sob $2 \mathrm{R}, 31$ de exatidão satisfatória e 78 de exatidão adequada. 
IV) Agrupamentos Eci-1I-1bt-070 (tabela única para as 4 instrumentações)

Tabela 5.1.2.2.4 - Agrupamentos de módulo tangente inicial (Eci), por betonada (1bt), do Concreto a/c 0,70 (070), por instrumentação: cálculo dos indicadores de exatidão

Lab\Betonada

SG

\begin{tabular}{|c|c|c|c|} 
SG & \multicolumn{1}{c}{ bt1 } & bt2 & bt3 \\
\hline $\mathbf{1}$ & 25,6 & 26,7 & 25,8 \\
\hline $\mathbf{2}$ & 23,9 & 27,3 & 25,5 \\
\hline $\mathbf{3}$ & 25,0 & 23,9 & 26,7 \\
\hline $\mathbf{4}$ & 23,5 & 27,3 & 25,4 \\
\hline $\mathbf{5}$ & 23,2 & 22,3 & 25,8 \\
\hline $\mathbf{6}$ & 24,9 & 26,8 & 27,3 \\
\hline $\mathbf{7}$ & 21,3 & 26,4 & 23,8 \\
\hline $\mathbf{8}$ & 22,9 & 26,7 & 27,1 \\
\hline $\mathbf{9}$ & 23,3 & 27,1 & 24,3 \\
\hline $\mathbf{1 0}$ & 25,5 & 28,1 & 33,4 \\
\hline
\end{tabular}

CG

\begin{tabular}{|l|l|l|l|}
\hline $\mathbf{1}$ & 24,2 & 25,2 & 24,3 \\
\hline $\mathbf{2}$ & 24,7 & 25,8 & 24,0 \\
\hline $\mathbf{3}$ & 25,5 & 26,3 & 26,3 \\
\hline $\mathbf{4}$ & 24,2 & 26,3 & 26,6 \\
\hline $\mathbf{5}$ & 26,1 & 26,6 & 25,5 \\
\hline $\mathbf{6}$ & 25,5 & 26,3 & 26,0 \\
\hline $\mathbf{7}$ & 24,0 & 27,2 & 24,5 \\
\hline $\mathbf{8}$ & 25,8 & 25,0 & 25,5 \\
\hline $\mathbf{9}$ & 24,7 & 26,9 & 26,0 \\
\hline $\mathbf{1 0}$ & 23,2 & 25,7 & 27,8 \\
\hline
\end{tabular}

$1 R$

\begin{tabular}{|c|c|c|c|}
\hline $\mathbf{1}$ & 26,4 & 25,0 & 26,3 \\
\hline $\mathbf{2}$ & 30,1 & 31,2 & 27,8 \\
\hline $\mathbf{3}$ & 28,0 & 28,4 & 28,4 \\
\hline $\mathbf{4}$ & 29,4 & 29,0 & 24,5 \\
\hline $\mathbf{5}$ & 25,5 & 30,5 & 23,1 \\
\hline $\mathbf{6}$ & 28,6 & 29,0 & 28,7 \\
\hline $\mathbf{7}$ & 27,0 & 25,0 & 21,5 \\
\hline $\mathbf{8}$ & 27,3 & 26,0 & 30,5 \\
\hline $\mathbf{9}$ & 28,0 & 25,5 & 29,0 \\
\hline $\mathbf{1 0}$ & 30,9 & 29,0 & 30,5 \\
\hline
\end{tabular}
2R

\begin{tabular}{|c|c|c|c|}
\hline $\mathbf{1}$ & 27,3 & 29,7 & 26,0 \\
\hline $\mathbf{2}$ & 35,6 & 31,2 & 29,7 \\
\hline $\mathbf{3}$ & 24,5 & 24,5 & 25,0 \\
\hline $\mathbf{4}$ & 23,5 & 30,5 & 25,0 \\
\hline $\mathbf{5}$ & 31,4 & 26,6 & 30,5 \\
\hline $\mathbf{6}$ & 27,3 & 29,7 & 24,0 \\
\hline $\mathbf{7}$ & 28,6 & 37,8 & 32,0 \\
\hline $\mathbf{8}$ & 31,7 & 31,2 & 32,0 \\
\hline $\mathbf{9}$ & 26,7 & 32,0 & 31,2 \\
\hline $\mathbf{1 0}$ & 28,0 & 36,7 & 28,4 \\
\hline mediana & $\mathbf{2 5 , 5 5}$ & $\mathbf{2 6 , 8 5}$ & $\mathbf{2 6 , 1 5}$ \\
quartil 3 & $\mathbf{2 8 , 0 0}$ & $\mathbf{2 9 , 1 8}$ & $\mathbf{2 8 , 4 8}$ \\
quartil 1 & $\mathbf{2 4 , 2 0}$ & $\mathbf{2 5 , 9 5}$ & $\mathbf{2 5 , 0 0}$ \\
IQ & $\mathbf{3 , 8 0}$ & $\mathbf{3 , 2 3}$ & $\mathbf{3 , 4 8}$ \\
IQN & $\mathbf{2 , 8 2}$ & $\mathbf{2 , 3 9}$ & $\mathbf{2 , 5 8}$ \\
IQNmédio & $\mathbf{2 , 5 9}$ & &
\end{tabular}

Z-score

\begin{tabular}{|c|c|c|}
\multicolumn{1}{c}{ bt1 } & \multicolumn{1}{c}{ bt2 } & bt3 \\
\hline 0,02 & $-0,06$ & $-0,14$ \\
\hline$-0,59$ & 0,19 & $-0,25$ \\
\hline$-0,20$ & $-1,23$ & 0,21 \\
\hline$-0,73$ & 0,19 & $-0,29$ \\
\hline$-0,83$ & $-1,90$ & $-0,14$ \\
\hline$-0,23$ & $-0,02$ & 0,45 \\
\hline$-1,51$ & $-0,19$ & $-0,91$ \\
\hline$-0,94$ & $-0,06$ & 0,37 \\
\hline$-0,80$ & 0,10 & $-0,72$ \\
\hline$-0,02$ & 0,52 & 2,81 \\
\hline
\end{tabular}

\begin{tabular}{|c|c|c|}
\hline$-0,48$ & $-0,69$ & $-0,72$ \\
\hline$-0,30$ & $-0,44$ & $-0,83$ \\
\hline$-0,02$ & $-0,23$ & 0,06 \\
\hline$-0,48$ & $-0,23$ & 0,17 \\
\hline 0,20 & $-0,10$ & $-0,25$ \\
\hline$-0,02$ & $-0,23$ & $-0,06$ \\
\hline$-0,55$ & 0,15 & $-0,64$ \\
\hline 0,09 & $-0,77$ & $-0,25$ \\
\hline$-0,30$ & 0,02 & $-0,06$ \\
\hline$-0,83$ & $-0,48$ & 0,64 \\
\hline
\end{tabular}

\begin{tabular}{|c|c|c|}
\hline 0,30 & $-0,77$ & 0,06 \\
\hline 1,62 & 1,82 & 0,64 \\
\hline 0,87 & 0,65 & 0,87 \\
\hline 1,37 & 0,90 & $-0,64$ \\
\hline$-0,02$ & 1,53 & $-1,18$ \\
\hline 1,08 & 0,90 & 0,99 \\
\hline 0,51 & $-0,77$ & $-1,81$ \\
\hline 0,62 & $-0,36$ & 1,69 \\
\hline 0,87 & $-0,56$ & 1,11 \\
\hline 1,90 & 0,90 & 1,69 \\
\hline
\end{tabular}

\begin{tabular}{|c|c|c|}
\hline 0,62 & 1,19 & $-0,06$ \\
\hline 3,57 & 1,82 & 1,38 \\
\hline$-0,37$ & $-0,98$ & $-0,45$ \\
\hline$-0,73$ & 1,53 & $-0,45$ \\
\hline 2,08 & $-0,10$ & 1,69 \\
\hline 0,62 & 1,19 & $-0,83$ \\
\hline 1,08 & 4,58 & 2,27 \\
\hline 2,18 & 1,82 & 2,27 \\
\hline 0,41 & 2,15 & 1,96 \\
\hline 0,87 & 4,12 & 0,87 \\
\hline
\end{tabular}




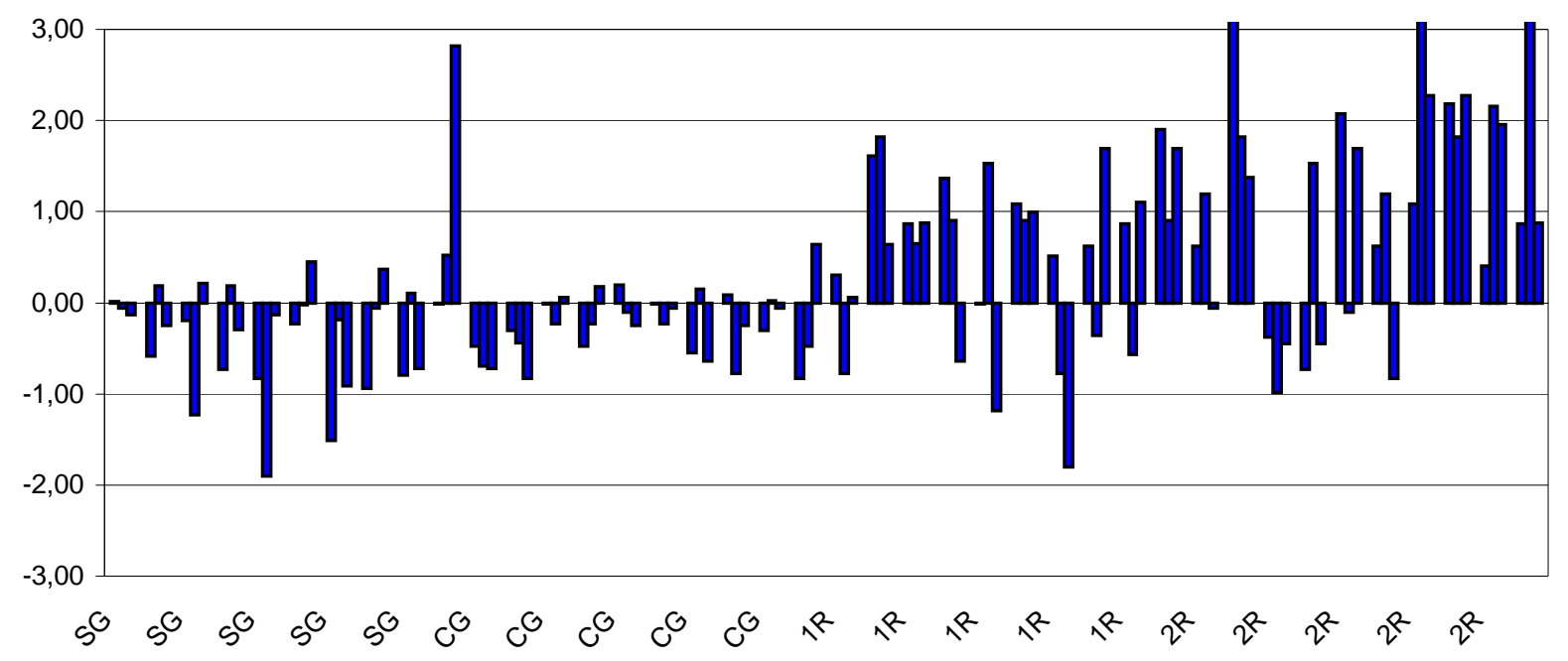

Figura 5.1.2.2.4 - Representação da distribuição dos Z-scores dos agrupamentos Eci-1l-1bt070, por betonada, por instrumentação

No agrupamento Eci-1l-3bt-070, apenas três foram os valores considerados de exatidão insatisfatória (2R-bt1, 2R-bt2 e 2R-bt2) e 6 de exatidão questionável dos quais 5 sob 2R, contra 23 de exatidão satisfatória e 88 de exatidão adequada.

V) Resumo

Pela técnica do Z-score, cada série de agrupamentos foi subdividida de forma em que aproximadamente $67,8 \%$ dos resultados eram classificados como de exatidão adequada (Z-score < 1), 27,5\% eram classificados como de exatidão satisfatória ( $1 \leq Z$-score $<2)$, 4,4\% de exatidão questionável $(2 \leq Z$-score $<3$ ) e 0,3\% de exatidão insatisfatória (Z-score $\geq 3)$.

Numa contagem simples da distribuição das classificações entre os resultados, nota-se que os resultados obtidos sob CG foram por mais vezes os mais próximos do valor verdadeiro adotado (mediana de cada betonada) e que os resultados sob $2 \mathrm{R}$ foram os mais distantes por mais vezes, conforme mostrado nas Tab. 5.1.2.2.5 e 5.1.2.2.6 e nas Fig. 5.1.2.2.5.a-d e 5.1.2.2.6.a-d. 
Tabela 5.1.2.2.5 - Freqüência de ocorrência das classificações de exatidão no conjunto dos agrupamentos de resultados de módulo de deformação secante (Ecs)

\begin{tabular}{|c|c|c|c|c|c|}
\hline \multirow{2}{*}{ Exatidão } & \multicolumn{5}{|c|}{ Freqüência de ocorrência (número de vezes) } \\
\cline { 2 - 6 } & $\mathbf{S G}$ & $\mathbf{C G}$ & $\mathbf{1 R}$ & $\mathbf{2 R}$ & Total \\
\hline Adequada & 43 & 54 & 30 & 27 & 154 \\
\hline Satisfatória & 11 & 5 & 24 & 20 & 60 \\
\hline Questionável & 5 & 0 & 2 & 9 & 16 \\
\hline Insatisfatória & 1 & 1 & 4 & 4 & 10 \\
\hline Total & 60 & 60 & 60 & 60 & 240 \\
\hline
\end{tabular}

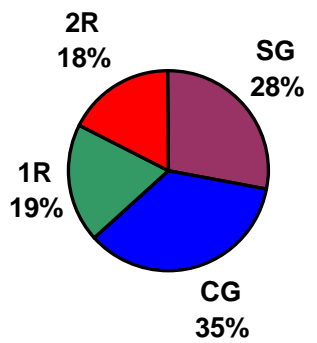

(a) Adequada

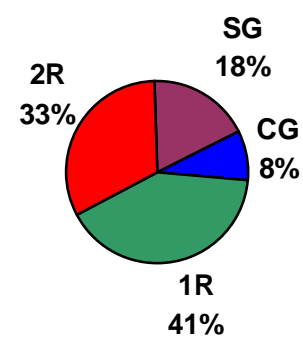

(b) Satisfatória

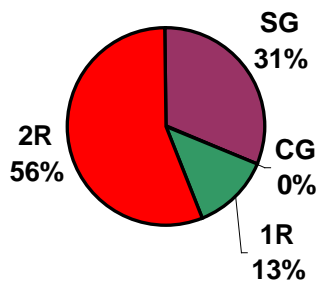

(c) Questionável

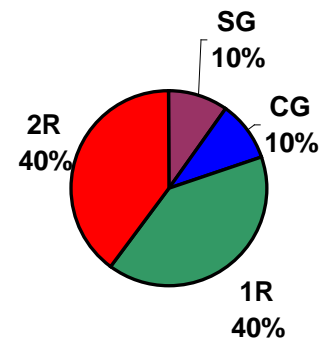

(d) Insatisfatória

Figura 5.1.2.2.5 - Representação da distribuição das classificações de exatidão (Ecs)

Tabela 5.1.2.2.6 - Freqüência de ocorrência das classificações de exatidão no conjunto dos agrupamentos de resultados de módulo de deformação tangente inicial (Eci)

\begin{tabular}{|c|c|c|c|c|c|}
\hline \multirow{2}{*}{ Exatidão } & \multicolumn{5}{|c|}{ Freqüência de ocorrência (número de vezes) } \\
\cline { 2 - 6 } & SG & CG & $\mathbf{1 R}$ & $\mathbf{2 R}$ & Total \\
\hline Adequada & 45 & 57 & 39 & 25 & 166 \\
\hline Satisfatória & 11 & 3 & 18 & 19 & 51 \\
\hline Questionável & 3 & 0 & 3 & 12 & 18 \\
\hline Insatisfatória & 1 & 0 & 0 & 4 & 5 \\
\hline Total & 60 & 60 & 60 & 60 & 240 \\
\hline
\end{tabular}

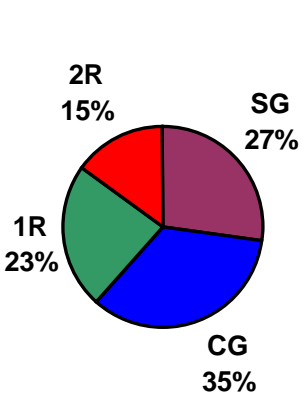

(a) Adequada

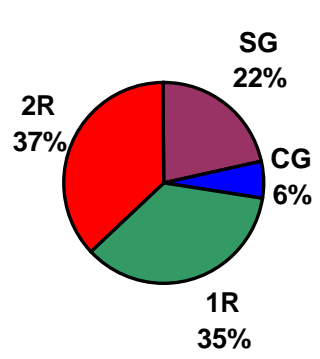

(b) Satisfatória

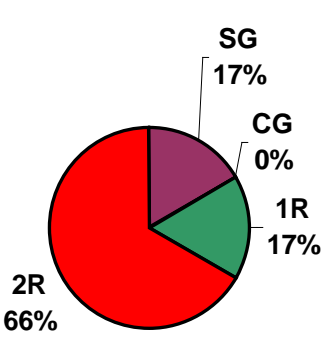

(c) Questionável

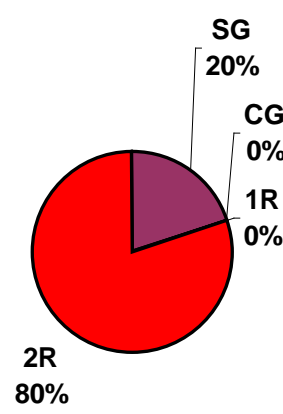

(d) Insatisfatória

Figura 5.1.2.2.6 - Representação da distribuição das classificações de exatidão (Eci) 
Note-se que, novamente, não cabe discussão objetiva sobre a Validação Quanto à Exatidão do método sob quaisquer das instrumentações. Há bases de conclusão unicamente sobre os resultados deste programa experimental que, mesmo assim, prefere-se tratar como apenas indicativas para a comparação dos procedimentos. De toda forma, esses resultados de exatidão corroboram com os resultados já obtidos para a precisão e delineiam com coerência a acurácia do método sob cada uma das instrumentações. Paralelamente, a metodologia da pesquisa parece desenvolver-se adequadamente para o tipo de ensaio, o material e os equipamentos utilizados dentro do regime de limitações relatado.

Cabe, agora, uma suposição: se a instrumentação $2 \mathrm{R}$ como se deu neste programa experimental sofreu tal nível de erros sistemáticos e aleatórios comparativamente maiores que os níveis de erros das demais, é viável que nos próximos itens que envolvem o cálculo da precisão e da exatidão globais do método de ensaio, isto é, independentemente das instrumentações, estude-se também a alternativa em que se vejam excluídos os resultados obtidos sob $2 \mathrm{R}$. Note-se que em termos de mecanismos de instrumentação, pode-se considerar o de $2 \mathrm{R}$ similar ao de $1 \mathrm{R}$, que continuará sendo contemplado. Neste caso, os outros mecanismos, SG e CG, completariam o estudo do método como um todo.

\subsubsection{Avaliação global do método de ensaio}

Na prática experimental da determinação do módulo de deformação do concreto, todas as instrumentações estudadas neste programa atendem à normalização vigente. Em outras palavras, subentende-se que o método de ensaio como um todo deveria ser independente da instrumentação para medição da deformação, ou, se dependente, o faria de modo não-significativo sobre o resultado final. Por isso, todos os resultados podem ser tratados como sendo de um único grupo. Os histogramas mostrados nas Fig. 5.1.3.1.a-d representam isso. 

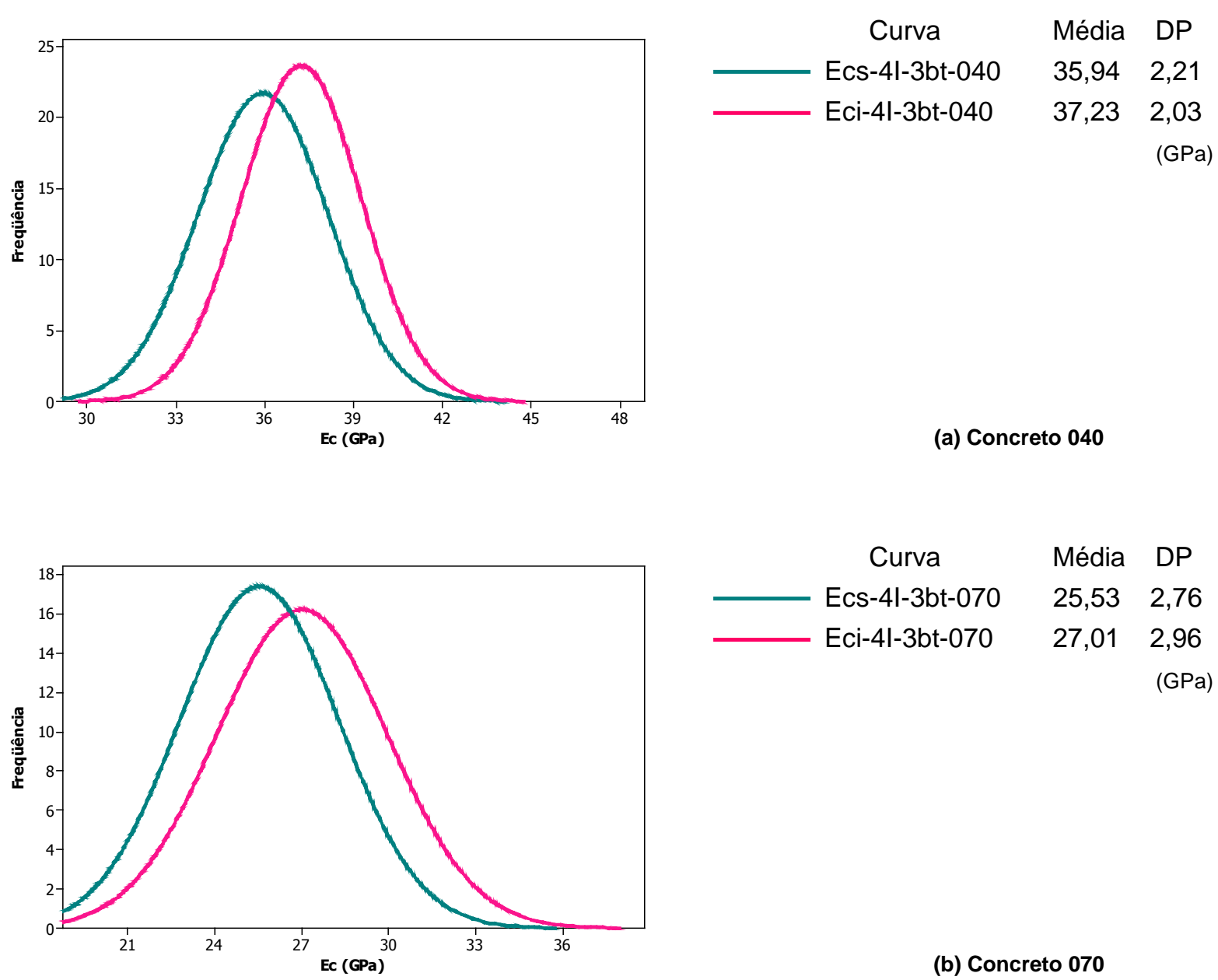

Figura 5.1.3.1 - Histogramas e estatística dos agrupamento globais por traço de concreto

Serão repetidos agora os roteiros de cálculo dos indicadores de precisão e exatidão para o método de ensaio, considerando os resultados globais independentemente das particularidades das instrumentações. Essa análise fornecerá também subsídios para a efetiva quantificação dos percentuais de variância decorrentes das fases de produção e de ensaio, além da comparação com os resultados do interlaboratorial relatado por Inácio; Andrade e Bittencourt (2006).

\subsubsection{Cálculos da precisão do método global}

A composição das variâncias será então baseada na variação dos procedimentos de amostragem (variação de produção das betonadas) e os de ensaio propriamente ditos, conforme a Fig. 5.1.3.1.1. 


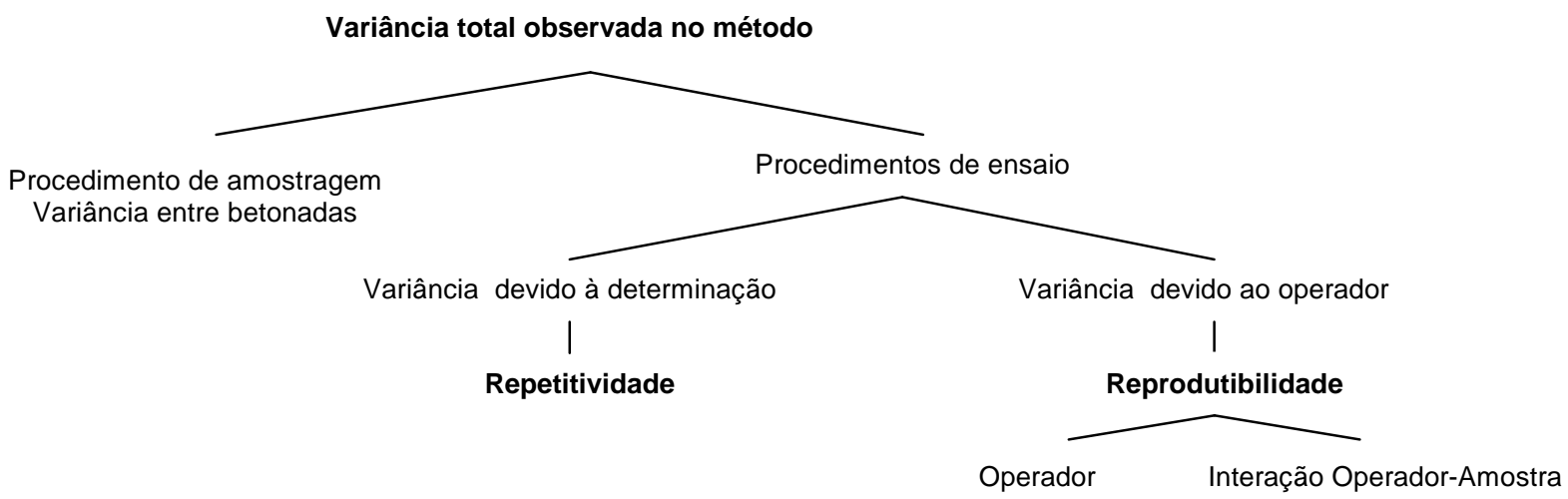

Figura 5.1.3.1.1 - Composição das variâncias dos resultados Independentemente da instrumentação

Admitiu-se que houve dois operadores diferentes nas determinações e que cada um deles ensaiou metade dos corpos-de-prova sob cada instrumentação em cada betonada, repetindo a tendência de anulação do valor do desvio de reprodutibilidade.

Seguem agora na Tab. 5.1.3.1.1 e nas Fig. 5.1.3.1.2.a-d os resultados dos indicadores de precisão para os valores de módulo de deformação obtidos com o método de ensaio independentemente da instrumentação, seguidos de alguns comentários.

I) Ecs-4I-3bt-040, Eci-4I-3bt-040, Ecs-4I-3bt-070 e Eci-4I-3bt-070

Tabela 5.1.3.1.1 - Agrupamentos de módulo secante (Ecs) e tangente inicial (Eci) de três betonadas (3bt) dos Concretos a/c 0,40 (040) e a/c 0,70 (070), independentemente das quatro instrumentações (4I): cálculo dos indicadores de precisão

\begin{tabular}{|c|c|c|c|c|}
\hline INDICADORES ESTATíSTICOS & Ecs-040 & Eci-040 & Ecs-070 & Eci-070 \\
\hline Média (GPa) & 35,94 & 37,23 & 25,53 & 27,01 \\
\hline Desvio-padrão (GPa) & 2,21 & 2,03 & 2,76 & 2,96 \\
\hline Desvio de repetitividade (GPa) & 2,19 & 1,97 & 2,69 & 2,89 \\
\hline Desvio de reprodutibilidade (GPa) & 0,00 & 0,00 & 0,38 & 0,50 \\
\hline Desvio R\&R (GPa) & 2,19 & 1,97 & 2,72 & 2,94 \\
\hline Desvio de betonadas (GPa) & 0,37 & 0,62 & 0,65 & 0,60 \\
\hline Desvio-padrão total (GPa) & 2,22 & 2,07 & 2,79 & 3,00 \\
\hline Desvio R\&R/Desvio total (\%) & 99 & 95 & 97 & 98 \\
\hline Variância R\&R/Variância total (\%) & 97 & 91 & 95 & 96 \\
\hline Betonadas distinguidas & 1 & 1 & 1 & 1 \\
\hline
\end{tabular}




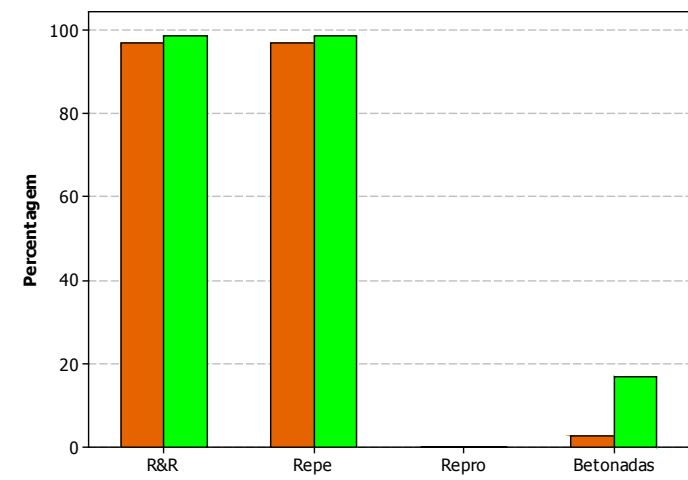

(a) Ecs-4I-3bt-040

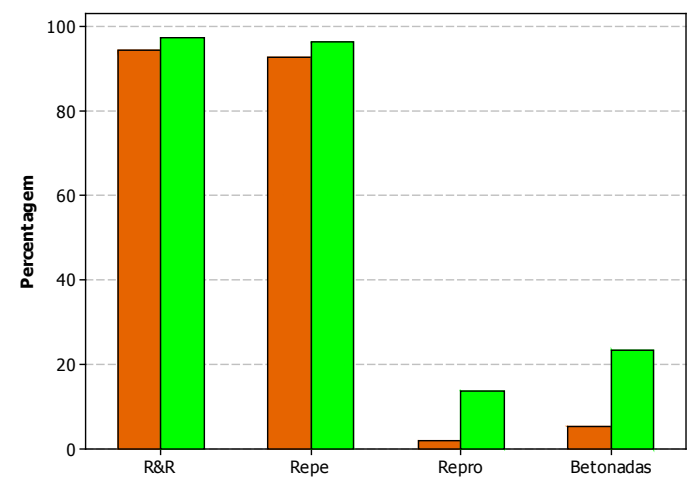

(c) Ecs-4I-3bt-070

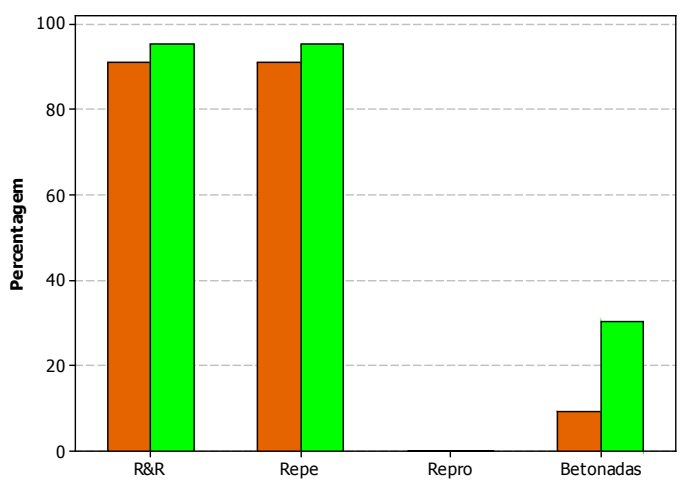

(b) Eci-4l-3bt-040

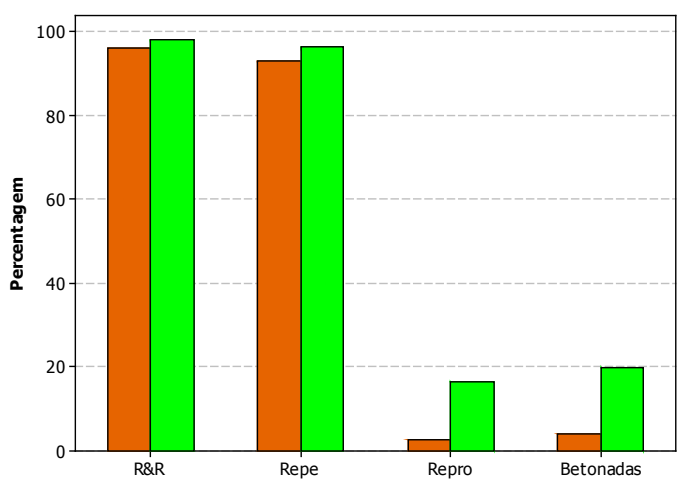

(d) Eci-4l-3bt-070

Figura 5.1.3.1.2 - Composição das variâncias e desvios-padrão dos agrupamentos dos concretos e planos de carregamento, independentemente das quatro instrumentações

Observa-se que todos os resultados mostraram uma preponderância da variação devido à $R \& R$ em relação à variação devido às betonadas. $A$ Variância devido à $R \& R$ ficou acima de $80 \%$ da Variância total em todos os casos. O resultado da relação 'Desvio R\&R / Desvio total (\%)' também indicou de forma generalizada a falta de percepção à Variação entre betonadas em todos os casos, ficando acima de $90 \%$. Note-se que em valores absolutos, os Desvios devido à R\&R e os Desviospadrão totais dos agrupamentos estiveram entre 2,0 e 3,0 GPa, valores significativos do ponto de vista da Engenharia.

No Desvio de R\&R predominou o Desvio devido à repetitividade. O Desvio de reprodutibilidade foi bastante baixo em todos os casos, tendo mesmo se anulado para o Concreto 040. É intuitivo, porém, que se houvesse operadores distintos esses valores tenderiam a ser maiores e aumentando ainda mais a importância final do valor do conjunto $(R \& R)$.

Analise-se agora a repetição do estudo anterior com a exclusão dos resultados obtidos sob a instrumentação $2 \mathrm{R}$. Esse critério é baseado nos resultados 
particulares mostrados anteriormente, onde o método sob $2 \mathrm{R}$ apresentou-se como o de maiores desvios. Os resultados constam da Tab. 5.1.3.1.2. e Fig. 5.1.3.1.3.a-d.

II) Ecs-3I-3bt-040, Eci-3I-3bt-040, Ecs-3I-3bt-070 e Eci-3I-3bt-070 (SG, CG e 1R)

Tabela 5.1.3.1.2 - Agrupamentos de módulo secante (Ecs) e tangente inicial (Eci) de três betonadas (3bt) dos Concretos a/c 0,40 (040) e a/c 0,70 (070), independentemente de três instrumentações (3I): cálculo dos indicadores de precisão

\begin{tabular}{|c|c|c|c|c|}
\hline INDICADORES ESTATÍSTICOS & Ecs-040 & Eci-040 & Ecs-070 & Eci-070 \\
\hline Média (GPa) & 35,57 & 36,80 & 25,03 & 26,25 \\
\hline Desvio-padrão (GPa) & 1,86 & 1,77 & 2,21 & 2,22 \\
\hline Desvio de repetitividade (GPa) & 1,80 & 1,70 & 2,17 & 2,20 \\
\hline Desvio de reprodutibilidade (GPa) & 0,00 & 0,00 & 0,65 & 0,00 \\
\hline Desvio R\&R (GPa) & 1,80 & 1,70 & 2,26 & 2,20 \\
\hline Desvio de betonadas (GPa) & 0,61 & 0,62 & 0,00 & 0,43 \\
\hline Desvio-padrão total (GPa) & 1,90 & 1,81 & 2,26 & 2,24 \\
\hline Desvio R\&R/Desvio total (\%) & 95 & 94 & 100 & 98 \\
\hline Variância R\&R/Variância total (\%) & 90 & 88 & 100 & 96 \\
\hline Betonadas distinguidas & 1 & 1 & 1 & 1 \\
\hline
\end{tabular}

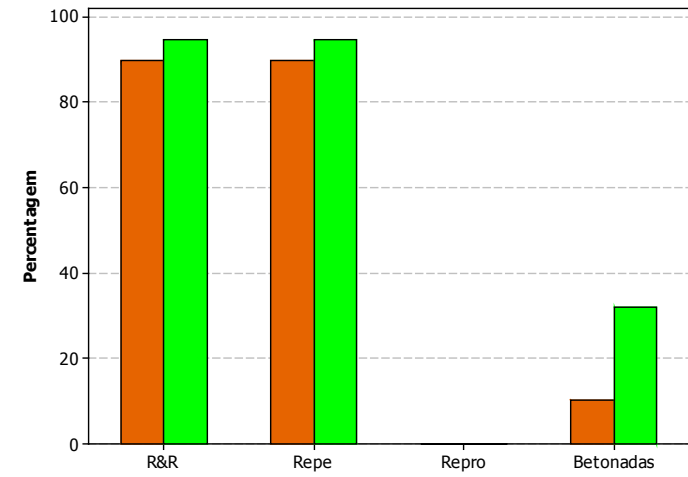

(a) Ecs-3I-3bt-040

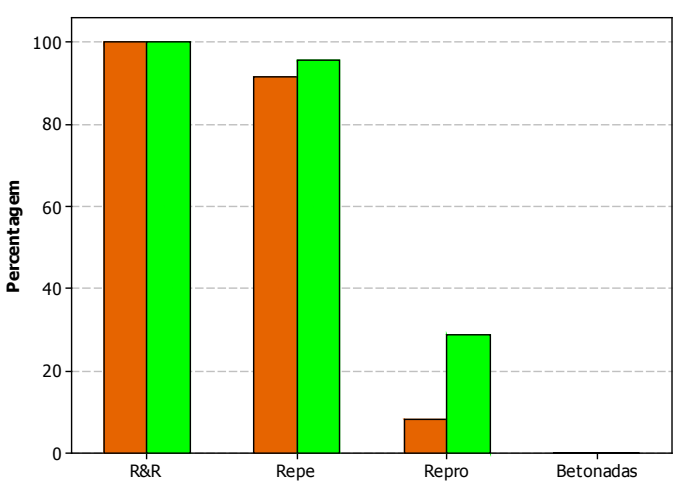

(c) Ecs-3I-3bt-070

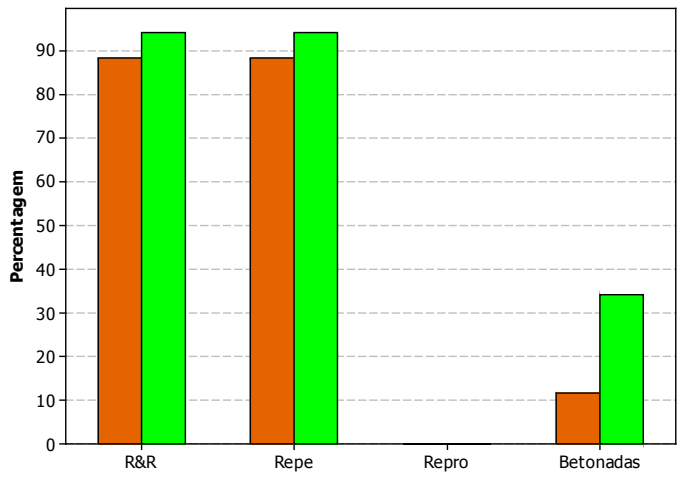

(b) Eci-3I-3bt-040

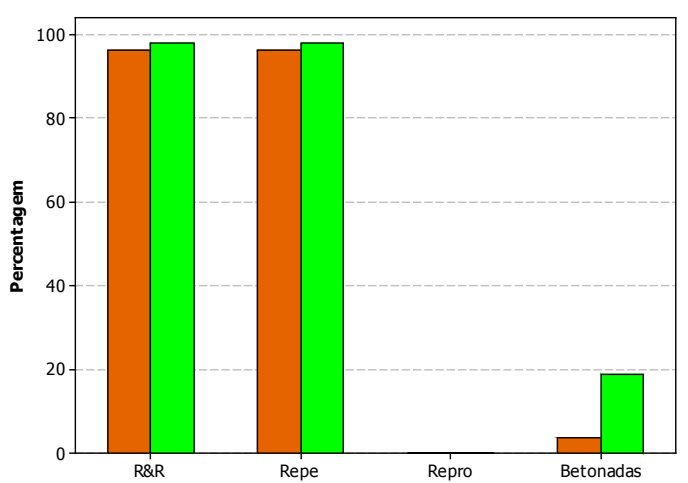

(d) Eci-3I-3bt-070

Figura 5.1.3.1.3 - Composição das variâncias e desvios-padrão dos agrupamentos dos concretos e planos de carregamento, independentemente de três instrumentações (3I) 
Observa-se que os resultados continuam mostrando uma preponderância do Desvio devido à $R \& R$ em relação ao Desvio devido às betonadas, mas a magnitude dos valores do Desvio devido à R\&R decresceu da faixa de 1,97 a 2,89 GPa com as quatro instrumentações para a faixa de 1,70 a $2,26 \mathrm{GPa}$ com as três instrumentações, o que é significativo. A Variância devido à $R \& R$ permaneceu acima de $80 \%$ da Variância total em todos os casos. O resultado da relação 'Desvio $R \& R$ / Desvio total (\%)' também permaneceu acima de 90\%.

O comentário que se deve fazer a respeito desses novos resultados é que as magnitudes desses valores de dispersão continuam insuficientes para a validação ou invalidação do método de ensaio, ainda que continuem imperceptíveis as variações dos resultados entre betonadas.

$\mathrm{Na}$ prática experimental normal, as três betonadas seriam mesmo consideradas iguais. Da mesma forma, valores de desvio-padrão total na faixa de 1,77 a 2,22 GPa como foi obtido para 3I-3bt - contemplando-se as variações de produção e ensaio, ainda que defasado da variação de reprodutibilidade independentemente da instrumentação considerando-se SG, CG e 1R, poderiam também ser considerados satisfatórios.

II.a) Verificação extra entre instrumentações e influência sobre o método global

Uma outra verificação ainda pode ser feita no sentido de calcular o impacto da variabilidade causada pela exclusão na análise dos resultados obtidos sob $2 \mathrm{R}$.

Suponha-se a análise global que considera cada instrumentação como realizada por um operador diferente conforme a Tab. 5.1.3.1.3 e as Fig. 5.1.3.1.4.ad. Tem-se que o desvio devido à repetitividade indicará a variação "dentro" das instrumentações e o desvio devido à reprodutibilidade indicará a variação "entre" as instrumentações. 
Tabela 5.1.3.1.3 - Agrupamentos de módulo secante (Ecs) e tangente inicial (Eci) de três betonadas (3bt) dos Concretos a/c 0,40 (040) e a/c 0,70 (070), independentemente de três instrumentações (3I), sendo operador=instrumentação: cálculo dos indicadores de precisão

\begin{tabular}{|c|c|c|c|c|}
\hline INDICADORES ESTATísTICOS & Ecs-040 & Eci-040 & Ecs-070 & Eci-070 \\
\hline Média (GPa) & 35,57 & 36,80 & 25,03 & 26,25 \\
\hline Desvio-padrão (GPa) & 1,86 & 1,77 & 2,21 & 2,22 \\
\hline Desvio de repetitividade (GPa) & 1,75 & 1,56 & 2,10 & 1,90 \\
\hline Desvio de reprodutibilidade (GPa) & 0,46 & 0,82 & 0,80 & 1,32 \\
\hline Desvio R\&R (GPa) & 1,81 & 1,76 & 2,24 & 2,32 \\
\hline Desvio de betonadas (GPa) & 0,61 & 0,60 & 0,32 & 0,20 \\
\hline Desvio-padrão total (GPa) & 1,91 & 1,86 & 2,27 & 2,32 \\
\hline Desvio R\&R/Desvio total (\%) & 95 & 95 & 99 & 100 \\
\hline Variância Repe/Variância total (\%) & 84 & 70 & 85 & 67 \\
\hline Variância Repro/Variância total (\%) & 6 & 20 & 13 & 32 \\
\hline Variância R\&R/Variância total (\%) & 90 & 90 & 98 & 99 \\
\hline Variância Bet/Variância total (\%) & 10 & 10 & 2 & 1 \\
\hline Betonadas distinguidas & 1 & 1 & 1 & 1 \\
\hline
\end{tabular}

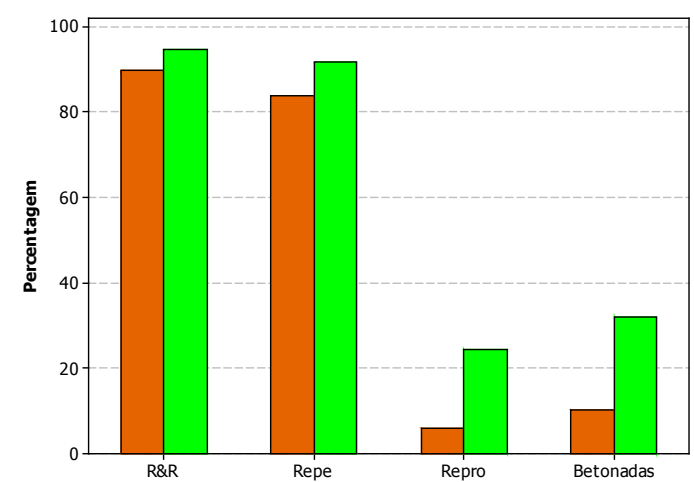

(a) Ecs-3I-3bt-040

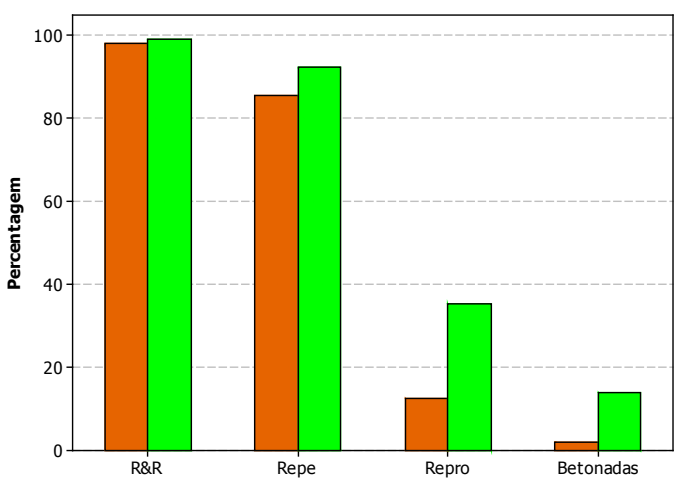

(c) Ecs-3I-3bt-070

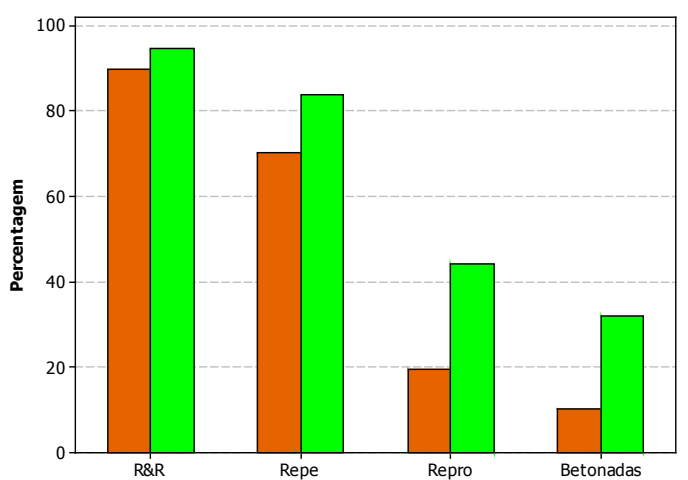

(b) Eci-3l-3bt-040

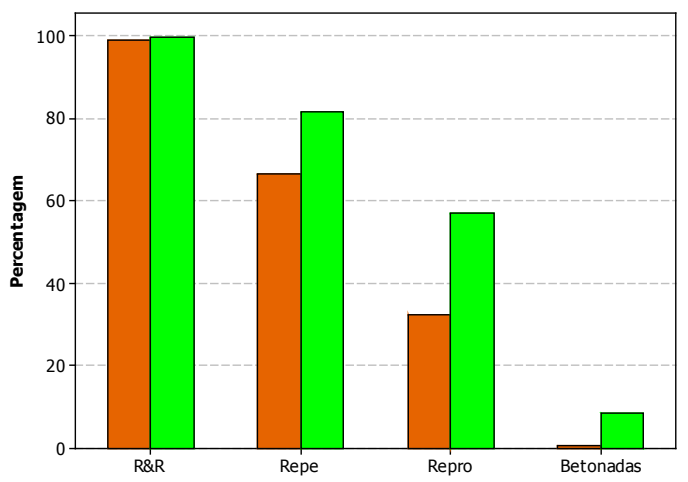

(d) Eci-3l-3bt-070

Figura 5.1.3.1.4 - Composição das variâncias e desvios-padrão dos agrupamentos dos concretos e planos de carregamento, independentemente de três instrumentações (3I), sendo operador=instrumentação

Observa-se que os resultados mostram uma preponderância do Desvio devido à repetitividade em relação ao Desvio devido à reprodutibilidade, 
evidenciados nos itens 'Variância Repe/Variância total (\%)' e 'Variância Repro/Variância total (\%)' acrescentados à tabela. A Variância devido à repetitividade ficou entre 67 e $85 \%$ da Variância total enquanto que a devido à reprodutibilidade ficou menor ou igual a 32\%. Então, a variação "entre" instrumentações mostrou-se menor que aquela "dentro" das instrumentações, considerando-se os resultados globais. A variância "entre" betonadas dada pelo indicador 'Variância Bet/Variância total (\%)' se mostrou pequena em todos os casos.

Não se deve esquecer que associada à variação de repetitividade de ensaio está a consideração de que os corpos-de-prova irmão são iguais entre si, o que explicaria uma parte da variação "dentro" das instrumentações.

Como a variação "entre" instrumentações mostrou-se mais baixa, cabe também a reexecução de uma outra verificação realizada no início do capítulo, mas agora adaptada a desconsideração dos resultados sob 2R:

- Os resultados do método de ensaio sob cada uma das três instrumentações (SG, CG e 1R) podem ser considerados estatisticamente iguais?

- As três betonadas ensaiadas com sob estes procedimentos podem ser consideradas estatisticamente iguais?

Através da função ANOVA, tem-se que (Tab. 5.1.3.1.4):

Tabela 5.1.3.1.4 - Verificação de 3I-3bt: instrumentações e betonadas

\begin{tabular}{|c|c|c|c|}
\cline { 3 - 4 } \multicolumn{2}{c|}{} & \multicolumn{2}{c|}{ São estatisticamente iguais ? } \\
\hline \multirow{2}{*}{ Plano } & Concreto & Instrumentações & Betonadas \\
\hline \multirow{2}{*}{ Ecs } & 040 & Sim & Não \\
\cline { 2 - 4 } & 070 & Não & Sim \\
\hline \multirow{2}{*}{ Eci } & 040 & Não & Não \\
\cline { 2 - 4 } & 070 & Não & Sim \\
\hline
\end{tabular}

Nota-se que ao se considerar os resultados sob três instrumentações e três betonadas (3I-3bt), a análise de variâncias identifica que continua havendo diferença estatisticamente significativa de pelo menos uma das instrumentações em relação às demais na maioria dos casos analisados. E entre as betonadas, percebe-se que diminuiu a percepção das diferenças, principalmente no concreto 070 .

A mudança ocorrida quanto às betonadas é passível de entendimento: a instrumentação $2 \mathrm{R}$ era das mais suscetíveis à geração de variabilidade para os 
concretos de menor resistência e, mesmo entre betonadas de um mesmo traço, obteve-se sob esta instrumentação grandes diferenças que contribuíam para a percepção geral.

Quanto às instrumentações, porém, essa evidência da continuidade da diferença do método sob cada uma delas é contraditória à expectativa criada pela informação anteriormente identificada de que a variação "entre" instrumentações mostrava-se bastante menor que aquela "dentro" das instrumentações.

O que se verifica é que apenas no agrupamento Ecs-3l-3bt-040 em que a Variância devido à instrumentação dada pela 'Variância Repro' foi de 6\% da Variância total é que as instrumentações foram consideradas iguais. Nas demais, em que a Variância devido à instrumentação foi de 20, 13 e 32\% da Variância total para Eci-3I-3bt-040, Ecs-3I-3bt-070 e Eci-3I-3bt-070, respectivamente, esses baixos percentuais não foram suficientes para a consideração da semelhança dos procedimentos.

Por outro lado, esses mesmos baixos percentuais indicam que uma pequena correção dada por uma expressão de correlação pode ser suficiente para eliminar as diferenças de maneira generalizada. Então:

- Como a maior quantidade de médias compatíveis se deu entre SG e CG, admitam-se essas duas instrumentações (2I) como semelhantes. Por ANOVA, o teste desta hipótese se concretiza (Tab. 5.1.3.1.5):

Tabela 5.1.3.1.5 - Verificação de 2l-3bt: instrumentações e betonadas

\begin{tabular}{|c|c|c|c|}
\cline { 3 - 4 } \multicolumn{2}{c|}{} & \multicolumn{2}{c|}{ São estatisticamente iguais ? } \\
\hline \multirow{2}{*}{ Plano } & Concreto & Instrumentações & Betonadas \\
\hline \multirow{2}{*}{ Ecs } & 040 & Sim & Não \\
\cline { 2 - 4 } & 070 & Sim & Não \\
\hline \multirow{2}{*}{$E c i$} & 040 & Sim & Não \\
\cline { 2 - 4 } & 070 & Sim & Não \\
\hline
\end{tabular}

E note-se que volta a aumentar a percepção das diferenças entre betonadas;

- Assim sendo, pode-se tomar uma destas instrumentações - SG, por exemplo - para se construir uma curva de correlação com 1R do tipo $E c_{S G}=K_{1}+K_{2} \cdot E c_{1 R}$ para cada plano de carregamento (Tab. 5.1.3.1.6 e Fig. $5.1 \cdot 3 \cdot 1 \cdot 5 \cdot a-b)$. 
Tabela 5.1.3.1.6 - Regressão para SG e 1R

\begin{tabular}{|c|c|c|c|c|c|c|}
\hline Plano & Concreto & Betonada & $\begin{array}{c}\text { Média sob } \\
\text { SG (GPa) }\end{array}$ & $\begin{array}{c}\text { Média sob } \\
1 R(G P a)\end{array}$ & $K_{1}$ & $K_{2}$ \\
\hline \multirow{6}{*}{ Ecs } & \multirow{3}{*}{040} & bt1 & 35,31 & 35,31 & \multirow{6}{*}{$-4,01$} & \multirow{6}{*}{1,09} \\
\hline & & bt2 & 36,18 & 36,56 & & \\
\hline & & bt3 & 34,96 & 36,66 & & \\
\hline & \multirow{3}{*}{070} & bt1 & 22,90 & 26,31 & & \\
\hline & & bt2 & 25,12 & 26,07 & & \\
\hline & & bt3 & 24,84 & 25,67 & & \\
\hline \multirow{6}{*}{ Eci } & \multirow{3}{*}{040} & bt1 & 36,33 & 36,88 & \multirow{6}{*}{$-3,53$} & \multirow{6}{*}{1,06} \\
\hline & & bt2 & 36,75 & 38,27 & & \\
\hline & & bt3 & 36,07 & 38,08 & & \\
\hline & \multirow{3}{*}{070} & bt1 & 23,91 & 28,12 & & \\
\hline & & bt2 & 26,26 & 27,86 & & \\
\hline & & bt3 & 26,51 & 27,03 & & \\
\hline
\end{tabular}

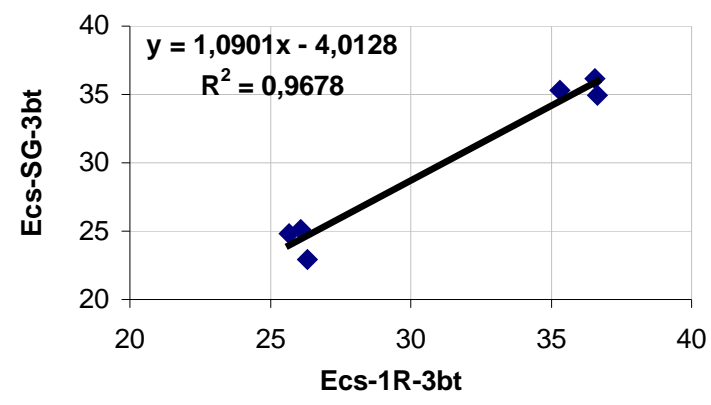

(a) Plano secante

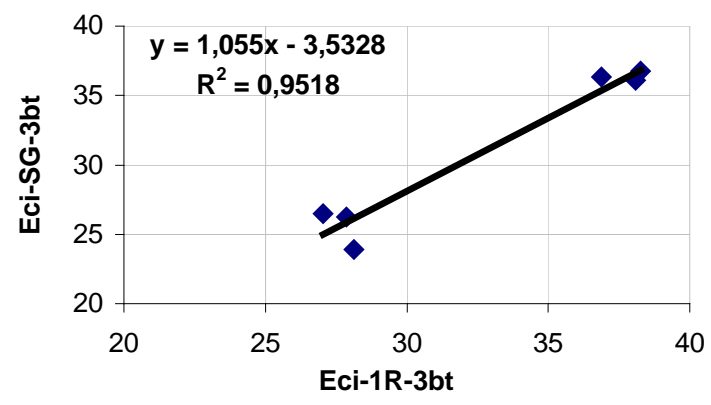

(b) Plano tangente inicial

Figura 5.1.3.1.5 - Curvas de correlação: SG e 1R

Os coeficientes de correlação ' $r$ ' obtidos foram de 0,97 e 0,95 para Ecs e Eci, respectivamente. Note-se, portanto, que há grande assertividade da curva de correlação para os resultados experimentais obtidos e ainda que a curva parece ser bastante adequada ao uso para os concretos de relação água/cimento intermediários entre 0,40 e 0,70 pois o coeficiente angular da reta que se configura é próximo do valor 1,00 (1,09 para Ecs e 1,06 para Eci);

- A título de verificação, resta aplicar a conversão aos valores de $1 \mathrm{R}$ através da curva de correlação (adota-se o termo 1R-corrigido) e repetir a análise de variâncias. Então (Tab. 5.1.3.1.7): 
Tabela 5.1.3.1.7 - Verificação de 3I-3bt (1R-corrigido): instrumentações e betonadas

\begin{tabular}{|c|c|c|c|}
\cline { 2 - 4 } \multicolumn{2}{c|}{} & \multicolumn{2}{c|}{ São estatisticamente iguais ? } \\
\hline \multirow{2}{*}{ Plano } & Concreto & Instrumentações & Betonadas \\
\hline \multirow{2}{*}{ Ecs } & 040 & Sim & Não \\
\cline { 2 - 4 } & 070 & Sim & Sim \\
\hline \multirow{2}{*}{ Eci } & 040 & Sim & Não \\
\cline { 2 - 4 } & 070 & Sim & Sim \\
\hline
\end{tabular}

Note-se que diminui a percepção das diferenças entre betonadas para o Concreto 070 pela inclusão da variabilidade causada pelo sistema de 1R, mas o método sob as três instrumentações torna-se realmente único.

- Refazendo-se, enfim, a análise global que considera cada instrumentação como um operador diferente, tem-se (Tab. 5.1.3.1.8 e Fig. 5.1.3.1.6.a-d):

Tabela 5.1.3.1.8 - Agrupamentos de módulo secante (Ecs) e tangente inicial (Eci) de três betonadas (3bt), Concretos a/c 0,40 (040) e a/c 0,70 (070), independentemente de três instrumentações (SG, CG e 1R-corrigido), operador=instrumentação: cálculos de precisão

\begin{tabular}{|c|c|c|c|c|}
\hline INDICADORES ESTATÍSTICOS & Ecs-040 & Eci-040 & Ecs-070 & Eci-070 \\
\hline Média (GPa) & 35,32 & 36,31 & 24,47 & 25,58 \\
\hline Desvio-padrão (GPa) & 1,88 & 1,68 & 2,22 & 2,04 \\
\hline Desvio de repetitividade (GPa) & 1,82 & 1,59 & 2,22 & 1,96 \\
\hline Desvio de reprodutibilidade (GPa) & 0,00 & 0,34 & 0,00 & 0,75 \\
\hline Desvio R\&R (GPa) & 1,82 & 1,63 & 2,22 & 2,10 \\
\hline Desvio de betonadas (GPa) & 0,63 & 0,61 & 0,28 & 0,14 \\
\hline Desvio-padrão total (GPa) & 1,92 & 1,74 & 2,24 & 2,10 \\
\hline Desvio R\&R/Desvio total (\%) & 95 & 94 & 99 & 100 \\
\hline Variância Repe/Variância total (\%) & 89 & 84 & 98 & 87 \\
\hline Variância Repro/Variância total (\%) & 0 & 4 & 0 & 13 \\
\hline Variância R\&R/Variância total (\%) & 89 & 88 & 98 & 100 \\
\hline Variância Bet/Variância total (\%) & 11 & 12 & 2 & 0 \\
\hline Betonadas distinguidas & 1 & 1 & 1 & 1 \\
\hline
\end{tabular}

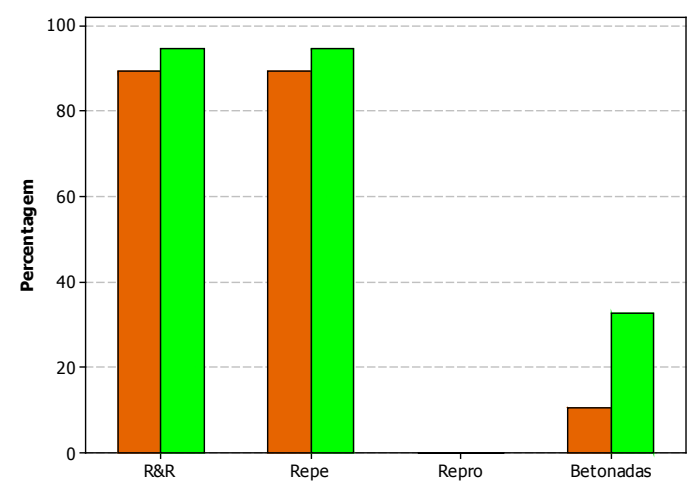

(a) Ecs-3I-3bt-040 (SG, CG, 1R-corrigido)

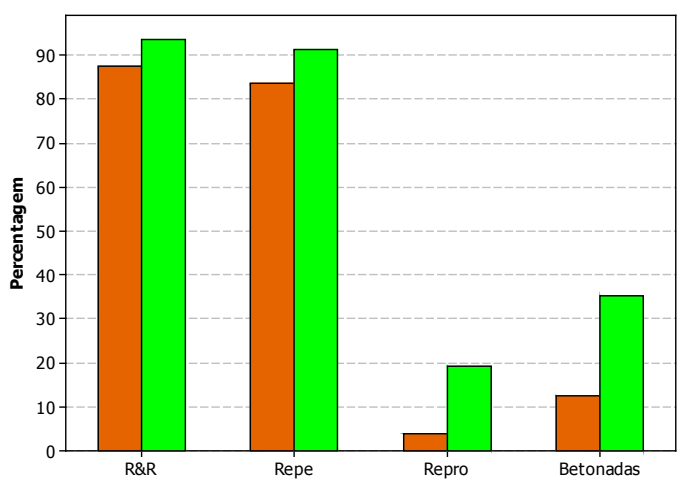

(b) Eci-3I-3bt-040 (SG, CG, 1R-corrigido) 


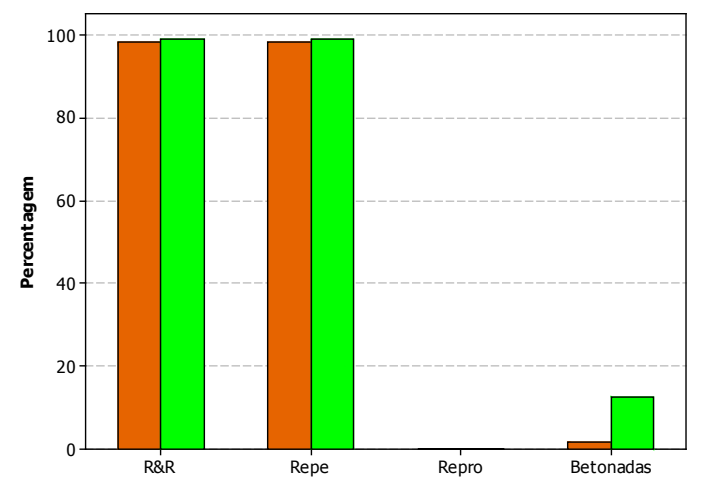

(c) Ecs-3I-3bt-070 (SG, CG, 1R-corrigido)

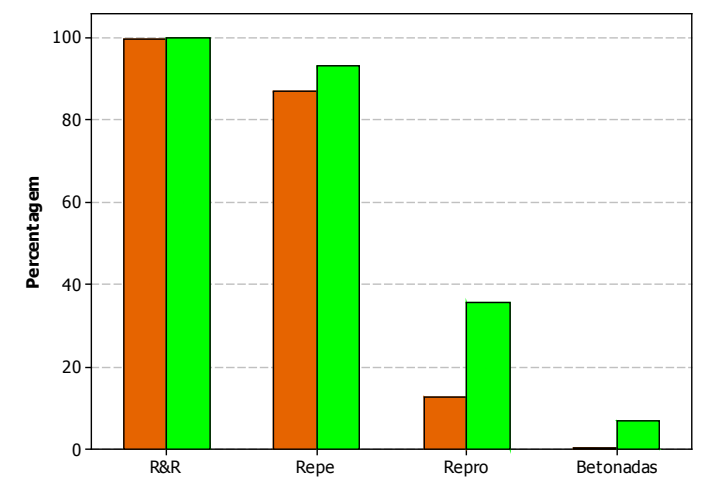

(d) Eci-3I-3bt-070 (SG, CG, 1R-corrigido)

Figura 5.1.3.1.6 - Composição das variâncias e desvios-padrão dos agrupamentos dos concretos e planos de carregamento, independentemente de três instrumentações (SG, CG e $1 \mathrm{r}$-corrigido), sendo operador=instrumentação

Note-se que, como era de se esperar ao se considerar o grupo SG, CG e 1Rcorrigido, a Variância devido à instrumentação ('Variância Repro') diminuiu significativamente em todos os casos em relação aos resultados obtidos com o grupo SG, CG e 1R, como é mostrado na Tab. 5.1.3.1.9.

Tabela 5.1.3.1.9 - Cálculos de precisão: 3l-3bt

\begin{tabular}{|c|c|c|c|c|}
\hline \multirow{2}{*}{ Grupo } & \multicolumn{4}{|c|}{ Variância de reprodutibilidade (GPa $\left.{ }^{\mathbf{2}}\right)$} \\
\cline { 2 - 5 } & Ecs-040 & Eci-040 & Ecs-070 & Eci-070 \\
\hline SG, CG e 1R & 0,21 & 0,67 & 0,64 & 1,74 \\
\hline SG, CG e 1R-corrigido & 0,00 & 0,11 & 0,00 & 0,56 \\
\hline Diferença (\%) & -100 & -84 & -100 & -68 \\
\hline
\end{tabular}

Assim, a conclusão dirigida aos resultados dos ensaios deste programa experimental deve indicar que o método global (independentemente das instrumentações, se SG, CG ou 1R-corrigido) pode ser considerado com grande tendência à aceitação prática, se admissíveis para os ensaios individuais sob o plano secante o Desvio-padrão devido à R\&R entre 1,82 e 2,22 GPa e para os ensaios individuais sob o plano tangente inicial o Desviopadrão devido à $R \& R$ entre 1,63 e 2,10 GPa. Lembra-se que esta dispersão está vinculada à análise de resultados individuais, e não médios - a dispersão deve ser menor se consideradas na análise as médias dos resultados individuais de três corpos-de-prova, como preconiza a NBR 
8522:2003; este critério não foi seguido neste momento porque diminuiria a sensibilidade da sistemática (metodologia) de análise.

Além disso, deve haver a consideração generalizada do Desvio-padrão devido às betonadas da ordem de 0,5 GPa, independentemente de se considerarem resultados individuais ou médios.

Dessa forma, os Desvios-padrão totais para os planos de carregamento secante e tangente inicial estariam entre 1,9 e 2,3 GPa para o primeiro e 1,7 e 2,1 GPa para o segundo, em se tratando de resultados individuais. O cálculo do desvio-padrão total para resultados médios, de acordo com a NBR 8522:2003, será realizado adiante, quando da discussão da aplicação do conceito semiprobabilístico normativo sobre a propriedade.

Note-se, por fim, que ao se considerarem apenas os resultados obtidos neste programa experimental, não seria possível trabalhar de forma independente da instrumentação se fossem desprezadas as modificações testadas, quais sejam a exclusão dos resultados obtidos sob $2 \mathrm{R}$ e a correção através de curva de correlação dos resultados obtidos sob 1R. Ressalta-se que não se testou a correção de $2 \mathrm{R}$ através de correlação devido à grande dispersão dos resultados individuais sob esta instrumentação.

II.b) Comparação entre resultados da dissertação e do interlaboratorial nacional

Para finalizar a análise de acurácia do método de ensaio, pode-se aplicar a técnica de considerar a instrumentação como um operador sobre os resultados obtidos no interlaboratorial relatado por Inácio; Andrade e Bittencourt (2006) e realizar uma comparação. Neste caso, dispõe-se de 22 laboratórios com três resultados individuais de módulo de deformação tangente inicial cada, para dois traços de concreto de resultados médios semelhantes. Como a comparação deve se dar nas mesmas bases, será recalculada a precisão de um grupo de resultados do programa experimental desta dissertação simulando o ensaio por 12 "laboratórios" de um conjunto de duas betonadas - como há 10 resultados individuais disponíveis por betonada (traço) por instrumentação, e considerando-se as quatro instrumentações, serão aproveitados 3 grupos de três resultados individuais sob cada instrumentação, num total de 12 grupos. Optou-se por manter os resultados 
obtidos sob $2 \mathrm{R}$ e os originais obtidos sob $1 \mathrm{R}$ por uma questão de admitir a maior dispersão obtida nesta etapa do programa experimental. A expectativa é de que mesmo nessa condição, e por envolver apenas um conjunto de procedimentos, equipamentos e operador, o resultado de precisão desta etapa ainda seja menor que o observado no interlaboratorial nacional.

Os resultados obtidos constam das Tab. 5.1.3.1.10 e Fig. 5.1.3.1.7.a-b e são acompanhados de algumas observações. Do programa desta dissertação foram selecionados os resultados de determinação sob plano de carregamento tangente inicial de duas betonadas (bt1 e bt3) do traço 070, para comparação com os resultados obtidos a partir dos Concretos 1 e 2 do interlaboratorial nacional.

Tabela 5.1.3.1.10 - Cálculos comparativos de precisão: Dissertação x Interlaboratorial nacional

\begin{tabular}{|c|c|c|}
\hline INDICADORES ESTATísTICOS & Eci-4I-bt1bt3-070 & Interlaboratorial \\
\hline Média (GPa) & 26,40 & 23,16 \\
\hline Desvio-padrão (GPa) & 2,71 & 3,49 \\
\hline Desvio de repetitividade (GPa) & 2,26 & 1,01 \\
\hline Desvio de reprodutibilidade (GPa) & 1,55 & 3,34 \\
\hline Desvio R\&R (GPa) & 2,75 & 3,49 \\
\hline Desvio de betonadas (GPa) & 0,00 & 0,88 \\
\hline Desvio-padrão total (GPa) & 2,75 & 3,60 \\
\hline Desvio R\&R/Desvio total (\%) & 100 & 97 \\
\hline Variância Repe/Variância total (\%) & 68 & 8 \\
\hline Variância Repro/Variância total (\%) & 32 & 86 \\
\hline Variância R\&R/Variância total (\%) & 100 & 94 \\
\hline Variância Bet/Variância total (\%) & 0 & 6 \\
\hline Betonadas distinguidas & 1 & 1 \\
\hline
\end{tabular}

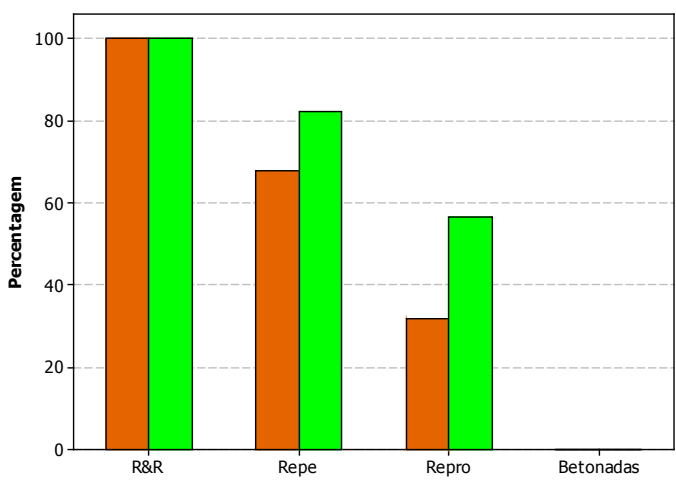

(a) Eci-4l-bt1bt3-070

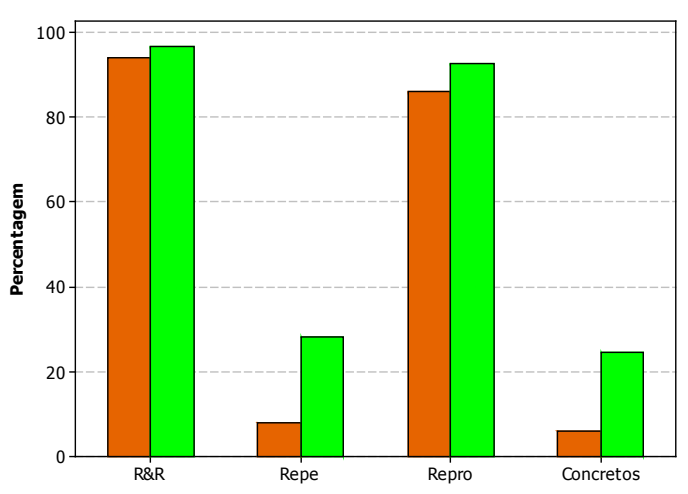

(b) Interlaboratorial nacional

Figura 5.1.3.1.7 - Composição de variância e desvio-padrão

Observa-se neste caso que, enquanto os resultados obtidos no programa experimental da dissertação mostraram uma preponderância do Desvio devido à 
repetitividade em relação ao Desvio devido à reprodutibilidade, no programa interlaboratorial nacional ficou evidenciado o contrário. Isto pode ser visto claramente nos itens 'Variância Repe/Variância total (\%)' e 'Variância Repro/Variância total (\%)' da tabela. Nota-se que as magnitudes dos Desvios devido à repetitividade foram bastante distintas entre si, e aquela realizada pelo operador único (dissertação) foi a maior - 2,26 contra 1,01 GPa. Essa informação não seria a esperada e não se pode afirmar nada sobre ela. A expectativa era de que os desvios quanto à repetitividade fossem semelhantes, o que não ocorreu, e que os desvios quanto à reprodutibilidade fossem maiores no programa interlaboratorial nacional pela mais ampla quantidade e tipologia/treinamento de instrumentações e operadores, conforme ocorreu.

\subsubsection{Cálculos da exatidão do método global}

A exatidão do método de ensaio global praticamente já foi contemplada quando do cálculo para os métodos sob instrumentações particulares.

Naquele momento, nos agrupamentos Ecs-1l-1bt-040 obteve-se um IQN médio calculado de 1,48 GPa. O IQN médio é um parâmetro adotado por esta dissertação para a medida indicativa e simplificada da exatidão dos agrupamentos, de forma que se considerasse idêntico o peso estatístico de cada betonada.

Nos agrupamentos Eci-1l-1bt-040, o IQN médio calculado foi de 1,69 GPa.

Nos agrupamentos Ecs-1I-3bt-070, o IQN médio calculado foi de 2,38 GPa.

E nos agrupamentos Eci-1l-3bt-070, o IQN médio calculado foi de 2,59 GPa.

Pela técnica do Z-score, isso quer dizer que aproximadamente $67,8 \%$ dos resultados médios distaram menos de um IQN médio (1,48 a 2,59 GPa) das medianas dos agrupamentos - admita-se metade disso (0,74 a 1,30 GPa) $27,5 \%$ distaram entre um e dois IQN médio - admita-se 1,5 vez o IQN médio $(2,22$ a 3,89 GPa) - 4,4\% dos resultados médios distaram entre dois e três IQN médio admita-se 2,5 vezes o IQN médio (3,70 a 6,48 GPa) — e, por fim, 0,3\% distou acima de três IQN médio - admita-se 4 vezes o IQN médio (5,92 a 10,36 GPa).

Esses resultados são aqueles para serem analisados do ponto de vista prático: se o valor verdadeiro da grandeza experimental fosse a mediana, admitir-seiam estes desvios em relação a ela? Provavelmente não.

Analise-se agora o arranjo excluindo-se $2 \mathrm{R}$ (Tab. 5.1.3.2.1 a 5.1.3.2.4): 
Tabela 5.1.3.2.1 - Planilha de cálculo de exatidão - Ecs-1I-1bt-040 (SG, CG, 1R)

Lab\Betonada

SG

\begin{tabular}{|c|c|c|c|} 
SG & \multicolumn{1}{c}{ bt1 } & bt2 & bt3 \\
\hline $\mathbf{1}$ & 35,4 & 40,1 & 35,8 \\
\hline $\mathbf{2}$ & 36,2 & 34,1 & 36,1 \\
\hline $\mathbf{3}$ & 34,5 & 36,1 & 35,7 \\
\hline $\mathbf{4}$ & 34,3 & 37,6 & 31,0 \\
\hline $\mathbf{5}$ & 35,5 & 40,3 & 35,9 \\
\hline $\mathbf{6}$ & 35,9 & 32,9 & 35,8 \\
\hline $\mathbf{7}$ & 37,6 & 36,3 & 35,1 \\
\hline $\mathbf{8}$ & 33,2 & 32,1 & 34,7 \\
\hline $\mathbf{9}$ & 36,2 & 35,8 & 33,8 \\
\hline $\mathbf{1 0}$ & 34,3 & 36,5 & 35,7 \\
\hline
\end{tabular}

CG

CG
\begin{tabular}{|c|c|c|c|}
\hline $\mathbf{1}$ & 33,2 & 35,8 & 30,1 \\
\hline $\mathbf{2}$ & 32,6 & 36,8 & 36,2 \\
\hline $\mathbf{3}$ & 34,3 & 36,8 & 37,6 \\
\hline $\mathbf{4}$ & 34,7 & 36,0 & 35,5 \\
\hline $\mathbf{5}$ & 33,2 & 34,7 & 35,3 \\
\hline $\mathbf{6}$ & 33,4 & 36,0 & 35,3 \\
\hline $\mathbf{7}$ & 35,1 & 37,0 & 35,0 \\
\hline $\mathbf{8}$ & 34,5 & 36,8 & 36,7 \\
\hline $\mathbf{9}$ & 34,4 & 34,7 & 36,6 \\
\hline $\mathbf{1 0}$ & 33,9 & 34,7 & 34,9 \\
\hline
\end{tabular}
$1 \mathrm{R}$

\begin{tabular}{|c|c|c|c|}
\hline $\mathbf{1}$ & 36,6 & 40,7 & 35,8 \\
\hline $\mathbf{2}$ & 37,2 & 36,8 & 37,6 \\
\hline $\mathbf{3}$ & 35,9 & 34,5 & 36,2 \\
\hline $\mathbf{4}$ & 33,7 & 33,6 & 35,1 \\
\hline $\mathbf{5}$ & 33,7 & 38,3 & 40,2 \\
\hline $\mathbf{6}$ & 32,7 & 36,0 & 37,6 \\
\hline $\mathbf{7}$ & 34,8 & 36,8 & 34,3 \\
\hline $\mathbf{8}$ & 36,8 & 38,9 & 35,3 \\
\hline $\mathbf{9}$ & 37,5 & 35,2 & 36,9 \\
\hline $\mathbf{1 0}$ & 34,2 & 34,8 & 37,6 \\
\hline mediana & $\mathbf{3 4 , 5 0}$ & $\mathbf{3 6 , 0 5}$ & $\mathbf{3 5 , 7 5}$ \\
quartil 3 & $\mathbf{3 5 , 9 0}$ & $\mathbf{3 6 , 8 0}$ & $\mathbf{3 6 , 5 0}$ \\
quartil 1 & $\mathbf{3 3 , 7 5}$ & $\mathbf{3 4 , 7 3}$ & $\mathbf{3 5 , 1 0}$ \\
IQ & $\mathbf{2 , 1 5}$ & $\mathbf{2 , 0 8}$ & $\mathbf{1 , 4 0}$ \\
IQN & $\mathbf{1 , 5 9}$ & $\mathbf{1 , 5 4}$ & $\mathbf{1 , 0 4}$ \\
IQNmédio & $\mathbf{1 , 3 9}$ &
\end{tabular}

Z-score

\begin{tabular}{|c|c|c|}
\multicolumn{1}{c}{ bt1 } & \multicolumn{1}{c}{ bt2 } & bt3 \\
\hline 0,56 & 2,63 & 0,05 \\
\hline 1,07 & $-1,27$ & 0,34 \\
\hline 0,00 & 0,03 & $-0,05$ \\
\hline$-0,13$ & 1,01 & $-4,58$ \\
\hline 0,63 & 2,76 & 0,14 \\
\hline 0,88 & $-2,05$ & 0,05 \\
\hline 1,95 & 0,16 & $-0,63$ \\
\hline$-0,82$ & $-2,57$ & $-1,01$ \\
\hline 1,07 & $-0,16$ & $-1,88$ \\
\hline$-0,13$ & 0,29 & $-0,05$ \\
\hline
\end{tabular}

\begin{tabular}{|c|c|c|}
\hline$-0,82$ & $-0,16$ & $-5,44$ \\
\hline$-1,19$ & 0,49 & 0,43 \\
\hline$-0,13$ & 0,49 & 1,78 \\
\hline 0,13 & $-0,03$ & $-0,24$ \\
\hline$-0,82$ & $-0,88$ & $-0,43$ \\
\hline$-0,69$ & $-0,03$ & $-0,43$ \\
\hline 0,38 & 0,62 & $-0,72$ \\
\hline 0,00 & 0,49 & 0,92 \\
\hline$-0,06$ & $-0,88$ & 0,82 \\
\hline$-0,38$ & $-0,88$ & $-0,82$ \\
\hline
\end{tabular}

\begin{tabular}{|c|c|c|}
\hline 1,32 & 3,02 & 0,05 \\
\hline 1,69 & 0,49 & 1,78 \\
\hline 0,88 & $-1,01$ & 0,43 \\
\hline$-0,50$ & $-1,59$ & $-0,63$ \\
\hline$-0,50$ & 1,46 & 4,29 \\
\hline$-1,13$ & $-0,03$ & 1,78 \\
\hline 0,19 & 0,49 & $-1,40$ \\
\hline 1,44 & 1,85 & $-0,43$ \\
\hline 1,88 & $-0,55$ & 1,11 \\
\hline$-0,19$ & $-0,81$ & 1,78 \\
\hline
\end{tabular}

Tabela 5.1.3.2.2 - Planilha de cálculo de exatidão - Eci-1l-1bt-040 (SG, CG, 1R) Lab\Betonada

\begin{tabular}{|c|c|c|c|} 
SG & \multicolumn{1}{c}{ bt1 } & bt2 & bt3 \\
\hline $\mathbf{1}$ & 35,8 & 35,3 & 36,5 \\
\hline $\mathbf{2}$ & 38,5 & 35,3 & 37,5 \\
\hline $\mathbf{3}$ & 34,7 & 36,2 & 37,0 \\
\hline $\mathbf{4}$ & 36,4 & 39,7 & 32,1 \\
\hline $\mathbf{5}$ & 35,7 & 40,7 & 36,9 \\
\hline $\mathbf{6}$ & 36,5 & 35,2 & 37,0 \\
\hline $\mathbf{7}$ & 39,9 & 36,8 & 36,1 \\
\hline $\mathbf{8}$ & 34,0 & 32,5 & 36,1 \\
\hline $\mathbf{9}$ & 36,6 & 37,5 & 35,0 \\
\hline $\mathbf{1 0}$ & 35,2 & 38,3 & 36,5 \\
\hline
\end{tabular}

\begin{tabular}{|c|c|c|}
\multicolumn{3}{c}{ bt1 } \\
\hline 0,18 & $-1,32$ & $-0,43$ \\
\hline 2,57 & $-1,32$ & 0,80 \\
\hline$-0,80$ & $-0,72$ & 0,18 \\
\hline 0,71 & 1,58 & $-5,83$ \\
\hline 0,09 & 2,24 & 0,06 \\
\hline 0,80 & $-1,38$ & 0,18 \\
\hline 3,80 & $-0,33$ & $-0,92$ \\
\hline$-1,42$ & $-3,16$ & $-0,92$ \\
\hline 0,88 & 0,13 & $-2,27$ \\
\hline$-0,35$ & 0,66 & $-0,43$ \\
\hline
\end{tabular}


CG

\begin{tabular}{|c|c|c|c|}
\hline $\mathbf{1}$ & 34,3 & 37,7 & 36,9 \\
\hline $\mathbf{2}$ & 33,7 & 38,1 & 37,0 \\
\hline $\mathbf{3}$ & 35,0 & 36,6 & 38,6 \\
\hline $\mathbf{4}$ & 35,4 & 36,8 & 36,4 \\
\hline $\mathbf{5}$ & 34,3 & 36,6 & 36,4 \\
\hline $\mathbf{6}$ & 34,3 & 37,1 & 36,4 \\
\hline $\mathbf{7}$ & 36,2 & 38,3 & 36,2 \\
\hline $\mathbf{8}$ & 35,4 & 37,8 & 37,5 \\
\hline $\mathbf{9}$ & 35,2 & 35,8 & 37,5 \\
\hline $\mathbf{1 0}$ & 35,0 & 35,9 & 35,8 \\
\hline
\end{tabular}

\begin{tabular}{|c|c|c|}
\hline$-1,15$ & 0,26 & 0,06 \\
\hline$-1,68$ & 0,53 & 0,18 \\
\hline$-0,53$ & $-0,46$ & 2,15 \\
\hline$-0,18$ & $-0,33$ & $-0,55$ \\
\hline$-1,15$ & $-0,46$ & $-0,55$ \\
\hline$-1,15$ & $-0,13$ & $-0,55$ \\
\hline 0,53 & 0,66 & $-0,80$ \\
\hline$-0,18$ & 0,33 & 0,80 \\
\hline$-0,35$ & $-0,99$ & 0,80 \\
\hline$-0,53$ & $-0,92$ & $-1,29$ \\
\hline
\end{tabular}

1R

\begin{tabular}{|c|c|c|c|}
\hline $\mathbf{1}$ & 39,5 & 41,9 & 36,4 \\
\hline $\mathbf{2}$ & 38,2 & 38,5 & 39,3 \\
\hline $\mathbf{3}$ & 37,2 & 37,6 & 38,0 \\
\hline $\mathbf{4}$ & 35,5 & 36,4 & 36,8 \\
\hline $\mathbf{5}$ & 35,7 & 39,4 & 41,1 \\
\hline $\mathbf{6}$ & 35,3 & 37,6 & 39,0 \\
\hline $\mathbf{7}$ & 35,7 & 38,5 & 36,1 \\
\hline $\mathbf{8}$ & 37,2 & 40,4 & 36,8 \\
\hline $\mathbf{9}$ & 39,0 & 36,0 & 38,9 \\
\hline $\mathbf{1 0}$ & 35,5 & 36,4 & 38,4 \\
\hline mediana & $\mathbf{3 5 , 6 0}$ & $\mathbf{3 7 , 3 0}$ & $\mathbf{3 6 , 8 5}$ \\
quartil 3 & $\mathbf{3 6 , 5 8}$ & $\mathbf{3 8 , 3 0}$ & $\mathbf{3 7 , 5 0}$ \\
quartil 1 & $\mathbf{3 5 , 0 5}$ & $\mathbf{3 6 , 2 5}$ & $\mathbf{3 6 , 4 0}$ \\
IQ & $\mathbf{1 , 5 3}$ & $\mathbf{2 , 0 5}$ & $\mathbf{1 , 1 0}$ \\
IQN & $\mathbf{1 , 1 3}$ & $\mathbf{1 , 5 2}$ & $\mathbf{0 , 8 2}$ \\
IQNmédio & $\mathbf{1 , 1 6}$ & &
\end{tabular}

\begin{tabular}{|c|c|c|}
\hline 3,45 & 3,03 & $-0,55$ \\
\hline 2,30 & 0,79 & 3,00 \\
\hline 1,42 & 0,20 & 1,41 \\
\hline$-0,09$ & $-0,59$ & $-0,06$ \\
\hline 0,09 & 1,38 & 5,21 \\
\hline$-0,27$ & 0,20 & 2,64 \\
\hline 0,09 & 0,79 & $-0,92$ \\
\hline 1,42 & 2,04 & $-0,06$ \\
\hline 3,01 & $-0,86$ & 2,51 \\
\hline$-0,09$ & $-0,59$ & 1,90 \\
\hline
\end{tabular}

Tabela 5.1.3.2.3 - Planilha de cálculo de exatidão - Ecs-1l-1bt-070 (SG, CG, 1R)

Lab\Betonada

SG

\begin{tabular}{|c|c|c|c|} 
SG & \multicolumn{1}{c}{ bt1 } & bt2 & bt3 \\
\hline $\mathbf{1}$ & 24,9 & 25,3 & 24,3 \\
\hline $\mathbf{2}$ & 23,2 & 26,3 & 24,0 \\
\hline $\mathbf{3}$ & 23,9 & 23,4 & 25,2 \\
\hline $\mathbf{4}$ & 23,1 & 25,9 & 24,0 \\
\hline $\mathbf{5}$ & 21,5 & 21,2 & 24,1 \\
\hline $\mathbf{6}$ & 23,7 & 25,7 & 25,9 \\
\hline $\mathbf{7}$ & 20,0 & 25,1 & 22,6 \\
\hline $\mathbf{8}$ & 21,9 & 25,6 & 25,9 \\
\hline $\mathbf{9}$ & 22,2 & 25,9 & 22,9 \\
\hline $\mathbf{1 0}$ & 24,6 & 26,8 & 29,5 \\
\hline
\end{tabular}

CG

\begin{tabular}{|c|c|c|c|}
\hline $\mathbf{1}$ & 23,5 & 24,0 & 23,1 \\
\hline $\mathbf{2}$ & 24,7 & 25,2 & 23,6 \\
\hline $\mathbf{3}$ & 25,8 & 25,5 & 25,2 \\
\hline $\mathbf{4}$ & 24,5 & 26,0 & 25,7 \\
\hline $\mathbf{5}$ & 23,7 & 26,0 & 24,3 \\
\hline $\mathbf{6}$ & 25,8 & 25,2 & 25,0 \\
\hline $\mathbf{7}$ & 23,1 & 26,0 & 23,8 \\
\hline $\mathbf{8}$ & 25,5 & 24,5 & 24,5 \\
\hline $\mathbf{9}$ & 23,7 & 26,0 & 25,2 \\
\hline $\mathbf{1 0}$ & 22,8 & 24,5 & 27,2 \\
\hline
\end{tabular}

Z-score

\begin{tabular}{|c|c|c|}
\multicolumn{1}{c}{ bt1 } & \multicolumn{1}{c}{ bt2 } & bt3 \\
\hline 0,38 & $-0,31$ & $-0,20$ \\
\hline$-0,54$ & 0,58 & $-0,39$ \\
\hline$-0,16$ & $-2,02$ & 0,39 \\
\hline$-0,59$ & 0,22 & $-0,39$ \\
\hline$-1,46$ & $-4,00$ & $-0,33$ \\
\hline$-0,27$ & 0,04 & 0,86 \\
\hline$-2,27$ & $-0,49$ & $-1,32$ \\
\hline$-1,24$ & $-0,04$ & 0,86 \\
\hline$-1,08$ & 0,22 & $-1,12$ \\
\hline 0,22 & 1,03 & 3,22 \\
\hline
\end{tabular}

\begin{tabular}{|c|c|c|}
\hline$-0,38$ & $-1,48$ & $-0,99$ \\
\hline 0,27 & $-0,40$ & $-0,66$ \\
\hline 0,86 & $-0,13$ & 0,39 \\
\hline 0,16 & 0,31 & 0,72 \\
\hline$-0,27$ & 0,31 & $-0,20$ \\
\hline 0,86 & $-0,40$ & 0,26 \\
\hline$-0,59$ & 0,31 & $-0,53$ \\
\hline 0,70 & $-1,03$ & $-0,07$ \\
\hline$-0,27$ & 0,31 & 0,39 \\
\hline$-0,76$ & $-1,03$ & 1,71 \\
\hline
\end{tabular}


$1 R$

\begin{tabular}{|r|c|c|c|}
\hline $\mathbf{1}$ & 23,7 & 23,8 & 24,7 \\
\hline $\mathbf{2}$ & 27,3 & 30,8 & 24,3 \\
\hline $\mathbf{3}$ & 26,6 & 26,6 & 26,6 \\
\hline $\mathbf{4}$ & 27,3 & 27,4 & 22,5 \\
\hline $\mathbf{5}$ & 23,3 & 29,0 & 21,2 \\
\hline $\mathbf{6}$ & 28,0 & 25,7 & 27,4 \\
\hline $\mathbf{7}$ & 24,5 & 22,5 & 20,0 \\
\hline $\mathbf{8}$ & 25,0 & 24,0 & 31,2 \\
\hline $\mathbf{9}$ & 27,0 & 22,9 & 28,0 \\
\hline $\mathbf{1 0}$ & 30,4 & 28,0 & 30,8 \\
\hline mediana & $\mathbf{2 4 , 2 0}$ & $\mathbf{2 5 , 6 5}$ & $\mathbf{2 4 , 6 0}$ \\
quartil 3 & $\mathbf{2 5 , 7 3}$ & $\mathbf{2 6 , 0 0}$ & $\mathbf{2 5 , 9 0}$ \\
quartil 1 & $\mathbf{2 3 , 2 3}$ & $\mathbf{2 4 , 5 0}$ & $\mathbf{2 3 , 8 5}$ \\
IQ & $\mathbf{2 , 5 0}$ & $\mathbf{1 , 5 0}$ & $\mathbf{2 , 0 5}$ \\
IQN & $\mathbf{1 , 8 5}$ & $\mathbf{1 , 1 1}$ & $\mathbf{1 , 5 2}$ \\
IQNmédio & $\mathbf{1 , 4 9}$ & &
\end{tabular}

\begin{tabular}{|c|c|c|}
\hline$-0,27$ & $-1,66$ & 0,07 \\
\hline 1,67 & 4,63 & $-0,20$ \\
\hline 1,30 & 0,85 & 1,32 \\
\hline 1,67 & 1,57 & $-1,38$ \\
\hline$-0,49$ & 3,01 & $-2,24$ \\
\hline 2,05 & 0,04 & 1,84 \\
\hline 0,16 & $-2,83$ & $-3,03$ \\
\hline 0,43 & $-1,48$ & 4,34 \\
\hline 1,51 & $-2,47$ & 2,24 \\
\hline 3,35 & 2,11 & 4,08 \\
\hline
\end{tabular}

Tabela 5.1.3.2.4 - Planilha de cálculo de exatidão - Eci-1l-1bt-070 (SG, CG, 1R)

Lab\Betonada

SG

bt1

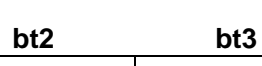

bt2

27,3

\begin{tabular}{|c|c|c|c|}
\hline $\mathbf{1}$ & 25,6 & 26,7 & 25,8 \\
\hline $\mathbf{2}$ & 23,9 & 27,3 & 25,5 \\
\hline $\mathbf{3}$ & 25,0 & 23,9 & 26,7 \\
\hline $\mathbf{4}$ & 23,5 & 27,3 & 25,4 \\
\hline $\mathbf{5}$ & 23,2 & 22,3 & 25,8 \\
\hline $\mathbf{6}$ & 24,9 & 26,8 & 27,3 \\
\hline $\mathbf{7}$ & 21,3 & 26,4 & 23,8 \\
\hline $\mathbf{8}$ & 22,9 & 26,7 & 27,1 \\
\hline $\mathbf{9}$ & 23,3 & 27,1 & 24,3 \\
\hline $\mathbf{1 0}$ & 25,5 & 28,1 & 33,4 \\
\hline
\end{tabular}

CG

\begin{tabular}{|l|l|l|l|}
\hline $\mathbf{1}$ & 24,2 & 25,2 & 24,3 \\
\hline $\mathbf{2}$ & 24,7 & 25,8 & 24,0 \\
\hline $\mathbf{3}$ & 25,5 & 26,3 & 26,3 \\
\hline $\mathbf{4}$ & 24,2 & 26,3 & 26,6 \\
\hline $\mathbf{5}$ & 26,1 & 26,6 & 25,5 \\
\hline $\mathbf{6}$ & 25,5 & 26,3 & 26,0 \\
\hline $\mathbf{7}$ & 24,0 & 27,2 & 24,5 \\
\hline $\mathbf{8}$ & 25,8 & 25,0 & 25,5 \\
\hline $\mathbf{9}$ & 24,7 & 26,9 & 26,0 \\
\hline $\mathbf{1 0}$ & 23,2 & 25,7 & 27,8 \\
\hline
\end{tabular}

$1 \mathrm{R}$

\begin{tabular}{|l|l|l|l|}
\hline $\mathbf{1}$ & 26,4 & 25,0 & 26,3 \\
\hline $\mathbf{2}$ & 30,1 & 31,2 & 27,8 \\
\hline $\mathbf{3}$ & 28,0 & 28,4 & 28,4 \\
\hline $\mathbf{4}$ & 29,4 & 29,0 & 24,5 \\
\hline $\mathbf{5}$ & 25,5 & 30,5 & 23,1 \\
\hline $\mathbf{6}$ & 28,6 & 29,0 & 28,7 \\
\hline $\mathbf{7}$ & 27,0 & 25,0 & 21,5 \\
\hline $\mathbf{8}$ & 27,3 & 26,0 & 30,5 \\
\hline $\mathbf{9}$ & 28,0 & 25,5 & 29,0 \\
\hline $\mathbf{1 0}$ & 30,9 & 29,0 & 30,5 \\
\hline
\end{tabular}

Z-score

\begin{tabular}{|c|c|c|}
\multicolumn{1}{c}{ bt1 } & bt2 & bt3 \\
\hline 0,05 & 0,04 & $-0,09$ \\
\hline$-0,77$ & 0,56 & $-0,23$ \\
\hline$-0,24$ & $-2,36$ & 0,32 \\
\hline$-0,96$ & 0,56 & $-0,27$ \\
\hline$-1,11$ & $-3,73$ & $-0,09$ \\
\hline$-0,29$ & 0,13 & 0,59 \\
\hline$-2,02$ & $-0,21$ & $-1,01$ \\
\hline$-1,25$ & 0,04 & 0,50 \\
\hline$-1,06$ & 0,39 & $-0,78$ \\
\hline 0,00 & 1,24 & 3,38 \\
\hline
\end{tabular}

\begin{tabular}{|c|c|c|}
\hline$-0,63$ & $-1,24$ & $-0,78$ \\
\hline$-0,39$ & $-0,73$ & $-0,91$ \\
\hline 0,00 & $-0,30$ & 0,14 \\
\hline$-0,63$ & $-0,30$ & 0,27 \\
\hline 0,29 & $-0,04$ & $-0,23$ \\
\hline 0,00 & $-0,30$ & 0,00 \\
\hline$-0,72$ & 0,47 & $-0,69$ \\
\hline 0,14 & $-1,41$ & $-0,23$ \\
\hline$-0,39$ & 0,21 & 0,00 \\
\hline$-1,11$ & $-0,81$ & 0,82 \\
\hline
\end{tabular}

\begin{tabular}{|c|c|c|}
\hline 0,43 & $-1,41$ & 0,14 \\
\hline 2,22 & 3,90 & 0,82 \\
\hline 1,20 & 1,50 & 1,10 \\
\hline 1,88 & 2,01 & $-0,69$ \\
\hline 0,00 & 3,30 & $-1,33$ \\
\hline 1,49 & 2,01 & 1,23 \\
\hline 0,72 & $-1,41$ & $-2,06$ \\
\hline 0,87 & $-0,56$ & 2,06 \\
\hline 1,20 & $-0,98$ & 1,37 \\
\hline 2,60 & 2,01 & 2,06 \\
\hline
\end{tabular}




$\begin{array}{lccc}\text { mediana } & 25,50 & 26,65 & 26,00 \\ \text { quartil 3 } & 26,85 & 27,30 & 27,68 \\ \text { quartil 1 } & 24,05 & 25,73 & 24,73 \\ \text { IQ } & 2,80 & 1,58 & 2,95 \\ \text { IQN } & 2,08 & 1,17 & 2,19 \\ \text { IQNmédio } & 1,81 & & \end{array}$

Considerando-se apenas os ensaios sob três instrumentações (SG, CG e 1R), a distância em relação às novas medianas se mostrou menor - IQN médio dos agrupamentos com valores entre 1,16 e 1,81 GPa.

Seguindo 0 raciocínio de análise anterior, pode-se admitir que aproximadamente $67,8 \%$ dos resultados médios distaram entre 0,58 e 0,91 GPa das medianas dos agrupamentos (0,5 vez o IQN médio), 27,5\% distaram entre 1,74 e 2,72 GPa (1,5 vez o IQN médio), 4,4\% distaram entre 2,90 e 4,53 GPa (2,5 vezes o IQN médio) e 0,3\% distaram entre 4,64 e 7,24 GPa (4 vezes o IQN médio).

O novo resultado é significativamente mais aceitável do ponto de vista prático em termos de exatidão para os resultados individuais. Analise-se agora o arranjo excluindo-se $2 \mathrm{R}$ e considerando $1 \mathrm{R}$-corrigido, obtido da mesma forma que a descrita durante $o$ item de cálculo dos indicadores de precisão (Tab. 5.1.3.2.5 a 5.1.3.2.8):

Tabela 5.1.3.2.5 - Planilha de cálculo de exatidão - Ecs-1I-1bt-040 (SG, CG, 1R-corrigido)

\begin{tabular}{|c|c|c|c|}
\hline \multicolumn{4}{|l|}{ Lab/Betor } \\
\hline SG & bt1 & bt2 & bt3 \\
\hline 1 & 35,4 & 40,1 & 35,8 \\
\hline 2 & 36,2 & 34,1 & 36,1 \\
\hline 3 & 34,5 & 36,1 & 35,7 \\
\hline 4 & 34,3 & 37,6 & 31,0 \\
\hline 5 & 35,5 & 40,3 & 35,9 \\
\hline 6 & 35,9 & 32,9 & 35,8 \\
\hline 7 & 37,6 & 36,3 & 35,1 \\
\hline 8 & 33,2 & 32,1 & 34,7 \\
\hline 9 & 36,2 & 35,8 & 33,8 \\
\hline 10 & 34,3 & 36,5 & 35,7 \\
\hline \multicolumn{4}{|l|}{ CG } \\
\hline 1 & 33,2 & 35,8 & 30,1 \\
\hline 2 & 32,6 & 36,8 & 36,2 \\
\hline 3 & 34,3 & 36,8 & 37,6 \\
\hline 4 & 34,7 & 36,0 & 35,5 \\
\hline 5 & 33,2 & 34,7 & 35,3 \\
\hline 6 & 33,4 & 36,0 & 35,3 \\
\hline 7 & 35,1 & 37,0 & 35,0 \\
\hline 8 & 34,5 & 36,8 & 36,7 \\
\hline 9 & 34,4 & 34,7 & 36,6 \\
\hline 10 & 33,9 & 34,7 & 34,9 \\
\hline
\end{tabular}

\begin{tabular}{|c|c|c|}
\hline \multicolumn{3}{|c|}{ Z-score } \\
\hline bt1 & bt2 & bt3 \\
\hline 0,52 & 2,60 & 0,21 \\
\hline 0,95 & $-1,25$ & 0,53 \\
\hline 0,03 & 0,03 & 0,11 \\
\hline$-0,08$ & 1,00 & $-4,83$ \\
\hline 0,57 & 2,73 & 0,32 \\
\hline 0,79 & $-2,02$ & 0,21 \\
\hline 1,71 & 0,16 & $-0,53$ \\
\hline$-0,68$ & $-2,54$ & $-0,95$ \\
\hline 0,95 & $-0,16$ & $-1,89$ \\
\hline$-0,08$ & 0,29 & 0,11 \\
\hline
\end{tabular}

\begin{tabular}{|c|c|c|}
\hline$-0,68$ & $-0,16$ & $-5,78$ \\
\hline$-1,00$ & 0,48 & 0,63 \\
\hline$-0,08$ & 0,48 & 2,10 \\
\hline 0,14 & $-0,03$ & $-0,11$ \\
\hline$-0,68$ & $-0,87$ & $-0,32$ \\
\hline$-0,57$ & $-0,03$ & $-0,32$ \\
\hline 0,35 & 0,61 & $-0,63$ \\
\hline 0,03 & 0,48 & 1,16 \\
\hline$-0,03$ & $-0,87$ & 1,05 \\
\hline$-0,30$ & $-0,87$ & $-0,74$ \\
\hline
\end{tabular}


1R-corrigido

\begin{tabular}{|c|c|c|c|}
\hline $\mathbf{1}$ & 35,9 & 40,4 & 35,0 \\
\hline $\mathbf{2}$ & 36,5 & 36,1 & 37,0 \\
\hline $\mathbf{3}$ & 35,1 & 33,6 & 35,4 \\
\hline $\mathbf{4}$ & 32,7 & 32,6 & 34,2 \\
\hline $\mathbf{5}$ & 32,7 & 37,7 & 39,8 \\
\hline $\mathbf{6}$ & 31,6 & 35,2 & 37,0 \\
\hline $\mathbf{7}$ & 33,9 & 36,1 & 33,4 \\
\hline $\mathbf{8}$ & 36,1 & 38,4 & 34,5 \\
\hline $\mathbf{9}$ & 36,9 & 34,4 & 36,2 \\
\hline $\mathbf{1 0}$ & 33,3 & 33,9 & 37,0 \\
\hline mediana & $\mathbf{3 4 , 4 5}$ & $\mathbf{3 6 , 0 5}$ & $\mathbf{3 5 , 6 0}$ \\
quartil 3 & $\mathbf{3 5 , 7 9}$ & $\mathbf{3 6 , 8 0}$ & $\mathbf{3 6 , 2 1}$ \\
quartil 1 & $\mathbf{3 3 , 3 0}$ & $\mathbf{3 4 , 7 0}$ & $\mathbf{3 4 , 9 3}$ \\
IQ & $\mathbf{2 , 4 9}$ & $\mathbf{2 , 1 0}$ & $\mathbf{1 , 2 8}$ \\
IQN & $\mathbf{1 , 8 4}$ & $\mathbf{1 , 5 6}$ & $\mathbf{0 , 9 5}$ \\
IQNmédio & $\mathbf{1 , 4 5}$ & &
\end{tabular}

\begin{tabular}{|c|c|c|}
\hline 0,78 & 2,76 & $-0,62$ \\
\hline 1,13 & 0,03 & 1,44 \\
\hline 0,36 & $-1,58$ & $-0,16$ \\
\hline$-0,94$ & $-2,21$ & $-1,42$ \\
\hline$-0,94$ & 1,08 & 4,42 \\
\hline$-1,53$ & $-0,53$ & 1,44 \\
\hline$-0,29$ & 0,03 & $-2,33$ \\
\hline 0,90 & 1,50 & $-1,19$ \\
\hline 1,31 & $-1,09$ & 0,64 \\
\hline$-0,64$ & $-1,37$ & 1,44 \\
\hline
\end{tabular}

Tabela 5.1.3.2.6 - Planilha de cálculo de exatidão - Eci-1l-1bt-040 (SG, CG, 1R-corrigido)

Lab\Betonada

SG

\begin{tabular}{|c|c|c|c|} 
SG & bt1 & bt2 & bt3 \\
\hline $\mathbf{1}$ & 35,8 & 35,3 & 36,5 \\
\hline $\mathbf{2}$ & 38,5 & 35,3 & 37,5 \\
\hline $\mathbf{3}$ & 34,7 & 36,2 & 37,0 \\
\hline $\mathbf{4}$ & 36,4 & 39,7 & 32,1 \\
\hline $\mathbf{5}$ & 35,7 & 40,7 & 36,9 \\
\hline $\mathbf{6}$ & 36,5 & 35,2 & 37,0 \\
\hline $\mathbf{7}$ & 39,9 & 36,8 & 36,1 \\
\hline $\mathbf{8}$ & 34,0 & 32,5 & 36,1 \\
\hline $\mathbf{9}$ & 36,6 & 37,5 & 35,0 \\
\hline $\mathbf{1 0}$ & 35,2 & 38,3 & 36,5 \\
\hline
\end{tabular}

CG

\begin{tabular}{|l|l|l|l|}
\hline $\mathbf{1}$ & 34,3 & 37,7 & 36,9 \\
\hline $\mathbf{2}$ & 33,7 & 38,1 & 37,0 \\
\hline $\mathbf{3}$ & 35,0 & 36,6 & 38,6 \\
\hline $\mathbf{4}$ & 35,4 & 36,8 & 36,4 \\
\hline $\mathbf{5}$ & 34,3 & 36,6 & 36,4 \\
\hline $\mathbf{6}$ & 34,3 & 37,1 & 36,4 \\
\hline $\mathbf{7}$ & 36,2 & 38,3 & 36,2 \\
\hline $\mathbf{8}$ & 35,4 & 37,8 & 37,5 \\
\hline $\mathbf{9}$ & 35,2 & 35,8 & 37,5 \\
\hline $\mathbf{1 0}$ & 35,0 & 35,9 & 35,8 \\
\hline
\end{tabular}

1R-corrigido

\begin{tabular}{|c|c|c|c|}
\hline $\mathbf{1}$ & 38,1 & 40,7 & 34,9 \\
\hline $\mathbf{2}$ & 36,8 & 37,1 & 37,9 \\
\hline $\mathbf{3}$ & 35,7 & 36,1 & 36,6 \\
\hline $\mathbf{4}$ & 33,9 & 34,9 & 35,3 \\
\hline $\mathbf{5}$ & 34,1 & 38,0 & 39,8 \\
\hline $\mathbf{6}$ & 33,7 & 36,1 & 37,6 \\
\hline $\mathbf{7}$ & 34,1 & 37,1 & 34,6 \\
\hline $\mathbf{8}$ & 35,7 & 39,1 & 35,3 \\
\hline $\mathbf{9}$ & 37,6 & 34,4 & 37,5 \\
\hline $\mathbf{1 0}$ & 33,9 & 34,9 & 37,0 \\
\hline
\end{tabular}

Z-score

\begin{tabular}{|c|c|c|}
\multicolumn{1}{c}{ bt1 } & \multicolumn{1}{c}{ bt2 } & bt3 \\
\hline 0,33 & $-0,94$ & $-0,03$ \\
\hline 2,11 & $-0,94$ & 1,03 \\
\hline$-0,39$ & $-0,38$ & 0,50 \\
\hline 0,72 & 1,82 & $-4,69$ \\
\hline 0,26 & 2,45 & 0,39 \\
\hline 0,79 & $-1,00$ & 0,50 \\
\hline 3,03 & 0,00 & $-0,45$ \\
\hline$-0,86$ & $-2,70$ & $-0,45$ \\
\hline 0,86 & 0,44 & $-1,62$ \\
\hline$-0,07$ & 0,94 & $-0,03$ \\
\hline
\end{tabular}

\begin{tabular}{|c|c|c|}
\hline$-0,66$ & 0,56 & 0,39 \\
\hline$-1,05$ & 0,82 & 0,50 \\
\hline$-0,20$ & $-0,13$ & 2,19 \\
\hline 0,07 & 0,00 & $-0,14$ \\
\hline$-0,66$ & $-0,13$ & $-0,14$ \\
\hline$-0,66$ & 0,19 & $-0,14$ \\
\hline 0,59 & 0,94 & $-0,35$ \\
\hline 0,07 & 0,63 & 1,03 \\
\hline$-0,07$ & $-0,63$ & 1,03 \\
\hline$-0,20$ & $-0,56$ & $-0,77$ \\
\hline
\end{tabular}

\begin{tabular}{|c|c|c|}
\hline 1,87 & 2,43 & $-1,76$ \\
\hline 0,97 & 0,18 & 1,48 \\
\hline 0,27 & $-0,42$ & 0,03 \\
\hline$-0,91$ & $-1,21$ & $-1,31$ \\
\hline$-0,77$ & 0,77 & 3,49 \\
\hline$-1,05$ & $-0,42$ & 1,15 \\
\hline$-0,77$ & 0,18 & $-2,09$ \\
\hline 0,27 & 1,44 & $-1,31$ \\
\hline 1,52 & $-1,48$ & 1,03 \\
\hline$-0,91$ & $-1,21$ & 0,48 \\
\hline
\end{tabular}




$\begin{array}{lccc}\text { mediana } & 35,30 & 36,80 & 36,53 \\ \text { quartil 3 } & 36,35 & 37,98 & 37,38 \\ \text { quartil 1 } & 34,30 & 35,83 & 36,10 \\ \text { IQ } & 2,05 & 2,15 & 1,28 \\ \text { IQN } & 1,52 & 1,59 & 0,95 \\ \text { IQNmédio } & 1,35 & & \end{array}$

Tabela 5.1.3.2.7 - Planilha de cálculo de exatidão - Ecs-1l-1bt-070 (SG, CG, 1R-corrigido)

Lab\Betonada

SG

SG
\begin{tabular}{|c|c|c|c|}
\hline $\mathbf{1}$ & bt1 & bt2 & bt3 \\
\hline $\mathbf{2}$ & 24,9 & 25,3 & 24,3 \\
\hline $\mathbf{3}$ & 23,2 & 26,3 & 24,0 \\
\hline $\mathbf{4}$ & 23,9 & 23,4 & 25,2 \\
\hline $\mathbf{5}$ & 21,1 & 25,9 & 24,0 \\
\hline $\mathbf{6}$ & 23,7 & 21,2 & 24,1 \\
\hline $\mathbf{7}$ & 20,0 & 25,7 & 25,9 \\
\hline $\mathbf{8}$ & 21,9 & 25,1 & 22,6 \\
\hline $\mathbf{9}$ & 22,2 & 25,6 & 25,9 \\
\hline $\mathbf{1 0}$ & 24,6 & 25,9 & 22,9 \\
\hline
\end{tabular}

CG

\begin{tabular}{|c|c|c|c|}
\hline $\mathbf{1}$ & 23,5 & 24,0 & 23,1 \\
\hline $\mathbf{2}$ & 24,7 & 25,2 & 23,6 \\
\hline $\mathbf{3}$ & 25,8 & 25,5 & 25,2 \\
\hline $\mathbf{4}$ & 24,5 & 26,0 & 25,7 \\
\hline $\mathbf{5}$ & 23,7 & 26,0 & 24,3 \\
\hline $\mathbf{6}$ & 25,8 & 25,2 & 25,0 \\
\hline $\mathbf{7}$ & 23,1 & 26,0 & 23,8 \\
\hline $\mathbf{8}$ & 25,5 & 24,5 & 24,5 \\
\hline $\mathbf{9}$ & 23,7 & 26,0 & 25,2 \\
\hline $\mathbf{1 0}$ & 22,8 & 24,5 & 27,2 \\
\hline
\end{tabular}

1R-corrigido

\begin{tabular}{|c|c|c|c|}
\hline $\mathbf{1}$ & 21,8 & 21,9 & 22,9 \\
\hline $\mathbf{2}$ & 25,7 & 29,6 & 22,5 \\
\hline $\mathbf{3}$ & 25,0 & 25,0 & 25,0 \\
\hline $\mathbf{4}$ & 25,7 & 25,9 & 20,5 \\
\hline $\mathbf{5}$ & 21,4 & 27,6 & 19,1 \\
\hline $\mathbf{6}$ & 26,5 & 24,0 & 25,9 \\
\hline $\mathbf{7}$ & 22,7 & 20,5 & 17,8 \\
\hline $\mathbf{8}$ & 23,2 & 22,1 & 30,0 \\
\hline $\mathbf{9}$ & 25,4 & 21,0 & 26,5 \\
\hline $\mathbf{1 0}$ & 29,1 & 26,5 & 29,6 \\
\hline mediana & $\mathbf{2 3 , 7 0}$ & $\mathbf{2 5 , 4 0}$ & $\mathbf{2 4 , 4 0}$ \\
quartil 3 & $\mathbf{2 5 , 3 1}$ & $\mathbf{2 6 , 0 0}$ & $\mathbf{2 5 , 8 2}$ \\
quartil 1 & $\mathbf{2 2 , 8 8}$ & $\mathbf{2 4 , 1 3}$ & $\mathbf{2 3 , 2 3}$ \\
IQ & $\mathbf{2 , 4 4}$ & $\mathbf{1 , 8 7}$ & $\mathbf{2 , 5 9}$ \\
IQN & $\mathbf{1 , 8 1}$ & $\mathbf{1 , 3 9}$ & $\mathbf{1 , 9 2}$ \\
IQNmédio & $\mathbf{1 , 7 1}$ & &
\end{tabular}

Z-score

\begin{tabular}{|c|c|c|}
\multicolumn{1}{c}{ bt1 } & \multicolumn{1}{c}{ bt2 } & bt3 \\
\hline 0,66 & $-0,07$ & $-0,05$ \\
\hline$-0,28$ & 0,65 & $-0,21$ \\
\hline 0,11 & $-1,44$ & 0,42 \\
\hline$-0,33$ & 0,36 & $-0,21$ \\
\hline$-1,22$ & $-3,03$ & $-0,16$ \\
\hline 0,00 & 0,22 & 0,78 \\
\hline$-2,05$ & $-0,22$ & $-0,94$ \\
\hline$-1,00$ & 0,14 & 0,78 \\
\hline$-0,83$ & 0,36 & $-0,78$ \\
\hline 0,50 & 1,01 & 2,65 \\
\hline
\end{tabular}

\begin{tabular}{|c|c|c|}
\hline$-0,11$ & $-1,01$ & $-0,68$ \\
\hline 0,55 & $-0,14$ & $-0,42$ \\
\hline 1,16 & 0,07 & 0,42 \\
\hline 0,44 & 0,43 & 0,68 \\
\hline 0,00 & 0,43 & $-0,05$ \\
\hline 1,16 & $-0,14$ & 0,31 \\
\hline$-0,33$ & 0,43 & $-0,31$ \\
\hline 1,00 & $-0,65$ & 0,05 \\
\hline 0,00 & 0,43 & 0,42 \\
\hline$-0,50$ & $-0,65$ & 1,46 \\
\hline
\end{tabular}

\begin{tabular}{|c|c|c|}
\hline$-1,04$ & $-2,50$ & $-0,77$ \\
\hline 1,13 & 3,00 & $-1,00$ \\
\hline 0,71 & $-0,30$ & 0,30 \\
\hline 1,13 & 0,33 & $-2,02$ \\
\hline$-1,28$ & 1,58 & $-2,76$ \\
\hline 1,56 & $-1,01$ & 0,76 \\
\hline$-0,56$ & $-3,52$ & $-3,44$ \\
\hline$-0,25$ & $-2,34$ & 2,91 \\
\hline 0,95 & $-3,20$ & 1,10 \\
\hline 3,01 & 0,80 & 2,69 \\
\hline
\end{tabular}


Tabela 5.1.3.2.8 - Planilha de cálculo de exatidão - Eci-1l-1bt-070 (SG, CG, 1R-corrigido)

\begin{tabular}{|c|c|c|c|}
\hline \multicolumn{4}{|c|}{ Lab\Betonada } \\
\hline 1 & 25,6 & 26,7 & 25,8 \\
\hline 2 & 23,9 & 27,3 & 25,5 \\
\hline 3 & 25,0 & 23,9 & 26,7 \\
\hline 4 & 23,5 & 27,3 & 25,4 \\
\hline 5 & 23,2 & 22,3 & 25,8 \\
\hline 6 & 24,9 & 26,8 & 27,3 \\
\hline 7 & 21,3 & 26,4 & 23,8 \\
\hline 8 & 22,9 & 26,7 & 27,1 \\
\hline 9 & 23,3 & 27,1 & 24,3 \\
\hline 10 & 25,5 & 28,1 & 33,4 \\
\hline \multicolumn{4}{|l|}{ CG } \\
\hline 1 & 24,2 & 25,2 & 24,3 \\
\hline 2 & 24,7 & 25,8 & 24,0 \\
\hline 3 & 25,5 & 26,3 & 26,3 \\
\hline 4 & 24,2 & 26,3 & 26,6 \\
\hline 5 & 26,1 & 26,6 & 25,5 \\
\hline 6 & 25,5 & 26,3 & 26,0 \\
\hline 7 & 24,0 & 27,2 & 24,5 \\
\hline 8 & 25,8 & 25,0 & 25,5 \\
\hline 9 & 24,7 & 26,9 & 26,0 \\
\hline 10 & 23,2 & 25,7 & 27,8 \\
\hline \multicolumn{4}{|c|}{ 1R-corrigido } \\
\hline \begin{tabular}{|l|}
1 \\
\end{tabular} & 24,3 & 22,8 & 24,2 \\
\hline 2 & 28,2 & 29,4 & 25,8 \\
\hline 3 & 26,0 & 26,4 & 26,4 \\
\hline 4 & 27,5 & 27,1 & 22,3 \\
\hline 5 & 23,4 & 28,6 & 20,8 \\
\hline 6 & 26,6 & 27,1 & 26,7 \\
\hline 7 & 25,0 & 22,8 & 19,1 \\
\hline 8 & 25,3 & 23,9 & 28,6 \\
\hline 9 & 26,0 & 23,4 & 27,1 \\
\hline 10 & 29,1 & 27,1 & 28,6 \\
\hline mediana & 24,93 & 26,51 & 25,80 \\
\hline quartil 3 & 25,75 & 27,06 & 26,73 \\
\hline quartil 1 & 23,93 & 25,33 & 24,35 \\
\hline IQ & 1,83 & 1,74 & 2,38 \\
\hline IQN & 1,35 & 1,29 & 1,77 \\
\hline IQNmédio & 1,47 & & \\
\hline
\end{tabular}

\begin{tabular}{|c|c|c|}
\hline \multicolumn{3}{|c|}{ Z-score } \\
\hline bt1 & bt2 & bt3 \\
\hline 0,50 & 0,14 & 0,00 \\
\hline$-0,76$ & 0,61 & $-0,17$ \\
\hline 0,05 & $-2,03$ & 0,51 \\
\hline$-1,05$ & 0,61 & $-0,23$ \\
\hline$-1,28$ & $-3,27$ & 0,00 \\
\hline$-0,02$ & 0,22 & 0,85 \\
\hline$-2,68$ & $-0,09$ & $-1,13$ \\
\hline$-1,50$ & 0,14 & 0,74 \\
\hline$-1,20$ & 0,45 & $-0,85$ \\
\hline 0,42 & 1,23 & 4,30 \\
\hline
\end{tabular}

\begin{tabular}{|c|c|c|}
\hline$-0,54$ & $-1,02$ & $-0,85$ \\
\hline$-0,17$ & $-0,55$ & $-1,02$ \\
\hline 0,42 & $-0,17$ & 0,28 \\
\hline$-0,54$ & $-0,17$ & 0,45 \\
\hline 0,87 & 0,07 & $-0,17$ \\
\hline 0,42 & $-0,17$ & 0,11 \\
\hline$-0,68$ & 0,53 & $-0,74$ \\
\hline 0,65 & $-1,18$ & $-0,17$ \\
\hline$-0,17$ & 0,30 & 0,11 \\
\hline$-1,28$ & $-0,63$ & 1,13 \\
\hline
\end{tabular}

\begin{tabular}{|c|c|c|}
\hline$-0,45$ & $-2,85$ & $-0,90$ \\
\hline 2,44 & 2,23 & 0,00 \\
\hline 0,80 & $-0,07$ & 0,36 \\
\hline 1,89 & 0,43 & $-1,97$ \\
\hline$-1,15$ & 1,65 & $-2,81$ \\
\hline 1,27 & 0,43 & 0,54 \\
\hline 0,02 & $-2,85$ & $-3,76$ \\
\hline 0,25 & $-2,03$ & 1,61 \\
\hline 0,80 & $-2,44$ & 0,71 \\
\hline 3,06 & 0,43 & 1,61 \\
\hline
\end{tabular}

Considerando-se os ensaios sob as três instrumentações (SG, CG e 1Rcorrigido) a distância em relação às novas medianas se mostrou praticamente constante em relação a SG, CG e 1R - IQN médio dos agrupamentos com valores entre 1,35 e 1,71 GPa. De fato, a correção dos valores de 1R através da correlação garante a aproximação das médias, mas não garante a eliminação dos valores extremos alocados no $1^{\circ}$ e no $3^{\circ}$ quartis.

Tal ordem de grandeza parece ser aceitável em termos de exatidão de resultados individuais, o que tenderia a colaborar com a tendência de aceitação 
prática do método como um todo independentemente de SG, CG e 1R-corrigido. Novamente, lembra-se, esta dispersão está vinculada à análise de resultados individuais, e não médios; deve ser menor, em tese, se consideradas as médias dos resultados individuais de três corpos-de-prova, como preconiza a NBR 8522:2003.

A título de informação, o estudo de exatidão realizado no interlaboratorial relatado por Inácio; Andrade e Bittencourt (2006), obteve para o ensaio de módulo estático de deformação do concreto o IQN médio de 3,1 GPa, considerando-se resultados médios de três corpos-de-prova. Em verdade, esta é a demonstração da realidade praticada neste ensaio no âmbito nacional considerando-se a diversidade de operadores e equipamentos para o ensaio.

Vale dizer que o intuito dos comentários acerca da tendência de aceitação prática - e não de Validação - do método de ensaio não é de serem definitivos, pelo simples fato de ter havido restrições no alcance do programa experimental. $O$ que se quer, essencialmente, é elaborar as conclusões ao final de cada avaliação dentro do alcance conseguido, isto é, com as amostras e os equipamentos utilizados, para o próprio teste da metodologia de pesquisa. Obviamente, por outro lado, também não se quer dizer que os resultados sejam desprezáveis.

\subsection{Discussão da aplicabilidade do conceito semiprobabilístico normativo}

Os resultados dos ensaios de módulo de deformação da segunda parte do programa experimental são apresentados nas Tab. 5.2.1 e 5.2.2 e detalhados no Apêndice B, Tab. B.1 e B.2.

Tabela 5.2.1 - Resultados prévios de resistência à compressão (MPa): a/c 0,42, 0,50 e 0,58

\begin{tabular}{|c|c|c|c|}
\hline $100 \pm 20$ & a/c 0,42 & $\mathrm{a} / \mathrm{c} \mathbf{0 , 5 0}$ & $\mathrm{a} / \mathrm{c} \quad 0,58$ \\
\hline 1 & 61,0 & 46,1 & 37,8 \\
\hline 2 & 60,0 & 47,0 & 38,8 \\
\hline Média & 60,45 & 46,53 & 38,35 \\
\hline
\end{tabular}

$\mathbf{1 8 0} \pm \mathbf{3 0}$
\begin{tabular}{|c|c|c|c|}
\hline $\mathbf{1}$ & 57,3 & 46,7 & 42,5 \\
\hline $\mathbf{2}$ & 59,7 & 47,1 & 41,0 \\
\hline Média & $\mathbf{5 8 , 5 2}$ & $\mathbf{4 6 , 9 0}$ & $\mathbf{4 1 , 7 2}$ \\
\hline
\end{tabular}


Tabela 5.2.2 - Resultados de módulo de deformação (GPa): a/c 0,42, 0,50 e 0,58

\begin{tabular}{|c|c|c|c|}
\hline $100 \pm 20$ & $\mathrm{a} / \mathrm{c} \quad 0,42$ & $\mathrm{a} / \mathrm{c} 0,50$ & $a / c 0,58$ \\
\hline 1 & 33,3 & 31,3 & 29,2 \\
\hline 2 & 33,3 & 31,5 & 29,6 \\
\hline 3 & 32,8 & 31,0 & 28,3 \\
\hline Média & 33,13 & 31,27 & 29,03 \\
\hline
\end{tabular}

$\mathbf{1 8 0} \pm \mathbf{3 0}$
\begin{tabular}{|c|c|c|c|}
\hline $\mathbf{1}$ & 30,3 & 29,4 & 27,7 \\
\hline $\mathbf{2}$ & 30,9 & 27,9 & 28,0 \\
\hline $\mathbf{3}$ & 30,1 & 27,6 & 26,5 \\
\hline Média & $\mathbf{3 0 , 4 3}$ & $\mathbf{2 8 , 3 0}$ & $\mathbf{2 7 , 4 0}$ \\
\hline
\end{tabular}

\subsubsection{Consideração geral}

Nos itens anteriores, viu-se que a variabilidade experimental dos resultados dos ensaios de determinação do módulo estático de deformação do concreto possui características estatísticas marcantes, como aquelas originadas na alternância dos planos de carregamento de ensaio ou das instrumentações para medida das deformações.

Foi ilustrada naqueles momentos, porém, a análise sobre resultados individuais. Sobre a análise de resultados médios de três corpos-de-prova, de acordo com a NBR 8522:2003, ressaltou-se que se poderia esperar menores valores de dispersão, o que é intuitivo.

Analisem-se agora, então, os resultados médios, tendo sido cada um deles obtido a partir de três resultados individuais de cada betonada - média dos resultados 1 a 3, 4 a 6 e 7 a 9 de cada instrumentação, betonada a betonada; ou seja, considerando-se SG, CG e 1R-corrigido, cada betonada resultou em nove resultados médios (Tab. 5.2.1.1 a 5.2.1.4).

Tabela 5.2.1.1 - Resultados médios de módulo - Ecs,m-1l-1bt-040 (SG, CG, 1R-corrigido)

\begin{tabular}{l}
\multicolumn{2}{c}{ Lab/Betonada } \\
\begin{tabular}{|c|c|c|c|c|}
\multicolumn{3}{c}{ bt1 } & bt2 & bt3 \\
\hline \multirow{3}{*}{ SG } & $\mathbf{1}$ & 35,4 & 36,8 & 35,9 \\
\cline { 2 - 5 } & $\mathbf{2}$ & 35,2 & 36,9 & 34,2 \\
\cline { 2 - 5 } & $\mathbf{3}$ & 35,7 & 34,7 & 34,5 \\
\hline \multirow{3}{*}{ CG } & $\mathbf{4}$ & 33,4 & 36,5 & 34,6 \\
\cline { 2 - 5 } & $\mathbf{5}$ & 33,8 & 35,6 & 35,4 \\
\cline { 2 - 5 } & $\mathbf{6}$ & 34,7 & 36,2 & 36,1 \\
\hline
\end{tabular}
\end{tabular}




\begin{tabular}{r|r|c|c|c|}
\hline \multirow{2}{*}{ 1R-corrigido } & $\mathbf{7}$ & 35,8 & 36,7 & 35,8 \\
\cline { 2 - 5 } & $\mathbf{8}$ & 32,4 & 35,2 & 37,0 \\
\cline { 2 - 5 } & $\mathbf{9}$ & 35,6 & 36,3 & 34,7 \\
\hline & Média & $\mathbf{3 4 , 6 7}$ & $\mathbf{3 6 , 1 0}$ & $\mathbf{3 5 , 3 6}$ \\
& Média geral & $\mathbf{3 5 , 3 7}$ & & \\
& Desvio & $\mathbf{1 , 2 0}$ & $\mathbf{0 , 7 7}$ & $\mathbf{0 , 9 2}$ \\
& Desvio médio & $\mathbf{0 , 9 6}$ & &
\end{tabular}

Tabela 5.2.1.2 - Resultados médios de módulo - Eci,m-1l-1bt-040 (SG, CG, 1R-corrigido) Lab\Betonada

\begin{tabular}{|c|c|c|c|c|}
\hline & & bt1 & bt2 & bt3 \\
\hline \multirow{3}{*}{ SG } & 1 & 36,3 & 35,6 & 37,0 \\
\hline & 2 & 36,2 & 38,5 & 35,3 \\
\hline & 3 & 36,8 & 35,6 & 35,7 \\
\hline \multirow{3}{*}{ CG } & 4 & 34,3 & 37,5 & 37,5 \\
\hline & 5 & 34,7 & 36,8 & 36,4 \\
\hline & 6 & 35,6 & 37,3 & 37,1 \\
\hline \multirow{3}{*}{ 1R-corrigido } & 7 & 36,9 & 38,0 & 36,5 \\
\hline & 8 & 33,9 & 36,3 & 37,6 \\
\hline & 9 & 35,8 & 36,9 & 35,8 \\
\hline \multicolumn{2}{|r|}{ Média } & 35,61 & 36,94 & 36,54 \\
\hline \multicolumn{2}{|r|}{ Média geral } & 36,37 & & \\
\hline \multicolumn{2}{|r|}{ Desvio } & 1,08 & 1,00 & 0,82 \\
\hline \multicolumn{2}{|r|}{ Desvio médio } & 0,97 & & \\
\hline
\end{tabular}

Tabela 5.2.1.3 - Resultados médios de módulo - Ecs,m-11-1bt-070 (SG, CG, 1R-corrigido)

Lab\Betonada

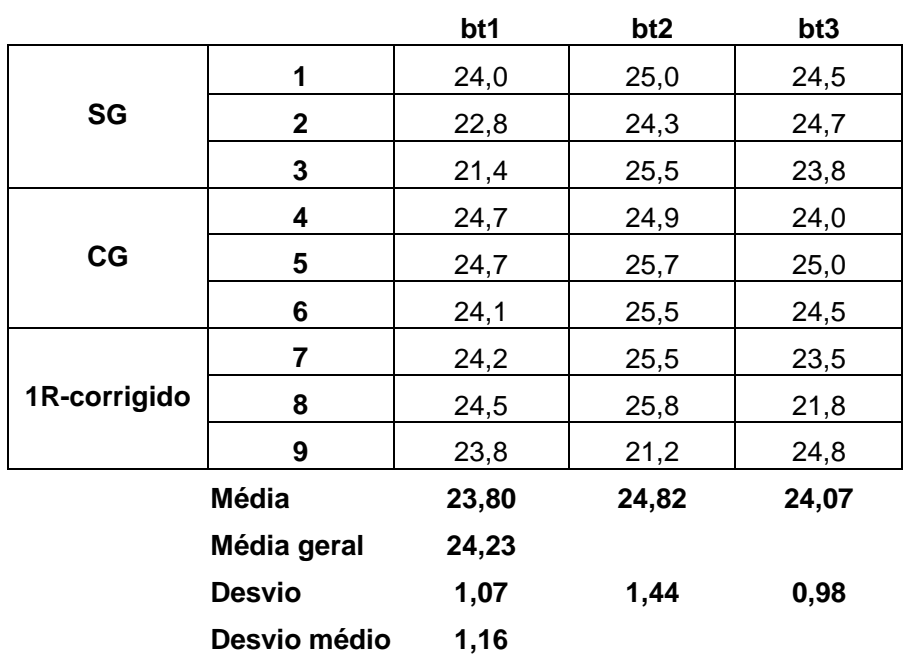


Tabela 5.2.1.4 - Resultados médios de módulo - Eci,m-1l-1bt-070 (SG, CG, 1R-corrigido)

Lab\Betonada

\begin{tabular}{|c|c|c|c|c|}
\hline & & bt1 & bt2 & bt3 \\
\hline \multirow{3}{*}{ SG } & 1 & 24,8 & 26,0 & 26,0 \\
\hline & 2 & 23,9 & 25,5 & 26,2 \\
\hline & 3 & 22,5 & 26,7 & 25,1 \\
\hline \multirow{3}{*}{ CG } & 4 & 24,8 & 25,8 & 24,9 \\
\hline & 5 & 25,3 & 26,4 & 26,0 \\
\hline & 6 & 24,8 & 26,4 & 25,3 \\
\hline \multirow{3}{*}{ 1R-corrigido } & 7 & 26,2 & 26,2 & 25,5 \\
\hline & 8 & 25,8 & 27,6 & 23,3 \\
\hline & 9 & 25,4 & 23,4 & 25,0 \\
\hline \multicolumn{2}{|r|}{ Média } & 24,83 & 26,00 & 25,26 \\
\hline \multicolumn{2}{|r|}{ Média geral } & 25,36 & & \\
\hline \multicolumn{2}{|r|}{ Desvio } & 1,10 & 1,14 & 0,87 \\
\hline & Desvio médio & 1,04 & & \\
\hline
\end{tabular}

Comparando-se esses resultados com os obtidos a partir da análise dos resultados individuais, tem-se (Tab. 5.2.1.5 e 5.2.1.6):

Tabela 5.2.1.5 - Resultados de módulo de deformação do Concreto a/c 0,40 (040): Individuais X Médios (SG, CG, 1R-corrigido)

\begin{tabular}{|c|c|c|c|c|}
\hline \multirow{4}{*}{$\begin{array}{l}\text { Média geral } \\
\text { Desvio médio }\end{array}$} & \multicolumn{2}{|c|}{$\begin{array}{c}\text { Resultados individuais } \\
\text { (GPa) }\end{array}$} & \multicolumn{2}{|c|}{$\begin{array}{l}\text { Resultados médios } \\
\text { (GPa) }\end{array}$} \\
\hline & Ecs & Eci & Ecs & Eci \\
\hline & 35,32 & 36,31 & 35,37 & 36,37 \\
\hline & 1,79 & 1,58 & 0,96 & 0,97 \\
\hline
\end{tabular}

Tabela 5.2.1.6 - Resultados de módulo de deformação do Concreto a/c 0,70 (070): Individuais X Médios (SG, CG, 1R-corrigido)

\begin{tabular}{|c|c|c|c|c|}
\hline \multirow{4}{*}{$\begin{array}{c}\text { Média geral } \\
\text { Desvio médio }\end{array}$} & \multicolumn{2}{|c|}{$\begin{array}{c}\text { Resultados individuais } \\
\text { (GPa) }\end{array}$} & \multicolumn{2}{|c|}{$\begin{array}{c}\text { Resultados médios } \\
(\mathrm{GPa})\end{array}$} \\
\hline & \begin{tabular}{|l|} 
Ecs \\
\end{tabular} & Eci & Ecs & Eci \\
\hline & 24,47 & 25,58 & 24,23 & 25,36 \\
\hline & 2,18 & 1.96 & 1,16 & 1.04 \\
\hline
\end{tabular}

Note-se que, como era de se esperar, as médias gerais dos resultados dos experimentos obtidas a partir dos resultados individuais ou das médias de três corpos-de-prova mostraram-se praticamente iguais. Porém, realmente, o desvio- 
padrão total dos resultados individuais e o desvio-padrão total dos resultados médios sob SG, CG e 1R-corrigido têm diferenças significativas entre si.

Essa conclusão desmistifica uma parte da incerteza acerca dos resultados experimentais e valoriza o termo de consideração dos resultados médios preconizado na NBR 8522:2003.

No entanto, deve-se ressaltar que as magnitudes destes parâmetros foram obtidas no âmbito deste programa experimental.

Como se viu no interlaboratorial nacional, mesmo com resultados médios temse chegado a desvios-padrão totais da ordem de 3,5 GPa.

Por isso, para a continuidade deste item da dissertação optou-se por considerar o desvio-padrão total o valor de 2,5 GPa.

Assim, considere-se um projeto cuja especificação do concreto contenha:

- Resistência característica $\left(f_{c k}\right)$ de $30 \mathrm{MPa}$

- Módulo de deformação secante $\left(E_{c s}\right)$ de 26 GPa

Considere-se também o cenário hipotético de fornecimento do material:

- Dois traços de mercado atendem à especificação por deficiência de detalhamento de desempenho nominal em norma:

- Fornecedor $A-f_{c k} 30$ MPa e $E_{c s, k}$ (característico) $26 \mathrm{GPa}$

- Fornecedor $B-f_{c k} 30$ MPa e $E_{c s, m}$ (médio) $26 \mathrm{GPa}$

Se considerado um intervalo de confiança de $90 \%$ e um desvio padrão total para a propriedade de 2,50 GPa (desvio de produção e ensaio; no caso o desvio de produção a ser considerado seria aquele entre caminhões-betoneira), o controle de qualidade em obra do concreto fornecido por B obteria resultados de até $22 \mathrm{GPa}$, enquanto A garantiria os $26 \mathrm{GPa}$.

Qual seria a implicação dessa diferença de 4 GPa sobre a deformação dos elementos construtivos e sobre a produção do concreto? 


\subsubsection{Implicações sobre a deformação estrutural}

Inúmeras avaliações da estimativa das implicações sobre a deformação estrutural poderiam ser apresentadas. É intuitivo, inclusive, que diferentes projetos estruturais naturalmente apresentem diferentes níveis de implicação.

A seguir é apresentada uma dessas estimativas possíveis. A escolha obedeceu unicamente à premissa de que se deveria tratar de realizar uma nova verificação de deformação máxima de uma peça de concreto armado comum, sabidamente de acordo com os limites preconizados na NBR 6118:2003 para o Estado Limite de Serviço para Deformações Excessivas (ELS-DEF) em um admitido nível de módulo de deformação do concreto. A opção escolhida foi o detalhamento de Bittencourt e Assis (2003) para o qual o módulo de deformação do concreto considerado foi de $26 \mathrm{GPa}$. Os demais dados desse projeto constam da Fig. 5.2.2.1. Os resultados da verificação realizada pelos autores com este nível de rigidez está reproduzida na Tab. 5.2.2.1 e outra com o nível de 22 GPa considerando-se a situação hipotética de que a execução da viga tivesse se dado com uma betonada de concreto com esta característica está reproduzida em seguida na Tab. 5.2.2.2:

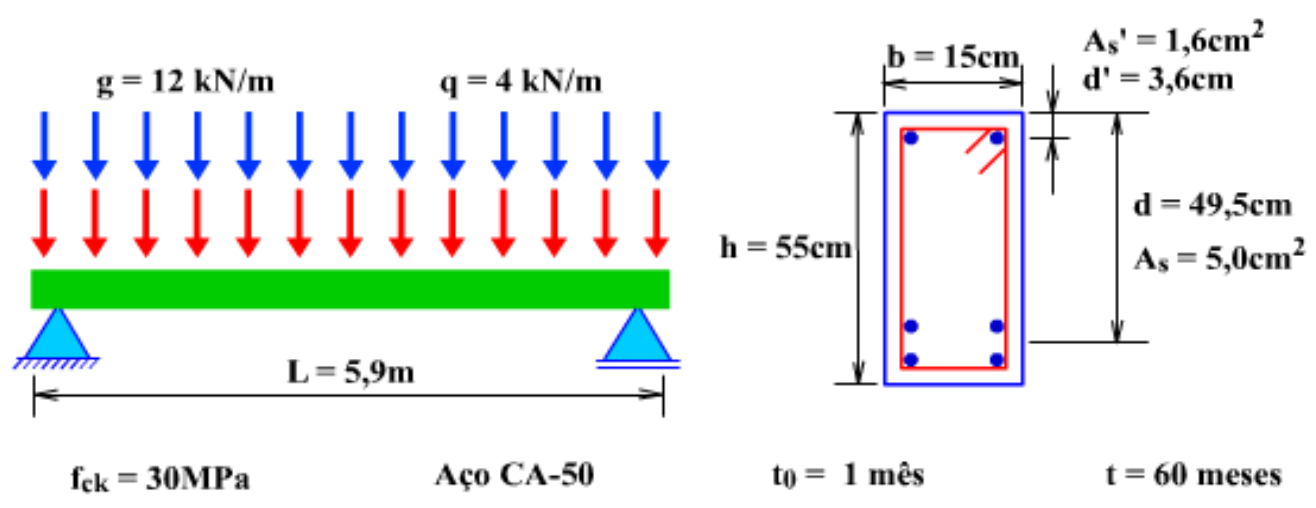

Figura 5.2.2.1 - Viga verificada quanto à deformação máxima admissível

Fonte: Bittencourt e Assis (2003) 
Tabela 5.2.2.1 - Verificação de ELS-DEF: módulo de deformação do concreto de 26 GPa

\begin{tabular}{|l|r|}
\hline$g(k N / m)$ & 12,0 \\
\hline$q(k N / m)$ & 4,0 \\
\hline$L(m)$ & 5,9 \\
\hline
\end{tabular}

\begin{tabular}{|l|r|}
\hline$b(\mathrm{~cm})$ & 15 \\
\hline$h(\mathrm{~cm})$ & 55 \\
\hline$d(\mathrm{~cm})$ & 49,5 \\
\hline$d^{\prime}(\mathrm{cm})$ & 3,6 \\
\hline
\end{tabular}

\begin{tabular}{|l|r|}
\hline aço & CA 50 \\
\hline fck $(\mathrm{MPa})$ & 30 \\
\hline
\end{tabular}

\begin{tabular}{|l|r|}
\hline Es $(\mathrm{GPa})$ & 210 \\
\hline Ecs $(\mathrm{GPa})$ & $\mathbf{2 6}$ \\
\hline alfae & 8,08 \\
\hline
\end{tabular}

\begin{tabular}{|l|r|}
\hline As $(\mathrm{cm} 2)$ & 5,0 \\
\hline As $^{\prime}(\mathrm{cm} 2)$ & 1,6 \\
\hline
\end{tabular}

\begin{tabular}{|l|r|}
\hline$X_{I I}(\mathrm{~cm})$ & 13,34 \\
\hline
\end{tabular}

\begin{tabular}{|l|r|}
\hline $\mathrm{lo}\left(\mathrm{cm}^{4}\right)$ & 207969 \\
\hline $\mathrm{III}\left(\mathrm{cm}^{4}\right)$ & 65900 \\
\hline $\mathrm{fct}, \mathrm{m}\left(\mathrm{kN} / \mathrm{cm}^{2}\right)$ & 0,29 \\
\hline alfa $($ seção retang) & 1,5 \\
\hline $\mathrm{Mr}(\mathrm{kN} . \mathrm{cm})$ & 3286 \\
\hline
\end{tabular}

\begin{tabular}{|c|c|c|c|}
\hline le,perm $\left(\mathrm{cm}^{4}\right)$ & 101299 & $<$ & 207969 \\
\hline le,qp $\left(\mathrm{cm}^{4}\right)$ & 92496 & & 207969 \\
\hline le,rara $\left(\mathrm{cm}^{4}\right)$ & 80834 & $<$ & 207969 \\
\hline
\end{tabular}

\begin{tabular}{|l|r|}
\hline $\mathrm{a}^{\prime}$ & 0,0022 \\
\hline coef 1 mês & 0,6773 \\
\hline coef 60 meses & 1,9819 \\
\hline alfaf & 1,18 \\
\hline $\mathrm{L} / 250(\mathrm{~cm})$ & 2,36 \\
\hline $\mathrm{L} / 350(\mathrm{~cm})$ & 1,69 \\
\hline
\end{tabular}

\begin{tabular}{|l|r|}
\hline Dimed,qp (cm) & 0,87 \\
\hline Ddif,qp $(\mathrm{cm})$ & 1,02 \\
\hline Dtot,qp $(\mathrm{cm})$ & $\mathbf{1 , 8 9}$ \\
\hline
\end{tabular}

\begin{tabular}{|l|r|}
\hline Mmáx,perm (kN.cm) & 5222 \\
\hline Mmáx,qp (kN.cm) & 5744 \\
\hline Mmáx,rara (kN.cm) & 6962 \\
\hline
\end{tabular}

\begin{tabular}{|l|r|}
\hline Dimed, $\mathrm{g}(\mathrm{cm})$ & 0,72 \\
\hline Dimed, $\mathrm{g}+\mathrm{q}(\mathrm{cm})$ & 1,20 \\
\hline Dimed, $\mathrm{q}(\mathrm{cm})$ & $\mathbf{0 , 4 8}$ \\
\hline
\end{tabular}

Tabela 5.2.2.2 - Verificação de ELS-DEF: módulo de deformação do concreto de 22 GPa

\begin{tabular}{|l|r|}
\hline$g(k N / m)$ & 12,0 \\
\hline$q(k N / m)$ & 4,0 \\
\hline$L(m)$ & 5,9 \\
\hline
\end{tabular}

\begin{tabular}{|l|r|}
\hline$b(\mathrm{~cm})$ & 15 \\
\hline$h(\mathrm{~cm})$ & 55 \\
\hline$d(\mathrm{~cm})$ & 49,5 \\
\hline$d^{\prime}(\mathrm{cm})$ & 3,6 \\
\hline
\end{tabular}

\begin{tabular}{|l|r|}
\hline aço & CA 50 \\
\hline fck (MPa) & 30 \\
\hline & \\
\hline Es $(\mathrm{GPa})$ & 210 \\
\hline Ecs $(\mathrm{GPa})$ & $\mathbf{2 2}$ \\
\hline alfae & 9,55 \\
\hline
\end{tabular}

\begin{tabular}{|l|r|}
\hline As (cm2) & 5,0 \\
\hline As ${ }^{\prime}(\mathrm{cm} 2)$ & 1,6 \\
\hline \multicolumn{2}{|c|}{} \\
\hline$X_{\| I}(\mathrm{~cm})$ & 14,24 \\
\hline
\end{tabular}

\begin{tabular}{|l|r|}
\hline $\mathrm{lo}\left(\mathrm{cm}^{4}\right)$ & 207969 \\
\hline $\mathrm{l}$ II $\left(\mathrm{cm}^{4}\right)$ & 75505 \\
\hline $\mathrm{fct}, \mathrm{m}\left(\mathrm{kN} / \mathrm{cm}^{2}\right)$ & 0,29 \\
\hline alfa (seção retang) & 1,5 \\
\hline $\mathrm{Mr}(\mathrm{kN} . \mathrm{cm})$ & 3286 \\
\hline
\end{tabular}

\begin{tabular}{|l|r|}
\hline le,perm $\left(\mathrm{cm}^{4}\right)$ & 108510 \\
\hline le, $q p\left(\mathrm{~cm}^{4}\right)$ & 100302 \\
\hline le,rara $\left(\mathrm{cm}^{4}\right)$ & 89429 \\
\hline
\end{tabular}

\begin{tabular}{|l|r|}
\hline$a^{\prime}$ & 0,0022 \\
\hline coef 1 mês & 0,6773 \\
\hline coef 60 meses & 1,9819 \\
\hline alfaf & 1,18 \\
\hline L/250 $(\mathrm{cm})$ & 2,36 \\
\hline L/350 $(\mathrm{cm})$ & 1,69 \\
\hline
\end{tabular}

\begin{tabular}{|l|r|}
\hline Mmáx,perm (kN.cm) & 5222 \\
\hline Mmáx,qp (kN.cm) & 5744 \\
\hline Mmáx,rara (kN.cm) & 6962 \\
\hline
\end{tabular}

\begin{tabular}{l|r|}
\hline Dimed,qp (cm) & 0,94 \\
\hline Ddif,qp $(\mathrm{cm})$ & 1,11 \\
\hline Diot,qp $(\mathrm{cm})$ & $\mathbf{2 , 0 6}$ \\
\hline \multicolumn{1}{|l|}{ Visual } \\
\hline Dimed,g $(\mathrm{cm})$ & 0,79 \\
\hline Dimed,g+q $(\mathrm{cm})$ & $\mathbf{1 , 2 8}$ \\
\hline Dimed,q $(\mathrm{cm})$ & $\mathbf{0 , 4 9}$ \\
\hline
\end{tabular}


onde:

- Momento fletor atuante máximo (combinação permanente): $M_{\text {máx, } \text { perm }}=\frac{g \cdot L^{2}}{8}$

- Momento

máximo (combinação

quase

$$
\text { permanente): } M_{\text {máx }, q p}=\frac{(g+0,3 \cdot q) \cdot L^{2}}{8}
$$

- $\quad$ Momento máximo (combinação rara): $M_{\text {máx, } r a r a}=\frac{(g+q) \cdot L^{2}}{8}$

- Momento de inércia da seção não fissurada: $I_{0}=b \cdot h^{3} / 12$

- Itens auxiliares: $\alpha_{e}=E_{s} / E_{c s} ; \frac{b \cdot x_{I I}^{2}}{2}-\left[\alpha_{e} \cdot A s \cdot\left(d-x_{I I}\right)\right]+\alpha_{e} \cdot A s^{\prime} \cdot\left(x_{I I}-d^{\prime}\right)=0$

- Inércia da seção fissurada: $I_{I I}=\frac{b \cdot x_{I I}^{3}}{3}+\alpha_{e} \cdot A s \cdot\left(d-x_{I I}\right)^{2}+\alpha_{e} \cdot A s^{\prime} \cdot\left(x_{I I}-d^{\prime}\right)^{2}$

- Momento de fissuração: $M_{r}=\frac{\alpha_{s r} \cdot f c t, m \cdot I_{0}}{h / 2}$

- Inércia equivalente entre seções (fórmula de Branson):

$$
I_{e}=\left(\frac{M_{r}}{M_{\text {máx }}}\right)^{3} \cdot I_{0}+\left[1-\left(\frac{M_{r}}{M_{\text {máx }}}\right)^{3}\right] \cdot I_{I I} \leq I_{0}
$$

- Itens auxiliares (fluência): $a^{\prime}=\frac{A s^{\prime}}{b \cdot d} ; \quad \xi(t)=0,68 \cdot 0,996^{t} \cdot t^{0,32} ; \quad \alpha_{f}=\frac{\xi_{60}-\xi_{1}}{1+50 \cdot a^{\prime}}$

- Flecha imediata (combinação quase permanente): $D_{\text {imed }, q p}=\frac{5 \cdot(g+0,3 \cdot q) \cdot L^{4}}{384 \cdot E_{c s} \cdot I_{e, q p}}$

- Flecha diferida ao longo do tempo: $D_{d i f, q p}=\alpha_{f} . D_{\text {imed }, q p}$

- Limite de norma (conforto visual): $D_{\text {tot, } q p}=D_{\text {imed, } q p}+D_{\text {dif }, q p} \leq L / 250$

- Flecha imediata (carga permanente): $D_{i m e d, g}=\frac{5 \cdot g \cdot L^{4}}{384 \cdot E_{c s} \cdot I_{e, p e r m}}$

- Flecha imediata (cargas permanente e acidental):

$$
D_{\text {imed }, g+q}=\frac{5 \cdot(g+q) \cdot L^{4}}{384 \cdot E_{c s} \cdot I_{e, r a r a}}
$$

- Limite de norma (conforto a vibrações): $D_{\text {imed }, q}=D_{\text {imed, }, g+q}-D_{\text {imed, }, g} \leq L / 350$ 
Assim sendo, a diminuição de 4 GPa considerada no módulo de deformação do concreto implicou no aumento do deslocamento vertical total da viga - flecha imediata, 'Dimed,qp', somada à flecha diferida acumulada ao longo de 60 meses, 'Ddif,qp', ambas para a combinação de esforços quase-permanente - de 1,89 cm para 2,06 cm, representando um incremento de aproximadamente $9 \%$ na direção do índice preconizado em norma como limite de conforto visual do usuário da edificação que seria de 2,36 cm neste caso.

Unicamente sob este critério, a diferença de $4 \mathrm{GPa}$ não implicou então em uma mudança no projeto; mesmo assim, pode-se dizer que não deve ser simplesmente desprezada no dia-a-dia.

A relação do módulo de deformação com a curvatura do elemento estrutural é normalmente apresentada sob a forma de curva momento-curvatura (Fig. 5.2.2.2). Nela, o coeficiente angular da reta que representa a deformação da seção já fissurada pela solicitação acima de momento de fissuração (Mr) é numericamente igual à rigidez à flexão $E_{c s} \cdot I_{e}$.

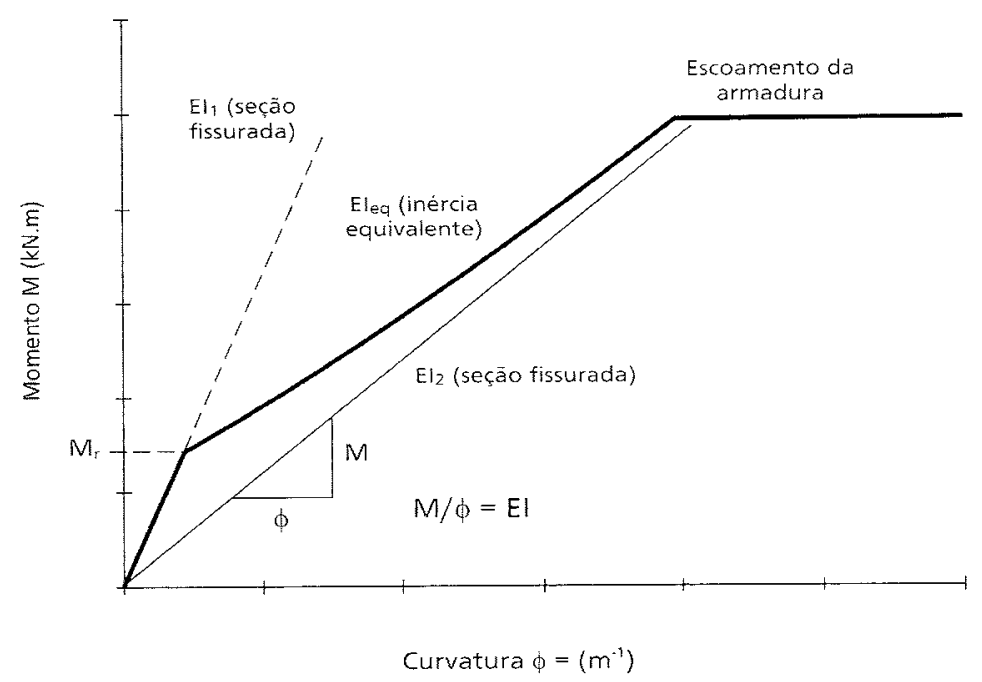

Figura 5.2.2.1 - Viga verificada quanto à deformação máxima admissível

Fonte: Silva e Melo (2005)

Uma outra forma de identificar a importância dessa diferença seria através do cálculo do próprio coeficiente de rigidez à flexão ou ainda da rigidez secante 
adimensional $(\kappa)$ para as duas situações. Considerando-se esta última e a formulação e as condições admitidas na Tab. 5.2.2.3 e na Fig. 5.2.2.3, tem-se:

$$
\kappa=\frac{I_{e} \cdot E_{c s}}{b \cdot h^{3} \cdot f_{c d}}
$$

Tabela 5.2.2.3 - Diferença na rigidez secante adimensional

\begin{tabular}{|c|c|c|c|}
\hline Mmáx,qp / Mr & $\begin{array}{c}\text { Kapa } \\
\text { Ecs=26 GPa }\end{array}$ & $\begin{array}{c}\text { Kapa } \\
\text { Ecs=22 GPa }\end{array}$ & Diferença (\%) \\
\hline 1,0 & 101 & 86 & $-15,4$ \\
\hline 1,5 & 53 & 47 & $-10,1$ \\
\hline $1,75^{*}$ & 45 & 41 & $-8,2$ \\
\hline 2,0 & 41 & 38 & $-6,9$ \\
\hline 2,5 & 36 & 35 & $-5,2$ \\
\hline
\end{tabular}

* Esta relação corresponde à solicitação considerada na verificação exemplificada anteriormente.

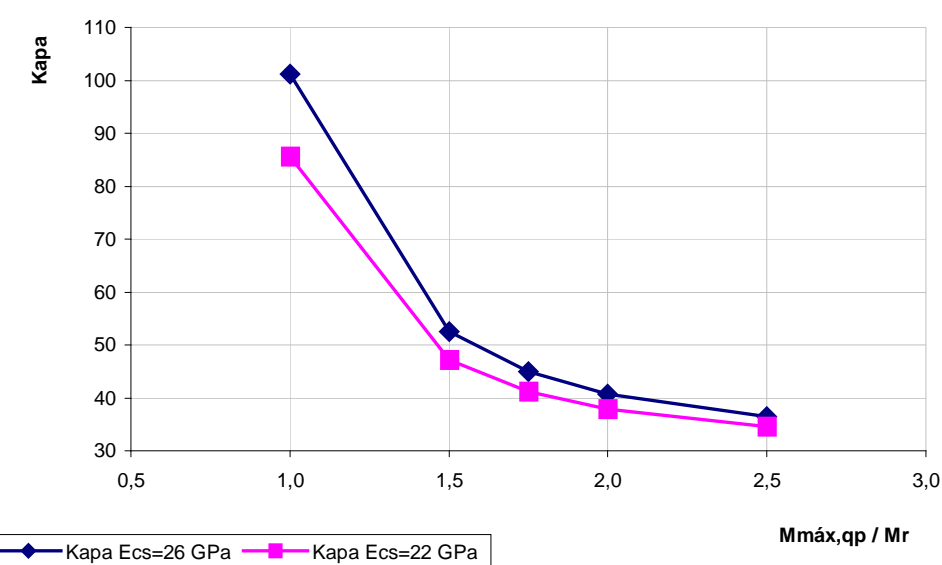

Figura 5.2.2.3 - Diferença na rigidez secante adimensional

Note-se que a diferença percentual entre os coeficientes de rigidez de $8,2 \%$ para os elementos concretados com o materiais fornecidos por A e B no nível de solicitação Mmáx,qp/Mr igual a 1,75 - correspondente ao mesmo nível utilizado no verificação do ELS-DEF — é da mesma ordem de grandeza que o incremento percentual da flecha máxima dada a diferença de 4 GPa entre os concretos, que foi de $9 \%$.

Por fim, deve-se ressaltar que o módulo de deformação do concreto é variável destacada também nas análises de estabilidade global das edificações. A importância disto em projeto não será verificada aqui. Lembra-se, porém, que no 
caso das análises de estabilidade global, recomenda-se a utilização do módulo de deformação tangente inicial em formulação como a da verificação do deslocamento dos nós da edificação através do parâmetro de instabilidade $\alpha_{g}$ $\alpha_{g}=H_{t o t} \cdot \sqrt{\frac{N_{k}}{E_{c i} \cdot I}} \leq \alpha_{1}$, onde $H_{t o t}$ é a altura total da edificação, $N_{k}$ a somatória das cargas verticais características, I é o momento de inércia em cada direção dos elementos verticais de contraventamento ou estabilização da edificação, como os pilares-parede da caixa de elevadores ou os próprios pórticos da estrutura reticulada e $\alpha_{1}$ é o limite de norma para aceitação de deslocamento dos nós, dependente do número de pavimentos da edificação. Evidentemente, a diferença de desempenho dos concretos fornecidos por A e B também seria percebida neste tipo de verificação. Quanto menor o módulo de deformação, maior a instabilidade global.

\subsubsection{Implicações sobre a dosagem}

Admita-se inicialmente que os dois fornecedores, A e B, disponham dos mesmos materiais e tecnologia de produção. Isso os permitiria trabalhar com 0 mesmo Diagrama de Dosagem e apenas diferenciar os fornecimentos baseando-se na questão terminológica da especificação nominal (valor característico) ou não.

Assim sendo, a segunda parte do programa experimental constitui um estudo rápido de caracterização de dosagens que permite a construção de um Diagrama de Dosagem real hipoteticamente utilizado por $A$ e $B$ e que permite também, como objetivo principal, a avaliação das implicações sobre a dosagem dada a diferença de $4 \mathrm{GPa}$ entre os dois possíveis fornecimentos. Ressalte-se que o mais comum é a utilização do Diagrama de Dosagem que contém as relações da resistência (fcm) com a relação água/cimento $(\mathrm{a} / \mathrm{c})$ - conhecida como curva de Abrams - da relação água/cimento com o teor de materiais secos $(\mathrm{m})$ - conhecida como curva de Lyse - e da relação do teor de materiais secos com o consumo de cimento do concreto (C) - conhecida como curva de Molinari ou Priszkulnik e Kirilos - mas não é muito comum a inserção neste dos resultados de módulo de deformação do concreto. No entanto, isto é facilmente conseguido. Para tal, o resumo dos resultados médios obtidos a partir dos traços da segunda etapa do programa experimental consta da Tab. 5.2.3.1. 
Tabela 5.2.3.1 - Resumo da caracterização de dosagens da segunda etapa

\begin{tabular}{|c|c|c|c|c|}
\hline Traço & Abatimento $(\mathrm{mm})$ & $\mathrm{a} / \mathrm{c}(\mathrm{kg} / \mathrm{kg})$ & fc,médio (MPa) & Ecs,médio (GPa) \\
\hline T3-042-A100 & \multirow{3}{*}{$100 \pm 20$} & 0,42 & 60,5 & 33,1 \\
\hline T4-050-A100 & & 0,50 & 46,5 & 31,3 \\
\hline T5-058-A100 & & 0,58 & 38,4 & 29,0 \\
\hline T6-042-A180 & \multirow{3}{*}{$180 \pm 30$} & 0,42 & 58,5 & 30,4 \\
\hline T7-050-A180 & & 0,50 & 46,9 & 28,3 \\
\hline T8-058-A180 & & 0,58 & 41,7 & 27,4 \\
\hline
\end{tabular}

O Diagrama de Dosagem completo é então construído a partir das equações de correlação dos parâmetros de dosagem vinculados aos resultados experimentais obtidos. As equações de correlação, por sua vez, dependem da obtenção dos coeficientes de correlação ( $k_{1}$ a $k_{8}$, neste caso) dada através de regressões lineares e não-lineares, conforme segue:

- Curva de Abrams: exponencial do tipo $f_{c j}=\frac{k_{1}}{k_{2}{ }^{a / c}}$ (Tab. 5.2.3.2)

Tabela 5.2.3.2 - Regressão para Curva de Abrams

\begin{tabular}{|c|c|c|c|c|}
\hline Traço & a/c (kg/kg) & fcm (MPa) & $\boldsymbol{k}_{\mathbf{1}}$ & \multirow{2}{*}{$\boldsymbol{k}_{\mathbf{2}}$} \\
\hline T3-042-A100 e T6-042-A180 & 0,42 & 59,5 & \multirow{2}{*}{155,3} & \multirow{2}{*}{10,4} \\
\cline { 1 - 3 } T4-050-A100 e T7-050-A180 & 0,50 & 46,7 & & \\
\hline T5-058-A100 e T8-058-A180 & 0,58 & 40,1 & & \\
\hline
\end{tabular}

- Curva de Lyse: reta do tipo $m=k_{3}+k_{4} \cdot a / c$ para cada uma das consistências (Tab. 5.2.3.3)

Tabela 5.2.3.3 - Regressão para Curva de Lyse

\begin{tabular}{|c|c|c|c|c|c|}
\hline Traço & $\begin{array}{c}\text { Abatimento } \\
(\mathrm{mm})\end{array}$ & $\mathrm{a} / \mathrm{c}(\mathrm{kg} / \mathrm{kg})$ & $\mathrm{m}(\mathrm{kg} / \mathrm{kg})$ & $k_{3}$ & $k_{4}$ \\
\hline T3-042-A100 & \multirow{3}{*}{$100 \pm 20$} & 0,42 & 3,76 & \multirow{3}{*}{$-1,92$} & \multirow{3}{*}{13,66} \\
\hline T4-050-A100 & & 0,50 & 4,91 & & \\
\hline T5-058-A100 & & 0,58 & 6,07 & & \\
\hline T6-042-A180 & \multirow{3}{*}{$180 \pm 30$} & 0,42 & 3,04 & \multirow{3}{*}{$-1,97$} & \multirow{3}{*}{12,00} \\
\hline T7-050-A180 & & 0,50 & 4,03 & & \\
\hline T8-058-A180 & & 0,58 & 5,00 & & \\
\hline
\end{tabular}


- Curva de Molinari: hipérbole do tipo $\frac{1000}{C}=k_{5}+k_{6} \cdot m \quad$ (Tab. 5.2.3.4)

Tabela 5.2.3.4 - Regressão para Curva de Molinari

\begin{tabular}{|c|c|c|c|c|}
\hline Traço & $\mathrm{m}(\mathrm{kg} / \mathrm{kg})$ & C (kg) & $k_{5}$ & $k_{6}$ \\
\hline T3-042-A100 & 3,76 & 460 & \multirow{6}{*}{0,55} & \multirow{6}{*}{0,4} \\
\hline T4-050-A100 & 4,91 & 372 & & \\
\hline T5-058-A100 & 6,07 & 310 & & \\
\hline T6-042-A180 & 3,04 & 525 & & \\
\hline T7-050-A180 & 4,03 & 423 & & \\
\hline T8-058-A180 & 5,00 & 354 & & \\
\hline
\end{tabular}

- Curva do módulo de deformação: exponencial do tipo $E_{c s}=k_{7} \cdot k_{8}{ }^{m}$ para cada uma das consistências (Tab. 5.2.3.5)

Tabela 5.2.3.5 - Regressão para Curva de módulo de deformação $\mathrm{x}$ teor de materiais secos

\begin{tabular}{|c|c|c|c|c|c|}
\hline Traço & $\begin{array}{c}\text { Abatimento } \\
(\mathrm{mm})\end{array}$ & m (kg/kg) & Ecs (GPa) & $k_{7}$ & $k_{8}$ \\
\hline T3-042-A100 & \multirow{3}{*}{$100 \pm 20$} & 3,76 & 33,1 & \multirow{3}{*}{41,21} & \multirow{3}{*}{0,94} \\
\hline T4-050-A100 & & 4,91 & 31,3 & & \\
\hline T5-058-A100 & & 6,07 & 29,0 & & \\
\hline T6-042-A180 & \multirow{3}{*}{$180 \pm 30$} & 3,04 & 30,4 & \multirow{3}{*}{35,48} & \multirow{3}{*}{0,95} \\
\hline T7-050-A180 & & 4,03 & 28,3 & & \\
\hline T8-058-A180 & & 5,00 & 27,4 & & \\
\hline
\end{tabular}

A partir das expressões e coeficientes encontrados, pode-se gerar os resultados da Tab. 5.2.3.6 e obter o Diagrama de Dosagem mostrado na Fig. 5.2.3.1.

Tabela 5.2.3.6 - Diagrama de Dosagem

\begin{tabular}{|c|c|c|c|c|c|}
\hline Abatimento (mm) & $\mathbf{a / c ~ ( k g / k g )}$ & $\mathbf{f c j} \mathbf{( M P a )}$ & $\mathbf{m ~ ( k g / k g )}$ & $\mathbf{C ~ ( k g )}$ & Ecs (GPa) \\
\hline \multirow{3}{*}{$100 \pm 20$} & 0,4 & 60,8 & 3,5 & 471 & 33,6 \\
\cline { 2 - 6 } & 0,5 & 48,1 & 4,9 & 367 & 31,1 \\
\cline { 2 - 6 } & 0,6 & 38,0 & 6,3 & 300 & 28,7 \\
\cline { 2 - 6 } & 0,7 & 30,1 & 7,6 & 254 & 26,6 \\
\hline \multirow{3}{*}{$180 \pm 30$} & 0,4 & 60,8 & 2,8 & 554 & 30,5 \\
\cline { 2 - 6 } & 0,5 & 48,1 & 4,0 & 428 & 28,7 \\
\cline { 2 - 6 } & 0,6 & 38,0 & 5,2 & 349 & 26,9 \\
\cline { 2 - 6 } & 0,7 & 30,1 & 6,4 & 294 & 25,2 \\
\hline
\end{tabular}




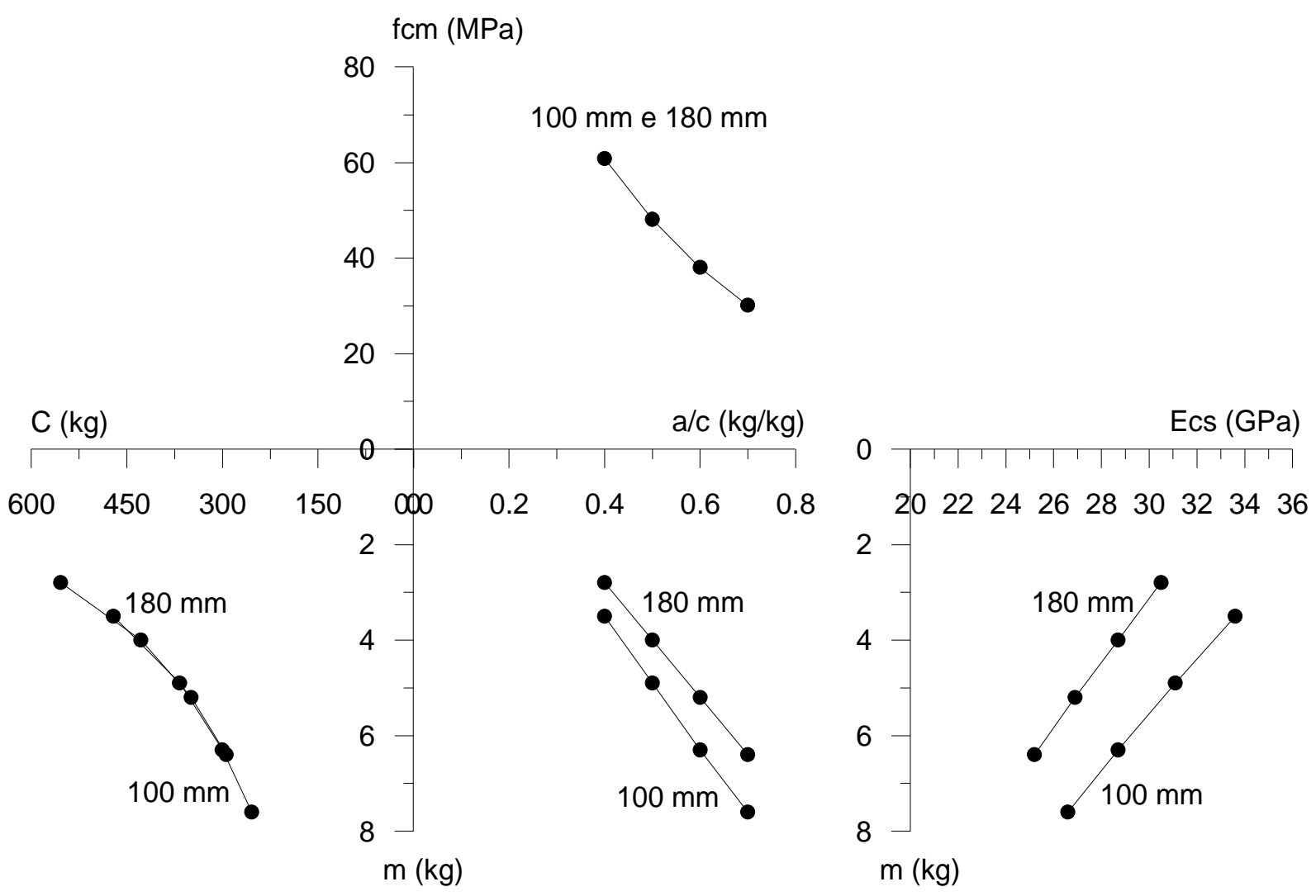

Figura 5.2.3.1 - Diagrama de Dosagem

Com o diagrama fica evidente, por exemplo, que o consumo de cimento apenas implica em maior módulo de deformação se vier acompanhado da conservação do abatimento do concreto, o que só é possível diminuindo-se a relação água/cimento. Ou seja, terá havido melhora na qualidade da pasta em termos de rigidez.

Outra evidência a partir do Diagrama de Dosagem é que a relação entre a resistência e o módulo de deformação do concreto não pode ser considerada como única já que varia de acordo com a consistência. É importante a consciência de que concretos com significativa diferença de custo decorrente de aumento do consumo de cimento pela demanda por fluidez implicará em decréscimo acentuado do módulo de deformação ainda que sem prejuízo significativo da resistência à compressão. Isso apenas ratifica que o módulo de deformação é dependente do teor de materiais secos do traço, o que, em outros termos, significa dizer ser dependente das frações volumétricas das fases constituintes do concreto.

Essas constatações evidenciam a variação dos resultados dessa propriedade com a aqui chamada rigidez contributiva-interativa das fases. No caso desta etapa 
do programa experimental que não variou o tipo de cimento ou dos agregados, a rigidez dependeu fundamentalmente da quantidade e da qualidade da pasta de cimento endurecida e da quantidade de agregado no concreto. Por qualidade da pasta entenda-se a porosidade global no seio da pasta e na zona de transição inerente às diferentes relações água/cimento, o que, a rigor, não deixa de ter também um viés quantitativo.

Do ponto de vista prático e em relação ao caso dos Fornecedores A e B, pode-se notar que a diferença de 4 GPa na especificação implicaria para a produção nas seguintes diferenças de consumo de cimento:

\section{Fornecedor A: Ecs,k = 26 GPa}

Fornecedor B: Ecs,m = $26 \mathrm{GPa}$

- consistência plástica (100 $\pm 20 \mathrm{~mm})$ :

$$
\begin{array}{l|l}
E_{c s}=k_{7} \cdot k_{8}{ }^{m}=41,21 \cdot 0,94^{m}=30 & E_{c s}=k_{7} \cdot k_{8}{ }^{m}=41,21 \cdot 0,94^{m}=26 \\
\therefore m=5,13 & \therefore m=7,44 \\
\frac{1000}{C}=k_{5}+k_{6} \cdot m=0,55+0,44 \cdot 5,13 & \frac{1000}{C}=k_{5}+k_{6} \cdot m=0,55+0,44 \cdot 7,44 \\
\therefore C=356 & \therefore C=262
\end{array}
$$

Diferença no consumo de cimento: $94 \mathrm{~kg} / \mathrm{m}^{3}$

- consistência fluida $(180 \pm 30 \mathrm{~mm})$ :

$$
\begin{array}{l|l}
E_{c s}=k_{7} \cdot k_{8}{ }^{m}=35,48 \cdot 0,95^{m}=30 & E_{c s}=k_{7} \cdot k_{8}{ }^{m}=35,48 \cdot 0,95^{m}=26 \\
\therefore m=3,27 & \therefore m=6,06 \\
\frac{1000}{C}=k_{5}+k_{6} \cdot m=0,55+0,44 \cdot 3,27 & \frac{1000}{C}=k_{5}+k_{6} \cdot m=0,55+0,44 \cdot 6,06 \\
\therefore C=503 & \therefore C=311
\end{array}
$$

Diferença no consumo de cimento: $192 \mathrm{~kg} / \mathrm{m}^{3}$

Nota: Os resultados de módulo de deformação utilizados para simulação das dosagens dos fornecedores A e B foram resultados médios (Ecs, $m$ ), que correspondem aos utilizados nas expressões das curvas de correlação.

Nos dois casos, supõe-se que a resistência à compressão especificada seja atingida.

As diferenças de consumo de cimento entre os fornecimentos são significativas, atingindo aproximadamente $100 \mathrm{~kg} / \mathrm{m}^{3}$ para a consistência plástica e $200 \mathrm{~kg} / \mathrm{m}^{3}$ para a consistência fluida.

Note-se também que a tendência das curvas é de que quanto maior o valor especificado para o módulo de deformação, mais a qualidade da pasta torna-se 
importante para o caso da consistência constante e, conseqüentemente, mais significativo será o incremento no consumo de cimento pela diminuição da relação água/cimento.

Ainda que baseadas unicamente neste programa experimental, essas constatações são bastante importantes em termos de incremento de custos de insumos, operação e controle interno para a produção destes tipos de concreto. E, inegavelmente, estas diferenças estariam em discussão no momento da contratação do fornecimento.

A título de aproveitamento das informações, note-se que ao se comparar os traços de um mesmo fornecedor, e simular um fornecimento a uma edificação sob o cenário hipotético (mas muito comum) de solicitação de incremento gradual da consistência do concreto ao longo da construção dos pavimentos, a diferença incremental de consumo entre os traços de $E_{c s, k}$ atinge $218 \mathrm{~kg} / \mathrm{m}^{3}$ e entre os traços de $E_{c s, m}$ atinge $100 \mathrm{~kg} / \mathrm{m}^{3}$, no caso da mudança de da consistência plástica para a consistência fluida. Estes valores também são igualmente significativos.

Ainda no item Implicações sobre a dosagem, pode ser ressaltado outro comentário que diz respeito à modelagem para a produção, conforme segue.

\subsubsection{Modelagem de previsão de desempenho}

Aplicando-se aos traços da segunda etapa a mesma modelagem aplicada aos traços da primeira etapa para estimativa da composição microestrutural e da previsão do desempenho das dosagens, tem-se (Tab. 5.2.3.1.1 e Fig. 5.2.3.1.1):

Tabela 5.2.3.1.1 - Cálculo dos compostos resistentes e não-resistentes

\begin{tabular}{|c|c|c|c|c|c|c|c|c|c|c|c|}
\hline & \multirow{2}{*}{\multicolumn{2}{|c|}{ Compostos }} & \multicolumn{3}{|c|}{ T3-042-A100 } & \multicolumn{3}{|c|}{ T4-050-A100 } & \multicolumn{3}{|c|}{ T5-058-A100 } \\
\hline & & & $\begin{array}{c}\text { Volume } \\
\text { absoluto } \\
\left(\mathrm{dm}^{3}\right)\end{array}$ & $\begin{array}{c}\text { Volume } \\
\text { individual } \\
(\%)\end{array}$ & $\begin{array}{l}\text { Total } \\
(\%) \\
\end{array}$ & $\begin{array}{c}\text { Volume } \\
\text { absoluto } \\
\left(\mathrm{dm}^{3}\right)\end{array}$ & $\begin{array}{c}\text { Volume } \\
\text { individual } \\
(\%)\end{array}$ & $\begin{array}{c}\text { Total } \\
(\%) \\
\end{array}$ & $\begin{array}{c}\text { Volume } \\
\text { absoluto } \\
\left(\mathrm{dm}^{3}\right)\end{array}$ & $\begin{array}{c}\text { Volume } \\
\text { individual } \\
(\%)\end{array}$ & $\begin{array}{l}\text { Total } \\
\text { (\%) }\end{array}$ \\
\hline \multirow{5}{*}{$\begin{array}{l}\text { compostos } \\
\text { resistentes }\end{array}$} & \multirow{2}{*}{$\begin{array}{c}\text { volume de } \\
\text { gel }\end{array}$} & sólidos & 0,30 & 13,8 & \multirow{5}{*}{88,3} & 0,30 & 11,1 & \multirow{5}{*}{87,1} & 0,30 & 9,3 & \multirow{5}{*}{86,1} \\
\hline & & água de gel & 0,12 & 5,4 & & 0,12 & 4,3 & & 0,12 & 3,6 & \\
\hline & \multicolumn{2}{|c|}{ volume de areia } & 0,65 & 29,8 & & 0,89 & 33,0 & & 1,13 & 35,1 & \\
\hline & \multicolumn{2}{|c|}{ volume pedra } & 0,75 & 34,4 & & 0,93 & 34,6 & & 1,12 & 34,7 & \\
\hline & \multicolumn{2}{|c|}{ volume de cimento anidro } & 0,11 & 5,0 & & 0,11 & 4,0 & & 0,11 & 3,4 & \\
\hline \multirow{3}{*}{$\begin{array}{c}\text { compostos não } \\
\text { resistentes }\end{array}$} & \multicolumn{2}{|c|}{ volume de ar aprisionado } & 0,04 & 1,7 & \multirow{3}{*}{11,7} & 0,04 & 1,6 & \multirow{3}{*}{12,9} & 0,06 & 1,9 & \multirow{3}{*}{13,9} \\
\hline & \multicolumn{2}{|c|}{ volume de poros de gel } & 0,03 & 1,3 & & 0,03 & 1,0 & & 0,03 & 0,8 & \\
\hline & \multicolumn{2}{|c|}{ volume de água livre } & 0,19 & 8,8 & & 0,28 & 10,3 & & 0,36 & 11,2 & \\
\hline \multicolumn{3}{|c|}{$\begin{array}{l}\text { volume total do concreto endurecido igual ao } \\
\text { do concreto fresco }\end{array}$} & 2,17 & 100,0 & 100,0 & 2,69 & 100,0 & 100,0 & 3,22 & 100,0 & 100,0 \\
\hline \multicolumn{3}{|c|}{ Volume de vazios permeáveis (\%) } & \multicolumn{3}{|c|}{10,5} & \multicolumn{3}{|c|}{11,8} & \multicolumn{3}{|c|}{13,1} \\
\hline
\end{tabular}




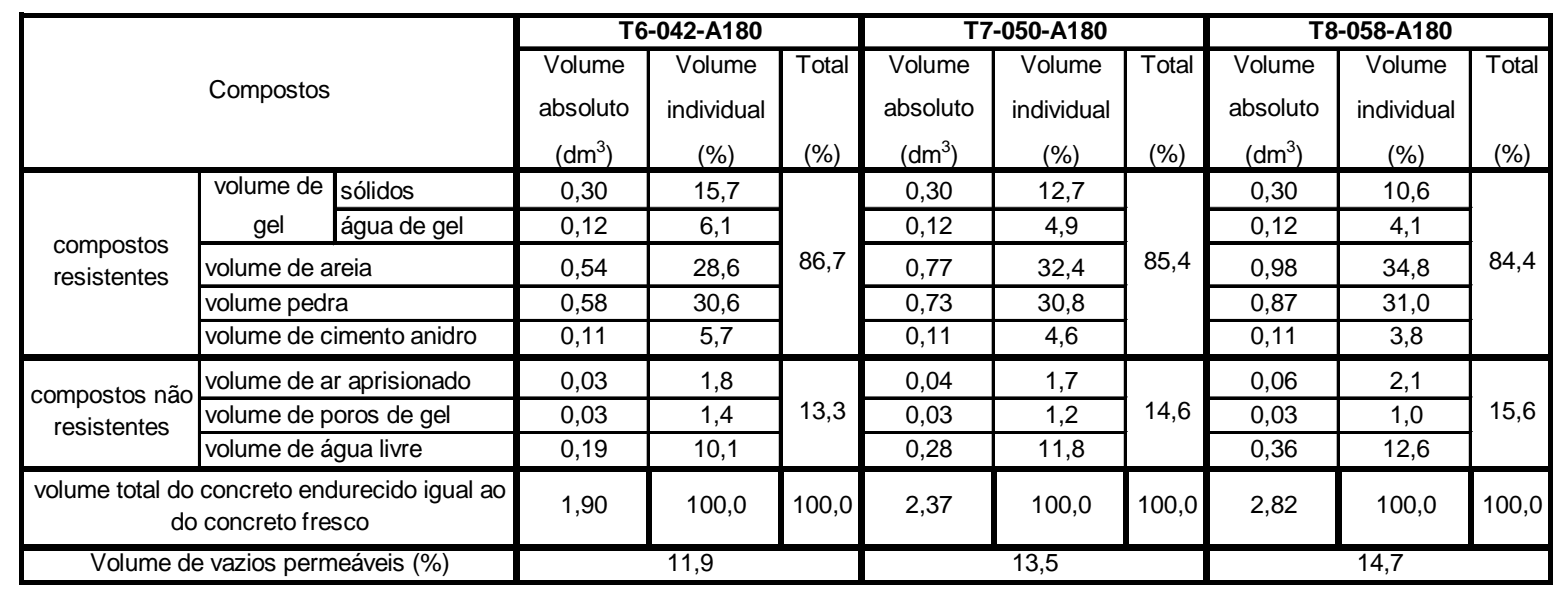

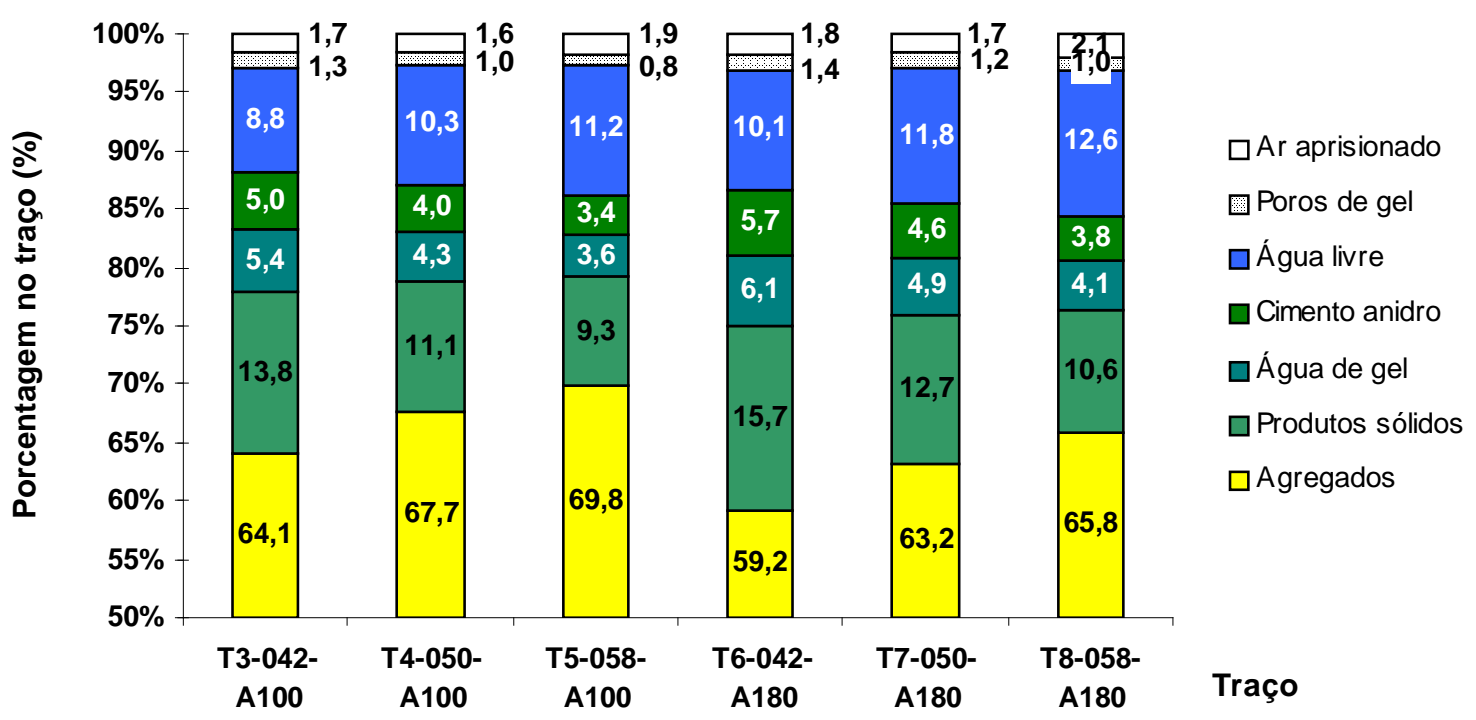

Figura 5.2.3.1.1 - Distribuição volumétrica dos compostos resistentes e não-resistentes

Com esses percentuais volumétricos pode-se estimar o módulo de elasticidade das pastas endurecidas conforme agrupamentos por relação água/cimento apresentados na Tab. 5.2.3.1.2.

Tabela 5.2.3.1.2 - Características das pastas

\begin{tabular}{|c|c|c|c|c|}
\hline Traço & Esolglobais(GPa) & Vsolglobais (\%) & Vcapilares (\%) & Epasta=Em (GPa) \\
\hline T3-042-A100 & \multirow{2}{*}{30} & 73,2 & 26,8 & 14,3 \\
\hline T6-042-A180 & & 73,1 & 26,9 & 14,3 \\
\hline T4-050-A100 & \multirow{2}{*}{30} & 65,5 & 34,5 & 11,6 \\
\hline T7-050-A180 & & 65,3 & 34,7 & 11,6 \\
\hline T5-058-A100 & \multirow{2}{*}{30} & 59,2 & 40,8 & 9,8 \\
\hline T8-058-A180 & & 59,5 & 40,5 & 9,9 \\
\hline
\end{tabular}


Agora, pode-se calcular os módulos de deformação previstos para os concretos através dos diversos modelos micromecânicos e compará-los com a média obtida experimentalmente em todas as dosagens - admitidos valores do módulo de deformação obtidos sob o plano de carregamento secante (Ecs). Assim, tem-se que as características ensaiadas dos traços constantes da Tab. 5.2.3.1.3 dão origem aos resultados constantes da Tab. 5.2.3.1.4.

Tabela 5.2.3.1.3 - Características dos traços ensaiados

\begin{tabular}{|c|c|c|c|c|}
\hline Traço & Em (GPa) & & Vm (\%) & Ep (GPa) \\
** & Vp (\%) \\
\hline T3-042-A100 & 14,3 & 35,9 & & 64,1 \\
\hline T6-042-A180 & 14,3 & 40,9 & & 59,1 \\
\hline T4-050-A100 & 11,6 & 32,4 & \multirow{2}{*}{59,0} & 67,6 \\
\hline T7-050-A180 & 11,6 & 36,8 & & 63,2 \\
\hline T5-058-A100 & 9,8 & 30,2 & & 69,8 \\
\hline T8-058-A180 & 9,9 & 34,2 & & 65,8 \\
\hline
\end{tabular}

* Os índices c, p, m indicam concreto, particulado (agregados) e matriz (pasta endurecida) respectivamente.

** Considerando-se $\gamma=2,70 \mathrm{~kg} / \mathrm{dm}^{3}$.

Tabela 5.2.3.1.4 - Característica dos concretos obtida a partir dos modelos e dos experimentos

\begin{tabular}{|c|c|c|c|c|c|c|c|c|}
\hline \multirow[t]{2}{*}{ Traço } & \multicolumn{7}{|c|}{$\begin{array}{l}\text { Módulo de deformação do concreto de acordo com o modelo } \\
\qquad \mathrm{Ec}(\mathrm{GPa})\end{array}$} & \multirow{2}{*}{$\begin{array}{c}\text { Média } \\
\text { experimental } \\
\text { Ecs (GPa) }\end{array}$} \\
\hline & Voigt & Reuss & $\mathrm{H}-\mathrm{S}^{\text {sup * }}$ & H-S S $^{\text {inf }}$ & Counto & Hansen & $\mathbf{Y}-\mathrm{H}^{* *}$ & \\
\hline $\begin{array}{c}\text { T3-042- } \\
\text { A100 }\end{array}$ & 43,0 & 27,8 & 37,8 & 32,7 & 33,4 & 32,7 & 32,7 & 33,1 \\
\hline $\begin{array}{c}\text { T6-042- } \\
\text { A180 }\end{array}$ & 40,7 & 25,9 & 35,4 & 30,4 & 31,3 & 30,4 & 30,4 & 30,4 \\
\hline $\begin{array}{c}\text { T4-050- } \\
\text { A100 }\end{array}$ & 43,6 & 25,4 & 37,9 & 30,9 & 31,7 & 30,9 & 30,9 & 31,3 \\
\hline $\begin{array}{c}\text { T7-050- } \\
\text { A180 }\end{array}$ & 41,6 & 23,6 & 35,6 & 28,7 & 29,6 & 28,7 & 28,7 & 28,3 \\
\hline $\begin{array}{c}\text { T5-058- } \\
\text { A100 }\end{array}$ & 44,1 & 23,4 & 38,0 & 29,3 & 30,1 & 29,3 & 29,3 & 29,0 \\
\hline $\begin{array}{c}\text { T8-058- } \\
\text { A180 }\end{array}$ & 42,2 & 21,9 & 35,9 & 27,4 & 28,3 & 27,4 & 27,4 & 27,4 \\
\hline
\end{tabular}

* H-S: Hashin e Shtrikman

** Y-H: Yang e Huang. Coeficiente de Poisson das fases e do concreto igual a 0,20.

Já se sabia que os modelos Hashin-Shtrickman ${ }^{\text {inferior }}\left(H-S^{\text {inf }}\right)$, Counto e Hansen, da década de 1960, e Yang e Huang (Y-H), de 1996, convergiam. São semelhantes também os valores de convergência e os valores obtidos 
experimentalmente, independentemente da relação água/cimento $(0,42,0,50$ e 0,58 $\mathrm{kg} / \mathrm{kg}$ ) ou da consistência do traço (100 220 ou $180 \pm 30 \mathrm{~mm}$ ).

Ainda que não se possa afirmar que os resultados obtidos sejam os valores verdadeiros, pode-se considerar que representam aproximações aceitáveis de magnitude das grandezas medidas ou admitidas. $E$ que estas podem ser disponibilizadas para a diagramação de novas curvas de dosagem que permitam a comparação com traços que utilizam, por exemplo, outras situações de composição granulométrica ou de natureza mineralógica de agregados.

De outro lado, pode-se ainda associar a composição microestrutural aos resultados dos ensaios mecânicos. Inicialmente, para a ordem crescente de resistência à compressão (Fig. 5.2.3.1.2) tem-se:

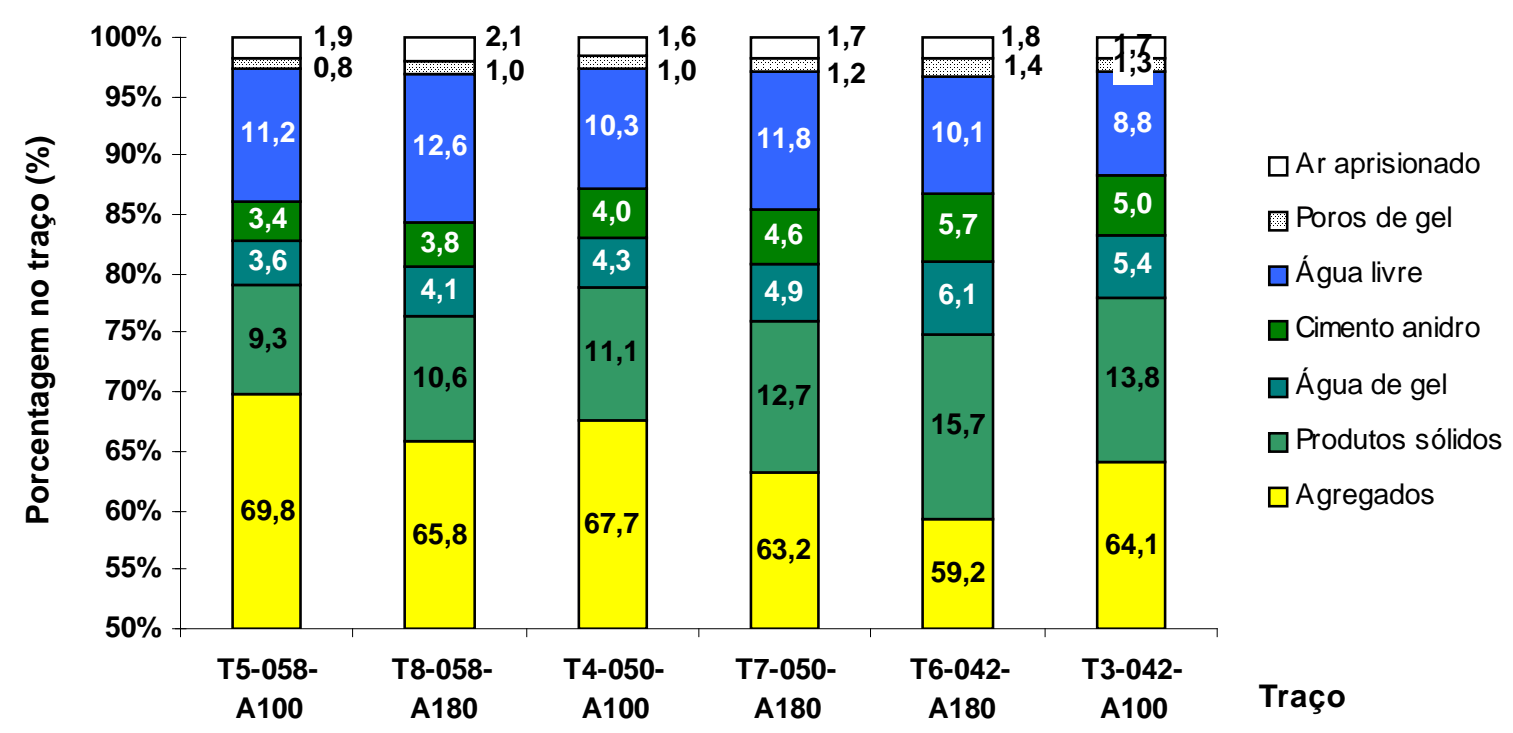

Figura 5.2.3.1.2 - Distribuição volumétrica dos traços: ordem crescente de resistência

Seguindo a mesma ordem crescente de resistência, na Tab. 5.2.3.1.5 nota-se o porquê dos resultados obtidos através da relação entre o volume de compostos não-rígidos ou resistentes e o de compostos resistentes (CNR/CR). Isto configura uma aplicação indireta da Lei de Abrams, mas com as mesmas conclusões. 
Tabela 5.2.3.1.5 - Modelo de composição para os resultados de resistência

\begin{tabular}{|c|c|c|c|c|}
\hline Traço & CNR (\%) & CR (\%) & CNR/CR & fcj (Mpa) \\
\hline T5-058-A100 & 13,9 & 16,3 & 0,85 & 38,4 \\
\hline T8-058-A180 & 15,6 & 18,6 & 0,84 & 41,7 \\
\hline T4-050-A100 & 12,9 & 19,5 & 0,66 & 46,5 \\
\hline T7-050-A180 & 14,6 & 22,2 & 0,66 & 46,9 \\
\hline T6-042-A180 & 13,3 & 27,5 & 0,48 & 58,5 \\
\hline T3-042-A100 & 11,7 & 24,1 & 0,49 & 60,5 \\
\hline
\end{tabular}

Agora seguem as mesmas distribuições organizadas por ordem crescente de módulo de deformação (Fig. 5.2.3.1.3):

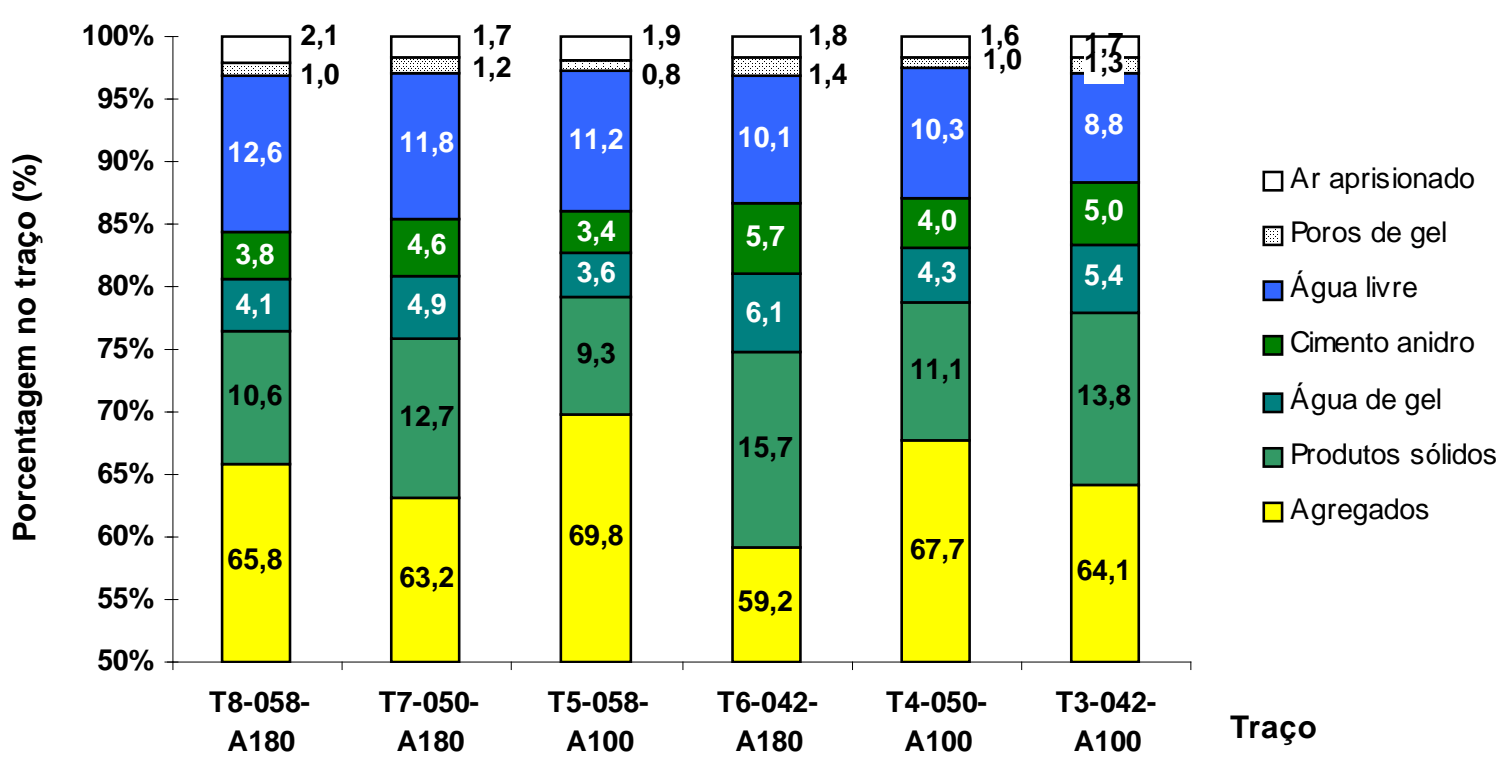

Figura 5.2.3.1.3 - Distribuição volumétrica dos traços: ordem crescente de módulo

Seguindo a mesma ordem crescente de módulo de deformação, na Tab. 5.2.3.1.6 nota-se o porquê dos resultados obtidos através da comparação simples dos volumes de compostos não-rígidos (CNR). Em outras palavras, quanto maior volume percentual de compostos não-rígidos, menor o módulo de deformação. Na mesma tabela são apresentados os resultados da regressão linear entre os valores na forma $E_{c s}=k_{9}-k_{10} \cdot C N R$, cuja representação gráfica consta da Fig. 5.2.3.1.4. 
Tabela 5.2.3.1.6 - Cálculo dos compostos resistentes e não-resistentes e Curva de regressão

\begin{tabular}{|c|c|c|c|c|}
\hline Traço & CNR (\%) & Ecs (GPa) & \multirow{2}{*}{$\boldsymbol{k}_{\mathbf{5}}$} & \multirow{2}{*}{$\boldsymbol{k}_{\mathbf{6}}$} \\
\hline T8-058-A180 & 15,6 & 27,4 & & \\
\cline { 1 - 3 } T7-050-A180 & 14,6 & 28,3 & & \multirow{2}{*}{0,55} \\
\cline { 1 - 3 } T5-058-A100 & 13,9 & 29,0 & & \\
\cline { 1 - 3 } T6-042-A180 & 13,3 & 30,4 & & \\
\cline { 1 - 3 } T4-050-A100 & 12,9 & 31,3 & & \\
\cline { 1 - 3 } T3-042-A100 & 11,7 & 33,1 & & \\
\hline
\end{tabular}

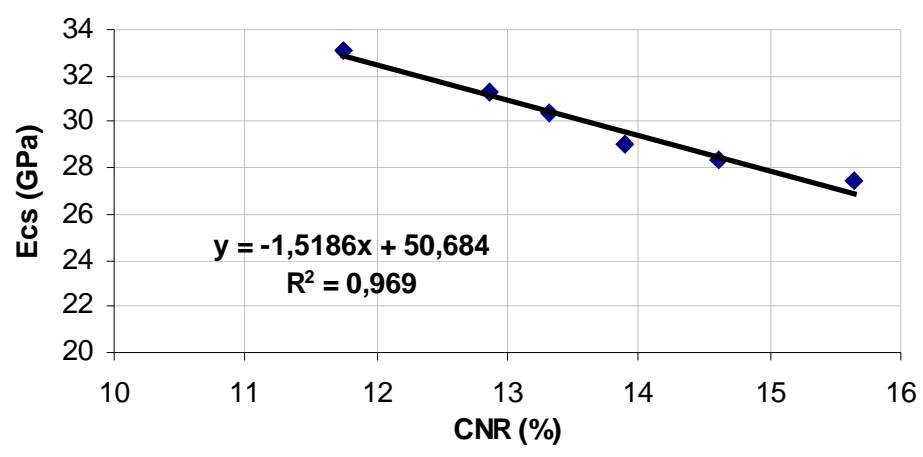

Figura 5.2.3.1.4 - Regressão linear: Ecs x CNR

Disto, conclui-se que há outras possibilidades de previsão do módulo de deformação ainda no momento da dosagem.

Note-se que a distribuição volumétrica dos compostos tidos como rígidos e resistentes - agregados, produtos de hidratação, água de gel e cimento anidro - e dos não-resistentes - poros de gel, água livre nos poros capilares e ar aprisionado - não significa instantaneamente a mesma tendência para o desempenho em termos de resistência e de módulo de deformação. Se a resistência fundamentalmente trata de propagação de fissuras em regiões do concreto sob deformações plásticas, o módulo de deformação, por sua vez, é uma propriedade mais propriamente contributiva e interativa, exercida através das deformações elásticas de cada uma das frações constituintes. Por isso, quanto maior a fração contribuindo com mais rigidez, maior a tendência do todo ser mais rígido.

Assim, aquilo a que se denomina 'qualidade da pasta', isto é, a relação de quantidade de poros por unidade de volume da pasta, apesar de fundamental importância tanto para a resistência quanto para a rigidez, nitidamente passa a pesar de maneira diferente para as duas propriedades quando se insere outro princípio, o da 'quantidade de pasta'. Se a resistência depende da propagação das fissuras, e existem regiões preferenciais para isto tanto nos concretos com maior ou com menor quantidade de pasta - região das zonas de transição pasta-agregados 
e regiões da pasta com poros capilares - , o módulo de deformação depende mais do somatório das falhas ou descontinuidades de rigidez no todo. Intuitivamente, pode-se concluir que ao se produzir dois concretos com a mesma qualidade de pasta mas com quantidades de pasta diferentes - o que se consegue basicamente ao produzir dois concretos com a mesma relação água/cimento mas com consistências diferentes - ambos tenderão a ter a mesma resistência mas não o mesmo módulo de deformação, pois aquele com maior quantidade de pasta terá, no todo, maior quantidade de descontinuidades de rigidez.

Por fim, pode-se, a título de informação, adaptar o primeiro quadro-resumo apresentado no Capítulo 2 desta dissertação aos resultados do estudo dos traços da segunda etapa do programa experimental, conforme mostrado na Tab. 5.2.3.1.7.

Tabela 5.2.3.1.7 - Atualização do quadro-resumo de distribuição volumétrica e rigidez (28 dias)

\begin{tabular}{|c|c|c|c|}
\hline Componentes & $\begin{array}{c}\text { Volume na } \\
\text { pasta } \\
(\%)\end{array}$ & $\begin{array}{c}\text { Volume no } \\
\text { concreto } \\
(\%)\end{array}$ & $\begin{array}{c}\text { Módulo de } \\
\text { elasticidade } \\
(\mathbf{G P a})\end{array}$ \\
\hline Produtos hidratados & $40-55$ & $10-25$ & $20-40$ \\
\hline C & $10-15$ & $3-6$ & 120 \\
\hline PG & $3-4$ & $1-2$ & 0 \\
\hline PC & $25-35$ & $8-13$ & 0 \\
\hline PA & $5-6$ & 2 & 0 \\
\hline Pasta & 100 & $30-40$ & $5-20$ \\
\hline Agregados & & $60-70$ & 60 \\
\hline Concreto & & 100 & $25-35$ \\
\hline
\end{tabular}

Acrescente-se ainda uma última constatação: todos os ensaios de módulo de deformação se deram entre a tensão básica e 30\% da resistência do concreto $\left(f_{c}\right)$ tensão admitida como de limite elástico - e envolveram deformações absolutas da ordem de 30 a $50 \mu \mathrm{m}$ em uma base de medida de $100 \mathrm{~mm}$. Essa dimensão de encurtamento representa, como visto no Capítulo 2, o tamanho de um grão de cimento médio-grosso. Em termos de deformação específica, o resultado corresponde a uma faixa de 0,3 a $0,5 \mathrm{~mm} / \mathrm{m}$, isto é, da ordem de 15 a $25 \%$ da deformação usualmente observada na deformação de ruptura do concreto por compressão que é de $2,0 \mathrm{~mm} / \mathrm{m}$. Assim sendo, realmente nota-se que mesmo no cenário de evolução até o nível de limite elástico de $30 \%$ da tensão última considerado em muitos casos como um valor baixo - ainda não se configura como 
perfeitamente linear a relação tensão-deformação específica, pois as taxas de evolução dadas pelos percentuais do todo não são correspondentes $\left(30 \%\right.$ de $f_{c}$ contra 15 a $25 \%$ da deformação em $\mathrm{f}_{\mathrm{c}}$ ).

\subsubsection{Implicações sobre o controle de qualidade de obra}

Ao se aceitar indiscriminadamente o fornecimento realizado por $B$ que considera a especificação ' $E_{\mathrm{cs}, \mathrm{m}}$ (médio) 26 GPa' estar-se-á aceitando o seguinte nível de risco: caso a distribuição estatística dos resultados dos ensaios de qualidade da propriedade inseridos no controle tecnológico global da obra tiver a média coincidente com a mediana, praticamente $50 \%$ dos resultados não terão atendido à especificação de 26 GPa (Fig. 5.2.4.1).

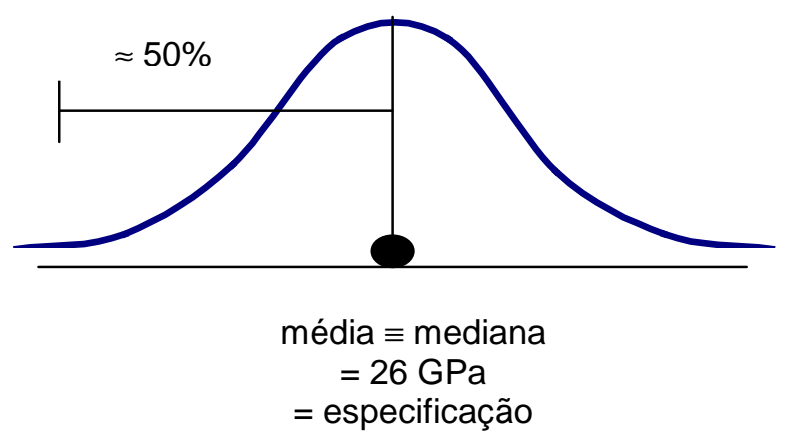

Figura 5.2.4.1 - Risco de não-conformidades em fornecimento de concreto

Essa situação é, usualmente, agravada pelo seguinte fato: a amostragem realizada para a formação dos lotes de controle da propriedade módulo de deformação não obedece a qualquer critério estatístico. Freqüentemente se dá através do ensaio do concreto de uma única betonada - a rigor, não há distribuição estatística de resultados por lote como se dá com a resistência à compressão. Considerando-se então que ocorra a distribuição hipotética acima, o resultado do concreto desta betonada terá a probabilidade de praticamente $50 \%$ de ser menor que o valor de especificação, ao nível de $100 \%$ de confiança.

A não-formação de lotes para o controle do módulo de deformação desobedece ao conceito semiprobabilístico de maneira frontal. Note-se que se for traçado um paralelo com o ensaio de controle de outra propriedade em que não há a formação de lotes sem que, com isso, haja desobediência ao conceito 
semiprobabilístico para a aprovação do concreto, ou, qual seja, cada betonada constitui por si um lote como se dá no ensaio de consistência (abatimento), por exemplo, é intrínseco ao controle a necessidade de que se amostre e ensaie o concreto de todas as betonadas. A conclusão que embasa o conceito é simples: ou ensaiam-se todas as amostras ou ensaia-se parcialmente obedecendo-se a um critério estatístico para a formação de um lote representativo do todo.

Nesse sentido, suponha-se uma concretagem de $100 \mathrm{~m}^{3}$ de concreto em um único dia fornecidos em 15 betonadas. Admitindo-se um erro amostral tolerável para a propriedade a ser avaliada de $10 \%$ (equivalente ao coeficiente de variação ' $C V$ ' dos resultados), tem-se:

- Primeira aproximação do tamanho da amostra: $n_{0}=\frac{1}{C V^{2}}=100$

- Tamanho da população: $N=15$ betonadas (admitidas homogêneas)

- Tamanho da amostra: $n=\frac{N \cdot n_{0}}{N+n_{0}}=13$ betonadas

Note-se que a análise estatística impõe que se amostre e ensaie, então, 87\% das betonadas. Este valor também seria criticável.

Por isso, a fim de que atenda ao conceito semiprobabilístico, seria recomendável utilizar os coeficientes e expressões já normalizados na NBR 12655:2006 para a formação de lotes de ensaios de resistência à compressão, adaptando-os ao controle do módulo estático de deformação do concreto. E essa adaptação, na verdade, poderia ser simplesmente dada pela substituição das grandezas para a conservação do intervalo de confiança.

Caso se admita, do ponto de vista estrutural, que o controle da propriedade módulo de deformação possa ser menos rigoroso que o da resistência à compressão, seria este o momento de inserção do menor rigor: ao invés de se exigir um intervalo de $90 \%$ de confiança para os resultados - garantindo que $95 \%$ dos casos atenderiam à especificação - poder-se-ia exigir um intervalo de confiança menor, como o de $80 \%$, garantindo $90 \%$ acima da especificação, ou mesmo o de $68 \%$, que garantiria $84 \%$ de atendimento à especificação, sem que com isso, ressalte-se, estivesse se desobedecendo ao conceito semiprobabilístico normativo. Isto é viável também pela própria expectativa de realização de menor quantidade de 
experimentos do que é usualmente feito para o controle da resistência à compressão.

\subsubsection{Classificação normativa}

Outra questão viável à discussão ainda no que diz respeito ao conceito semiprobabilístico e à formação dos lotes de controle tecnológico é a relação do módulo de deformação com a resistência à compressão segundo a classificação técnico-comercial dos traços de concreto.

A classificação do concreto normalizada no país foi criada baseando-se na dispersão dos resultados observados nos ensaios de resistência à compressão. $O$ intervalo usual entre classes é de $5 \mathrm{MPa}$, o que garante que não haja sobreposição de distribuições estatísticas dada pelas variações de produção e de ensaio.

$\mathrm{Na}$ dosagem dos traços da segunda parte do programa experimental foram utilizados concretos de classes de resistência bastante distintas: T3-042-A100 e T6042-A180 apresentaram resistência final média de 59,5 MPa, T4-050-A100 e T7050-A180 apresentaram resistência final média de 46,7 MPa e T5-058-A100 e T8058-A180 apresentaram resistência final média de 40,1 MPa, se agrupados unicamente pela relação água/cimento comum e apesar dos teores de argamassa distintos.

Caso se admita, por exemplo, o intervalo de confiança de $90 \%$ - que garante $95 \%$ dos resultados acima do $\mathrm{f}_{\mathrm{ck}}$ - e um desvio-padrão de dosagem de 2,50 MPa, tem-se que (Tab. 5.2.4.1.1):

Tabela 5.2.4.1.1 - Classes de resistência atendidas

\begin{tabular}{|c|c|c|c|}
\hline Traço & $\begin{array}{c}\text { Resistência média } \\
-\mathbf{f c m}- \\
(\mathbf{M P a})\end{array}$ & $\begin{array}{c}\text { Resistência } \\
\text { característica - fck } \\
\text { (MPa) }\end{array}$ & $\begin{array}{c}\text { Classe de resistência } \\
\text { máxima atendida }\end{array}$ \\
\hline T3-042-A100 e T6-042-A180 & 59,5 & 55 & C55 \\
\hline T4-050-A100 e T7-050-A180 & 46,7 & 43 & C40 \\
\hline T5-058-A100 e T8-058-A180 & 40,1 & 36 & C35 \\
\hline
\end{tabular}

Existe, então, cinco classes de resistência entre cada grupo de traços de abatimentos iguais: C35, C40, C45, C50 e C55. 
Quanto ao módulo de deformação, no entanto, observa-se que entre os traços T3-042-A100 e T5-058-A100 há apenas 4,1 GPa de diferença, e que entre os traços T6-042-A180 e T8-058-A180 a diferença é de apenas 3,0 GPa.

Haveria possibilidade de identificação entre os resultados de módulo de deformação do mesmo número de classes intermediárias existentes entre os resultados de resistência à compressão?

Provavelmente não, se considerados os dois grupos (abatimento $100 \pm 20$ $\mathrm{mm}$ e $180 \pm 30 \mathrm{~mm})$.

Apenas no grupo de abatimento $100 \pm 20 \mathrm{~mm}$, haveria a possibilidade de identificação de 5 classes, se considerado o intervalo de 1 GPa entre-classes, na especificação.

Aliás, esse é o intervalo praticado usualmente pelo meio técnico nacional.

Porém, retomando a questão da variabilidade experimental e de produção, é necessário verificar se a dispersão observada nos resultados dos ensaios permite tal sensibilidade, ou, em outras palavras, que não haverá sobreposição de distribuições estatísticas dada pelas variações de produção e de ensaio em tal intervalo entreclasses que comprometa tecnicamente a sua utilização.

Pode-se fazer esta verificação através de um teste de hipóteses de comparação entre duas médias amostrais, considerando que elas são iguais (Hipótese inicial), que o desvio-padrão total de ambas seja igual e que o nível de significância (probabilidade de rejeitar que as amostras sejam iguais sendo elas realmente iguais) seja de apenas 5\%. Para tal, de acordo com Costa Neto (2002), a formulação a ser seguida é:

$$
t=\frac{\overline{x_{1}}-\overline{x_{2}}}{s d \cdot \sqrt{\frac{1}{n_{1}}+\frac{1}{n_{2}}}} \leq t_{n_{1}+n_{2}-2 ; 5 \% \ldots(\text { tabelado })}
$$

onde:

$t$ é o valor calculado para a comparação com o valor tabelado de Student;

$\overline{x_{1}}$ é a média do primeiro grupo de resultados amostrais;

$\overline{x_{2}}$ é a média do segundo grupo de resultados amostrais;

$n_{1}$ é o número de resultados do primeiro grupo;

$n_{2}$ é o número de resultados do segundo grupo; 
Assim sendo, segue na Fig. 5.2.4.1.1 alguns testes de grupos de resultados com um total de $n$ amostras $\left(n_{1}+n_{2}\right)$, do qual uma parte $m$ está distanciada de $1 \mathrm{GPa}$ do restante $(n-m)$.

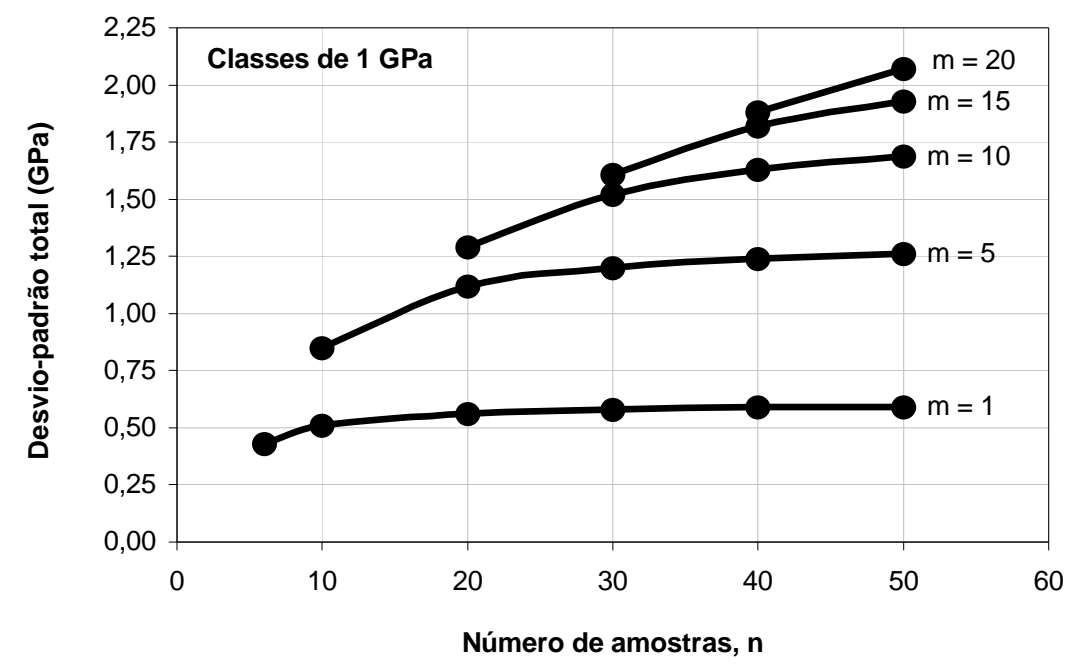

\begin{tabular}{|c|c|c|c|c|c|}
\hline \multirow{2}{*}{$\begin{array}{c}\text { Número de } \\
\text { amostras, } \mathbf{n}\end{array}$} & \multicolumn{5}{|c|}{ Número de amostras distantes $\mathbf{1} \mathbf{G P a} \mathbf{~ m}$} \\
\cline { 2 - 6 } & $\mathbf{1}$ & $\mathbf{5}$ & $\mathbf{1 0}$ & $\mathbf{1 5}$ & $\mathbf{2 0}$ \\
\hline $\mathbf{6}$ & 0,43 & & & & \\
\hline $\mathbf{1 0}$ & 0,51 & 0,85 & & & \\
\hline $\mathbf{2 0}$ & 0,56 & 1,12 & 1,29 & & \\
\hline $\mathbf{3 0}$ & 0,58 & 1,20 & 1,52 & 1,61 & \\
\hline $\mathbf{4 0}$ & 0,59 & 1,24 & 1,63 & 1,82 & 1,88 \\
\hline $\mathbf{5 0}$ & 0,59 & 1,26 & 1,69 & 1,93 & 2,07 \\
\hline
\end{tabular}

Figura 5.2.4.1.1 - Gráfico: Número de amostras total x Desvio-padrão total x Número de amostras distantes $1 \mathrm{GPa}$ (intervalo entre-classes)

Os valores de $t$-Student tabelados foram (Tab. 5.2.4.1.2):

Tabela 5.2.4.1.2 - Valores de $t$-Student para nível de significância de 5\%

\begin{tabular}{|c|c|}
\hline$n$ & $t$ (tabelado) \\
\hline 6 & 2,132 \\
\hline 10 & 1,86 \\
\hline 20 & 1,734 \\
\hline 30 & 1,701 \\
\hline 40 & 1,685 \\
\hline 50 & 1,677 \\
\hline
\end{tabular}

Considere-se agora a mudança da magnitude do intervalo entre-classes para 3 GPa (Fig. 5.2.4.1.2) e 5 GPa (Fig. 5.2.4.1.3). 


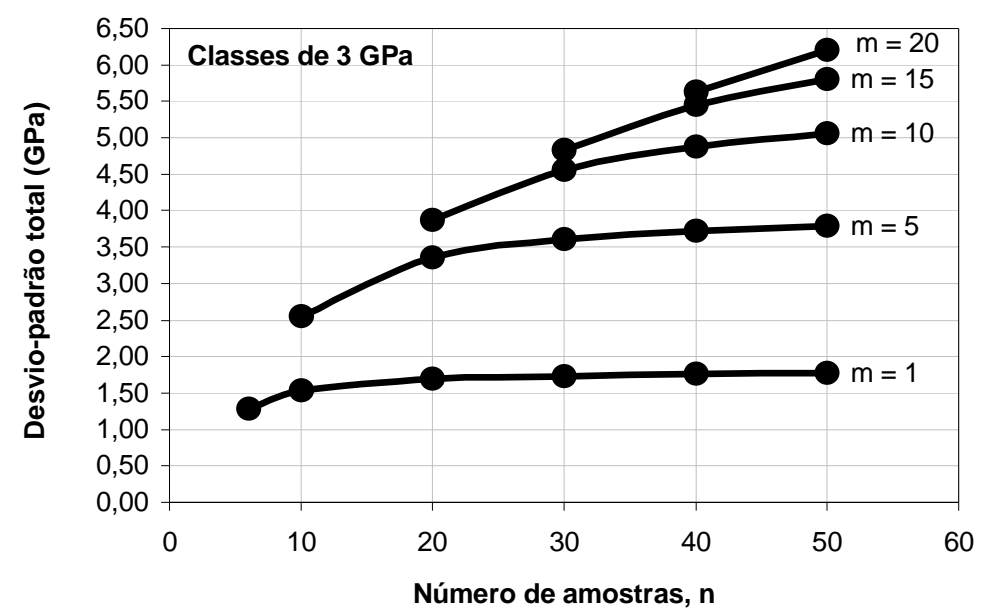

\begin{tabular}{|c|c|c|c|c|c|}
\hline \multirow{2}{*}{$\begin{array}{c}\text { Número de } \\
\text { amostras, } \mathbf{n}\end{array}$} & \multicolumn{5}{|c|}{ Número de amostras distantes 3 GPa, $\mathbf{~}$} \\
\cline { 2 - 6 } & $\mathbf{1}$ & $\mathbf{5}$ & $\mathbf{1 0}$ & $\mathbf{1 5}$ & $\mathbf{2 0}$ \\
\hline $\mathbf{6}$ & 1,28 & & & & \\
\hline $\mathbf{1 0}$ & 1,53 & 2,55 & & & \\
\hline $\mathbf{2 0}$ & 1,69 & 3,35 & 3,87 & & \\
\hline $\mathbf{3 0}$ & 1,73 & 3,60 & 4,55 & 4,83 & \\
\hline $\mathbf{4 0}$ & 1,76 & 3,72 & 4,88 & 5,45 & 5,63 \\
\hline $\mathbf{5 0}$ & 1,77 & 3,79 & 5,06 & 5,80 & 6,20 \\
\hline
\end{tabular}

Figura 5.2.4.1.2 - Gráfico: Número de amostras total x Desvio-padrão total x Número de amostras distantes $3 \mathrm{GPa}$ (intervalo entre-classes)

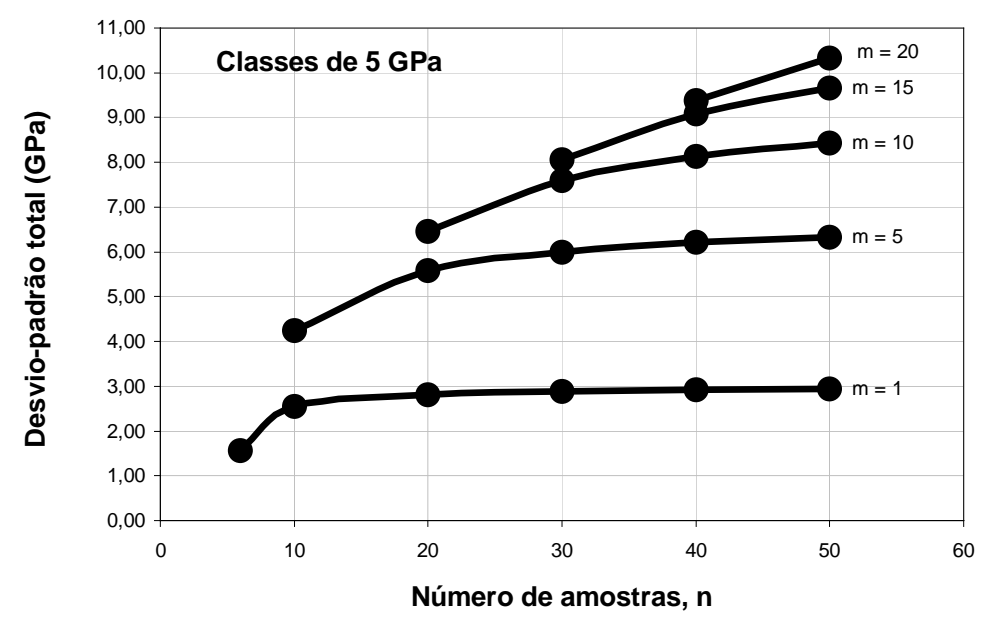

\begin{tabular}{|c|c|c|c|c|c|}
\hline \multirow{2}{*}{$\begin{array}{c}\text { Número de } \\
\text { amostras, } \mathbf{n}\end{array}$} & \multicolumn{5}{|c|}{ Número de amostras distantes 5 GPa, $\mathbf{m}$} \\
\cline { 2 - 6 } & $\mathbf{1}$ & $\mathbf{5}$ & $\mathbf{1 0}$ & $\mathbf{1 5}$ & $\mathbf{2 0}$ \\
\hline $\mathbf{6}$ & 1,56 & & & & \\
\hline $\mathbf{1 0}$ & 2,55 & 4,25 & & & \\
\hline $\mathbf{2 0}$ & 2,81 & 5,58 & 6,45 & & \\
\hline $\mathbf{3 0}$ & 2,89 & 6,00 & 7,59 & 8,05 & \\
\hline $\mathbf{4 0}$ & 2,93 & 6,21 & 8,13 & 9,09 & 9,38 \\
\hline $\mathbf{5 0}$ & 2,95 & 6,32 & 8,43 & 9,66 & 10,33 \\
\hline
\end{tabular}

Figura 5.2.4.1.3 - Gráfico: Número de amostras total x Desvio-padrão total x Número de amostras distantes $5 \mathrm{GPa}$ (intervalo entre-classes) 
Os valores de $t$-Student utilizados foram os mesmos já citados.

Dos gráficos, fica nítido que:

- quanto maior o número total de amostras (n), maior o desvio-padrão admissível para a detecção das amostras eventualmente desviadas $(m)$;

- quanto maior o intervalo entre-classes adotado, maior o desvio-padrão admissível para a detecção, considerando-se um mesmo número total de amostras $(n)$;

- quanto maior a sensibilidade do controle (menor número de amostras desviadas detectável, $m$ ), menor o desvio-padrão admissível para um mesmo número total de amostras $(n)$.

Dessa forma, se for considerado um desvio-padrão total (produção e ensaio) de 2,5 GPa, como tem sido neste item de estudo, e se realizar formação de lote para controle tecnológico de apenas 6 ou 10 amostras com sensibilidade de detecção de qualquer amostra desviada, ainda que única $(m=1)$, o intervalo entre-classes de especificação de módulo de deformação exigido será de $5 \mathrm{GPa}$.

Se for considerado o desvio-padrão total de 1,0 GPa que corresponde àquele observado a partir dos resultados médios da primeira etapa do programa experimental, resumidos no início deste item de discussão, o intervalo entre-classes exigido para o mesmo nível de sensibilidade será de aproximadamente $2 \mathrm{GPa}-$ dos gráficos anteriores, o intervalo de $1 \mathrm{GPa}$ garantiria um desvio-padrão de aproximadamente $0,5 \mathrm{GPa}$ quando $(n=10 ; m=1)$ e o intervalo de $3 \mathrm{GPa}$ garantiria um desvio-padrão de aproximadamente $1,5 \mathrm{GPa}$ quando $(n=10 ; m=1)$.

Essas constatações não inviabilizam uma classificação hipotética do concreto pelo módulo de deformação combinada com a dada pela resistência, caso se admita a repetição das classes de módulo.

Como um exemplo, considere-se o caso da aplicação deste critério aos resultados da segunda etapa do programa experimental, considerando-se o desviopadrão da resistência e do módulo de deformação de 2,5 $\mathrm{MPa}$ e 2,5 $\mathrm{GPa}$, respectivamente. Uma das classificações teóricas possíveis seria a constante da Tab. 5.2.4.1.3. 
Tabela 5.2.4.1.3- Classes de resistência e módulo de deformação atendidas na segunda etapa do programa experimental

\begin{tabular}{|c|c|c|c|c|}
\hline Traço & $\begin{array}{c}\text { Resistência } \\
\text { característica } \\
\text { fck (MPa) }\end{array}$ & $\begin{array}{c}\text { Classe de } \\
\text { resistência } \\
\text { máxima atendida }\end{array}$ & $\begin{array}{c}\text { Módulo } \\
\text { característico } \\
\text { Eck (GPa) }\end{array}$ & $\begin{array}{c}\text { Classe de módulo } \\
\text { máxima atendida } \\
\text { (hipotética) }\end{array}$ \\
\hline T3-042-A100 & 55 & C55 & 29 & M29 \\
\hline T4-050-A100 & 43 & C40 & 27 & M24 \\
\hline T5-058-A100 & 36 & C35 & 25 & M24 \\
\hline T6-042-A180 & 55 & C55 & 26 & M24 \\
\hline T7-050-A180 & 43 & C40 & 24 & M24 \\
\hline T8-058-A180 & 36 & C35 & 23 & M19 \\
\hline
\end{tabular}

* $O$ intervalo de $5 \mathrm{GPa}$ entre as classes de módulo obedece aos resultados dos gráficos para sd =2,5, $n=10$ e $m=1$.

Uma classificação deste tipo colaboraria com o atendimento ao conceito semiprobabilístico normativo quanto à especificação de ambas as propriedades (resistência e módulo de deformação).

Nota-se, claramente, que ainda existem muitas outras possíveis sob os mesmos parâmetros, além das destinadas a outras combinações de $s d, n$ e $m$.

Contudo, dificilmente se encontra uma combinação praticável que atende ao intervalo entre-classes de $1 \mathrm{GPa}$ utilizado atualmente.

Por fim, é necessário que se registre que a aplicação da correlação entre o módulo de deformação e a resistência do concreto na prática atual da especificação e do controle de qualidade da propriedade tem sido um pouco confusa. Tem-se visto, algumas vezes, a especificação única da resistência com a suposição de que o módulo de deformação correlato de acordo com a expressão normalizada na NBR 6118:2003 será automaticamente atendido, o que pode não ser verdade de acordo com o já demonstrado. Outras vezes, mas na mesma direção, espera-se obter no ensaio de controle de qualidade da propriedade o atendimento da correlação e identifica-se o não-atendimento como uma "não-conformidade" do processo de produção, o que, ao questionamento técnico, acrescenta-se um outro de ordem comercial e jurídica.

Pode-se dizer que esses cenários de aplicação indevida dos modelos do tipo resistência-módulo $(\sigma / E)$ tem contribuído para a incerteza atual de especificação, produção e controle do módulo de deformação do concreto. Observa-se, por vezes, que essa incerteza tem implicado em acréscimo imediato ou em reserva de custos 
para o futuro que se agregam aos custos passivos da obra previstos para a assistência técnica pós-entrega. Acredita-se que esta lembrança deva ser agregada à discussão realizada como aspecto prático relevante à questão das implicações da desconsideração de maior base estatística sobre a propriedade módulo de deformação do concreto na normalização técnica nacional. 


\section{CONCLUSÕES}

Para atender devidamente à tendência de ampliação da cultura de especificação de uma propriedade como o módulo estático de deformação do concreto é necessário investir também na própria qualidade do ensaio e dos critérios de utilização dos resultados.

Seguindo essa idéia, atendeu-se a um primeiro objetivo ao apresentar e testar uma sistemática de avaliação da acurácia do método de ensaio através de ferramentas estatísticas que permitissem a identificação das parcelas da variabilidade oriundas da produção e do ensaio propriamente dito, com especial atenção àquela parcela originada no tipo utilizado de instrumentação para medida das deformações. As quatro instrumentações utilizadas para tal foram: strain gages de colagem superficial com sistema condicionador e amplificador de sinais elétricos ligado a um microcomputador para aquisição dos dados (SG); clip gages com sistema condicionador e amplificador simplesmente ligado a um mostrador digital para leitura pelo operador (CG); e dispositivo do tipo compressômetro com um (1R) ou dois (2R) relógios comparadores com mostrador digital para leitura da deformação pelo operador.

Um resumo do que foi observado na análise dos resultados desta etapa do programa experimental da dissertação é apresentado agora de forma itemizada.

a) A análise de variância ( $A N O V A)$ dos resultados das três betonadas de cada um dos 2 traços de concreto selecionados (a/c 0,40 e 0,70 kg/kg) as considerou como estatisticamente diferentes;

b) A análise de variância $(A N O V A)$ dos resultados do método de ensaio sob as quatro instrumentações selecionadas as considerou como estatisticamente diferentes;

c) Os resultados obtidos com os dois relógios comparadores (2R) produziram sempre as maiores médias e desvios-padrão, seja para o plano de carregamento secante ou tangente inicial; discutiram-se hipóteses para a causa disto como a ausência de um ponto de ancoragem no yoke superior, o risco de desestabilização do sistema dado por aparafusamento diferencial dos pontos de ancoragem e a possibilidade de geração de deformações de alongamento nos medidores dado pela deformação transversal do corpo-de-prova e o conseqüente deslocamento do sistema de medida; 
d) O cálculo do indicador de precisão 'Desvio-padrão devido à repetitividade' do método de ensaio sob cada uma das instrumentações em particular indicou valores divergentes: para os strain gages (SG) o indicador obtido foi da ordem de 1,70 a 2,00 GPa; para os clip gages (CG), foi da ordem de 0,80 a 1,40 GPa; para o compressômetro com um relógio comparador (1R), foi da ordem de 1,70 a 2,80 GPa; e para o compressômetro com dois relógios comparadores (2R), foi da ordem de 2,20 a 3,40 GPa. O indicador 'Desvio-padrão devido à reprodutibilidade' tendeu à nulidade pela inexistência de um segundo operador. Mesmo assim, em apenas um caso dentro de um universo de 16 condições de análise, a porcentagem da 'Variância devido à repetitividade e à reprodutibilidade (R\&R)' em relação à 'Variância total' ficou abaixo de $70 \%$ : esta se deu para a instrumentação de clip gages (CG). O complemento aos 100\% se deu com a 'Variância devido às Betonadas', da ordem de 0,5 a 1,0 GPa em todos os casos. Ressalte-se que toda esta dispersão estava vinculada à análise de resultados individuais, e não médios;

d.1) Observou-se, no entanto, que a consideração da distribuição estatística dos resultados através do cálculo de valores característicos ou nominais

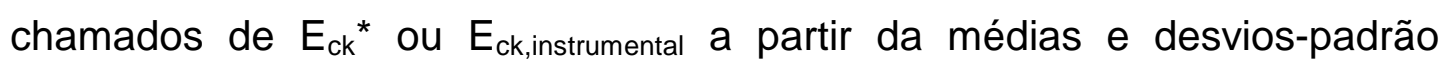
particulares aproximava os resultados das instrumentações;

d.2) Observou-se também que a exclusão dos resultados obtidos sob o compressômetro com dois relógios comparadores (2R), dadas as constatações de elevada dispersão em relação às demais instrumentações, levava a uma grande comparabilidade entre os resultados obtidos com as outras instrumentações, mesmo de forma independente da consideração estatística de uso do $E_{c k}{ }^{*}$. $O$ ápice desta proximidade se deu com a obtenção de curvas de correlação entre strain gages (SG) e compressômetro com um relógio comparador (1R) através das expressões $E c s_{S G}=-4,01+1,09 \cdot E c s_{1 R}$ e $E c i_{S G}=-3,53+1,06 \cdot E c i_{1 R}$, que permitiram a reconsideração da análise dos resultados, via $A N O V A$, para a conclusão de que os resultados do método sob quaisquer dessas três instrumentações (strain gages, SG, clip gages, $\mathrm{CG}$, e compressômetro com 1 relógio comparador com resultados corrigidos pelas expressões de correlação, 1R-corrigido) poderiam ser definidos como estatisticamente iguais. 
Essa consideração, observou-se, serviria à verificação de tendência de aceitação prática do método de ensaio no que se referia aos resultados deste programa experimental obtidos sob quaisquer dessas três formas.

e) O cálculo do indicador de exatidão (Z-score) do método de ensaio sob cada uma das quatro instrumentações em particular indicou novamente grande divergência dos resultados do compressômetro com dois relógios comparadores (2R) em relação aos demais, com o maior número absoluto de classificações da exatidão como questionável ou insatisfatória $(50 \%$ do total de resultados individuais com este tipo de classificação). Os desvios em relação ao valor verdadeiro adotado (a mediana dos resultados) foram de 1,48 a 2,59 GPa nos diversos agrupamentos de plano de carregamento e tipos de concreto. Ao considerar-se apenas os resultados de strain gages (SG), clip gages (CG) e compressômetro com um relógio comparador corrigidos pelas expressões de correlação (1R-corrigido), pode-se dizer que os desvios passaram à faixa de 1,35 e 1,71 GPa, em que podia-se admitir $67,8 \%$ dos resultados médios distando entre 0,68 e 0,86 GPa e outros 27,5\% distando entre 2,03 e 2,57 GPa da mediana dos agrupamentos. Novamente, observou-se, que os últimos resultados poderiam servir à verificação de tendência de aceitação prática do método de ensaio.

Lembrou-se que toda esta dispersão calculada estava vinculada à análise de resultados individuais, e não médios de três corpos-de-prova, como preconizava a NBR 8522:2003; isto se deu porque o critério adotado ampliava a sensibilidade da sistemática de análise, principalmente para a comparação do método de ensaio sob cada tipo de instrumentação. A título de informação, calcularam-se as diferenças entre os parâmetros estatísticos obtidos a partir dos resultados individuais e médios: o desvio-padrão total, por exemplo, diminuía da faixa de 1,58 a 2,18 GPa para 0,96 a 1,16 GPa quando da mudança da consideração dos individuais para os médios, o que realmente prejudicaria a comparação. Notouse, porém, quaisquer dessas magnitudes obtidas no âmbito deste programa experimental estavam bastante distantes da realidade de interlaboratoriais nacionais, que indicavam desvio-padrão total, a partir de resultados médios, da ordem de 3,5 GPa. A principal justificativa para esse resultado pode ser predominantemente associada à variação operacional e à qualidade (calibrações, manutenções) dos equipamentos utilizados por estes laboratórios, em detrimento 
de variações de produção ou inerentes à teoria que embasa o método de ensaio propriamente dito.

Coube ressaltar, então, que faltava às verificações deste programa experimental a amplitude de um interlaboratorial com outros equipamentos e operadores para a devida validação do método e a formatação definitiva dos parâmetros que permitiriam definir suas tolerâncias admissíveis. Porém, reafirmou-se que a sistemática é adequada a este tipo de avaliação de propriedade, equipamentos e material, o que atende ao objetivo formulado de apresentar e testar uma sistemática de avaliação da acurácia deste método de ensaio.

Além deste objetivo, procurou-se discutir a aplicação do conceito semiprobabilístico das normas nacionais de projeto, dosagem e controle tecnológico de estruturas de concreto no que se referia à propriedade módulo de deformação, avaliando de forma breve a desconsideração, pelas normas técnicas, da variabilidade observada nos resultados experimentais.

A principal questão colocada para a discussão da aplicação deste conceito foi a simulação de dois cenários de fornecimento de concreto com diferença de $4 \mathrm{GPa}$ devido a diferentes interpretações da especificação.

Um resumo do que foi observado na análise dos resultados da segunda etapa do programa experimental da dissertação é apresentado agora.

a) Os seis traços de concreto selecionados (a/c 0,42, 0,50 e 0,58 kg/kg, de consistências $100 \pm 20 \mathrm{~mm}$ e $180 \pm 30 \mathrm{~mm}$ ) permitiram a construção de um Diagrama de Dosagem com a inclusão da propriedade módulo de deformação $\left(E_{c s, m}\right)$ relacionada com o parâmetro de dosagem 'm' (materiais secos). $O$ diagrama evidenciou que a diferença causada pela especificação desta propriedade sem a consideração da distribuição estatística inerente à determinação experimental - especificação simples do valor do módulo de deformação do concreto $\left(E_{c}\right)$ sem a definição de médio ou característico - , pode levar a diferenças de 100 a $200 \mathrm{~kg}$ no consumo de cimento para concretos de mesmo abatimento;

b) Por outro lado, a simples verificação de uma viga genérica no ELS-DEF considerando-se a mesma possibilidade de diferença de resultados entre um fornecimento de $E_{c k}$ e $E_{c m}$, admitida de $4 \mathrm{GPa}$, mostrou um queda no coeficiente 
de rigidez secante do elemento e um aumento na flecha final da ordem de $9 \%$ para o caso de $\mathrm{E}_{\mathrm{cm}}$ comparado ao de $\mathrm{E}_{\mathrm{ck}}$;

c) Por fim, ressalte-se que no caso do controle de qualidade em obra, há a necessidade de consideração de um critério probabilístico na formação dos lotes, por todas as evidências de variabilidade já expostas aqui. Foi feita a sugestão de adoção do mesmo critério utilizado na verificação da resistência à compressão, podendo-se adotar menor intervalo de confiança de garantia de atendimento à especificação já que a tendência é de se realizar menor quantidade de experimentos.

Ainda sobre o controle tecnológico, ressalte-se que é possível estabelecer uma classificação do concreto de acordo com a propriedade módulo de deformação, de forma relacionada com a já consolidada classificação com base na resistência à compressão característica. Para tal, simularam-se algumas combinações de formação de lotes cujos resultados mostraram que, se considerados os desviospadrão totais de 2,5 MPa e de 2,5 GPa para as propriedades, o melhor intervalo entre-classes seria de $5 \mathrm{MPa}$ para a resistência, como já existe, e de 5 GPa para o módulo de deformação.

Cabe ainda destacar nestas conclusões que a aplicação de modelos de previsão do comportamento microestrutural e mecânico aos concretos dosados no programa experimental mostrou resultados muito satisfatórios, sendo que todos eles estiveram de acordo com as expectativas iniciais.

Em suma, e de maneira mais holística, viu-se que o investimento na qualidade do controle experimental do módulo de deformação colabora:

- com a garantia da segurança e da funcionalidade das estruturas de concreto no atendimento às premissas de projeto;

- com a redução do desperdício na cadeia produtiva;

- com a identificação devida dos "agentes" do processo causadores da variabilidade.

Isto porque:

- a rejeição de um produto adequado (que atende às especificações de módulo de deformação) originada por deficiência no controle pode gerar desperdício 
de terapia estrutural e nos custos diretos e indiretos da obra, inclusive de ordem comercial e jurídica.

- a aceitação de um produto inadequado originada por deficiência no controle pode gerar um custo passivo provável em decorrência da terapia estrutural futura e normalmente imprevista.

- o sub/superdimensionamento do produto em termos da propriedade controlada experimentalmente gera o desperdício de material e suas conseqüências de custos diretos e indiretos.

Todos esses itens são de interesse direto do produtor de concreto (tecnologistas e/ou fornecedores), do consumidor primário (construtoras/projetistas) e do consumidor final. 


\section{SUGESTÕES DE CONTINUIDADE DA PESQUISA}

A continuidade desta pesquisa deve se dar fundamentalmente no que se refere à resolução de suas limitações de teste. Ou seja:

- ampliação do escopo de laboratórios, insumos materiais e equipamentos contemplados no programa experimental de avaliação da acurácia do método de ensaio, seguindo possivelmente a mesma sistemática;

- discussão dos valores de tolerância para a dispersão dos experimentos de determinação da propriedade módulo de deformação;

- desenvolvimento da discussão a respeito da aplicação do conceito semiprobabilístico à propriedade do ponto de vista do projeto estrutural, com medições de deformações em elementos estruturais-modelo;

- desenvolvimento da discussão a respeito da aplicação do conceito semiprobabilístico à propriedade do ponto de vista da produção e do controle de qualidade de concreto, com estudo econômico-financeiro vinculado à área de projeto estrutural. 


\section{REFERÊNCIAS BIBLIOGRÁFICAS}

AïTCIN, P.C. Concreto de alto desempenho. São Paulo: Pini, 2000.

AIITCIN, P.C.; MEHTA, P.K. Effect of coarse-aggregate characteristics on mechanical properties of high-strength concrete. ACI Materials Journal, p. 103-107, Mar./Apr. 1990.

ALMEIDA, P.A.O. Transdutores para medida de deslocamentos lineares. Notas de aula. Escola Politécnica, Universidade de São Paulo. São Paulo, 2004.

AMERICAN SOCIETY FOR TESTING AND MATERIALS. ASTM C-39: Standard test method for compressive strength of cylindrical concrete specimens. Philadelphia, 2003.

. ASTM C-469: Standard test method for static modulus of elasticity and poisson's ratio in concrete in compression. Philadelphia, 2002.

ANDRADE, W.P. (Ed.). Concretos massa, estrutural, projetado e compactado com rolo - Ensaios e propriedades. São Paulo: Pini, 1997.

ANDRIOLO, F.R.; SGARBOZA, B.C. Inspeção e controle de qualidade do concreto. São Paulo: Newswork, 1993.

ASSOCIAÇÃO BRASILEIRA DE NORMAS TÉCNICAS. NBR NM 33: Amostragem de concreto fresco. Rio de Janeiro, 1998.

. NBR 5738: Moldagem e cura de corpos-de-prova cilíndricos de concreto. Rio de Janeiro, 2003.

. NBR 5739: Determinação da resistência à compressão de corpos-de-prova cilíndricos de concreto. Rio de Janeiro, 1994.

NBR 6118: Projeto e execução de obras de concreto armado - Procedimento -. Rio de Janeiro, 2003.

. NBR 8522: Concreto - Determinação de módulo de deformação estática e diagrama tensão-deformação. Rio de Janeiro, 2003.

. NBR 12655: Concreto de cimento Portland - Preparo, controle e recebimento - Procedimento. Rio de Janeiro, 2006.

BAALBAKI, W. et.al. Influence of coarse aggregate on elastic properties of highperformance concrete. ACI Materials Journal, p. 499-503, Sep./Oct., 1991.

BITTENCOURT, T.N.; ASSIS, W. Verificação dos deslocamentos em vigas de concreto armado - Estado limite de deformações excessivas (ELS-DEF). Notas de aula. Escola Politécnica, Universidade de São Paulo. São Paulo, 2003. Disponível em <http://www.lmc.ep.usp.br/pesquisas/TecEdu/>. 
BOX, G.E.P.; HUNTER, W.G.; HUNTER, J.S. Statistics for experimenters: an introduction to design, data analysis and model building. New York: John Wiley \& Sons, 1978.

BOUMIZ, A. et al. Modelling the development of the elastic moduli as a function of the degree of hydration of cement pastes and mortars. In Nonat A. (Ed.). Proceedings 13 of the $2^{\text {nd }}$ RILEM Workshop on Hydration and Setting: Why does cement set? An interdisciplinary approach, Dijon, 1997.

BRANDT, A.M. A discussion of the paper "Young's modulus of concrete reconsidered" by J.M. Torrenti, C. Boulay and C. Puch. Cement and Concrete Research, Vol. 25, No. 5, p. 1123, 1995.

CALEGARE, A.J.A. Introdução ao delineamento de experimentos. $1^{\text {a }}$ ed. São Paulo: Edgard Blücher, 2001.

CALLISTER, W.D., Jr. Ciência e engenharia de materiais: uma introdução. $5^{a}$ ed. Rio de Janeiro: LTC, 2002.

CARPINETTI, L.C.R. Controle da qualidade de processo. Escola de Engenharia de São Carlos, Universidade de São Paulo. $2^{a}$ ed. São Carlos, 2003.

COSTA NETO, P.L.O. Estatística. $2^{a}$ ed. São Paulo: Edgard Blücher, 2002.

CUNHA, C.H.M. Deformabilidade das estruturas de concreto: impacto da variabilidade do módulo de elasticidade secante e da resistência à tração, decorrente das modificações dos materiais, cimentos e agregados. Dissertação (Mestrado) - Escola Politécnica, Universidade de São Paulo. São Paulo, 2000.

DAL MOLIN, D.C.C. Contribuição ao estudo das propriedades mecânicas dos concretos de alta resistência com e sem adições de microssílica. Tese (Doutorado) Escola Politécnica, Universidade de São Paulo. São Paulo, 1995.

DAMIDOT, D.; VELEZ, K.; SORRENTINO, F. Characterisation of interstitial transition zone (ITZ) of high performance cement by nanoindentation technique. $11^{\text {th }}$ International Congress on the Chemistry of Cement, Durban, 2003.

FEDÉRATION INTERNATIONALE DU BÉTON (FIB/CEB-FIP). Structural concrete textbook on behavior, design and performance updated knowledge of CEB-FIP Model Code. Vol. 2, 1990.

FIGUEIREDO, A.D. Princípios de ciência dos materiais. Notas de aula. Escola Politécnica, Universidade de São Paulo. São Paulo, 2004.

FIGUEIREDO, A.D.; FIGUEIREDO, E.P; SOUZA, F.L. Medidas de deformação através de strain gages. Notas de aula. Escola Politécnica, Universidade de São Paulo. São Paulo, 1991. 
FREY, D. Materials selection in mechanical design. Disponível em $<$ http://web.mit.edu/2.72/www/lectures/session 8 v2.pdf $>$. Acesso em Janeiro, 2007.

GARBOCZI, E.J. et al. An electronic monograph: modeling and measuring the structure and properties of cement-based materials. Building and Fire Research Laboratory, National Institute of Standards and Technology, Gaithersburg. Acesso em Janeiro, 2006.

HANSEN, T.C. Influence of aggregate and voids on modulus of elasticity of concrete, cement mortar and cement paste. Journal of American Concrete Institute, p. 193215, Feb., 1965.

HASHIN, Z.; MONTEIRO, P.J.M. An inverse method to determine the elastic properties of the interphase between the aggregate and the cement paste. Cement and Concrete Research, Vol. 32, p. 1291-1300, 2002.

HELENE, P.R.L. Controle de qualidade do concreto. Boletim Técnico no 03 - Escola Politécnica, Universidade de São Paulo. São Paulo, 1986.

HELENE, P.R.L. Estudo da variação do módulo de elasticidade do concreto com a composição e características do concreto fresco e endurecido. Escola Politécnica da Universidade de São Paulo, Relatório Técnico n 10.122 à Associação Brasileira de Cimento Portland. São Paulo, 1998.

HELENE, P.R.L.; MONTEIRO, P.J.M. Design concrete mixtures for strength, elastic modulus and fracture energy, Materials and Structures, Vol. 26, No. 162, p. 443-452, Oct., 1993.

HELENE, P.R.L.; TERZIAN, P.R. Manual de Dosagem e Controle do Concreto. São Paulo: Pini/Senai, 1993.

HELENE, P.R.L. Dosagem de concreto de cimento Portland. Notas de Aula. Escola Politécnica, Universidade de São Paulo. São Paulo, 2004.

HIRSCH, T.J., Modulus of elasticity of concrete affected by elastic moduli of cement paste matrix and aggregate, Journal of American Concrete Institute, p. 427-451, Mar., 1962.

HSIEH, C.; TUAN, W. Elastic modulus of two-phase materials, Bulletin of the College of Engineering, N.T.U., No. 89, p. 35-44, Oct., 2003.

ILLSTON, J.M. (Ed.). Construction materials: their nature and behaviour. $2^{\text {nd }}$ ed. London: E \& FN Spon, 1994.

INÁCIO, J.J.; ANDRADE, M.A.S.; BITTENCOURT, R.M. Relatório do X programa interlaboratorial de ensaios de concreto/2004. Furnas Centrais Elétricas S.A., Relatório DCT.T.01.028.2005-R0 à Comissão Técnica de Laboratórios de Ensaios em Construção Civil do Instituto Nacional de Metrologia, Normalização e Qualidade Industrial (INMETRO/CTLE-01). Goiânia, 2005. 
INÁCIO, J.J.; ANDRADE, M.A.S.; BITTENCOURT, R.M. Relatório do XI programa interlaboratorial de ensaios de concreto/2005, Furnas Centrais Elétricas S.A., Relatório DCT.C.01.034.2006-R0 à Comissão Técnica de Laboratórios de Ensaios em Construção Civil do Instituto Nacional de Metrologia, Normalização e Qualidade Industrial (INMETRO/CTLE-01). Goiânia, 2006.

INSTITUTO NACIONAL DE METROLOGIA, NORMALIZAÇÃO E QUALIDADE INDUSTRIAL (INMETRO). Orientações sobre validação de métodos de ensaios químicos. Rio de Janeiro, 2003.

INTERNATIONAL ORGANIZATION FOR STANDARDIZATION. ISO 5725 - Parts 16: Accuracy (trueness and precision) of measurement methods and results. Switzerland, 2000.

ISO 4012: Concrete - Determination of compressive strength of test specimens. 1978.

. ISO 6784: Concrete - Determination of static modulus of elasticity in compression. 1982.

KAEFER, L.F. Considerações sobre a microestrutura do concreto. Notas de aula. Escola Politécnica, Universidade de São Paulo. São Paulo, 2002.

KLINK, S.A., Aggregates, elastic-modulus, and Poisson's ratio of concrete. ACI Journal, p. 961-965, Nov./Dec., 1986.

KLINK, S.A. Axial strain variations in concrete under uniform uniaxial compressive stress. Cement and Concrete Research, Vol. 5, p. 405-418, 1975.

KLINK, S.A. Cement and the elastic constants of concrete. Cement and Concrete Research, Vol. 22, p. 761-768, 1992.

KOTSOVOS, M.D.; PAVLOVIC, M.N. Structural concrete: finite-element analysis for limit-state design. London: Thomas Telford, 1995.

LI, G.; ZHAO, Y.; PANG, S.S.; LI, Y. Effective Young's modulus estimation of concrete. Cement and Concrete Research, Vol. 29, p. 1455-1462, 1999.

LIMA, E.P. Influência do volume de pasta na zona de transição pasta/agregado com relação às propriedades mecânicas e de durabilidade do concreto. Dissertação (Mestrado) - Escola Politécnica, Universidade de São Paulo. São Paulo, 2000.

LINIERS, A.D. Tecnología y propiedades mecánicas del hormigón. 2ª . ed. Madrid: Intemac, 1993.

LUTZ, M.P.; MONTEIRO, P.J.M.; ZIMMERMAN, R.W. Inhomogeneous interfacial transition zone model for the bulk modulus of mortar. Cement and Concrete Research, Vol. 27, No. 7, p. 1113-1122, 1997. 
MEHTA, P.K.; MONTEIRO, P.J.M. Concreto: estrutura, propriedades e materiais. São Paulo: Pini, 1994.

MONDAL, P.; SHAH, S.P.; MARKS, L. Characterization of cementitious materials at nanoscale with a focus on mechanical properties. NSF Workshop on nanomodification of cementitious materials: Portland cement concrete and asphalt concrete. Gainesville, 2006. Disponível em <http://www.ce.ufl.edu/nanoworkshop/ Mondal.pdf>.

MONTEIRO, P.J.M. Portland cement. Disponível em <http://www.ce.berkeley.edu/ $\sim$ paulmont/CE60New/cement.pdf>. Acesso em Janeiro, 2007.

MONTEIRO, P.J.M.; CHANG, C.T. The elastic moduli of calcium hydroxide. Cement and Concrete Research, Vol. 25, p. 1605-1609, 1995.

MORANVILLE-REGOURD, M., In MALIER, Y. (Ed.). Microstructure of high performance concrete. London: E\&FN Spon, 1992.

MURDOCK, L.J.; BROOK, K.M.; DEWAR, J.D. Concrete: materials \& practice. $6^{a}$ ed. London: Edward Arnold, 1991.

NASCIMENTO, H.L.N. Ferramentas estatísticas para escolha, validação, comparação e monitoramento de métodos analíticos. Publicado na AllChemy-Série Alfa, 2001. Disponível em <http://allchemy.iq.usp.br/metabolizando/alfa.html>.

NEVILLE, A.M. Propriedades do Concreto. $2^{\mathrm{a}}$ ed. São Paulo: Pini, 1997.

NILSEN, A.U.; MONTEIRO, P.J.M. Concrete: a three phase material. Cement and Concrete Research, Vol. 23, p. 147-151, 1993.

NILSEN, A.U.; MONTEIRO, P.J.M.; GJORV, O.E. Estimation of the elastic moduli of lightweight aggregate. Cement and Concrete Research, Vol. 25, No. 2, p. 276-280, 1995.

PAULON, V.A. Estudo da microestrutura da zona de transição entre a pasta de cimento e o agregado. Tese (Doutorado) - Escola Politécnica, Universidade de São Paulo. São Paulo, 1991.

PAULON, V.A. A microestrutura do concreto convencional. In: ISAIA, G.C. Concreto: ensino, pesquisa e realizações. São Paulo: Ibracon, 2005. Vol. 1, cap. 19, p. 583604.

PEREIRA NETO, P.M. Efeito do agregado graúdo em algumas propriedades do concreto de alta resistência com microssílica. Dissertação (Mestrado) - Escola Politécnica, Universidade de São Paulo. São Paulo, 1994.

POWERS, T.C. The nature of concrete. Research and Development Laboratories of the Portland Cement Association, Bulletin 196, Illinois: American Society for Testing and Materials, 1966. 
RODRIGUES, G.S.S. Módulo de deformação estático do concreto pelo método ultrasônico: estudo da correlação e fatores influentes, Dissertação (Mestrado) - Escola de Engenharia Civil, Universidade Federal de Goiás. Goiânia, 2003.

RODRIGUES, G.S.S.; FIGUEIREDO, E.J.P. Estudo dos fatores influentes sobre os resultados de módulo de deformação estático do concreto, Anais do $46^{\circ}$ Congresso Brasileiro do Concreto, Vol. 2, p. 956-971, 2004.

SBRIGHI NETO, C. Agregados para concreto. In: ISAIA, G.C. Concreto: ensino, pesquisa e realizações. São Paulo: Ibracon, 2005. Vol. 1, cap. 11, p. 323-343.

SHEHATA, L.D. Deformações instantâneas do concreto. In: ISAIA, G.C. Concreto: ensino, pesquisa e realizações. São Paulo: Ibracon, 2005. Vol. 1, cap. 21, p. 633654.

SILVA, F.H.B.; MELO, G.S. Modelos de dimensionamento e verificação. In: ISAIA, G.C. Concreto: ensino, pesquisa e realizações. São Paulo: Ibracon, 2005. Vol. 1, cap. 5 , p. 143-163.

TANGO, C.E.S.; TARRAN, F.C. Determinação experimental da deformabilidade do concreto. Comunicação Técnica $n^{0} 29$. Instituto de Pesquisas Tecnológicas do Estado de São Paulo. São Paulo: IPT, 1983.

TAYLOR, H.F.W. Cement chemistry. London: Academic Press, 1990.

TIMOSHENKO, S.P.; GOODIER, J.N. Teoria da elasticidade. $3^{\mathrm{a}}$ ed. Rio de Janeiro: Guanabara Dois, 1980.

TORRENTI, J.M.; BOULAY, C.; PUCH, C. The Young's modulus of concrete reconsidered. Cement and Concrete Research, Vol. 24, No.4, p. 641-649, 1994.

VALAVALA, P.K.; ODEGARD, G.M. Modeling techniques for determination of mechanical properties of polymer nanocomposites. Advanced Materials Science, Vol. 9, p. 34-44, 2005.

VAN VLACK, L.H. Princípios de ciência dos materiais. Brasília: Edgard Blücher, 1973.

VASCONCELOS, A.C.; GIAMMUSSO, S.E. O misterioso módulo de elasticidade, Anais do $40^{\circ}$ Congresso Brasileiro do Concreto, Artigo No. 90, 1998.

VICHIT-VADAKAN, W.; CARINO, N.J.; MULLINGS, G.M. Effect of elastic modulus of capping material on measured strength of high-strength concrete cylinders. Cement, Concrete and Aggregates, Vol. 20, No.2, p. 227-234, Dec., 1998.

VILARDELL, J. et al. Estimation of the modulus of elasticity for dam concrete, Cement and Concrete Research, Vol. 28, No.1, p. 93-101, 1998.

VUOLO, J.H. Introdução à teoria de erros. Notas de aula. Instituto de Física, Universidade de São Paulo. São Paulo, 1992. 
WADDELL, J.J. Practical quality control for concrete. New York: McGraw-Hill, 1962.

WAENY, J.C.C. Distribuição normal. Publicação Interna $n^{\circ}$ 4. Instituto de Pesquisas Tecnológicas do Estado de São Paulo. São Paulo: IPT, 1979.

- Repetitividade e Reprodutividade I. Publicação Interna $n^{0} 5$. Instituto de Pesquisas Tecnológicas do Estado de São Paulo. São Paulo: IPT, 1980.

Repetitividade e Reprodutividade II. Instituto de Pesquisas Tecnológicas do Estado de São Paulo. São Paulo: IPT, 1980.

YANG, C.C. Approximate elastic moduli of lightweight aggregate. Cement and Concrete Research, Vol. 27, No.7, p. 1021-1030, 1997.

YANG, C.C.; HUANG, R. Double inclusion model for approximate elastic moduli of concrete material. Cement and Concrete Research, Vol. 26, No.1, p. 83-91, 1996.

ZAGOTTIS, D.L. Pontes e grandes estruturas: elasticidade, elementos finitos. São Paulo: Edusp, 1979.

ZHOU, F.P.; LYDON, F.D.; BARR, B.I.G. Effect of coarse aggregate on elastic modulus and compressive strength of high performance concrete. Cement and Concrete Research, Vol. 25, No.1, p. 177-186, 1995. 


\section{APÊNDICE A - RESULTADOS DOS ENSAIOS DA PRIMEIRA ETAPA}

Tabela A.1 - Resultados dos ensaios prévios de resistência à compressão: a/c 0,40

\begin{tabular}{|c|c|c|c|c|c|c|}
\hline \multirow[b]{2}{*}{$\mathrm{CP}$} & \multicolumn{2}{|c|}{ Betonada 1} & \multicolumn{2}{|c|}{ Betonada 2} & \multicolumn{2}{|c|}{ Betonada 3} \\
\hline & $\begin{array}{c}\text { Força } \\
\text { (tf) }\end{array}$ & $\begin{array}{c}\text { Tensão } \\
\text { (MPa) }\end{array}$ & $\begin{array}{c}\text { Força } \\
\text { (tf) }\end{array}$ & $\begin{array}{c}\text { Tensão } \\
\text { (MPa) }\end{array}$ & $\begin{array}{c}\text { Força } \\
\text { (tf) }\end{array}$ & $\begin{array}{c}\text { Tensão } \\
\text { (MPa) }\end{array}$ \\
\hline 1 & 47,1 & 58,8 & 46,75 & 58,4 & 47,75 & 59,6 \\
\hline 2 & 44,1 & 55,0 & 47,45 & 59,3 & 47,00 & 58,7 \\
\hline 3 & 45,0 & 56,1 & 46,65 & 58,3 & 50,80 & 63,5 \\
\hline 4 & 46,8 & 58,5 & 49,05 & 61,3 & 51,40 & 64,2 \\
\hline 5 & 45,9 & 57,3 & 45,55 & 56,9 & 49,10 & 61,3 \\
\hline 6 & 45,7 & 57,0 & 47,15 & 58,9 & 50,45 & 63,0 \\
\hline 7 & 46,6 & 58,2 & 46,80 & 58,5 & 49,50 & 61,8 \\
\hline 8 & 45,4 & 56,7 & 46,45 & 58,0 & 51,70 & 64,6 \\
\hline 9 & 46,3 & 57,8 & 47,20 & 59,0 & 49,90 & 62,3 \\
\hline 10 & 46,0 & 57,5 & 46,80 & 58,5 & 50,10 & 62,6 \\
\hline Média & 45,87 & 57,29 & 46,99 & 58,69 & 49,77 & 62,16 \\
\hline Desvio & 0,91 & 1,13 & 0,89 & 1,11 & 1,50 & 1,88 \\
\hline
\end{tabular}

Tabela A.2 - Resultados de módulo de deformação: a/c 0,40

strain gages

a/c 0,40 Betonada 1

\begin{tabular}{|c|c|c|c|c|c|c|c|}
\hline $\mathrm{CP}$ & Plano & $\begin{array}{c}\begin{array}{c}\text { Força } \\
\text { (tf) }\end{array} \\
\end{array}$ & $\begin{array}{l}\text { Tensão } \\
\text { (MPa) }\end{array}$ & \begin{tabular}{l|} 
e1 \\
(um)
\end{tabular} & $\begin{array}{l}\text { e2 } \\
\text { (um) }\end{array}$ & $\begin{array}{l}\text { em } \\
\text { (um) }\end{array}$ & $\begin{array}{c}\mathrm{Ec} \\
\text { (GPa) }\end{array}$ \\
\hline \multirow{6}{*}{1} & \multirow[t]{3}{*}{ Secante } & 1,05 & 1,31 & 98,959 & 371,573 & 235,266 & \multirow{4}{*}{35,4} \\
\hline & & 13,95 & 17,42 & 654,037 & 726,403 & 690,220 & \\
\hline & & 12,900 & 16,113 & 555,078 & 354,830 & 454,954 & \\
\hline & \multirow{3}{*}{$\begin{array}{l}\text { Tangente } \\
\text { Inicial }\end{array}$} & 1,05 & 1,31 & 111,554 & 374,034 & 242,794 & \\
\hline & & 13,95 & 17,42 & 647,713 & 738,015 & 692,864 & \multirow[b]{2}{*}{35,8} \\
\hline & & 12,900 & 16,113 & 536,159 & 363,981 & 450,070 & \\
\hline \multirow{6}{*}{2} & \multirow[t]{3}{*}{ Secante } & 1,05 & 1,31 & 74,455 & 42,295 & 58,375 & \multirow[b]{3}{*}{36,2} \\
\hline & & 13,95 & 17,42 & 513,997 & 493,721 & 503,859 & \\
\hline & & 12,900 & 16,113 & 439,542 & 451,426 & 445,484 & \\
\hline & \multirow{3}{*}{$\begin{array}{l}\text { Tangente } \\
\text { Inicial }\end{array}$} & 1,05 & 1,31 & 79,456 & 121,800 & 100,628 & \multirow[b]{3}{*}{38,5} \\
\hline & & 13,95 & 17,42 & 504,231 & 533,277 & 518,754 & \\
\hline & & 12,900 & 16,113 & 424,775 & 411,477 & 418,126 & \\
\hline \multirow{6}{*}{3} & \multirow[t]{3}{*}{ Secante } & 1,00 & 1,25 & 50,745 & 64,355 & 57,550 & \multirow[b]{3}{*}{34,5} \\
\hline & & 14,00 & 17,49 & 550,343 & 507,419 & 528,881 & \\
\hline & & 13,000 & 16,238 & 499,598 & 443,064 & 471,331 & \\
\hline & \multirow{3}{*}{$\begin{array}{l}\text { Tangente } \\
\text { Inicial }\end{array}$} & 1,05 & 1,31 & 73,670 & 86,314 & 79,992 & \multirow[b]{3}{*}{34,7} \\
\hline & & 14,00 & 17,49 & 580,499 & 510,881 & 545,690 & \\
\hline & & 12,950 & 16,175 & 506,829 & 424,567 & 465,698 & \\
\hline \multirow{6}{*}{4} & \multirow[t]{3}{*}{ Secante } & 1,05 & 1,31 & 37,933 & 97,348 & 67,641 & \multirow[b]{3}{*}{34,3} \\
\hline & & 13,95 & 17,42 & 496,839 & 577,674 & 537,257 & \\
\hline & & 12,900 & 16,113 & 458,906 & 480,326 & 469,616 & \\
\hline & \multirow{3}{*}{$\begin{array}{l}\text { Tangente } \\
\text { Inicial }\end{array}$} & 1,05 & 1,31 & 49,225 & 141,986 & 95,606 & \multirow[b]{3}{*}{36,4} \\
\hline & & 13,95 & 17,42 & 457,329 & 619,228 & 538,279 & \\
\hline & & 12,900 & 16,113 & 408,104 & 477,242 & 442,673 & \\
\hline \multirow{6}{*}{5} & \multirow[t]{3}{*}{ Secante } & 1,05 & 1,31 & $\begin{array}{l}33,987 \\
\end{array}$ & 50,209 & 62,098 & \multirow[b]{3}{*}{35,5} \\
\hline & & 13,95 & 17,42 & 557,254 & 474,665 & 515,960 & \\
\hline & & 12,900 & 16,113 & 483,267 & 424,456 & 453,862 & \\
\hline & \multirow{3}{*}{$\begin{array}{l}\text { Tangente } \\
\text { Inicial }\end{array}$} & 1,05 & 1,31 & 94,409 & 73,019 & 83,714 & \multirow[b]{3}{*}{35,7} \\
\hline & & 13,95 & 17,42 & 566,233 & 504,226 & 535,230 & \\
\hline & & 12,900 & 16,113 & 471,824 & 431,207 & 451,516 & \\
\hline \multirow{6}{*}{6} & \multirow[t]{3}{*}{ Secante } & 1,05 & 1,31 & 78,777 & 47,765 & 63,271 & \\
\hline & & 13,95 & 17,42 & 533,742 & 490,894 & 512,318 & \\
\hline & & 12,900 & 16,113 & 454,965 & 443,129 & 449,047 & 35,9 \\
\hline & Tangente & 1,05 & 1,31 & 99,738 & 61,660 & 80,699 & \\
\hline & Inicial & 13,95 & 17,42 & 541,316 & 501,870 & 521,593 & \\
\hline & & 12,900 & 16,113 & 441,578 & 440,210 & 440,894 & 36,5 \\
\hline
\end{tabular}




\begin{tabular}{|c|c|c|c|c|c|c|c|}
\hline \multirow{6}{*}{7} & \multirow[t]{3}{*}{ Secante } & 1,05 & 1,31 & 14,657 & 71,693 & 43,175 & \multirow[b]{3}{*}{37,6} \\
\hline & & 13,95 & 17,42 & 502,853 & 440,529 & 471,691 & \\
\hline & & 12,900 & 16,113 & 488,196 & 368,836 & 428,516 & \\
\hline & \multirow{3}{*}{$\begin{array}{l}\text { Tangente } \\
\text { Inicial }\end{array}$} & 1,05 & 1,31 & 41,593 & 103,991 & 72,792 & \multirow[b]{3}{*}{39,9} \\
\hline & & 13,95 & 17,42 & 466,650 & 487,544 & 477,097 & \\
\hline & & 12,900 & 16,113 & 425,057 & 383,553 & 404,305 & \\
\hline \multirow{6}{*}{8} & \multirow[t]{3}{*}{ Secante } & 1,05 & 1,31 & 45,234 & 58,296 & 51,765 & \multirow[b]{3}{*}{33,2} \\
\hline & & 14,00 & 17,49 & 534,911 & 544,381 & 539,646 & \\
\hline & & 12,950 & 16,175 & 489,677 & 486,085 & 487,881 & \\
\hline & \multirow{3}{*}{$\begin{array}{l}\text { Tangente } \\
\text { Inicial }\end{array}$} & 1,05 & 1,31 & 59,518 & 91,268 & 75,393 & \multirow[b]{3}{*}{34,0} \\
\hline & & 14,00 & 17,49 & 542,409 & 559,469 & 550,939 & \\
\hline & & 12,950 & 16,175 & 482,891 & 468,201 & 475,546 & \\
\hline \multirow{6}{*}{9} & \multirow[t]{3}{*}{ Secante } & 1,05 & 1,31 & 41,235 & 18,679 & 29,957 & \multirow[b]{3}{*}{36,2} \\
\hline & & 13,95 & 17,42 & 547,024 & 402,622 & 474,823 & \\
\hline & & 12,900 & 16,113 & 505,789 & 383,943 & 444,866 & \\
\hline & \multirow{3}{*}{$\begin{array}{l}\text { Tangente } \\
\text { Inicial }\end{array}$} & 1,05 & 1,31 & 90,158 & 38,896 & 64,527 & \multirow[b]{3}{*}{36,6} \\
\hline & & 13,95 & 17,42 & 577,641 & 431,459 & 504,550 & \\
\hline & & 12,900 & 16,113 & 487,483 & 392,563 & 440,023 & \\
\hline \multirow{6}{*}{10} & \multirow[t]{3}{*}{ Secante } & 1,05 & 1,31 & 65,146 & 58,204 & 61,675 & \multirow[b]{3}{*}{34,3} \\
\hline & & 13,95 & 17,42 & 431,336 & 630,558 & 530,947 & \\
\hline & & 12,900 & 16,113 & 366,190 & 572,354 & 469,272 & \\
\hline & \multirow{3}{*}{$\begin{array}{l}\text { Tangente } \\
\text { Inicial }\end{array}$} & 1,05 & 1,31 & 104,463 & 63,963 & 84,213 & \multirow[b]{3}{*}{35,2} \\
\hline & & 13,95 & 17,42 & 439,799 & 644,723 & 542,261 & \\
\hline & & 12,900 & 16,113 & 335,336 & 580,760 & 458,048 & \\
\hline
\end{tabular}

strain gages

a/c 0,40 Betonada 2

\begin{tabular}{|c|c|c|c|c|c|c|c|}
\hline CP & Plano & $\begin{array}{l}\begin{array}{c}\text { Força } \\
\text { (tf) }\end{array} \\
\end{array}$ & $\begin{array}{c}\begin{array}{c}\text { Tensão } \\
\text { (MPa) }\end{array} \\
\end{array}$ & $\begin{array}{c}\begin{array}{c}\text { e1 } \\
\text { (um) }\end{array} \\
\end{array}$ & $\begin{array}{c}\text { e2 } \\
\text { (um) }\end{array}$ & $\begin{array}{l}\text { em } \\
\text { (um) }\end{array}$ & $\begin{array}{c}\mathrm{Ec} \\
(\mathrm{GPa})\end{array}$ \\
\hline \multirow{6}{*}{1} & \multirow[t]{3}{*}{ Secante } & 1,05 & 1,31 & 35,483 & 44,012 & 39,748 & \multirow[b]{3}{*}{40,1} \\
\hline & & 14,25 & 17,80 & 394,719 & 507,115 & 450,917 & \\
\hline & & & 16,487 & 359,236 & 463,103 & 411,170 & \\
\hline & \multirow{3}{*}{$\begin{array}{l}\text { Tangente } \\
\text { Inicial }\end{array}$} & 1,05 & 1,31 & 167,907 & 284,357 & 226,132 & \multirow[b]{3}{*}{35,3} \\
\hline & & 14,25 & 17,80 & 554,086 & 832,560 & 693,323 & \\
\hline & & & 16,487 & 386,179 & 548,203 & 467,191 & \\
\hline \multirow{6}{*}{2} & \multirow[t]{3}{*}{ Secante } & 1,00 & 1,25 & 59,112 & 53,198 & 56,155 & \multirow[b]{3}{*}{34,1} \\
\hline & & 14,30 & 17,86 & 578,976 & 508,556 & 543,766 & \\
\hline & & & 16,612 & 519,864 & 455,358 & 487,611 & \\
\hline & \multirow{3}{*}{$\begin{array}{l}\text { Tangente } \\
\text { Inicial }\end{array}$} & 1,00 & 1,25 & 86,908 & 82,604 & 84,756 & \multirow[b]{3}{*}{35,3} \\
\hline & & 14,30 & 17,86 & 585,486 & 525,628 & 555,557 & \\
\hline & & & 16,612 & 498,578 & 443,024 & 470,801 & \\
\hline \multirow{6}{*}{3} & \multirow[t]{3}{*}{ Secante } & 1,05 & 1,31 & 14,361 & 80,131 & 47,246 & \multirow[b]{3}{*}{36,1} \\
\hline & & 14,30 & 17,86 & 447,575 & 565,055 & 506,315 & \\
\hline & & & 16,550 & 433,214 & 484,924 & 459,069 & \\
\hline & \multirow{3}{*}{$\begin{array}{l}\text { Tangente } \\
\text { Inicial }\end{array}$} & 1,05 & 1,31 & 45,104 & 110,539 & 77,822 & \multirow[b]{3}{*}{36,2} \\
\hline & & 14,30 & 17,86 & 488,156 & 581,120 & 534,638 & \\
\hline & & & 16,550 & 443,052 & 470,581 & 456,817 & \\
\hline \multirow{6}{*}{4} & \multirow[t]{3}{*}{ Secante } & 1,05 & 1,31 & 35,503 & 46,805 & 41,154 & \multirow[b]{3}{*}{37,6} \\
\hline & & 14,30 & 17,86 & 546,741 & 415,821 & 481,281 & \\
\hline & & & 16,550 & 511,238 & 369,016 & 440,127 & \\
\hline & \multirow{3}{*}{$\begin{array}{l}\text { Tangente } \\
\text { Inicial }\end{array}$} & 1,05 & 1,31 & 78,150 & 71,534 & 74,842 & \multirow[b]{3}{*}{39,7} \\
\hline & & 14,30 & 17,86 & 563,159 & 421,038 & 492,099 & \\
\hline & & & 16,550 & 485,009 & 349,504 & 417,257 & \\
\hline \multirow{6}{*}{5} & \multirow[t]{3}{*}{ Secante } & 1,05 & 1,31 & 80,221 & 3,744 & 41,983 & \multirow[b]{3}{*}{40,3} \\
\hline & & 14,30 & 17,86 & 577,414 & 327,123 & 452,269 & \\
\hline & & & 16,550 & 497,193 & 323,379 & 410,286 & \\
\hline & \multirow{3}{*}{$\begin{array}{l}\text { Tangente } \\
\text { Inicial }\end{array}$} & 1,05 & 1,31 & 104,742 & 25,062 & 64,902 & \\
\hline & & 14,30 & 17,86 & 582,512 & 359,893 & 471,203 & \\
\hline & & & 16,550 & 477,770 & 334,831 & 406,301 & 40,7 \\
\hline & Secante & 1,05 & 1,31 & 74,079 & 65,204 & 69,642 & \\
\hline & & 14,30 & 17,86 & 477,277 & 667,424 & 572,351 & \\
\hline 6 & & & 16,550 & 403,198 & 602,220 & 502,709 & 32,9 \\
\hline b & Tangente & 1,05 & 1,31 & 80,423 & 126,639 & 103,531 & \\
\hline & Inicial & 14,30 & 17,86 & 483,797 & 663,576 & 573,687 & \\
\hline & & & 16,550 & 403,374 & 536,937 & 470,156 & 35,2 \\
\hline & Secante & 1,05 & 1,31 & 40,392 & 59,792 & 50,092 & \\
\hline & & 14,30 & 17,86 & 481,391 & 530,825 & 506,108 & \\
\hline 7 & & & 16,550 & 440,999 & 471,033 & 456,016 & 36,3 \\
\hline 7 & Tangente & 1,00 & 1,25 & 62,336 & 86,387 & 74,362 & \\
\hline & Inicial & 14,30 & 17,86 & 487,054 & 565,124 & 526,089 & \\
\hline & & & 16,612 & 424,718 & 478,737 & 451,728 & 36,8 \\
\hline
\end{tabular}




\begin{tabular}{|c|c|c|c|c|c|c|c|}
\hline \multirow{6}{*}{8} & \multirow[t]{3}{*}{ Secante } & 1,00 & 1,25 & 106,448 & 21,384 & 63,916 & \multirow[b]{3}{*}{32,1} \\
\hline & & 14,30 & 17,86 & 695,029 & 467,032 & 581,031 & \\
\hline & & & 16,612 & 588,581 & 445,648 & 517,115 & \\
\hline & \multirow{3}{*}{$\begin{array}{l}\text { Tangente } \\
\text { Inicial }\end{array}$} & 1,00 & 1,25 & 127,632 & 46,665 & 87,149 & \multirow[b]{3}{*}{32,5} \\
\hline & & 14,30 & 17,86 & 681,756 & 513,720 & 597,738 & \\
\hline & & & 16,612 & 554,124 & 467,055 & 510,590 & \\
\hline \multirow{6}{*}{9} & \multirow[t]{3}{*}{ Secante } & 1,05 & 1,31 & 89,532 & 16,928 & 53,230 & \multirow[b]{3}{*}{35,8} \\
\hline & & 14,30 & 17,86 & 548,206 & 483,438 & 515,822 & \\
\hline & & & 16,550 & 458,674 & 466,510 & 462,592 & \\
\hline & \multirow{3}{*}{$\begin{array}{l}\text { Tangente } \\
\text { Inicial }\end{array}$} & 1,05 & 1,31 & 112,091 & 48,969 & 80,530 & \multirow[b]{3}{*}{37,5} \\
\hline & & 14,30 & 17,86 & 538,160 & 505,334 & 521,747 & \\
\hline & & & 16,550 & 426,069 & 456,365 & 441,217 & \\
\hline \multirow{6}{*}{10} & \multirow[t]{3}{*}{ Secante } & 1,05 & 1,31 & 9,541 & 79,585 & 44,563 & \multirow[b]{3}{*}{36,5} \\
\hline & & 14,30 & 17,86 & 358,852 & 637,050 & 497,951 & \\
\hline & & & 16,550 & 349,311 & 557,465 & 453,388 & \\
\hline & \multirow{3}{*}{$\begin{array}{l}\text { Tangente } \\
\text { Inicial }\end{array}$} & 1,05 & 1,31 & 39,069 & 105,971 & 72,520 & \multirow[b]{3}{*}{38,3} \\
\hline & & 14,30 & 17,86 & 390,407 & 619,479 & 504,943 & \\
\hline & & & 16,550 & 351,338 & 513,508 & 432,423 & \\
\hline
\end{tabular}

strain gages

\begin{tabular}{|c|c|c|c|c|c|c|c|}
\hline CP & Plano & $\begin{array}{c}\text { Força } \\
\text { (tf) }\end{array}$ & $\begin{array}{c}\text { Tensão } \\
\text { (MPa) }\end{array}$ & $\begin{array}{c}\mathrm{e} 1 \\
\text { (um) }\end{array}$ & $\begin{array}{c}\mathrm{e} 2 \\
\text { (um) }\end{array}$ & $\begin{array}{c}\text { em } \\
\text { (um) }\end{array}$ & $\begin{array}{c}\text { Ec } \\
(\mathrm{GPa})\end{array}$ \\
\hline \multirow{6}{*}{1} & \multirow[t]{3}{*}{ Secante } & 1,05 & 1,31 & 91,051 & 26,149 & 58,600 & \multirow[b]{3}{*}{35,8} \\
\hline & & 15,05 & 18,80 & 504,843 & 588,801 & 546,822 & \\
\hline & & & 17,487 & 413,792 & 562,652 & 488,222 & \\
\hline & \multirow{3}{*}{$\begin{array}{l}\text { Tangente } \\
\text { Inicial }\end{array}$} & 1,05 & 1,31 & 110,370 & 50,667 & 80,519 & \multirow[b]{3}{*}{36,5} \\
\hline & & 15,05 & 18,80 & 490,243 & 629,195 & 559,719 & \\
\hline & & & 17,487 & 379,873 & 578,528 & 479,201 & \\
\hline \multirow{6}{*}{2} & \multirow[t]{3}{*}{ Secante } & 1,05 & 1,31 & 47,975 & 6,699 & 27,337 & \multirow[b]{3}{*}{36,1} \\
\hline & & 15,05 & 18,80 & 583,763 & 440,889 & 512,326 & \\
\hline & & & 17,487 & 535,788 & 434,190 & 484,989 & \\
\hline & \multirow{3}{*}{$\begin{array}{l}\text { Tangente } \\
\text { Inicial }\end{array}$} & 1,05 & 1,31 & 82,631 & 27,583 & 55,107 & \multirow[b]{3}{*}{37,5} \\
\hline & & 15,05 & 18,80 & 582,515 & 459,773 & 521,144 & \\
\hline & & & 17,487 & 499,884 & 432,190 & 466,037 & \\
\hline \multirow{6}{*}{3} & \multirow[t]{3}{*}{ Secante } & 1,05 & 1,31 & 67,702 & 73,010 & 70,356 & \multirow[b]{3}{*}{35,7} \\
\hline & & 15,05 & 18,80 & 426,525 & 693,511 & 560,018 & \\
\hline & & & 17,487 & 358,823 & 620,501 & 489,662 & \\
\hline & \multirow{3}{*}{$\begin{array}{l}\text { Tangente } \\
\text { Inicial }\end{array}$} & 1,05 & 1,31 & 92,887 & 102,761 & 97,824 & \multirow[b]{3}{*}{37,0} \\
\hline & & 15,05 & 18,80 & 434,535 & 706,581 & 570,558 & \\
\hline & & & 17,487 & 341,648 & 603,820 & 472,734 & \\
\hline \multirow{6}{*}{4} & \multirow[t]{3}{*}{ Secante } & 1,00 & 1,25 & 46,533 & 96,669 & 71,601 & \multirow[b]{3}{*}{31,0} \\
\hline & & 15,05 & 18,80 & 560,704 & 714,884 & 637,794 & \\
\hline & & & 17,549 & 514,171 & 618,215 & 566,193 & \\
\hline & \multirow{3}{*}{$\begin{array}{l}\text { Tangente } \\
\text { Inicial }\end{array}$} & 1,05 & 1,31 & 69,221 & 137,353 & 103,287 & \multirow[b]{3}{*}{32,1} \\
\hline & & 15,05 & 18,80 & 568,178 & 728,042 & 648,110 & \\
\hline & & & 17,487 & 498,957 & 590,689 & 544,823 & \\
\hline \multirow{6}{*}{5} & Secante & 1,05 & 1,31 & 80,384 & 32,110 & 56,247 & \\
\hline & & 15,05 & 18,80 & 671,893 & 415,156 & 543,525 & \\
\hline & & & 17,487 & 591,509 & 383,046 & 487,278 & 35,9 \\
\hline & Tangente & 1,05 & 1,31 & 97,827 & 62,463 & 80,145 & \\
\hline & Inicial & 15,05 & 18,80 & 667,565 & 440,631 & 554,098 & \\
\hline & & & 17,487 & 569,738 & 378,168 & 473,953 & 36,9 \\
\hline & Secante & 1,05 & 1,31 & 70,735 & 47,961 & 59,348 & \\
\hline & & 15,05 & 18,80 & 442,721 & 654,193 & 548,457 & \\
\hline 6 & & & 17,487 & 371,986 & 606,232 & 489,109 & 35,8 \\
\hline 0 & Tangente & 1,05 & 1,31 & 87,227 & 84,917 & 86,072 & \\
\hline & Inicial & 15,05 & 18,80 & 441,662 & 676,612 & 559,137 & \\
\hline & & & 17,487 & 354,435 & 591,695 & 473,065 & 37,0 \\
\hline & Secante & 1,05 & 1,31 & 70,475 & 48,287 & 59,381 & \\
\hline & & 15,05 & 18,80 & 659,364 & 455,172 & 557,268 & \\
\hline 7 & & & 17,487 & 588,889 & 406,885 & 497,887 & 35,1 \\
\hline 7 & Tangente & 1,05 & 1,31 & 92,899 & 74,261 & 83,580 & \\
\hline & Inicial & 15,05 & 18,80 & 661,503 & 475,138 & 568,321 & \\
\hline & & & 17,487 & 568,604 & 400,877 & 484,741 & 36,1 \\
\hline & Secante & 1,05 & 1,31 & 60,589 & 38,943 & 49,766 & \\
\hline & & 15,05 & 18,80 & 445,761 & 662,439 & 554,100 & \\
\hline 8 & & & 17,487 & 385,172 & 623,496 & 504,334 & 34,7 \\
\hline 0 & Tangente & 1,05 & 1,31 & 92,464 & 70,134 & 81,299 & \\
\hline & Inicial & 15,05 & 18,80 & 462,514 & 669,544 & 566,029 & \\
\hline & & & 17,487 & 370,050 & 599,410 & 484,730 & 36,1 \\
\hline
\end{tabular}




\begin{tabular}{|c|c|c|c|c|c|c|c|}
\hline \multirow{6}{*}{9} & \multirow[t]{3}{*}{ Secante } & 1,05 & 1,31 & 16,468 & 29,470 & 22,969 & \multirow[b]{3}{*}{33,8} \\
\hline & & 15,05 & 18,80 & 531,972 & 547,785 & 539,879 & \\
\hline & & & 17,487 & 515,504 & 518,315 & 516,910 & \\
\hline & \multirow{3}{*}{$\begin{array}{l}\text { Tangente } \\
\text { Inicial }\end{array}$} & 1,05 & 1,31 & 48,602 & 42,189 & 45,396 & \\
\hline & & 15,05 & 18,80 & 534,013 & 557,146 & 545,580 & \multirow[b]{2}{*}{35,0} \\
\hline & & & 17,487 & 485,411 & 514,957 & 500,184 & \\
\hline \multirow{6}{*}{10} & \multirow[t]{3}{*}{ Secante } & 1,05 & 1,31 & 78,917 & 40,119 & 59,518 & \multirow{4}{*}{35,7} \\
\hline & & 15,05 & 18,80 & 643,353 & 453,980 & 548,667 & \\
\hline & & & 17,487 & 564,436 & 413,861 & 489,149 & \\
\hline & \multirow{3}{*}{$\begin{array}{l}\text { Tangente } \\
\text { Inicial }\end{array}$} & 1,00 & 1,25 & 102,657 & 70,173 & 86,415 & \\
\hline & & 15,05 & 18,80 & 678,478 & 455,188 & 566,833 & \multirow[b]{2}{*}{36,5} \\
\hline & & & 17,549 & 575,821 & 385,015 & 480,418 & \\
\hline
\end{tabular}

clip gages

\begin{tabular}{|c|c|c|c|c|c|c|c|}
\hline CP & Plano & $\begin{array}{l}\text { Força } \\
\text { (tf) }\end{array}$ & $\begin{array}{c}\text { Tensão } \\
\text { (MPa) }\end{array}$ & $\begin{array}{c}\text { e1 } \\
\text { (um) }\end{array}$ & $\begin{array}{l}\text { e2 } \\
\text { (um) }\end{array}$ & $\begin{array}{l}\text { em } \\
\text { (um) }\end{array}$ & $\begin{array}{c}\mathrm{Ec} \\
(\mathrm{GPa})\end{array}$ \\
\hline \multirow{6}{*}{1} & \multirow[t]{3}{*}{ Secante } & 1,05 & 1,31 & 45,000 & 65,000 & 55,000 & \\
\hline & & 13,95 & 17,42 & 580,000 & 500,000 & 540,000 & \\
\hline & & & 16,113 & 535,000 & 435,000 & 485,000 & 33,2 \\
\hline & \multirow{3}{*}{$\begin{array}{l}\text { Tangente } \\
\text { Inicial }\end{array}$} & 1,05 & 1,31 & 50,000 & 105,000 & 77,500 & \\
\hline & & 13,95 & 17,42 & 570,000 & 525,000 & 547,500 & \\
\hline & & & 16,113 & 520,000 & 420,000 & 470,000 & 34,3 \\
\hline \multirow{6}{*}{2} & \multirow[t]{3}{*}{ Secante } & 1,05 & 1,31 & 120,000 & 50,000 & 85,000 & \\
\hline & & 13,95 & 17,42 & 670,000 & 490,000 & 580,000 & \\
\hline & & & 16,113 & 550,000 & 440,000 & 495,000 & 32,6 \\
\hline & \multirow{3}{*}{$\begin{array}{l}\text { Tangente } \\
\text { Inicial }\end{array}$} & 1,05 & 1,31 & 185,000 & $\begin{array}{l}75,000 \\
\end{array}$ & 130,000 & \\
\hline & & 13,95 & 17,42 & 705,000 & 510,000 & 607,500 & \\
\hline & & & 16,113 & 520,000 & 435,000 & 477,500 & 33,7 \\
\hline \multirow{6}{*}{3} & \multirow[t]{3}{*}{ Secante } & 1,05 & 1,31 & 30,000 & 20,000 & 25,000 & \\
\hline & & 13,95 & 17,42 & 410,000 & 580,000 & 495,000 & \\
\hline & & & 16,113 & 380,000 & 560,000 & 470,000 & 34,3 \\
\hline & \multirow{3}{*}{$\begin{array}{l}\text { Tangente } \\
\text { Inicial }\end{array}$} & 1,05 & 1,31 & 5,000 & 35,000 & 20,000 & \\
\hline & & 13,95 & 17,42 & 380,000 & 580,000 & 480,000 & \\
\hline & & & 16,113 & 375,000 & 545,000 & 460,000 & 35,0 \\
\hline \multirow{6}{*}{4} & \multirow[t]{3}{*}{ Secante } & 0,90 & 1,12 & 30,000 & 15,000 & 22,500 & \\
\hline & & 13,95 & 17,42 & 405,000 & 580,000 & 492,500 & \\
\hline & & & 16,300 & 375,000 & 565,000 & 470,000 & 34,7 \\
\hline & \multirow{3}{*}{$\begin{array}{l}\text { Tangente } \\
\text { Inicial }\end{array}$} & 1,05 & 1,31 & 15,000 & 55,000 & 35,000 & \\
\hline & & 13,95 & 17,42 & 395,000 & 585,000 & 490,000 & \\
\hline & & & 16,113 & 380,000 & 530,000 & 455,000 & 35,4 \\
\hline \multirow{6}{*}{5} & \multirow[t]{3}{*}{ Secante } & 1,05 & 1,31 & 25,000 & 45,000 & 35,000 & \\
\hline & & 13,95 & 17,42 & 535,000 & 505,000 & 520,000 & \\
\hline & & & 16,113 & 510,000 & 460,000 & 485,000 & 33,2 \\
\hline & \multirow{3}{*}{$\begin{array}{l}\text { Tangente } \\
\text { Inicial }\end{array}$} & 1,05 & 1,31 & 55,000 & 50,000 & 52,500 & \\
\hline & & 13,95 & 17,42 & 565,000 & 480,000 & 522,500 & \\
\hline & & & 16,113 & 510,000 & 430,000 & 470,000 & 34,3 \\
\hline \multirow{6}{*}{6} & \multirow[t]{3}{*}{ Secante } & 1,05 & 1,31 & 60,000 & 20,000 & 40,000 & \\
\hline & & 13,95 & 17,42 & 515,000 & 530,000 & 522,500 & \\
\hline & & & 16,113 & 455,000 & 510,000 & 482,500 & 33,4 \\
\hline & \multirow{3}{*}{$\begin{array}{l}\text { Tangente } \\
\text { Inicial }\end{array}$} & 1,05 & 1,31 & 80,000 & 20,000 & 50,000 & \\
\hline & & 13,95 & 17,42 & 515,000 & 525,000 & 520,000 & \\
\hline & & & 16,113 & 435,000 & 505,000 & 470,000 & 34,3 \\
\hline & Secante & 0,95 & 1,19 & 85,000 & $-35,000$ & 25,000 & \\
\hline & & 13,95 & 17,42 & 690,000 & 285,000 & 487,500 & \\
\hline 7 & & & 16,238 & 605,000 & 320,000 & 462,500 & 35,1 \\
\hline$r$ & Tangente & 1,05 & 1,31 & 145,000 & $-80,000$ & 32,500 & \\
\hline & Inicial & 13,95 & 17,42 & 715,000 & 240,000 & 477,500 & \\
\hline & & & 16,113 & 570,000 & 320,000 & 445,000 & 36,2 \\
\hline & Secante & 1,05 & 1,31 & 40,000 & 45,000 & 42,500 & \\
\hline & & 13,95 & 17,42 & 600,000 & 420,000 & 510,000 & \\
\hline 8 & & & 16,113 & 560,000 & 375,000 & 467,500 & 34,5 \\
\hline 0 & Tangente & 1,05 & 1,31 & 50,000 & 60,000 & 55,000 & \\
\hline & Inicial & 13,95 & 17,42 & 590,000 & 430,000 & 510,000 & \\
\hline & & & 16,113 & 540,000 & 370,000 & 455,000 & 35,4 \\
\hline & Secante & 1,00 & 1,25 & 35,000 & 25,000 & 30,000 & \\
\hline & & 13,95 & 17,42 & 545,000 & 455,000 & 500,000 & \\
\hline & & & 16,175 & 510,000 & 430,000 & 470,000 & 34,4 \\
\hline$y$ & Tangente & 1,00 & 1,25 & 35,000 & 25,000 & 30,000 & \\
\hline & Inicial & 13,95 & 17,42 & 535,000 & 445,000 & 490,000 & \\
\hline & & & 16,175 & 500,000 & 420,000 & 460,000 & 35,2 \\
\hline
\end{tabular}




\begin{tabular}{|c|l|r|r|r|r|r|r|}
\hline \multirow{3}{*}{10} & Secante & 1,05 & 1,31 & 90,000 & 70,000 & 80,000 \\
\cline { 3 - 7 } & & 13,95 & 17,42 & 610,000 & 500,000 & 555,000 \\
\cline { 3 - 7 } & & & 16,113 & 520,000 & 430,000 & 475,000 & $\mathbf{3 3 , 9}$ \\
\cline { 2 - 7 } & \multirow{2}{*}{\begin{tabular}{l} 
Tangente \\
\cline { 2 - 7 }
\end{tabular}} & 1,05 & 1,31 & 165,000 & 105,000 & 135,000 & \\
\cline { 2 - 7 } & 13,95 & 17,42 & 680,000 & 510,000 & 595,000 \\
\cline { 2 - 7 } & & 16,113 & 515,000 & 405,000 & 460,000 & $\mathbf{3 5 , 0}$ \\
\hline
\end{tabular}

\section{clip gages}

a/c 0,40 Betonada 2

\begin{tabular}{|c|c|c|c|c|c|c|c|}
\hline CP & Plano & $\begin{array}{c}\text { Força } \\
\text { (tf) }\end{array}$ & $\begin{array}{l}\text { Tensão } \\
\text { (MPa) }\end{array}$ & $\begin{array}{l}\text { e1 } \\
\text { (um) }\end{array}$ & $\begin{array}{c}\text { e2 } \\
\text { (um) }\end{array}$ & $\begin{array}{l}\text { em } \\
\text { (um) }\end{array}$ & $\begin{array}{c}\mathrm{Ec} \\
(\mathrm{GPa})\end{array}$ \\
\hline \multirow{6}{*}{1} & \multirow[t]{3}{*}{ Secante } & 1,05 & 1,31 & 50,000 & 50,000 & 50,000 & \\
\hline & & 14,25 & 17,80 & 400,000 & 620,000 & 510,000 & \\
\hline & & & 16,487 & 350,000 & 570,000 & 460,000 & 35,8 \\
\hline & \multirow{3}{*}{$\begin{array}{l}\text { Tangente } \\
\text { Inicial }\end{array}$} & 1,05 & 1,31 & 75,000 & 80,000 & 77,500 & \\
\hline & & 14,25 & 17,80 & 415,000 & 615,000 & 515,000 & \\
\hline & & & 16,487 & 340,000 & 535,000 & 437,500 & 37,7 \\
\hline \multirow{6}{*}{2} & \multirow[t]{3}{*}{ Secante } & 1,00 & 1,25 & 5,000 & 50,000 & 27,500 & \\
\hline & & 14,25 & 17,80 & 470,000 & 485,000 & 477,500 & \\
\hline & & & 16,550 & 465,000 & 435,000 & 450,000 & 36,8 \\
\hline & \multirow{3}{*}{$\begin{array}{l}\text { Tangente } \\
\text { Inicial }\end{array}$} & 1,05 & 1,31 & 10,000 & 70,000 & 40,000 & \\
\hline & & 14,25 & 17,80 & 465,000 & 480,000 & 472,500 & \\
\hline & & & 16,487 & 455,000 & 410,000 & 432,500 & 38,1 \\
\hline \multirow{6}{*}{3} & \multirow[t]{3}{*}{ Secante } & 1,05 & 1,31 & 30,000 & 5,000 & 17,500 & \\
\hline & & 14,25 & 17,80 & 435,000 & 495,000 & 465,000 & \\
\hline & & & 16,487 & 405,000 & 490,000 & 447,500 & 36,8 \\
\hline & \multirow{3}{*}{$\begin{array}{l}\text { Tangente } \\
\text { Inicial }\end{array}$} & 1,05 & 1,31 & 15,000 & $-15,000$ & 0,000 & \\
\hline & & 14,25 & 17,80 & 425,000 & 475,000 & 450,000 & \\
\hline & & & 16,487 & 410,000 & 490,000 & 450,000 & 36,6 \\
\hline \multirow{6}{*}{4} & \multirow[t]{3}{*}{ Secante } & 1,00 & 1,25 & 35,000 & 25,000 & 30,000 & \\
\hline & & 14,25 & 17,80 & 465,000 & 515,000 & 490,000 & \\
\hline & & & 16,550 & 430,000 & 490,000 & 460,000 & 36,0 \\
\hline & \multirow{3}{*}{$\begin{array}{l}\text { Tangente } \\
\text { Inicial }\end{array}$} & 1,05 & 1,31 & 55,000 & 45,000 & 50,000 & \\
\hline & & 14,25 & 17,80 & 465,000 & 530,000 & 497,500 & \\
\hline & & & 16,487 & 410,000 & 485,000 & 447,500 & 36,8 \\
\hline \multirow{6}{*}{5} & \multirow[t]{3}{*}{ Secante } & 1,00 & 1,25 & 15,000 & 65,000 & 40,000 & \\
\hline & & 14,25 & 17,80 & 530,000 & 505,000 & 517,500 & \\
\hline & & & 16,550 & 515,000 & 440,000 & 477,500 & 34,7 \\
\hline & \multirow{3}{*}{$\begin{array}{l}\text { Tangente } \\
\text { Inicial }\end{array}$} & 1,05 & 1,31 & 15,000 & 75,000 & 45,000 & \\
\hline & & 14,25 & 17,80 & 520,000 & 470,000 & 495,000 & \\
\hline & & & 16,487 & 505,000 & 395,000 & 450,000 & 36,6 \\
\hline & Secante & 1,05 & 1,31 & 35,000 & 30,000 & 32,500 & \\
\hline & & 14,25 & 17,80 & 415,000 & 565,000 & 490,000 & \\
\hline & & & 16,487 & 380,000 & 535,000 & 457,500 & 36,0 \\
\hline 6 & Tangente & 0,95 & 1,19 & 40,000 & 40,000 & 40,000 & \\
\hline & Inicial & 14,25 & 17,80 & 405,000 & 570,000 & 487,500 & \\
\hline & & & 16,612 & 365,000 & 530,000 & 447,500 & 37,1 \\
\hline & Secante & 1,00 & 1,25 & 25,000 & 55,000 & 40,000 & \\
\hline & & 14,25 & 17,80 & 545,000 & 430,000 & 487,500 & \\
\hline 7 & & & 16,550 & 520,000 & 375,000 & 447,500 & 37,0 \\
\hline 7 & Tangente & 1,05 & 1,31 & 40,000 & 70,000 & 55,000 & \\
\hline & Inicial & 14,25 & 17,80 & 530,000 & 440,000 & 485,000 & \\
\hline & & & 16,487 & 490,000 & 370,000 & 430,000 & 38,3 \\
\hline & Secante & 1,05 & 1,31 & 45,000 & $-25,000$ & 10,000 & \\
\hline & & 14,25 & 17,80 & 440,000 & 475,000 & 457,500 & \\
\hline 8 & & & 16,487 & 395,000 & 500,000 & 447,500 & 36,8 \\
\hline 0 & Tangente & 1,05 & 1,31 & 55,000 & $-30,000$ & 12,500 & \\
\hline & Inicial & 14,30 & 17,86 & 435,000 & 465,000 & 450,000 & \\
\hline & & & 16,550 & 380,000 & 495,000 & 437,500 & 37,8 \\
\hline & Secante & 1,05 & 1,31 & 45,000 & 55,000 & 50,000 & \\
\hline & & 14,25 & 17,80 & 640,000 & 410,000 & 525,000 & \\
\hline 9 & & & 16,487 & 595,000 & 355,000 & 475,000 & 34,7 \\
\hline$y$ & Tangente & 1,05 & 1,31 & 65,000 & 65,000 & 65,000 & \\
\hline & Inicial & 14,30 & 17,86 & 630,000 & 425,000 & 527,500 & \\
\hline & & & 16,550 & 565,000 & 360,000 & 462,500 & 35,8 \\
\hline & Secante & 1,00 & 1,25 & 65,000 & 0,000 & 32,500 & \\
\hline & & 14,25 & 17,80 & 510,000 & 510,000 & 510,000 & \\
\hline 10 & & & 16,550 & 445,000 & 510,000 & 477,500 & 34,7 \\
\hline 10 & Tangente & 1,00 & 1,25 & 100,000 & $-45,000$ & 27,500 & \\
\hline & Inicial & 14,30 & 17,86 & 530,000 & 450,000 & 490,000 & \\
\hline & & & 16,612 & 430,000 & 495,000 & 462,500 & 35,9 \\
\hline
\end{tabular}


clip gages

\begin{tabular}{|c|c|c|c|c|c|c|c|}
\hline CP & Plano & $\begin{array}{c}\text { Força } \\
\text { (tf) }\end{array}$ & $\begin{array}{c}\text { Tensão } \\
\text { (MPa) }\end{array}$ & $\begin{array}{c}\text { e1 } \\
\text { (um) }\end{array}$ & $\begin{array}{c}\text { e2 } \\
\text { (um) }\end{array}$ & $\begin{array}{l}\text { em } \\
\text { (um) }\end{array}$ & $\begin{array}{c}\text { Ec } \\
(\mathrm{GPa})\end{array}$ \\
\hline \multirow{6}{*}{1} & \multirow[t]{3}{*}{ Secante } & 1,05 & 1,31 & 50,000 & 50,000 & 50,000 & \\
\hline & & 15,05 & 18,80 & 675,000 & 585,000 & 630,000 & \\
\hline & & & 17,487 & 625,000 & 535,000 & 580,000 & 30,1 \\
\hline & \multirow{3}{*}{$\begin{array}{l}\text { Tangente } \\
\text { Inicial }\end{array}$} & 1,05 & 1,31 & 45,000 & 80,000 & 62,500 & \\
\hline & & 15,05 & 18,80 & 655,000 & 610,000 & 632,500 & \\
\hline & & & 17,487 & 610,000 & 530,000 & 570,000 & 30,7 \\
\hline \multirow{6}{*}{2} & \multirow[t]{3}{*}{ Secante } & 1,05 & $\begin{array}{l}1,31 \\
\end{array}$ & 35,000 & 20,000 & 27,500 & \\
\hline & & 15,05 & 18,80 & 590,000 & 430,000 & 510,000 & \\
\hline & & & 17,487 & 555,000 & 410,000 & 482,500 & 36,2 \\
\hline & \multirow{3}{*}{$\begin{array}{l}\text { Tangente } \\
\text { Inicial }\end{array}$} & 1,05 & 1,31 & 45,000 & 30,000 & 37,500 & \\
\hline & & 15,05 & 18,80 & 595,000 & 425,000 & 510,000 & \\
\hline & & & 17,487 & 550,000 & 395,000 & 472,500 & 37,0 \\
\hline \multirow{6}{*}{3} & \multirow[t]{3}{*}{ Secante } & 1,05 & 1,31 & 70,000 & 25,000 & 47,500 & \\
\hline & & 15,05 & 18,80 & 500,000 & 525,000 & 512,500 & \\
\hline & & & 17,487 & 430,000 & 500,000 & 465,000 & 37,6 \\
\hline & \multirow{3}{*}{$\begin{array}{l}\text { Tangente } \\
\text { Inicial }\end{array}$} & 1,05 & 1,31 & 75,000 & 45,000 & 60,000 & \\
\hline & & 15,05 & 18,80 & 485,000 & 540,000 & 512,500 & \\
\hline & & & 17,487 & 410,000 & 495,000 & 452,500 & 38,6 \\
\hline \multirow{6}{*}{4} & \multirow[t]{3}{*}{ Secante } & 1,05 & 1,31 & 15,000 & 15,000 & 15,000 & \\
\hline & & 15,05 & 18,80 & 615,000 & 400,000 & 507,500 & \\
\hline & & & 17,487 & 600,000 & 385,000 & 492,500 & 35,5 \\
\hline & \multirow{3}{*}{$\begin{array}{l}\text { Tangente } \\
\text { Inicial }\end{array}$} & 1,00 & 1,25 & 25,000 & 15,000 & 20,000 & \\
\hline & & 15,05 & 18,80 & 610,000 & 395,000 & 502,500 & \\
\hline & & & 17,549 & 585,000 & 380,000 & 482,500 & 36,4 \\
\hline \multirow{6}{*}{5} & \multirow[t]{3}{*}{ Secante } & 1,05 & $\begin{array}{l}1,31 \\
\end{array}$ & 70,000 & 50,000 & 60,000 & \\
\hline & & 15,10 & 18,86 & 490,000 & 625,000 & 557,500 & \\
\hline & & & 17,549 & 420,000 & 575,000 & 497,500 & 35,3 \\
\hline & \multirow{3}{*}{$\begin{array}{l}\text { Tangente } \\
\text { Inicial }\end{array}$} & 1,05 & $\begin{array}{r}1,31 \\
\end{array}$ & 85,000 & 75,000 & 80,000 & \\
\hline & & 15,05 & 18,80 & 485,000 & 635,000 & 560,000 & \\
\hline & & & 17,487 & 400,000 & 560,000 & 480,000 & 36,4 \\
\hline & Secante & 1,05 & 1,31 & 30,000 & 40,000 & 35,000 & \\
\hline & & 15,05 & 18,80 & 575,000 & 485,000 & 530,000 & \\
\hline 6 & & & 17,487 & 545,000 & 445,000 & 495,000 & 35,3 \\
\hline b & Tangente & 1,05 & 1,31 & 40,000 & 45,000 & 42,500 & \\
\hline & Inicial & 15,10 & 18,86 & 580,000 & 470,000 & 525,000 & \\
\hline & & & 17,549 & 540,000 & 425,000 & 482,500 & 36,4 \\
\hline & Secante & 1,05 & $\begin{array}{r}1,31 \\
\end{array}$ & 55,000 & 30,000 & 42,500 & \\
\hline & & 15,05 & 18,80 & 650,000 & 435,000 & 542,500 & \\
\hline 7 & & & 17,487 & 595,000 & 405,000 & 500,000 & 35,0 \\
\hline 7 & Tangente & 1,05 & 1,31 & 70,000 & 40,000 & 55,000 & \\
\hline & Inicial & 15,10 & 18,86 & 645,000 & 435,000 & 540,000 & \\
\hline & & & 17,549 & 575,000 & 395,000 & 485,000 & 36,2 \\
\hline & Secante & 1,00 & 1,25 & 65,000 & 30,000 & 47,500 & \\
\hline & & 15,10 & 18,86 & 465,000 & 590,000 & 527,500 & \\
\hline 8 & & & 17,612 & 400,000 & 560,000 & 480,000 & 36,7 \\
\hline 0 & Tangente & 1,05 & 1,31 & 80,000 & 50,000 & 65,000 & \\
\hline & Inicial & 15,10 & 18,86 & 470,000 & 595,000 & 532,500 & \\
\hline & & & 17,549 & 390,000 & 545,000 & 467,500 & 37,5 \\
\hline & Secante & 1,05 & $\begin{array}{l}1,31 \\
\end{array}$ & 35,000 & 20,000 & 27,500 & \\
\hline & & 15,10 & 18,86 & 435,000 & 580,000 & 507,500 & \\
\hline 9 & & & 17,549 & 400,000 & 560,000 & 480,000 & 36,6 \\
\hline$y$ & Tangente & 1,05 & 1,31 & 50,000 & 30,000 & 40,000 & \\
\hline & Inicial & 15,10 & 18,86 & 445,000 & 570,000 & 507,500 & \\
\hline & & & 17,549 & 395,000 & 540,000 & 467,500 & 37,5 \\
\hline & Secante & 1,05 & 1,31 & 20,000 & 95,000 & 57,500 & \\
\hline & & 15,10 & 18,86 & 555,000 & 565,000 & 560,000 & \\
\hline 10 & & & 17,549 & 535,000 & 470,000 & 502,500 & 34,9 \\
\hline 10 & Tangente & 1,05 & 1,31 & 10,000 & 145,000 & 77,500 & \\
\hline & Inicial & 15,10 & 18,86 & 535,000 & 600,000 & 567,500 & \\
\hline & & & 17,549 & 525,000 & 455,000 & 490,000 & 35,8 \\
\hline
\end{tabular}




\section{1 relógio}

\begin{tabular}{|c|c|c|c|c|c|c|c|}
\hline $\mathrm{CP}$ & $\begin{array}{r}\text { Plano } \\
\end{array}$ & $\begin{array}{c}\text { Força } \\
\text { (tf) }\end{array}$ & $\begin{array}{c}\text { Tensão } \\
\text { (MPa) }\end{array}$ & $\begin{array}{c}\mathrm{e1} \\
\text { (um) }\end{array}$ & $\begin{array}{c}\mathrm{e} 2 \\
\text { (um) }\end{array}$ & $\begin{array}{c}\text { em } \\
\text { (um) }\end{array}$ & $\begin{array}{c}\text { Ec } \\
(\mathrm{GPa})\end{array}$ \\
\hline \multirow{6}{*}{1} & \multirow[t]{3}{*}{ Secante } & 1,05 & 1,31 & 130,000 & & 130,000 & \multirow[b]{3}{*}{36,6} \\
\hline & & 13,95 & 17,42 & 1010,000 & & 1010,000 & \\
\hline & & & 16,113 & 880,000 & 0,000 & 440,000 & \\
\hline & \multirow{3}{*}{$\begin{array}{l}\text { Tangente } \\
\text { Inicial }\end{array}$} & 1,05 & 1,31 & 180,000 & & 180,000 & \multirow[b]{3}{*}{39,5} \\
\hline & & 14,00 & 17,49 & 1000,000 & & 1000,000 & \\
\hline & & & 16,175 & 820,000 & 0,000 & 410,000 & \\
\hline \multirow{6}{*}{2} & \multirow[t]{3}{*}{ Secante } & 1,05 & 1,31 & 70,000 & & 70,000 & \multirow[b]{3}{*}{37,2} \\
\hline & & 14,00 & 17,49 & 940,000 & & 940,000 & \\
\hline & & & 16,175 & 870,000 & 0,000 & 435,000 & \\
\hline & \multirow{3}{*}{$\begin{array}{l}\text { Tangente } \\
\text { Inicial }\end{array}$} & 1,00 & 1,25 & 100,000 & & 100,000 & \multirow[b]{3}{*}{38,2} \\
\hline & & 14,00 & 17,49 & 950,000 & & 950,000 & \\
\hline & & & 16,238 & 850,000 & 0,000 & 425,000 & \\
\hline \multirow{6}{*}{3} & \multirow[t]{3}{*}{ Secante } & 1,05 & 1,31 & 160,000 & & 160,000 & \multirow[b]{3}{*}{35,9} \\
\hline & & 14,00 & 17,49 & 1060,000 & & 1060,000 & \\
\hline & & & 16,175 & 900,000 & 0,000 & 450,000 & \\
\hline & \multirow{3}{*}{$\begin{array}{l}\text { Tangente } \\
\text { Inicial }\end{array}$} & 1,05 & 1,31 & 220,000 & & 220,000 & \multirow[b]{3}{*}{37,2} \\
\hline & & 14,00 & 17,49 & 1090,000 & & 1090,000 & \\
\hline & & & 16,175 & 870,000 & 0,000 & 435,000 & \\
\hline & Secante & 1,05 & 1,31 & 160,000 & & 160,000 & \\
\hline & & 14,00 & 17,49 & 1120,000 & & 1120,000 & \\
\hline 4 & & & 16,175 & 960,000 & 0,000 & 480,000 & 33,7 \\
\hline 4 & Tangente & 1,05 & 1,31 & 220,000 & & 220,000 & \\
\hline & Inicial & 14,00 & 17,49 & 1130,000 & & 1130,000 & \\
\hline & & & 16,175 & 910,000 & 0,000 & 455,000 & 35,5 \\
\hline & Secante & 1,05 & 1,31 & 140,000 & & 140,000 & \\
\hline & & 14,00 & 17,49 & 1100,000 & & 1100,000 & \\
\hline 5 & & & 16,175 & 960,000 & 0,000 & 480,000 & 33,7 \\
\hline 5 & Tangente & 0,95 & 1,19 & 160,000 & & 160,000 & \\
\hline & Inicial & 13,95 & 17,42 & 1070,000 & & 1070,000 & \\
\hline & & & 16,238 & 910,000 & 0,000 & 455,000 & 35,7 \\
\hline & Secante & 1,05 & 1,31 & 200,000 & & 200,000 & \\
\hline & & 14,00 & 17,49 & 1190,000 & & 1190,000 & \\
\hline & & & 16,175 & 990,000 & 0,000 & 495,000 & 32,7 \\
\hline 6 & Tangente & 1,00 & 1,25 & 250,000 & & 250,000 & \\
\hline & Inicial & 14,00 & 17,49 & 1170,000 & & 1170,000 & \\
\hline & & & 16,238 & 920,000 & 0,000 & 460,000 & 35,3 \\
\hline & Secante & 1,05 & 1,31 & 150,000 & & 150,000 & \\
\hline & & 14,00 & 17,49 & 1080,000 & & 1080,000 & \\
\hline 7 & & & 16,175 & 930,000 & 0,000 & 465,000 & 34,8 \\
\hline 7 & Tangente & 1,05 & 1,31 & 170,000 & & 170,000 & \\
\hline & Inicial & 13,90 & 17,36 & 1070,000 & & 1070,000 & \\
\hline & & & 16,050 & 900,000 & 0,000 & 450,000 & 35,7 \\
\hline & Secante & 1,05 & 1,31 & 240,000 & & 240,000 & \\
\hline & & 14,00 & 17,49 & 1120,000 & & 1120,000 & \\
\hline 8 & & & 16,175 & 880,000 & 0,000 & 440,000 & 36,8 \\
\hline 8 & Tangente & 1,05 & 1,31 & 280,000 & & 280,000 & \\
\hline & Inicial & 14,00 & 17,49 & 1150,000 & & 1150,000 & \\
\hline & & & 16,175 & 870,000 & 0,000 & 435,000 & 37,2 \\
\hline & Secante & 1,05 & 1,31 & 120,000 & & 120,000 & \\
\hline & & 13,95 & 17,42 & 980,000 & & 980,000 & \\
\hline 0 & & & 16,113 & 860,000 & 0,000 & 430,000 & 37,5 \\
\hline 9 & Tangente & 1,05 & 1,31 & 160,000 & & 160,000 & \\
\hline & Inicial & 14,00 & 17,49 & 990,000 & & 990,000 & \\
\hline & & & 16,175 & 830,000 & 0,000 & 415,000 & 39,0 \\
\hline & Secante & 1,00 & 1,25 & 90,000 & & 90,000 & \\
\hline & & 14,00 & 17,49 & 1040,000 & & 1040,000 & \\
\hline 10 & & & 16,238 & 950,000 & 0,000 & 475,000 & 34,2 \\
\hline 10 & Tangente & 1,00 & 1,25 & 120,000 & & 120,000 & \\
\hline & Inicial & 13,95 & 17,42 & 1030,000 & & 1030,000 & \\
\hline & & & 16,175 & 910,000 & 0,000 & 455,000 & 35,5 \\
\hline
\end{tabular}




\begin{tabular}{|c|c|c|c|c|c|c|c|}
\hline $\mathrm{CP}$ & Plano & $\begin{array}{c}\begin{array}{c}\text { Força } \\
\text { (tf) }\end{array} \\
\end{array}$ & \begin{tabular}{c|}
$\begin{array}{c}\text { Tensão } \\
\text { (MPa) }\end{array}$ \\
\end{tabular} & $\begin{array}{c}\mathrm{e} 1 \\
\text { (um) }\end{array}$ & $\begin{array}{c}\text { e2 } \\
\text { (um) }\end{array}$ & $\begin{array}{l}\text { em } \\
\text { (um) }\end{array}$ & $\begin{array}{c}\mathrm{Ec} \\
(\mathrm{GPa})\end{array}$ \\
\hline \multirow{6}{*}{1} & \multirow[t]{3}{*}{ Secante } & 0,95 & 1,19 & 90,000 & & 90,000 & \multirow[b]{3}{*}{40,7} \\
\hline & & 14,30 & 17,86 & 910,000 & & 910,000 & \\
\hline & & & 16,675 & 820,000 & 0,000 & 410,000 & \\
\hline & \multirow{3}{*}{$\begin{array}{l}\text { Tangente } \\
\text { Inicial }\end{array}$} & 1,05 & 1,31 & 120,000 & & 120,000 & \multirow[b]{3}{*}{41,9} \\
\hline & & 14,30 & 17,86 & 910,000 & & 910,000 & \\
\hline & & & 16,550 & 790,000 & 0,000 & 395,000 & \\
\hline \multirow{6}{*}{2} & \multirow[t]{3}{*}{ Secante } & 1,05 & 1,31 & 120,000 & & 120,000 & \multirow[b]{3}{*}{36,8} \\
\hline & & 14,30 & 17,86 & 1020,000 & & 1020,000 & \\
\hline & & & 16,550 & 900,000 & 0,000 & 450,000 & \\
\hline & \multirow{3}{*}{$\begin{array}{l}\text { Tangente } \\
\text { Inicial }\end{array}$} & 1,05 & 1,31 & 160,000 & & 160,000 & \multirow[b]{3}{*}{38,5} \\
\hline & & 14,30 & 17,86 & 1020,000 & & 1020,000 & \\
\hline & & & 16,550 & 860,000 & 0,000 & 430,000 & \\
\hline \multirow{6}{*}{3} & \multirow[t]{3}{*}{ Secante } & 1,05 & 1,31 & 150,000 & & 150,000 & \multirow[b]{3}{*}{34,5} \\
\hline & & 14,30 & 17,86 & 1110,000 & & 1110,000 & \\
\hline & & & 16,550 & 960,000 & 0,000 & 480,000 & \\
\hline & \multirow{3}{*}{$\begin{array}{l}\text { Tangente } \\
\text { Inicial }\end{array}$} & 1,05 & 1,31 & 230,000 & & 230,000 & \multirow[b]{3}{*}{37,6} \\
\hline & & 14,30 & 17,86 & 1110,000 & & 1110,000 & \\
\hline & & & 16,550 & 880,000 & 0,000 & 440,000 & \\
\hline & Secante & 1,00 & 1,25 & 300,000 & & 300,000 & \\
\hline & & 14,30 & 17,86 & 1290,000 & & 1290,000 & \\
\hline 4 & & & 16,612 & 990,000 & 0,000 & 495,000 & 33,6 \\
\hline 4 & Tangente & 1,05 & 1,31 & 400,000 & & 400,000 & \\
\hline & Inicial & 14,30 & 17,86 & 1310,000 & & 1310,000 & \\
\hline & & & 16,550 & 910,000 & 0,000 & 455,000 & 36,4 \\
\hline & Secante & 1,10 & $\begin{array}{r}1,37 \\
\end{array}$ & 70,000 & & 70,000 & \\
\hline & & 14,30 & 17,86 & 930,000 & & 930,000 & \\
\hline 5 & & & 16,487 & 860,000 & 0,000 & 430,000 & 38,3 \\
\hline 5 & Tangente & 1,05 & 1,31 & 120,000 & & 120,000 & \\
\hline & Inicial & 14,30 & 17,86 & 960,000 & & 960,000 & \\
\hline & & & 16,550 & 840,000 & 0,000 & 420,000 & 39,4 \\
\hline & Secante & 1,05 & $\begin{array}{l}1,31 \\
\end{array}$ & 140,000 & & 140,000 & \\
\hline & & 14,30 & 17,86 & 1060,000 & & 1060,000 & \\
\hline 6 & & & 16,550 & 920,000 & 0,000 & 460,000 & 36,0 \\
\hline 0 & Tangente & 1,05 & 1,31 & $\begin{array}{l}160,000 \\
\end{array}$ & & 160,000 & \\
\hline & |Inicial & 14,30 & 17,86 & 1040,000 & & 1040,000 & \\
\hline & & & 16,550 & 880,000 & 0,000 & 440,000 & 37,6 \\
\hline & Secante & 1,05 & 1,31 & 30,000 & & 30,000 & \\
\hline & & 14,30 & 17,86 & 930,000 & & 930,000 & \\
\hline 7 & & & 16,550 & 900,000 & 0,000 & 450,000 & 36,8 \\
\hline 7 & Tangente & 1,05 & 1,31 & 70,000 & & 70,000 & \\
\hline & Inicial & 14,30 & 17,86 & 930,000 & & 930,000 & \\
\hline & & & 16,550 & 860,000 & 0,000 & 430,000 & 38,5 \\
\hline & Secante & 1,05 & 1,31 & 220,000 & & 220,000 & \\
\hline & & 14,30 & 17,86 & 1070,000 & & 1070,000 & \\
\hline 8 & & & 16,550 & 850,000 & 0,000 & 425,000 & 38,9 \\
\hline 8 & Tangente & 1,05 & 1,31 & 260,000 & & 260,000 & \\
\hline & Inicial & 14,30 & 17,86 & 1080,000 & & 1080,000 & \\
\hline & & & 16,550 & 820,000 & 0,000 & 410,000 & 40,4 \\
\hline & Secante & 1,05 & 1,31 & 190,000 & & 190,000 & \\
\hline & & 14,30 & 17,86 & 1130,000 & & 1130,000 & \\
\hline 9 & & & 16,550 & 940,000 & 0,000 & 470,000 & 35,2 \\
\hline$y$ & Tangente & 1,05 & 1,31 & 230,000 & & 230,000 & \\
\hline & Inicial & 14,30 & 17,86 & 1150,000 & & 1150,000 & \\
\hline & & & 16,550 & 920,000 & 0,000 & 460,000 & 36,0 \\
\hline & Secante & 1,05 & 1,31 & 110,000 & & 110,000 & \\
\hline & & 14,30 & 17,86 & 1060,000 & & 1060,000 & \\
\hline 10 & & & 16,550 & 950,000 & 0,000 & 475,000 & 34,8 \\
\hline 10 & Tangente & 1,05 & 1,31 & 130,000 & & 130,000 & \\
\hline & Inicial & 14,30 & 17,86 & 1040,000 & & 1040,000 & \\
\hline & & & 16,550 & 910,000 & 0,000 & 455,000 & 36,4 \\
\hline
\end{tabular}




\section{1 relógio}

\begin{tabular}{|c|c|c|c|c|c|c|c|}
\hline $\mathrm{CP}$ & $\begin{array}{r}\text { Plano } \\
\end{array}$ & $\begin{array}{c}\text { Força } \\
\text { (tf) }\end{array}$ & $\begin{array}{c}\text { Tensão } \\
\text { (MPa) }\end{array}$ & $\begin{array}{c}\mathrm{e} 1 \\
\text { (um) }\end{array}$ & $\begin{array}{c}\mathrm{e} 2 \\
\text { (um) }\end{array}$ & $\begin{array}{c}\text { em } \\
\text { (um) }\end{array}$ & $\begin{array}{c}\text { Ec } \\
(\mathrm{GPa})\end{array}$ \\
\hline \multirow{6}{*}{1} & \multirow[t]{3}{*}{ Secante } & 1,00 & 1,25 & 100,000 & & 100,000 & \multirow[b]{3}{*}{35,8} \\
\hline & & 15,05 & 18,80 & 1080,000 & & 1080,000 & \\
\hline & & & 17,549 & 980,000 & 0,000 & 490,000 & \\
\hline & \multirow{3}{*}{$\begin{array}{l}\text { Tangente } \\
\text { Inicial }\end{array}$} & 1,05 & 1,31 & 130,000 & & 130,000 & \multirow[b]{3}{*}{36,4} \\
\hline & & 15,05 & 18,80 & 1090,000 & & 1090,000 & \\
\hline & & & 17,487 & 960,000 & 0,000 & 480,000 & \\
\hline \multirow{6}{*}{2} & \multirow[t]{3}{*}{ Secante } & 1,05 & 1,31 & 140,000 & & 140,000 & \multirow[b]{3}{*}{37,6} \\
\hline & & 15,05 & 18,80 & 1070,000 & & 1070,000 & \\
\hline & & & 17,487 & 930,000 & 0,000 & 465,000 & \\
\hline & \multirow{3}{*}{$\begin{array}{l}\text { Tangente } \\
\text { Inicial }\end{array}$} & 1,05 & 1,31 & 180,000 & & 180,000 & \multirow[b]{3}{*}{39,3} \\
\hline & & 15,05 & 18,80 & 1070,000 & & 1070,000 & \\
\hline & & & 17,487 & 890,000 & 0,000 & 445,000 & \\
\hline \multirow{6}{*}{3} & \multirow[t]{3}{*}{ Secante } & 1,00 & 1,25 & 120,000 & & 120,000 & \multirow[b]{3}{*}{36,2} \\
\hline & & 15,05 & 18,80 & 1090,000 & & 1090,000 & \\
\hline & & & 17,549 & 970,000 & 0,000 & 485,000 & \\
\hline & \multirow{3}{*}{$\begin{array}{l}\text { Tangente } \\
\text { Inicial }\end{array}$} & 1,05 & 1,31 & 170,000 & & 170,000 & \multirow[b]{3}{*}{38,0} \\
\hline & & 15,05 & 18,80 & 1090,000 & & 1090,000 & \\
\hline & & & 17,487 & 920,000 & 0,000 & 460,000 & \\
\hline & Secante & 1,00 & 1,25 & 180,000 & & 180,000 & \\
\hline & & 15,05 & 18,80 & 1180,000 & & 1180,000 & \\
\hline 4 & & & 17,549 & 1000,000 & 0,000 & 500,000 & 35,1 \\
\hline 4 & Tangente & 1,05 & 1,31 & 240,000 & & 240,000 & \\
\hline & Inicial & 15,05 & 18,80 & 1190,000 & & 1190,000 & \\
\hline & & & 17,487 & 950,000 & 0,000 & 475,000 & 36,8 \\
\hline & Secante & 1,05 & 1,31 & 110,000 & & 110,000 & \\
\hline & & 15,05 & 18,80 & 980,000 & & 980,000 & \\
\hline 5 & & & 17,487 & 870,000 & 0,000 & 435,000 & 40,2 \\
\hline 5 & Tangente & 1,05 & 1,31 & 170,000 & & 170,000 & \\
\hline & Inicial & 15,05 & 18,80 & 1020,000 & & 1020,000 & \\
\hline & & & 17,487 & 850,000 & 0,000 & 425,000 & 41,1 \\
\hline & Secante & 1,05 & 1,31 & 100,000 & & 100,000 & \\
\hline & & 15,05 & 18,80 & 1030,000 & & 1030,000 & \\
\hline & & & 17,487 & 930,000 & 0,000 & 465,000 & 37,6 \\
\hline 6 & Tangente & 1,00 & 1,25 & 150,000 & & 150,000 & \\
\hline & Inicial & 15,05 & 18,80 & 1050,000 & & 1050,000 & \\
\hline & & & 17,549 & 900,000 & 0,000 & 450,000 & 39,0 \\
\hline & Secante & 1,05 & 1,31 & 230,000 & & 230,000 & \\
\hline & & 15,05 & 18,80 & 1250,000 & & 1250,000 & \\
\hline 7 & & & 17,487 & 1020,000 & 0,000 & 510,000 & 34,3 \\
\hline 7 & Tangente & 1,05 & 1,31 & 290,000 & & 290,000 & \\
\hline & Inicial & 15,05 & 18,80 & 1260,000 & & 1260,000 & \\
\hline & & & 17,487 & 970,000 & 0,000 & 485,000 & 36,1 \\
\hline & Secante & 1,05 & 1,31 & 160,000 & & 160,000 & \\
\hline & & 15,05 & 18,80 & 1150,000 & & 1150,000 & \\
\hline 8 & & & 17,487 & 990,000 & 0,000 & 495,000 & 35,3 \\
\hline 8 & Tangente & 1,05 & 1,31 & 230,000 & & 230,000 & \\
\hline & Inicial & 15,05 & 18,80 & 1180,000 & & 1180,000 & \\
\hline & & & 17,487 & 950,000 & 0,000 & 475,000 & 36,8 \\
\hline & Secante & 1,00 & 1,25 & 120,000 & & 120,000 & \\
\hline & & 15,05 & 18,80 & 1070,000 & & 1070,000 & \\
\hline 0 & & & 17,549 & 950,000 & 0,000 & 475,000 & 36,9 \\
\hline$y$ & Tangente & 1,05 & 1,31 & 180,000 & & 180,000 & \\
\hline & Inicial & 15,05 & 18,80 & 1080,000 & & 1080,000 & \\
\hline & & & 17,487 & 900,000 & 0,000 & 450,000 & 38,9 \\
\hline & Secante & 1,05 & 1,31 & 90,000 & & 90,000 & \\
\hline & & 15,05 & 18,80 & 1020,000 & & 1020,000 & \\
\hline 10 & & & 17,487 & 930,000 & 0,000 & 465,000 & 37,6 \\
\hline 10 & Tangente & 1,05 & 1,31 & 120,000 & & 120,000 & \\
\hline & Inicial & 15,05 & 18,80 & 1030,000 & & 1030,000 & \\
\hline & & & 17,487 & 910,000 & 0,000 & 455,000 & 38,4 \\
\hline
\end{tabular}




\section{2 relógios}

\begin{tabular}{|c|c|c|c|c|c|c|c|}
\hline CP & Plano & $\begin{array}{c}\text { Força } \\
\text { (tf) }\end{array}$ & $\begin{array}{c}\text { Tensão } \\
\text { (MPa) }\end{array}$ & $\begin{array}{c}\mathrm{e} 1 \\
\text { (um) }\end{array}$ & $\begin{array}{c}\mathrm{e} 2 \\
\text { (um) }\end{array}$ & $\begin{array}{c}\text { em } \\
\text { (um) }\end{array}$ & $\begin{array}{c}\text { Ec } \\
(\mathrm{GPa})\end{array}$ \\
\hline \multirow{6}{*}{1} & \multirow[t]{3}{*}{ Secante } & 0,95 & 1,19 & 140,000 & $-40,000$ & 50,000 & \multirow[b]{3}{*}{34,5} \\
\hline & & 13,95 & 17,42 & 680,000 & 360,000 & 520,000 & \\
\hline & & & 16,238 & 540,000 & 400,000 & 470,000 & \\
\hline & \multirow{3}{*}{$\begin{array}{l}\text { Tangente } \\
\text { Inicial }\end{array}$} & 1,05 & 1,31 & 330,000 & $-170,000$ & 80,000 & \multirow[b]{3}{*}{35,2} \\
\hline & & 14,00 & 17,49 & 830,000 & 250,000 & 540,000 & \\
\hline & & & 16,175 & 500,000 & 420,000 & 460,000 & \\
\hline \multirow{6}{*}{2} & \multirow[t]{3}{*}{ Secante } & 1,05 & 1,31 & 70,000 & 110,000 & 90,000 & \multirow[b]{3}{*}{36,6} \\
\hline & & 13,95 & 17,42 & 570,000 & 490,000 & 530,000 & \\
\hline & & & 16,113 & 500,000 & 380,000 & 440,000 & \\
\hline & \multirow{3}{*}{$\begin{array}{l}\text { Tangente } \\
\text { Inicial }\end{array}$} & 1,05 & 1,31 & 90,000 & 140,000 & 115,000 & \multirow[b]{3}{*}{37,0} \\
\hline & & 13,95 & 17,42 & 590,000 & 510,000 & 550,000 & \\
\hline & & & 16,113 & 500,000 & 370,000 & 435,000 & \\
\hline \multirow{6}{*}{3} & \multirow[t]{3}{*}{ Secante } & 1,05 & 1,31 & 330,000 & $-180,000$ & 75,000 & \multirow[b]{3}{*}{36,6} \\
\hline & & 13,95 & 17,42 & 810,000 & 220,000 & 515,000 & \\
\hline & & & 16,113 & 480,000 & 400,000 & 440,000 & \\
\hline & \multirow{3}{*}{$\begin{array}{l}\text { Tangente } \\
\text { Inicial }\end{array}$} & 1,05 & 1,31 & 1270,000 & $-1030,000$ & 120,000 & \multirow[b]{3}{*}{38,8} \\
\hline & & 13,95 & 17,42 & 1640,000 & $-570,000$ & 535,000 & \\
\hline & & & 16,113 & 370,000 & 460,000 & 415,000 & \\
\hline & Secante & 1,05 & 1,31 & $-40,000$ & 90,000 & 25,000 & \\
\hline & & 13,95 & 17,42 & 480,000 & 390,000 & 435,000 & \\
\hline 4 & & & 16,113 & 520,000 & 300,000 & 410,000 & 39,3 \\
\hline 4 & Tangente & 1,05 & 1,31 & $-20,000$ & 120,000 & 50,000 & \\
\hline & Inicial & 13,95 & 17,42 & 490,000 & 420,000 & 455,000 & \\
\hline & & & 16,113 & 510,000 & 300,000 & 405,000 & 39,8 \\
\hline & Secante & 1,05 & 1,31 & 110,000 & $-30,000$ & 40,000 & \\
\hline & & 13,95 & 17,42 & 680,000 & 330,000 & 505,000 & \\
\hline 5 & & & 16,113 & 570,000 & 360,000 & 465,000 & 34,7 \\
\hline$\checkmark$ & Tangente & 1,05 & 1,31 & 200,000 & $-70,000$ & 65,000 & \\
\hline & Inicial & 14,00 & 17,49 & 720,000 & 320,000 & 520,000 & \\
\hline & & & 16,175 & 520,000 & 390,000 & 455,000 & 35,5 \\
\hline & Secante & 1,00 & 1,25 & 60,000 & 40,000 & 50,000 & \\
\hline & & 13,95 & 17,42 & 550,000 & 440,000 & 495,000 & \\
\hline 6 & & & 16,175 & 490,000 & 400,000 & 445,000 & 36,3 \\
\hline b & Tangente & 1,05 & 1,31 & 130,000 & 20,000 & 75,000 & \\
\hline & Inicial & 13,95 & 17,42 & 550,000 & 460,000 & 505,000 & \\
\hline & & & 16,113 & 420,000 & 440,000 & 430,000 & 37,5 \\
\hline & Secante & 1,00 & 1,25 & $-40,000$ & 100,000 & 30,000 & \\
\hline & & 13,95 & 17,42 & 430,000 & 430,000 & 430,000 & \\
\hline 7 & & & 16,175 & 470,000 & 330,000 & 400,000 & 40,4 \\
\hline 7 & Tangente & 1,05 & 1,31 & $-30,000$ & 120,000 & 45,000 & \\
\hline & Inicial & 13,95 & 17,42 & 430,000 & 460,000 & 445,000 & \\
\hline & & & 16,113 & 460,000 & 340,000 & 400,000 & 40,3 \\
\hline & Secante & 1,05 & 1,31 & 190,000 & $-110,000$ & 40,000 & \\
\hline & & 13,95 & 17,42 & 710,000 & 280,000 & 495,000 & \\
\hline 8 & & & 16,113 & 520,000 & 390,000 & 455,000 & 35,4 \\
\hline 8 & Tangente & 1,05 & 1,31 & 420,000 & $-310,000$ & 55,000 & \\
\hline & Inicial & 13,95 & 17,42 & 810,000 & 180,000 & 495,000 & \\
\hline & & & 16,113 & 390,000 & 490,000 & 440,000 & 36,6 \\
\hline & Secante & 1,00 & 1,25 & 270,000 & $-250,000$ & 10,000 & \\
\hline & & 13,95 & 17,42 & 740,000 & 100,000 & 420,000 & \\
\hline 9 & & & 16,175 & 470,000 & 350,000 & 410,000 & 39,5 \\
\hline$y$ & Tangente & 1,05 & 1,31 & 550,000 & $-500,000$ & 25,000 & \\
\hline & Inicial & 13,95 & 17,42 & 960,000 & $-90,000$ & 435,000 & \\
\hline & & & 16,113 & 410,000 & 410,000 & 410,000 & 39,3 \\
\hline & Secante & 1,05 & 1,31 & 40,000 & 110,000 & 75,000 & \\
\hline & & 13,95 & 17,42 & 510,000 & 530,000 & 520,000 & \\
\hline 10 & & & 16,113 & 470,000 & 420,000 & 445,000 & 36,2 \\
\hline 10 & Tangente & 1,05 & 1,31 & 70,000 & 150,000 & 110,000 & \\
\hline & Inicial & 13,95 & 17,42 & 520,000 & 560,000 & 540,000 & \\
\hline & & & 16,113 & 450,000 & 410,000 & 430,000 & 37,5 \\
\hline
\end{tabular}




\section{2 relógios}

\begin{tabular}{|c|c|c|c|c|c|c|c|}
\hline $\mathrm{CP}$ & Plano & $\begin{array}{l}\text { Força } \\
\text { (tf) }\end{array}$ & \begin{tabular}{c|}
$\begin{array}{c}\text { Tensão } \\
\text { (MPa) }\end{array}$ \\
\end{tabular} & $\begin{array}{l}\text { e1 } \\
\text { (um) }\end{array}$ & $\begin{array}{c}\text { e2 } \\
\text { (um) }\end{array}$ & $\begin{array}{l}\text { em } \\
\text { (um) }\end{array}$ & $\begin{array}{c}\mathrm{Ec} \\
(\mathrm{GPa})\end{array}$ \\
\hline \multirow{6}{*}{1} & \multirow[t]{3}{*}{ Secante } & 1,00 & 1,25 & 90,000 & 40,000 & 65,000 & \multirow[b]{3}{*}{36,0} \\
\hline & & 14,25 & 17,80 & 630,000 & 420,000 & 525,000 & \\
\hline & & & 16,550 & 540,000 & 380,000 & 460,000 & \\
\hline & \multirow{3}{*}{$\begin{array}{l}\text { Tangente } \\
\text { Inicial }\end{array}$} & 1,00 & 1,25 & 230,000 & $-40,000$ & 95,000 & \multirow[b]{3}{*}{38,6} \\
\hline & & 14,30 & 17,86 & 740,000 & 310,000 & 525,000 & \\
\hline & & & 16,612 & 510,000 & 350,000 & 430,000 & \\
\hline \multirow{6}{*}{2} & \multirow[t]{3}{*}{ Secante } & 1,00 & 1,25 & 110,000 & 0,000 & 55,000 & \multirow[b]{3}{*}{37,3} \\
\hline & & 14,30 & 17,86 & 620,000 & 380,000 & 500,000 & \\
\hline & & & 16,612 & 510,000 & 380,000 & 445,000 & \\
\hline & \multirow{3}{*}{$\begin{array}{l}\text { Tangente } \\
\text { Inicial }\end{array}$} & 1,05 & 1,31 & 330,000 & $-150,000$ & 90,000 & \multirow[b]{3}{*}{39,4} \\
\hline & & 14,30 & 17,86 & 780,000 & 240,000 & 510,000 & \\
\hline & & & 16,550 & 450,000 & 390,000 & 420,000 & \\
\hline \multirow{6}{*}{3} & \multirow[t]{3}{*}{ Secante } & 1,05 & 1,31 & $-80,000$ & 30,000 & $-25,000$ & \multirow[b]{3}{*}{39,7} \\
\hline & & 14,25 & 17,80 & 330,000 & 450,000 & 390,000 & \\
\hline & & & 16,487 & 410,000 & 420,000 & 415,000 & \\
\hline & \multirow{3}{*}{$\begin{array}{l}\text { Tangente } \\
\text { Inicial }\end{array}$} & 1,00 & 1,25 & $-150,000$ & 160,000 & 5,000 & \multirow[b]{3}{*}{41,0} \\
\hline & & 14,30 & 17,86 & 320,000 & 500,000 & 410,000 & \\
\hline & & & 16,612 & 470,000 & 340,000 & 405,000 & \\
\hline & Secante & 1,05 & 1,31 & 50,000 & 80,000 & 65,000 & \\
\hline & & 14,25 & 17,80 & 560,000 & 520,000 & 540,000 & \\
\hline 4 & & & 16,487 & 510,000 & 440,000 & 475,000 & 34,7 \\
\hline 4 & Tangente & 1,05 & 1,31 & 60,000 & 120,000 & 90,000 & \\
\hline & Inicial & 14,25 & 17,80 & 510,000 & 540,000 & 525,000 & \\
\hline & & & $\begin{array}{l}16,487 \\
\end{array}$ & 450,000 & 420,000 & 435,000 & 37,9 \\
\hline & Secante & 1,00 & 1,25 & 200,000 & $-70,000$ & 65,000 & \\
\hline & & 14,25 & 17,80 & 600,000 & 460,000 & 530,000 & \\
\hline 5 & & & 16,550 & 400,000 & 530,000 & 465,000 & 35,6 \\
\hline 5 & Tangente & 1,00 & 1,25 & 390,000 & $-270,000$ & 60,000 & \\
\hline & Inicial & 14,25 & 17,80 & 770,000 & 250,000 & 510,000 & \\
\hline & & & 16,550 & 380,000 & 520,000 & 450,000 & 36,8 \\
\hline & Secante & 1,05 & 1,31 & 130,000 & 30,000 & 80,000 & \\
\hline & & 14,25 & 17,80 & 640,000 & 440,000 & 540,000 & \\
\hline 6 & & & 16,487 & 510,000 & 410,000 & 460,000 & 35,8 \\
\hline 0 & Tangente & 1,05 & 1,31 & 210,000 & $-20,000$ & 95,000 & \\
\hline & Inicial & 14,25 & 17,80 & 680,000 & 380,000 & 530,000 & \\
\hline & & & 16,487 & 470,000 & 400,000 & 435,000 & 37,9 \\
\hline & Secante & 1,00 & 1,25 & 100,000 & $-20,000$ & 40,000 & \\
\hline & & 14,25 & 17,80 & 650,000 & 370,000 & 510,000 & \\
\hline 7 & & & 16,550 & 550,000 & 390,000 & 470,000 & 35,2 \\
\hline 7 & Tangente & 1,00 & 1,25 & 250,000 & $-110,000$ & 70,000 & \\
\hline & Inicial & 14,25 & 17,80 & 650,000 & 410,000 & 530,000 & \\
\hline & & & 16,550 & 400,000 & 520,000 & 460,000 & 36,0 \\
\hline & Secante & 1,00 & 1,25 & 430,000 & $-370,000$ & 30,000 & \\
\hline & & 14,25 & 17,80 & 1010,000 & $-100,000$ & 455,000 & \\
\hline 8 & & & 16,550 & 580,000 & 270,000 & 425,000 & 38,9 \\
\hline 8 & Tangente & 1,05 & 1,31 & 510,000 & $-390,000$ & 60,000 & \\
\hline & Inicial & 14,25 & 17,80 & 1000,000 & $-70,000$ & 465,000 & \\
\hline & & & 16,487 & 490,000 & 320,000 & 405,000 & 40,7 \\
\hline & Secante & 1,05 & 1,31 & 470,000 & $-290,000$ & 90,000 & \\
\hline & & 14,30 & 17,86 & 930,000 & 130,000 & 530,000 & \\
\hline 9 & & & 16,550 & 460,000 & 420,000 & 440,000 & 37,6 \\
\hline$y$ & Tangente & 1,05 & 1,31 & 1190,000 & $-810,000$ & 190,000 & \\
\hline & Inicial & 14,30 & 17,86 & 1190,000 & $-70,000$ & 560,000 & \\
\hline & & & 16,550 & 0,000 & 740,000 & 370,000 & 44,7 \\
\hline & Secante & 1,05 & 1,31 & 50,000 & $-90,000$ & $-20,000$ & \\
\hline & & 14,25 & 17,80 & 470,000 & 380,000 & 425,000 & \\
\hline 10 & & & 16,487 & 420,000 & 470,000 & 445,000 & 37,1 \\
\hline 10 & Tangente & 1,05 & 1,31 & 80,000 & $-40,000$ & 20,000 & \\
\hline & Inicial & 14,25 & 17,80 & 510,000 & 380,000 & 445,000 & \\
\hline & & & $\begin{array}{l}16,487 \\
\end{array}$ & 430,000 & 420,000 & 425,000 & 38,8 \\
\hline
\end{tabular}




\section{2 relógios}

\begin{tabular}{|c|c|c|c|c|c|c|c|}
\hline CP & Plano & $\begin{array}{c}\text { Força } \\
\text { (tf) }\end{array}$ & $\begin{array}{c}\text { Tensão } \\
\text { (MPa) }\end{array}$ & $\begin{array}{c}\mathrm{e} 1 \\
\text { (um) }\end{array}$ & $\begin{array}{c}\mathrm{e} 2 \\
\text { (um) }\end{array}$ & $\begin{array}{c}\text { em } \\
\text { (um) }\end{array}$ & $\begin{array}{c}\text { Ec } \\
(\mathrm{GPa})\end{array}$ \\
\hline \multirow{6}{*}{1} & \multirow[t]{3}{*}{ Secante } & 1,00 & 1,25 & 300,000 & 0,000 & 150,000 & \multirow[b]{3}{*}{47,9} \\
\hline & & 15,00 & 18,74 & 670,000 & 360,000 & 515,000 & \\
\hline & & & 17,487 & 370,000 & 360,000 & 365,000 & \\
\hline & \multirow{3}{*}{$\begin{array}{l}\text { Tangente } \\
\text { Inicial }\end{array}$} & 1,05 & 1,31 & 140,000 & $-10,000$ & 65,000 & \multirow[b]{3}{*}{40,5} \\
\hline & & 15,00 & 18,74 & 590,000 & 400,000 & 495,000 & \\
\hline & & & 17,424 & 450,000 & 410,000 & 430,000 & \\
\hline \multirow{6}{*}{2} & \multirow[t]{3}{*}{ Secante } & 1,05 & 1,31 & 280,000 & $-100,000$ & 90,000 & \multirow[b]{3}{*}{37,1} \\
\hline & & 15,00 & 18,74 & 710,000 & 410,000 & 560,000 & \\
\hline & & & 17,424 & 430,000 & 510,000 & 470,000 & \\
\hline & \multirow{3}{*}{$\begin{array}{l}\text { Tangente } \\
\text { Inicial }\end{array}$} & 1,05 & 1,31 & 200,000 & $-20,000$ & 90,000 & \multirow[b]{3}{*}{41,0} \\
\hline & & 15,00 & 18,74 & 630,000 & 400,000 & 515,000 & \\
\hline & & & 17,424 & 430,000 & 420,000 & 425,000 & \\
\hline \multirow{6}{*}{3} & \multirow[t]{3}{*}{ Secante } & 1,05 & 1,31 & 570,000 & 430,000 & 500,000 & \multirow[b]{3}{*}{33,2} \\
\hline & & 15,00 & 18,74 & 1100,000 & 950,000 & 1025,000 & \\
\hline & & & 17,424 & 530,000 & 520,000 & 525,000 & \\
\hline & \multirow{3}{*}{$\begin{array}{l}\text { Tangente } \\
\text { Inicial }\end{array}$} & 1,05 & 1,31 & 570,000 & 390,000 & 480,000 & \multirow[b]{3}{*}{34,8} \\
\hline & & 15,00 & 18,74 & 1050,000 & 910,000 & 980,000 & \\
\hline & & & 17,424 & 480,000 & 520,000 & 500,000 & \\
\hline & Secante & 1,00 & 1,25 & 70,000 & $-90,000$ & $-10,000$ & \\
\hline & & 15,00 & 18,74 & 640,000 & 410,000 & 525,000 & \\
\hline 4 & & & 17,487 & 570,000 & 500,000 & 535,000 & 32,7 \\
\hline 4 & Tangente & 1,05 & 1,31 & 40,000 & 0,000 & 20,000 & \\
\hline & Inicial & 15,00 & 18,74 & 550,000 & 490,000 & 520,000 & \\
\hline & & & 17,424 & 510,000 & 490,000 & 500,000 & 34,8 \\
\hline & Secante & 1,05 & 1,31 & 110,000 & 160,000 & 135,000 & \\
\hline & & 15,00 & 18,74 & 740,000 & 460,000 & 600,000 & \\
\hline 5 & & & 17,424 & 630,000 & 300,000 & 465,000 & 37,5 \\
\hline 0 & Tangente & 1,05 & 1,31 & 90,000 & 130,000 & 110,000 & \\
\hline & Inicial & 15,00 & 18,74 & 680,000 & 410,000 & 545,000 & \\
\hline & & & 17,424 & 590,000 & 280,000 & 435,000 & 40,1 \\
\hline & Secante & 1,05 & 1,31 & 460,000 & $-330,000$ & 65,000 & \\
\hline & & 15,00 & 18,74 & 810,000 & 280,000 & 545,000 & \\
\hline 6 & & & 17,424 & 350,000 & 610,000 & 480,000 & 36,3 \\
\hline b & Tangente & 1,05 & 1,31 & 750,000 & $-80,000$ & 335,000 & \\
\hline & Inicial & 15,00 & 18,74 & 1050,000 & 490,000 & 770,000 & \\
\hline & & & 17,424 & 300,000 & 570,000 & 435,000 & 40,1 \\
\hline & Secante & 1,05 & 1,31 & 230,000 & 90,000 & 160,000 & \\
\hline & & 15,00 & 18,74 & 670,000 & 560,000 & 615,000 & \\
\hline 7 & & & 17,424 & 440,000 & 470,000 & 455,000 & 38,3 \\
\hline 7 & Tangente & 1,05 & 1,31 & 440,000 & 50,000 & 245,000 & \\
\hline & Inicial & 15,00 & 18,74 & 850,000 & 530,000 & 690,000 & \\
\hline & & & 17,424 & 410,000 & 480,000 & 445,000 & 39,2 \\
\hline & Secante & 1,05 & 1,31 & 140,000 & $-50,000$ & 45,000 & \\
\hline & & 15,00 & 18,74 & 520,000 & 530,000 & 525,000 & \\
\hline 8 & & & 17,424 & 380,000 & 580,000 & 480,000 & 36,3 \\
\hline 0 & Tangente & 1,05 & 1,31 & 240,000 & $-280,000$ & $-20,000$ & \\
\hline & Inicial & 15,00 & 18,74 & 650,000 & 230,000 & 440,000 & \\
\hline & & & 17,424 & 410,000 & 510,000 & 460,000 & 37,9 \\
\hline & Secante & 1,05 & 1,31 & 30,000 & $-90,000$ & $-30,000$ & \\
\hline & & 15,00 & 18,74 & 470,000 & 370,000 & 420,000 & \\
\hline 9 & & & 17,424 & 440,000 & 460,000 & 450,000 & 38,7 \\
\hline$y$ & Tangente & 1,05 & 1,31 & $-20,000$ & $-60,000$ & $-40,000$ & \\
\hline & Inicial & 15,00 & 18,74 & 400,000 & 380,000 & 390,000 & \\
\hline & & & 17,424 & 420,000 & 440,000 & 430,000 & 40,5 \\
\hline & Secante & 1,05 & 1,31 & 220,000 & 160,000 & 190,000 & \\
\hline & & 15,00 & 18,74 & 670,000 & 690,000 & 680,000 & \\
\hline 10 & & & 17,424 & 450,000 & 530,000 & 490,000 & 35,6 \\
\hline 10 & Tangente & 1,05 & 1,31 & 180,000 & 110,000 & 145,000 & \\
\hline & Inicial & 15,00 & 18,74 & 570,000 & 650,000 & 610,000 & \\
\hline & & & 17,424 & 390,000 & 540,000 & 465,000 & 37,5 \\
\hline
\end{tabular}


Tabela A.3 - Resultados dos ensaios prévios de resistência à compressão: a/c 0,70

Betonada 1

\begin{tabular}{|c|c|c|c|c|c|c|}
\hline \multirow[b]{2}{*}{$\mathrm{CP}$} & \multicolumn{2}{|c|}{ Betonada 1} & \multicolumn{2}{|c|}{ Betonada 2} & \multicolumn{2}{|c|}{ Betonada 3} \\
\hline & $\begin{array}{c}\text { Força } \\
\text { (tf) }\end{array}$ & $\begin{array}{c}\text { Tensão } \\
\text { (MPa) }\end{array}$ & $\begin{array}{c}\text { Força } \\
\text { (tf) }\end{array}$ & $\begin{array}{c}\text { Tensão } \\
\text { (MPa) }\end{array}$ & $\begin{array}{c}\text { Força } \\
\text { (tf) }\end{array}$ & $\begin{array}{c}\text { Tensão } \\
\text { (MPa) }\end{array}$ \\
\hline 1 & 18,80 & 23,5 & 21,10 & 26,4 & 19,40 & 24,2 \\
\hline 2 & 19,60 & 24,5 & 20,40 & 25,5 & 19,80 & 24,7 \\
\hline 3 & 19,00 & 23,7 & 19,45 & 24,3 & 19,75 & 24,7 \\
\hline 4 & 18,90 & 23,6 & 19,95 & 24,9 & 20,15 & 25,2 \\
\hline 5 & 19,20 & 24,0 & 20,05 & 25,0 & 21,65 & 27,0 \\
\hline 6 & 18,95 & 23,7 & 21,80 & 27,2 & 19,90 & 24,9 \\
\hline 7 & 18,75 & 23,4 & 20,50 & 25,6 & 20,25 & 25,3 \\
\hline 8 & 18,35 & 22,9 & 19,30 & 24,1 & 19,00 & 23,7 \\
\hline 9 & 18,70 & 23,4 & 19,55 & 24,4 & 19,75 & 24,7 \\
\hline 10 & 18,85 & 23,5 & 18,95 & 23,7 & 20,05 & 25,0 \\
\hline Média & 18,91 & 23,62 & 20,11 & 25,11 & 19,97 & 24,94 \\
\hline Desvio & 0,33 & 0,41 & 0,87 & 1,09 & 0,69 & 0,87 \\
\hline
\end{tabular}

Tabela A.4 - Resultados de módulo de deformação: a/c 0,70

strain gages

a/c 0,70 - Betonada 1

\begin{tabular}{|c|c|c|c|c|c|c|c|}
\hline CP & Plano & $\begin{array}{c}\text { Força } \\
\text { (tf) }\end{array}$ & $\begin{array}{c}\text { Tensão } \\
\text { (MPa) }\end{array}$ & $\begin{array}{c}\text { e1 } \\
\text { (um) }\end{array}$ & $\begin{array}{c}\text { e2 } \\
\text { (um) }\end{array}$ & $\begin{array}{c}\text { em } \\
\text { (um) }\end{array}$ & $\begin{array}{c}\text { Ec } \\
(\mathrm{GPa})\end{array}$ \\
\hline \multirow{6}{*}{1} & \multirow[t]{3}{*}{ Secante } & 0,90 & 1,12 & 74,461 & 882,788 & 478,625 & \multirow[b]{3}{*}{24,9} \\
\hline & & 5,75 & 7,18 & 304,535 & 1139,190 & 721,863 & \\
\hline & & 4,850 & 6,058 & 230,074 & 256,402 & 243,238 & \\
\hline & \multirow{3}{*}{$\begin{array}{l}\text { Tangente } \\
\text { Inicial }\end{array}$} & 0,90 & 1,12 & 92,297 & 896,462 & 494,380 & \multirow[b]{3}{*}{25,6} \\
\hline & & 5,75 & 7,18 & 302,930 & 1158,580 & 730,755 & \\
\hline & & 4,850 & 6,058 & 210,633 & 262,118 & 236,376 & \\
\hline \multirow{6}{*}{2} & \multirow[t]{3}{*}{ Secante } & 0,95 & 1,19 & 148,010 & 7,594 & 77,802 & \multirow[b]{3}{*}{23,2} \\
\hline & & 5,75 & 7,18 & 375,218 & 296,300 & 335,759 & \\
\hline & & 4,800 & 5,995 & 227,208 & 288,706 & 257,957 & \\
\hline & \multirow{3}{*}{$\begin{array}{l}\text { Tangente } \\
\text { Inicial }\end{array}$} & 0,95 & 1,19 & 140,092 & 52,134 & 96,113 & \multirow[b]{3}{*}{23,9} \\
\hline & & 5,75 & 7,18 & 346,572 & 348,055 & 347,314 & \\
\hline & & 4,800 & 5,995 & 206,480 & 295,921 & 251,201 & \\
\hline \multirow{6}{*}{3} & \multirow[t]{3}{*}{ Secante } & 0,95 & 1,19 & 86,077 & 55,657 & 70,867 & \multirow[b]{3}{*}{23,9} \\
\hline & & 5,75 & 7,18 & 303,291 & 340,670 & 321,980 & \\
\hline & & 4,800 & 5,995 & 217,214 & 285,013 & 251,113 & \\
\hline & \multirow{3}{*}{$\begin{array}{l}\text { Tangente } \\
\text { Inicial }\end{array}$} & 0,95 & 1,19 & 93,365 & 87,919 & 90,642 & \multirow[b]{3}{*}{25,0} \\
\hline & & 5,75 & 7,18 & 311,556 & 349,315 & 330,435 & \\
\hline & & 4,800 & 5,995 & 218,192 & 261,395 & 239,793 & \\
\hline \multirow{6}{*}{4} & \multirow[t]{3}{*}{ Secante } & 0,95 & 1,19 & 68,878 & 86,613 & 77,746 & \multirow[b]{3}{*}{23,1} \\
\hline & & 5,75 & 7,18 & 308,237 & 365,964 & 337,101 & \\
\hline & & 4,800 & 5,995 & 239,359 & 279,351 & 259,355 & \\
\hline & \multirow{3}{*}{$\begin{array}{l}\text { Tangente } \\
\text { Inicial }\end{array}$} & 0,95 & 1,19 & 86,153 & 92,932 & 89,542 & \multirow[b]{3}{*}{23,5} \\
\hline & & 5,75 & 7,18 & 322,128 & 367,299 & 344,714 & \\
\hline & & 4,800 & 5,995 & 235,975 & 274,368 & 255,171 & \\
\hline \multirow{6}{*}{5} & \multirow[t]{3}{*}{ Secante } & 1,00 & 1,25 & 52,045 & 83,453 & 67,749 & \multirow[b]{3}{*}{21,5} \\
\hline & & 5,75 & 7,18 & 285,326 & 401,811 & 343,569 & \\
\hline & & 4,750 & 5,933 & 233,281 & 318,358 & 275,819 & \\
\hline & \multirow{3}{*}{$\begin{array}{l}\text { Tangente } \\
\text { Inicial }\end{array}$} & 1,00 & 1,25 & 78,123 & 106,589 & 92,356 & \multirow[b]{3}{*}{23,2} \\
\hline & & 5,75 & 7,18 & 295,383 & 401,365 & 348,374 & \\
\hline & & 4,750 & 5,933 & 217,260 & 294,776 & 256,018 & \\
\hline \multirow{6}{*}{6} & \multirow[t]{3}{*}{ Secante } & 1,00 & 1,25 & 101,704 & 30,892 & 66,298 & \\
\hline & & 5,75 & 7,18 & 357,389 & 275,531 & 316,460 & \\
\hline & & 4,750 & 5,933 & 255,685 & 244,639 & 250,162 & 23,7 \\
\hline & Tangente & 1,00 & 1,25 & 127,264 & 52,645 & 89,955 & \\
\hline & Inicial & 5,75 & 7,18 & 355,875 & 301,118 & 328,497 & \\
\hline & & 4,750 & 5,933 & 228,612 & 248,473 & 238,542 & 24,9 \\
\hline
\end{tabular}




\begin{tabular}{|c|c|c|c|c|c|c|c|}
\hline \multirow{6}{*}{7} & \multirow[t]{3}{*}{ Secante } & 1,00 & 1,25 & 66,240 & 86,634 & 76,437 & \multirow[b]{3}{*}{20,0} \\
\hline & & 5,75 & 7,18 & 401,221 & 346,314 & 373,767 & \\
\hline & & 4,750 & 5,933 & 334,981 & 259,680 & 297,330 & \\
\hline & \multirow{3}{*}{$\begin{array}{l}\text { Tangente } \\
\text { Inicial }\end{array}$} & 1,00 & 1,25 & 86,704 & 113,922 & 100,313 & \\
\hline & & 5,75 & 7,18 & 398,107 & 360,314 & 379,211 & \multirow[b]{2}{*}{21,3} \\
\hline & & 4,750 & 5,933 & 311,403 & 246,392 & 278,898 & \\
\hline \multirow{6}{*}{8} & \multirow[t]{3}{*}{ Secante } & 1,00 & 1,25 & 70,128 & 78,631 & 74,379 & \multirow[b]{3}{*}{21,9} \\
\hline & & 5,75 & 7,18 & 244,901 & 445,637 & 345,269 & \\
\hline & & 4,750 & 5,933 & 174,774 & 367,006 & 270,890 & \\
\hline & \multirow{3}{*}{$\begin{array}{l}\text { Tangente } \\
\text { Inicial }\end{array}$} & 1,00 & 1,25 & 96,851 & 95,739 & 96,295 & \\
\hline & & 5,75 & 7,18 & 259,777 & 451,429 & 355,603 & \multirow[b]{2}{*}{22,9} \\
\hline & & 4,750 & 5,933 & 162,926 & 355,690 & 259,308 & \\
\hline \multirow{6}{*}{9} & \multirow[t]{3}{*}{ Secante } & 1,00 & 1,25 & 56,257 & 102,389 & 79,323 & \multirow{4}{*}{22,2} \\
\hline & & 5,75 & 7,18 & 214,518 & 478,974 & 346,746 & \\
\hline & & 4,750 & 5,933 & 158,261 & 376,585 & 267,423 & \\
\hline & \multirow{3}{*}{$\begin{array}{l}\text { Tangente } \\
\text { Inicial }\end{array}$} & 1,00 & 1,25 & 64,737 & 139,994 & 102,366 & \\
\hline & & 5,75 & 7,18 & 227,372 & 486,994 & 357,183 & \multirow[b]{2}{*}{23,3} \\
\hline & & 4,750 & 5,933 & 162,635 & 347,000 & 254,817 & \\
\hline \multirow{6}{*}{10} & \multirow[t]{3}{*}{ Secante } & $\begin{array}{l}1,00 \\
\end{array}$ & $\begin{array}{l}1,25 \\
\end{array}$ & 27,581 & 58,328 & 42,955 & \multirow{4}{*}{24,6} \\
\hline & & 5,75 & 7,18 & 316,945 & 250,369 & 283,657 & \\
\hline & & 4,750 & 5,933 & 289,364 & 192,041 & 240,703 & \\
\hline & \multirow{3}{*}{$\begin{array}{l}\text { Tangente } \\
\text { Inicial }\end{array}$} & 1,00 & 1,25 & 59,219 & 71,269 & 65,244 & \\
\hline & & 5,75 & 7,18 & 308,668 & 287,512 & 298,090 & \multirow[b]{2}{*}{25,5} \\
\hline & & 4,750 & 5,933 & 249,449 & 216,243 & 232,846 & \\
\hline
\end{tabular}

strain gages

\begin{tabular}{|c|c|c|c|c|c|c|c|}
\hline CP & Plano & $\begin{array}{c}\text { Força } \\
\text { (tf) }\end{array}$ & $\begin{array}{c}\text { Tensão } \\
\text { (MPa) }\end{array}$ & $\begin{array}{c}\text { e1 } \\
\text { (um) }\end{array}$ & $\begin{array}{c}\text { e2 } \\
\text { (um) }\end{array}$ & $\begin{array}{l}\text { em } \\
\text { (um) }\end{array}$ & $\begin{array}{c}\mathrm{Ec} \\
(\mathrm{GPa})\end{array}$ \\
\hline \multirow{6}{*}{1} & \multirow[t]{3}{*}{ Secante } & 1,00 & 1,25 & 66,998 & 33,502 & 50,250 & \\
\hline & & 6,05 & 7,56 & 272,865 & 325,574 & 299,220 & \\
\hline & & 5,050 & 6,308 & 205,867 & 292,072 & 248,970 & 25,3 \\
\hline & \multirow{3}{*}{$\begin{array}{l}\text { Tangente } \\
\text { Inicial }\end{array}$} & 1,00 & 1,25 & 83,019 & 55,688 & 69,354 & \\
\hline & & 6,05 & 7,56 & 279,363 & 332,168 & 305,765 & \\
\hline & & 5,050 & 6,308 & 196,344 & 276,479 & 236,412 & 26,7 \\
\hline \multirow{6}{*}{2} & \multirow[t]{3}{*}{ Secante } & 1,00 & 1,25 & 57,504 & 58,460 & $\begin{array}{l}57,982 \\
\end{array}$ & \\
\hline & & 6,05 & 7,56 & 228,413 & 367,186 & 297,800 & \\
\hline & & 5,050 & 6,308 & 170,909 & 308,727 & 239,818 & 26,3 \\
\hline & \multirow{3}{*}{$\begin{array}{l}\text { Tangente } \\
\text { Inicial }\end{array}$} & 1,00 & 1,25 & 74,417 & 78,317 & 76,367 & \\
\hline & & 6,05 & 7,56 & 243,278 & 371,372 & 307,325 & \\
\hline & & 5,050 & 6,308 & 168,862 & 293,054 & 230,958 & 27,3 \\
\hline \multirow{6}{*}{3} & \multirow[t]{3}{*}{ Secante } & 1,00 & 1,25 & 149,641 & 91,404 & 120,522 & \\
\hline & & 6,05 & 7,56 & 395,321 & 384,628 & 389,974 & \\
\hline & & 5,050 & 6,308 & 245,680 & 293,224 & 269,452 & 23,4 \\
\hline & \multirow{3}{*}{$\begin{array}{l}\text { Tangente } \\
\text { Inicial }\end{array}$} & 1,00 & 1,25 & 170,671 & 95,778 & 133,224 & \\
\hline & & 6,05 & 7,56 & 410,291 & 383,021 & 396,656 & \\
\hline & & 5,050 & 6,308 & 239,621 & 287,244 & 263,432 & 23,9 \\
\hline \multirow{6}{*}{4} & \multirow[t]{3}{*}{ Secante } & 1,00 & 1,25 & 83,877 & 51,917 & $\begin{array}{l}67,897 \\
\end{array}$ & \\
\hline & & 6,10 & 7,62 & 252,436 & 376,199 & 314,317 & \\
\hline & & 5,100 & 6,370 & 168,558 & 324,282 & 246,420 & 25,9 \\
\hline & \multirow{3}{*}{$\begin{array}{l}\text { Tangente } \\
\text { Inicial }\end{array}$} & 1,00 & 1,25 & 116,928 & 74,882 & 95,905 & \\
\hline & & 6,10 & 7,62 & 278,966 & 378,879 & 328,922 & \\
\hline & & 5,100 & 6,370 & 162,038 & 303,997 & 233,017 & 27,3 \\
\hline \multirow{6}{*}{5} & \multirow[t]{3}{*}{ Secante } & 1,00 & 1,25 & 50,599 & 92,291 & 71,445 & \\
\hline & & 6,05 & 7,56 & 210,829 & 526,361 & 368,595 & \\
\hline & & 5,050 & 6,308 & 160,230 & 434,070 & 297,150 & 21,2 \\
\hline & \multirow{3}{*}{$\begin{array}{l}\text { Tangente } \\
\text { Inicial }\end{array}$} & 1,00 & 1,25 & 75,277 & 113,821 & 94,549 & \\
\hline & & 6,05 & 7,56 & 231,246 & 522,456 & 376,851 & \\
\hline & & 5,050 & 6,308 & 155,969 & 408,635 & 282,302 & 22,3 \\
\hline \multirow{6}{*}{6} & \multirow[t]{3}{*}{ Secante } & 1,00 & 1,25 & 73,525 & 49,724 & $\begin{array}{l}61,625 \\
\end{array}$ & \\
\hline & & 6,05 & 7,56 & 302,885 & 312,157 & 307,521 & \\
\hline & & 5,050 & 6,308 & 229,360 & 262,433 & 245,897 & 25,7 \\
\hline & \multirow{3}{*}{$\begin{array}{l}\text { Tangente } \\
\text { Inicial }\end{array}$} & 1,00 & 1,25 & 89,399 & 76,190 & 82,794 & \\
\hline & & 6,05 & 7,56 & 298,159 & 338,267 & 318,213 & \\
\hline & & 5,050 & 6,308 & 208,760 & 262,077 & 235,418 & 26,8 \\
\hline \multirow{6}{*}{7} & \multirow[t]{3}{*}{ Secante } & 1,00 & 1,25 & $\begin{array}{l}44,624 \\
\end{array}$ & $\begin{array}{l}76,577 \\
\end{array}$ & 60,600 & \\
\hline & & 6,05 & 7,56 & 223,834 & 399,361 & 311,597 & \\
\hline & & 5,050 & 6,308 & 179,210 & 322,785 & 250,997 & 25,1 \\
\hline & \multirow{3}{*}{$\begin{array}{l}\text { Tangente } \\
\text { Inicial }\end{array}$} & 1,00 & 1,25 & 57,756 & 101,694 & 79,725 & \\
\hline & & 6,05 & 7,56 & 233,303 & 404,527 & 318,915 & \\
\hline & & 5,050 & 6,308 & 175,547 & 302,833 & 239,190 & 26,4 \\
\hline
\end{tabular}




\begin{tabular}{|c|c|c|c|c|c|c|c|}
\hline \multirow{6}{*}{8} & \multirow[t]{3}{*}{ Secante } & 1,00 & 1,25 & 70,392 & 61,940 & 66,166 & \multirow[b]{3}{*}{25,6} \\
\hline & & 6,05 & 7,56 & 258,463 & 367,519 & 312,991 & \\
\hline & & 5,050 & 6,308 & 188,070 & 305,579 & 246,824 & \\
\hline & \multirow{3}{*}{$\begin{array}{l}\text { Tangente } \\
\text { Inicial }\end{array}$} & 1,00 & 1,25 & \begin{tabular}{|l|}
91,071 \\
\end{tabular} & 78,600 & 84,836 & \multirow[b]{3}{*}{26,7} \\
\hline & & 6,05 & 7,56 & 267,287 & 375,537 & 321,412 & \\
\hline & & 5,050 & 6,308 & 176,216 & 296,937 & 236,576 & \\
\hline \multirow{6}{*}{9} & \multirow[t]{3}{*}{ Secante } & 1,00 & 1,25 & 78,044 & 39,655 & 58,849 & \multirow[b]{3}{*}{25,9} \\
\hline & & 6,05 & 7,56 & 275,746 & 329,130 & 302,438 & \\
\hline & & 5,050 & 6,308 & 197,703 & 289,475 & 243,589 & \\
\hline & \multirow{3}{*}{$\begin{array}{l}\text { Tangente } \\
\text { Inicial }\end{array}$} & 1,00 & 1,25 & $\begin{array}{l}96,737 \\
\end{array}$ & $\begin{array}{l}61,167 \\
\end{array}$ & 78,952 & \multirow[b]{3}{*}{27,1} \\
\hline & & 6,05 & 7,56 & 290,523 & 332,254 & 311,389 & \\
\hline & & 5,050 & 6,308 & 193,786 & 271,087 & 232,437 & \\
\hline \multirow{6}{*}{10} & \multirow[t]{3}{*}{ Secante } & 1,00 & 1,25 & 114,133 & 0,958 & 57,545 & \\
\hline & & 6,05 & 7,56 & 329,813 & 256,560 & 293,187 & \multirow[b]{2}{*}{26,8} \\
\hline & & 5,050 & 6,308 & 215,681 & 255,602 & 235,641 & \\
\hline & \multirow{3}{*}{$\begin{array}{l}\text { Tangente } \\
\text { Inicial }\end{array}$} & 1,00 & 1,25 & 129,075 & 25,912 & 77,493 & \multirow[b]{3}{*}{28,1} \\
\hline & & 6,05 & 7,56 & 321,631 & 281,603 & 301,617 & \\
\hline & & 5,050 & 6,308 & 192,556 & 255,691 & 224,124 & \\
\hline
\end{tabular}

strain gages

\begin{tabular}{|c|c|c|c|c|c|c|c|}
\hline $\mathrm{CP}$ & Plano & \begin{tabular}{c|} 
Força \\
(tf)
\end{tabular} & $\begin{array}{l}\text { Tensão } \\
\text { (MPa) }\end{array}$ & $\begin{array}{c}\text { e1 } \\
\text { (um) }\end{array}$ & \begin{tabular}{c|} 
e2 \\
(um)
\end{tabular} & \begin{tabular}{c|} 
em \\
(um)
\end{tabular} & $\begin{array}{c}\mathrm{Ec} \\
\text { (GPa) }\end{array}$ \\
\hline \multirow{6}{*}{1} & \multirow[t]{3}{*}{ Secante } & 1,00 & 1,25 & 75,243 & 14,922 & 45,083 & \\
\hline & & 6,05 & 7,56 & 276,934 & 331,430 & 304,182 & \\
\hline & & 5,050 & 6,308 & 201,690 & 316,507 & 259,099 & 24,3 \\
\hline & \multirow{3}{*}{$\begin{array}{l}\text { Tangente } \\
\text { Inicial }\end{array}$} & 1,00 & 1,25 & 94,886 & 38,871 & 66,878 & \\
\hline & & 6,05 & 7,56 & 281,309 & 342,153 & 311,731 & \\
\hline & & 5,050 & 6,308 & 186,423 & 303,282 & 244,853 & 25,8 \\
\hline \multirow{6}{*}{2} & \multirow[t]{3}{*}{ Secante } & 1,00 & 1,25 & 42,779 & 58,641 & 50,710 & \\
\hline & & 6,05 & 7,56 & 355,326 & 271,136 & 313,231 & \\
\hline & & 5,050 & 6,308 & 312,548 & 212,494 & 262,521 & 24,0 \\
\hline & \multirow{3}{*}{$\begin{array}{l}\text { Tangente } \\
\text { Inicial }\end{array}$} & 1,00 & 1,25 & 67,632 & 74,100 & 70,866 & \\
\hline & & 6,05 & 7,56 & 363,551 & 273,280 & 318,416 & \\
\hline & & 5,050 & 6,308 & 295,919 & 199,180 & 247,549 & 25,5 \\
\hline \multirow{6}{*}{3} & \multirow[t]{3}{*}{ Secante } & 1,00 & 1,25 & 80,223 & 33,774 & \begin{tabular}{|l|}
56,998 \\
\end{tabular} & \\
\hline & & 6,00 & 7,49 & 293,021 & 316,613 & 304,817 & \\
\hline & & 5,000 & 6,245 & 212,798 & 282,840 & 247,819 & 25,2 \\
\hline & \multirow{3}{*}{$\begin{array}{l}\text { Tangente } \\
\text { Inicial }\end{array}$} & 1,00 & 1,25 & 108,471 & 52,220 & 80,345 & \\
\hline & & 6,00 & 7,49 & 301,843 & 327,128 & 314,485 & \\
\hline & & 5,000 & 6,245 & 193,372 & 274,909 & 234,140 & 26,7 \\
\hline \multirow{6}{*}{4} & \multirow[t]{3}{*}{ Secante } & 1,00 & 1,25 & 39,733 & 75,641 & $\begin{array}{l}57,687 \\
\end{array}$ & \\
\hline & & 6,05 & 7,56 & 210,683 & 431,025 & 320,854 & \\
\hline & & 5,050 & 6,308 & 170,950 & 355,384 & 263,167 & 24,0 \\
\hline & \multirow{3}{*}{$\begin{array}{l}\text { Tangente } \\
\text { Inicial }\end{array}$} & 1,00 & 1,25 & 58,430 & 98,176 & 78,303 & \\
\hline & & 6,05 & 7,56 & 224,483 & 428,264 & 326,374 & \\
\hline & & 5,050 & 6,308 & 166,053 & 330,088 & 248,071 & 25,4 \\
\hline \multirow{6}{*}{5} & \multirow[t]{3}{*}{ Secante } & 1,00 & 1,25 & \begin{tabular}{|l|}
$-5,387$ \\
\end{tabular} & 128,607 & 61,610 & \\
\hline & & 6,05 & 7,56 & 101,368 & 544,662 & 323,015 & \\
\hline & & 5,050 & 6,308 & 106,755 & 416,055 & 261,405 & 24,1 \\
\hline & \multirow{3}{*}{$\begin{array}{l}\text { Tangente } \\
\text { Inicial }\end{array}$} & 1,00 & 1,25 & 3,873 & 169,900 & 86,886 & \\
\hline & & 6,05 & $\begin{array}{l}1,54 \\
7,56\end{array}$ & 118,908 & 542,967 & 330,937 & \\
\hline & & 5,050 & 6,308 & 115,035 & 373,067 & 244,051 & 25,8 \\
\hline \multirow{6}{*}{6} & \multirow[t]{3}{*}{ Secante } & 1,00 & 1,25 & 39,133 & 72,457 & 55,795 & \\
\hline & & 6,05 & 7,56 & 210,097 & 388,562 & 299,329 & \\
\hline & & 5,050 & 6,308 & 170,964 & 316,104 & 243,534 & 25,9 \\
\hline & \multirow{3}{*}{$\begin{array}{l}\text { Tangente } \\
\text { Inicial }\end{array}$} & 1,00 & 1,25 & 54,991 & $\begin{array}{l}91,429 \\
\end{array}$ & 73,210 & \\
\hline & & 6,05 & 7,56 & 221,946 & 386,780 & 304,363 & \\
\hline & & 5,050 & 6,308 & 166,955 & 295,352 & 231,153 & 27,3 \\
\hline \multirow{6}{*}{7} & \multirow[t]{3}{*}{ Secante } & 1,00 & 1,25 & 11,912 & 117,546 & 64,729 & \\
\hline & & 6,05 & 7,56 & 152,637 & 535,089 & 343,863 & \\
\hline & & 5,050 & 6,308 & 140,725 & 417,543 & 279,134 & 22,6 \\
\hline & \multirow{3}{*}{$\begin{array}{l}\text { Tangente } \\
\text { Inicial }\end{array}$} & 1,00 & 1,25 & 29,603 & 149,129 & 89,366 & \\
\hline & & 6,00 & 7,49 & 168,106 & 536,427 & 352,266 & \\
\hline & & 5,000 & 6,245 & 138,503 & 387,298 & 262,900 & 23,8 \\
\hline & Secante & 1,00 & 1,25 & 40,441 & 66,833 & 53,637 & \\
\hline & & 6,05 & 7,56 & 209,674 & 385,025 & 297,349 & \\
\hline 0 & & 5,050 & 6,308 & 169,233 & 318,192 & 243,713 & 25,9 \\
\hline 8 & Tangente & 1,00 & 1,25 & 65,964 & \begin{tabular}{|l|}
84,679 \\
\end{tabular} & 75,321 & \\
\hline & Inicial & $\begin{array}{l}6,05 \\
\end{array}$ & 7,56 & 222,836 & 393,323 & 308,079 & \\
\hline & & 5,050 & 6,308 & 156,872 & 308,644 & 232,758 & 27,1 \\
\hline
\end{tabular}




\begin{tabular}{|c|c|c|c|c|c|c|c|}
\hline \multirow{6}{*}{9} & \multirow[t]{3}{*}{ Secante } & 1,00 & 1,25 & 2,271 & 127,308 & 64,790 & \\
\hline & & 6,05 & 7,56 & 273,396 & 406,772 & 340,084 & \multirow[b]{2}{*}{22,9} \\
\hline & & 5,050 & 6,308 & 271,125 & 279,464 & 275,294 & \\
\hline & \multirow{3}{*}{$\begin{array}{l}\text { Tangente } \\
\text { Inicial }\end{array}$} & 1,00 & 1,25 & 24,004 & 151,888 & 87,946 & \multirow[b]{3}{*}{24,3} \\
\hline & & 6,05 & 7,56 & 294,773 & 400,627 & 347,700 & \\
\hline & & 5,050 & 6,308 & 270,768 & 248,739 & 259,754 & \\
\hline \multirow{6}{*}{10} & \multirow[t]{3}{*}{ Secante } & 1,00 & 1,25 & 65,238 & 85,418 & 75,328 & \multirow[b]{3}{*}{29,5} \\
\hline & & 6,00 & 7,49 & 301,267 & 272,437 & 286,852 & \\
\hline & & 5,000 & 6,245 & 236,029 & 187,019 & 211,524 & \\
\hline & \multirow{3}{*}{$\begin{array}{l}\text { Tangente } \\
\text { Inicial }\end{array}$} & 1,00 & 1,25 & $\begin{array}{l}99,787 \\
\end{array}$ & 114,593 & 107,190 & \multirow[b]{3}{*}{33,4} \\
\hline & & 6,00 & 7,49 & 261,014 & 327,862 & 294,438 & \\
\hline & & 5,000 & 6,245 & 161,227 & 213,269 & 187,248 & \\
\hline
\end{tabular}

\section{clip gages}

a/c 0,70 - Betonada 1

\begin{tabular}{|c|c|c|c|c|c|c|c|}
\hline CP & Plano & $\begin{array}{c}\text { Força } \\
\text { (tf) }\end{array}$ & $\begin{array}{c}\text { Tensão } \\
\text { (MPa) }\end{array}$ & $\begin{array}{c}\mathrm{e} 1 \\
\text { (um) }\end{array}$ & $\begin{array}{c}\mathrm{e} 2 \\
\text { (um) }\end{array}$ & $\begin{array}{l}\text { em } \\
\text { (um) }\end{array}$ & $\begin{array}{c}\text { Ec } \\
(\mathrm{GPa})\end{array}$ \\
\hline \multirow{6}{*}{1} & \multirow[t]{3}{*}{ Secante } & 1,00 & 1,25 & 105,000 & 10,000 & 57,500 & \multirow[b]{3}{*}{23,5} \\
\hline & & 5,75 & 7,18 & 330,000 & 290,000 & 310,000 & \\
\hline & & 4,750 & 5,933 & 225,000 & 280,000 & 252,500 & \\
\hline & \multirow{3}{*}{$\begin{array}{l}\text { Tangente } \\
\text { Inicial }\end{array}$} & 1,00 & 1,25 & 95,000 & 35,000 & 65,000 & \multirow[b]{3}{*}{24,2} \\
\hline & & 5,75 & 7,18 & 295,000 & 325,000 & 310,000 & \\
\hline & & 4,750 & 5,933 & 200,000 & 290,000 & 245,000 & \\
\hline \multirow{6}{*}{2} & \multirow[t]{3}{*}{ Secante } & 0,95 & 1,19 & 25,000 & 10,000 & 17,500 & \multirow[b]{3}{*}{24,7} \\
\hline & & 5,75 & 7,18 & 335,000 & 185,000 & 260,000 & \\
\hline & & 4,800 & 5,995 & 310,000 & 175,000 & 242,500 & \\
\hline & \multirow{3}{*}{$\begin{array}{l}\text { Tangente } \\
\text { Inicial }\end{array}$} & 1,05 & 1,31 & 30,000 & 0,000 & 15,000 & \multirow[b]{3}{*}{24,7} \\
\hline & & 5,75 & 7,18 & 330,000 & 175,000 & 252,500 & \\
\hline & & 4,700 & 5,871 & 300,000 & 175,000 & 237,500 & \\
\hline \multirow{6}{*}{3} & \multirow[t]{3}{*}{ Secante } & 0,95 & 1,19 & 60,000 & $-20,000$ & 20,000 & \multirow[b]{3}{*}{25,8} \\
\hline & & 5,75 & 7,18 & 295,000 & 210,000 & 252,500 & \\
\hline & & 4,800 & 5,995 & 235,000 & 230,000 & 232,500 & \\
\hline & \multirow{3}{*}{$\begin{array}{l}\text { Tangente } \\
\text { Inicial }\end{array}$} & 1,05 & 1,31 & 50,000 & $-35,000$ & 7,500 & \multirow[b]{3}{*}{25,5} \\
\hline & & 5,75 & 7,18 & 270,000 & 205,000 & 237,500 & \\
\hline & & 4,700 & 5,871 & 220,000 & 240,000 & 230,000 & \\
\hline \multirow{6}{*}{4} & \multirow[t]{3}{*}{ Secante } & 1,00 & 1,25 & 65,000 & 20,000 & 42,500 & \multirow[b]{3}{*}{24,5} \\
\hline & & 5,75 & 7,18 & 265,000 & 305,000 & 285,000 & \\
\hline & & 4,750 & 5,933 & 200,000 & 285,000 & 242,500 & \\
\hline & Tangente & 1,00 & 1,25 & 60,000 & 15,000 & 37,500 & \\
\hline & Inicial & 5,75 & 7,18 & 255,000 & 310,000 & 282,500 & \\
\hline & & 4,750 & 5,933 & 195,000 & 295,000 & 245,000 & 24,2 \\
\hline & Secante & 0,95 & 1,19 & 65,000 & 40,000 & 52,500 & \\
\hline & & 5,75 & 7,18 & 355,000 & 255,000 & 305,000 & \\
\hline 5 & & 4,800 & 5,995 & 290,000 & 215,000 & 252,500 & 23,7 \\
\hline 3 & Tangente & 1,05 & 1,31 & 75,000 & 45,000 & 60,000 & \\
\hline & Inicial & 5,75 & 7,18 & 350,000 & 220,000 & 285,000 & \\
\hline & & 4,700 & 5,871 & 275,000 & 175,000 & 225,000 & 26,1 \\
\hline & Secante & 1,00 & 1,25 & 85,000 & 5,000 & 45,000 & \\
\hline & & 5,75 & 7,18 & 245,000 & 305,000 & 275,000 & \\
\hline 6 & & 4,750 & 5,933 & 160,000 & 300,000 & 230,000 & 25,8 \\
\hline 0 & Tangente & 1,00 & 1,25 & 85,000 & 0,000 & 42,500 & \\
\hline & Inicial & 5,75 & 7,18 & 245,000 & 305,000 & 275,000 & \\
\hline & & 4,750 & 5,933 & 160,000 & 305,000 & 232,500 & 25,5 \\
\hline & Secante & 0,95 & 1,19 & 25,000 & 85,000 & 55,000 & \\
\hline & & 5,75 & 7,18 & 305,000 & 325,000 & 315,000 & \\
\hline 7 & & 4,800 & 5,995 & 280,000 & 240,000 & 260,000 & 23,1 \\
\hline 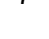 & Tangente & 1,05 & 1,31 & 25,000 & 125,000 & 75,000 & \\
\hline & Inicial & 5,75 & 7,18 & 300,000 & 340,000 & 320,000 & \\
\hline & & 4,700 & 5,871 & 275,000 & 215,000 & 245,000 & 24,0 \\
\hline & Secante & 1,00 & 1,25 & 40,000 & 25,000 & 32,500 & \\
\hline & & 5,75 & 7,18 & 255,000 & 275,000 & 265,000 & \\
\hline 8 & & 4,750 & 5,933 & 215,000 & 250,000 & 232,500 & 25,5 \\
\hline 0 & Tangente & 1,00 & 1,25 & 35,000 & 15,000 & 25,000 & \\
\hline & Inicial & 5,75 & 7,18 & 250,000 & 260,000 & 255,000 & \\
\hline & & 4,750 & 5,933 & 215,000 & 245,000 & 230,000 & 25,8 \\
\hline & Secante & 0,95 & 1,19 & 75,000 & 25,000 & 50,000 & \\
\hline & & 5,75 & 7,18 & 260,000 & 345,000 & 302,500 & \\
\hline 9 & & 4,800 & 5,995 & 185,000 & 320,000 & 252,500 & 23,7 \\
\hline 9 & Tangente & 1,00 & 1,25 & 100,000 & 25,000 & 62,500 & \\
\hline & Inicial & 5,75 & 7,18 & 270,000 & 335,000 & 302,500 & \\
\hline & & 4,750 & 5,933 & 170,000 & 310,000 & 240,000 & 24,7 \\
\hline
\end{tabular}




\begin{tabular}{|c|c|c|c|c|c|c|c|}
\hline \multirow{6}{*}{10} & \multirow[t]{3}{*}{ Secante } & 0,95 & 1,19 & 10,000 & 90,000 & 50,000 & \multirow[b]{3}{*}{22,8} \\
\hline & & 5,75 & 7,18 & 300,000 & 325,000 & 312,500 & \\
\hline & & 4,800 & 5,995 & 290,000 & 235,000 & 262,500 & \\
\hline & \multirow{3}{*}{$\begin{array}{l}\text { Tangente } \\
\text { Inicial }\end{array}$} & 1,05 & 1,31 & 20,000 & 90,000 & 55,000 & \multirow[b]{3}{*}{23,2} \\
\hline & & 5,75 & 7,18 & 290,000 & 325,000 & 307,500 & \\
\hline & & 4,700 & 5,871 & 270,000 & 235,000 & 252,500 & \\
\hline
\end{tabular}

clip gages

a/c 0,70 - Betonada 2

\begin{tabular}{|c|c|c|c|c|c|c|c|}
\hline $\mathrm{CP}$ & Plano & $\begin{array}{c}\text { Força } \\
\text { (tf) }\end{array}$ & $\begin{array}{l}\text { Tensão } \\
\text { (MPa) }\end{array}$ & $\begin{array}{c}\text { e1 } \\
\text { (um) }\end{array}$ & $\begin{array}{c}\mathrm{e} 2 \\
\text { (um) }\end{array}$ & $\begin{array}{c}\text { em } \\
\text { (um) }\end{array}$ & $\begin{array}{c}\text { Ec } \\
(\mathrm{GPa})\end{array}$ \\
\hline \multirow{6}{*}{1} & \multirow[t]{3}{*}{ Secante } & 1,05 & 1,31 & 50,000 & 60,000 & 55,000 & \multirow[b]{3}{*}{24,0} \\
\hline & & 6,05 & 7,56 & 375,000 & 255,000 & 315,000 & \\
\hline & & 5,000 & 6,245 & 325,000 & 195,000 & 260,000 & \\
\hline & \multirow{3}{*}{$\begin{array}{l}\text { Tangente } \\
\text { Inicial }\end{array}$} & 1,05 & 1,31 & 65,000 & 90,000 & 77,500 & \multirow[b]{3}{*}{25,2} \\
\hline & & 6,05 & 7,56 & 380,000 & 270,000 & 325,000 & \\
\hline & & 5,000 & 6,245 & 315,000 & 180,000 & 247,500 & \\
\hline \multirow{6}{*}{2} & \multirow[t]{3}{*}{ Secante } & 1,05 & 1,31 & 10,000 & 60,000 & 35,000 & \multirow[b]{3}{*}{25,2} \\
\hline & & 6,05 & 7,56 & 330,000 & 235,000 & 282,500 & \\
\hline & & 5,000 & 6,245 & 320,000 & 175,000 & 247,500 & \\
\hline & \multirow{3}{*}{$\begin{array}{l}\text { Tangente } \\
\text { Inicial }\end{array}$} & 1,05 & 1,31 & 5,000 & 65,000 & 35,000 & \multirow[b]{3}{*}{25,8} \\
\hline & & 6,05 & 7,56 & 325,000 & 230,000 & 277,500 & \\
\hline & & 5,000 & 6,245 & 320,000 & 165,000 & 242,500 & \\
\hline \multirow{6}{*}{3} & \multirow[t]{3}{*}{ Secante } & 1,05 & 1,31 & 85,000 & $-5,000$ & 40,000 & \multirow[b]{3}{*}{25,5} \\
\hline & & 6,05 & 7,56 & 280,000 & 290,000 & 285,000 & \\
\hline & & 5,000 & 6,245 & 195,000 & 295,000 & 245,000 & \\
\hline & \multirow{3}{*}{$\begin{array}{l}\text { Tangente } \\
\text { Inicial }\end{array}$} & 1,05 & 1,31 & 80,000 & 0,000 & 40,000 & \multirow[b]{3}{*}{26,3} \\
\hline & & 6,05 & 7,56 & 260,000 & 295,000 & 277,500 & \\
\hline & & 5,000 & 6,245 & 180,000 & 295,000 & 237,500 & \\
\hline & Secante & 1,05 & 1,31 & $-5,000$ & 50,000 & 22,500 & \\
\hline & & 6,05 & 7,56 & 270,000 & 255,000 & 262,500 & \\
\hline 4 & & 5,000 & 6,245 & 275,000 & 205,000 & 240,000 & 26,0 \\
\hline 4 & Tangente & 1,05 & 1,31 & $-10,000$ & 45,000 & 17,500 & \\
\hline & Inicial & 6,05 & 7,56 & 265,000 & 245,000 & 255,000 & \\
\hline & & 5,000 & 6,245 & 275,000 & 200,000 & 237,500 & 26,3 \\
\hline & Secante & 1,05 & 1,31 & 45,000 & $-5,000$ & 20,000 & \\
\hline & & 6,05 & 7,56 & 240,000 & 280,000 & 260,000 & \\
\hline 5 & & 5,000 & 6,245 & 195,000 & 285,000 & 240,000 & 26,0 \\
\hline 5 & Tangente & 1,05 & 1,31 & 40,000 & $-10,000$ & 15,000 & \\
\hline & Inicial & 6,05 & 7,56 & 220,000 & 280,000 & 250,000 & \\
\hline & & 5,000 & 6,245 & 180,000 & 290,000 & 235,000 & 26,6 \\
\hline & Secante & 1,05 & 1,31 & 25,000 & 40,000 & 32,500 & \\
\hline & & 6,05 & 7,56 & 355,000 & 205,000 & 280,000 & \\
\hline 6 & & 5,000 & 6,245 & 330,000 & 165,000 & 247,500 & 25,2 \\
\hline b & Tangente & 1,05 & 1,31 & 30,000 & 60,000 & 45,000 & \\
\hline & Inicial & 6,05 & 7,56 & 350,000 & 215,000 & 282,500 & \\
\hline & & 5,000 & 6,245 & 320,000 & 155,000 & 237,500 & 26,3 \\
\hline & Secante & 1,05 & 1,31 & 50,000 & 30,000 & 40,000 & \\
\hline & & 6,05 & 7,56 & 210,000 & 350,000 & 280,000 & \\
\hline 7 & & 5,000 & 6,245 & 160,000 & 320,000 & 240,000 & 26,0 \\
\hline 7 & Tangente & 1,05 & 1,31 & 60,000 & 45,000 & 52,500 & \\
\hline & Inicial & 6,05 & 7,56 & 210,000 & 355,000 & 282,500 & \\
\hline & & 5,000 & 6,245 & 150,000 & 310,000 & 230,000 & 27,2 \\
\hline & Secante & 1,05 & 1,31 & 20,000 & 10,000 & 15,000 & \\
\hline & & 6,05 & 7,56 & 230,000 & 310,000 & 270,000 & \\
\hline 8 & & 5,000 & 6,245 & 210,000 & 300,000 & 255,000 & 24,5 \\
\hline 8 & Tangente & 1,05 & 1,31 & 15,000 & 20,000 & 17,500 & \\
\hline & Inicial & 6,05 & 7,56 & 225,000 & 310,000 & 267,500 & \\
\hline & & 5,000 & 6,245 & 210,000 & 290,000 & 250,000 & 25,0 \\
\hline & Secante & 1,05 & 1,31 & 50,000 & 20,000 & 35,000 & \\
\hline & & 6,05 & 7,56 & 200,000 & 350,000 & 275,000 & \\
\hline 9 & & 5,000 & 6,245 & 150,000 & 330,000 & 240,000 & 26,0 \\
\hline 9 & Tangente & 1,05 & 1,31 & 60,000 & 20,000 & 40,000 & \\
\hline & Inicial & 6,05 & 7,56 & 205,000 & 340,000 & 272,500 & \\
\hline & & 5,000 & 6,245 & 145,000 & 320,000 & 232,500 & 26,9 \\
\hline & Secante & 1,05 & 1,31 & 5,000 & 90,000 & 47,500 & \\
\hline & & 6,05 & 7,56 & 305,000 & 300,000 & 302,500 & \\
\hline 10 & & 5,000 & 6,245 & 300,000 & 210,000 & 255,000 & 24,5 \\
\hline 10 & Tangente & 1,00 & 1,25 & 5,000 & 100,000 & 52,500 & \\
\hline & Inicial & 6,05 & 7,56 & 310,000 & 285,000 & 297,500 & \\
\hline & & 5,050 & 6,308 & 305,000 & 185,000 & 245,000 & 25,7 \\
\hline
\end{tabular}


clip gages

\begin{tabular}{|c|c|c|c|c|c|c|c|}
\hline $\mathrm{CP}$ & Plano & $\begin{array}{c}\text { Força } \\
\text { (tf) }\end{array}$ & $\begin{array}{c}\text { Tensão } \\
\text { (MPa) }\end{array}$ & $\begin{array}{c}\mathrm{e1} \\
\text { (um) }\end{array}$ & $\begin{array}{c}\text { e2 } \\
\text { (um) }\end{array}$ & $\begin{array}{l}\text { em } \\
\text { (um) }\end{array}$ & $\begin{array}{c}\text { Ec } \\
(\mathrm{GPa})\end{array}$ \\
\hline \multirow{6}{*}{1} & \multirow[t]{3}{*}{ Secante } & 1,05 & 1,31 & 120,000 & $-5,000$ & 57,500 & \multirow[b]{3}{*}{23,1} \\
\hline & & 6,05 & 7,56 & 470,000 & 185,000 & 327,500 & \\
\hline & & 5,000 & 6,245 & 350,000 & 190,000 & 270,000 & \\
\hline & \multirow{3}{*}{$\begin{array}{l}\text { Tangente } \\
\text { Inicial }\end{array}$} & 1,05 & 1,31 & 135,000 & 25,000 & 80,000 & \multirow[b]{3}{*}{24,3} \\
\hline & & 6,05 & 7,56 & 470,000 & 205,000 & 337,500 & \\
\hline & & 5,000 & 6,245 & 335,000 & 180,000 & 257,500 & \\
\hline \multirow{6}{*}{2} & \multirow[t]{3}{*}{ Secante } & 1,05 & 1,31 & 75,000 & 15,000 & 45,000 & \multirow[b]{3}{*}{23,6} \\
\hline & & 6,05 & 7,56 & 360,000 & 260,000 & 310,000 & \\
\hline & & 5,000 & 6,245 & 285,000 & 245,000 & 265,000 & \\
\hline & \multirow{3}{*}{$\begin{array}{l}\text { Tangente } \\
\text { Inicial }\end{array}$} & 1,05 & 1,31 & 50,000 & 15,000 & 32,500 & \multirow[b]{3}{*}{24,0} \\
\hline & & 6,05 & 7,56 & 320,000 & 265,000 & 292,500 & \\
\hline & & 5,000 & 6,245 & 270,000 & 250,000 & 260,000 & \\
\hline \multirow{6}{*}{3} & \multirow[t]{3}{*}{ Secante } & 1,05 & 1,31 & 45,000 & 50,000 & 47,500 & \multirow[b]{3}{*}{25,2} \\
\hline & & 6,05 & 7,56 & 280,000 & 310,000 & 295,000 & \\
\hline & & 5,000 & 6,245 & 235,000 & 260,000 & 247,500 & \\
\hline & \multirow{3}{*}{$\begin{array}{l}\text { Tangente } \\
\text { Inicial }\end{array}$} & 1,05 & 1,31 & 55,000 & 50,000 & 52,500 & \multirow[b]{3}{*}{26,3} \\
\hline & & 6,05 & 7,56 & 280,000 & 300,000 & 290,000 & \\
\hline & & 5,000 & 6,245 & 225,000 & 250,000 & 237,500 & \\
\hline & Secante & 1,00 & 1,25 & 55,000 & $-10,000$ & 22,500 & \\
\hline & & 6,05 & 7,56 & 350,000 & 185,000 & 267,500 & \\
\hline 4 & & 5,050 & 6,308 & 295,000 & 195,000 & 245,000 & 25,7 \\
\hline 4 & Tangente & 1,05 & 1,31 & 50,000 & $-10,000$ & 20,000 & \\
\hline & Inicial & 6,05 & 7,56 & 330,000 & 180,000 & 255,000 & \\
\hline & & 5,000 & 6,245 & 280,000 & 190,000 & 235,000 & 26,6 \\
\hline & Secante & 1,05 & 1,31 & 25,000 & 75,000 & 50,000 & \\
\hline & & 6,05 & 7,56 & 345,000 & 270,000 & 307,500 & \\
\hline 5 & & 5,000 & 6,245 & 320,000 & 195,000 & 257,500 & 24,3 \\
\hline 5 & Tangente & 1,05 & 1,31 & 30,000 & 90,000 & 60,000 & \\
\hline & Inicial & 6,05 & 7,56 & 335,000 & 275,000 & 305,000 & \\
\hline & & 5,000 & 6,245 & 305,000 & 185,000 & 245,000 & 25,5 \\
\hline & Secante & 1,05 & 1,31 & 40,000 & 15,000 & 27,500 & \\
\hline & & 6,05 & 7,56 & 365,000 & 190,000 & 277,500 & \\
\hline 6 & & 5,000 & 6,245 & 325,000 & 175,000 & 250,000 & 25,0 \\
\hline 0 & Tangente & 1,05 & 1,31 & 45,000 & 15,000 & 30,000 & \\
\hline & Inicial & 6,05 & 7,56 & 355,000 & 185,000 & 270,000 & \\
\hline & & 5,000 & 6,245 & 310,000 & 170,000 & 240,000 & 26,0 \\
\hline & Secante & 1,05 & 1,31 & 30,000 & 65,000 & 47,500 & \\
\hline & & 6,05 & 7,56 & 235,000 & 385,000 & 310,000 & \\
\hline 7 & & 5,000 & 6,245 & 205,000 & 320,000 & 262,500 & 23,8 \\
\hline 7 & Tangente & 1,05 & 1,31 & 45,000 & 75,000 & 60,000 & \\
\hline & Inicial & 6,05 & 7,56 & 245,000 & 385,000 & 315,000 & \\
\hline & & 5,000 & 6,245 & 200,000 & 310,000 & 255,000 & 24,5 \\
\hline & Secante & 1,05 & 1,31 & 15,000 & 80,000 & 47,500 & \\
\hline & & 6,05 & 7,56 & 295,000 & 310,000 & 302,500 & \\
\hline 8 & & 5,000 & 6,245 & 280,000 & 230,000 & 255,000 & 24,5 \\
\hline 0 & Tangente & 1,05 & 1,31 & 10,000 & 90,000 & 50,000 & \\
\hline & Inicial & 6,05 & 7,56 & 280,000 & 310,000 & 295,000 & \\
\hline & & 5,000 & 6,245 & 270,000 & 220,000 & 245,000 & 25,5 \\
\hline & Secante & 1,05 & 1,31 & 55,000 & 40,000 & 47,500 & \\
\hline & & 6,05 & 7,56 & 365,000 & 225,000 & 295,000 & \\
\hline 9 & & 5,000 & 6,245 & 310,000 & 185,000 & 247,500 & 25,2 \\
\hline 9 & Tangente & 1,05 & 1,31 & 45,000 & 55,000 & 50,000 & \\
\hline & Inicial & 6,05 & 7,56 & 345,000 & 235,000 & 290,000 & \\
\hline & & 5,000 & 6,245 & 300,000 & 180,000 & 240,000 & 26,0 \\
\hline & Secante & 1,05 & 1,31 & $-10,000$ & 85,000 & 37,500 & \\
\hline & & 6,05 & 7,56 & 250,000 & 285,000 & 267,500 & \\
\hline 10 & & 5,000 & 6,245 & 260,000 & 200,000 & 230,000 & 27,2 \\
\hline 10 & Tangente & 1,05 & 1,31 & 10,000 & 90,000 & 50,000 & \\
\hline & Inicial & 6,05 & 7,56 & 270,000 & 280,000 & 275,000 & \\
\hline & & 5,000 & 6,245 & 260,000 & 190,000 & 225,000 & 27,8 \\
\hline
\end{tabular}


1 relógio

\begin{tabular}{|c|c|c|c|c|c|c|c|}
\hline CP & Plano & $\begin{array}{c}\text { Força } \\
\text { (tf) }\end{array}$ & $\begin{array}{l}\text { Tensão } \\
\text { (MPa) }\end{array}$ & $\begin{array}{c}\text { e1 } \\
\text { (um) }\end{array}$ & $\begin{array}{c}\text { e2 } \\
\text { (um) }\end{array}$ & \begin{tabular}{l|} 
em \\
(um)
\end{tabular} & $\begin{array}{c}\mathrm{Ec} \\
(\mathrm{GPa})\end{array}$ \\
\hline \multirow{6}{*}{1} & \multirow[t]{3}{*}{ Secante } & 1,00 & 1,25 & 190,000 & & 190,000 & \multirow[b]{3}{*}{23,7} \\
\hline & & 5,75 & 7,18 & 690,000 & & 690,000 & \\
\hline & & 4,750 & 5,933 & 500,000 & 0,000 & 250,000 & \\
\hline & \multirow{3}{*}{$\begin{array}{l}\text { Tangente } \\
\text { Inicial }\end{array}$} & 1,00 & 1,25 & 260,000 & & 260,000 & \multirow[b]{3}{*}{26,4} \\
\hline & & 5,75 & 7,18 & 710,000 & & 710,000 & \\
\hline & & 4,750 & 5,933 & 450,000 & 0,000 & 225,000 & \\
\hline \multirow{6}{*}{2} & \multirow[t]{3}{*}{ Secante } & 0,95 & 1,19 & 110,000 & & 110,000 & \multirow[b]{3}{*}{27,3} \\
\hline & & 5,75 & 7,18 & 550,000 & & 550,000 & \\
\hline & & 4,800 & 5,995 & 440,000 & 0,000 & 220,000 & \\
\hline & \multirow{3}{*}{$\begin{array}{l}\text { Tangente } \\
\text { Inicial }\end{array}$} & 1,05 & 1,31 & 160,000 & & 160,000 & \multirow[b]{3}{*}{30,1} \\
\hline & & 5,75 & 7,18 & 550,000 & & 550,000 & \\
\hline & & 4,700 & 5,871 & 390,000 & 0,000 & 195,000 & \\
\hline \multirow{6}{*}{3} & \multirow[t]{3}{*}{ Secante } & 0,95 & 1,19 & 70,000 & & 70,000 & \multirow[b]{3}{*}{26,6} \\
\hline & & 5,75 & 7,18 & 520,000 & & 520,000 & \\
\hline & & 4,800 & 5,995 & 450,000 & 0,000 & 225,000 & \\
\hline & \multirow{3}{*}{$\begin{array}{l}\text { Tangente } \\
\text { Inicial }\end{array}$} & 1,05 & 1,31 & 110,000 & & 110,000 & \multirow[b]{3}{*}{28,0} \\
\hline & & 5,75 & 7,18 & 530,000 & & 530,000 & \\
\hline & & 4,700 & 5,871 & 420,000 & 0,000 & 210,000 & \\
\hline & Secante & 0,95 & 1,19 & 90,000 & & 90,000 & \\
\hline & & 5,75 & 7,18 & 530,000 & & 530,000 & \\
\hline 4 & & 4,800 & 5,995 & 440,000 & 0,000 & 220,000 & 27,3 \\
\hline 4 & Tangente & 1,05 & 1,31 & 160,000 & & 160,000 & \\
\hline & Inicial & 5,75 & 7,18 & 560,000 & & 560,000 & \\
\hline & & 4,700 & 5,871 & 400,000 & 0,000 & 200,000 & 29,4 \\
\hline & Secante & 1,00 & 1,25 & 180,000 & & 180,000 & \\
\hline & & 5,75 & 7,18 & 690,000 & & 690,000 & \\
\hline 5 & & 4,750 & 5,933 & 510,000 & 0,000 & 255,000 & 23,3 \\
\hline 3 & Tangente & 0,95 & 1,19 & 230,000 & & 230,000 & \\
\hline & Inicial & 5,75 & 7,18 & 700,000 & & 700,000 & \\
\hline & & 4,800 & 5,995 & 470,000 & 0,000 & 235,000 & 25,5 \\
\hline & Secante & 1,05 & 1,31 & 80,000 & & 80,000 & \\
\hline & & 5,75 & 7,18 & 500,000 & & 500,000 & \\
\hline 6 & & 4,700 & 5,871 & 420,000 & 0,000 & 210,000 & 28,0 \\
\hline 0 & Tangente & 1,05 & 1,31 & 100,000 & & 100,000 & \\
\hline & Inicial & 5,75 & 7,18 & 510,000 & & 510,000 & \\
\hline & & 4,700 & 5,871 & 410,000 & 0,000 & 205,000 & 28,6 \\
\hline & Secante & 0,95 & 1,19 & 200,000 & & 200,000 & \\
\hline & & 5,75 & 7,18 & 690,000 & & 690,000 & \\
\hline 7 & & 4,800 & 5,995 & 490,000 & 0,000 & 245,000 & 24,5 \\
\hline t & Tangente & 1,00 & 1,25 & 270,000 & & 270,000 & \\
\hline & |Inicial & 5,75 & 7,18 & 710,000 & & 710,000 & \\
\hline & & 4,750 & 5,933 & 440,000 & 0,000 & 220,000 & 27,0 \\
\hline & Secante & 1,05 & 1,31 & 80,000 & & 80,000 & \\
\hline & & 5,75 & 7,18 & 550,000 & & 550,000 & \\
\hline 8 & & 4,700 & 5,871 & 470,000 & 0,000 & 235,000 & 25,0 \\
\hline 0 & Tangente & 1,05 & 1,31 & 130,000 & & 130,000 & \\
\hline & Inicial & 5,75 & 7,18 & 560,000 & & 560,000 & \\
\hline & & 4,700 & 5,871 & 430,000 & 0,000 & 215,000 & 27,3 \\
\hline & Secante & 1,00 & 1,25 & 0,000 & & 0,000 & \\
\hline & & 5,75 & 7,18 & 440,000 & & 440,000 & \\
\hline 9 & & 4,750 & 5,933 & 440,000 & 0,000 & 220,000 & 27,0 \\
\hline$y$ & Tangente & 1,05 & 1,31 & 30,000 & & 30,000 & \\
\hline & Inicial & 5,75 & 7,18 & 450,000 & & 450,000 & \\
\hline & & 4,700 & 5,871 & 420,000 & 0,000 & 210,000 & 28,0 \\
\hline & Secante & 1,00 & 1,25 & 100,000 & & 100,000 & \\
\hline & & 5,75 & 7,18 & 490,000 & & 490,000 & \\
\hline 10 & & 4,750 & 5,933 & 390,000 & 0,000 & 195,000 & 30,4 \\
\hline 10 & Tangente & 1,05 & 1,31 & 140,000 & & 140,000 & \\
\hline & Inicial & 5,75 & 7,18 & 520,000 & & 520,000 & \\
\hline & & 4,700 & 5,871 & 380,000 & 0,000 & 190,000 & 30,9 \\
\hline
\end{tabular}


1 relógio

\begin{tabular}{|c|c|c|c|c|c|c|c|}
\hline CP & Plano & $\begin{array}{c}\text { Força } \\
\text { (tf) }\end{array}$ & $\begin{array}{c}\text { Tensão } \\
\text { (MPa) }\end{array}$ & $\begin{array}{c}\text { e1 } \\
\text { (um) }\end{array}$ & $\begin{array}{c}\text { e2 } \\
\text { (um) }\end{array}$ & $\begin{array}{l}\text { em } \\
\text { (um) }\end{array}$ & $\begin{array}{c}\mathrm{Ec} \\
(\mathrm{GPa})\end{array}$ \\
\hline \multirow{6}{*}{1} & \multirow[t]{3}{*}{ Secante } & 1,00 & 1,25 & 220,000 & & 220,000 & \\
\hline & & 6,05 & 7,56 & 750,000 & & 750,000 & \\
\hline & & 5,050 & 6,308 & 530,000 & 0,000 & 265,000 & 23,8 \\
\hline & \multirow{3}{*}{$\begin{array}{l}\text { Tangente } \\
\text { Inicial }\end{array}$} & 1,05 & 1,31 & 260,000 & & 260,000 & \\
\hline & & 6,05 & 7,56 & 760,000 & & 760,000 & \\
\hline & & 5,000 & 6,245 & 500,000 & 0,000 & 250,000 & 25,0 \\
\hline \multirow{6}{*}{2} & \multirow[t]{3}{*}{ Secante } & 1,00 & 1,25 & 110,000 & & 110,000 & \\
\hline & & 6,05 & 7,56 & 520,000 & & 520,000 & \\
\hline & & 5,050 & 6,308 & 410,000 & 0,000 & 205,000 & 30,8 \\
\hline & \multirow{3}{*}{$\begin{array}{l}\text { Tangente } \\
\text { Inicial }\end{array}$} & 1,05 & 1,31 & 140,000 & & 140,000 & \\
\hline & & 6,05 & 7,56 & 540,000 & & 540,000 & \\
\hline & & 5,000 & 6,245 & 400,000 & 0,000 & 200,000 & 31,2 \\
\hline \multirow{6}{*}{3} & \multirow[t]{3}{*}{ Secante } & 1,05 & 1,31 & 160,000 & & 160,000 & \\
\hline & & 6,05 & 7,56 & 630,000 & & 630,000 & \\
\hline & & 5,000 & 6,245 & 470,000 & 0,000 & 235,000 & 26,6 \\
\hline & \multirow{3}{*}{$\begin{array}{l}\text { Tangente } \\
\text { Inicial }\end{array}$} & 1,05 & 1,31 & 190,000 & & 190,000 & \\
\hline & & 6,05 & 7,56 & 630,000 & & 630,000 & \\
\hline & & 5,000 & 6,245 & 440,000 & 0,000 & 220,000 & 28,4 \\
\hline \multirow{6}{*}{4} & \multirow[t]{3}{*}{ Secante } & 1,00 & 1,25 & 150,000 & & 150,000 & \\
\hline & & 6,05 & 7,56 & 610,000 & & 610,000 & \\
\hline & & 5,050 & 6,308 & 460,000 & 0,000 & 230,000 & 27,4 \\
\hline & \multirow{3}{*}{$\begin{array}{l}\text { Tangente } \\
\text { Inicial }\end{array}$} & 1,05 & 1,31 & 200,000 & & 200,000 & \\
\hline & & 6,05 & 7,56 & 630,000 & & 630,000 & \\
\hline & & 5,000 & 6,245 & 430,000 & 0,000 & 215,000 & 29,0 \\
\hline \multirow{6}{*}{5} & \multirow[t]{3}{*}{ Secante } & 1,05 & 1,31 & 130,000 & & 130,000 & \\
\hline & & 6,05 & 7,56 & 560,000 & & 560,000 & \\
\hline & & 5,000 & 6,245 & 430,000 & 0,000 & 215,000 & 29,0 \\
\hline & \multirow{3}{*}{$\begin{array}{l}\text { Tangente } \\
\text { Inicial }\end{array}$} & 1,05 & 1,31 & 170,000 & & 170,000 & \\
\hline & & 6,05 & 7,56 & 580,000 & & 580,000 & \\
\hline & & 5,000 & 6,245 & 410,000 & 0,000 & 205,000 & 30,5 \\
\hline & Secante & 1,00 & 1,25 & 150,000 & & 150,000 & \\
\hline & & 6,05 & 7,56 & 640,000 & & 640,000 & \\
\hline 6 & & 5,050 & 6,308 & 490,000 & 0,000 & 245,000 & 25,7 \\
\hline 0 & Tangente & 1,05 & 1,31 & 220,000 & & 220,000 & \\
\hline & Inicial & 6,05 & 7,56 & 650,000 & & 650,000 & \\
\hline & & 5,000 & 6,245 & 430,000 & 0,000 & 215,000 & 29,0 \\
\hline & Secante & 1,00 & 1,25 & 170,000 & & 170,000 & \\
\hline & & 6,05 & 7,56 & 730,000 & & 730,000 & \\
\hline 7 & & 5,050 & 6,308 & 560,000 & 0,000 & 280,000 & 22,5 \\
\hline 1 & Tangente & 1,05 & 1,31 & 240,000 & & 240,000 & \\
\hline & Inicial & 6,05 & 7,56 & 740,000 & & 740,000 & \\
\hline & & 5,000 & 6,245 & 500,000 & 0,000 & 250,000 & 25,0 \\
\hline & Secante & 1,05 & 1,31 & 190,000 & & 190,000 & \\
\hline & & 6,05 & 7,56 & 710,000 & & 710,000 & \\
\hline 8 & & 5,000 & 6,245 & 520,000 & 0,000 & 260,000 & 24,0 \\
\hline 0 & Tangente & 1,05 & 1,31 & 210,000 & & 210,000 & \\
\hline & Inicial & 6,05 & 7,56 & 690,000 & & 690,000 & \\
\hline & & 5,000 & 6,245 & 480,000 & 0,000 & 240,000 & 26,0 \\
\hline & Secante & 1,00 & 1,25 & 210,000 & & 210,000 & \\
\hline & & 6,05 & 7,56 & 760,000 & & 760,000 & \\
\hline 9 & & 5,050 & 6,308 & 550,000 & 0,000 & 275,000 & 22,9 \\
\hline$y$ & Tangente & 1,05 & 1,31 & 280,000 & & 280,000 & \\
\hline & Inicial & 6,05 & 7,56 & 770,000 & & 770,000 & \\
\hline & & 5,000 & 6,245 & 490,000 & 0,000 & 245,000 & 25,5 \\
\hline & Secante & 1,00 & 1,25 & 130,000 & & 130,000 & \\
\hline & & 6,05 & 7,56 & 580,000 & & 580,000 & \\
\hline 10 & & 5,050 & 6,308 & 450,000 & 0,000 & 225,000 & 28,0 \\
\hline 10 & Tangente & 1,05 & 1,31 & 160,000 & & 160,000 & \\
\hline & Inicial & 6,05 & 7,56 & 590,000 & & 590,000 & \\
\hline & & 5,000 & 6,245 & 430,000 & 0,000 & 215,000 & 29,0 \\
\hline
\end{tabular}


1 relógio

\begin{tabular}{|c|c|c|c|c|c|c|c|}
\hline CP & Plano & $\begin{array}{c}\text { Força } \\
\text { (tf) }\end{array}$ & $\begin{array}{c}\text { Tensão } \\
\text { (MPa) }\end{array}$ & $\begin{array}{c}\text { e1 } \\
\text { (um) }\end{array}$ & $\begin{array}{c}\text { e2 } \\
\text { (um) }\end{array}$ & $\begin{array}{l}\text { em } \\
\text { (um) }\end{array}$ & $\begin{array}{c}\mathrm{Ec} \\
(\mathrm{GPa})\end{array}$ \\
\hline \multirow{6}{*}{1} & \multirow[t]{3}{*}{ Secante } & 1,00 & 1,25 & 140,000 & & 140,000 & \multirow[b]{3}{*}{24,7} \\
\hline & & 6,05 & 7,56 & 650,000 & & 650,000 & \\
\hline & & 5,050 & 6,308 & 510,000 & 0,000 & 255,000 & \\
\hline & \multirow{3}{*}{$\begin{array}{l}\text { Tangente } \\
\text { Inicial }\end{array}$} & 1,00 & 1,25 & 190,000 & & 190,000 & \multirow[b]{3}{*}{26,3} \\
\hline & & 6,05 & 7,56 & 670,000 & & 670,000 & \\
\hline & & 5,050 & 6,308 & 480,000 & 0,000 & 240,000 & \\
\hline \multirow{6}{*}{2} & \multirow[t]{3}{*}{ Secante } & 1,00 & 1,25 & 110,000 & & 110,000 & \multirow[b]{3}{*}{24,3} \\
\hline & & 6,05 & 7,56 & 630,000 & & 630,000 & \\
\hline & & 5,050 & 6,308 & 520,000 & 0,000 & 260,000 & \\
\hline & \multirow{3}{*}{$\begin{array}{l}\text { Tangente } \\
\text { Inicial }\end{array}$} & 1,05 & 1,31 & 200,000 & & 200,000 & \multirow[b]{3}{*}{27,8} \\
\hline & & 6,05 & 7,56 & 650,000 & & 650,000 & \\
\hline & & 5,000 & 6,245 & 450,000 & 0,000 & 225,000 & \\
\hline \multirow{6}{*}{3} & \multirow[t]{3}{*}{ Secante } & 1,05 & 1,31 & 100,000 & & 100,000 & \multirow[b]{3}{*}{26,6} \\
\hline & & 6,05 & 7,56 & 570,000 & & 570,000 & \\
\hline & & 5,000 & 6,245 & 470,000 & 0,000 & 235,000 & \\
\hline & \multirow{3}{*}{$\begin{array}{l}\text { Tangente } \\
\text { Inicial }\end{array}$} & 1,05 & 1,31 & 150,000 & & 150,000 & \multirow[b]{3}{*}{28,4} \\
\hline & & 6,05 & 7,56 & 590,000 & & 590,000 & \\
\hline & & 5,000 & 6,245 & 440,000 & 0,000 & 220,000 & \\
\hline & Secante & 1,00 & 1,25 & 140,000 & & 140,000 & \\
\hline & & 6,05 & 7,56 & 700,000 & & 700,000 & \\
\hline 4 & & 5,050 & 6,308 & 560,000 & 0,000 & 280,000 & 22,5 \\
\hline 4 & Tangente & 1,05 & 1,31 & 190,000 & & 190,000 & \\
\hline & Inicial & 6,05 & 7,56 & 700,000 & & 700,000 & \\
\hline & & 5,000 & 6,245 & 510,000 & 0,000 & 255,000 & 24,5 \\
\hline & Secante & 1,05 & 1,31 & 140,000 & & 140,000 & \\
\hline & & 6,05 & 7,56 & 730,000 & & 730,000 & \\
\hline 5 & & 5,000 & 6,245 & 590,000 & 0,000 & 295,000 & 21,2 \\
\hline 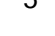 & Tangente & 1,05 & 1,31 & 210,000 & & 210,000 & \\
\hline & Inicial & 6,05 & 7,56 & 750,000 & & 750,000 & \\
\hline & & 5,000 & 6,245 & 540,000 & 0,000 & 270,000 & 23,1 \\
\hline & Secante & 1,00 & 1,25 & 70,000 & & 70,000 & \\
\hline & & 6,05 & 7,56 & 530,000 & & 530,000 & \\
\hline 6 & & 5,050 & 6,308 & 460,000 & 0,000 & 230,000 & 27,4 \\
\hline 0 & Tangente & 1,00 & 1,25 & 110,000 & & 110,000 & \\
\hline & Inicial & 6,05 & 7,56 & 550,000 & & 550,000 & \\
\hline & & 5,050 & 6,308 & 440,000 & 0,000 & 220,000 & 28,7 \\
\hline & Secante & 1,00 & 1,25 & 200,000 & & 200,000 & \\
\hline & & 6,05 & 7,56 & 830,000 & & 830,000 & \\
\hline 7 & & 5,050 & 6,308 & 630,000 & 0,000 & 315,000 & 20,0 \\
\hline 7 & Tangente & 1,05 & 1,31 & 270,000 & & 270,000 & \\
\hline & Inicial & 6,05 & 7,56 & 850,000 & & 850,000 & \\
\hline & & 5,000 & 6,245 & 580,000 & 0,000 & 290,000 & 21,5 \\
\hline & Secante & 1,05 & 1,31 & 40,000 & & 40,000 & \\
\hline & & 6,05 & 7,56 & 440,000 & & 440,000 & \\
\hline 8 & & 5,000 & 6,245 & 400,000 & 0,000 & 200,000 & 31,2 \\
\hline 0 & Tangente & 1,05 & 1,31 & 40,000 & & 40,000 & \\
\hline & Inicial & 6,05 & 7,56 & 450,000 & & 450,000 & \\
\hline & & 5,000 & 6,245 & 410,000 & 0,000 & 205,000 & 30,5 \\
\hline & Secante & 1,00 & 1,25 & 80,000 & & 80,000 & \\
\hline & & 6,05 & 7,56 & 530,000 & & 530,000 & \\
\hline 9 & & 5,050 & 6,308 & 450,000 & 0,000 & 225,000 & 28,0 \\
\hline 9 & Tangente & 1,05 & 1,31 & 120,000 & & 120,000 & \\
\hline & Inicial & 6,05 & 7,56 & 550,000 & & 550,000 & \\
\hline & & 5,000 & 6,245 & 430,000 & 0,000 & 215,000 & 29,0 \\
\hline & Secante & 1,00 & 1,25 & 0,000 & & 0,000 & \\
\hline & & 6,05 & 7,56 & 410,000 & & 410,000 & \\
\hline 10 & & 5,050 & 6,308 & 410,000 & 0,000 & 205,000 & 30,8 \\
\hline 10 & Tangente & 1,05 & 1,31 & 30,000 & & 30,000 & \\
\hline & Inicial & 6,05 & 7,56 & 440,000 & & 440,000 & \\
\hline & & 5,000 & 6,245 & 410,000 & 0,000 & 205,000 & 30,5 \\
\hline
\end{tabular}


2 relógios

\begin{tabular}{|c|c|c|c|c|c|c|c|}
\hline CP & Plano & $\begin{array}{c}\text { Força } \\
\text { (tf) }\end{array}$ & $\begin{array}{c}\text { Tensão } \\
\text { (MPa) }\end{array}$ & $\begin{array}{c}\text { e1 } \\
\text { (um) }\end{array}$ & $\begin{array}{c}\text { e2 } \\
\text { (um) }\end{array}$ & $\begin{array}{l}\text { em } \\
\text { (um) }\end{array}$ & $\begin{array}{c}\mathrm{Ec} \\
(\mathrm{GPa})\end{array}$ \\
\hline \multirow{6}{*}{1} & \multirow[t]{3}{*}{ Secante } & 0,90 & 1,12 & 130,000 & 50,000 & 90,000 & \\
\hline & & 5,75 & 7,18 & 350,000 & 270,000 & 310,000 & \\
\hline & & 4,850 & 6,058 & 220,000 & 220,000 & 220,000 & 27,5 \\
\hline & \multirow{3}{*}{$\begin{array}{l}\text { Tangente } \\
\text { Inicial }\end{array}$} & 1,05 & 1,31 & 190,000 & 0,000 & 95,000 & \\
\hline & & 5,75 & 7,18 & 390,000 & 230,000 & 310,000 & \\
\hline & & 4,700 & 5,871 & 200,000 & 230,000 & 215,000 & 27,3 \\
\hline \multirow{6}{*}{2} & \multirow[t]{3}{*}{ Secante } & 1,05 & 1,31 & 160,000 & $-70,000$ & 45,000 & \\
\hline & & 5,75 & $\begin{array}{l}7,18 \\
\end{array}$ & 330,000 & 120,000 & 225,000 & \\
\hline & & 4,700 & 5,871 & 170,000 & 190,000 & 180,000 & 32,6 \\
\hline & \multirow{3}{*}{$\begin{array}{l}\text { Tangente } \\
\text { Inicial }\end{array}$} & 1,05 & 1,31 & 590,000 & $-410,000$ & 90,000 & \\
\hline & & 5,75 & 7,18 & 700,000 & $-190,000$ & 255,000 & \\
\hline & & 4,700 & 5,871 & 110,000 & 220,000 & 165,000 & 35,6 \\
\hline \multirow{6}{*}{3} & \multirow[t]{3}{*}{ Secante } & 1,00 & 1,25 & 220,000 & $-30,000$ & 95,000 & \\
\hline & & 5,75 & 7,18 & 570,000 & 170,000 & 370,000 & \\
\hline & & 4,750 & 5,933 & 350,000 & 200,000 & 275,000 & 21,6 \\
\hline & \multirow{3}{*}{$\begin{array}{l}\text { Tangente } \\
\text { Inicial }\end{array}$} & 1,05 & 1,31 & 700,000 & $-440,000$ & 130,000 & \\
\hline & & 5,75 & 7,18 & 970,000 & $-230,000$ & 370,000 & \\
\hline & & 4,700 & 5,871 & 270,000 & 210,000 & 240,000 & 24,5 \\
\hline \multirow{6}{*}{4} & \multirow[t]{3}{*}{ Secante } & 1,05 & 1,31 & 150,000 & 60,000 & 105,000 & \\
\hline & & 5,75 & 7,18 & 480,000 & 300,000 & 390,000 & \\
\hline & & 4,700 & 5,871 & 330,000 & 240,000 & 285,000 & 20,6 \\
\hline & \multirow{3}{*}{$\begin{array}{l}\text { Tangente } \\
\text { Inicial }\end{array}$} & 1,05 & 1,31 & 200,000 & 70,000 & 135,000 & \\
\hline & & 5,75 & 7,18 & 540,000 & 230,000 & 385,000 & \\
\hline & & 4,700 & 5,871 & 340,000 & 160,000 & 250,000 & 23,5 \\
\hline \multirow{6}{*}{5} & \multirow[t]{3}{*}{ Secante } & 1,00 & 1,25 & 200,000 & $-60,000$ & 70,000 & \\
\hline & & 5,75 & 7,18 & 340,000 & 200,000 & 270,000 & \\
\hline & & 4,750 & 5,933 & 140,000 & 260,000 & 200,000 & 29,7 \\
\hline & \multirow{3}{*}{$\begin{array}{l}\text { Tangente } \\
\text { Inicial }\end{array}$} & 1,10 & 1,37 & 230,000 & $-40,000$ & 95,000 & \\
\hline & & 5,75 & 7,18 & 330,000 & 230,000 & 280,000 & \\
\hline & & 4,650 & 5,808 & 100,000 & 270,000 & 185,000 & 31,4 \\
\hline & Secante & 1,05 & 1,31 & $-40,000$ & 130,000 & 45,000 & \\
\hline & & 5,75 & 7,18 & 220,000 & 330,000 & 275,000 & \\
\hline 6 & & 4,700 & 5,871 & 260,000 & 200,000 & 230,000 & 25,5 \\
\hline 0 & Tangente & 1,05 & 1,31 & 60,000 & 50,000 & 55,000 & \\
\hline & Inicial & 5,75 & 7,18 & 220,000 & 320,000 & 270,000 & \\
\hline & & 4,700 & 5,871 & 160,000 & 270,000 & 215,000 & 27,3 \\
\hline & Secante & 1,05 & 1,31 & 240,000 & $-110,000$ & 65,000 & \\
\hline & & 5,75 & 7,18 & 530,000 & 20,000 & 275,000 & \\
\hline 7 & & 4,700 & 5,871 & 290,000 & 130,000 & 210,000 & 28,0 \\
\hline 7 & Tangente & 1,05 & 1,31 & 1050,000 & $-850,000$ & 100,000 & \\
\hline & Inicial & 5,75 & 7,18 & 1290,000 & $-680,000$ & 305,000 & \\
\hline & & 4,700 & 5,871 & 240,000 & 170,000 & 205,000 & 28,6 \\
\hline & Secante & 1,05 & 1,31 & 360,000 & $-180,000$ & 90,000 & \\
\hline & & 5,75 & 7,18 & 500,000 & 70,000 & 285,000 & \\
\hline 8 & & 4,700 & 5,871 & 140,000 & 250,000 & 195,000 & 30,1 \\
\hline 0 & Tangente & 1,05 & 1,31 & 640,000 & $-430,000$ & 105,000 & \\
\hline & Inicial & 5,75 & 7,18 & 690,000 & $-110,000$ & 290,000 & \\
\hline & & 4,700 & 5,871 & 50,000 & 320,000 & 185,000 & 31,7 \\
\hline & Secante & 1,00 & 1,25 & 270,000 & $-130,000$ & 70,000 & \\
\hline & & 5,75 & 7,18 & 430,000 & 180,000 & 305,000 & \\
\hline 9 & & 4,750 & 5,933 & 160,000 & 310,000 & 235,000 & 25,2 \\
\hline$y$ & Tangente & 1,05 & 1,31 & 650,000 & $-470,000$ & 90,000 & \\
\hline & Inicial & 5,75 & 7,18 & 740,000 & $-120,000$ & 310,000 & \\
\hline & & 4,700 & 5,871 & 90,000 & 350,000 & 220,000 & 26,7 \\
\hline & Secante & 1,00 & 1,25 & 110,000 & $-10,000$ & 50,000 & \\
\hline & & 5,75 & 7,18 & 160,000 & 390,000 & 275,000 & \\
\hline 10 & & 4,750 & 5,933 & 50,000 & 400,000 & 225,000 & 26,4 \\
\hline 10 & Tangente & 1,05 & 1,31 & 120,000 & 40,000 & 80,000 & \\
\hline & Inicial & 5,75 & 7,18 & 160,000 & 420,000 & 290,000 & \\
\hline & & 4,700 & 5,871 & 40,000 & 380,000 & 210,000 & 28,0 \\
\hline
\end{tabular}




\section{2 relógios}

\begin{tabular}{|c|c|c|c|c|c|c|c|}
\hline CP & Plano & $\begin{array}{c}\text { Força } \\
\text { (tf) }\end{array}$ & $\begin{array}{c}\text { Tensão } \\
\text { (MPa) }\end{array}$ & $\begin{array}{c}\mathrm{e1} \\
\text { (um) }\end{array}$ & $\begin{array}{c}\mathrm{e} 2 \\
\text { (um) }\end{array}$ & $\begin{array}{c}\text { em } \\
\text { (um) }\end{array}$ & $\begin{array}{c}\text { Ec } \\
(\mathrm{GPa})\end{array}$ \\
\hline \multirow{6}{*}{1} & \multirow[t]{3}{*}{ Secante } & 1,05 & 1,31 & 40,000 & 110,000 & 75,000 & \multirow[b]{3}{*}{29,0} \\
\hline & & 6,05 & 7,56 & 320,000 & 260,000 & 290,000 & \\
\hline & & 5,000 & 6,245 & 280,000 & 150,000 & 215,000 & \\
\hline & \multirow{3}{*}{$\begin{array}{l}\text { Tangente } \\
\text { Inicial }\end{array}$} & 1,05 & 1,31 & 310,000 & $-100,000$ & 105,000 & \multirow[b]{3}{*}{29,7} \\
\hline & & 6,05 & 7,56 & 570,000 & 60,000 & 315,000 & \\
\hline & & 5,000 & 6,245 & 260,000 & 160,000 & 210,000 & \\
\hline \multirow{6}{*}{2} & \multirow[t]{3}{*}{ Secante } & 1,00 & 1,25 & 220,000 & $-120,000$ & 50,000 & \multirow[b]{3}{*}{28,7} \\
\hline & & 6,05 & 7,56 & 520,000 & 20,000 & 270,000 & \\
\hline & & 5,050 & 6,308 & 300,000 & 140,000 & 220,000 & \\
\hline & \multirow{3}{*}{$\begin{array}{l}\text { Tangente } \\
\text { Inicial }\end{array}$} & 1,05 & 1,31 & 430,000 & $-270,000$ & 80,000 & \multirow[b]{3}{*}{31,2} \\
\hline & & 6,05 & 7,56 & 650,000 & $-90,000$ & 280,000 & \\
\hline & & 5,000 & 6,245 & 220,000 & 180,000 & 200,000 & \\
\hline \multirow{6}{*}{3} & \multirow[t]{3}{*}{ Secante } & 1,05 & 1,31 & 510,000 & $-260,000$ & 125,000 & \multirow[b]{3}{*}{24,5} \\
\hline & & 6,05 & 7,56 & 820,000 & $-60,000$ & 380,000 & \\
\hline & & 5,000 & 6,245 & 310,000 & 200,000 & 255,000 & \\
\hline & \multirow{3}{*}{$\begin{array}{l}\text { Tangente } \\
\text { Inicial }\end{array}$} & 1,05 & 1,31 & 660,000 & $-410,000$ & 125,000 & \multirow[b]{3}{*}{24,5} \\
\hline & & 6,05 & 7,56 & 950,000 & $-190,000$ & 380,000 & \\
\hline & & 5,000 & 6,245 & 290,000 & 220,000 & 255,000 & \\
\hline & Secante & 1,05 & 1,31 & 40,000 & 80,000 & 60,000 & \\
\hline & & 6,05 & 7,56 & 290,000 & 240,000 & 265,000 & \\
\hline 4 & & 5,000 & 6,245 & 250,000 & 160,000 & 205,000 & 30,5 \\
\hline 4 & Tangente & 1,05 & 1,31 & 110,000 & 50,000 & 80,000 & \\
\hline & Inicial & 6,05 & 7,56 & 340,000 & 230,000 & 285,000 & \\
\hline & & 5,000 & 6,245 & 230,000 & 180,000 & 205,000 & 30,5 \\
\hline & Secante & 1,05 & 1,31 & 110,000 & 50,000 & 80,000 & \\
\hline & & 6,05 & 7,56 & 410,000 & 260,000 & 335,000 & \\
\hline 5 & & 5,000 & 6,245 & 300,000 & 210,000 & 255,000 & 24,5 \\
\hline 0 & Tangente & 1,05 & 1,31 & 190,000 & 20,000 & 105,000 & \\
\hline & Inicial & 6,05 & 7,56 & 460,000 & 220,000 & 340,000 & \\
\hline & & 5,000 & 6,245 & 270,000 & 200,000 & 235,000 & 26,6 \\
\hline & Secante & 1,05 & 1,31 & 80,000 & 10,000 & 45,000 & \\
\hline & & 6,05 & 7,56 & 370,000 & 150,000 & 260,000 & \\
\hline & & 5,000 & 6,245 & 290,000 & 140,000 & 215,000 & 29,0 \\
\hline 6 & Tangente & 1,05 & 1,31 & 150,000 & $-10,000$ & 70,000 & \\
\hline & Inicial & 6,05 & 7,56 & 420,000 & 140,000 & 280,000 & \\
\hline & & 5,000 & 6,245 & 270,000 & 150,000 & 210,000 & 29,7 \\
\hline & Secante & 1,00 & 1,25 & 510,000 & $-360,000$ & 75,000 & \\
\hline & & 6,05 & 7,56 & 740,000 & $-210,000$ & 265,000 & \\
\hline 7 & & 5,050 & 6,308 & 230,000 & 150,000 & 190,000 & 33,2 \\
\hline 7 & Tangente & 1,05 & 1,31 & 790,000 & $-560,000$ & 115,000 & \\
\hline & Inicial & 6,05 & 7,56 & 800,000 & $-240,000$ & 280,000 & \\
\hline & & 5,000 & 6,245 & 10,000 & 320,000 & 165,000 & 37,8 \\
\hline & Secante & 1,05 & 1,31 & 170,000 & $-60,000$ & 55,000 & \\
\hline & & 6,05 & 7,56 & 310,000 & 240,000 & 275,000 & \\
\hline 8 & & 5,000 & 6,245 & 140,000 & 300,000 & 220,000 & 28,4 \\
\hline 0 & Tangente & 1,05 & 1,31 & 420,000 & $-250,000$ & 85,000 & \\
\hline & Inicial & 6,05 & 7,56 & 450,000 & 120,000 & 285,000 & \\
\hline & & 5,000 & 6,245 & 30,000 & 370,000 & 200,000 & 31,2 \\
\hline & Secante & 1,00 & 1,25 & 390,000 & $-270,000$ & 60,000 & \\
\hline & & 6,05 & 7,56 & 650,000 & $-110,000$ & 270,000 & \\
\hline 9 & & 5,050 & 6,308 & 260,000 & 160,000 & 210,000 & 30,0 \\
\hline$y$ & Tangente & 1,05 & 1,31 & 850,000 & $-710,000$ & 70,000 & \\
\hline & Inicial & 6,05 & 7,56 & 990,000 & $-460,000$ & 265,000 & \\
\hline & & 5,000 & 6,245 & 140,000 & 250,000 & 195,000 & 32,0 \\
\hline & Secante & 1,05 & 1,31 & 370,000 & $-230,000$ & 70,000 & \\
\hline & & 6,05 & 7,56 & 540,000 & $-40,000$ & 250,000 & \\
\hline 10 & & 5,000 & 6,245 & 170,000 & 190,000 & 180,000 & 34,7 \\
\hline 10 & Tangente & 1,05 & 1,31 & 870,000 & $-650,000$ & 110,000 & \\
\hline & Inicial & 6,05 & 7,56 & 1020,000 & $-460,000$ & 280,000 & \\
\hline & & 5,000 & 6,245 & 150,000 & 190,000 & 170,000 & 36,7 \\
\hline
\end{tabular}


2 relógios

\begin{tabular}{|c|c|c|c|c|c|c|c|}
\hline CP & Plano & $\begin{array}{c}\text { Força } \\
\text { (tf) }\end{array}$ & $\begin{array}{c}\text { Tensão } \\
\text { (MPa) }\end{array}$ & $\begin{array}{c}\text { e1 } \\
\text { (um) }\end{array}$ & $\begin{array}{l}\text { e2 } \\
\text { (um) }\end{array}$ & $\begin{array}{l}\text { em } \\
\text { (um) }\end{array}$ & $\begin{array}{c}\mathrm{Ec} \\
(\mathrm{GPa})\end{array}$ \\
\hline \multirow{6}{*}{1} & \multirow[t]{3}{*}{ Secante } & 1,00 & 1,25 & 380,000 & $-240,000$ & 70,000 & \\
\hline & & 6,05 & 7,56 & 760,000 & $-120,000$ & 320,000 & \\
\hline & & 5,050 & 6,308 & 380,000 & $\begin{array}{l}120,000 \\
\end{array}$ & 250,000 & 25,2 \\
\hline & \multirow{3}{*}{$\begin{array}{l}\text { Tangente } \\
\text { Inicial }\end{array}$} & 1,05 & 1,31 & 1360,000 & $-1070,000$ & 145,000 & \\
\hline & & 6,05 & 7,56 & 1610,000 & $-840,000$ & 385,000 & \\
\hline & & 5,000 & 6,245 & 250,000 & 230,000 & 240,000 & 26,0 \\
\hline \multirow{6}{*}{2} & \multirow[t]{3}{*}{ Secante } & 1,05 & 1,31 & 140,000 & 70,000 & 105,000 & \\
\hline & & 6,05 & 7,56 & 310,000 & 390,000 & 350,000 & \\
\hline & & 5,000 & 6,245 & 170,000 & 320,000 & 245,000 & 25,5 \\
\hline & \multirow{3}{*}{\begin{tabular}{|l} 
Tangente \\
Inicial
\end{tabular}} & 1,05 & 1,31 & 400,000 & $-100,000$ & 150,000 & \\
\hline & & 6,05 & 7,56 & 410,000 & 310,000 & 360,000 & \\
\hline & & 5,000 & 6,245 & 10,000 & 410,000 & 210,000 & 29,7 \\
\hline \multirow{6}{*}{3} & \multirow[t]{3}{*}{ Secante } & 1,05 & 1,31 & 650,000 & $-30,000$ & 310,000 & \\
\hline & & 6,05 & 7,56 & 1190,000 & $-30,000$ & 580,000 & \\
\hline & & 5,000 & 6,245 & 540,000 & 0,000 & 270,000 & 23,1 \\
\hline & \multirow{3}{*}{$\begin{array}{l}\text { Tangente } \\
\text { Inicial }\end{array}$} & 1,05 & 1,31 & 2150,000 & $-1410,000$ & 370,000 & \\
\hline & & 6,05 & 7,56 & 2650,000 & $-1410,000$ & 620,000 & \\
\hline & & 5,000 & 6,245 & 500,000 & 0,000 & 250,000 & 25,0 \\
\hline \multirow{6}{*}{4} & \multirow[t]{3}{*}{ Secante } & 1,00 & 1,25 & 340,000 & $-140,000$ & 100,000 & \\
\hline & & 6,05 & 7,56 & 780,000 & 0,000 & 390,000 & \\
\hline & & 5,050 & 6,308 & 440,000 & 140,000 & 290,000 & 21,8 \\
\hline & \multirow{3}{*}{$\begin{array}{l}\text { Tangente } \\
\text { Inicial }\end{array}$} & 1,05 & 1,31 & 1370,000 & $-970,000$ & 200,000 & \\
\hline & & 6,05 & 7,56 & 1650,000 & $-750,000$ & 450,000 & \\
\hline & & 5,000 & 6,245 & 280,000 & 220,000 & 250,000 & 25,0 \\
\hline \multirow{6}{*}{5} & \multirow[t]{3}{*}{ Secante } & 1,05 & 1,31 & 100,000 & $-30,000$ & 35,000 & \\
\hline & & 6,05 & 7,56 & 310,000 & 190,000 & 250,000 & \\
\hline & & 5,000 & 6,245 & 210,000 & 220,000 & 215,000 & 29,0 \\
\hline & \multirow{3}{*}{$\begin{array}{l}\text { Tangente } \\
\text { Inicial }\end{array}$} & 1,05 & 1,31 & 230,000 & $-90,000$ & 70,000 & \\
\hline & & 6,05 & 7,56 & 410,000 & 140,000 & 275,000 & \\
\hline & & 5,000 & 6,245 & 180,000 & 230,000 & 205,000 & 30,5 \\
\hline & Secante & 1,00 & 1,25 & 370,000 & $-110,000$ & 130,000 & \\
\hline & & 6,05 & 7,56 & 730,000 & $\begin{array}{l}120,000 \\
\end{array}$ & 425,000 & \\
\hline 6 & & 5,050 & 6,308 & 360,000 & 230,000 & 295,000 & 21,4 \\
\hline 0 & Tangente & 1,05 & 1,31 & 1360,000 & $-980,000$ & 190,000 & \\
\hline & Inicial & 6,05 & 7,56 & 1460,000 & $-560,000$ & 450,000 & \\
\hline & & 5,000 & 6,245 & 100,000 & 420,000 & 260,000 & 24,0 \\
\hline & Secante & 1,05 & 1,31 & 50,000 & 60,000 & 55,000 & \\
\hline & & 6,05 & 7,56 & 180,000 & 360,000 & 270,000 & \\
\hline 7 & & 5,000 & 6,245 & 130,000 & 300,000 & 215,000 & 29,0 \\
\hline$r$ & Tangente & 1,05 & 1,31 & 710,000 & $-950,000$ & $-120,000$ & \\
\hline & Inicial & 6,05 & 7,56 & 850,000 & $-700,000$ & 75,000 & \\
\hline & & 5,000 & 6,245 & 140,000 & 250,000 & 195,000 & 32,0 \\
\hline & Secante & 0,95 & 1,19 & 250,000 & $-140,000$ & 55,000 & \\
\hline & & 6,05 & 7,56 & 400,000 & 160,000 & 280,000 & \\
\hline 8 & & 5,100 & 6,370 & 150,000 & 300,000 & 225,000 & 28,3 \\
\hline 0 & Tangente & 1,05 & 1,31 & 110,000 & $-360,000$ & $-125,000$ & \\
\hline & Inicial & 6,05 & 7,56 & 160,000 & $-20,000$ & 70,000 & \\
\hline & & 5,000 & 6,245 & 50,000 & 340,000 & 195,000 & 32,0 \\
\hline & Secante & 1,05 & 1,31 & 310,000 & $-130,000$ & 90,000 & \\
\hline & & 6,05 & 7,56 & 660,000 & 20,000 & 340,000 & \\
\hline 9 & & 5,000 & 6,245 & 350,000 & 150,000 & 250,000 & 25,0 \\
\hline$y$ & Tangente & 1,05 & 1,31 & 1240,000 & $-850,000$ & 195,000 & \\
\hline & Inicial & 6,05 & 7,56 & 1510,000 & $-720,000$ & 395,000 & \\
\hline & & 5,000 & 6,245 & 270,000 & 130,000 & 200,000 & 31,2 \\
\hline & Secante & 1,05 & 1,31 & 800,000 & $-560,000$ & 120,000 & \\
\hline & & 6,05 & 7,56 & 1070,000 & $-290,000$ & 390,000 & \\
\hline 10 & & 5,000 & 6,245 & 270,000 & 270,000 & 270,000 & 23,1 \\
\hline 10 & Tangente & 1,05 & 1,31 & 1270,000 & $-890,000$ & 190,000 & \\
\hline & Inicial & 6,05 & 7,56 & 1280,000 & $-460,000$ & 410,000 & \\
\hline & & 5,000 & 6,245 & 10,000 & 430,000 & 220,000 & 28,4 \\
\hline
\end{tabular}




\section{APÊNDICE B - RESULTADOS DOS ENSAIOS DA SEGUNDA ETAPA}

Tabela B.1 - Resultados dos ensaios prévios de resistência à compressão: a/c 0,42. 0,50 e 0,58 , abatimento $100 \pm 20$ e $180 \pm 30 \mathrm{~mm}$

\begin{tabular}{cccccc}
\multicolumn{2}{c}{$a / c$} & 0,42 & \multicolumn{2}{c}{$a / c 0,50$} & \multicolumn{2}{c}{$a / c 0,58$} \\
Força & Tensão & Força & Tensão & Força & Tensão \\
$(\mathrm{tf})$ & $(\mathrm{MPa})$ & $(\mathrm{tf})$ & $(\mathrm{MPa})$ & (tf) & $(\mathrm{MPa})$
\end{tabular}

\begin{tabular}{|c|c|c|c|c|c|c|}
\hline & & & & & & \\
\hline CP 1 & 48,8 & 61,0 & 36,9 & 46,1 & 30,3 & 37,8 \\
\hline CP 2 & 47,9 & 59,8 & 37,6 & 47,0 & 31,1 & 38,8 \\
\hline Média & 48,35 & 60,39 & 37,25 & 46,53 & 30,70 & 38,35 \\
\hline
\end{tabular}

$\mathbf{1 8 0} \pm \mathbf{3 0}$
\begin{tabular}{|c|c|c|c|c|c|c|}
\hline CP $\mathbf{1}$ & 45,9 & 57,3 & 37,4 & 46,7 & 34,0 & 42,5 \\
\hline CP $\mathbf{2}$ & 47,8 & 59,7 & 37,7 & 47,1 & 32,8 & 41,0 \\
\hline Média & $\mathbf{4 6 , 8 5}$ & $\mathbf{5 8 , 5 2}$ & $\mathbf{3 7 , 5 5}$ & $\mathbf{4 6 , 9 0}$ & $\mathbf{3 3 , 4 0}$ & $\mathbf{4 1 , 7 2}$ \\
\hline
\end{tabular}

Tabela B.2 - Resultados de módulo de deformação: a/c 0,42. 0,50 e 0,58, abatimento $100 \pm 20$ e $180 \pm 30 \mathrm{~mm}$

clip gages

abatimento $100 \mathrm{~mm}$

\begin{tabular}{|c|c|c|c|c|c|c|c|}
\hline Traço & Plano & $\begin{array}{c}\text { Força } \\
\text { (tf) }\end{array}$ & $\begin{array}{c}\text { Tensão } \\
\text { (MPa) }\end{array}$ & $\begin{array}{c}\text { e1 } \\
\text { (um) }\end{array}$ & $\begin{array}{c}\text { e2 } \\
\text { (um) }\end{array}$ & $\begin{array}{l}\text { em } \\
\text { (um) }\end{array}$ & $\begin{array}{c}\mathrm{Ec} \\
(\mathrm{GPa})\end{array}$ \\
\hline \multirow{9}{*}{ T3-042-A100 } & \multirow{3}{*}{$\begin{array}{l}\text { CP 1 } \\
\text { Secante }\end{array}$} & 1,25 & 1,56 & 55,000 & 45,000 & 50,000 & \multirow[b]{3}{*}{33,3} \\
\hline & & 14,50 & 18,11 & 570,000 & 525,000 & 547,500 & \\
\hline & & 13,250 & 16,550 & 515,000 & 480,000 & 497,500 & \\
\hline & \multirow{3}{*}{$\begin{array}{l}\text { CP } 2 \\
\text { Secante }\end{array}$} & 1,25 & 1,56 & $-20,000$ & 10,000 & $-5,000$ & \multirow[b]{3}{*}{33,3} \\
\hline & & 14,50 & 18,11 & 485,000 & 500,000 & 492,500 & \\
\hline & & 13,250 & 16,550 & 505,000 & 490,000 & 497,500 & \\
\hline & \multirow{3}{*}{$\begin{array}{l}\text { CP 3 } \\
\text { Secante }\end{array}$} & 1,25 & 1,56 & 60,000 & 105,000 & 82,500 & \multirow[b]{3}{*}{32,8} \\
\hline & & 14,50 & 18,11 & 565,000 & 610,000 & 587,500 & \\
\hline & & 13,250 & 16,550 & 505,000 & 505,000 & 505,000 & \\
\hline \multirow{9}{*}{ T4-050-A100 } & \multirow{3}{*}{$\begin{array}{l}\text { CP } 1 \\
\text { Secante }\end{array}$} & 1,25 & 1,56 & 40,000 & 60,000 & 50,000 & \multirow[b]{3}{*}{31,3} \\
\hline & & 11,10 & 13,86 & 420,000 & 465,000 & 442,500 & \\
\hline & & 9,850 & 12,303 & 380,000 & 405,000 & 392,500 & \\
\hline & \multirow{3}{*}{$\begin{array}{l}\text { CP } 2 \\
\text { Secante }\end{array}$} & 1,25 & 1,56 & 80,000 & 20,000 & 50,000 & \multirow[b]{3}{*}{31,5} \\
\hline & & 11,10 & 13,86 & 450,000 & 430,000 & 440,000 & \\
\hline & & 9,850 & 12,303 & 370,000 & 410,000 & 390,000 & \\
\hline & \multirow{3}{*}{$\begin{array}{l}\text { CP } 3 \\
\text { Secante }\end{array}$} & 1,25 & 1,56 & 50,000 & $-5,000$ & 22,500 & \multirow[b]{3}{*}{31,0} \\
\hline & & 11,10 & 13,86 & 465,000 & 375,000 & 420,000 & \\
\hline & & 9,850 & 12,303 & 415,000 & 380,000 & 397,500 & \\
\hline \multirow{9}{*}{ T5-058-A100 } & \multirow{3}{*}{$\begin{array}{l}\text { CP 1 } \\
\text { Secante }\end{array}$} & 1,25 & 1,56 & 45,000 & 10,000 & 27,500 & \multirow[b]{3}{*}{29,2} \\
\hline & & 9,20 & 11,49 & 375,000 & 360,000 & 367,500 & \\
\hline & & 7,950 & 9,930 & 330,000 & 350,000 & 340,000 & \\
\hline & \multirow{3}{*}{$\begin{array}{l}\text { CP } 2 \\
\text { Secante }\end{array}$} & 1,25 & 1,56 & 15,000 & 50,000 & 32,500 & \multirow[b]{3}{*}{29,6} \\
\hline & & 9,25 & 11,55 & 350,000 & 390,000 & 370,000 & \\
\hline & & 8,000 & 9,992 & 335,000 & 340,000 & 337,500 & \\
\hline & \multirow{3}{*}{$\begin{array}{l}\text { CP 3 } \\
\text { Secante }\end{array}$} & 1,25 & 1,56 & 30,000 & 55,000 & 42,500 & \multirow[b]{3}{*}{28,3} \\
\hline & & 9,25 & 11,55 & 380,000 & 410,000 & 395,000 & \\
\hline & & 8,000 & 9,992 & 350,000 & 355,000 & 352,500 & \\
\hline
\end{tabular}


clip gages

abatimento $180 \mathrm{~mm}$

\begin{tabular}{|c|c|c|c|c|c|c|c|}
\hline Traço & Plano & $\begin{array}{c}\text { Força } \\
\text { (tf) }\end{array}$ & $\begin{array}{l}\text { Tensão } \\
\text { (MPa) }\end{array}$ & $\begin{array}{c}\text { e1 } \\
\text { (um) }\end{array}$ & $\begin{array}{c}\mathrm{e} 2 \\
\text { (um) }\end{array}$ & $\begin{array}{c}\text { em } \\
\text { (um) }\end{array}$ & $\begin{array}{c}\text { Ec } \\
\text { (GPa) }\end{array}$ \\
\hline \multirow{9}{*}{ T6-042-A180 } & \multirow{3}{*}{$\begin{array}{l}\text { CP 1 } \\
\text { Secante }\end{array}$} & 1,25 & 1,56 & 5,000 & 30,000 & 17,500 & \multirow[b]{3}{*}{30,3} \\
\hline & & 14,10 & 17,61 & 535,000 & 560,000 & 547,500 & \\
\hline & & 12,850 & 16,050 & 530,000 & 530,000 & 530,000 & \\
\hline & \multirow{3}{*}{$\begin{array}{l}\text { CP } 2 \\
\text { Secante }\end{array}$} & 1,25 & 1,56 & 60,000 & 10,000 & 35,000 & \multirow[b]{3}{*}{30,9} \\
\hline & & 14,10 & 17,61 & 580,000 & 530,000 & 555,000 & \\
\hline & & 12,850 & 16,050 & 520,000 & 520,000 & 520,000 & \\
\hline & \multirow{3}{*}{$\begin{array}{l}\text { CP 3 } \\
\text { Secante }\end{array}$} & 1,25 & 1,56 & 25,000 & 40,000 & 32,500 & \multirow[b]{3}{*}{30,1} \\
\hline & & 14,10 & 17,61 & 520,000 & 610,000 & 565,000 & \\
\hline & & 12,850 & 16,050 & 495,000 & 570,000 & 532,500 & \\
\hline \multirow{9}{*}{ T7-050-A180 } & \multirow{3}{*}{$\begin{array}{l}\text { CP 1 } \\
\text { Secante }\end{array}$} & 1,25 & 1,56 & 20,000 & 50,000 & 35,000 & \multirow[b]{3}{*}{29,4} \\
\hline & & 11,20 & 13,99 & 455,000 & 460,000 & 457,500 & \\
\hline & & 9,950 & 12,428 & 435,000 & 410,000 & 422,500 & \\
\hline & \multirow{3}{*}{$\begin{array}{l}\text { CP } 2 \\
\text { Secante }\end{array}$} & 1,25 & 1,56 & 70,000 & $-15,000$ & 27,500 & \multirow[b]{3}{*}{27,9} \\
\hline & & 11,20 & 13,99 & 505,000 & 440,000 & 472,500 & \\
\hline & & 9,950 & 12,428 & 435,000 & 455,000 & 445,000 & \\
\hline & \multirow{3}{*}{$\begin{array}{l}\text { CP 3 } \\
\text { Secante }\end{array}$} & 1,25 & 1,56 & 80,000 & 0,000 & 40,000 & \multirow[b]{3}{*}{27,6} \\
\hline & & 11,20 & 13,99 & 525,000 & 455,000 & 490,000 & \\
\hline & & 9,950 & 12,428 & 445,000 & 455,000 & 450,000 & \\
\hline \multirow{9}{*}{ T8-058-A180 } & \multirow{3}{*}{$\begin{array}{l}\text { CP 1 } \\
\text { Secante }\end{array}$} & 1,25 & 1,56 & 0,000 & 35,000 & 17,500 & \multirow[b]{3}{*}{27,7} \\
\hline & & 10,05 & 12,55 & 400,000 & 430,000 & 415,000 & \\
\hline & & 8,800 & 10,992 & 400,000 & 395,000 & 397,500 & \\
\hline & \multirow{3}{*}{$\begin{array}{l}\text { CP } 2 \\
\text { Secante }\end{array}$} & 1,25 & 1,56 & 10,000 & $-10,000$ & 0,000 & \multirow[b]{3}{*}{28,0} \\
\hline & & 10,05 & 12,55 & 415,000 & 370,000 & 392,500 & \\
\hline & & 8,800 & 10,992 & 405,000 & 380,000 & 392,500 & \\
\hline & \multirow{3}{*}{$\begin{array}{l}\text { CP 3 } \\
\text { Secante }\end{array}$} & 1,25 & 1,56 & 50,000 & $-20,000$ & 15,000 & \multirow[b]{3}{*}{26,5} \\
\hline & & 10,05 & 12,55 & 470,000 & 390,000 & 430,000 & \\
\hline & & 8,800 & 10,992 & 420,000 & 410,000 & 415,000 & \\
\hline
\end{tabular}

